\title{
Gamma and other cephalocondylic intramedullary nails versus extramedullary implants for extracapsular hip fractures in adults (Review)
}

\author{
Parker MJ, Handoll HHG
}

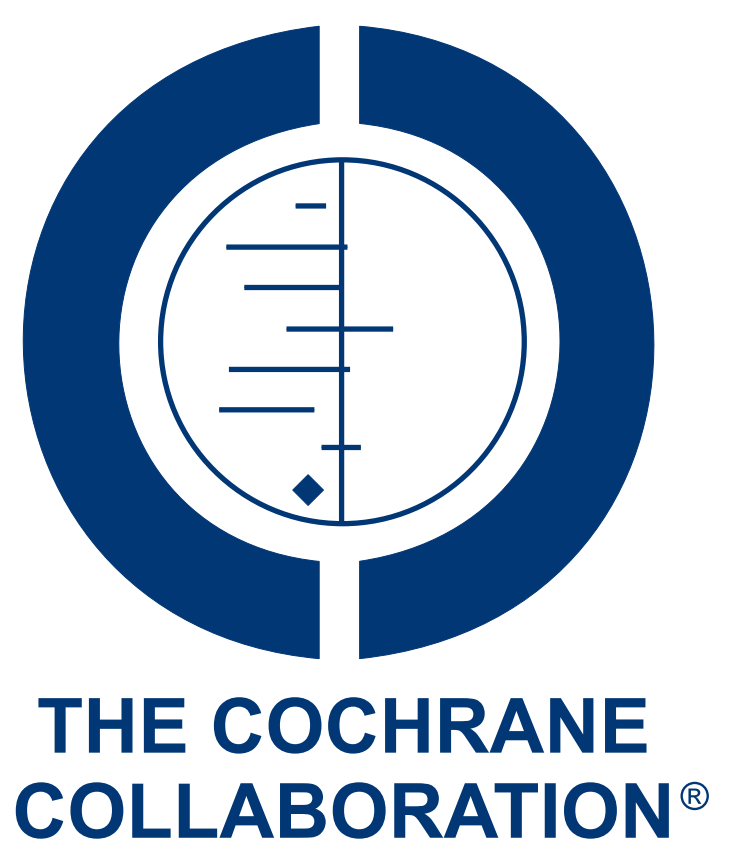

This is a reprint of a Cochrane review, prepared and maintained by The Cochrane Collaboration and published in The Cochrane Library 2010, Issue 9

http://www.thecochranelibrary.com

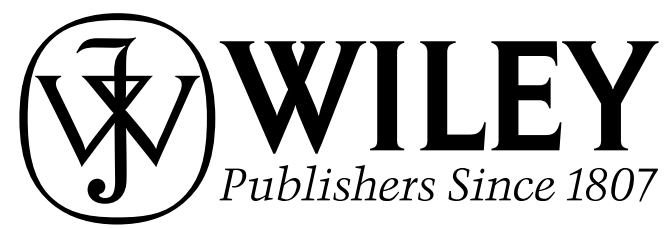

Gamma and other cephalocondylic intramedullary nails versus extramedullary implants for extracapsular hip fractures in adults (Review) Copyright (C) 2010 The Cochrane Collaboration. Published by John Wiley \& Sons, Ltd. 
TABLE OF CONTENTS

HEADER . . . . . . . . . . . . . . . . . . . . . . . . . . . . . . . . 1

ABSTRACT .. . . . . . . . . . . . . . . . . . . . . . . . . . . . . . . . . . . . . . . . . . . . . . . . .

PLAIN LANGUAGE SUMMARY . . . . . . . . . . . . . . . . . . . . . . . . . . . . . . . . . . . $\quad$. 2

BACKGROUND . . . . . . . . . . . . . . . . . . . . . . . . . . . . . . . . . . . . . 3

OBJECTIVES . . . . . . . . . . . . . . . . . . . . . . . . . . . . . . . . . . . . . . . 5

METHODS . . . . . . . . . . . . . . . . . . . . . . . . . . . . . . . . . . . . . . 5

RESULTS . . . . . . . . . . . . . . . . . . . . . . . . . . . . . . . . . . . . . . . 8

Figure 1. . . . . . . . . . . . . . . . . . . . . . . . . . . . . . . . . . . . . . 11

Figure 2. . . . . . . . . . . . . . . . . . . . . . . . . . . . . . . . . . . . . . 12

DISCUSSION . . . . . . . . . . . . . . . . . . . . . . . . . . . . . . . . 20

AUTHORS' CONCLUSIONS . . . . . . . . . . . . . . . . . . . . . . . . . . . . . . . . . . . . . .

ACKNOWLEDGEMENTS . . . . . . . . . . . . . . . . . . . . . . . . . . . . . . . . . . . . . . . . 22

REFERENCES . . . . . . . . . . . . . . . . . . . . . . . . . . . . . . . . . 22

CHARACTERISTICS OF STUDIES . . . . . . . . . . . . . . . . . . . . . . . . . . . . . 29

DATA AND ANALYSES . . . . . . . . . . . . . . . . . . . . . . . . . . . . . . . . . . . . . . . . . . ..

Analysis 1.1. Comparison 1 Summary: Femoral nail (all types) versus sliding hip screw (SHS), Outcome 1 Length of surgery (minutes). . . . . . . . . . . . . . . . . . . . . . . . . . . . . . . . .

Analysis 1.2. Comparison 1 Summary: Femoral nail (all types) versus sliding hip screw (SHS), Outcome 2 Operative fracture of the femur. . . . . . . . . . . . . . . . . . . . . . . . . . . . . . . . 103

Analysis 1.3. Comparison 1 Summary: Femoral nail (all types) versus sliding hip screw (SHS), Outcome 3 Later fracture of the femur. . . . . . . . . . . . . . . . . . . . . . . . . . . . . . . . . . . . 105

Analysis 1.4. Comparison 1 Summary: Femoral nail (all types) versus sliding hip screw (SHS), Outcome 4 Cut-out (overall denominators used). . . . . . . . . . . . . . . . . . . . . . . . . . . . . . . . 107

Analysis 1.5. Comparison 1 Summary: Femoral nail (all types) versus sliding hip screw (SHS), Outcome 5 Non-union (overall denominators used). . . . . . . . . . . . . . . . . . . . . . . . . . . . . . . . . . . . . . 110

Analysis 1.6. Comparison 1 Summary: Femoral nail (all types) versus sliding hip screw (SHS), Outcome 6 Reoperation (overall denominators used). . . . . . . . . . . . . . . . . . . . . . . . . . . . . . . . . . . . . . . . .

Analysis 1.7. Comparison 1 Summary: Femoral nail (all types) versus sliding hip screw (SHS), Outcome 7 Deep wound infection.

Analysis 1.8. Comparison 1 Summary: Femoral nail (all types) versus sliding hip screw (SHS), Outcome 8 Mortality.
Analysis 1.9. Comparison 1 Summary: Femoral nail (all types) versus sliding hip screw (SHS), Outcome 9 Pain at followup. . . . . . . . . . . . . . . . . . . . . . . . . . . . . . . . . . . . . . 118

Analysis 1.10. Comparison 1 Summary: Femoral nail (all types) versus sliding hip screw (SHS), Outcome 10 Non return to previous residence or dead. . . . . . . . . . . . . . . . . . . . . . . . . . . . . . . . . . . . . . . . 119

Analysis 2.1. Comparison 2 Gamma nail versus sliding hip screw (SHS), Outcome 1 Length of surgery (minutes). $\quad . \quad 121$

Analysis 2.2. Comparison 2 Gamma nail versus sliding hip screw (SHS), Outcome 2 Blood loss (ml). . . . . . . . . 122

Analysis 2.3. Comparison 2 Gamma nail versus sliding hip screw (SHS), Outcome 3 Number of people given transfusion.

Analysis 2.4. Comparison 2 Gamma nail versus sliding hip screw (SHS), Outcome 4 Radiographic screening time (seconds).

Analysis 2.5. Comparison 2 Gamma nail versus sliding hip screw (SHS), Outcome 5 Operative fracture of femur.

Analysis 2.6. Comparison 2 Gamma nail versus sliding hip screw (SHS), Outcome 6 Operative fracture of femur (reported experience with devices). . . . . . . . . . . . . . . . . . . . . . . . . . . . . . . . . . . 125

Analysis 2.7. Comparison 2 Gamma nail versus sliding hip screw (SHS), Outcome 7 Later fracture of femur. . . . 126

Analysis 2.8. Comparison 2 Gamma nail versus sliding hip screw (SHS), Outcome 8 Cut-out. . . . . . . . . . 128

Analysis 2.9. Comparison 2 Gamma nail versus sliding hip screw (SHS), Outcome 9 Cut-out (reported experience with devices). . . . . . . . . . . . . . . . . . . . . . . . . . . . . . . . . . . . . 129

Analysis 2.10. Comparison 2 Gamma nail versus sliding hip screw (SHS), Outcome 10 Non-union. . . . . . . . 130

Analysis 2.11. Comparison 2 Gamma nail versus sliding hip screw (SHS), Outcome 11 Reoperation. . . . . . . . 131

Analysis 2.12. Comparison 2 Gamma nail versus sliding hip screw (SHS), Outcome 12 Wound infection or haematoma. 133

Analysis 2.13. Comparison 2 Gamma nail versus sliding hip screw (SHS), Outcome 13 Pneumonia. . . . . . . . 135

Gamma and other cephalocondylic intramedullary nails versus extramedullary implants for extracapsular hip fractures in adults (Review)

Copyright () 2010 The Cochrane Collaboration. Published by John Wiley \& Sons, Ltd. 
Analysis 2.14. Comparison 2 Gamma nail versus sliding hip screw (SHS), Outcome 14 Pressure sore. . . . . . . 136

Analysis 2.15. Comparison 2 Gamma nail versus sliding hip screw (SHS), Outcome 15 Thromboembolic complications.

Analysis 2.16. Comparison 2 Gamma nail versus sliding hip screw (SHS), Outcome 16 Any medical complication (other than wound infection or haematoma). . . . . . . . . . . . . . . . . . . . . . . . . . . .

Analysis 2.17. Comparison 2 Gamma nail versus sliding hip screw (SHS), Outcome 17 Length of hospital stay (days).

Analysis 2.18. Comparison 2 Gamma nail versus sliding hip screw (SHS), Outcome 18 Anatomical deformity. . .

Analysis 2.19. Comparison 2 Gamma nail versus sliding hip screw (SHS), Outcome 19 Mortality. . . . . . . . . .

Analysis 2.20. Comparison 2 Gamma nail versus sliding hip screw (SHS), Outcome 20 Mortality (grouped by allocation concealment). . . . . . . . . . . . . . . . . . . . . . . . . . . . . . . . . . .

Analysis 2.21. Comparison 2 Gamma nail versus sliding hip screw (SHS), Outcome 21 Pain at follow-up. . . . .

Analysis 2.22. Comparison 2 Gamma nail versus sliding hip screw (SHS), Outcome 22 Non-return to previous residence. . . . . . . . . . . . . . . . . . . . . . . . . . . . . . . . . . . .

Analysis 2.23. Comparison 2 Gamma nail versus sliding hip screw (SHS), Outcome 23 Impaired walking. . . . .

Analysis 3.1. Comparison 3 Intramedullary hip screw (IMHS) versus sliding hip screw (SHS), Outcome 1 Length of surgery (minutes).

Analysis 3.2. Comparison 3 Intramedullary hip screw (IMHS) versus sliding hip screw (SHS), Outcome 2 Blood loss $(\mathrm{ml})$.

Analysis 3.3. Comparison 3 Intramedullary hip screw (IMHS) versus sliding hip screw (SHS), Outcome 3 Transfusion (units of red cells).

Analysis 3.4. Comparison 3 Intramedullary hip screw (IMHS) versus sliding hip screw (SHS), Outcome 4 Number of patients transfused.

Analysis 3.5. Comparison 3 Intramedullary hip screw (IMHS) versus sliding hip screw (SHS), Outcome 5 Radiographic screening time (minutes). . . . . . . . . . . . . . . . . . . . . . . . . . . . . . .

Analysis 3.6. Comparison 3 Intramedullary hip screw (IMHS) versus sliding hip screw (SHS), Outcome 6 Fracture fixation complications. . . . . . . . . . . . . . . . . . . . . . . . . . . . . . . . . . 149

Analysis 3.7. Comparison 3 Intramedullary hip screw (IMHS) versus sliding hip screw (SHS), Outcome 7 Wound infection or haematoma. . . . . . . . . . . . . . . . . . . . . . . . . . . . . . . . . . 151

Analysis 3.8. Comparison 3 Intramedullary hip screw (IMHS) versus sliding hip screw (SHS), Outcome 8 Post-operative complications.

Analysis 3.9. Comparison 3 Intramedullary hip screw (IMHS) versus sliding hip screw (SHS), Outcome 9 Length of hospital stay (days).

Analysis 3.10. Comparison 3 Intramedullary hip screw (IMHS) versus sliding hip screw (SHS), Outcome 10 Mean limb shortening $(\mathrm{cm})$. . . . . . . . . . . . . . . . . . . . . . . . . . . . . . . . . .

Analysis 3.11. Comparison 3 Intramedullary hip screw (IMHS) versus sliding hip screw (SHS), Outcome 11 Final outcome measures.

Analysis 4.1. Comparison 4 Proximal femoral nail (PFN) versus sliding hip screw (SHS), Outcome 1 Length of surgery (minutes).

Analysis 4.2. Comparison 4 Proximal femoral nail (PFN) versus sliding hip screw (SHS), Outcome 2 Blood loss and transfusion.

Analysis 4.3. Comparison 4 Proximal femoral nail (PFN) versus sliding hip screw (SHS), Outcome 3 Number of patients transfused.

Analysis 4.4. Comparison 4 Proximal femoral nail (PFN) versus sliding hip screw (SHS), Outcome 4 Radiographic screening time (minutes). . . . . . . . . . . . . . . . . . . . . . . . . . . . . . .

Analysis 4.5. Comparison 4 Proximal femoral nail (PFN) versus sliding hip screw (SHS), Outcome 5 Fracture fixation complications.

Analysis 4.6. Comparison 4 Proximal femoral nail (PFN) versus sliding hip screw (SHS), Outcome 6 Wound infection or haematoma. . . . . . . . . . . . . . . . . . . . . . . . . . . . . . . . . . .

Analysis 4.7. Comparison 4 Proximal femoral nail (PFN) versus sliding hip screw (SHS), Outcome 7 Post-operative complications.

Analysis 4.8. Comparison 4 Proximal femoral nail (PFN) versus sliding hip screw (SHS), Outcome 8 Length of hospital stay (days). . . . . . . . . . . . . . . . . . . . . . . . . . . . . . . . . . . . . . . . . .

Analysis 4.9. Comparison 4 Proximal femoral nail (PFN) versus sliding hip screw (SHS), Outcome 9 Final outcome measures. 
Analysis 5.1. Comparison 5 Proximal femoral nail antirotation (PFNA) versus sliding hip screw (SHS), Outcome 1 Length of surgery (minutes)

Analysis 5.2. Comparison 5 Proximal femoral nail antirotation (PFNA) versus sliding hip screw (SHS), Outcome 2 Operative blood loss (ml).

Analysis 5.3. Comparison 5 Proximal femoral nail antirotation (PFNA) versus sliding hip screw (SHS), Outcome 3 Radiographic screening time (minutes). . . . . . . . . . . . . . . . . . . . . . . . . .

Analysis 5.4. Comparison 5 Proximal femoral nail antirotation (PFNA) versus sliding hip screw (SHS), Outcome 4 Fracture fixation complications. . . . . . . . . . . . . . . . . . . . . . . . . . . . . . . .

Aalysis 5.5. Comparison 5 Proximal femoral nail antirotation (PFNA) versus sliding hip screw (SHS), Outcome 5 Wound infection.

Analysis 5.6. Comparison 5 Proximal femoral nail antirotation (PFNA) versus sliding hip screw (SHS), Outcome 6 Postoperative complications. . . . . . . . . . . . . . . . . . . . . . . . . . . . . . . . . . . . . . . . . . . .

Analysis 5.7. Comparison 5 Proximal femoral nail antirotation (PFNA) versus sliding hip screw (SHS), Outcome 7 Poor or fair hip function score $(1$ year). . . . . . . . . . . . . . . . . . . . . . . . . . . . . 167

Analysis 6.1. Comparison 6 Targon PF (proximal femoral) nail versus sliding hip screw (SHS), Outcome 1 Fracture fixation complications. . . . . . . . . . . . . . . . . . . . . . . . . . . . . . . . . . . . . .

Analysis 6.2. Comparison 6 Targon PF (proximal femoral) nail versus sliding hip screw (SHS), Outcome 2 Wound infection.

alysis 6.3. Comparison 6 Targon PF (proximal femoral) nail versus sliding hip screw (SHS), Outcome 3 Post-operative compiications.

Analysis 6.4. Comparison 6 Targon PF (proximal femoral) nail versus sliding hip screw (SHS), Outcome 4 Mortality (3 months).

Analysis 7.1. Comparison 7 Holland nail versus sliding hip screw (SHS), Outcome 1 Length of anaesthesia and surgery.

Analysis 7.2. Comparison 7 Holland nail versus sliding hip screw (SHS), Outcome 2 Radiographic screening time (minutes). . . . . . . . . . . . . . . . . . . . . . . . . . . . . . . . . . .

Analysis 7.3. Comparison 7 Holland nail versus sliding hip screw (SHS), Outcome 3 Blood loss (ml). . . . . . .

Analysis 7.4. Comparison 7 Holland nail versus sliding hip screw (SHS), Outcome 4 Number of patients given transfusion.

Analysis 7.5. Comparison 7 Holland nail versus sliding hip screw (SHS), Outcome 5 Days till mobilisation. . . .

Analysis 7.6. Comparison 7 Holland nail versus sliding hip screw (SHS), Outcome 6 Fracture fixation complications.

Analysis 7.7. Comparison 7 Holland nail versus sliding hip screw (SHS), Outcome 7 Wound infection. . . . . .

Analysis 7.8. Comparison 7 Holland nail versus sliding hip screw (SHS), Outcome 8 Postoperative complications.

Analysis 7.9. Comparison 7 Holland nail versus sliding hip screw (SHS), Outcome 9 Final outcome measures. . .

Analysis 7.10. Comparison 7 Holland nail versus sliding hip screw (SHS), Outcome 10 Final outcome measures: mobility score $(0$ to 9: best result). . . . . . . . . . . . . . . . . . . . . . . . . . . . . . . . . . . . . . . . .

Analysis 8.1. Comparison 8 Long Gamma nail versus sliding hip screw (SHS), Outcome 1 Number of patients transfused. . . . . . . . . . . . . . . . . . . . . . . . . . . . . . . . . . . .

Analysis 8.2. Comparison 8 Long Gamma nail versus sliding hip screw (SHS), Outcome 2 Fracture fixation complications. . . . . . . . . . . . . . . . . . . . . . . . . . . . . . . . . .

Analysis 8.3. Comparison 8 Long Gamma nail versus sliding hip screw (SHS), Outcome 3 Wound infection. . . .

Analysis 8.4. Comparison 8 Long Gamma nail versus sliding hip screw (SHS), Outcome 4 Mortality (at one year).

Analysis 9.1. Comparison 9 Mini-invasive static (experimental) nail versus sliding hip screw (SHS), Outcome 1 Length of surgery (minutes). . . . . . . . . . . . . . . . . . . . . . . . . . . . . . . . . . . .

Analysis 9.2. Comparison 9 Mini-invasive static (experimental) nail versus sliding hip screw (SHS), Outcome 2 Blood loss. . . . . . . . . . . . . . . . . . . . . . . . . . . . . . . . . . . . . . . . . . . .

Analysis 9.3. Comparison 9 Mini-invasive static (experimental) nail versus sliding hip screw (SHS), Outcome 3 Radiographic screening time (seconds). . . . . . . . . . . . . . . . . . . . . . . . . .

Analysis 9.4. Comparison 9 Mini-invasive static (experimental) nail versus sliding hip screw (SHS), Outcome 4 Time to radiographic healing (weeks).

Analysis 9.5. Comparison 9 Mini-invasive static (experimental) nail versus sliding hip screw (SHS), Outcome 5 Mortality (6 months).

Analysis 9.6. Comparison 9 Mini-invasive static (experimental) nail versus sliding hip screw (SHS), Outcome 6 Time to effective weight bearing (weeks). 
Analysis 10.1. Comparison 10 Kuntscher-Y nail versus sliding hip screw (SHS), Outcome 1 Fracture fixation complications. . . . . . . . . . . . . . . . . . . . . . . . . . . . . . . . . . Analysis 10.2. Comparison 10 Kuntscher-Y nail versus sliding hip screw (SHS), Outcome 2 Wound infection. Analysis 10.3. Comparison 10 Kuntscher-Y nail versus sliding hip screw (SHS), Outcome 3 Post-operative complications. 180 Analysis 10.4. Comparison 10 Kuntscher-Y nail versus sliding hip screw (SHS), Outcome 4 Anatomical deformity. .

Analysis 10.5. Comparison 10 Kuntscher-Y nail versus sliding hip screw (SHS), Outcome 5 Final outcome measures (1 year). . . . . . . . . . . . . . . . . . . . . . . . . . . . . . . . . . . .

Analysis 11.1. Comparison 11 Two nail types versus sliding hip screw (SHS), Outcome 1 Operative outcomes. . .

Analysis 11.2. Comparison 11 Two nail types versus sliding hip screw (SHS), Outcome 2 Operative fracture of the femur.

Analysis 11.3. Comparison 11 Two nail types versus sliding hip screw (SHS), Outcome 3 Superficial wound infection.

Analysis 11.4. Comparison 11 Two nail types versus sliding hip screw (SHS), Outcome 4 Post-operative complications.

Analysis 11.5. Comparison 11 Two nail types versus sliding hip screw (SHS), Outcome 5 Mortality (in hospital). . .

Analysis 11.6. Comparison 11 Two nail types versus sliding hip screw (SHS), Outcome 6 Days to independent walking.

Analysis 12.1. Comparison 12 Femoral nail (2 types) versus Medoff sliding plate, Outcome 1 Length of surgery (minutes).

Analysis 12.2. Comparison 12 Femoral nail (2 types) versus Medoff sliding plate, Outcome 2 Operative blood loss (ml).

Analysis 12.3. Comparison 12 Femoral nail (2 types) versus Medoff sliding plate, Outcome 3 Radiographic screening time (minutes).

Analysis 12.4. Comparison 12 Femoral nail (2 types) versus Medoff sliding plate, Outcome 4 Operative fracture of the femur.

Analysis 12.5. Comparison 12 Femoral nail (2 types) versus Medoff sliding plate, Outcome 5 Later fracture of femur.

Analysis 12.6. Comparison 12 Femoral nail (2 types) versus Medoff sliding plate, Outcome 6 Cut-out. . . . . . .

Analysis 12.7. Comparison 12 Femoral nail (2 types) versus Medoff sliding plate, Outcome 7 Non-union. . . . . .

Analysis 12.8. Comparison 12 Femoral nail (2 types) versus Medoff sliding plate, Outcome 8 Reoperation. . . . .

Analysis 12.9. Comparison 12 Femoral nail (2 types) versus Medoff sliding plate, Outcome 9 Wound infection - any type. . . . . . . . . . . . . . . . . . . . . . . . . . . . . . . . . . .

Analysis 12.10. Comparison 12 Femoral nail (2 types) versus Medoff sliding plate, Outcome 10 Deep wound infection.

Analysis 12.11. Comparison 12 Femoral nail (2 types) versus Medoff sliding plate, Outcome 11 Wound haematoma.

Analysis 12.12. Comparison 12 Femoral nail (2 types) versus Medoff sliding plate, Outcome 12 Severe medical complications. . . . . . . . . . . . . . . . . . . . . . . . . . . . . . . . . .

Analysis 12.13. Comparison 12 Femoral nail (2 types) versus Medoff sliding plate, Outcome 13 Mortality at 1 year. .

Analysis 12.14. Comparison 12 Femoral nail (2 types) versus Medoff sliding plate, Outcome 14 Inability to walk 15 metres at one year. . . . . . . . . . . . . . . . . . . . . . . . . . . . . . . . . . . .

Analysis 12.15. Comparison 12 Femoral nail (2 types) versus Medoff sliding plate, Outcome 15 Inability to rise from a chair at one year. . . . . . . . . . . . . . . . . . . . . . . . . . . . . . . . . .

Analysis 12.16. Comparison 12 Femoral nail (2 types) versus Medoff sliding plate, Outcome 16 Inability to climb a curb at one year.

Analysis 12.17. Comparison 12 Femoral nail (2 types) versus Medoff sliding plate, Outcome 17 Need to use walking aids at one year. .

Analysis 13.1. Comparison 13 Gamma nail versus percutaneous compression plate (PCCP), Outcome 1 Number of patients transfused. . . . . . . . . . . . . . . . . . . . . . . . . . . . . . . . .

Analysis 13.2. Comparison 13 Gamma nail versus percutaneous compression plate (PCCP), Outcome 2 Fracture fixation complications.

Analysis 13.3. Comparison 13 Gamma nail versus percutaneous compression plate (PCCP), Outcome 3 Post-operative complications.

Analysis 13.4. Comparison 13 Gamma nail versus percutaneous compression plate (PCCP), Outcome 4 Discharged to intermediate care.

Analysis 13.5. Comparison 13 Gamma nail versus percutaneous compression plate (PCCP), Outcome 5 Mortality.

Analysis 13.6. Comparison 13 Gamma nail versus percutaneous compression plate (PCCP), Outcome 6 Failure to regain mobility at one year. . . . . . . . . . . . . . . . . . . . . . . . . . . . . . . .

Analysis 14.1. Comparison 14 Femoral nail versus condylar screw or blade plate for trochanteric fractures, Outcome 1 Length of surgery (minutes). 
Analysis 14.2. Comparison 14 Femoral nail versus condylar screw or blade plate for trochanteric fractures, Outcome 2

Number of patients transfused.

Analysis 14.3. Comparison 14 Femoral nail versus condylar screw or blade plate for trochanteric fractures, Outcome 3

Radiographic screening time (minutes). . . . . . . . . . . . . . . . . . . . . . . . . . .

Analysis 14.4. Comparison 14 Femoral nail versus condylar screw or blade plate for trochanteric fractures, Outcome 4

Non-union.

Analysis 14.5. Comparison 14 Femoral nail versus condylar screw or blade plate for trochanteric fractures, Outcome 5

Operative fracture of femur. . . . . . . . . . . . . . . . . . . . . . . . . . . . . .

Analysis 14.6. Comparison 14 Femoral nail versus condylar screw or blade plate for trochanteric fractures, Outcome 6 Cut-

out. . . . . . . . . . . . . . . . . . . . . . . . . . . . . . . . . . . . . .

Analysis 14.7. Comparison 14 Femoral nail versus condylar screw or blade plate for trochanteric fractures, Outcome 7 Plate breakage. . . . . . . . . . . . . . . . . . . . . . . . . . . . . . . . . . .

Analysis 14.8. Comparison 14 Femoral nail versus condylar screw or blade plate for trochanteric fractures, Outcome 8 Reoperation (major). . . . . . . . . . . . . . . . . . . . . . . . . . . . . . . . . . .

Analysis 14.9. Comparison 14 Femoral nail versus condylar screw or blade plate for trochanteric fractures, Outcome 9 Deep wound infection. . . . . . . . . . . . . . . . . . . . . . . . . . . . . . .

Analysis 14.10. Comparison 14 Femoral nail versus condylar screw or blade plate for trochanteric fractures, Outcome 10 Pneumonia.

Analysis 14.11. Comparison 14 Femoral nail versus condylar screw or blade plate for trochanteric fractures, Outcome 11 Pressure sores.

Analysis 14.12. Comparison 14 Femoral nail versus condylar screw or blade plate for trochanteric fractures, Outcome 12

Deep vein thrombosis. . . . . . . . . . . . . . . . . . . . . . . . . . . . . . . .

Analysis 14.13. Comparison 14 Femoral nail versus condylar screw or blade plate for trochanteric fractures, Outcome 13 Pulmonary embolism. . . . . . . . . . . . . . . . . . . . . . . . . . . . . . .

Analysis 14.14. Comparison 14 Femoral nail versus condylar screw or blade plate for trochanteric fractures, Outcome 14 All medical complications.

Analysis 14.15. Comparison 14 Femoral nail versus condylar screw or blade plate for trochanteric fractures, Outcome 15 Length of hospital stay (days).

Analysis 14.16. Comparison 14 Femoral nail versus condylar screw or blade plate for trochanteric fractures, Outcome 16 Mortality (1 year). . . . . . . . . . . . . . . . . . . . . . . . . . . . . . . . .

Analysis 14.17. Comparison 14 Femoral nail versus condylar screw or blade plate for trochanteric fractures, Outcome 17 Pain at follow-up.

Analysis 14.18. Comparison 14 Femoral nail versus condylar screw or blade plate for trochanteric fractures, Outcome 18 In nursing home at one year from injury. . . . . . . . . . . . . . . . . . . . . . . . . . 208

Analysis 14.19. Comparison 14 Femoral nail versus condylar screw or blade plate for trochanteric fractures, Outcome 19 In nursing home or dead at one year from injury. $\quad . \quad$. . . . . . . . . . . . . . . . . . . . . . . . . . .

Analysis 14.20. Comparison 14 Femoral nail versus condylar screw or blade plate for trochanteric fractures, Outcome 20

Use of walking aids. . . . . . . . . . . . . . . . . . . . . . . . . . . . . . . . . . 202

Analysis 15.1. Comparison 15 Femoral nail versus condylar screw or blade plate for subtrochanteric fractures, Outcome 1 Length of surgery (minutes).

Analysis 15.2. Comparison 15 Femoral nail versus condylar screw or blade plate for subtrochanteric fractures, Outcome 2 Radiographic screening time (seconds)

Analysis 15.3. Comparison 15 Femoral nail versus condylar screw or blade plate for subtrochanteric fractures, Outcome 3

\begin{tabular}{c} 
Operative blood loss $(\mathrm{ml})$. \\
Analysis 15.4 . Comparison $15 \mathrm{Femoral} \mathrm{nail} \mathrm{versus} \mathrm{condylar} \mathrm{screw} \mathrm{or} \mathrm{blade} \mathrm{plate} \mathrm{for} \mathrm{subtrochanteric} \mathrm{fractures,}$ \\
\hline
\end{tabular} Number of patients given transfusion.

Analysis 15.5. Comparison 15 Femoral nail versus condylar screw or blade plate for subtrochanteric fractures, Outcome 5 Non-union.

Analysis 15.6. Comparison 15 Femoral nail versus condylar screw or blade plate for subtrochanteric fractures, Outcome 6 Reoperation.

Analysis 15.7. Comparison $15 \mathrm{Femoral} \mathrm{nail} \mathrm{versus} \mathrm{condylar} \mathrm{screw} \mathrm{or} \mathrm{blade} \mathrm{plate} \mathrm{for} \mathrm{subtrochanteric} \mathrm{fractures,} \mathrm{Outcome} 7$ Any wound infection. 
Analysis 15.8. Comparison 15 Femoral nail versus condylar screw or blade plate for subtrochanteric fractures, Outcome 8

Length of hospital stay (days). . . . . . . . . . . . . . . . . . . . . . . . . . . . .

Analysis 15.9. Comparison 15 Femoral nail versus condylar screw or blade plate for subtrochanteric fractures, Outcome 9 Mortality. . . . . . . . . . . . . . . . . . . . . . . . . . . . . . . . . . . .

Analysis 15.10. Comparison 15 Femoral nail versus condylar screw or blade plate for subtrochanteric fractures, Outcome

10 Pain score (1: no pain to 4: worst pain). . . . . . . . . . . . . . . . . . . . . . . . .

Analysis 15.11. Comparison 15 Femoral nail versus condylar screw or blade plate for subtrochanteric fractures, Outcome

11 Mobility score $(0$ : complete disability, 9: no difficulty). . . . . . . . . . . . . . . . . . . 214

APPENDICES . . . . . . . . . . . . . . . . . . . . . . . . . . . . . . . . . . . . . . . . . . 214

WHAT'S NEW . . . . . . . . . . . . . . . . . . . . . . . . . . . . . . . . . . . . . 221

HISTORY . . . . . . . . . . . . . . . . . . . . . . . . . . . . . . . . . 222

CONTRIBUTIONS OF AUTHORS . . . . . . . . . . . . . . . . . . . . . . . . . . . . . 225

DECLARATIONS OF INTEREST . . . . . . . . . . . . . . . . . . . . . . . . . . . . . . . . . . . . . . . . 225

SOURCES OF SUPPORT . . . . . . . . . . . . . . . . . . . . . . . . . . . . . . . . . . . . . . . . . . . . . . . . . . $\quad . \quad 225$

DIFFERENCES BETWEEN PROTOCOL AND REVIEW . . . . . . . . . . . . . . . . . . . . . 225

INDEX TERMS . . . . . . . . . . . . . . . . . . . . . . . . . . . . . . . . . . . . 226

Gamma and other cephalocondylic intramedullary nails versus extramedullary implants for extracapsular hip fractures in adults (Review) vi Copyright () 2010 The Cochrane Collaboration. Published by John Wiley \& Sons, Ltd. 
[Intervention Review]

\title{
Gamma and other cephalocondylic intramedullary nails versus extramedullary implants for extracapsular hip fractures in adults
}

\author{
Martyn J Parker ${ }^{1}$, Helen HG Handoll ${ }^{2}$ \\ ${ }^{1}$ Department of Trauma \& Orthopaedics, Peterborough and Stamford Hospitals NHS Foundation Trust, Peterborough, UK. ${ }^{2}$ Centre \\ for Rehabilitation Sciences (CRS), Research Institute for Health Sciences and Social Care, University of Teesside, Middlesborough, \\ UK \\ Contact address: Martyn J Parker, Department of Trauma \& Orthopaedics, Peterborough and Stamford Hospitals NHS Foundation \\ Trust, Peterborough District Hospital, Thorpe Road, Peterborough, Cambridgeshire, PE3 6DA, UK. martyn.parker@pbh-tr.nhs.uk.
}

Editorial group: Cochrane Bone, Joint and Muscle Trauma Group.

Publication status and date: New search for studies and content updated (conclusions changed), published in Issue 9, 2010.

Review content assessed as up-to-date: 7 July 2010.

Citation: Parker MJ, Handoll HHG. Gamma and other cephalocondylic intramedullary nails versus extramedullary implants for extracapsular hip fractures in adults. Cochrane Database of Systematic Reviews 2010, Issue 9. Art. No.: CD000093. DOI: 10.1002/14651858.CD000093.pub5.

Copyright (C) 2010 The Cochrane Collaboration. Published by John Wiley \& Sons, Ltd.

\begin{abstract}
A B S T R A C T
Background

Two types of implants used for the surgical fixation of extracapsular hip fractures are cephalocondylic intramedullary nails, which are inserted into the femoral canal proximally to distally across the fracture, and extramedullary implants (e.g. the sliding hip screw).

Objectives

To compare cephalocondylic intramedullary nails with extramedullary implants for extracapsular hip fractures in adults.

Search strategy

We searched the Cochrane Bone, Joint and Muscle Trauma Group Specialised Register (April 2010), The Cochrane Central Register of Controlled Trials (The Cochrane Library 2010, Issue 1), MEDLINE (1950 to March 2010), EMBASE (1980 to 2010 Week 13), and other sources.
\end{abstract}

\section{Selection criteria}

All randomised and quasi-randomised controlled trials comparing cephalocondylic nails with extramedullary implants for extracapsular hip fractures.

Data collection and analysis

Both authors independently assessed trial quality and extracted data. Wherever appropriate, results were pooled.

Main results

We included 43 trials containing predominantly older people with mainly trochanteric fractures.

Gamma and other cephalocondylic intramedullary nails versus extramedullary implants for extracapsular hip fractures in adults (Review) Copyright $(2010$ The Cochrane Collaboration. Published by John Wiley \& Sons, Ltd. 
Twenty-two trials (3749 participants) compared the Gamma nail with the sliding hip screw (SHS). The Gamma nail was associated with increased risk of operative and later fracture of the femur and increased reoperation rate. There were no major differences between implants in wound infection, mortality or medical complications.

Five trials (623 participants) compared the intramedullary hip screw (IMHS) with the SHS. Fracture fixation complications were more common in the IMHS group. Results for post-operative complications, mortality and functional outcomes were similar in both groups.

Three trials (394 participants) showed no difference in fracture fixation complications, reoperation, wound infection and length of hospital stay for proximal femoral nail (PFN) versus the SHS.

None of the 10 trials (1491 participants) of other nail versus extramedullary implant comparisons for trochanteric fractures provided sufficient evidence to establish definite differences between the implants under test.

Two trials (65 participants) found intramedullary nails were associated with fewer fracture fixation complications than fixed nail plates for unstable fractures at the level of the lesser trochanter.

Two trials (124 participants) found a tendency to less fracture healing complications with the intramedullary nails compared with fixed nail plates for subtrochanteric fractures.

\section{Authors' conclusions}

With its lower complication rate in comparison with intramedullary nails, and absence of functional outcome data to the contrary, the SHS appears superior for trochanteric fractures. Further studies are required to confirm whether more recently developed designs of intramedullary nail avoid the complications of previous nails. Intramedullary nails may have advantages over fixed angle plates for subtrochanteric and some unstable trochanteric fractures, but further studies are required.

\section{PLAIN LANGUAGESUMMARY}

\section{Cephalocondylic intramedullary nails versus extramedullary implants for extracapsular hip fractures in adults}

Fractures of the thigh bone (femur) just below the hip joint capsule (extracapsular hip fractures) may be surgically fixed using a variety of implants. One particular type of implant is the sliding hip screw, which consists of a screw that is inserted into the upper part of the (femur) to bridge (fix) the fracture. This screw can move within a metal barrel connected to a plate that is screwed to the outside of the femur. Implants of this sort of design are called 'extramedullary'. Intramedullary implants are nails inserted from the top of the femur into the inner cavity of the femur bone ('the medulla') and held in place with screws. This review compared these two types of implants in predominantly older populations.

The main results were for the comparisons of various types of intramedullary nails with the sliding hip screw. Twenty-two trials, involving 3749 participants, tested the Gamma nail. Five trials, involving 623 participants, tested the intramedullary hip screw (IMHS). Three trials, involving 394 participants, tested the proximal femoral nail. Other trials involved newer varieties of intramedullary nails. Most older trials showed a tendency for the nails to be associated with an increased risk of fracture of the thigh bone both during and after the operation. More recent trials testing newer varieties of nails seemed to avoid this specific problem to some extent. The review found that using intramedullary nails resulted in one extra reoperation in every 50 people. Mortality and, where data were available, other long-term outcomes were similar between the implants.

The review concluded that current evidence supports the continued use of the sliding hip screw for fixing the more common types of extracapsular hip fractures. This may not be the case for some of the more recently developed designs of intramedullary nails or for specific fracture types, but further research is required to confirm this. 


\section{B A C K G R O U N D}

\section{Description of the condition}

Hip fracture is the general term for fracture of the proximal (upper) femur. These fractures can be subdivided into intracapsular fractures (those occurring within or proximal to the attachment of the hip joint capsule to the femur) and extracapsular (those occurring outside or distal to the hip joint capsule). Extracapsular hip fractures are defined as those fractures of the proximal femur within the area of bone from the attachment of the hip joint capsule to a level of five centimetres below the distal (lower) border of the lesser trochanter. Other terms used to describe these fractures include trochanteric, subtrochanteric, pertrochanteric and intertrochanteric fractures. As implied above, these terms reflect the proximity of these fractures to the greater and lesser trochanters (Parker 2002).

Numerous subdivisions and classification methods exist for these fractures. The most practical classification, and that used for this review, is the basic division into four types: stable trochanteric fractures (AO classification type A1) (Muller 1991), unstable trochanteric (AO classification type $\mathrm{A} 2$ ), those fractures at the level of the lesser trochanter (transtrochanteric or AO classification type A3) and subtrochanteric fractures. Stable trochanteric fractures are two part fractures in which the fracture line runs obliquely between the lesser and greater trochanter of the femur. Unstable trochanteric fractures again have an oblique fracture line running between the trochanters but in addition there is comminution of the fracture site. The comminution fragments may be the lesser trochanter, greater trochanter or both these parts of the femur. Those fractures at the level of the lesser trochanter (AO A3, transtrochanteric) have a slightly more distally based fracture line which either runs transversely at the level of the lesser trochanter or in an oblique direction that is opposite to that of the stable and unstable trochanteric fractures. These fractures may be two part or comminuted. This fracture pattern allows the femur to be displaced medially due to the pull of the abductor muscles. Subtrochanteric fractures are those fractures in which the fracture crossing the femur is predominately found within the five centimetres of bone immediately below the lesser trochanter. These fractures may be two part or comminuted and, in some instances, the fracture may extend proximally into the trochanteric region or distally into the shaft of the femur.

\section{Description of the intervention}

Operative treatment of extracapsular hip fractures was introduced in the 1950s using a variety of different implants. Implants may be either extramedullary or intramedullary in nature. The most commonly used extramedullary implant is the sliding hip screw (SHS) which is synonymous with the term compression hip screw and equivalent models such as the Dynamic, Richards or Ambi hip screws. The SHS consists of a lag screw passed up the femoral neck to the femoral head. This lag screw is then attached to a plate on the side of the femur. These are considered 'dynamic' implants as they have the capacity for sliding at the plate/screw junction to allow for collapse at the fracture site. The Medoff plate (Medoff 1991) is a modification of the sliding hip screw. The difference is that the plate has an inner and outer sleeve, which can slide between each other. This creates an additional capacity for sliding to occur at the level of the lesser trochanter as well as at the lag screw. Sliding at the lag screw can be prevented with a locking screw to create a 'one way' sliding Medoff instead of a 'two way' sliding Medoff. At a later date the locking device on the lag screw can be removed to 'dynamise' the fracture.

Static implants include the fixed nail plates such as the Jewett and the McLaughlin nail plates. The 90 or 95-degree blade plate is also a static implant of a more recent design. Though, theoretically, the dynamic condylar screw plate has the capacity for sliding at the screw plate junction, it is more likely to act as a fixed device when used at the hip, with no slide occurring.

Intramedullary nails used for internal fixation of extracapsular fractures can either be inserted from distal to proximal (condylocephalic nails) or from proximal to distal (cephalocondylic nails). Condylocephalic nails are inserted at the level of the femoral condyle above the knee and passed across the trochanteric fracture and up into the femoral head. These are the subject of another review (Parker 1998). Cephalocondylic nails are inserted through the greater trochanter of the femur and secured by a cross pin or screw which is passed up the femoral neck into the femoral head. Theoretical biomechanical advantages of these intramedullary nails over screw and plate fixation are attributed to a reduced distance between the hip joint and the implant, which diminishes the bending moment across the implant/fracture construct. Examples of these intramedullary nails are the Gamma nail, the intramedullary hip screw (IMHS), the proximal femoral nail (PFN), the proximal femoral nail antirotation (PFNA), the Targon PF (proximal femoral) nail, the Holland nail and the Kuntscher-Y nail (Cuthbert 1976). These nails plus an experimental nail tested in Dujardin 2001 are described in Table 1. A review comparing different intramedullary nails for these fractures is available (Parker 2006). 
Table 1. Intramedullary nails evaluated by the included trials

\begin{tabular}{ll}
\hline Name & Description \\
\hline Gamma nail & $\begin{array}{l}\text { The Gamma nail (Howmedica Ltd) was introduced in the late } 1980 \text { s for the treat- } \\
\text { ment of extracapsular hip fractures. The implant consists of a sliding lag screw } \\
\text { which passes through a short intramedullary nail. One or two screws may be passed } \\
\text { through the nail tip to secure it to the femoral shaft (distal locking). Theoretical } \\
\text { advantages of this implant are due to a percutaneous insertion technique and in- } \\
\text { clude reduced blood loss, reduced sepsis, minimal tissue trauma and short operating } \\
\text { time. Modifications to the design of the Gamma nail and its instrumentation have } \\
\text { occurred since its introduction. The trochanteric Gamma nail is referred to as a } \\
\text { third generation Gamma nail. It is shorter in length than the standard Gamma nail } \\
\text { (200 mm versus } 180 \mathrm{~mm}) \text {, has a lower mediolateral curvature (4 degrees) and has } \\
\text { a diameter of } 17 \mathrm{~mm} \text { proximally and } 11 \text { mm distally. The long Gamma nail has a } \\
\text { range of different lengths from } 280 \text { to } 460 \text { mm with two distal locking screws. }\end{array}$ \\
\hline
\end{tabular}

Intramedullary hip screw (IMHS)

The IMHS (Richards Medical Ltd) - length $210 \mathrm{~mm}$ - was introduced in 1995 for the treatment of extracapsular femoral fractures. Like the Gamma nail, it consists of a nail inserted via the greater trochanter into the medullary cavity and a lag screw, which is passed up the femoral neck to the head.

Proximal femoral nail (PFN)

The PFN (Synthes Ltd) - length $240 \mathrm{~mm}$ - was introduced in 1998 for the treatment of extracapsular fractures. Like the Gamma and IMHS, it consists of a nail inserted via the greater trochanter in to the medullary cavity. Two proximal lag screws are passed up the femoral neck to the head.

Proximal femoral nail antirotation (PFNA)

The PFNA (Synthes Ltd) - length 170, 200 or $240 \mathrm{~mm}$ - is similar to the PFN nail apart from not having two proximal lag screws but instead a single helically-shaped blade.

Targon PF (proximal femoral) nail

The Targon PF nail - length $220 \mathrm{~mm}$ - is also inserted in a similar fashion into the intramedullary cavity. Proximally, this nail has a sliding lag screw and an antirotation pin.

Holland nail

The Holland nail (Biomet ltd) is like the Gamma and IMHS; it consists of a nail inserted via the greater trochanter in to the medullary cavity. Two proximal lag screws are passed up the femoral neck to the head.

Experimental nail (reported in Dujardin 2001)

An experimental mini-invasive static intramedullary nail, which is not commercially available, is reported in Dujardin 2001. This consists of an intramedullary nail which is 170 millimetres long with a distal diameter of 12 millimetres and a proximal diameter of 13 millimetres. There are two five millimetre distal locking holes. The proximal hold of the femur is with two seven millimetre cannulated screws which diverge at a 30 degrees angle. Unlike the other proximal femoral nails, there is no sliding mechanism within the nail construct.

Kuntscher-Y nail

The Kuntscher-Y nail (Cuthbert 1976) is an early design of an intramedullary nail. It consists of a side arm and a separate slotted Kuntscher nail. The side arm is passed up the femoral neck, and then attached to an alignment jig to enable a slotted

Gamma and other cephalocondylic intramedullary nails versus extramedullary implants for extracapsular hip fractures in adults (Review) 4 Copyright $(2010$ The Cochrane Collaboration. Published by John Wiley \& Sons, Ltd. 
Kuntscher nail to be passed via the greater trochanter through a hole in the side arm and distally within the medullary cavity. The assembled implant construct has no capacity for sliding at the side arm and neither has it the capacity for distal locking.

\section{Why it is important to do this review}

The controversy over the choice of implant, specifically the use of intramedullary nails versus sliding hip screws, for extracapsular hip fractures continues. Indeed, recent studies reporting a rapid increase in the use of intramedullary nails in the USA have pointed out, citing this review, that this phenomenon is not supported by the available evidence (Anglen 2008; Forte 2008). The availability of new evidence, often on new implants that are aimed at avoiding the complications, specifically operative and later femoral fracture, of intramedullary fixation, point to the need for this update of our review, which continues to compare different types of cephalocondylic nails with extramedullary implants.

\section{O B JE C T IVES}

To assess the relative effects of cephalocondylic intramedullary nails versus extramedullary fixation implants for treating extracapsular proximal femoral (hip) fractures in adults. Effects were assessed in terms of 'operative details' (duration of surgery, exposure to ionising radiation, blood loss); 'fracture fixation complications', including wound infection; 'post-operative complications' and length of hospital stay; 'anatomical restoration'; and 'final outcome measures' (mortality, functional outcome and pain).

\section{METHODS}

\section{Criteria for considering studies for this review}

\section{Types of studies}

uAll randomised or quasi-randomised (e.g. alternation) controlled trials comparing any design of cephalocondylic intramedullary nail with any design of extramedullary fixation implant.

\section{Types of participants}

Skeletally mature adults with an extracapsular proximal femoral fracture (trochanteric or subtrochanteric), whether stable or unstable.

\section{Types of interventions}

Surgical fixation of the fracture with a cephalocondylic intramedullary nail compared with using an extramedullary implant.

\section{Types of outcome measures}

The following outcomes were sought.

1. Operative details

- length of surgery (in minutes)

- operative blood loss (in millilitres)

- number of patients transfused

- radiographic screening time (in seconds or minutes)

2. Fracture fixation complications

- operative fracture of the femur (around or below the implant, but excluding comminution of the fracture site)

- later fracture of the femur (around or below the implant)

- cut-out of the implant from the femoral head

- non-union of the fracture

- detachment of the implant from the femur

- breakage of the implant

- reoperation (within the follow-up period of the study)

- wound infection: any (i.e. deep or superficial) or all deep wound infection (i.e. infection beneath the deep fascia)

- wound haematoma

3. Post-operative complications

- pressure sores

- pneumonia

- thromboembolic complications (deep vein thrombosis or pulmonary embolism)

- any medical complication (as detailed in each individual study, excluding wound infections)

- length of hospital stay (in days)

4. Anatomical restoration

- leg shortening (preferably using the criterion of a $>2 \mathrm{~cm}$ reduction)

- varus deformity

- external rotation deformity (preferably using the criterion of $\mathrm{a}>20$ degrees deformity)

5. Final outcome measures

- mortality (within the follow-up period of the study)

- pain (persistent pain at the final follow-up assessment) 
- mobility and use of walking aids

- failure to return to pre-fracture residential status

- functional activities of daily living

- composite function and hip scores

In our methodology quality assessment tool (see Methods) we have specified six months follow-up for all surviving trial participants as being acceptable. However, longer-term follow-up of at least one year or, better still, two years, is preferable to get a full view on mortality, function and reoperation resulting from complications and implant failure.

\section{Search methods for identification of studies}

\section{Electronic searches}

We searched the Cochrane Bone, Joint and Muscle Trauma Group Specialised Register (April 2010), the Cochrane Central Register of Controlled Trials (2010, Issue 1), MEDLINE (1950 to March week 5 2010) and EMBASE (1980 to 2010 Week 13). We searched the WHO International Clinical Trials Registry Platform Search Portal, Current Controlled Trials, and the UK National Research Register (NRR) Archive (all to April 2009) to identify ongoing and recently completed trials. No language or publication restrictions were applied.

The generic search strategies for hip fracture trials run in The Cochrane Library (Wiley Interscience) and MEDLINE (2002 onwards) are shown in Appendix 1. This MEDLINE search was combined with all three stages of the optimal trial search strategy (Higgins 2006). The general search strategy for hip fracture trials in EMBASE (2002 onwards) is shown in Appendix 1.

\section{Searching other resources}

We searched reference lists of articles and our own reference databases. We included the findings from handsearches of the British Volume of the Journal of Bone and Joint Surgery supplements (1996 to 2006), abstracts of the American Orthopaedic Trauma Association annual meetings (1996 to 2006) and American Academy of Orthopaedic Surgeons annual meetings (2004 to 2007). We also included handsearch results from the final programmes of SICOT (1996 and 1999) and SICOT/SIROT (2003), EFORT (2007) and the British Orthopaedic Association Congress (2000, 2001, 2002, 2003, 2005 and 2006). Up to 2007, we scrutinised weekly downloads of "Fracture" articles in new issues of Acta Orthopaedica Scandinavica (subsequently Acta Orthopaedica); American Journal of Orthopedics; Archives of Orthopaedic and Trauma Surgery; Clinical Orthopedics and Related
Research; Injury; Journal of the American Academy of Orthopedic Surgeons; Journal of Arthroplasty; Journal of Bone and Joint Surgery (American and British Volumes); Journal of Orthopedic Trauma; Journal of Trauma; Orthopedics from AMEDEO. We contacted Howmedica Ltd UK (manufacturers of the Gamma nail) and Richards Ltd (manufacturers of the Intramedullary Hip Screw) and corresponded with colleagues.

Details of other searches conducted prior to 2000 are documented in Appendix 2.

\section{Data collection and analysis}

\section{Selection of studies}

Both review authors independently screened downloads from electronic databases and other sources for potentially eligible trials. We then independently selected trials for inclusion, usually based on full text reports. Trial authors were approached for further details of trial methods where necessary. Any disagreement was resolved by discussion.

\section{Data extraction and management}

Data for the outcomes listed above were independently extracted by both authors using a data extraction form. Any differences were resolved by discussion. Where necessary and practical, we contacted trialists for additional data and clarification.

\section{Assessment of risk of bias in included studies}

In the update of the review (2010), three aspects of risk of bias were assessed by one author $(\mathrm{HH})$ and reported. These were sequence generation, allocation concealment and surgeons' experience with the devices. In this assessment, incomplete or a lack of information on sequence generation or allocation concealment was judged as 'unclear' risk of bias unless the trial was quasi-randomised, in which case both were rated 'no'. For risk of bias related to surgeons' experience with the devices prior to commencement of the trial, this was generally rated as 'high' where there was a lack of information on measures taken to avoid learning curve problems, often in the context of a large number of operating surgeons. In addition, both authors independently assessed, without masking, each trial for 11 aspects of internal and external validity (see Table 2). Any disagreement was resolved by discussion. Care was taken to ensure consistency between item 1 (allocation concealment) and item 5 (surgeons' experience) of this assessment and the risk of bias judgements; both items were considered key items of assessment of trial validity in this and all previous versions of the review. Trial authors were contacted for further details of trial methodology where this was unclear. 
Table 2. Methodological quality assessment scheme

\begin{tabular}{l|l}
\hline Items & Scores \\
\hline 1. Was there clear concealment of allocation? & $\begin{array}{l}\text { Score } 3 \text { if allocation was concealed (e.g. numbered sealed opaque } \\
\text { envelopes drawn consecutively). Score } 2 \text { if there was a possible } \\
\text { chance of disclosure before allocation. Score } 1 \text { if the method of } \\
\text { allocation concealment or randomisation was not stated or was } \\
\text { unclear. Score } 0 \text { if allocation concealment was clearly not con- } \\
\text { cealed such as those trials using quasi-randomisation (e.g. even or } \\
\text { odd date of birth). }\end{array}$ \\
\hline
\end{tabular}

2. Were the inclusion and exclusion criteria clearly defined?

Score 1 if text states the type of fracture and which patients were included and/or excluded. Otherwise score 0 .

3. Were the outcomes of trial participants who withdrew or excluded after allocation described and included in an intention-totreat analysis?

Score 1 if yes or text states that no withdrawals occurred, or data are presented that, by clearly showing 'participant flow', allow this to be inferred. Otherwise score 0 .

4. Were the treatment and control groups adequately described at entry and if so were the groups well matched or appropriate covariate adjustment made?

Score 1 if at least four admission details given (e.g. age, sex, mobility, function score, mental test score, fracture type) with no significant difference between groups or appropriate adjustment made. Otherwise score 0.

5. Did the surgeons have prior experience of the operations they performed in the trial, prior to its commencement?

Score 1 if text states there was an introductory period or that surgeons were experienced. Otherwise score 0.

6. Were the care programmes other than trial options identical?

Score 1 if text states they were or if this can be inferred. Otherwise score 0 .

7. Were the outcome measures clearly defined in the text with a Score 1 if yes. Otherwise score 0.

definition of any ambiguous terms encountered?

8. Were the outcome assessors blind to assignment status?

Score 1 if assessors of pain and function at follow-up were blinded to treatment outcome. Otherwise score 0 .

9. Was the timing of outcome measures appropriate? A minimum Score 1 if yes. Otherwise score 0. of six-months follow-up for all surviving trial participants.

10. Was loss to follow-up reported and if so were less than $5 \%$ of Score 1 if yes. Otherwise score 0 . trial participants lost to follow-up?

11. Were the authors able to provide supplementary details of the Score 1 if yes. Otherwise score 0. trial in addition to published data?

\section{Dealing with missing data}

Where the number of participants providing data for any particular outcome was reported, we used these provided data. In studies for which a number of events were reported, but the denominator was unclear, we used numbers randomised or alive at follow-up. Sensitivity analyses using numbers randomised were done for any outcome for which denominators other than number randomised 
had been used, in order to assess any impact of missing data on results.

\section{Assessment of heterogeneity}

Heterogeneity between comparable trials was assessed by inspection of the overlap of confidence intervals amongst included studies and tested using a standard $\mathrm{Chi}^{2}$ test, with additional consideration of the $\mathrm{I}^{2}$ statistic (Higgins 2003); an $\mathrm{I}^{2}$ of $50 \%$ or over representing substantial heterogeneity.

\section{Data synthesis}

For dichotomous outcomes, we reported risk ratios (RR) with 95\% confidence intervals and for continuous outcomes, mean differences (MD) and 95\% confidence intervals. Results of comparable groups of trials were pooled, using the Mantel-Haenszel method for dichotomous outcomes, and inverse variance for continuous data, and the fixed-effect model; unless heterogeneity was substantial (nominally, $\mathrm{P}<0.10 ; \mathrm{I}^{2}>50 \%$ ), when the random-effects model was used.

\section{Subgroup analysis and investigation of heterogeneity}

We recognised the possibility that developments of individual intramedullary or extramedullary implant designs, and implants produced by different manufacturers, while possessing many common features, might show some differences in effectiveness or adverse effects. We have therefore presented some analyses in which studies are grouped by implant design as well as others without subgroups. These enable readers to inspect the data, but where appropriate, we have explored the possibility that implant types do perform differently by performing test for subgroup differences. Some exploratory subgroup analyses, based on allocation concealment and the reportage of surgical experience, were performed to test potential bias. To test whether the subgroups were statistically significantly different from one another, we tested the interaction using the technique outlined by Altman 2003 .

\section{Sensitivity analysis}

Some exploratory sensitivity analyses, based on allocation concealment and the reportage of surgical experience, were performed to test potential bias. Sensitivity analyses using numbers randomised were done for any outcome for which denominators other than number randomised had been used, in order to assess any impact of missing data on results.

\section{R E S U L T S}

\section{Description of studies}

See: Characteristics of included studies; Characteristics of excluded studies; Characteristics of studies awaiting classification; Characteristics of ongoing studies.

In all 43 trials were included, 28 were excluded, three are awaiting assessment and five are ongoing. Details of the individual studies of these various groups are respectively in the Characteristics of included studies, Characteristics of excluded studies, Characteristics of studies awaiting classification; and Characteristics of ongoing studies.

Seven new trials were included in this update. Five involved participants with trochanteric fractures: Barton 2010 compared the long Gamma nail with the sliding hip screw (SHS); Little 2008 compared the long Holland nail with the SHS; Varela-Egocheaga 2009 compared the Gamma nail with the percutaneous compression plate (PCCP); Verettas 2010 compared two intramedullary nails (Gamma nail, Endovis BA nail) with the SHS; and Zou 2009 compared the proximal femoral nail antirotation with the SHS. The remaining two trials involved people with subtrochanteric fractures. Lee 2007 compared the Russel-Taylor Recon intramedullary nail with the dynamic condylar screw; and Rahme 2007 compared the proximal femoral nail (PFN) with the 95 degree blade plate. Two trials (Little 2008, formerly Fenando 2006; Rahme 2007, formerly Harris 2005) were in 'Studies awaiting classification' in the previous version of the review.

One newly identified study (Rafiq 2009) was added to studies awaiting assessment. Nine newly identified studies (Cao 2009; Hu 2006; Liu 2008; Nouisri 2006; Pan 2009; Saarenpaa 2009; Zhang 2009; Zhao 2009; Ziran 2009) were excluded. Four more ongoing studies were identified (Matre; Molnar; REGAIN; Schipper). The trial populations for the various implant comparisons in the included trials are summarised below.

\section{Gamma nail versus SHS}

Twenty-two trials (Adams 2001; Ahrengart 1994; Benum 1994; Bridle 1991; Butt 1995; Goldhagen 1994; Guyer 1991; Haynes 1996; Hoffman 1996; Kukla 1997; Kuwabara 1998; Leung 1992; Marques Lopez 2002; Michos 2001; Mott 1993; O’Brien 1995; Ovesen 2006; Pahlpatz 1993; Papasimos 2005; Park 1998; Radford 1993; Utrilla 2005) compared the Gamma nail with the SHS in 3749, predominantly older, people. Benum 1994 was a multi-centre study for which data were only available for a subgroup of hospitals. The other multi-centre study (Ahrengart 1994) was based in Scandinavian countries. Since the results for participants with subtrochanteric fractures and 66 others who were lost to follow-up were not published in the full report of this trial (Ahrengart 2002), we continue to present the results from two centres reported in Fornander 1994. This means that the results for only 3080 trial participants, with 3082 fractures, are included in this review. 
Eight trials (Ahrengart 1994; Benum 1994; Butt 1995; Goldhagen 1994; Guyer 1991; Haynes 1996; Michos 2001; Mott 1993) included subtrochanteric fractures as well as trochanteric fractures. Where recorded, the mean ages of trial participants ranged between 73 and 84 years and the proportion of male patients varied from $15 \%$ to $40 \%$ in individual studies.

\section{Intramedullary hip screw (IMHS) versus SHS}

The five trials (Baumgaertner 1998; Hardy 1998: Harrington 2002; Hoffmann 1999, Mehdi 2000) comparing the IMHS with the SHS involved a total of 623 people with 627 stable or unstable trochanteric fractures. The mean ages of the participants of individual trials were between 76 and 83 years and, where reported, proportion of males varied from $20 \%$ to $34 \%$.

Full published reports were available for four trials (Baumgaertner 1998; Hardy 1998; Harrington 2002, Hoffmann 1999). A limited translation from German was obtained for Hoffmann 1999. A conference abstract (Hardy 1999) presenting the results of 160 people at 18 months follow-up is available for Hardy 1998 but, pending clarification of the limited results presented in the abstract, so far we have not included the results for the extra 60 participants. Mehdi 2000 has only been reported as a conference abstract, however unpublished material for this trial indicate that the limited results in the abstract applied to the whole trial population.

\section{Proximal femoral nail (PFN) versus SHS}

Three trials (Pajarinen 2005; Papasimos 2005; Saudan 2002), compared the proximal femoral nail (PFN) with the SHS in 394 people with trochanteric hip fractures. The mean ages of participants of the three trials ranged between 81 and 83 years, and the proportion of males varied between $22 \%$ to $39 \%$.

\section{Proximal femoral nail antirotation (PFNA) versus SHS}

One trial (Zou 2009) compared the proximal femoral nail antirotation (PFNA) with the SHS in 121 people with trochanteric hip fractures. The mean age of the participants was 65 years, and $22 \%$ were male.

\section{Targon PF (proximal femoral) nail versus SHS}

One trial (Giraud 2005) compared a Targon PF intramedullary nail with the SHS in 60 people with stable or unstable trochanteric fractures. The mean age of trial participants was 82 years and $23 \%$ were male.

\section{Long Holland nail versus SHS}

One trial (Little 2008) compared a long Holland intramedullary nail with the SHS in 190 people with stable or unstable trochanteric fractures. The mean age of trial participants was 83 years and $15 \%$ were male.

\section{Long Gamma nail versus SHS}

One trial (Barton 2010) compared a long Gamma intramedullary nail with the SHS in 210 people with unstable trochanteric fractures. The mean age of trial participants was 83 years and $21 \%$ were male.

\section{Mini-invasive static intramedullary nail versus SHS}

One trial (Dujardin 2001) compared an experimental mini-invasive static intramedullary nail with the SHS in 60 people with stable or unstable trochanteric fractures. The mean age of trial participants was 83.5 years and $20 \%$ were male.

\section{Kuntscher-Y nail versus SHS}

One trial (Davis 1988) compared the Kuntscher-Y nail with the SHS. The 230 participants with trochanteric fractures had a mean age of 81 years and $17 \%$ were male.

\section{Intramedullary nail (two types) versus the SHS}

One study (Verettas 2010) compared two intramedullary nails (38 Gamma, 22 Endovis BA nails) versus the SHS. The 120 participants with trochanteric fractures had a mean age of 80 years and $30 \%$ were male. Follow-up was only for the duration of the hospital stay.

\section{Intramedullary nails (various types) versus Medoff sliding plate}

One trial (Miedel 2005) compared the Gamma nail with a Medoff sliding plate in 217 people with either an unstable trochanteric fracture (189 cases) or a subtrochanteric fracture $(28$ cases). The mean age of participants was 84 years and $19 \%$ were male. Another trial (Ekstrom 2007) compared the proximal femoral nail (PFN) with a Medoff sliding plate in 203 people (out of 210 recruited) with either an unstable trochanteric fracture (172 cases) or a subtrochanteric fracture (31 cases). The mean age of participants was 82 years and $24 \%$ were male.

\section{Gamma nail versus the percutaneous compression plate (PCCP)}

One trial (Varela-Egocheaga 2009) compared the Gamma nail with a PCCP in 80 people with a trochanteric fracture. The mean age of participants was 82 years and $21 \%$ were male. 


\section{Intramedullary nails (various types) versus fixed (static) extramedullary plates for lower trochanteric fractures}

One trial (Pelet 2001) compared the Gamma nail with a blade plate in 26 people (mean age 71 years; $35 \%$ male) with a comminuted trochanteric fracture, classified as Kyle type IV. These fracture patterns approximate to those of type 31A3 fractures in the AO classification of fractures with reversed fracture pattern or transverse fracture lines at the level of the lesser trochanter (Muller 1991). Sadowski 2002 compared the PFN with the dynamic condylar screw in 39 people (mean age 79 years; $31 \%$ male) with type $31 \mathrm{~A} 3$ fractures.

\section{Intramedullary nails (various types) versus fixed (static) extramedullary plates for subtrochanteric fractures}

One trial (Lee 2007) compared the Russell-Taylor Recon nail with a dynamic condylar screw in 66 people (mean age 36 years; $77 \%$ male) with a subtrochanteric fracture; data for an additional 11 participants were excluded from the trial results. Rahme 2007 compared the PFN with a blade plate in 60 people (mean age 70 years; $43 \%$ male) with a subtrochanteric fracture.

\section{Risk of bias in included studies}

Figure 1 shows the risk of bias judgements for individual trials for sequence generation (selection bias), allocation concealment (selection bias) and surgeons' experience (performance bias). These are also described in the Characteristics of included studies, both in the 'Methods' and 'Risk of bias' sections. Figure 2 is a visual presentation of the proportions 'low', 'unclear' and 'high' risk of bias judgements across all the included studies for the three assessed items. These judgements were dependent to a great extent on the quality of reporting of trials and whether clarification had been received from authors on the method of randomisation and surgeons' experience. Low risk of bias judgements on sequence generation were assigned to 14 trials $(33 \%)$ and on allocation concealment for eight trials (19\%). Only five trials provided sufficient evidence of adequate sequence generation and allocation concealment (Baumgaertner 1998; Davis 1988; Hoffman 1996; Ovesen 2006; Pajarinen 2005). All nine quasi-randomised trials (Butt 1995; Goldhagen 1994; Guyer 1991; Hardy 1998; Lee 2007; Leung 1992; Marques Lopez 2002; Park 1998; Verettas 2010) were judged at high risk of bias for both items. In 13 trials, information indicating that surgeons had prior experience with the implants under investigation was sufficient to judge that there was a low risk of related performance bias. However, over half the trials (23/43) were judged at high risk of bias for this item. This included five trials (Baumgaertner 1998; Harrington 2002; Leung 1992; Marques Lopez 2002; Pelet 2001) where there was a confirmed disparity in the experience of surgeons with respect to the devices being compared. More details of this and randomisation methods are presented below. 
Figure I. Risk of bias summary: judgements about each risk of bias item for each included study.

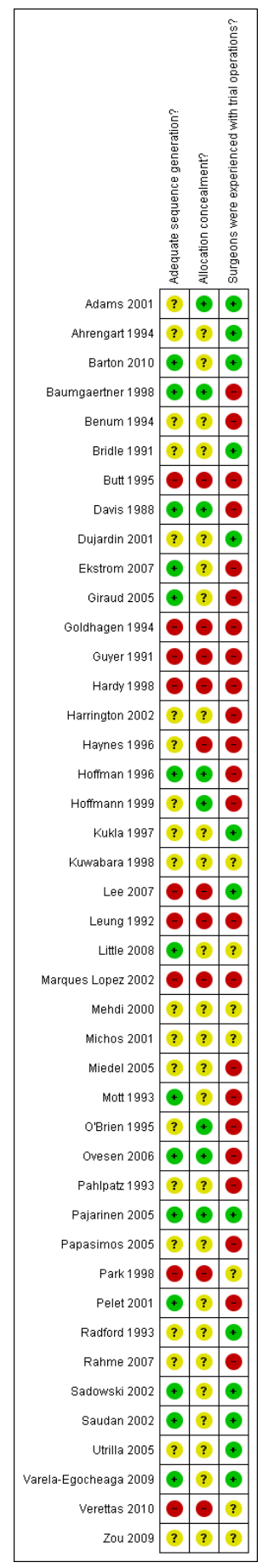

Gamma and other cephalocondylic intramedullary nails versus extramedullary implants for extracapsular hip fractures in adults (Review) II Copyright $\odot 2010$ The Cochrane Collaboration. Published by John Wiley \& Sons, Ltd. 
Figure 2. Risk of bias graph: judgements about each risk of bias item presented as percentages across all included studies.

\begin{tabular}{|c|c|c|c|c|c|c|}
\hline \multirow{4}{*}{\multicolumn{2}{|c|}{$\begin{array}{r}\text { Adequate sequence generation } \\
\text { Allocation concealment } \\
\text { Surgeons were experienced with trial operations }\end{array}$}} & & & & & \\
\hline & & & & & & \\
\hline & & & & & & \\
\hline & & $0 \%$ & $25 \%$ & $50 \%$ & $75 \%$ & $100 \%$ \\
\hline Yes (low risk of bias) & ]Unclear & & & (high & bias) & \\
\hline
\end{tabular}

The results of the methodological assessment for individual trials are given in Appendix 3. These are ordered by comparison; note that Papasimos 2005 appears in two categories. Further details of allocation concealment and randomisation (Item 1), surgeon's experience (Item 5) and assessor blinding (Item 8) are also presented. Sixteen trials randomised using envelopes; these were described as sealed in 14 trials (Adams 2001; Ahrengart 1994; Baumgaertner 1998; Davis 1988; Ekstrom 2007; Harrington 2002; Hoffman 1996; Hoffmann 1999; Kukla 1997; Mehdi 2000; Miedel 2005; Ovesen 2006; Pajarinen 2005; Utrilla 2005), mixed in Benum 1994 and blinded in O'Brien 1995. Seven trials (Baumgaertner 1998; Davis 1988; Hoffman 1996; Hoffmann 1999; O’Brien 1995; Ovesen 2006; Pajarinen 2005) indicated that the randomisation was blinded. Blinded randomisation was also claimed for Pelet 2001, which used the drawing of lots, but safeguards were not described. Computer generated randomised numbers were used for Mott 1993, Sadowski 2002 and Saudan 2002. Computer-mediated randomisation was reported for Little 2008. Giraud 2005 and Varela-Egocheaga 2009 used a random numbers table. A further nine trials were quasi-randomised in which the treatment allocation was inadequately concealed using either alternating patient admission (Guyer 1991; Leung 1992; Verettas 2010), medical record numbers (Goldhagen 1994; Hardy 1998; Lee 2007; Marques Lopez 2002; Park 1998), or an even or odd week of admission (Butt 1995). Though Haynes 1996 used randomisation cards, allocation concealment was deemed unlikely as the imbalance in the treatment group numbers was attributed to surgeons withdrawing a patient from the trial when they considered themselves unfamiliar with the Gamma nail. The remaining trials did not specify their method of randomisation.

Brief details of surgical experience (item 5) as reported for individual trials are given in the Characteristics of included studies.
For several trials, surgeons may have been more experienced with the SHS than the newer implant (the intramedullary nail). This disparity of experience was certainly true for Baumgaertner 1998 and Harrington 2002 where the participating surgeons had experience with using sliding hip screws but not specifically with the IMHS despite being familiar with the techniques involved. Also in Leung 1992, where most of the Gamma nail operations were performed by one senior surgeon with a special interest in intramedullary nailing whilst the SHS operations were performed by a variety of often less experienced surgeons. And in Marques Lopez 2002, where the majority of Gamma nail operations were performed by specialists and conversely the majority of SHS operations were done by junior or senior residents. In addition, surgeons were more experienced with the Gamma nail than with the blade plate in Pelet 2001.

Only four trials (Adams 2001; Harrington 2002; Hardy 1998; Hoffman 1996) included blinded assessment of some outcomes (item 8).

We note the possibility of selective reporting from either those trials apparently completed but for which complete trial data have neither been published nor made available (Ahrengart 1994; Benum 1994; Hogh 1992), or trials which may not have been completed (Pahlpatz 1993; Prinz 1996).

\section{Effects of interventions}

These are presented by the type of cephalocondylic nail being compared with the extramedullary plate device (sliding hip screw, the Medoff plate, or the percutaneous compression plate) and, for four studies, a fixed nail plate (dynamic condylar screw or blade plate). The outcome measures listed earlier were sought for all 
studies and, where available, results are presented in the analyses. Reported outcomes are also listed in the Characteristics of included studies. The key pooled outcomes for all except two (see below) of the femoral nails versus the sliding hip screw are given first, followed by the results for each type of nail. The experimental nature, including the lack of commercial availability, of the miniinvasive intramedullary nail should be noted when viewing the results of this trial and was the reason for not including it at present in the pooled femoral nail analysis. The results for the KuntscherY nail were also not pooled with the other nails because this earlier version of a cephalocondylic nail does not have the capacity for distal locking.

The included trials generally used similar outcome measures with regard to surgical fixation failure and operative details. Wound infection was usually more difficult to quantify and it was not possible to differentiate between superficial and deep wound infection for many of the trials. Mortality was taken as that which occurred within the follow-up period for each study. The outcome measures of residual pain, change in mobility and function are more difficult to quantify and were recorded in far fewer trials. Moreover, because no standardised assessment was used for all trials, only a limited evaluation was possible for these outcomes. Data from each trial which could be pooled are presented graphically. As reported in Methods, we performed sensitivity analyses to explore the effects of our choice for denominators when these were not clearly stated in trial reports. No significant changes in the pooled results were encountered.

\section{Femoral nails (Gamma, IMHS, PFN, Targon PF, Holland nail, PFNA, Long Gamma nail) versus the sliding hip screw (SHS)}

To avoid double counting of the participants of the SHS group, where available the combined data for the Gamma nail and PFN groups of Papasimos 2005 are presented in a separate sub-category (8 in Analyses 1.2 to 1.6). Thus the results for Papasimos 2005 do not appear in the Gamma nail (sub-category 1) or PFN (subcategory 3) analyses. The pooled results for these nails demonstrate a significantly lower incidence for operative fracture of the femur (see Analysis 1.2: 37/1963 versus 7/1968; RR 3.16, 95\% CI 1.73 to 5.79) and later fracture of the femur (see Analysis 1.3:39/1933 versus 2/1916; RR 5.22, 95\% CI 2.56 to 10.64 ) in favour of the SHS. Although dominated by the results from the Gamma nail, there was remarkable homogeneity in the results of the trials within and between the separate categories for these outcomes. These complications contribute to the significantly greater reoperation rate for femoral nails (see Analysis 1.6: 108/1948 versus 70/1961; RR $1.49,95 \%$ CI 1.12 to 1.98 ).

Pooled results for cut-out (see Analysis 1.4), non union (see Analysis 1.5), deep wound infection (see Analysis 1.7) and mortality (see Analysis 1.8) show no difference between the two types of implant, and again show uniformity. Far fewer data were available for the three other outcomes (length of surgery, pain and non return to previous residence or dead) presented graphically (see Analysis 1.1, Analysis 1.9 and Analysis 1.10 respectively); none showed a statistically significant difference between the two groups. The heterogeneity in the length of surgery results continues to be striking.

\section{Individual comparisons}

\section{Gamma nail versus the sliding hip screw (SHS)}

Data for 3080 people were available from the 22 randomised controlled trials (Adams 2001; Ahrengart 1994; Benum 1994; Bridle 1991; Butt 1995; Goldhagen 1994; Guyer 1991; Haynes 1996; Hoffman 1996; Kukla 1997; Kuwabara 1998; Leung 1992; Marques Lopez 2002; Michos 2001; Mott 1993; O’Brien 1995; Ovesen 2006; Pahlpatz 1993; Papasimos 2005; Park 1998; Radford 1993; Utrilla 2005) comparing the Gamma nail with the SHS. Eight trials (Ahrengart 1994; Benum 1994; Butt 1995; Goldhagen 1994; Guyer 1991; Haynes 1996; Michos 2001; Mott 1993) included subtrochanteric fractures as well as trochanteric fractures. It is important to note that data are unavailable and may be lost for over 1000 trial participants from either those trials apparently completed but for which complete trial data have neither been published nor made available (Ahrengart 1994; Benum 1994; Hogh 1992) or trials which may not have been completed (Pahlpatz 1993; Prinz 1996). Different versions of the Gamma nail were used: the early studies used the 'Gamma 1' nail and the later studies used the Gama 3 or trochanteric Gamma nail (Ovesen 2006; Papasimos 2005; Utrilla 2005). The results of all these trials have been pooled in this review. Inspection of the analyses for various fracture fixation complications and reoperation shows no indication of a marked difference in results in the two groups of trials; overall, there was no statistical heterogeneity in any of the pooled results ( $\mathrm{I}^{2}=0 \%$ in all analyses). We subgrouped these trials by Gamma nail design (Gamma 1 and Trochanteric Gamma nail) for operative fracture and reoperation.

\section{Operative details}

Most trials reporting length of surgery indicated that there was no difference or no significant difference between the two implants for this outcome (Bridle 1991; Butt 1995; Goldhagen 1994; Hoffman 1996; Leung 1992; Kukla 1997; Kuwabara 1998; Marques Lopez 2002; Mott 1993; Radford 1993). Five trials, however, found increased operating times for the Gamma nail (Ahrengart 1994; Benum 1994; Haynes 1996; O’Brien 1995; Ovesen 2006). Conversely, Adams 2001 and Park 1998 reported a significant reduction in operating times for the Gamma nail. This probably applied also to Papasimos 2005. Data for Leung 1992 which also showed a significant reduction in operating times for the Gamma nail were removed from the analysis as they were inconsistent with the statements in the text. Pooled results of the six trials (see Analysis 2.1) providing data for length of surgery showed no evidence of 
difference between the two implants but also considerable heterogeneity $\left(\mathrm{chi}^{2}=34.80, \mathrm{P}<0.00001 ; \mathrm{I}^{2}=86 \%\right)$.

There were no significant differences for blood loss or for transfusion requirements reported in 12 studies (Adams 2001; Ahrengart 1994; Benum 1994; Bridle 1991; Butt 1995; Goldhagen 1994; Guyer 1991; Kukla 1997; Kuwabara 1998; Mott 1993; O’Brien 1995; Papasimos 2005). Others (Haynes 1996; Leung 1992; Park 1998; Radford 1993) found a significantly lower blood loss for the Gamma nail, as did Fornander (Fornander 1994) in the twocentre analysis for Ahrengart 1994. Michos 2001 also reported a lower blood loss for the Gamma nail group but did not indicate if this was a statistically significant result. One study (Hoffman 1996) found an increased blood loss for the Gamma nail. Whilst data from five studies (Adams 2001; Kukla 1997; Leung 1992; O'Brien 1995; Ovesen 2006) are shown in Analysis 2.2, the lack of available data from other trials means that no firm conclusion can be drawn. The significant heterogeneity of the pooled results $\left(\mathrm{chi}^{2}=8.31, \mathrm{P}=0.08 ; \mathrm{I}^{2}=52 \%\right)$ can be attributed to the inclusion of the more extreme results of Leung 1992; removal of these reveals the more homogenous results of the other four trials (mean difference $-11.64 \mathrm{ml}, 95 \% \mathrm{CI}-40.14$ to $16.85, \mathrm{chi}^{2}=0.71, \mathrm{P}=$ 0.87; analysis not shown). The three trials (Adams 2001; Ovesen 2006; Utrilla 2005) reporting the numbers of people receiving blood transfusion had significantly heterogeneous results $\left(\mathrm{chi}^{2}=\right.$ 9.77, $\mathrm{P}=0.008$ ); when pooled these showed no significant difference between the two groups (see Analysis 2.3).

Seven studies reported radiographic screening time. Goldhagen 1994, Marques Lopez 2002 and Papasimos 2005 reported that the increased time for the Gamma nail did not reach statistical significance. Data for the other four trials, all of which had statistically significant findings, are presented in Analysis 2.4. Pooling of the limited data was not done in view of the very major heterogeneity $\left(\mathrm{chi}^{2}=130.84, \mathrm{P}<0.00001\right)$, with Leung 1992 and Utrilla 2005 reporting a significantly lower screening time for the Gamma nail and the other two studies (Hoffman 1996; O'Brien 1995), a significantly higher time. While we conjecture that the results for Leung 1992 may reflect the disparate experience of the surgeons performing the two operations in this trial, this probably does not apply to Utrilla 2005.

\section{Fracture fixation complications}

Pooled data from 18 trials shows the incidence of operative fracture of the femoral diaphysis is significantly increased when the Gamma nail is used (see Analysis 2.5: 27/1351 versus 6/1379; RR 3.02, $95 \%$ CI 1.51 to 6.03 ). (Visually, no obvious trend in the incidence of this outcome is observed when the trials are arranged by date of publication.) Test for interaction showed no statistically significant difference (two tail z-test $=0.656$ ) between the two Gamma nail designs. When the trials were subgrouped (see Analysis 2.6) according to the trial report of surgeon's experience with the devices used, the test of interaction showed no statisti- cally significant difference (two tail z-test $=0.374$ ) in results of the trials where the surgeons were reported to be experienced with the devices and those trials where either no information was provided or a lack of prior experience was reported.

Subsequent fracture of the femur around the implant occurred in 35 cases of Gamma nailing but in only two cases of SHS fixation (see Analysis 2.7: 35/1332 versus 2/1341; RR 5.23, 95\% CI 2.46 to 11.14$)$.

Pooled data for cut-out of the implant from the femoral head showed no difference between implants (see Analysis 2.8: 46/1334 versus 41/1361; RR 1.15, 95\% CI 0.76 to 1.72). Analysis 2.9 shows the trials subgrouped by reported experience of surgeons with the devices: there was no statistically significant difference between the two subgroups (test for interaction: two tail z-test $=0.539$ ). Where reported, there was also no difference in the incidence of non-union (or non healed fractures) (see Analysis 2.10), or time to union or for fracture healing (no analyses shown). Fracture of the femur was the main reason for a significantly increased reoperation rate for the Gamma nail (see Analysis 2.11, pooled results from 18 studies: 86/1320 versus 52/1345; RR 1.66, $95 \%$ CI 1.19 to 2.31 ). Test for interaction showed no statistically significant difference (two tail z-test $=0.347$ ) between the two Gamma nail designs.

Wound infection (presented as either any infection or deep wound infection) and, when reported, wound haematoma showed no significant difference between the two implants as shown in Analysis 2.12 .

\section{Post-operative complications}

The available data showed no statistically significant differences between implants for the complications of pneumonia (nine studies: see Analysis 2.13), pressure sores (five studies: see Analysis 2.14), thromboembolic complications (12 studies: see Analysis 2.15), and any medical complications other than wound infection or haematoma (six studies: see Analysis 2.16).

With the exception of Michos 2001, all studies reporting hospital stay stated there were no differences or no significant differences in this outcome between the two implants (Ahrengart 1994; Benum 1994; Bridle 1991; Butt 1995; Goldhagen 1994; Haynes 1996; Hoffman 1996; Kukla 1997; Leung 1992; Marques Lopez 2002; O’Brien 1995; Ovesen 2006; Papasimos 2005; Radford 1993). This is supported by the limited data available for pooling (five trials: see Analysis 2.17).

\section{Anatomical restoration}

Three measures of anatomical deformity are presented in Analysis 2.18.

Pooled data on limb shortening from three trials, two (Kukla 1997; Leung 1992) which reported numbers of people with over two centimetres of shortening and one (Guyer 1991) which reported 
numbers of people with over one centimetre of shortening, showed no statistically significant differences between implants (RR 0.46, 95\% CI 0.21 to 1.03). All the three other trials (Ahrengart 1994; Hoffman 1996; Utrilla 2005) reporting this outcome found no significant differences between the two groups.

The results, which tended to favour the Gamma nail group are dominated by the results of the latter trial in the pooled results of data from just three of the five trials. Utrilla 2005 reported no statistically significant difference between the two groups (mean shortening: $4.5 \mathrm{~mm}$ versus $3.2 \mathrm{~mm}$; $\mathrm{P}=0.35$ ).

Data for varus deformity (expressed as angulation greater than 10 degrees, malunion or deformity) provided by five studies reporting this outcome, showed no statistically significant difference between the two groups.

External rotation deformity was reported by two studies ( Kuwabara 1998; Leung 1992), which found no difference between the two groups.

\section{Final outcome measures}

Mortality data measured from between three and 12 months, available for pooling from 16 studies, show no significant difference in mortality between the two implants (see Analysis 2.19: 209/1136 versus 228/1170; RR 0.95, 95\% CI 0.81 to 1.12 ). The potential effect of selection bias (testing a post-hoc hypothesis that there would be a tendency to place more frail and ill patients in the SHS group) was investigated by subgrouping the data according to allocation concealment (see Analysis 2.20). Although Analysis 2.20 is consistent with a higher risk of mortality in the SHS group when allocation is not concealed, the test of interaction between trials with allocation concealment and those with no concealment of allocation was not statistically significant (two tail z-test $=0.533$ ); thus there is insufficient evidence to draw conclusions.

Of the seven studies reporting post-operative pain (Ahrengart 1994; Goldhagen 1994; Guyer 1991; Hoffman 1996; Leung 1992; O'Brien 1995; Utrilla 2005), only Ahrengart 1994 reported a significant difference between the two implants. Pooling of pain outcome data is hampered by the different methods of assessing residual pain performed at different time intervals from injury. When pooled, data from five trial showed no significant difference between the two implants in patients with residual pain (see Analysis 2.21).

The return to pre-fracture residential status, expressed in various ways such as transfer to long-term care and stay in institutions, as well as return to pre-fracture residence, was stated or implied as being no different in nine trials (Ahrengart 1994 (two centre data); Adams 2001; Benum 1994; Bridle 1991; Goldhagen 1994; Hoffman 1996; O’Brien 1995; Pahlpatz 1993; Radford 1993). Four trials (Ahrengart 1994; Guyer 1991; Haynes 1996; Pahlpatz 1993) provided data for pooling. Neither the analysis for nonreturn to previous residence for survivors nor that for overall nonreturn including deaths showed a significant difference between the two implants (see Analysis 2.22).

Measures of mobility varied between studies and were broadly based on the numbers able to walk independently, the numbers requiring walking aids and those who were bed or chair bound. Some studies (Hoffman 1996; Marques Lopez 2002) further refined this by ranking or scoring systems and recorded the difference in levels of attainment between pre-fracture and postfracture mobility. Utrilla 2005 also presented a walking ability score. Where reported, pre-fracture mobility was said to be comparable between implant groups with the exception of Hoffman 1996 where the pre-fracture status was better in the Ambi (SHS) group. Eleven studies (Ahrengart 1994; Benum 1994; Bridle 1991; Goldhagen 1994; Kukla 1997; Kuwabara 1998; Marques Lopez 2002; O’Brien 1995; Ovesen 2006; Radford 1993; Utrilla 2005) found no difference in post-operative mobility or changes in mobility. Hoffman 1996, the only study to use blinded assessment of mobility, reported better mobility with the SHS in the early stages, but no difference at 12 weeks. Although loss of mobility data were presented by a histogram in Bridle 1991, these differed from results given in text. Analysis 2.23 shows pooled results from seven trials for the numbers of trial participants with impaired walking (RR $0.99,95 \%$ CI 0.89 to 1.10 ). This provides an incomplete picture of mobility, but reinforces the claims from the other trials of there being no difference in mobility outcomes between the two implants.

Adams 2001 found no difference between the groups in the Harris hip scores for the survivors at one year. Papasimos 2005 reported a higher Salvati and Wilson score (based on pain, walking, muscle power and motion, function; 0: worst to 40: best) at one year for the nail group (mean: 33 versus 27; P value not reported).

\section{Economic evaluation}

None of the included trials reported costs or attempted an economic evaluation.

\section{Intramedullary hip screw (IMHS) versus the sliding hip screw (SHS)}

Five randomised trials (Baumgaertner 1998; Hardy 1998; Harrington 2002; Hoffmann 1999; Mehdi 2000) compared the IMHS with the SHS in 623 people with trochanteric fractures. Only very limited results were available for Mehdi 2000.

\section{Operative details}

Mean operating times in the IMHS group relative to those for SHS group were less in two trials (Baumgaertner 1998; Hoffmann 1999), but greater in the other three. Pooled results from three trials (Baumgaertner 1998; Hardy 1998; Harrington 2002) show highly significant heterogeneity $\left(\mathrm{P}=0.001 ; \mathrm{I}^{2}=85 \%\right)$, and a statistically non significant result when the random-effects model is applied (see Analysis 3.1). 
Mean operative blood loss was significantly lower in the IMHS group (see Analysis 3.2: mean difference -62.42 ml, 95\% CI -98.56 to $-26.28 \mathrm{ml}$; Hoffmann 1999 and Mehdi 2000 also reported lower mean values for the IMHS group $(380 \mathrm{ml}$ versus $400 \mathrm{ml} ; 247$ $\mathrm{ml}$ versus $270 \mathrm{ml}$ ). There were no significant differences between the two groups in units of blood transfused (see Analysis 3.3) or numbers of patients receiving transfusion.

Radiographic screening times were longer for the IMHS group were longer (see Analysis 3.5: mean difference 1.15 minutes, 95\% CI 0.83 to 1.47 minutes; Hoffmann 1999: 5.7 versus 5.4 minutes, reported as not significant).

\section{Fracture fixation complications}

Pooled data as available for operative fracture of the femur, later fracture of the femur, cut-out, non-union, plate detachment and reoperation are shown in Analysis 3.6. Only the result for operative fracture, which occurred only in the IMHS group, was statistically significant (8/313 versus 0/314; RR 5.01, 95\% CI 1.11 to 22.65 ). Complete data on reoperations (done mainly, where described, to remove painful hardware and for loss of fracture fixation) were available from two trials only.

There were no significant differences between groups in wound infection (the only reported case occurred in the SHS group of Mehdi 2000; see Analysis 3.7) or wound haematomas (see Analysis 3.7).

\section{Post-operative complications}

There were no significant differences between groups in post-operative medical complications (see Analysis 3.8), or length of hospital stay (see Analysis 3.9; Hoffmann 1999: median stay in orthopaedic ward: 10 versus 11 days).

\section{Anatomical restoration}

Hardy 1998 reported that, for those patients who underwent radiographic evaluation at fracture consolidation, there was a significantly reduced mean shortening of the fractured leg in the IMHS group (see Analysis 3.10: mean difference $-0.70 \mathrm{~cm}, 95 \% \mathrm{CI}$ 1.13 to $-0.27 \mathrm{~cm}$ ). Hoffmann 1999 reported that shortening of more than one centimetre occurred in one person of each group; and that one IMHS group participant had a "relevant" rotational deformity of the limb.

\section{Final outcome measures}

The available data for these outcomes are presented in Analysis 3.11. There were no significant differences between the two groups in mortality (54/221 versus 60/222; RR $0.91,95 \%$ CI 0.67 to
1.24), pain at final follow-up, failure to return home (survivors), failure to return home or dead, or mobility outcomes.

Hardy 1998 reported significantly better mobility scores for the IMHS group at one and three months but not at six or 12 months; however, walking ability outside the home remained better in the IMHS group. Hoffmann 1999 reported no significant difference between groups in the Merle d'Aubigne score; an unsatisfactory score was attained by two IMHS patients and three SHS patients. Mehdi 2000 considered that their study showed that functional outcome of the IMHS was equivalent to the SHS but provided no supporting data.

\section{Economic evaluation}

Baumgaertner 1998 provided data for hospital charges which showed that on average those for the IMHS group were $\$ 6000$ (USA) more. This difference was reported not to be statistically significant. It was unclear how the hospital charges were derived.

\section{Proximal femoral nail (PFN) versus sliding hip screw (SHS)}

This comparison was evaluated by three trials (Pajarinen 2005; Papasimos 2005; Saudan 2002) in 394 people with trochanteric hip fractures.

\section{Operative details}

Both Pajarinen 2005 and Papasimos 2005 reported a statistically significantly higher median length of surgery for the PFN group (respectively: 55 versus 45 minutes, reported $P=0.011$; 71 versus 59 minutes, reported $\mathrm{P}<0.05$ ), whilst Saudan 2002 found no difference between the two groups (see Analysis 4.1). There were no significant differences reported between groups in mean blood losses (see Analysis 4.2; for Papasimos 2005, operative blood loss: $265.0 \mathrm{ml}$ versus $282.4 \mathrm{ml}$; reported $\mathrm{P}>0.05$ ) or for mean number of units of blood transfused (see Analysis 4.2). However, fewer people received transfusion in the PFN group of Saudan 2002 (see Analysis 4.3: 55/100 versus 72/106; RR 0.81, 95\% CI 0.65 to 1.01). Saudan 2002 found the mean radiographic screening time was about one minute longer in the PFN group (see Analysis 4.4), while Papasimos 2005 found no significant difference $(0.26$ versus 0.21 minutes; reported $\mathrm{P}>0.05$ ).

\section{Fracture fixation complications}

There were no intra-operative or later fractures of the femur. Similar numbers of cut-out occurred in the two groups (see Analysis 4.5) and there was one case of non-union in the SHS group of Papasimos 2005. There was a statistically non-significant tendency for a higher reoperation rate (13/194 versus 7/200; RR 1.90, 95\% CI 0.78 to 4.62) for the PFN. No details of the reoperations were 
given in Pajarinen 2005. In the other two trials, reoperations entailed implant removal (four versus one), implant removal and debridement (three versus one), a hip prothesis (four versus two) and an alternative fixation method (zero versus one).

There were no significant differences in the reported incidences of wound infections and haematomas (see Analysis 4.6).

\section{Post-operative complications}

As shown in Analysis 4.7, there were no significant differences between the two groups in the incidence of individual post-operative complications, except for urinary tract infection in Sadowski 2002. However, there was no statistically significant difference in the overall numbers of people with any medical complication (52/ 100 versus 49/106; RR $1.12,95 \%$ CI 0.85 to 1.49 ) in this trial. There were no statistically significant differences between the two devices in the mean lengths of hospital stay for all three trials (see Analysis 4.8; for Papasimos 2005: 8.8 versus 9.9 days).

\section{Anatomical restoration}

Clinical measures such as limb shortening were not reported by any of the trials. Papasimos 2005 reported two cases of malrotation and two cases of varus or valgus deformity in each of the nail and SHS groups.

\section{Final outcome measures}

These outcomes presented in Analysis 4.9. There were no statistically significant differences in mortality, in residential status at final follow up, either in terms of the numbers of people in institutional care (Saudan 2002) or failing to return to the same residential status (Pajarinen 2005). Combined outcomes representing unfavourable outcomes (e.g. in nursing home or dead) also showed no significant differences between the two groups (see Analysis 4.9). Papasimos 2005 reported there was no difference between the two groups in return to pre-fracture level of independence or ambulation. Though, Pajarinen 2005 found that significantly fewer PFN group participants failed to recover their pre-fracture mobility (10/ 42 versus $19 / 41$, RR $0.51,95 \%$ CI 0.27 to 0.97 ), this result is not robust as shown by the combined outcome of failure to recover previous mobility or dead at four months (RR $0.67,95 \% 0.38$ to 1.17). For survivors available at one year, Saudan 2002 found no statistically significant differences between groups in pain, mobility or social function (mean scores: 2.88 versus 2.65). Papasimos 2005 reported comparable mean Salvati and Wilson scores (based on pain, walking, muscle power and motion, function; 0: worst to 40: best) at one year: 30 versus 27 .

\section{Proximal femoral nail antirotation (PFNA) versus sliding hip} screw (SHS)
This comparison was evaluated by one trial (Zou 2009) in 121 people with trochanteric hip fractures. Use of the PFNA was associated with significantly reduced operative time and operative blood loss (see Analysis 5.1 and Analysis 5.2), but a significantly increased radiographic screening time (see Analysis 5.3). There were no statistically significant differences between PFNA and SHS for implant cut-out, later fracture of the femur, non-union, implant breakage, or reoperation (see Analysis 5.4), wound infection (see Analysis 5.5), post-operative complications (see Analysis 5.6), mean hospital stay (14 days in both groups), or function (poor or fair Salvati and Wilson score) at one year (see Analysis 5.7).

\section{Targon PF nail versus the sliding hip screw (SHS)}

One study (Giraud 2005) compared the Targon PF nail with the sliding hip screw in 60 people with intertrochanteric fractures. There was no statistically significant differences found between implants for mean length of surgery (34 versus 42 minutes), mean operative blood loss (410 versus $325 \mathrm{ml}$ ), cut-out (all five cases were reoperated) or reoperation (see Analysis 6.1), wound infection (see Analysis 6.2), post-operative complications (see Analysis 6.3), or mean length of hospital stay (11 days in both groups). Similar findings apply to mortality at three months (see Analysis 6.4), mean times to walking (20 versus 25 days), and mean Harris hip scores (60 versus 59; 0: worst to 100: best function).

\section{Long Holland nail versus the sliding hip screw (SHS)}

One study (Little 2008) compared the long Holland nail with the sliding hip screw in 190 people with intertrochanteric fractures. Use of the long Holland Nail was associated with significantly longer mean lengths of anaesthesia and surgery (see Analysis 7.1), and radiographic screening (see Analysis 7.2), but with significantly less blood loss (see Analysis 7.3) and significantly fewer patients given transfusion (see Analysis 7.4: 7/92 versus 23/98; RR 0.32, $95 \%$ CI 0.15 to 0.72 ). Mean time to mobilisation was significantly lower in the nail group (see Analysis 7.5: 3.6 versus 4.3 days; mean difference -0.70 days, $95 \%$ CI -1.24 to -0.16 ).

There were no statistically significant differences between groups for fracture fixation complications or reoperation (one case of cutout in the SHS group was revised to an Holland nail) (see Analysis 7.6), wound infection (see Analysis 7.7), post-operative complications (see Analysis 7.8), or mortality at one year (see Analysis 7.9). More patients in the SHS group failed to regain their mobility (see Analysis 7.9: 27/76 versus 50/80; RR 0.57, 95\% CI 0.40 to 0.80 ). Also, survivors treated with the Holland nail had better mobility scores at one year (see Analysis 7.10: 5.9 versus 3.8; RR 2.10, 95\% CI 1.32 to 2.88 ).

\section{Long Gamma nail versus the sliding hip screw (SHS)}

One study (Barton 2010) compared the long Gamma nail with the sliding hip screw in 210 people with unstable intertrochanteric

Gamma and other cephalocondylic intramedullary nails versus extramedullary implants for extracapsular hip fractures in adults (Review) 17 Copyright (C) 2010 The Cochrane Collaboration. Published by John Wiley \& Sons, Ltd. 
fractures. In the trial report, adjustments were made to correct for the significantly lower mini-mental scores in the nail group at baseline.

There were no statistically significant differences between groups for the numbers of participants transfused (see Analysis 8.1), fracture fixation complications (all five patients with lag screw cut-out had a reoperation: see Analysis 8.2), wound infection (see Analysis 8.3), adjusted length of hospital stay, mortality at one year (see Analysis 8.4), change scores for measures of mobility and residence, and adjusted quality of life scores.

\section{Mini-invasive intramedullary nail versus the sliding hip screw} (SHS)

One study (Dujardin 2001) compared this experimental implant with the sliding hip screw in 60 people with trochanteric fractures. Mean length of surgery, operative and total blood loss (including the blood loss into wound drains) were all significantly less in the nail group (see Analysis 9.1 and Analysis 9.2). No participants of the nail group required transfusion, whilst on average 1.5 units of blood per participant were transfused in the SHS group (reported $\mathrm{P}<0.001)$. Radiographic screening time was equal in both groups (Analysis 9.3).

Dujardin 2001 reported an absence of early post-operative complications (specifically, thromboembolism, sepsis and further surgery). All fractures eventually united with no difference between the two implants in the time taken for fracture healing (see Analysis 9.4). There was no difference between groups in mortality at six months (see Analysis 9.5). Time to painless mobilisation and time to effective weight bearing (see Analysis 9.6) were both statistically significantly reduced for participants in the nail group, who also returned home earlier (46 versus 68 days; reported $\mathrm{P}<$ $0.05)$ than those in the SHS group.

The mean pain score was better for the nail group at six weeks (reported $\mathrm{P}<0.01$ ) but similar thereafter. No significant difference was noted for functional deficit at follow-up. However, the hip power and motion score was reported to be significantly better in the nail group at six months (reported $\mathrm{P}<0.05$ ).

\section{Kuntscher-Y nail versus the sliding hip screw (SHS)}

One randomised trial (Davis 1988) compared the Kuntscher-Y nail with the sliding hip screw (SHS) in 230 people with intertrochanteric fractures.

No significant differences were found between implants for fracture fixation complications or reoperation (see Analysis 10.1), wound infection (see Analysis 10.2) or post-operative complications (see Analysis 10.3).

Davis 1988 found a significant increase in the number of trial participants with more than $2.5 \mathrm{~cm}$ of shortening after Kuntscher nailing (17/48 versus 9/54; RR 2.13, 95\% CI 1.05 to 4.31; see
Analysis 10.4). There were no significant differences between implants for other measures of anatomical deformity, nor for mortality or mobility at one year (see Analysis 10.5).

\section{Intramedullary nail (two types) versus the sliding hip screw (SHS)}

Verettas 2010 compared 60 patients treated with an intramedullary nail (38 Gamma nails, 22 Endovis BA nail) with 60 patients treated with the SHS.

No significant differences were found between the use of nails or SHS for duration of surgery (means: 42 versus 45 minutes), operative blood loss (means: 150 versus $200 \mathrm{ml}$ ), radiographic exposure (see Analysis 11.1), operative fracture of the femur (see Analysis 11.2), wound infection (see Analysis 11.3), post-operative complications (see Analysis 11.4), length of hospital stay (means: 10.2 versus 10.3 days), mortality in hospital (see Analysis 11.5), or time to independent walking (see Analysis 11.6).

\section{Intramedullary nails (Gamma or PFN) versus the Medoff sliding plate}

Miedel 2005 compared the Gamma nail with the Medoff sliding plate in 217 people and Ekstrom 2007 compared the proximal femoral nail (PFN) with the Medoff sliding plate in 203 people. Both studies included people with either an unstable trochanteric fracture or a subtrochanteric fracture.

Neither trial found a statistically significant difference between the two groups in the mean length of surgery (Miedel 2005: 61 versus 65 minutes; for Ekstrom 2007, see Analysis 12.1). Both trials reported statistically significantly lower mean blood losses in the intramedullary nail groups: Miedel 2005 (276 versus 402 $\mathrm{ml}$, reported $\mathrm{P}<0.01$ ); the data for Ekstrom 2007 are shown in Analysis 12.2 (mean difference $-297.00 \mathrm{ml}$, 95\% CI -414.33 to -179.67). However, neither trial reported statistically significant differences in transfusion requirements: Miedel 2005, in terms of mean volume of blood transfused (864 versus $800 \mathrm{ml}$ ) and Ekstrom 2007, in the numbers having blood transfusions (no data provided). The mean radiographic screening time was two minutes greater in the PFN group of Ekstrom 2007 (see Analysis 12.3). There were no statistically significant differences between groups for operative fracture of the femur (all four cases occurred in the nail groups: see Analysis 12.4), later fractures of the femur (none occurred: see Analysis 12.5), cut-out (see Analysis 12.6) or nonunion (see Analysis 12.7). Opposite results were found for the two trials for reoperation (see Analysis 12.8): more reoperations, including three for excessive medial displacement of the femur, occurred in the Medoff group of Miedel 2005; conversely, Ekstrom 2007 reported a significantly higher reoperation rate in the PFN group. There were no statistically significant differences between the two groups for wound infection (see Analysis 12.9 and Analysis 12.10), wound haematoma (see Analysis 12.11), post-operative 
complications (see Analysis 12.12), or mortality at one year (see Analysis 12.13).

Miedel 2005 reported no significant differences between the two groups in pain, hip movement or walking ability scores assessed in the Charnley score for hip function, nor in activities of daily living (Katz) or health related quality of life scores (EuroQol) in those participants without severe cognitive dysfunction. Ekstrom 2007 reported, without supporting data, there was no statistically significant difference between the two groups in pain or return home at one year from injury. There were no statistically significant differences between the two groups of Ekstrom 2007 for four measures of mobility at one year (see Analysis 12.13, Analysis 12.14, Analysis 12.15 and Analysis 12.16).

\section{Gamma nail versus the percutaneous compression plate (PCCP)}

One trial (Varela-Egocheaga 2009) compared the Gamma 3 nail with the percutaneous compression plate (PCCP) in 80 people with trochanteric fractures.

This study reported no evidence of significant differences between groups for mean operation times ( 85.8 versus 86.5 minutes), fall in haemoglobin after surgery, or number of patients receiving transfusion (see Analysis 13.1). The need for analgesia after surgery was reported as similar for both groups.

Although all three cases of cut-out of the lag screw occurred in the Gamma nail group, the difference was not significant (see Analysis 13.2).

There were no significant differences between the two groups in post-operative complications (see Analysis 13.3), mean hospital stay (12.80 versus 11.77 days), the numbers of survivors discharged to intermediate care ( see Analysis 13.4), in-hospital and one year mortality (see Analysis 13.5), or non-recovery of former mobility (see Analysis 13.6).

\section{Femoral nails versus condylar screw or blade plates for lower trochanteric fractures}

Two trials compared a femoral nail with either a dynamic condylar screw (DCS) plate (Sadowski 2002) or a 90-degree angled blade plate (Pelet 2001) for specific types of lower trochanteric fracture (AO type A3), including reversed fracture lines and transverse fractures at the level of the lesser trochanter. Since the fracture types, as well as the implants being compared, are similar these two trials are considered together, though presented as separate subcategories in the analyses. These fractures are uncommon and the trial populations in the two trials were small, with 39 participants in Sadowski 2002 and 26 participants in Pelet 2001.

In Sadowski 2002, the mean length of surgery for the proximal femoral nail (PFN) group was significantly less that of the DCS group (see Analysis 14.1: 82 versus 166 minutes; mean difference -84.00 minutes, $95 \%$ CI -115.71 to -52.29 ). A similar difference in mean operation times between the Gamma nail and blade plate groups was found in Pelet 2001 (86 versus 169 minutes, reported $\mathrm{P}<0.05)$. Significantly fewer participants of the PFN group of Sadowski 2002 received blood transfusion (see Analysis 14.2: 11/ 20 versus $18 / 19$; RR $0.58,95 \%$ CI 0.39 to 0.88 ). The mean number of units of blood transfused was also less in the PFN group (1.5 versus 3.0 units). Pelet 2001 reported the mean operative blood loss was lower in the Gamma nail $(550$ versus $1150 \mathrm{ml}$, reported $\mathrm{P}<0.05$ ). The mean radiographic screening time was around four minutes for both implants of Sadowski 2002 (see Analysis 14.3).

There were no significant differences between groups for the individual outcomes of non-union (see Analysis 14.4), operative fracture of the femur (see Analysis 14.5), cut out (see Analysis 14.6), major reoperations (see Analysis 14.8: 0/33 versus 6/32; RR 0.07, $95 \%$ CI 0.00 to 1.22) or deep wound infection (see Analysis 14.9). However, this does not present the full picture, partly because of other major complications (e.g. plate breakage: see Analysis 14.7; three cases of avascular necrosis in the blade plate group of Pelet 2001) and mainly because reoperations were not performed/merited for other reasons: one person with cut-out in the DCS group of Sadowski 2002 was too ill and three patients in the plate group (two non-unions and one plate breakage) of Pelet 2001 had "low functional demand". Five "major" reoperations in Sadowski 2002 involved implant removal and debridement and the sixth, implantation of a hip prosthesis. (Two "minor" reoperations undertaken to remove the distal locking screw in order to change the PFN to a dynamic construct in Sadowski 2002 were not included in Analysis 14.8.)

There were no significant differences between groups in post-operative complications (see Analysis 14.10 to Analysis 14.14). Length of hospital stay was significantly shorter in the PFN group of Sadowski 2002 (see Analysis 14.15: 13 versus 18 days; mean difference -5.00 days, $95 \%$ CI -8.60 to -1.40 ); and also less for the nail group of Pelet 2001: 33 versus 44 days. There was no evidence of significant differences between groups in mortality at one year (see Analysis 14.16), numbers of people with residual pain at one year (see Analysis 14.17), numbers in a nursing home (see Analysis 14.18; Analysis 14.19) or numbers requiring walking aids (see Analysis 14.20). Sadowski 2002 found no statistically significant differences between implants for pain, mobility and social function at one year for survivors without fracture healing complications.

\section{Femoral nails versus condylar screw or blade plates for subtrochanteric fractures}

Two trials compared a femoral nail with a fixed nail plate for subtrochanteric fractures. Lee 2007 compared the Russell-Taylor nail with the dynamic condylar screw (DCS) in 66 participants (11 others were excluded from the analysis); Rahme 2007 compared the proximal femoral nail (PFN) with a 95 degree blade plate in 60 
participants. The results of the two trials are presented as separate subcategories in the analyses; no pooling was undertaken given visually and numerically significant heterogeneity.

There was no significant difference between the two groups in mean length of surgery for either trial: Lee 2007 (80 versus 74 minutes, see Analysis 15.1); Rahme 2007 (166 versus 171 minutes, reported $\mathrm{P}=0.8$ ). In Lee 2007, radiographic screening time for the nail group was significantly longer (see Analysis 15.2: 84.9 versus 65.5 seconds, mean difference 19.40 seconds, $95 \%$ CI 7.61 to 31.19); operative blood was significantly greater for the nail group (see Analysis 15.3: $543 \mathrm{ml}$ versus $386 \mathrm{ml}$; mean difference $158 \mathrm{ml}$, 95\% CI 59.40 to 256.60), and significantly more patients in the nail group received transfusion (see Analysis 15.4: 20/34 versus 8/32; RR 2.35, 95\% CI 1.21 to 4.56). Rahme 2007 found no significant difference for the mean units of blood transfused (3.2 units versus 5.1 units; reported $\mathrm{P}=0.4$ ).

In Lee 2007, there was one case of non-union (coupled with implant breakage) and one case of secondary subcapital fracture (with cut-out) in the nail group versus one case of delayed/non-union in the plate group. All three cases required revision surgery. Significantly more patients in the blade plate group of Rahme 2007 had delayed/non-union (see Analysis 15.5); all eight cases of nonunion in this group required revision surgery (see Analysis 15.6; RR $0.06,95 \%$ CI 0.00 to 0.98 ).

There were no significant differences between groups for the wound infection (see Analysis 15.7), length of hospital stay (see Analysis 15.8; Rahme 2007: 25 versus 22 days), mortality (see Analysis 15.9; group allocations of five patients who died in hospital were not provided in Lee 2007), pain scores (see Analysis 15.10), or mobility score (see Analysis 15.11). Rahme 2007 reported no significant differences between the two groups in the general health assessed using the SF-36 at one year for 41 of the 60 trial participants.

\section{DISCUSSION}

\section{Summary of main results}

The use of the Gamma nail for stabilisation of stable or unstable trochanteric (AO type A1 and A2) fractures, although an attractive biomechanical concept, has been associated with a significantly increased risk of adverse events (intra-operative and later fracture around or below the implant). Of these two complications, later fracture is more devastating for the patient as it requires either major revision surgery or a prolonged period of traction and bed rest. Results from randomised trials comparing the Intramedullary Hip Screw (IMHS) with the SHS suggest that this implant has been associated with similar complications. There is insufficient evidence to say whether more recent development of the Gamma nail (Trochanteric Gamma nail), or of other designs, has overcome these adverse effects. It is, however, notable that the more recent trials evaluating newer intramedullary nails devices (Barton 2010: Long Gamma nail; Giraud 2005: Targon PF nail; Little 2008: Holland nail; Pajarinen 2005 and Papasimos 2005: PFN nail; Zou 2009: PNFA nail) have not reported either operative fracture and later femur fracture. This raises the possibility that there have been improvements to the design of the nails that now make the results for the incidence of fracture healing complications comparable to that of the SHS. But, despite the recent inclusion in the review of trials of the newer implants, overall pooled data from trial comparing femoral nails versus the sliding hip screw still point to an increased risk of one extra reoperation in every 50 patients $(95 \%$ CI 1 in 33 to 1 in 100) with trochanteric fractures treated with an intramedullary nail.

There is no evidence of superiority of intramedullary devices in respect of fracture union, or cut-out of the fixation screw in the femoral head, a feature of both intramedullary and extramedullary devices.

Neither is there definite evidence for any difference in mortality nor, based on incomplete evidence, patient functional outcomes between the two types of implant.

For fractures occurring at the level of the lesser trochanter (AO type A3 - transverse and reverse obliquity fractures) types, the intramedullary nails were associated with better results, in comparison with extramedullary devices, for length of surgery, transfusion requirements, fixation failure rate, reoperation rate and hospital stay. Final outcome measures appeared to be similar between the two groups. Although based on results from two trials including a total of 65 participants, it appears likely that an intramedullary nail may give superior results to those of static plate fixation for these fractures.

\section{Overall completeness and applicability of evidence}

Lack of consistency and other deficiencies in the reporting of functional outcomes, and the limited use of validated measures are disappointing features of the body of trials included in this review. Inclusion of meaningful health related quality of life measures, and validated lower limb function scores have only recently begun to be reported in a few studies. Many of the outcomes reported have been intermediate, or concerned with process. The general adoption of an agreed set of outcomes for trials comparing the effectiveness of different implant designs would be a useful development.

We were unable to obtain adequate information from the included studies to make any distinction in outcome for unstable versus stable trochanteric fractures; nor separate data for those studies that included subtrochanteric fractures. This situation is unhelpful for clinical practice and a source of continuing frustration. Recognising this, in our next update we will consider the potential for presenting a summary of the evidence based on fracture type, 
backed up by some exploratory subgroup analyses. Intramedullary devices may have advantages for selected fracture types such as subtrochanteric fractures and trochanteric fractures with a reversed obliquity fracture line. Further studies are required to clarify if the Gamma nail, or another intramedullary nail, is superior for these fractures.

In evaluating the effectiveness of surgical implants, the experience and technique of the surgeon are believed to be important variables. For example, inadequate reaming and the use of excessive force on nail insertion have been implicated as the cause of femoral fracture. The problem of a learning curve for a new implant may jeopardise effective assessment within randomised trials. Thus it may be that some of the complications experienced with the Gamma nail would not have occurred had the surgeons been as familiar with the operative technique as they were with the SHS, the more established implant. Five trials (Benum 1994; Goldhagen 1994; Guyer 1991; Hoffman 1996; Utrilla 2005) specifically referred to a learning curve for Gamma nail insertion, and a further trial (O’Brien 1995) mentioned a performance bias with regards to surgery. However, our exploration of apparent surgical experience in subgroup analysis did not confirm any evidence of significant difference; it remains uncertain whether refining of operative technique and more rigorous training, or changes in implant design, will be the dominant factor in reducing the risk of later fracture of the femur. There were insufficient data to examine this issue for other comparisons.

\section{Quality of the evidence}

Forty-three studies (with data from 5750 participants) were included. With an average size of 134 participants, many individual studies lacked power to identify differences between the outcomes of the interventions compared.

Twenty-three of the 43 studies were considered at high risk of bias on the grounds of lack of experience of the surgeons with the newer technology, or disparate experiences of the operative procedures by the operating surgeons. Ten out of 43 trials were at high risk of bias on the grounds of inadequate concealment of allocation. Overall, 31 trials provided insufficient evidence to make a judgment on one or more of the three risk of bias items.

Despite these limitations, the evidence of increased risk of operative or later fracture of the femur associated with the use of intramedullary fixation of trochanteric fractures of the femur is consistent, and in view of the negligible heterogeneity amongst the studies, may be considered robust. A similar lack of heterogeneity supports the findings of a lack of differences between implants for other fracture healing complications and mortality. However, for other outcomes, in particular functional outcomes and morbidity, more limited and incomplete reporting of results and the lack of consistent and validated measures limit our ability to pool data and draw conclusions.

\section{Potential biases in the review process}

We searched widely, without imposing restrictions on language or publication status, but it remains possible that we may have missed some relevant studies. These may, for instance, have been unpublished trials, raising the possibility of publication bias, or not published in journals listed in the main databases. However, our scrutiny of other reviews and articles on this topic over the years has been reassuring in that these have not identified trials of which we had not been aware already. We have also contacted authors for clarification of methods and data as well as authors of ongoing trials. We anticipate, however, that unpublished data from early studies, which might have augmented some comparisons, may not now be available. The potential impact of these data on the review findings is now considerably less than for previous versions of the review. Our selection procedures were rigorous and both authors participated fully in all stages of the review.

\section{AUTHORS, CONCLUSIONS}

\section{Implications for practice}

In the management of trochanteric fractures (AO type A1 or A2), accumulated data from randomised controlled trials available up to April 2010 show no evidence of advantages to patients from the use of the Gamma nail, Intramedullary Hip Screw (IMHS) or other types of cephalocondylic intramedullary nails when compared with extramedullary implants of the sliding hip screw (SHS) design.

The use of the Gamma nail has been associated with a significantly increased risk of adverse events (intra-operative and later fracture around or below the implant), and results from randomised trials comparing the Intramedullary Hip Screw (IMHS) with the SHS suggest that this implant suffers from similar complications. While it is plausible that more recent designs of intramedullary nail might reduce the frequency of these specific complications, published evidence has not so far demonstrated either equivalence with, or superiority over the SHS in respect of these complications, or of functional advantage for patients. Despite the recent inclusion in the review of trials of the newer implants, pooled data still point to an increased risk of one extra reoperation in every 50 patients with trochanteric fractures treated with an intramedullary nail.

Intramedullary nails may have advantages over extramedullary fixation using fixed angle plates for more distal reverse and transverse transtrochanteric (AO type A3) fractures, and subtrochanteric fractures, although there is as yet insufficient evidence to confirm significant superiority over extramedullary devices.

\section{Implications for research}

Appropriate directions for future research include the role of 
intramedullary nails in subtrochanteric and reversed-obliquity trochanteric fractures. Design changes to different types of intramedullary nails, claimed to reduce the risk of post-operative fracture, should be tested versus the SHS in studies which record functional outcomes at a minimum of six months from surgery, are adequately powered to be capable of demonstrating both equivalence and difference, and meet the CONSORT criteria for design and reporting of non-pharmacological studies (Boutron 2008).

Particular deficiencies in the published literature are poor concealment of allocation, failure to report outcomes related to fracture type and limited information on participants who withdrew or for whom follow-up was incomplete, lack of blinded assessment of functional outcomes, limited reporting of functional outcomes and patient-derived quality of life measures, and insufficiently long follow-up. For trials comparing different surgical implants, the development of a benchmark set of outcomes, and concurrent economic evaluation are warranted.

\section{ACKNOWLEDG EMENTS}

We thank Dr Joanne Elliott for her help with the search for trials, Prof William Gillespie for substantial editorial contribution to this and previous updates, and to Mrs Lesley Gillespie for editorial contribution and search for trials in previous updates. We would also like to thank the following for helpful comments and corrections from editorial review of one or more of the review updates: Mrs Lindsey Elstub, Prof James Hutchison, Mr David Sands Johnson, Dr Vicki Livingstone, Prof Rajan Madhok, Prof Gordon Murray, Ms Kate Rowntree, Prof Marc Swiontkowski and Dr Janet Wale.

We thank Bal Appadu for assistance in the translation of Pelet 2001, Mireya Fernandez for the translation of Marques Lopez 2002 and Zhou Xiang for the translation of Liu 2008

Helen Handoll's work on the first two versions of the review was supported by the Chief Scientist Office, Department of Health, The Scottish Office, UK.

\section{R E F E R E N C E S}

\section{References to studies included in this review}

Adams 2001 \{published and unpublished data\}

* Adams CI, Robinson CM, Court-Brown C, McQueen MM.

Prospective randomised controlled trial of an intramedullary nail versus dynamic hip screw and plate for intertrochanteric fractured femur. Journal of Orthopaedic Trauma 2001;15(6):394-400. Bartonicek I, Dousa P. Prospective randomized controlled trial of an intramedullary nail versus dynamic screw and plate of intertrochanteric fractures of the femur [letter]. Journal of Orthopaedic Trauma 2002;16(5):363-4.

\section{Ahrengart 1994 \{published and unpublished data\}}

Ahrengart L, Thornkvist H, Lindgren U, Fornander P, Thorngren KG, Wahlstrom P, et al.Gamma nail vs. compression hip screw for trochanteric fractures - complications and patient outcome [abstract]. Acta Orthopaedica Scandinavica. Supplementum 1995; 265:23.

Ahrengart L, Tornkvist H, Fornander P, Thorngren KG, Pasanen L, Wahlstrom P, et al.A randomized study of the compression hip screw and Gamma nail in 426 fractures. Clinical Orthopaedics and Related Research 2002;(401):209-22.

Ahrengart L, Tornkvist H, Lindgren U, Fornander P, Thorngren $\mathrm{KG}$, Wahlstrom P, et al.Gamma nail vs. compression hip screw for trochanteric and subtrochanteric fractures. Complications and patient outcome [abstract]. Orthopaedic Transactions 1995;19(1): 154.

Fornander P, Thorngren K-G, Tornqvist H, Ahrengart L, Lindgren U. Swedish experience of the first 209 randomized patients with Gamma nail vs. screw-plate [abstract]. Acta Orthopaedica Scandinavica. Supplementum 1992;248:90.

* Fornander P, Thorngren K-G, Tornqvist H, Ahrengart L, Lingren U. Swedish experience with the Gamma nail vs. sliding hip screw in
209 randomised cases. International Journal of Orthopaedic Trauma 1994;4(3):118-22.

\section{Barton 2010 \{published data only\}}

Barton T. personal communication May 52010.

* Barton TM, Gleeson R, Topliss C, Greenwood R, Harries WJ, Chesser TJ. A comparison of the long Gamma nail with the sliding hip screw for the treatment of AO/OTA 31-A2 fractures of the proximal part of the femur; a prospective randomized trial. Journal of Bone \& Joint Surgery - American Volume 2010;92(4):792-8. Chesser T. A prospective randomised controlled trial comparing the long gamma nail with the sliding hip screw for the treatment of unstable pertrochanteric hip fractures [http://www.controlledtrials.com/ISRCTN79362886]. WHO International Clinical Trials Registry Platform (accessed 23/04/09). [: ISRCTN79362886]

Baumgaertner 1998 \{published and unpublished data\} Baumgaertner MR, Curtin SL, Lindskog D. A randomized, prospective comparison of the intramedullary hip screw (IMHS) to the compression hip screw and sideplate [abstract]. Orthopaedic Transactions 1995;19(1):153-4.

* Baumgaertner MR, Curtin SL, Lindskog DM. Intramedullary versus extramedullary fixation for the treatment of intertrochanteric hip fractures. Clinical Orthopaedics and Related Research 1998; (348):87-94. [MEDLINE: 1998214154]

Baumgaertner MR, Curtin SL, Lindskog DM. The Intramedullary Hip Screw (IMHS) and the Compression Hip Screw (CHS): A prospective clinical trial [poster]. Final programme of the 20th World Congress SICOT; 1996 Aug 18-23; Amsterdam. 1996:313. Curtin S, Baumgaertner M. The IMHS: a better way to fix hip fractures? [abstract]. Orthopaedic Transactions 1994;18(1):198.

Benum 1994 \{published data only\} Aune AK, Ekeland A, Odegaard B, Grogaard B, Alho A. Gamma 
nail vs compression screw for trochanteric femoral fractures. 15 reoperations in a prospective, randomized study of 378 patients. Acta Orthopaedica Scandinavica 1994;65:127-30. [MEDLINE: 1994256194]

* Benum P, Grontvedt T, Braten M, Rossvoll I, Walloe A, Ekeland A, et al.Gamma nailing versus CHS in intertrochanteric and subtrochanteric femoral fractures: a prospective randomized multicentre study [abstract]. Acta Orthopaedica Scandinavica. Supplementum 1994;260:33-4.

Benum P, Grontvedt T, Braten M, Walloe A, Ekeland A, Raugstad $S$, et al.Gamma nail versus CHS in intertrochanteric and subtrochanteric femoral fractures - a preliminary report of a prospective randomized study [abstract]. Acta Orthopaedica Scandinavica. Supplementum 1992;247:7-8.

Ekeland A, Aune AK, Odegaard B, Grogaard B, Alho A. Complications after Gamma nailing of proximal femoral fractures [abstract]. Orthopaedic Transactions 1993;17:1049.

Ekeland A, Aune AK, Odegaard B, Grogaard B, Alho A.

Reoperations after use of gamma nail or hip compression screw for proximal femoral fractures [abstract]. Journal of Bone and Joint Surgery - British Volume 1993;75 Suppl 2:199.

Madsen JE, Naess L, Aune AK, Alho A, Ekeland A, Stromsoe K. Dynamic hip screw with trochanteric stabilizing plate in the treatment of unstable proximal femoral fractures: A comparative study with the Gamma nail and compression hip screw. Journal of Orthopaedic Trauma 1998;12(4):241-8. [MEDLINE: 1998280757]

Madsen JE, Noess L, Aune AK, Alho A, Ekeland A, Stromsoe K. Unstable per- and subtrochanteric femoral fractures - a comparison of treatment with the Gamma nail, compression hip screw, or dynamic hip screw with a trochanter stabilizing plate [abstract]. Acta Orthopaedica Scandinavica. Supplementum 1996;270:35-6.

Bridle 1991 \{published data only\}

Bridle SH, Bircher M, Patel AD, Calvert PT. The gamma nail for pertrochanteric fractures of the femur: a prospective comparison with the dynamic hip screw [abstract]. Journal of Bone and Joint Surgery - British Volume 1990;72(6):1085.

* Bridle SH, Patel AD, Bircher M, Calvert PT. Fixation of intertrochanteric fractures of the femur: a randomised prospective comparison of the gamma nail and the dynamic hip screw. Journal of Bone and Joint Surgery - British Volume 1991;73:330-4. [MEDLINE: 1991170321]

Butt 1995 \{published data only\} Butt MS, Krikler SJ, Nafie S, Ali MS. Comparison of dynamic hip screw and gamma nail: a prospective, randomized, controlled trial. Injury 1995;26(9):615-8. [MEDLINE: 1996142644]

\section{Davis 1988 \{published data only\}}

Davis TR, Sher JL, Checketts RG, Porter BB. Intertrochanteric fractures of the femur: a prospective study comparing the use of the Kuntscher-Y nail and a sliding hip screw. Injury 1988;19(6):421-6. [MEDLINE: 1990007680]

\section{Dujardin 2001 \{published data only\}}

Dujardin FH, Benez C, Polle G, Alain J, Biga N, Thomine JM. Prospective randomized comparison between a dynamic hip screw and a mini-invasive statis nail in fractures of the trochanateric area: preliminary results. Journal of Orthopaedic Trauma 2001;15(6): 401-6.

\section{Ekstrom 2007 \{published data only\}}

Ekstrom W, Karlsson-Thur C, Larsson S, Ragnarsson B, Alberts KA. Functional outcome in treatment of unstable trochanteric and subtrochanteric fractures with the proximal femoral nail and the Medoff sliding plate. Journal of Orthopaedic Trauma 2007;21(1): $18-25$.

\section{Giraud 2005 \{published and unpublished data\}}

Giraud B. personal communication July 42007.

* Giraud B, Dehoux E, Jovenin N, Madi K, Harisboure A, Usandizaga $\mathrm{G}$, et al.Pertrochanteric fractures: a randomized prospective study comparing dynamic screw plate and intramedullary fixation [Comparaison vis-plaque dynamique et osteosynthese intra-medullaire anterograde dans les fractures pertrochanteriennes: une etude prospective randomisee]. Revue de Chirurgie Orthopedique et Reparatrice de l'Appareil Moteur 2005;91 (8):732-6.

Giraud B, Dehoux E, Madi K, Harisboure A, Segal P. Intratrochanteric fractures; randomized prospective comparison of treatment with a dynamic hip screw (DHS) and anterograde intramedullary nailing (Targon PF). Journal of Bone and Joint Surgery - British Volume 2008;90(Supp II):291.

\section{Goldhagen 1994 \{published data only\}}

Goldhagen P, O'Connor DR, Schwarze D, Schwartz EA. A prospective comparative study of compression hip screw and the Gamma nail [abstract]. Orthopaedic Transactions 1993;17(4): 1048-9.

* Goldhagen PR, O’Connor DR, Schwarze D, Schwartz E. A prospective comparative study of the compression hip screw and the gamma nail. Journal of Orthopaedic Trauma 1994;8(5):367-72. [MEDLINE: 1995088782]

\section{Guyer 1991 \{published data only\}}

* Guyer P, Landolt M, Eberle C, Keller H. The gamma nail as a resilient alternative to the dynamic hip screw in unstable proximal femoral fractures in the elderly [Der Gamma-nagel als belastungsstabile alternative zur DHS bei der instabilen proximalen femurfraktur des alten menschen]. Helvetica Chirurgica Acta 1991; 58(5):697-703. [MEDLINE: 1992276042]

Guyer P, Landolt M, Keller H, Eberle C. The Gamma Nail in perand intertrochanteric femoral fractures - alternative or supplement to the dynamic hip screw? A prospective randomized study of 100 patients with per- and intertrochanteric femoral fractures in the surgical clinic of the City Hospital of Triemli, Zurich, September 1989 - June 1990 [Der Gamma-Nagel bei per- und

intertrochantaren Femurfrakturen-Alternative oder Erganzung zur DHS? Eine prospektive randomisierte Studie anhand von 100 Patienten mit per- und intertrochantaren Femurfrakturen an der Chirurgischen Klinik des Stadtspitals Triemli, Zurich, September 1989-Juni 1990]. Aktuelle Traumatolologie 1991;21(6):242-9. [MEDLINE: 1992116890]

Guyer P, Landolt M, Keller H, Eberle Ch. The Gamma nail in perand intertrochanteric femoral fractures - alternative or complementary to the DHS? A prospective randomised study. In: Marti RK, Dunki Jacobs PB editor(s). Proximal femoral fractures. Operative technique and complications. Vol. 2, London: Medical Press Limited, 1993:481-98.

Guyer P, Landolt M, Kelter H, Eberle C. Gamma-nails verses DHS be per- and intertrochateral femur fractures. Hefte zur der 
Unfallchirurg 1993;230:854-6.

Hardy 1998 \{published data only\}

de Ridder VA, de Lange S. Use of an intramedullary hip-screw compared with a compression hip-screw with a plate for intertrochanteric femoral fractures. A prospective, randomized study of one hundred patients [letter; comment]. Journal of Bone and Joint Surgery - American Volume 1999;81(10):1502-3.

* Hardy DC, Descamps P, Krallis P, Fabeck L, Smets P, Bertens CL, et al.Use of an intramedullary hip-screw compared with a compression hip-screw with a plate for intertrochanteric femoral fractures. A prospective, randomized study of one hundred patients. Journal of Bone and Joint Surgery - American Volume 1998; 80(5):618-30. [MEDLINE: 1998272578]

Hardy DCR, Delince P. Intramedullary hip screw (IMHS) versus compression hip screw plate (CHSP) for intertrochanteric hip fractures. A prospective, randomised trial of 160 patients [Abstract]. Journal of Bone and Joint Surgery - British Volume 1999; 81 Suppl 2:163-4.

Harrington 2002 \{published and unpublished data\} Harrington P, Nihal A, Singania A, Howell F. Compression hip syndrome or intramedullary hip screw for unstable peri-trochanteric fractures? A prospective randomised study [abstract]. Journal of Bone and Joint Surgery - British Volume 1999;81 Suppl 3:296. * Harrington P, Nihal A, Singhania AK, Howell FR. Intramedullary hip screw versus sliding hip screw for unstable intertrochanteric femoral fractures in the elderly. Injury 2002;33(1):23-8.

Haynes 1996 \{unpublished data only\} Haynes RC. Internal hip fracture fixation systems [PhD thesis]. Bath (UK): Univ. of Bath, 1996.

\section{Hoffman 1996 \{published and unpublished data\}} Hoffman CW, Lyndskey TG. Intertrochanteric fractures of the femur; a randomised prospective comparison of the gamma nail and the Ambi hip screw [abstract]. Journal of Bone and Joint Surgery - British Volume 1993;75 Suppl 1:50.

* Hoffman CW, Lynskey TG. Intertrochanteric fractures of the femur: a randomized prospective comparison of the Gamma nail and the Ambi hip screw. New Zealand Journal of Surgery 1996;66 (3):151-5. [MEDLINE: 1996207784]

Hoffmann 1999 \{published data only\}

Hoffmann R, Schmidmaier G, Schulz R, Schutz M, Sudkamp NP. Classic nail versus DHS. A prospective randomised study of fixation of trochanteric femur fractures [Classic-Nagel vs. dynamische Huftschraube (DHS). Eine prospektiv-randomisierte Studie zur Behandlung pertrochantarer Femurfrakturen.]. Unfallchirurg 1999;102:182-90.

Kukla 1997 \{published and unpublished data\}

Kukla C, Berger G. Randomised comparison of the Gamma nail and the Dynamic Hip Screw in 120 patients over 60 years of age. In: Gahr RH, Leung WS, Rosenwasser MO, Roth W editor(s). The Gamma locking nail - ten years results and surgical experience. Reinbek:Einhorn-Presse Verlag, 1999:294-302.

* Kukla C, Heinz T, Berger G, Kwasny O, Rosenberger A, Vecsei V. Gamma nail vs. Dynamic Hip Screw in 120 patients over 60 years a randomized trial. Acta Chirurgica Austriaca 1997;29(5):290-3. Kukla C, Heinz T, Berger G, Kwasny O, Wien A. Prospective randomised comparison of the Gamma nail and DHS in 120 patients [Prospektiv randomisierter vergleich zwischen Gammanagel und DHS bei 120 Patienten]. In: Rommens PM, Vecsei $\mathrm{V}$ editor(s). Osteosynthese International. Leuven: Leuven University Press, 1994:265-8.

Vecsei V, Kukla C, Heinz T. Gamma-Nail versus DHS: Prospective randomised comparison in 120 cases [abstract]. 5th International Orthopaedic and Trauma Meeting. Combined meeting of Austrian Trauma Association and Malaysian Orthopaedic Association; 1995 Oct 26-31; Kuala Lumpur. 1995:1-2.

Vecsei V, Kukla C, Heinz T. Gamma nail versus DHS - a prospective randomised trial of 120 patients [abstract]. Journal of Bone and Joint Surgery - British Volume 1995;77 Suppl 2:136.

\section{Kuwabara 1998 \{published data only\}}

Kuwabara H, Wada T, Minagi Y, Iwasaki T, Tsuji H. [Compression hip screw and gamma nail for intertrochanteric fractures -

Randomized prospective study]. Hokkaido Journal of Orthopaedics \& Traumatology 1998;40(2):29-33.

\section{Lee 2007 \{published data only\}}

Lee P-C, Hsieh P-H, Yu S-W, ShIao C-W, Kao H-K, Wu C-C. Biologic plating versus intramedullary nailing for comminuted subtrochanteric fractures in young adults: a prospective, randomised study of 66 cases. Journal of Trauma-Injury Infection \& Critical Care 2007;63(6):1283-91.

\section{Leung 1992 \{published and unpublished data\}} Leung KS, So WS, Shen WY, Hui PW. Gamma nails and dynamic hip screws for peritrochanteric fractures. A randomised prospective study in elderly patients. Journal of Bone and Joint Surgery - British Volume 1992;74(3):345-51. [MEDLINE: 1992268159]

\section{Little 2008 \{published data only\}}

Justin Fernando C, Khaleel A, Elliot D. Holland nail vs DHS in intertrochanteric femoral fractures [abstract]. Journal of Bone and Joint Surgery - British Volume 2006;88(Suppl 1):71.

* Little NJ, Verma V, Fernando C, Elliott DS, Khaleel A. A prospective trial comparing the Holland nail with the dynamic hip screw in the treatment of intertrochanteric fractures of the hip. Journal of Bone and Joint Surgery - British Volume 2008;90(8): 1073-8.

Marques Lopez 2002 \{published data only\}

Marques Lopez F, Pelfort Lopez X, Garcia Casas O, Ramirez Valencia M, Leon Garcia Vao A, Ballester Soleda J. Prospective, comparative, randomized study of the sliding screw and Gamma nail in the treatment of pertrochanteric fractures [Estudio prospectivo aleatorio comparativo del tornillo deslizante y el clavo gamma en el tratamiento de las fracturas pertrocantereas]. Revista de Ortopedia y Traumatologia 2002;46(6):505-9.

\section{Mehdi 2000 \{published data only\}}

Kinninmonth A. Comparison of the intramedullary hip screw with Richard's classic hip screw in the management of pertrochanteric hip fractures. In: National Research Register, Issue 2, 2001. Oxford: Update Software.

Mehdi SA. personal communication April 242006.

* Mehdi SA, Kinninmonth AWG, MacLeod C, McKenzie E, James PJ. Extracapsular hip fracture fixation: a prospective randomised comparison of the intramedullary hip screw with the sliding hip screw [abstract]. Injury 2000;31:287. 


\section{Michos 2001 \{published data only\}}

Michos I, Brakoulakis E, Pastroudis A, Loutriotis A, Adamopoulo G. The Gamma nail system compared to sliding nail and plate for peritrochanteric fractures [abstract]. Journal of Bone and Joint Surgery - British Volume 2001;83 Suppl 2:193.

Miedel 2005 \{published data only\}

* Miedel R, Ponzer S, Tornkvist H, Soderqvist A, Tidermark J. The standard Gamma nail or the Medoff sliding plate for unstable trochanteric and sub-trochanteric fractures: a randomised, controlled trial. Journal of Bone and Joint Surgery - British Volume 2005;87(1):68-75.

Tidermark J, Miedel R, Ponzer S, Tornkvist H. The standard Gamma nail or the Medoff sliding plate for unstable trochanteric and sub-trochanteric fractures: A randomized controlled trial [abstract]. Orthopaedic Trauma Association Annual Meeting; 2004 Oct 8-10; Hollywood, Florida. Monroe, NY: HWB Foundation, 2004:http://www.hwbf.org/ota/am/ota04/otapa/OTA041059.htm (accessed 24/01/2004).

Mott 1993 \{published data only\}

Mott MP, Kronik JL, Fitzgerald RH Jr, Morawa LG, Georgiadis GM, Salot WH. Gamma nail versus the sliding hip screw: A prospective randomized comparison [abstract]. Orthopaedic Transactions 1993;17:1049.

\section{O'Brien 1995 \{published and unpublished data\}}

* O'Brien PJ, Meek RN, Blachut PA, Broekhuyse HM, Sabharwal $S$. Fixation of intertrochanteric hip fractures: Gamma nail versus dynamic hip screw. A randomised, prospective study. Canadian Journal of Surgery 1995;38(6):516-20. [MEDLINE: 1996101465] O'Brien PJ, Meek RN, Blachut PA, Broekhuyse HM, Sabharwal S. Intertrochanteric hip fracture fixation - Gamma nail vs dynamic hip screw. A randomized, prospective study [abstract]. Orthopaedic Transactions 1994;18(1):19.

Sabharwal S, O’Brien PJ, Meek RN, Blackut PA, Broekhuyse HM. Intertrochanteric hip fracture fixation - Gamma nail versus dynamic hip screw. A randomized prospective study [abstract]. Journal of Bone and Joint Surgery - British Volume 1992;74 Suppl 3:281.

\section{Ovesen 2006 \{published and unpublished data\}}

Ovesen O. personal communication June 252007.

* Ovesen O, Andersen M, Poulsen T, Nymark T, Overgaard S, Rock ND. The trochanteric gamma nail versus the dynamic hip screw: a prospective randomised study. One-year follow-up of 146 intertrochanteric fractures. Hip International 2006;16(4):293-8. Svenson O, Andersen M, Poulsen T, Nymark T, Overgaard S, Rock ND. A prospective randomised study comparing the trochanteric gamma nail (TGN) and the dynamic hip screw (DHS) in 146 intertrochanteric fractures [abstract]. Journal of Bone and Joint Surgery - British Volume 2006;88 Suppl 1:70.

\section{Pahlpatz 1993 \{published data only\}}

Pahlplatz PVM, Langius FB. Comparing the Gamma nail and the Dynamic Hip Screw in the treatment of pertrochanteric fractures. Preliminary results of a prospective randomised study. In: Marti RK, Dunki Jacobs PB editor(s). Proximal femoral fractures. Operative technique and complications. Vol. 2, London: Medical Press Limited, 1993:475-80.

\section{Pajarinen 2005 \{published data only\}}

Pajarinen J. personal communication February 242005.

* Pajarinen J, Lindahl J, Michelsson O, Savolainen V, Hirvensalo E. Pertrochanteric femoral fractures treated with a dynamic hip screw or a proximal femoral nail; a randomised study comparing postoperative rehabilitation. Journal of Bone and Joint Surgery - British Volume 2005;87(1):76-81.

Pajarinen J, Lindahl J, Savolainen V, Michelsson O, Hirvensalo E. Femoral shaft medialisation and neck-shaft angle in unstable pertrochanteric femoral fractures. International Orthopaedics 2004; 28(6):347-53.

Papasimos 2005 \{published data only\}

Papasimos S, Koutsojannis CM, Panagopoulos A, Megas P, Lambiris E. A randomised comparison of AMBI, TGN and PFN for treatment of unstable trochanteric fractures. Archives of Orthopaedic and Trauma Surgery 2005;125(7):462-8.

Park 1998 \{published data only\}

Kang JS, Park SR, Lee WH, Kim YH. Treatment of intertrochanteric fracture with the Gamma AP nail [poster]. Final programme of the 20th World Congress SICOT; 1996 Aug 18-23; Amsterdam. 1996:315.

* Park SR, Kang JS, Kim HS, Lee WH. Treatment of intertrochanteric fracture with the Gamma AP locking nail or by a compression hip screw - a randomised prospective trial. International Orthopaedics 1998;22(3):157-60. [MEDLINE: 1998397553]

\section{Pelet 2001 \{published data only\}}

Pelet S, Arlettaz Y, Chevalley F. Osteosynthesis of per- and subtrochanteric fractures by blade plate versus gamma nail. A randomized prospective study [Osteosynthese des fractures per- et sous-trochanteriennes par plaque angulee versus clou Gamma. Une etude prospective randomisee]. Swiss Surgery 2001;7(3):126-33.

Radford 1993 \{published data only\}

Radford PJ, Needoff M. Intramedullary or extramedullary fixation for pertrochanteric fractures of the femur? [abstract]. Journal of Bone and Joint Surgery - British Volume 1992;74 Suppl 3:281.

* Radford PJ, Needoff M, Webb JK. A prospective randomised comparison of the dynamic hip screw and the gamma locking nail. Journal of Bone and Joint Surgery - British Volume 1993;75(5): 789-93. [MEDLINE: 1993388676]

Radford PJ, Needoff M, Webb JK. The Gamma nail compared to the dynamic hip screw for pertrochanteric fractures of the femur [abstract]. Journal of Bone and Joint Surgery - British Volume 1992; 74 Suppl 2:133-4.

\section{Rahme 2007 \{published data only\}}

Harris I, Rahme D. A prospective randomised controlled trial of subtrochanteric femur fractures treated with a proximal femoral nail compared to a 95-degree blade plate [abstract]. Journal of Bone and Joint Surgery - British Volume 2005;87(Suppl 3):310-1.

* Rahme DM, Harris IA. Intramedullary nailing versus fixed angle blade plating for subtrochanteric femoral fractures: a prospective randomised controlled trial. Journal of Orthopaedic Surgery 2007;15 (3):278-81.

Sadowski 2002 \{published and unpublished data\}

* Sadowski C, Lubbeke A, Saudan M, Riand N, Stern R, Hoffmeyer P. Treatment of reverse oblique and transverse 
intertrochanteric fractures with use of an intramedullary nail or a 95 degree screw-plate. Journal of Bone and Joint Surgery - American Volume 2002;84(3):372-81.

Saudan M, Lubecke A, Sadowski Ch, Riand N, Stern R, Hoffmeyer $P$. Is there an indication for intramedullary fixation of intertrochanteric fractures? [abstract]. European Federation of National Associations of Orthopaedics and Traumatology; 2001 Jun 1-7; Rhodes (Greece). 2001.

Saudan 2002 \{published and unpublished data\}

* Saudan M, Lubbeke A, Sadowski C, Riand N, Stern R, Hoffmeyer P. Pertrochanteric fractures: is there an advantage to an intramedullary nail? A randomized, prospective study of 206 patients comparing the dynamic hip screw and proximal femoral nail. Journal of Orthopaedic Trauma 2002;16(6):386-93.

Saudan M, Lubecke A, Sadowski Ch, Riand N, Stern R, Hoffmeyer $P$. Is there an indication for intramedullary fixation of intertrochanteric fractures? [abstract]. European Federation of National Associations of Orthopaedics and Traumatology; 2001 Jun 1-7; Rhodes (Greece). 2001.

Saudan M, Lubecke-Wolff A, Sadowski C, Riand N, Hoffmeyer P. The proximal femoral nail (PFN) and the dynamic hip screw (DHS): a prospective clinical trial [abstract]. Journal of Bone and Joint Surgery - British Volume 1999;81 Suppl 2:163.

Stern RE, Sadowski C, Lubbeke A, Saudan M, Riand N,

Hoffmeyer P. Pertrochanteric fractures: is there an advantage to an intramedullary nail? [abstract]. Annual Meeting of the Orthopaedic Trauma Association; 2001 Oct 18-20; San Diego (California). Orthopaedic Trauma Association, 2001:http://www.hwbf.org/ota/ am/ota01/otapo/OTP01065.htm (accessed 14/11/01).

Utrilla 2005 \{published data only\}

Utrilla AL, Reig JS, Munoz FM, Tufanisco CB. Trochanteric Gamma nail and compression hip screw for trochanteric fractures: A randomized, prospective, comparative study in 210 elderly patients with a new design of the Gamma nail. Journal of Orthopaedic Trauma 2005;19(4):229-33.

Varela-Egocheaga 2009 \{published data only\}

Varela-Egocheaga JR, Iglesias-Colao R, Suarez-Suarez MA, Fernandez-Villan M, Gonzalez-Sastre V, Murcia-Mazon A. Minimally invasive osteosynthesis in stable trochanteric fractures: A comparative study between Gotfried percutaneous compression plate and Gamma 3 intramedullary nail. Archives of Orthopaedic and Trauma Surgery 2009;129(10):1401-7.

Verettas 2010 \{published data only\}

Verettas DAJ. personal communication May 252010.

Verettas D-AJ, Ifantidis P, Chatzipapas CN, Drosos GI, Xarchas $\mathrm{KC}$, Chloropoulou P, et al.Systematic effects of surgical treatment on hip fractures: Gliding screw-plating vs intramedullary nailing. Injury 2010;41(3):279-84.

Zou 2009 \{published data only\}

Zou J, Xu Y, Yang H. A comparison of proximal femoral nail antirotation and dynamic hip screw devices in trochanteric fractures. Journal of International Medical Research 2009;37(4): 1057-64.

\section{References to studies excluded from this review}

Azzoni 2004 \{published data only\}

Azzoni R, Riva R, Cabitza P. Lateral fractures of the femural neck in elderly: Results of treatment with intramedullary nail versus dynamic compression hip screw [Fratture laterali del collo di femore nell'anziano: Confronto dei risultati del trattamento con chiodo endomidollare e vite-placca in compressione]. Giornale di Gerontologia 2004;52(1):15-23.

Bhatti 2003 \{published data only\}

* Bhatti A, Power D, Khan I, Qureshi S. To nail or to screw? A prospective trial of proximal femoral nail versus dynamic hip screw for unstable inter-trochanteric fractures of the femur [abstract]. Injury 2003;34:608.

Bhatti A, Power DM, Qureshi S, Khan I, Tan S. A prospective trial of proximal femoral nail versus dynamic hip screw for unstable and complex intertrochanteric fractures of the femur [abstract]. Journal of Bone and Joint Surgery - British Volume 2004;86 Suppl 3:377. Khan IA, Bhatti A, Power D, Qureshi S. Nail or to screw? [abstract]. Journal of Bone and Joint Surgery - British Volume 2004; 86 Suppl 3:225.

\section{Bienkowski 2006 \{published data only\}}

Bienkowski P, Reindl R, Berry GK, Lakoub E, Harvey EJ. A new intramedullary nail device for the treatment of intertrochanteric hip fractures: Perioperative experience. Journal of Trauma-Injury Infection \& Critical Care 2006;61(6):1458-62.

Cao 2009 \{published data only\}

Cao L-H, Liu X-W, Su J-C, Zhang C-C. Dynamic hip screw, Gamma nail and proximal femoral nail in treating intertrochanteric fractures in the elderly: A prospective randomized biocompatibility study of 95 patients. [Chinese]. Journal of Clinical Rehabilitative Tissue Engineering Research 2009;13(17):3342-6.

Davison 1996 \{published data only\}

Davison J. Prospective, randomised trial of treatment for extracapsular fractures of the hip. In: National Resarch Register, 2005, Issue 1. Oxford: Update Software.

* Davison JNS, Wildin CJ, Hui ACW, Harper WM. Nail versus plate: A prospective randomised trial comparing the intramedullary hip screw and classic hip screw for internal fixation of extracapsular fractures of the proximal femur. Results after one year [abstract]. Journal of Bone and Joint Surgery - British Volume 1996;78 Suppl 2 and 3:147.

DiCicco 2000 \{published data only\}

DiCicco JD III, Jenkins M, Ostrum RF. Retrograde nailing for subtrochanteric femur fractures. American Journal of Orthopedics 2000;29 Suppl 9:4-8.

Fritz 1999 \{published data only\}

Fritz T, Hiersemann K, Krieglstein C, Friedl W. Prospective randomized comparison of gliding nail and gamma nail in the therapy of trochanteric fractures. Archives of Orthopaedic and Trauma Surgery 1999;119(1):1-6.

Hardy 2003 \{published data only\} Hardy DCR, Drossos K. Slotted intramedullary hip screw nails reduce proximal mechanical unloading. Clinical Orthopaedics and Related Research 2003;406:176-84.

Herrera 2002 \{published data only\} Herrera A, Domingo LJ, Calvo A, Martinez A, Cuenca J. A comparative study of trochanteric fractures treated with the 
Gamma nail or the proximal femoral nail. International

Orthopaedics 2002;26(6):365-9.

\section{Hogh 1992 \{published data only\}}

Hogh J, Anderson K, Duus B, Hansen D, Hellberg S, Jakobsen B, et al.Gamma nail versus DHS in the treatment of trochanteric and subtrochanteric fractures [abstract]. Acta Orthopaedica Scandinavica 1992;248:86-7.

Hogh J, Anderson K, Duus B, Hansen D, Hellberg S, Jakobsen B, et al.Gamma nail versus DHS in the treatment of trochanteric and subtrochanteric fractures [abstract]. Journal of Bone and Joint Surgery - British Volume 1993;75 Suppl 2:199.

Hogh J, Anderson K, Duus B, Hansen D, Hellberg S, Jakobsen B, et al.Gamma nail versus DHS in the treatment of trochanteric and subtrochanteric fractures [abstract]. Orthopaedic Transactions 1993; 17:1049-50.

Hu 2006 \{published data only\}

$\mathrm{Hu}$ W, Luo Y, Fang H. Comparison of various kinds of internal fixations in unstable intertrochanteric femoral fracture [Chinese]. Chung Kuo Hsiu Fu Chung Chien Wai Ko Tsa Chih/Chinese Journal of Reparative \& Reconstructive Surgery 2006;20(7):690-4.

\section{Kafer 2005 \{published data only\}}

Kafer M, Palm M, Zwank L, Cakir B, Puhl W, Kafer W. Does the perioperative morbidity following internal fixation of proximal femur fracture depend on the type of implant? Analysis of dynamic hip screw and proximal femur nail [Welchen einfluss hat das implantat auf die perioperative morbiditat bei osteosynthetischer versorgung pertrochantarer femurfrakturen? Analyse von dynamischer huftschraube hüftschraube und proximalem femurnagel]. Zeitschrift fur Orthopadie und Ihre Grenzgebiete 2005; 143(1):64-71.

Khan 2002 \{unpublished data only\}

Khan SA. personal communication June 272005.

* Khan SA. Fixation of subtrochanteric fractures of the femur. A prospective randomised comparison of the trochanteric intramedullary nail and the dynamic compression screw. In: National Research Register, Issue 1, 2005. Oxford: Update Software.

Klinger 2005 \{published data only\}

Klinger HM, Baums MH, Eckert M, Neugebauer R. A comparative study of unstable per- and intertrochanteric femoral fractures treated with dynamic hip screw (DHS) and trochanteric butt-press plate vs. proximal femoral nail (PFN) [Eine vergleichende untersuchung der versorgung instabiler per- und intertrochantarer femurfrakturen mittels dhs-osteosynthese unter verwendung der trochanterabstutzplatte und dem proximalen femurnagel (PFN)]. Zentralblatt fur Chirurgie 2005;130(4):301-6.

Liu 2008 \{published data only\}

Liu X-W, Su J-C, Guan H-P, Chen Y-Y, Zhang C-C. Dynamic hip screw versus Gamma nail in treating intertrochanteric fractures in patients over 70 years: A prospective randomized biocompatibility observation [Chinese]. Journal of Clinical Rehabilitative Tissue Engineering Research 2008;12(13):2433-6.

Merenyi 1995 \{published data only\} Merenyi G, Zagh I, Kovacs A. Gamma nail versus Ender nails and angle-plate in the proximal fractures of the femur - a randomized prospective study [abstract]. Journal of Bone and Joint Surgery British Volume 1995;77 Suppl 2:215.

Moran 2000 \{unpublished data only\}

Moran. Unstable intertrochanteric fractures of the femur. A prospective randomised trial of the proximal femoral nail and the dynamic hip screw. In: National Resarch Register, Issue 1, 2001. Oxford: Update Software.

Moran CG. personal communication January 2000.

\section{Nouisri 2006 \{published data only\}}

Nouisri L, Chaabane TB, Kchelfi S, Hamdi M, Khelil A. Gamma nail or dynamic hip screw for trochanteric fractures: which osteosynthesis?. European Journal of Trauma 2006;32(Supplement 1):90.

\section{Nuber 2003 \{published data only\}}

Nuber S, Schonweiss T, Ruter A. Stabilisation of unstable trochanteric femoral fractures. Dynamic hip screw (DHS) with trochanteric stabilisation plate vs. proximal femur nail (PFN) [Stabilisierung von instabilen trochantaren mehrfragmentfrakturen. Vergleich zwischen PFN und DHS mit trochanterabstutzplatte]. Unfallchirug 2003;106(1):39-47.

Pan 2009 \{published data only\}

Pan S-H, Liu X-W, Zhang C-C, Xu S-G, Fu Q-G. Implantation of Gamma nail and proximal femoral nail for the treatment of femoral intertrochanteric fractures in the elderly: A randomized follow-up for 131 cases. [Chinese]. Journal of Clinical Rehabilitative Tissue Engineering Research 2009;13(39):7647-50.

Prinz 1996 \{published data only\}

Prinz S, Letsch R, Buscher D. Gamma nails and classic nails (intramedullary stabilisation) versus DHS ( extramedullary stabilisation) in proximal femur frcatures - perioperative preliminary results within a prospective randomised study [abstract] [Gamma-nagel und Glassic-nagel (intramedullare stabilisierung) versus DHS (extramedullare stabilisierung) bei proximalen femurfrakturen - Perioperative fruhergebnisse im rahmen einer prospektivv randomisierten studie]. Hefte zur der Unfallchirurg 1996;262:14.

Roder 1995 \{published data only\}

Roder W, Isemer FE, Weigel TF, Zimmermann F, Peifer A. Bone marrow introvasion during operative pertrochanteric femur fracture-care - Gamma nail versus DHS [Markeinschwemmung bei operativer Versorgung pertrochantarer Femurfrakturen. Vergleich Gammanagel gegen DHS]. Aktuelle Traumatologie 1995;25:67-71.

\section{Saarenpaa 2009 \{published data only\}}

Saarenpaa I, Heikkinen T, Ristiniemi J, Hyvonen P, Leppilahti J, Jalovaara P. Functional comparison of the dynamic hip screw and the Gamma locking nail in trochanteric hip fractures: a matchedpair study of 268 patients. International Orthopaedics 2009;33(1): 255-60.

\section{Schipper 2004 \{published data only\}}

Schipper IB, Steyerberg EW, Castelein RM, van der Heijden FH, den Hoed PT, Kerver AJ, et al.Treatment of unstable trochanteric fractures: randomised comparison of the gamma nail and the proximal femoral nail. Journal of Bone and Joint Surgery - British Volume 2004;86(1):86-94. 
Tarantino 2005 \{published data only\}

Tarantino U, Oliva F, Impagliazzo A, Mattei A, Cannata G, Pompili GF, et al.A comparative prospective study of dynamic variable angle hip screw and Gamma nail in intertrochanteric hip fractures. Disability \& Rehabilitation 2005;27(18-19):1157-65.

Zhang 2009 \{published data only\}

Zhang Z, Ge J, Lu X, Chen G, Zhuo N. Evaluation on curative effect of three operative methods in treatment of senile intertrochanteric fracture [Chinese].. Chung Kuo Hsiu Fu Chung Chien Wai Ko Tsa Chib/Chinese Journal of Reparative \& Reconstructive Surgery 2009;23(5):556-61.

Zhao 2009 \{published data only\} Zhao C, Liu DY, Guo JJ, Li LP, Zheng YF, Yang HB, et al.Comparison of proximal femoral nail and dynamic hip screw for treating intertrochanteric fractures [Chinese]. Zhongguo Gushang 2009;22(7):535-7.

\section{Ziran 2009 \{published data only\}}

Ziran BH, Heckman DS, Olarte CM, Chou K, Baranick J. Intramedullary hip screw versus standard compression hip screw: Early postoperative rehabilitation comparisons. Orthopedics 2009; 32(2):83.

\section{References to studies awaiting assessment}

\section{Ahmad \{unpublished data only\}}

Ahmad M. Randomised controlled trial to compare the magnitude and incidence of haemodynamic changes during fixation of extracapsular fractures of the neck of femur using the compression hip screw versus the intramedullary hip screw (https:// portal.nihr.ac.uk/Profiles/NRR.aspx?Publication'ID= N0227149002). National Research Register Archive (accessed $07 /$ 06/2010).

* Ahmad M, Bhattacharya R, Nanda R, Bajwa A, Danjoux G, Hui AC. An RCT comparing haemodynamic changes during the fixation of extracapsular proximal femoral fractures using the compression hip screw versus the intramedullary hip screw [abstract]. The Surgeon: Journal of the Royal Colleges of Surgeons of Edinburgh and Ireland 2005;3(3 Suppl):S10.

Rafiq 2009 \{published data only\}

Rafiq I, Ahmed S, Kapoor A, Shafique S, Quyyum H, Zaki SH, et al.Fixation of subtrochanteric femoral fractures with dynamic condylar screw and interlocking nail? A prospective randomised controlled trial. Journal of Bone and Joint Surgery - British Volume 2009;91(Supp I):88.

White \{unpublished data only\}

White J. Randomised control trial of the DHS versus the PFN for unstable hip fractures (https://portal.nihr.ac.uk/Profiles/NRR.aspx? Publication ID=N0020092997). National Research Register Archive (accessed 07/06/2010).

\section{References to ongoing studies}

\section{Matre \{unpublished data only\}}

Matre K. A prospective randomised multicenter study comparing the sliding hip screw and the Intertan nail in trochanteric and subtrochanteric femoral fractures [http://clinicaltrials.gov/ct2/
show/record/NCT00621088]. WHO International Clinical Trials Registry Platform (accessed 23/04/2009). [: NCT00621088]

\section{Molnar \{unpublished data only\}}

Molnar R. Prospective randomised pilot study comparing the dynamic hip screw and intramedullary gamma nail regarding functional recovery following the treatment of intertrochanteric hip fracture [http://www.anzctr.org.au/ACTRN12608000162314]. WHO International Clinical Trials Registry Platform (accessed 23/ 04/2009). [: ACTRN12608000162314]

Parker \{unpublished data only\}

* Parker M. Randomised trial of extracapsular hip fractures treated with either a sliding hip screw or an intramedullary nail [https:// portal.nihr.ac.uk/Profiles/NRR.aspx?Publication ${ }^{\prime} \mathrm{ID}=$

N0181115108]. National Research Register Archive (accessed 07/ 06/2010).

Parker MJ. personal communication 2003.

REGAIN \{unpublished data only\}

Bhandari M. Re-evaluation of Gamma3 intramedullary nails in hip fracture (REGAIN) [http://clinicaltrials.gov/show/

NCT00555945]. ClinicalTrials.gov (accessed 09/06/2008). [: NCT00555945]

Schipper \{unpublished data only\}

Shipper IB. RSA study on trochanteric fractures: DHS versus gamma-nail [http://www.trialregister.nl/trialreg/admin/rctview.asp? $\mathrm{TC}=2221]$. Nederlands Trial Register (accessed 26/05/2010). [: NTR2221]

\section{Additional references}

\section{Ahrengart 2002}

Ahrengart L, Tornkvist H, Fornander P, Thorngren KG, Pasanen L, Wahlstrom P, et al.A randomized study of the compression hip screw and Gamma nail in 426 fractures. Clinical Orthopaedics \& Related Research 2002;(401):209-22.

\section{Altman 2003}

Altman DG, Bland JM. Interaction revisited: the difference between two estimates. BMJ 2003;326(7382):219.

Anglen 2008

Anglen JO, Weinstein JN. Nail or plate fixation of intertrochanteric hip fractures: Changing pattern of practice - A review of the American Board of Orthopaedic Surgery database. Journal of Bone and Joint Surgery - American Volume 2008;90(4):700-7.

\section{Boutron 2008}

Boutron I, Moher D, Altman DG, Schulz KF, Ravaud P, CONSORT Group. Extending the CONSORT statement to randomized trials of nonpharmacologic treatment: explanation and elaboration. Annals of Internal Medicine 2008;148(4):295-309.

\section{Cuthbert 1976}

Cuthbert H, Howat TW. The use of the Kuntscher $Y$ nail in the treatment of intertrochanteric and subtrochanteric fractures of the femur. Injury 1976;8:135-42.

\section{Fornander 1994}

Fornander P, Thorngren K-G, Tornqvist H, Ahrengart L, Lingren U. Swedish experience with the Gamma nail vs. sliding hip screw in 209 randomised cases. International Journal of Orthopaedic Trauma 1994;4(3):118-22. 


\section{Forte 2008}

Forte ML, Virnig BA, Kane RL, Durham S, Bhandari M, Feldman $\mathrm{R}$, et al.Geographic variation in device use for intertrochanteric hip fractures. Journal of Bone and Joint Surgery - American Volume 2008; 90(4):691-9.

\section{Hardy 1999}

Hardy DCR, Delince P. Intramedullary hip screw (IMHS) versus compression hip screw plate (CHSP) for intertrochanteric hip fractures. A prospective, randomised trial of 160 patients [abstract]. Journal of Bone and Joint Surgery - British Volume 1999;81 Suppl 2: $163-4$.

\section{Higgins 2003}

Higgins JPT, Thompson SG, Deeks JJ, Altman DG. Measuring inconsistency in meta-analyses. BMJ 2003;327:557-60.

\section{Higgins 2006}

Higgins JPT, Green S, editors. Highly sensitive search strategies for identifying reports of randomized controlled trials in MEDLINE.

Cochrane Handbook for Systematic Reviews of Interventions 4.2.6 [updated September 2006]; Appendix 5b. www.cochrane.org/ resources/handbook/hbook.htm (accessed 01 May 2007).

\section{Medoff 1991}

Medoff RJ, Maes K. A new device for the fixation of unstable pertrochanteric fractures of the hip. Journal of Bone and Joint Surgery - American Volume 1991;73(8):1992-9.

\section{Muller 1991}

Muller ME, Allgower M, Shneider R, Willenegger H. The comprehensive classification of fractures of long bones. In: Allgower M editor(s). Manual of internal fixation. Berlin: SpringerVerlag, 1991.

\section{Parker 1998}

Parker MJ, Handoll HHG. Condylocephalic nails versus extramedullary implants for extracapsular hip fractures. Cochrane Database of Systematic Reviews 1998, Issue 4. [DOI: 10.1002/ 14651858.CD000338]

\section{Parker 2002}

Parker MJ. Trochanteric and subtrochanteric fractures. In: Bulstrode C, Buckwalter J, Carr A, Marsh L, Fairbank J, WilsonMacDonald J, et al. editor(s). Oxford Textbook of Orthopaedics and Trauma. 1st Edition. Oxford: Oxford University Press, 2002: 2228-39.

\section{Parker 2006}

Parker MJ, Handoll HHG. Intramedullary nails for extracapsular hip fractures in adults. Cochrane Database of Systematic Reviews 2006, Issue 3. [DOI: 10.1002/14651858.CD004961]

\section{References to other published versions of this review}

\section{Parker 1996}

Parker MJ, Handoll HHG, Robinson CM. Gamma nail versus sliding hip screw for the treatment of extracapsular femoral fractures. Cochrane Database of Systematic Reviews 1996, Issue 3.

\section{Parker 1996a}

Parker MJ, Pryor GA. Gamma versus DHS nailing for extracapsular femoral fractures. Meta-analysis of ten randomised trials. International Orthopaedics 1996;20:163-8.

\section{Parker 1999}

Parker MJ, Handoll HHG. Gamma and other cephalocondylic intramedullary nails versus extramedullary implants for extracapsular hip fractures. Cochrane Database of Systematic Reviews 1999, Issue 2.

Parker 2002a

Parker MJ, Handoll HHG. Gamma and other cephalocondylic intramedullary nails versus extramedullary implants for extracapsular hip fractures. Cochrane Database of Systematic Reviews 2002, Issue 1.

\section{Parker 2002b}

Parker MJ, Handoll HHG. Gamma and other cephalocondylic intramedullary nails versus extramedullary implants for extracapsular hip fractures. Cochrane Database of Systematic Reviews 2002, Issue 4.

\section{Parker 2004}

Parker MJ, Handoll HHG. Gamma and other cephalocondylic intramedullary nails versus extramedullary implants for extracapsular hip fractures. Cochrane Database of Systematic Reviews 2004, Issue 1.

\section{Parker 2005a}

Parker MJ, Handoll HHG. Gamma and other cephalocondylic intramedullary nails versus extramedullary implants for extracapsular hip fractures in adults. Cochrane Database of Systematic Reviews 2005, Issue 4. [Art. No.: CD000093. DOI: 10.1002/14651858.CD000093.pub5]

* Indicates the major publication for the study 
CHARACTERISTICS OF STUDIES

Characteristics of included studies [ordered by study ID]

Adams 2001

Methods

Randomised by sequentially numbered closed opaque sealed envelopes

Surgical experience (see Footnotes): Yes (Claimed experience in both implants)

Oarticipants
$\begin{array}{ll}400 \text { participants } \\ \text { Trochanteric proximal femoral fractures. } \\ \text { Age: mean } 81 \text { years } \\ \text { \% male: } 22 \% \\ \text { Number lost to follow-up: } 0.3 \%\end{array}$

Interventions

Gamma intramedullary nail versus Richards Compression hip screw

\begin{tabular}{ll}
\hline Outcomes & Length of follow-up: 12 months \\
& Length of surgery \\
& Operative blood loss \\
Fall in haemoglobin & Number of patients transfused \\
& Operative fracture of the femur \\
& Later fracture of the femur \\
& Cut-out of implant \\
& Detachment of the plate from the femur \\
Reoperation & Deep wound infection \\
\hline Superficial wound infection & Deep vein thrombosis \\
Mortality \\
Use of walking aids \\
Place of residence at follow up \\
Harris hip score \\
\hline Notes & Information of study supplied by trialists prior to publication \\
\hline
\end{tabular}

Risk of bias

\begin{tabular}{|c|c|c|}
\hline Item & Authors' judgement & Description \\
\hline Adequate sequence generation? & Unclear & No details \\
\hline Allocation concealment? & Yes & $\begin{array}{l}\text { "At admission, patients were randomized } \\
\text { by a closed, opaque envelope method and } \\
\text { were assigned to receive either..." Con- } \\
\text { firmed by Adams in } 2001 \text { that "the opaque } \\
\text { envelopes were sequentially numbered" } \\
\text { and that there was concealment of alloca- }\end{array}$ \\
\hline
\end{tabular}

Gamma and other cephalocondylic intramedullary nails versus extramedullary implants for extracapsular hip fractures in adults (Review) 30 Copyright (@) 2010 The Cochrane Collaboration. Published by John Wiley \& Sons, Ltd. 
Adams 2001 (Continued)

tion.

Surgeons were experienced with trial oper- Yes ations?

"The surgeons were experienced in the insertion of both implants" Claim in draft report.

\section{Ahrengart 1994}

Methods

Randomised by consecutively opened sealed envelopes

Surgical experience: Yes (Gamma nail: learning period before trial; SHS: routine)

\begin{tabular}{|c|c|}
\hline Participants & $\begin{array}{l}\text { Five orthopaedic hospitals, Sweden and Finland } \\
548 \text { participants } \\
\text { Trochanteric and subtrochanteric fractures. But the } 2002 \text { report only included } 492 \\
\text { trochanteric proximal femoral fractures. The baseline data and early results for } 66 \text { patients } \\
\text { lost to follow-up were not reported. } \\
\text { Age: median } 80 \text { years (range } 32-99 \text { years) } \\
\% \text { male: } 29 \% \\
\text { Number lost to follow-up: } 13 \%\end{array}$ \\
\hline Interventions & Gamma intramedullary nail versus Compression hip screw \\
\hline Outcomes & $\begin{array}{l}\text { Length of follow-up: } 6 \text { months } \\
\text { Length of surgery } \\
\text { Blood loss } \\
\text { Transfusion } \\
\text { Operative fracture of the femur } \\
\text { Later fracture of the femur } \\
\text { Cut-out of implant } \\
\text { Non-union (pseudarthrosis) } \\
\text { Delayed healing } \\
\text { Reoperation } \\
\text { Wound infection } \\
\text { Deep wound infection } \\
\text { Superficial wound infection } \\
\text { Thromboembolic complication (deep vein thrombosis, pulmonary embolism) } \\
\text { Clinical complications (pneumonia) } \\
\text { Length of hospital stay } \\
\text { Shortening of leg } \\
\text { Varus displacement } \\
\text { Mortality at } 6 \text { months } \\
\text { Pain at follow-up (persisting lateral hip pain) } \\
\text { Return to pre-fracture residential status } \\
\text { Failure to regain mobility } \\
\text { Use of walking aids } \\
\text { Length of skin incision }\end{array}$ \\
\hline
\end{tabular}

Gamma and other cephalocondylic intramedullary nails versus extramedullary implants for extracapsular hip fractures in adults (Review) 3 I Copyright (C) 2010 The Cochrane Collaboration. Published by John Wiley \& Sons, Ltd. 


A report (2002) of the results for patients with trochanteric fractures from all five centres
of this study is now available. It is however less comprehensive than the report, used in
previous versions of this review, by Fornander et al 1994 which gave the results for two
centres and 209 patients, including 19 with subtrochanteric fractures. Fornander also
provided a pre-publication report and additional information for these two centres.
Clarification on results and methods from Leif Ahrengart is pending (September 2003).
Given the absence of information on 66 patients lost to follow-up in the five centre report
and some lack of clarity or potential inconsistencies with the two centre study regarding
surgical experience, trial inclusion criteria, outcome definitions and some results (i.e.
there was one deep wound infection in the SHS group in Fornander 1994 but none in
the five-centre report), we have kept the data from the two centre report.

Risk of bias

\begin{tabular}{|c|c|c|}
\hline Item & Authors' judgement & Description \\
\hline Adequate sequence generation? & Unclear & No details \\
\hline Allocation concealment? & Unclear & $\begin{array}{l}\text { "Randomization was achieved using sealed } \\
\text { envelopes in numerical order before the pa- } \\
\text { tient was taken to the operating room." In- } \\
\text { sufficient mention of safeguards. }\end{array}$ \\
\hline $\begin{array}{l}\text { Surgeons were experienced with trial oper- } \\
\text { ations? }\end{array}$ & Yes & $\begin{array}{l}\text { Surgery was done by various orthopaedic } \\
\text { surgeons from junior residents to staff sur- } \\
\text { geons. However, an exclusion criterion was } \\
\text { if the surgeon was unfamiliar with the } \\
\text { Gamma nail technique. } \\
\text { Fornander } 1994 \text { reports "The randomised } \\
\text { series was preceded by a learning curve } \\
\text { giving awareness of the technical details } \\
\text { and potential difficulties or hazards of the } \\
\text { Gamma method." }\end{array}$ \\
\hline
\end{tabular}

Barton 2010

Methods

\begin{tabular}{ll} 
& Surgical experience: Yes (All 32 surgeons familiar with both techniques) \\
\hline Participants & Orthopaedic hospital, Bristol, UK \\
& 210 participants \\
Unstable trochanteric proximal femoral fractures. & Age: mean 83 years (range 42 to 99 years) \\
$\%$ male: $21 \%$ \\
Number lost to follow-up: not stated
\end{tabular}

Long Gamma intramedullary nail versus sliding hip screw 
Barton 2010 (Continued)

\begin{tabular}{l|l}
\hline Outcomes & Length of follow-up: 12 months \\
Number of patients transfused \\
Operative fracture of the femur \\
Later fracture of the femur \\
Cut-out of implant \\
Non-union \\
Deep wound infection \\
Reoperation \\
Length of hospital stay \\
Mortality \\
Change in mobility score (measured on a 5 point ordinal scale) \\
Change in residential status (measured on a 5 point ordinal scale) \\
Mean quality adjusted life years \\
\hline Significance testing was corrected for a significantly higher proportion of patients with \\
a lower mini-mental score in the nail group.
\end{tabular}

\section{Risk of bias}

\begin{tabular}{|c|c|c|}
\hline Item & Authors' judgement & Description \\
\hline Adequate sequence generation? & Yes & $\begin{array}{l}\text { "Randomization was carried out with use } \\
\text { of sealed } \\
\text { envelopes generated by a medical statisti- } \\
\text { cian." Once a patient was considered to be } \\
\text { appropriate for inclusion, consent was ob- } \\
\text { tained. An envelope was then selected and } \\
\text { opened at a daily trauma meeting. }\end{array}$ \\
\hline Allocation concealment? & Unclear & $\begin{array}{l}\text { "Randomization was carried out with use } \\
\text { of sealed } \\
\text { envelopes generated by a medical statisti- } \\
\text { cian. Once a patient was considered to be } \\
\text { appropriate for inclusion, consent was ob- } \\
\text { tained. An envelope was then selected and } \\
\text { opened at a daily trauma meeting." } \\
\text { Inadequate mention of safeguards. }\end{array}$ \\
\hline $\begin{array}{l}\text { Surgeons were experienced with trial oper- } \\
\text { ations? }\end{array}$ & Yes & $\begin{array}{l}\text { All } 32 \text { surgeons were experienced with both } \\
\text { implants }\end{array}$ \\
\hline
\end{tabular}




\begin{tabular}{|c|c|}
\hline Methods & $\begin{array}{l}\text { Randomised by sealed opaque envelopes opened sequentially } \\
\text { Surgical experience: No (Gamma nail: familiar with IM nailing but not the Gamma nail; } \\
\text { SHS routine; surgery by residents under supervision, } 30 \text { participating surgeons) }\end{array}$ \\
\hline Participants & $\begin{array}{l}\text { Two orthopaedic hospitals, USA } \\
131 \text { participants } \\
135 \text { trochanteric femoral fractures ( } 4 \text { of these were fractures which occurred several } \\
\text { months later in the same patients) } \\
\text { Excluded: pathological fractures. } \\
\text { Age: mean } 79 \text { years (range } 40-99 \text { years) } \\
\% \text { male: } 34 \% \\
\text { Number lost to follow-up: none }\end{array}$ \\
\hline Interventions & Intramedullary hip screw versus sliding hip screw \\
\hline Outcomes & $\begin{array}{l}\text { Length of follow-up: mean } 28 \text { months (range } 4-54 \text { months) } \\
\text { Length of surgery } \\
\text { Operative blood loss } \\
\text { Transfusion } \\
\text { Radiographic screening time } \\
\text { Operative fracture of the femur } \\
\text { Later fracture of the femur } \\
\text { Cut-out of implant } \\
\text { Non-union } \\
\text { Wound haematoma } \\
\text { Major medical complication } \\
\text { Length of hospital stay } \\
\text { Mortality } \\
\text { Hip pain at follow-up } \\
\text { Return to pre-fracture residence } \\
\text { Patient mobility }\end{array}$ \\
\hline Notes & $\begin{array}{l}\text { Slight confusion with use of patient or fracture numbers in the trial report. Trialist ex- } \\
\text { plained that } 4 \text { patients had } 2 \text { fractures which were operated on several months apart (they } \\
\text { were not bilateral fractures). These were considered separate operations and different } \\
\text { cases for pre-op and operative data. Two of the } 4 \text { patients received both IMHS and SHS, } \\
\text { and were excluded from longer term follow-up data but not mortality (where they were } \\
\text { only counted once in the analysis). } \\
\text { Curtin's abstract reporting early results for } 70 \text { patients shows the dangers of interim trial } \\
\text { reports. }\end{array}$ \\
\hline
\end{tabular}

\section{Risk of bias}

\begin{tabular}{l|ll} 
Item & Authors' judgement & Description \\
\hline Adequate sequence generation? & Yes & ”cards were shuffled“"
\end{tabular}




\section{Baumgaertner 1998 (Continued)}

\begin{tabular}{l|l|l}
\hline & Yes & $\begin{array}{l}\text { "two hundred sealed opaque envelopes } \\
\text { were randomly (cards were shuffled) as- } \\
\text { signed to either the IMHS or CHS, and } \\
\text { numbered in sequential order, after enrol- } \\
\text { ment in the study the next envelope was } \\
\text { opened to reveal the device selected for the } \\
\text { patient, no one was aware of the next up- } \\
\text { coming device. }\end{array}$ \\
\hline $\begin{array}{l}\text { Surgeons were experienced with trial oper- } \\
\text { ations? }\end{array}$ & No & $\begin{array}{l}\text { All participating attending surgeons had } \\
\text { been using sliding hip screws ... before the } \\
\text { start of the study, and although they were } \\
\text { familiar with .. nailing, they previously had } \\
\text { not used the intramedullary hip screw. }\end{array}$ \\
\hline
\end{tabular}

\section{Benum 1994}

\begin{tabular}{|c|c|}
\hline Methods & $\begin{array}{l}\text { Randomised by envelopes } \\
\text { Surgical experience: No (Unknown for all centres but for sub-group from one centre, } \\
\text { Aune et al 1993: Gamma nail: residents with varying experience of IM nailing (refers to } \\
\text { learning curve); SHS: routine) }\end{array}$ \\
\hline Participants & $\begin{array}{l}\text { Orthopaedic hospitals, Norway } \\
912 \text { participants (interim results for } 460 \text { ) } \\
\text { Trochanteric and subtrochanteric proximal femoral fractures. } \\
\text { Age: not stated } \\
\% \text { male: not stated } \\
\text { Number lost to follow-up: } 21 \%\end{array}$ \\
\hline Interventions & Gamma intramedullary nail versus Compression hip screw \\
\hline Outcomes & $\begin{array}{l}\text { Length of follow-up: } 6 \text { months } \\
\text { Length of surgery } \\
\text { Blood loss } \\
\text { Operative fracture of the femur } \\
\text { Later fracture of the femur } \\
\text { Cut-out of implant (fracture dislocation) } \\
\text { Non-union (fracture healing) } \\
\text { Reoperation } \\
\text { Wound infection } \\
\text { Deep vein thrombosis } \\
\text { Pulmonary embolism } \\
\text { Length of hospital stay } \\
\text { Mortality } \\
\text { Institutional stay } \\
\text { Walking function }\end{array}$ \\
\hline
\end{tabular}


Benum 1994 (Continued)

\begin{tabular}{|c|c|c|}
\hline Notes & \multicolumn{2}{|c|}{$\begin{array}{l}\text { Data used in analyses tables are based on interim data for } 460 \text { patients published in } 1992 \\
\text { in an abstract. Details for the completed trial of } 912 \text { patients were given in an another } \\
\text { abstract published in } 1994 \text {. The references Aune et al } 1993 \text { and Ekeland et al } 1993 \text { (x2) } \\
\text { report the results of } 378 \text { patients recruited by one of the centres of the multicentre trial } \\
\text { reported by Benum. Madsen et al } 1996 \text { refers to a subgroup from this centre. The follow } \\
\text { up for these patients was } 10 \text { to } 27 \text { months. A later trial report by Madsen et al } 1998 \text { also } \\
\text { includes a subgroup from this trial. } \\
\text { A slightly modified Gamma nail was used ( } 6 \text { degree valgus angle). } \\
\text { Not included in the analyses for reoperation are the final data for Benum } 1994 \text { (29/429 } \\
\text { versus 7/467), which are consistent with the general result. }\end{array}$} \\
\hline \multicolumn{3}{|l|}{ Risk of bias } \\
\hline Item & Authors' judgement & Description \\
\hline Adequate sequence generation? & Unclear & No details. \\
\hline Allocation concealment? & Unclear & $\begin{array}{l}\text { "The randomization was done by drawing } \\
\text { on among mixed envelopes containing in- } \\
\text { formation allocating the patient to either } \\
\text { treatment." No mention of safeguards. }\end{array}$ \\
\hline $\begin{array}{l}\text { Surgeons were experienced with trial oper- } \\
\text { ations? }\end{array}$ & No & $\begin{array}{l}\text { Report from one centre (Aune et al 1993) } \\
\text { refers to treatment by "younger surgeons" } \\
\text { and in consequence that "the learning curve } \\
\text { becomes important". }\end{array}$ \\
\hline
\end{tabular}

Bridle 1991

\begin{tabular}{|c|c|}
\hline Methods & $\begin{array}{l}\text { "Randomised": method not specified } \\
\text { Surgical experience: Yes (All } 4 \text { surgeons familiar with closed nailing techniques) }\end{array}$ \\
\hline Participants & $\begin{array}{l}\text { Orthopaedic hospital, UK } \\
100 \text { participants } \\
\text { Trochanteric proximal femoral fractures. } \\
\text { Age: mean } 82 \text { years (all over } 60 \text { years) } \\
\% \text { male: } 16 \% \\
\text { Number lost to follow-up: } 6 \%\end{array}$ \\
\hline Interventions & Gamma intramedullary nail versus Dynamic hip screw \\
\hline Outcomes & $\begin{array}{l}\text { Length of follow-up: } 6 \text { months } \\
\text { Length of surgery } \\
\text { Blood loss } \\
\text { Operative fracture of the femur } \\
\text { Later fracture of the femur } \\
\text { Cut-out of implant }\end{array}$ \\
\hline
\end{tabular}

Gamma and other cephalocondylic intramedullary nails versus extramedullary implants for extracapsular hip fractures in adults (Review) 36 Copyright (@) 2010 The Cochrane Collaboration. Published by John Wiley \& Sons, Ltd. 
Bridle 1991 (Continued)

\begin{tabular}{ll} 
& Non-union \\
Reoperation (incomplete data) & Wound infection \\
Wound haematoma \\
Pneumonia \\
Pressure sore \\
Pulmonary embolism \\
Any medical complication \\
Length of hospital stay \\
Shortening of femur (leg) (no information) \\
Mortality \\
Pain (no information) \\
Eventual discharge residence \\
Patient mobility \\
\hline Notes & Some discrepancies between tables and text in report. \\
\hline
\end{tabular}

Risk of bias

\begin{tabular}{lll}
\hline Item & Authors' judgement & Description \\
\hline Adequate sequence generation? & Unclear & No details \\
\hline Allocation concealment? & Unclear & "randomly allocated" \\
\hline $\begin{array}{l}\text { Surgeons were experienced with trial oper- } \\
\text { ations? }\end{array}$ & Yes & $\begin{array}{l}\text { "All the operations were performed by one } \\
\text { of four senior surgeons, all experienced in } \\
\text { closed nailing techniques." }\end{array}$ \\
\hline
\end{tabular}

\section{Butt 1995}

Methods

Quasi-randomised by even or odd numbered weeks

Surgical experience: No (Unknown; same surgeons did both operations)

\begin{tabular}{ll} 
Participants & $\begin{array}{l}\text { Orthopaedic hospital, UK } \\
95 \text { participants } \\
\text { Trochanteric and subtrochanteric proximal femoral fractures. } \\
\text { Age: mean } 78.5 \text { years (range 47-101 years) } \\
\% \text { male: } 31 \% \\
\text { Number lost to follow-up: none }\end{array}$ \\
\hline Interventions & Gamma intramedullary nail versus Dynamic hip screw \\
\hline \multirow{2}{*}{ Outcomes } & $\begin{array}{l}\text { Length of follow-up: 'to fracture union' (generally }<6 \text { months) } \\
\text { Length of surgery } \\
\text { Blood loss } \\
\text { Later fracture of the femur } \\
\text { Cut-out of implant (incomplete data?) }\end{array}$ \\
\hline
\end{tabular}

Gamma and other cephalocondylic intramedullary nails versus extramedullary implants for extracapsular hip fractures in adults (Review) 37 Copyright (C) 2010 The Cochrane Collaboration. Published by John Wiley \& Sons, Ltd. 
Butt 1995 (Continued)

Non-union (time to union)

Reoperation (total inferred)

Wound infection

Pneumonia

Pressure sore

Deep vein thrombosis

Any medical complication

Length of hospital stay

Mortality

Notes

Gamma nail technique modified without apparent advantage after 37 Gamma nail patients.

\section{Risk of bias}

\begin{tabular}{|c|c|c|}
\hline Item & Authors' judgement & Description \\
\hline Adequate sequence generation? & No & $\begin{array}{l}\text { "Patients admitted on even-numbered } \\
\text { weeks were treated with a DHS and pa- } \\
\text { tients admitted on odd-numbered weeks } \\
\text { were treated with a gamma nail." }\end{array}$ \\
\hline Allocation concealment? & No & As above. \\
\hline $\begin{array}{l}\text { Surgeons were experienced with trial oper- } \\
\text { ations? }\end{array}$ & No & $\begin{array}{l}\text { Same surgeons did both operations, but no } \\
\text { mention of experience and interim modi- } \\
\text { fication of surgical technique by the man- } \\
\text { ufacturers. }\end{array}$ \\
\hline
\end{tabular}

\section{Davis 1988}

Methods

Randomised using numbered sealed opaque envelopes opened after patient assigned a trial numbers (via random numbers table)

Surgical experience: No (unknown; operations performed by consultants or trainees)

\begin{tabular}{ll}
\hline Participants & Two orthopaedic hospitals, UK \\
& 230 participants \\
& Intertrochanteric proximal femoral fractures. \\
& $\begin{array}{l}\text { Excluded: patients aged }<50, \text { pathological and Pagets fractures. } \\
\text { Age: mean } 81 \text { years } \\
\% \text { male: } 17 \% \\
\text { Number lost to follow-up: none }\end{array}$ \\
\hline Interventions & Kuntscher-Y nail versus sliding hip screw \\
\hline \multirow{2}{*}{ Outcomes } & Length of follow-up: 12 months \\
& Length of hospital stay \\
\hline
\end{tabular}

Gamma and other cephalocondylic intramedullary nails versus extramedullary implants for extracapsular hip fractures in adults (Review) 38 Copyright (C) 2010 The Cochrane Collaboration. Published by John Wiley \& Sons, Ltd. 
Davis 1988 (Continued)

Length of hospital stay and convalescence

Mortality (1 month and 6 months)

Radiographic healing time

Time to weight bearing

Salvati and Wilson score

Functional deficit

Power and motion at hip

Knee mobility

Time till painless mobilisation

\section{Notes}

Hip nail used was described as an experimental device which is not available commercially. This outdated implant is now superseded by newer intramedullary nails that have improved instrumentation and the capacity for distal locking to reduce the risk of limb shortening.

\section{Risk of bias}

\begin{tabular}{l|ll}
\hline Item & Authors' judgement & Description \\
\hline Adequate sequence generation? & Yes & "using random numbers table" \\
\hline Allocation concealment? & Yes & $\begin{array}{l}\text { "For each trial number, the name of the } \\
\text { allocated fixation device was stored in an } \\
\text { opaque sealed envelope which was opened } \\
\text { only after a patient had been assigned this } \\
\text { trial number." }\end{array}$ \\
\hline $\begin{array}{l}\text { Surgeons were experienced with trial oper- } \\
\text { ations? }\end{array}$ & No & $\begin{array}{l}\text { No details: "Similar proportions of each op- } \\
\text { eration were performed at the two hospi- } \\
\text { tals, by consultants or trainee surgeons." }\end{array}$ \\
\hline
\end{tabular}

\section{Dujardin 2001}

\begin{tabular}{ll} 
Methods & $\begin{array}{l}\text { Randomised: method not stated } \\
\text { Surgical experience: Yes (All operations were undertaken by two surgeons with experience } \\
\text { of the surgical technique; one surgeon did all the SHS operations and the other did all } \\
\text { the nail operations) }\end{array}$ \\
\hline Participants & $\begin{array}{l}\text { Orthopaedic hospital, Rouen, France } \\
60 \text { participants } \\
\text { Intertrochanteric proximal femoral fracture (stable and unstable fractures). } \\
\text { Excluded: patients aged }<60, \text { pathological, lower limb arteriopathy, fractures extending } \\
\text { to the diaphysis, previous lesions of the hip, surgery after } 2 \text { days from fracture, cutaneous } \\
\text { lesions, abnormal calcium or phosphorus metabolism and no consent. } \\
\text { Age: mean } 83.5 \text { years } \\
\% \text { male: } 20 \%\end{array}$ \\
Number lost to follow-up: not stated
\end{tabular}


Dujardin 2001 (Continued)

\begin{tabular}{|c|c|c|}
\hline Interventions & \multicolumn{2}{|c|}{ A mini-invasive static intramedullary nail versus sliding hip screw } \\
\hline Outcomes & \multicolumn{2}{|c|}{$\begin{array}{l}\text { Length of follow-up: } 6 \text { months } \\
\text { Length of surgery } \\
\text { Blood loss } \\
\text { Mean units blood transfused } \\
\text { Radiographic screening time } \\
\text { Non-union; time to union } \\
\text { Early post-op complications (infection, thromboembolism, further operation) } \\
\text { Pneumonia } \\
\text { Pressure sores } \\
\text { All medical complications } \\
\text { Length of hospital stay } \\
\text { Varus deformity (reported for the nail group) } \\
\text { Angular restoration } \\
\text { Mortality } \\
\text { Various aspects of hip function, including pain, power and mobility, were measured } \\
\text { using the Salvati and Wilson score. } \\
\text { Pain } \\
\text { Failure to regain mobility } \\
\text { Hip function } \\
\text { Knee mobility }\end{array}$} \\
\hline Notes & \multicolumn{2}{|c|}{$\begin{array}{l}\text { This experimental nail is not available commercially. } \\
\text { The paper reported on radiographic measurements of anatomical restoration (cervi- } \\
\text { cotrochanteric shortening and cervico-diaphyseal angle). However clinical outcomes } \\
\text { such as leg shortening were not reported. } \\
\text { The numbers of participants in each group returning home were not given. } \\
\text { We have yet to find evidence of the multicentre study of this experimental implant, stated } \\
\text { as underway in the report of this trial. }\end{array}$} \\
\hline \multicolumn{3}{|l|}{ Risk of bias } \\
\hline Item & Authors' judgement & Description \\
\hline Adequate sequence generation? & Unclear & No details \\
\hline Allocation concealment? & Unclear & "randomly allocated" \\
\hline $\begin{array}{l}\text { Surgeons were experienced with trial oper- } \\
\text { ations? }\end{array}$ & Yes & $\begin{array}{l}\text { All operations were undertaken by two sur- } \\
\text { geons with experience of the surgical tech- } \\
\text { nique; one surgeon did all the SHS opera- } \\
\text { tions and the other did all the nail opera- } \\
\text { tions. }\end{array}$ \\
\hline
\end{tabular}

Gamma and other cephalocondylic intramedullary nails versus extramedullary implants for extracapsular hip fractures in adults (Review) 40 Copyright $\odot 2010$ The Cochrane Collaboration. Published by John Wiley \& Sons, Ltd. 


\begin{tabular}{l|l} 
Methods & $\begin{array}{l}\text { Randomised using numbered sealed envelopes } \\
\text { Surgical experience: No (operations performed by } 43 \text { different surgeons, consultants or } \\
\text { trainees) }\end{array}$ \\
\hline Participants & $\begin{array}{l}\text { Two orthopaedic hospitals, Sweden } \\
210 \text { participants (see Notes) } \\
\text { Unstable intertrochanteric proximal femoral fractures (172) and subtrochanteric frac- } \\
\text { tures (31). } \\
\text { Excluded: people with stable trochanteric fractures, high energy trauma, pathological } \\
\text { fractures, previous surgery to the proximal femur, daily steroids of more than } 10 \text { mg } \\
\text { of prednisolone, ongoing chemotherapy, irradiation treatment, presence of degenerative } \\
\text { osteoarthrosis of the injured hip. } \\
\text { Age: mean } 82 \text { years (range } 48 \text { to } 97 \text { years) } \\
\% \text { male: } 24 \%\end{array}$ \\
$\begin{array}{l}\text { Number lost to follow-up: } 25 \% \text { (50 surviving patients were unable to attend the follow- } \\
\text { up clinic at one year from injury) }\end{array}$ \\
\hline
\end{tabular}

Proximal femoral nail versus the Medoff sliding plate ( 4 or 6 hole plate used in biaxial mode for trochanteric fractures and uni-axial mode for the subtrochanteric fractures)

\begin{tabular}{ll} 
Outcomes & Length of follow-up: 12 months \\
Length of surgery & Blood loss \\
Radiographic screening time & Cut-out of implant \\
Non-union & Operative fracture of the femur \\
& Later fracture of the femur \\
Other fracture healing complications & Reoperation \\
Wound infection & Wound haematoma \\
& Length of hospital stay \\
Mortality & Failure to return to pre-fracture residential status \\
Pain \\
Inability to walk 15 metres \\
Inability to rise from the chair \\
Inability to climb a curb \\
Need to use walking aids \\
Abductor strength \\
\hline Of 210 randomised patients, 7 were excluded: 5 wrong fracture and 2 wrong treatment \\
\hline \multirow{2}{*}{ Notes }
\end{tabular}

\section{Risk of bias}

Item

Authors' judgement

Description 
Ekstrom 2007 (Continued)

\begin{tabular}{l|l|l}
\hline Adequate sequence generation? & Yes & $\begin{array}{l}\text { "based on a computer generated list. Ran- } \\
\text { domization was stratified according to } \\
\text { trochanteric or subtrochanteric fractures." }\end{array}$ \\
\hline Allocation concealment? & Unclear & $\begin{array}{l}\text { Randomised "using consecutive numbered } \\
\text { and sealed envelopes". Insufficient mention } \\
\text { of safeguards. }\end{array}$ \\
\hline $\begin{array}{l}\text { Surgeons were experienced with trial oper- } \\
\text { ations? }\end{array}$ & No & $\begin{array}{l}\text { "Surgery was undertaken by 43 different } \\
\text { surgeons employed as regular staff at the } \\
\text { two hospital" While "two senior consul- } \\
\text { tations ... with extensive experience and } \\
\text { familiar with both surgical methods, gave } \\
\text { theoretical and practical instructions before } \\
\text { the start of the study", this was consid- } \\
\text { ered not sufficient protection against per- } \\
\text { formance bias. }\end{array}$ \\
\hline
\end{tabular}

Giraud 2005

Methods $\quad$ Randomised using random numbers table

Surgical experience: No (Unknown)

\begin{tabular}{l|l}
\hline Participants & Orthopaedic hospital, Reims, France \\
& 60 participants \\
Intertrochanteric proximal femoral fracture (stable and unstable fractures: AO 31-A1, \\
A2 and A3). \\
Age: mean $81 / 82$ years (range 23 to 97) \\
\% male: $23 \%$ \\
Number lost to follow-up: none \\
\hline Interventions & Targon PF (proximal femoral) nail versus Dynamic hip screw \\
\hline \multirow{2}{*}{ Outcomes } & Length of follow-up: 3 months \\
& Length of surgery \\
& Blood loss \\
Cut-out of implant \\
Later fracture of the femur \\
Reoperation \\
Wound infection (none) \\
Pneumonia (pulmonary congestion: "Pulmonaire") \\
Deep vein thrombosis \\
Length of hospital stay \\
Mortality \\
Time to walking \\
Harris hip score \\
\hline Extra information supplied by trialists. \\
\hline \multirow{2}{*}{ Notes }
\end{tabular}

Gamma and other cephalocondylic intramedullary nails versus extramedullary implants for extracapsular hip fractures in adults (Review) 42 Copyright $\odot 2010$ The Cochrane Collaboration. Published by John Wiley \& Sons, Ltd. 
Giraud 2005 (Continued)

\begin{tabular}{lll} 
Risk of bias & & \\
\hline Item & Authors' judgement & Description \\
\hline Adequate sequence generation? & Yes & Random numbers table \\
\hline Allocation concealment? & Unclear & No details of method \\
\hline $\begin{array}{l}\text { Surgeons were experienced with trial oper- } \\
\text { ations? }\end{array}$ & No & Unknown \\
\hline
\end{tabular}

\section{Goldhagen 1994}

\begin{tabular}{|c|c|}
\hline Methods & $\begin{array}{l}\text { Quasi-randomised according to patient's medical record number } \\
\text { Surgical experience: No (Gamma nail: refers to significant learning curve. A "multiplicity } \\
\text { of operating surgeons") }\end{array}$ \\
\hline Participants & $\begin{array}{l}\text { Orthopaedic hospital, USA } \\
75 \text { participants } \\
\text { Trochanteric and subtrochanteric proximal femoral fractures. } \\
\text { Age: median } 76 \text { years (range } 28-91 \text { years) } \\
\% \text { male: } 30 \% \\
\text { Number lost to follow-up: none }\end{array}$ \\
\hline Interventions & Gamma intramedullary nail versus Compression hip screw \\
\hline Outcomes & $\begin{array}{l}\text { Length of follow-up: 6-9 months } \\
\text { Length of surgery } \\
\text { Blood loss } \\
\text { Radiographic screening time } \\
\text { Operative fracture of the femur } \\
\text { Later fracture of the femur } \\
\text { Cut-out of implant } \\
\text { Non-union } \\
\text { Reoperation } \\
\text { Length of hospital stay } \\
\text { Mortality } \\
\text { Pain at follow-up } \\
\text { Non return to previous residence } \\
\text { Impaired walking }\end{array}$ \\
\hline Notes & Slight discrepancies in numbers Tables 1 and 2. \\
\hline
\end{tabular}

\section{Risk of bias}

Item

Authors' judgement

Description 
Goldhagen 1994 (Continued)

\begin{tabular}{|c|c|c|}
\hline Adequate sequence generation? & No & $\begin{array}{l}\text { ".ffractures ..were prospectively random- } \\
\text { ized into two groups according to their } \\
\text { medical record number." }\end{array}$ \\
\hline Allocation concealment? & No & $\begin{array}{l}\text { ".ffractures ..were prospectively random- } \\
\text { ized into two groups according to their } \\
\text { medical record number." }\end{array}$ \\
\hline $\begin{array}{l}\text { Surgeons were experienced with trial oper- } \\
\text { ations? }\end{array}$ & No & $\begin{array}{l}\text { Refers to "a significant learning curve for } \\
\text { the GN [Gamma nail]", and a "multiplicity } \\
\text { of operating surgeons" }\end{array}$ \\
\hline
\end{tabular}

\section{Guyer 1991}

Methods

Participants

Participants
Quasi-randomised by alternating patients

Surgical experience: No (Gamma nail: refers to inexperience of surgeons with implant)

Orthopaedic hospital, Switzerland

100 participants

Trochanteric and subtrochanteric proximal femoral fractures.

Age: mean 80 years

$\%$ male: $15 \%$

Number lost to follow-up: $24 \%$

Interventions

Gamma intramedullary nail versus Dynamic hip screw

\begin{tabular}{ll}
\hline Outcomes & Length of follow-up: 12 weeks \\
Length of surgery & Blood loss \\
& Operative fracture of the femur \\
Later fracture of the femur & Cut-out of implant \\
Non-union & Reoperation \\
Deep wound infection \\
Wound haematoma \\
Length of hospital stay \\
Shortening of leg $(>1 \mathrm{~cm})$ \\
Mortality \\
Pain at follow-up (pain on walking) \\
Non-return to previous residence \\
Impaired walking \\
\hline
\end{tabular}

Notes

Risk of bias
Description

Item

Authors' judgement

Description

Gamma and other cephalocondylic intramedullary nails versus extramedullary implants for extracapsular hip fractures in adults (Review)

Copyright @ 2010 The Cochrane Collaboration. Published by John Wiley \& Sons, Ltd. 


\section{Guyer 1991 (Continued)}

\begin{tabular}{|c|c|c|}
\hline Adequate sequence generation? & No & $\begin{array}{l}\text { "AO dynamic hip screws and gamma nails } \\
\text { were implanted alternatively." Translation } \\
\text { from German. }\end{array}$ \\
\hline Allocation concealment? & No & Alternation \\
\hline $\begin{array}{l}\text { Surgeons were experienced with trial oper- } \\
\text { ations? }\end{array}$ & No & $\begin{array}{l}\text { Refers to "the inexperience of the opera- } \\
\text { tors" }\end{array}$ \\
\hline
\end{tabular}

\section{Hardy 1998}

Methods
Quasi-randomised by even or odd medical record numbers

Surgical experience: No (IMHS: refers to prolonged learning curve required for insertion; SHS routine; 2 senior operating surgeons, 3 junior attending surgeons)

\begin{tabular}{|c|c|}
\hline Participants & $\begin{array}{l}\text { University hospital, Belgium } \\
100 \text { participants (see Notes) } \\
\text { Trochanteric proximal femoral fractures. } \\
\text { Excluded: Patients aged }<60 \text {, pathological fractures, incorrect anatomy, history of fracture } \\
\text { or operation involving same limb. } \\
\text { Age: mean } 81 \text { years } \\
\% \text { male: } 23 \% \\
\text { Number lost to follow-up: none }\end{array}$ \\
\hline Interventions & Intramedullary hip screw versus sliding hip screw \\
\hline Outcomes & $\begin{array}{l}\text { Length of follow-up: } 1 \text { year (see Notes) } \\
\text { Length of surgery } \\
\text { Operative blood loss } \\
\text { Transfusion } \\
\text { Operative fracture of the femur } \\
\text { Later fracture of the femur } \\
\text { Cut-out of implant } \\
\text { Non-union } \\
\text { Reoperation } \\
\text { Wound infection } \\
\text { Wound haematoma } \\
\text { Pneumonia } \\
\text { Thromboembolic complications (deep vein thrombosis, pulmonary embolism) } \\
\text { Urinary tract infection } \\
\text { Leg shortening } \\
\text { Mortality } \\
\text { Mid-thigh pain } \\
\text { Hip pain at follow-up } \\
\text { Eventual discharge residence } \\
\text { Patient mobility } \\
\text { Social function }\end{array}$ \\
\hline
\end{tabular}


Hardy 1998 (Continued)

Sotes
the results of 160 patients at 18 months follow up has become available (Hardy 1999).
The limited results presented within Hardy 1999 require clarification and thus have not
yet been included in this review.

Risk of bias

\begin{tabular}{l|l|l}
\hline Item & Authors' judgement & Description \\
\hline Adequate sequence generation? & No & $\begin{array}{l}\text { "prospectively randomized according into } \\
\text { two treatment groups according to the } \\
\text { medical record number" }\end{array}$ \\
\hline Allocation concealment? & No & $\begin{array}{l}\text { "prospectively randomized according into } \\
\text { two treatment groups according to the } \\
\text { medical record number" }\end{array}$ \\
\hline $\begin{array}{l}\text { Surgeons were experienced with trial oper- } \\
\text { ations? }\end{array}$ & No & $\begin{array}{l}\text { "The different levels of experience of the } \\
\text {...operating surgeons and ... attending sur- } \\
\text { geons ...and the prolonged learning curve } \\
\text { for insertion of intramedullary hip-screws } \\
\text { may have also affected the operative time." }\end{array}$ \\
\hline
\end{tabular}

\section{Harrington 2002}

\begin{tabular}{ll}
\hline Methods & $\begin{array}{l}\text { Randomised by opening sealed envelope on the admission ward } \\
\text { Surgical experience: No (reference made to some surgeons who had only used the IMHS } \\
\text { on bone model sessions) }\end{array}$ \\
\hline Participants & $\begin{array}{l}\text { Orthopaedic hospital, UK } \\
102 \text { participants } \\
\text { Unstable trochanteric proximal femoral fractures. } \\
\text { Excluded: Patients aged }<65 \text { years, pathological fractures, previous fracture, other frac- } \\
\text { ture. } \\
\text { Age: mean } 83 \text { years } \\
\text { \% male: } 21 \%\end{array}$ \\
Number lost to follow-up: not stated \\
\hline Interventions & $\begin{array}{l}\text { Intramedullary hip screw versus sliding hip screw } \\
\text { Outcomes }\end{array}$ \\
\hline $\begin{array}{l}\text { Length of follow-up: } 12 \text { months } \\
\text { Length of surgery } \\
\text { Radiographic screening time } \\
\text { Transfusion requirements } \\
\text { Operative fracture of the femur } \\
\text { Later fracture of the femur } \\
\text { Cut-out of implant } \\
\text { Non-union of fracture }\end{array}$ \\
\hline
\end{tabular}

Gamma and other cephalocondylic intramedullary nails versus extramedullary implants for extracapsular hip fractures in adults (Review) 46 Copyright (C) 2010 The Cochrane Collaboration. Published by John Wiley \& Sons, Ltd. 
Harrington 2002 (Continued)

\begin{tabular}{|c|c|c|}
\hline & $\begin{array}{l}\text { Other fracture healing complications } \\
\text { Length of hospital stay } \\
\text { Mortality } \\
\text { Patient mobility } \\
\text { Regain of pre-fracture living status }\end{array}$ & \\
\hline Notes & \multicolumn{2}{|l|}{ Additional information provided by authors } \\
\hline \multicolumn{3}{|l|}{ Risk of bias } \\
\hline Item & Authors' judgement & Description \\
\hline Adequate sequence generation? & Unclear & No details \\
\hline Allocation concealment? & Unclear & $\begin{array}{l}\text { "randomised on admission using a sealed } \\
\text { envelope method". No indication of safe- } \\
\text { guards. }\end{array}$ \\
\hline $\begin{array}{l}\text { Surgeons were experienced with trial oper- } \\
\text { ations? }\end{array}$ & No & $\begin{array}{l}\text { "Participating surgeons were required } \\
\text { to familiarise themselves with the in- } \\
\text { tramedullary implant and its insertion in } \\
\text { supervised bone model sessions prior to us- } \\
\text { ing it in the clinical setting". This was con- } \\
\text { sidered insufficient for the purposes of the } \\
\text { trial. }\end{array}$ \\
\hline
\end{tabular}

\section{Haynes 1996}

\begin{tabular}{ll} 
Methods & $\begin{array}{l}\text { Randomisation by cards, but trial entry optional } \\
\text { Surgical experience: No (Not clear. Gamma nail: prior experience with five insertions } \\
\text { but speaks of unfamiliarity of the surgeons (various) with the treatment as a reason for } \\
\text { exclusion (see Notes); SHS: routine) }\end{array}$ \\
\hline Participants & $\begin{array}{l}\text { Orthopaedic hospital, UK } \\
50 \text { participants } \\
\text { Trochanteric or 'high' subtrochanteric proximal femoral fractures. } \\
\text { Excluded: Previous non-consolidated femur fracture. } \\
\text { Age: mean } 80 \text { years. } \\
\text { \% male: } 28 \% \\
\text { Number lost to follow-up: none }\end{array}$ \\
\hline Interventions & Gamma intramedullary nail versus Dynamic hip screw \\
\hline Outcomes & $\begin{array}{l}\text { Length of follow-up: } 6 \text { months } \\
\text { Length of surgery } \\
\text { Blood loss } \\
\text { Operative fracture of femur* } \\
\text { Cut-out }\end{array}$ \\
\hline
\end{tabular}

Gamma and other cephalocondylic intramedullary nails versus extramedullary implants for extracapsular hip fractures in adults (Review) 47 Copyright (C) 2010 The Cochrane Collaboration. Published by John Wiley \& Sons, Ltd. 
Haynes 1996 (Continued)

\begin{tabular}{ll} 
Non-union* & Reoperation \\
Wound infection* & Pneumonia* \\
Pressure sore* & Wound haematoma* \\
Deep vein thrombosis* & Pulmonary embolism* \\
Length of hospital stay & Shortening of leg* \\
Mortality \\
Pain at follow-up* \\
Non return to previous residence \\
Impaired walking \\
* outcomes listed on data extraction form but not reported \\
\hline Trial report was part of PhD research. \\
$\begin{array}{l}\text { Trial sponsored and part administered by Howmedica. } \\
\text { Imbalance in numbers explained by unfamiliarity of surgeons with Gamma nail treat- } \\
\text { ment. "This resulted in a temptation to omit the patient from the trial if a Gamma nail } \\
\text { was drawn as treatment, from the randomisation cards". This was despite the efforts } \\
\text { made to familiarise the surgeons to the Gamma nail: "a minimum of } 5 \text { Gamma Nails } \\
\text { were then inserted by each surgeon before any cases were included in the trial" }\end{array}$ \\
\hline
\end{tabular}

Risk of bias

\begin{tabular}{|c|c|c|}
\hline Item & Authors' judgement & Description \\
\hline Adequate sequence generation? & Unclear & No details \\
\hline Allocation concealment? & No & $\begin{array}{l}\text { "randomisation cards" However, the imbal- } \\
\text { ance in numbers was explained by unfamil- } \\
\text { iarity of surgeons with Gamma nail treat- } \\
\text { ment. "This resulted in a temptation to } \\
\text { omit the patient from the trial if a Gamma } \\
\text { nail was drawn as treatment, from the ran- } \\
\text { domisation cards". }\end{array}$ \\
\hline $\begin{array}{l}\text { Surgeons were experienced with trial oper- } \\
\text { ations? }\end{array}$ & No & $\begin{array}{l}\text { Surgical procedures were as recommended } \\
\text { by the implant manufacturers, and "A min- } \\
\text { imum of } 5 \text { Gamma nails were then inserted } \\
\text { by each surgeon before any cases were in- } \\
\text { cluded in the trial". (SHS was routine). } \\
\text { However, mention of unfamiliarity of the } \\
\text { surgeons (various) with the treatment as a } \\
\text { putative reason for post-randomisation ex- } \\
\text { clusion (see above). }\end{array}$ \\
\hline
\end{tabular}




\begin{tabular}{|c|c|c|}
\hline Methods & \multicolumn{2}{|c|}{$\begin{array}{l}\text { Randomised by sealed opaque envelopes (a stiff card was used to prevent disclosure of } \\
\text { allocation) } \\
\text { Surgical experience: No (Gamma nail: refers to a longer learning curve than with SHS; } \\
4 \text { orthopaedic trainees, normal supervision) }\end{array}$} \\
\hline Participants & \multicolumn{2}{|c|}{$\begin{array}{l}\text { Orthopaedic hospital, New Zealand } \\
69 \text { participants } \\
\text { Trochanteric proximal femoral fractures. } \\
\text { Patients aged over } 50 \text { years. } \\
\text { Pathological fractures were excluded. } \\
\text { Age: mean } 81 \text { years } \\
\% \text { male: } 23 \% \\
\text { Number lost to follow-up: none }\end{array}$} \\
\hline Interventions & \multicolumn{2}{|c|}{ Gamma intramedullary nail versus Ambi hip screw } \\
\hline Outcomes & \multicolumn{2}{|c|}{$\begin{array}{l}\text { Length of follow-up: } 6 \text { months } \\
\text { Length of surgery } \\
\text { Blood loss } \\
\text { Radiographic screening time } \\
\text { Operative fracture of the femur } \\
\text { Later fracture of the femur } \\
\text { Cut-out of implant } \\
\text { Non-union (time to union) } \\
\text { Reoperation } \\
\text { Wound infection } \\
\text { Pneumonia } \\
\text { Pressure sores } \\
\text { Deep vein thrombosis } \\
\text { Any medical complication } \\
\text { Length of hospital stay } \\
\text { Shortening of leg } \\
\text { Mortality } \\
\text { Pain at follow-up (unresolved pain in patients with intertrochanteric fractures) } \\
\text { Non return to previous residence } \\
\text { Patient mobility }\end{array}$} \\
\hline Notes & \multicolumn{2}{|c|}{$\begin{array}{l}\text { Additional data received. There were } 69 \text { patients randomised but } 2 \text { died before surgery } \\
\text { and were therefore not included. } \\
\text { Updated recommendations on locking for Gamma nail insertion from manufacturers } \\
\text { were implemented after patient } 50 \text {. }\end{array}$} \\
\hline \multicolumn{3}{|l|}{ Risk of bias } \\
\hline Item & Authors' judgement & Description \\
\hline Adequate sequence generation? & Yes & $\begin{array}{l}\text { "computer-generated blocked randomiza- } \\
\text { tion" }\end{array}$ \\
\hline
\end{tabular}




\section{Hoffman 1996 (Continued)}

\begin{tabular}{|c|c|c|}
\hline Allocation concealment? & Yes & $\begin{array}{l}\text { "The treatment selections ... were sealed } \\
\text { into opaque numbered envelopes that also } \\
\text { contained a stiff card to further prevent dis- } \\
\text { closure of allocation." }\end{array}$ \\
\hline $\begin{array}{l}\text { Surgeons were experienced with trial oper- } \\
\text { ations? }\end{array}$ & No & $\begin{array}{l}\text { Most operation carried out by "one of four } \\
\text { orthopaedic trainees ... supervised as appro- } \\
\text { priate.." Referred to "longer learning curve } \\
\text { for the Gamma nail may be the reason for } \\
\text { the differences noted." }\end{array}$ \\
\hline
\end{tabular}

Hoffmann 1999

Methods

Randomised by sealed envelopes; blinding indicated

Surgical experience: No (Operations by junior and senior staff)

\begin{tabular}{|c|c|}
\hline Participants & $\begin{array}{l}\text { Orthopaedic hospital, Germany } \\
110 \text { participants } \\
\text { Trochanteric proximal femoral fractures. } \\
\text { Excluded: pathological fractures. } \\
\text { Age: mean } 82 \text { years } \\
\% \text { male: } 20 \% \\
\text { Number lost to follow-up: } 4 \%\end{array}$ \\
\hline
\end{tabular}

Interventions

Intramedullary hip screw versus Sliding hip screw

$\begin{array}{ll}\text { Outcomes } & \text { Length of follow-up: mean } 3.7 \text { months } \\ \text { Length of anaesthesia } \\ \text { Length of surgery } \\ \text { Operative blood loss } \\ \text { Difference in haemoglobin } \\ \text { Radiographic screening time } \\ \text { Operative fracture of the femur } \\ \text { Later fracture of the femur } \\ \text { Loss of fracture reduction requiring reoperation } \\ \text { Reoperation } \\ \text { Wound infection } \\ \text { Deep wound infection } \\ \text { Wound haematoma } \\ \text { Superficial wound infection } \\ \text { Thromboembolic complication } \\ \text { Clinical complications } \\ \text { Length of acute hospital stay } \\ \text { Shortening of leg (> } 1 \mathrm{~cm}) \\ \text { Rotational deformity ('relevant') } \\ \text { Mortality } \\ \text { Pain (on walking) } \\ \text { Return to pre-fracture residential status }\end{array}$

Gamma and other cephalocondylic intramedullary nails versus extramedullary implants for extracapsular hip fractures in adults (Review) 50 Copyright $(2010$ The Cochrane Collaboration. Published by John Wiley \& Sons, Ltd. 
Hoffmann 1999 (Continued)

Impaired walking

Merle d'Aubigne hip score

Notes

Article in German - limited translation only obtained.

\section{Risk of bias}

\begin{tabular}{lll}
\hline Item & Authors' judgement & Description \\
\hline Adequate sequence generation? & Unclear & No details \\
\hline Allocation concealment? & Yes & $\begin{array}{l}\text { referral to sealed envelopes and blinding in- } \\
\text { dicated }\end{array}$ \\
\hline $\begin{array}{l}\text { Surgeons were experienced with trial oper- } \\
\text { ations? }\end{array}$ & No & $\begin{array}{l}\text { Involved both senior and junior surgeons - } \\
\text { tendency for more senior surgeons for the } \\
\text { nail operations }\end{array}$ \\
\hline
\end{tabular}

\section{Kukla 1997}

\begin{tabular}{|c|c|}
\hline Methods & $\begin{array}{l}\text { Randomised using sealed envelopes } \\
\text { Surgical experience: Yes (Senior surgeons experienced in both operations) }\end{array}$ \\
\hline Participants & $\begin{array}{l}\text { Orthopaedic hospital, Austria } \\
120 \text { participants } \\
\text { Trochanteric proximal femoral fractures. } \\
\text { Excluded: Patients aged < } 60 \text { years, pathological fractures, multiple injury patients. } \\
\text { Age: mean } 83 \text { years (range } 60-99 \text { years) } \\
\% \text { male: } 15 \% \\
\text { Number lost to follow-up: } 3(3 \%)\end{array}$ \\
\hline Interventions & Gamma intramedullary nail versus Sliding hip screw \\
\hline Outcomes & $\begin{array}{l}\text { Length of follow-up: } 6 \text { months } \\
\text { Length of surgery } \\
\text { Blood loss } \\
\text { Operative fracture of the femur } \\
\text { Later fracture of the femur } \\
\text { Cut-out of implant } \\
\text { Non-union } \\
\text { Reoperation } \\
\text { Wound infection } \\
\text { Deep wound infection } \\
\text { Wound haematoma } \\
\text { Pneumonia } \\
\text { Deep vein thrombosis } \\
\text { Pulmonary embolism } \\
\text { Any medical complication }\end{array}$ \\
\hline
\end{tabular}


Kukla 1997 (Continued)

\begin{tabular}{|c|c|c|}
\hline & \multicolumn{2}{|c|}{$\begin{array}{l}\text { Length of hospital stay } \\
\text { Shortening of leg }(>2 \mathrm{~cm}) \\
\text { Mortality } \\
\text { Non-return to previous residence } \\
\text { Impaired walking }\end{array}$} \\
\hline Notes & \multicolumn{2}{|c|}{ Additional information received from authors included draft report prior to publication. } \\
\hline \multicolumn{3}{|l|}{ Risk of bias } \\
\hline Item & Authors' judgement & Description \\
\hline Adequate sequence generation? & Unclear & $\begin{array}{l}\text { "random permutation" letter from trial in- } \\
\text { vestigator }\end{array}$ \\
\hline Allocation concealment? & Unclear & $\begin{array}{l}\text { "Allocation to the } 2 \text { groups was achieved by } \\
\text { randomized, sealed envelopes". No indica- } \\
\text { tion of safeguards. }\end{array}$ \\
\hline $\begin{array}{l}\text { Surgeons were experienced with trial oper- } \\
\text { ations? }\end{array}$ & Yes & $\begin{array}{l}\text { "Senior surgeons who, having operated on } \\
\text { at least } 80 \text { cases each, were experienced in } \\
\text { the use of both devices.." }\end{array}$ \\
\hline
\end{tabular}

\section{Kuwabara 1998}

\begin{tabular}{ll}
\hline Methods & $\begin{array}{l}\text { Randomised trial: method not stated } \\
\text { Surgical experience: No (unknown) }\end{array}$ \\
\hline Participants & $\begin{array}{l}\text { Orthopaedic hospital, Japan } \\
43 \text { participants } \\
\text { Trochanteric proximal femoral fractures. } \\
\text { Excluded: patients }<65 \text { years. } \\
\text { Age: mean } 81 \text { years } \\
\text { \% male: } 28 \%\end{array}$ \\
Number lost to follow-up: not known \\
\hline Interventions & Gamma intramedullary nail versus Compression hip screw \\
\hline Outcomes & $\begin{array}{l}\text { Length of follow-up: mean } 6 \text { months }(5.7 \text { and } 6.5 \text { months respectively for the two } \\
\text { groups) } \\
\text { Length of surgery } \\
\text { Operative blood loss } \\
\text { Operative fracture of the femur } \\
\text { Later fracture of the femur } \\
\text { Cut-out of implant } \\
\text { Wound infection } \\
\text { Inversion deformity } \\
\text { Eversion deformity }\end{array}$ \\
\hline
\end{tabular}


Kuwabara 1998 (Continued)

Loss in mobility and use of walking aids

\begin{tabular}{lll}
\hline Notes & Trial published in Japanese. Only a limited translation obtained. \\
\hline Risk of bias & Authors' judgement & Description \\
\hline Item & Unclear & "randomized" \\
\hline Adequate sequence generation? & Unclear & "randomized" \\
\hline Allocation concealment? & Unclear & Not known \\
\hline $\begin{array}{l}\text { Surgeons were experienced with trial oper- } \\
\text { ations? }\end{array}$ & & \\
\hline
\end{tabular}

Lee 2007

\begin{tabular}{|c|c|}
\hline Methods & $\begin{array}{l}\text { Quasi-randomised by even or odd medical record numbers } \\
\text { Surgical experience: Yes: referred to extensive experience with devices }\end{array}$ \\
\hline Participants & $\begin{array}{l}\text { Orthopaedic hospital, Taoyuan, Taiwan } \\
77 \text { participants* } \\
\text { Subtrochanteric proximal femoral fractures (all unstable fracture pattern with comminu- } \\
\text { tion, Seinsheimer classification type III, IV and V) } \\
\text { Excluded: patients > } 55 \text { years. } \\
\text { Age (of } 66 \text { ): mean } 36 \text { years (range } 19 \text { to } 54 \text { ) } \\
\% \text { male: } 77 \% \\
\text { Number lost to follow-up: } 6 / 77(8 \%) \text {; } 5 \text { deaths in hospital from severe but not or- } \\
\text { thopaedic trauma }\end{array}$ \\
\hline Interventions & Russell-Taylor reconstruction intramedullary nail versus Dynamic condylar screw (DCS) \\
\hline Outcomes & $\begin{array}{l}\text { Length of follow-up: mean } 28.1 \text { months ( } 24 \text { months minimum) } \\
\text { Length of surgery } \\
\text { Operative blood loss } \\
\text { Radiographic screening time } \\
\text { Number of patient given transfusion } \\
\text { Mean units of blood transfused } \\
\text { Re-fracture around the implant } \\
\text { Non-union/delayed union of the fracture } \\
\text { Reoperation } \\
\text { Superficial wound infection } \\
\text { Deep wound infection } \\
\text { Mean time to fracture union } \\
\text { Length of hospital stay } \\
\text { Total degrees of hip movements } \\
\text { Mortality } \\
\text { Mobility score }\end{array}$ \\
\hline
\end{tabular}


Lee 2007 (Continued)

Notes

* 77 patients met inclusion criteria but 11 excluded from subsequently, either lost to follow-up or died in hospital.

Plate fixation involved a bridging plate method, in which small skin incisions are made and the plate passed along the femur without exposing the fracture.

\section{Risk of bias}

\begin{tabular}{ll|l}
\hline Item & Authors' judgement & Description \\
\hline Adequate sequence generation? & No & $\begin{array}{l}\text { Quasi-randomised: "Patients were ran- } \\
\text { domized according to their medical record } \\
\text { number" }\end{array}$ \\
\hline Allocation concealment? & No & $\begin{array}{l}\text { Quasi-randomised with no concealment of } \\
\text { allocation: "34 patients with an even med- } \\
\text { ical record number were treated by the } \\
\text { RTRN and 32 patients with an odd med- } \\
\text { ical record number were treated by the } \\
\text { DCS." }\end{array}$ \\
\hline $\begin{array}{l}\text { Surgeons were experienced with trial oper- } \\
\text { ations? }\end{array}$ & Yes & $\begin{array}{l}\text { "They [the senior surgeons] had extensive } \\
\text { experience using femoral nailing with a RT- } \\
\text { TRN and biologic plating with a DCS." }\end{array}$ \\
\hline
\end{tabular}

\section{Leung 1992}

Methods

\begin{tabular}{ll} 
& $\begin{array}{l}\text { Surgical experience: No (Imbalance in } \\
\text { one experienced surgeon; SHS: by less }\end{array}$ \\
\hline Participants & $\begin{array}{l}\text { Orthopaedic hospitals, Hong Kong } \\
225 \text { participants } \\
226 \text { trochanteric proximal femoral fra } \\
\text { Excluded: Patients aged }<65 \text { years. } \\
\text { Age: mean } 80 \text { years } \\
\% \text { male: } 30 \% \text { (excluding deaths) } \\
\text { Number lost to follow-up: none }\end{array}$ \\
\hline Interventions & Gamma intramedullary nail versus Dy \\
\hline Outcomes & $\begin{array}{l}\text { Length of follow-up: mean } 7 \text { months } \\
\text { Length of surgery } \\
\text { Blood loss } \\
\text { Radiographic screening time } \\
\text { Operative fracture of the femur } \\
\text { Later fracture of the femur }\end{array}$
\end{tabular}


Leung 1992 (Continued)

\begin{tabular}{|c|c|c|}
\hline & \multicolumn{2}{|c|}{$\begin{array}{l}\text { Cut-out of implant } \\
\text { Non-union (fracture healing) } \\
\text { Reoperation } \\
\text { Deep wound infection } \\
\text { Pneumonia } \\
\text { Any medical complication (incomplete) } \\
\text { Length of hospital stay (mixed location) } \\
\text { External rotational deformity } \\
\text { Shortening of leg ( }>2 \mathrm{~cm} \text { ) } \\
\text { Varus displacement (>10 degrees) } \\
\text { Mortality } \\
\text { Pain at follow-up (pain in hip and pain in thigh) } \\
\text { Impaired walking }\end{array}$} \\
\hline Notes & \multicolumn{2}{|c|}{$\begin{array}{l}\text { The } 40 \text { patients who died within } 6 \text { months of surgery were not included in the full } \\
\text { assessment of results. } \\
\text { Further information obtained from author. Most of the Gamma nail operations were } \\
\text { performed by one senior surgeon with a special interest in intramedullary nailing, whilst } \\
\text { the sliding hip screw operations were performed by a number of less experienced surgeons. }\end{array}$} \\
\hline \multicolumn{3}{|l|}{ Risk of bias } \\
\hline Item & Authors' judgement & Description \\
\hline Adequate sequence generation? & No & $\begin{array}{l}\text { Alternation: "fixation was randomly as- } \\
\text { signed according to the sequence of admis- } \\
\text { sion" }\end{array}$ \\
\hline Allocation concealment? & No & $\begin{array}{l}\text { Alternation: "fixation was randomly as- } \\
\text { signed according to the sequence of admis- } \\
\text { sion" }\end{array}$ \\
\hline $\begin{array}{l}\text { Surgeons were experienced with trial oper- } \\
\text { ations? }\end{array}$ & No & $\begin{array}{l}\text { Serious bias. Most of the Gamma nail } \\
\text { operations were performed by one se- } \\
\text { nior surgeon with a special interest in in- } \\
\text { tramedullary nailing, whilst the sliding hip } \\
\text { screw operations were performed by a num- } \\
\text { ber of less experienced surgeons. }\end{array}$ \\
\hline
\end{tabular}

Little 2008

\begin{tabular}{ll} 
Methods & $\begin{array}{l}\text { Randomised trial: use of a computer } \\
\text { Surgical experience: claimed but also referral to possible influenced of learning curve on } \\
\text { some outcomes }\end{array}$ \\
\hline Participants & $\begin{array}{l}\text { Orthopaedic hospital, Chertsey, United Kingdom } \\
190 \text { participants } \\
\text { Trochanteric proximal femoral fractures } \\
\text { Excluded: patients with subtrochanteric fractures }\end{array}$
\end{tabular}

Gamma and other cephalocondylic intramedullary nails versus extramedullary implants for extracapsular hip fractures in adults (Review) 55 Copyright (C) 2010 The Cochrane Collaboration. Published by John Wiley \& Sons, Ltd. 
Little 2008 (Continued)

Age: mean 83 years (range: 50 to 102 )

$\%$ male: $15 \%$

Number lost to follow-up: $0 \%$

\begin{tabular}{ll}
\hline Interventions & Long Holland intramedullary nail versus sliding hip screw (SHS) \\
\hline Outcomes & Length of follow-up: mean 12 months \\
& Length of surgery \\
& Operative blood loss \\
& Radiographic screening time \\
& Number of patients transfused \\
Cut-out of the implant & Re-fracture around the implant \\
& Reoperation \\
& Superficial wound infection \\
& Deep wound infection \\
Pneumonia \\
Deep vein thrombosis \\
Pulmonary embolism \\
Transient Ischaemic attack \\
Mortality \\
Failure to regain mobility \\
Mobility score \\
Days till mobilisation \\
\hline
\end{tabular}

Notes

Risk of bias

\begin{tabular}{l|l|l}
\hline Item & Authors' judgement & Description \\
\hline Adequate sequence generation? & Yes & $\begin{array}{l}\text { "Patients were allocated a sequential study } \\
\text { number and were randomised by computer } \\
\text { to be treated with a DHS or a Holland } \\
\text { nail." }\end{array}$ \\
\hline Allocation concealment? & Unclear & $\begin{array}{l}\text { "randomised by computer" but no mention } \\
\text { of safeguards }\end{array}$ \\
\hline $\begin{array}{l}\text { Surgeons were experienced with trial oper- } \\
\text { ations? }\end{array}$ & Unclear & $\begin{array}{l}\text { "Each procedure was carried out by a spe- } \\
\text { cialist registrar under supervision or by a } \\
\text { consultant who was familiar with both pro- } \\
\text { cedures." However, the report suggested } \\
\text { that the longer operating and radiation } \\
\text { times in the Holland nail group "may be a } \\
\text { function of the learning curve in its use". }\end{array}$ \\
\hline
\end{tabular}


Marques Lopez 2002

\begin{tabular}{|c|c|c|}
\hline Methods & \multicolumn{2}{|c|}{$\begin{array}{l}\text { Quasi-randomised according to medical record number } \\
\text { Surgical experience: No (variable) }\end{array}$} \\
\hline Participants & \multicolumn{2}{|c|}{$\begin{array}{l}\text { Orthopaedic hospital, Barcelona, Spain } \\
103 \text { participants } \\
\text { Trochanteric proximal femoral fractures. } \\
\text { Age: mean } 84 \text { years } \\
\% \text { male: } 35 \% \\
\text { Number lost to follow-up: not stated }\end{array}$} \\
\hline Interventions & \multicolumn{2}{|c|}{ Gamma intramedullary nail versus Dynamic hip screw } \\
\hline Outcomes & \multicolumn{2}{|c|}{$\begin{array}{l}\text { Length of follow-up: } 12 \text { months } \\
\text { Length of surgery } \\
\text { Post-operative transfusion } \\
\text { Change in haematocrit } \\
\text { Radiographic screening time } \\
\text { Operative fracture of the femur } \\
\text { Later fracture of the femur } \\
\text { Cut-out of implant } \\
\text { Reoperation } \\
\text { Wound infection } \\
\text { Wound haematoma } \\
\text { Deep vein thrombosis } \\
\text { Pneumonia } \\
\text { Pressure sores } \\
\text { Mortality } \\
\text { Mobility } \\
\text { Mean time to fracture consolidatio }\end{array}$} \\
\hline Notes & \multicolumn{2}{|c|}{$\begin{array}{l}\text { The outcome of post-operative transfusion was inadequately defined. Mortality at one } \\
\text { year was only given as percentages; there was inadequate information to determine if all } \\
\text { randomised patients were included in the calculation of these percentages. }\end{array}$} \\
\hline \multicolumn{3}{|l|}{ Risk of bias } \\
\hline Item & Authors' judgement & Description \\
\hline Adequate sequence generation? & No & $\begin{array}{l}\text { Quasi-randomised according to medical } \\
\text { record number }\end{array}$ \\
\hline Allocation concealment? & No & $\begin{array}{l}\text { Quasi-randomised according to medical } \\
\text { record number }\end{array}$ \\
\hline $\begin{array}{l}\text { Surgeons were experienced with trial oper- } \\
\text { ations? }\end{array}$ & No & Various levels of operating experience \\
\hline
\end{tabular}

Gamma and other cephalocondylic intramedullary nails versus extramedullary implants for extracapsular hip fractures in adults (Review) 57 Copyright (C) 2010 The Cochrane Collaboration. Published by John Wiley \& Sons, Ltd. 
Mehdi 2000

\begin{tabular}{|c|c|c|}
\hline Methods & \multicolumn{2}{|c|}{$\begin{array}{l}\text { Randomised by sealed envelopes. } \\
\text { Surgical experience: No (Reference made to relative inexperience with IMHS at start of } \\
\text { trial) }\end{array}$} \\
\hline Participants & \multicolumn{2}{|c|}{$\begin{array}{l}\text { Orthopaedic hospital, UK } \\
180 \text { participants } \\
\text { Extracapsular proximal femoral fractures. } \\
\text { Age: mean } 76 \text { years } \\
\% \text { male: unknown } \\
\text { Number lost to follow-up: } 19 \%\end{array}$} \\
\hline Interventions & \multicolumn{2}{|c|}{ Intramedullary hip screw versus sliding hip screw } \\
\hline Outcomes & \multicolumn{2}{|c|}{$\begin{array}{l}\text { Length of follow-up: minimum } 6 \text { months (mean } 13 \text { months, range } 6 \text { to } 36 \text { months) } \\
\text { Length of surgery } \\
\text { Operative blood loss } \\
\text { Operative fracture of the femur } \\
\text { Later fracture of femur (none) } \\
\text { Cut-out of implant } \\
\text { Peri-operative complication } \\
\text { Fracture reduction } \\
\text { Wound infection (superficial and deep) } \\
\text { Mortality } \\
\text { Mobility } \\
\text { Harris hip scores }\end{array}$} \\
\hline Notes & \multicolumn{2}{|c|}{$\begin{array}{l}\text { Abstract only published. } \\
\text { Unpublished report made available by trialist. } \\
\text { Because of the large range of final follow-up times and high and unequal losses to follow- } \\
\text { up, we decided against presenting final follow-up results (mortality, later fracture and } \\
\text { mobility) in the review. } \\
\text { Two cases of IMHS required conversion to SHS fixation due to "excessive bowing". }\end{array}$} \\
\hline \multicolumn{3}{|l|}{ Risk of bias } \\
\hline Item & Authors' judgement & Description \\
\hline Adequate sequence generation? & Unclear & No details \\
\hline Allocation concealment? & Unclear & $\begin{array}{l}\text { "Patients ... were randomised .. at the } \\
\text { daily trauma meeting by drawing sealed en- } \\
\text { velopes." No mention of safeguards. }\end{array}$ \\
\hline $\begin{array}{l}\text { Surgeons were experienced with trial oper- } \\
\text { ations? }\end{array}$ & Unclear & $\begin{array}{l}\text { "A three-month period of familiarisation } \\
\text { with the IMHS, prior to the trial, was un- } \\
\text { dertaken to avoid bias. Despite that, all sur- } \\
\text { geons were more familiar with the Richards } \\
\text { Classic Hip Screw..." }\end{array}$ \\
\hline
\end{tabular}

Gamma and other cephalocondylic intramedullary nails versus extramedullary implants for extracapsular hip fractures in adults (Review) 58 
Michos 2001

\begin{tabular}{|c|c|c|}
\hline Methods & \multicolumn{2}{|c|}{$\begin{array}{l}\text { Randomised: method not stated } \\
\text { Surgical experience: No (Unknown) }\end{array}$} \\
\hline Participants & \multicolumn{2}{|c|}{$\begin{array}{l}\text { Orthopaedic hospital, Greece } \\
52 \text { participants } \\
\text { Trochanteric proximal femoral fractures. Some may have had subtrochanteric extension. } \\
\text { Age: mean } 78.5 \text { years } \\
\% \text { male: unknown } \\
\text { Number lost to follow-up: not known }\end{array}$} \\
\hline Interventions & \multicolumn{2}{|c|}{$\begin{array}{l}\text { Gamma intramedullary nail ("Trochanteric Gamma Nail" used if no subtrochanteric } \\
\text { extension) versus sliding hip screw }\end{array}$} \\
\hline Outcomes & \multicolumn{2}{|c|}{$\begin{array}{l}\text { Length of follow-up: } 3 \text { to } 6 \text { months } \\
\text { Operative blood loss } \\
\text { Later fracture of the femur } \\
\text { Cut-out of implant } \\
\text { Non-union } \\
\text { Plate detachment } \\
\text { Mortality (peri-operative) }\end{array}$} \\
\hline Notes & \multicolumn{2}{|l|}{ Abstract only. } \\
\hline \multicolumn{3}{|l|}{ Risk of bias } \\
\hline Item & Authors' judgement & Description \\
\hline Adequate sequence generation? & Unclear & No details: "randomly allocated" \\
\hline Allocation concealment? & Unclear & No details: "randomly allocated" \\
\hline $\begin{array}{l}\text { Surgeons were experienced with trial oper- } \\
\text { ations? }\end{array}$ & Unclear & No information \\
\hline
\end{tabular}

Miedel 2005

Methods

Participants
Randomised by sealed envelopes

Surgical experience: No (Half of the operations in each group were by consultant orthopaedic surgeons) 
Miedel 2005 (Continued)

\begin{tabular}{|c|c|}
\hline Interventions & $\begin{array}{l}\text { Gamma intramedullary nail versus Medoff sliding plate (eight hole Medoff plate used } \\
\text { in biaxial dynamisation mode) }\end{array}$ \\
\hline Outcomes & $\begin{array}{l}\text { Length of follow-up: } 12 \text { months } \\
\text { Length of surgery } \\
\text { Operative blood loss } \\
\text { Post-operative transfusion } \\
\text { Operative fracture of the femur } \\
\text { Technical failure } \\
\text { Later fracture of the femur } \\
\text { Cut-out of implant } \\
\text { Displacement (medialisation of the femur requiring surgery) } \\
\text { Reoperation } \\
\text { Wound infection (superficial and deep) } \\
\text { Severe medical complications (cardiac, pulmonary, thromboembolic or cerebrovascular) } \\
\text { Length of hospital stay } \\
\text { Discharge location } \\
\text { Mortality } \\
\text { Mobility } \\
\text { Pain } \\
\text { Hip function } \\
\text { Activities of daily living } \\
\text { Health related quality of life }\end{array}$ \\
\hline Notes & $\begin{array}{l}\text { Details of the reoperations removed from the text in the update (issue 1, 2008): } \\
\text { All three reoperations, involving total hip replacement, in the Gamma group were for } \\
\text { cut-out. Nine reoperations were required in the Medoff group, two (one Girdlestone } \\
\text { arthroplasty and one multiple debridements) for sepsis, three (one Girdlestone arthro- } \\
\text { plasty and two total hip replacement) for cut-out, three (two to intramedullary nails and } \\
\text { one to a fixed nail plate with subsequent total hip replacement) for femur displacement } \\
\text { (medialisation), and one removal of the Medoff plate due to pain with later revision to } \\
\text { a total hip replacement. }\end{array}$ \\
\hline
\end{tabular}

Risk of bias

\begin{tabular}{l|ll}
\hline Item & Authors' judgement & Description \\
\hline Adequate sequence generation? & Unclear & No details \\
\hline Allocation concealment? & Unclear & $\begin{array}{l}\text { "The patients were randomised (sealed-en- } \\
\text { velope system)" }\end{array}$ \\
\hline $\begin{array}{l}\text { Surgeons were experienced with trial oper- } \\
\text { ations? }\end{array}$ & No & $\begin{array}{l}\text { Only half of the operations in each } \\
\text { group "were performed by consultant or- } \\
\text { thopaedic surgeons". }\end{array}$ \\
\hline
\end{tabular}


Mott 1993

\begin{tabular}{|c|c|c|}
\hline Methods & \multicolumn{2}{|c|}{$\begin{array}{l}\text { Randomised using computer-generated random numbers table } \\
\text { Surgical experience: No }\end{array}$} \\
\hline Participants & \multicolumn{2}{|c|}{$\begin{array}{l}\text { Three orthopaedic hospitals, Detroit, USA. } \\
69 \text { participants } \\
\text { Trochanteric proximal femoral fractures. } \\
\text { Age: mean } 76 \text { years (range } 19 \text { to } 99 \text { years) } \\
\% \text { male: } 42 \% \\
\text { Number lost to follow-up: not stated }\end{array}$} \\
\hline Interventions & \multicolumn{2}{|c|}{ Gamma intramedullary nail versus sliding hip screw } \\
\hline Outcomes & \multicolumn{2}{|c|}{$\begin{array}{l}\text { Length of follow-up: not stated } \\
\text { Length of surgery } \\
\text { Operative blood loss } \\
\text { Blood transfusion } \\
\text { Operative fracture of the femur } \\
\text { Later fracture of the femur } \\
\text { Cut-out of implant } \\
\text { Reoperation } \\
\text { Deep wound infection } \\
\text { Superficial wound infection } \\
\text { Wound haematoma } \\
\text { Deep vein thrombosis } \\
\text { Myocardial infarction } \\
\text { Pneumonia } \\
\text { Urinary tract infection } \\
\text { Mortality (1 week) }\end{array}$} \\
\hline Notes & \multicolumn{2}{|c|}{ Trial information supplied by trialists } \\
\hline \multicolumn{3}{|l|}{ Risk of bias } \\
\hline Item & Authors' judgement & Description \\
\hline Adequate sequence generation? & Yes & $\begin{array}{l}\text { Computer-generated random numbers ta- } \\
\text { ble }\end{array}$ \\
\hline Allocation concealment? & Unclear & No information on allocation process \\
\hline $\begin{array}{l}\text { Surgeons were experienced with trial oper- } \\
\text { ations? }\end{array}$ & No & $\begin{array}{l}\text { There was variation in the experience in the } \\
\text { three hospitals, with a "continual learning } \\
\text { curve" in hospital A, a "one-time" learning } \\
\text { curve in hospital B, and no learning curve } \\
\text { required in hospital C. }\end{array}$ \\
\hline
\end{tabular}

Gamma and other cephalocondylic intramedullary nails versus extramedullary implants for extracapsular hip fractures in adults (Review) 6 I Copyright (C) 2010 The Cochrane Collaboration. Published by John Wiley \& Sons, Ltd. 
O’Brien 1995

\begin{tabular}{|c|c|c|}
\hline Methods & \multicolumn{2}{|c|}{$\begin{array}{l}\text { Blinded randomisation of patients using envelopes } \\
\text { Surgical experience: No (refers to "performance bias" during operation) }\end{array}$} \\
\hline Participants & \multicolumn{2}{|c|}{$\begin{array}{l}\text { Orthopaedic hospital, Canada. } \\
101 \text { participants } \\
102 \text { trochanteric proximal femoral fractures. } \\
\text { Age: mean } 80 \text { years (range } 39 \text { to } 95 \text { years) } \\
\% \text { male: } 26 \% \\
\text { Number lost to follow-up: } 18 \%\end{array}$} \\
\hline Interventions & \multicolumn{2}{|c|}{ Gamma intramedullary nail versus Dynamic hip screw } \\
\hline Outcomes & \multicolumn{2}{|c|}{$\begin{array}{l}\text { Length of follow-up: average } 52 \text { weeks (range } 11 \text { to } 82 \text { weeks) } \\
\text { Length of surgery } \\
\text { Blood loss } \\
\text { Radiographic screening time } \\
\text { Operative fracture of the femur } \\
\text { Later fracture of the femur } \\
\text { Cut-out of implant } \\
\text { Non-union (time to union) } \\
\text { Reoperation } \\
\text { Wound infection } \\
\text { Deep wound infection } \\
\text { Wound haematoma } \\
\text { Pneumonia } \\
\text { Pressure sores } \\
\text { Pulmonary embolism } \\
\text { Any medical complication } \\
\text { Length of hospital stay } \\
\text { Mortality } \\
\text { Pain at follow-up } \\
\text { Loss of independence } \\
\text { Loss in mobility }\end{array}$} \\
\hline Notes & \multicolumn{2}{|c|}{$\begin{array}{l}\text { Additional information received from authors. The mortality rate may be higher than } \\
\text { that reported because of the number of patients lost to follow up. The number of patients } \\
\text { that may have died in the follow-up period is unclear. }\end{array}$} \\
\hline \multicolumn{3}{|l|}{ Risk of bias } \\
\hline Item & Authors' judgement & Description \\
\hline Adequate sequence generation? & Unclear & No details \\
\hline Allocation concealment? & Yes & $\begin{array}{l}\text { "randomly allocated by blind envelope se- } \\
\text { lection" }\end{array}$ \\
\hline
\end{tabular}


O’Brien 1995 (Continued) ations? ing operation.

\section{Ovesen 2006}

Methods

Randomised by consecutively opened sealed opaque envelopes (computer generated sequence)

Surgical experience: No (operations by surgical team on call: 49 surgeons participated in trial)

\begin{tabular}{|c|c|}
\hline Participants & $\begin{array}{l}\text { Orthopaedic hospital, Odense, Denmark } \\
150 \text { participants with } 151 \text { fractures (see Notes) } \\
\text { Trochanteric fractures. } \\
\text { Age: mean } 79 \text { years (range not stated) } \\
\% \text { male: } 28 \% \\
\text { Number lost to follow-up: } 17 \%\end{array}$ \\
\hline Interventions & Trochanteric Gamma intramedullary nail versus Dynamic hip screw \\
\hline Outcomes & $\begin{array}{l}\text { Length of follow-up: } 12 \text { months } \\
\text { Length of surgery } \\
\text { Blood loss } \\
\text { Transfusion } \\
\text { Operative fracture of the femur (none) } \\
\text { Later fracture of the femur } \\
\text { Cut-out of implant } \\
\text { Non-union (none) } \\
\text { Reoperation } \\
\text { Wound infection } \\
\text { Medical complications (none) } \\
\text { Length of hospital stay } \\
\text { Mortality at } 12 \text { months } \\
\text { Use of walking aids at discharge and } 4 \text { months }\end{array}$ \\
\hline Notes & $\begin{array}{l}\text { Five cases were excluded post-randomisation: } 2 \text { wrong diagnosis and } 3 \text { transferred out } \\
\text { of the hospital catchment area. } \\
\text { Extra information supplied by trialists. There were three cases of redislocation of the } \\
\text { fracture in which there was major loss of reduction and/or implant position. These cases } \\
\text { were included as cases of cut-out. }\end{array}$ \\
\hline
\end{tabular}

\section{Risk of bias}

\begin{tabular}{lll}
\hline Item & Authors' judgement & Description \\
\hline Adequate sequence generation? & Yes & $\begin{array}{l}\text { "computer generated" (communication } \\
\text { from trialist) }\end{array}$
\end{tabular}




\section{Ovesen 2006 (Continued)}

\begin{tabular}{|c|c|c|}
\hline Allocation concealment? & Yes & $\begin{array}{l}\text { "patients were randomized by consecutive } \\
\text { drawing of opaque envelopes". These were } \\
\text { confirmed as sealed by the trialist. }\end{array}$ \\
\hline $\begin{array}{l}\text { Surgeons were experienced with trial oper- } \\
\text { ations? }\end{array}$ & No & $\begin{array}{l}\text { Over two thirds of operations done by res- } \\
\text { idents: } 49 \text { surgeons participated in trial }\end{array}$ \\
\hline
\end{tabular}

\section{Pahlpatz 1993}

\begin{tabular}{|c|c|c|}
\hline Methods & \multicolumn{2}{|c|}{$\begin{array}{l}\text { Randomised: method not stated } \\
\text { Surgical experience: No (unknown: operations by surgical residents with assistance of } \\
\text { staff member as required) }\end{array}$} \\
\hline Participants & \multicolumn{2}{|c|}{$\begin{array}{l}\text { Orthopaedic hospital, Netherlands } \\
113 \text { participants } \\
\text { Trochanteric proximal femoral fractures. } \\
\text { Age: mean and range - not stated } \\
\% \text { male: not stated } \\
\text { Number lost to follow-up: not stated }\end{array}$} \\
\hline Interventions & \multicolumn{2}{|c|}{ Gamma intramedullary nail versus sliding hip screw } \\
\hline Outcomes & \multicolumn{2}{|c|}{$\begin{array}{l}\text { Length of follow-up: } 6 \text { months minimum } \\
\text { Mortality } \\
\text { Failure to regain residential status }\end{array}$} \\
\hline Notes & \multicolumn{2}{|c|}{$\begin{array}{l}\text { The paper states these are preliminary results of the study and only reports on two } \\
\text { outcome measures. No additional results have since been made available. }\end{array}$} \\
\hline \multicolumn{3}{|l|}{ Risk of bias } \\
\hline Item & Authors' judgement & Description \\
\hline Adequate sequence generation? & Unclear & No details \\
\hline Allocation concealment? & Unclear & $\begin{array}{l}\text { "Within each group [stable trochanteric, } \\
\text { unstable trochanteric; subtrochanteric frac- } \\
\text { tures] the patients were non-selectively ran- } \\
\text { domised ..." }\end{array}$ \\
\hline $\begin{array}{l}\text { Surgeons were experienced with trial oper- } \\
\text { ations? }\end{array}$ & No & $\begin{array}{l}\text { "Most of the procedures were done by sur- } \\
\text { gical residents ..., if necessary with the as- } \\
\text { sistance of a member of the staff." }\end{array}$ \\
\hline
\end{tabular}


Pajarinen 2005

\begin{tabular}{|c|c|}
\hline Methods & $\begin{array}{l}\text { Randomised by numbered sealed opaque envelopes; } \\
\text { Surgical experience: Yes (Trialist confirmed all surgeons were experienced in both pro- } \\
\text { cedures) }\end{array}$ \\
\hline Participants & $\begin{array}{l}\text { Orthopaedic hospital, Helsinki, Finland } \\
108 \text { participants } \\
\text { Trochanteric proximal femoral fracture. } \\
\text { Age: mean } 81 \text { years } \\
\% \text { male: } 25 \% \\
\text { Number lost to follow-up: } 15 \text { (14\%) }\end{array}$ \\
\hline Interventions & Proximal femoral nail versus Dynamic hip screw \\
\hline Outcomes & $\begin{array}{l}\text { Length of follow-up: } 4 \text { months } \\
\text { Length of surgery } \\
\text { Blood loss } \\
\text { Units of blood transfused } \\
\text { Later fracture of femur } \\
\text { Cut-out } \\
\text { Failure of fixation (redisplacement) } \\
\text { Reoperation } \\
\text { Superficial wound infection } \\
\text { Deep wound infection } \\
\text { Deep vein thrombosis } \\
\text { Femoral neck and shaft shortening on X-ray } \\
\text { Length of hospital stay } \\
\text { Mortality } \\
\text { Failure to regain pre-fracture residential status } \\
\text { Non recovery of previous mobility }\end{array}$ \\
\hline Notes & $\begin{array}{l}\text { Additional information supplied by trialists, who also confirmed that the participants of } \\
\text { a separately reported radiological study were also ("for most parts of the series") in the } \\
\text { trial. }\end{array}$ \\
\hline
\end{tabular}

\section{Risk of bias}

\begin{tabular}{lll}
\hline Item & Authors' judgement & Description \\
\hline Adequate sequence generation? & Yes & "strict randomisation" \\
\hline Allocation concealment? & Yes & $\begin{array}{l}\text { "The mode of treatment was determined } \\
\text { by strict randomisation, using sealed en- } \\
\text { velopes." Trialist conformed that "it was } \\
\text { impossible to see the number through the } \\
\text { envelope". }\end{array}$ \\
\hline
\end{tabular}

Surgeons were experienced with trial oper- Yes ations?
Trialist confirmed that "both procedures are standard procedures at our clinic" and that "our surgeons are very experienced". 
Papasimos 2005

\begin{tabular}{|c|c|}
\hline Methods & $\begin{array}{l}\text { Randomised trial: method not stated } \\
\text { Surgical experience: No (unknown) }\end{array}$ \\
\hline Participants & $\begin{array}{l}\text { Orthopaedic hospital, Patras Hellas, Greece } \\
141 \text { participants } \\
\text { Unstable trochanteric proximal femoral fracture (see Notes) } \\
\text { Age: mean } 81 \text { years } \\
\% \text { male: } 39 \% \\
\text { Number lost to follow-up (of } 141): 11(8 \%)\end{array}$ \\
\hline Interventions & $\begin{array}{l}\text { Proximal femoral nail (PFN) versus Trochanteric Gamma nail versus sliding hip screw. } \\
11 \text { or } 12 \mathrm{~mm} \text { diameter PFN with distal locking in } 37 \text { out of } 40 \text { participants. } 135 \text { degree } \\
\text { Trochanteric Gamma nail with } 17 \mathrm{~mm} \text { proximal diameter and } 11 \mathrm{~mm} \text { distal diameter } \\
\text { and distal locking in all participants. }\end{array}$ \\
\hline Outcomes & $\begin{array}{l}\text { Length of follow-up: mean } 12 \text { months } \\
\text { Length of surgery } \\
\text { Operative blood loss } \\
\text { Radiographic screening time } \\
\text { Operative fracture (some of greater trochanter) } \\
\text { Cut-out of implant } \\
\text { Later fracture of the femur } \\
\text { Non-union } \\
\text { Reoperation } \\
\text { Superficial wound infection } \\
\text { Haematoma } \\
\text { Medical complications } \\
\text { Chest infection } \\
\text { Pneumonia } \\
\text { Mental disturbances } \\
\text { Deep vein thrombosis } \\
\text { Pulmonary embolism } \\
\text { Urinary infection } \\
\text { Length of hospital stay } \\
\text { Time to fracture consolidation } \\
\text { Function: Salvati and Wilson score }\end{array}$ \\
\hline Notes & $\begin{array}{l}\text { There were } 141 \text { people randomised into this trial but the intervention groups for the } 10 \\
\text { participants who died before one year and the } 11 \text { who were lost to follow-up were not } \\
\text { identified. } \\
\text { Four of the five re-operations in the PFN group resulted from the ' } Z \text { effect', which } \\
\text { describes the cutting out of one of the PFN proximal pins with backing out of the other } \\
\text { pin. }\end{array}$ \\
\hline
\end{tabular}

\section{Risk of bias}

\begin{tabular}{lll}
\hline Item Authors' judgement & Description
\end{tabular}


Papasimos 2005 (Continued)

\begin{tabular}{lll}
\hline Adequate sequence generation? & Unclear & No details \\
\hline Allocation concealment? & Unclear & "Patients were... strictly randomised" \\
\hline $\begin{array}{l}\text { Surgeons were experienced with trial oper- } \\
\text { ations? }\end{array}$ & No & $\begin{array}{l}\text { Four surgeons involved and statement that } \\
\text { there was "good enough experience with } \\
\text { each implant in the clinic". However, also } \\
\text { referral in the Discusion of "our immature } \\
\text { learning curve". }\end{array}$ \\
\hline
\end{tabular}

\section{Park 1998}

Methods

Quasi-randomised according to medical record number

Surgical experience: No (unknown)

\begin{tabular}{|c|c|c|}
\hline Participants & \multicolumn{2}{|c|}{$\begin{array}{l}\text { University hospital, Korea } \\
60 \text { participants } \\
\text { Intertrochanteric femoral fracture. } \\
\text { Age: mean } 73 \text { years (all over } 60 \text { years) } \\
\% \text { male: } 40 \% \\
\text { Number lost to follow-up: none }\end{array}$} \\
\hline Interventions & \multicolumn{2}{|c|}{ Gamma AP (Asia-Pacific) intramedullary nail versus Compression hip screw } \\
\hline Outcomes & \multicolumn{2}{|c|}{$\begin{array}{l}\text { Length of follow-up: mean } 18.5 \text { months (range } 12 \text { to } 31 \text { months) } \\
\text { Length of surgery } \\
\text { Blood loss } \\
\text { Operative fracture of femur (none) } \\
\text { Later fracture of femur (greater trochanter) } \\
\text { Cut-out of implant } \\
\text { Non-union (time to union) } \\
\text { Wound infection } \\
\text { Varus deformity } \\
\text { Patient mobility }\end{array}$} \\
\hline Notes & \multicolumn{2}{|c|}{$\begin{array}{l}\text { The Gamma AP nail is a modification of the standard Gamma intramedullary nail for } \\
\text { use in oriental patients. } \\
\text { A request to the trialists for further information including mortality data has been sent }\end{array}$} \\
\hline \multicolumn{3}{|l|}{ Risk of bias } \\
\hline Item & Authors' judgement & Description \\
\hline Adequate sequence generation? & No & $\begin{array}{l}\text { "prospectively randomised into two groups } \\
\text { based on their medical record numbers" }\end{array}$ \\
\hline
\end{tabular}

Gamma and other cephalocondylic intramedullary nails versus extramedullary implants for extracapsular hip fractures in adults (Review) 67 
Park 1998 (Continued)

\begin{tabular}{|c|c|c|}
\hline Allocation concealment? & No & $\begin{array}{l}\text { "prospectively randomised into two groups } \\
\text { based on their medical record numbers" }\end{array}$ \\
\hline $\begin{array}{l}\text { Surgeons were experienced with trial oper- } \\
\text { ations? }\end{array}$ & Unclear & No information. \\
\hline
\end{tabular}

Pelet 2001

Methods

Randomised by the drawing of lots. Those with an even number drawn received one implant and those with an odd number the other implant.

Surgical experience: No (More experience with Gamma nail)

\begin{tabular}{|c|c|}
\hline Participants & $\begin{array}{l}\text { Orthopaedic hospital, Lausanne, Switzerland } \\
26 \text { participants } \\
\text { Trochanteric proximal femoral fractures, classified by the system of Kyle as type IV. These } \\
\text { are equivalent to type A3 (AO classification): reversed and transverse fracture lines at the } \\
\text { level of the lesser trochanter. } \\
\text { Age: mean } 71 \text { years (range } 21 \text { to } 96 \text { years) } \\
\% \text { male: } 35 \% \\
\text { Number lost to follow-up: none }\end{array}$ \\
\hline Interventions & Gamma nail versus the 90 degree angled blade plate \\
\hline Outcomes & $\begin{array}{l}\text { Length of follow-up: } 12 \text { months } \\
\text { Length of surgery } \\
\text { Operative blood loss } \\
\text { Operative fracture of the femur } \\
\text { Cut-out } \\
\text { Non-union (and time to consolidation) } \\
\text { Avascular necrosis } \\
\text { Implant failure } \\
\text { Reoperation } \\
\text { Wound infection } \\
\text { Pulmonary embolism } \\
\text { Cardiac failure } \\
\text { All medical complications } \\
\text { Length of hospital stay } \\
\text { External rotation deformity } \\
\text { Hip flexion } \\
\text { Mortality } \\
\text { Pain at follow-up } \\
\text { Use of walking aids } \\
\text { Time to start of weight bearing } \\
\text { Time to full weight bearing }\end{array}$ \\
\hline Notes & Article in French \\
\hline
\end{tabular}

Risk of bias

Gamma and other cephalocondylic intramedullary nails versus extramedullary implants for extracapsular hip fractures in adults (Review) 
Pelet 2001 (Continued)

\begin{tabular}{l|ll}
\hline Item & Authors' judgement & Description \\
\hline Adequate sequence generation? & Yes & Random numbers method \\
\hline Allocation concealment? & Unclear & $\begin{array}{l}\text { Trialist stated that randomisation was "fully } \\
\text { blinded", but gave no details of method } \\
\text { other than the drawing of lots. }\end{array}$ \\
\hline $\begin{array}{l}\text { Surgeons were experienced with trial oper- } \\
\text { ations? }\end{array}$ & No & $\begin{array}{l}\text { In correspondence, trialist indicated that } \\
\text { there "may be more experience in gamma } \\
\text { as plate" }\end{array}$ \\
\hline
\end{tabular}

\section{Radford 1993}

\begin{tabular}{|c|c|}
\hline Methods & $\begin{array}{l}\text { "Randomised": method not stated } \\
\text { Surgical experience: Yes (Gamma nail: personal training and } 2 \text { operations before trial; } \\
\text { SHS routine; registrar grade and above) }\end{array}$ \\
\hline Participants & $\begin{array}{l}\text { Orthopaedic hospital, UK } \\
200 \text { participants } \\
\text { Trochanteric proximal femoral fractures. } \\
\text { Age: mean } 80 \text { years (range } 60 \text { to } 97 \text { years) } \\
\% \text { male: } 22 \% \\
\text { Number lost to follow-up: not stated }\end{array}$ \\
\hline Interventions & Gamma intramedullary nail versus Dynamic hip screw \\
\hline Outcomes & $\begin{array}{l}\text { Length of follow-up: } 12 \text { months } \\
\text { Length of surgery } \\
\text { Blood loss } \\
\text { Operative fracture of the femur } \\
\text { Later fracture of the femur } \\
\text { Cut-out of implant } \\
\text { Non-union } \\
\text { Reoperation } \\
\text { Wound infection } \\
\text { Deep wound infection } \\
\text { Deep vein thrombosis } \\
\text { Length of hospital stay } \\
\text { Mortality } \\
\text { Transfer to long term care } \\
\text { Mobility level }\end{array}$ \\
\hline Notes & \\
\hline
\end{tabular}

Risk of bias 
Radford 1993 (Continued)

\begin{tabular}{|c|c|c|}
\hline Item & Authors' judgement & Description \\
\hline Adequate sequence generation? & Unclear & "randomly assigned" \\
\hline Allocation concealment? & Unclear & "randomly assigned" \\
\hline $\begin{array}{l}\text { Surgeons were experienced with trial oper- } \\
\text { ations? }\end{array}$ & Yes & $\begin{array}{l}\text { "only surgeons of registrar grade and above } \\
\text {.. took part in trial. They were already ex- } \\
\text { perienced in the use of the DHS and in- } \\
\text { tramedullary nailing, and were personally } \\
\text { instructed in the operative technique for } \\
\text { the Gamma nail. ...The first two Gamma } \\
\text { nail operations performed by each surgeon } \\
\text { were not included in the trial." }\end{array}$ \\
\hline
\end{tabular}

Rahme 2007

\begin{tabular}{ll} 
Methods & $\begin{array}{l}\text { "Randomised": method not stated } \\
\text { Surgical experience: No (unknown) }\end{array}$ \\
\hline Participants & $\begin{array}{l}\text { Orthopaedic hospitals, Sydney, Australia } \\
60 \text { participants } \\
\text { Subtrochanteric proximal femoral fractures, all types } \\
\text { Age (of 58): mean } 70 \text { years } \\
\text { \% male: } 43 \%\end{array}$ \\
\hline Number lost to follow-up: not stated (2 were protocol violations)
\end{tabular}

\section{Risk of bias}

\begin{tabular}{|c|c|c|}
\hline Item & Authors' judgement & Description \\
\hline Adequate sequence generation? & Unclear & "randomised": no details \\
\hline
\end{tabular}

Gamma and other cephalocondylic intramedullary nails versus extramedullary implants for extracapsular hip fractures in adults (Review) 70 Copyright (C) 2010 The Cochrane Collaboration. Published by John Wiley \& Sons, Ltd. 
Rahme 2007 (Continued)

\begin{tabular}{l|ll}
\hline Allocation concealment? & Unclear & "randomised": no details \\
\hline $\begin{array}{l}\text { Surgeons were experienced with trial oper- } \\
\text { ations? }\end{array}$ & No & No information \\
\hline
\end{tabular}

\section{Sadowski 2002}

\begin{tabular}{|c|c|}
\hline Methods & $\begin{array}{l}\text { Randomised using computer generated randomised numbers } \\
\text { Surgical experience: Yes (All surgeons had performed at least eight of each operation } \\
\text { before the study) }\end{array}$ \\
\hline Participants & $\begin{array}{l}\text { Orthopaedic hospital, Geneva, Switzerland } \\
39 \text { participants } \\
\text { Trochanteric proximal femoral fractures, type A3 (AO classification): reversed and trans- } \\
\text { verse fracture lines at the level of the lesser trochanter. } \\
\text { Age: mean } 79 \text { years } \\
\% \text { male: } 31 \% \\
\text { Number lost to follow-up: none (one patient was unable to attend clinic so had follow- } \\
\text { up by phone) }\end{array}$ \\
\hline Interventions & Proximal femoral nail versus the Dynamic condylar screw \\
\hline Outcomes & $\begin{array}{l}\text { Length of follow-up: } 12 \text { months } \\
\text { Length of surgery } \\
\text { Operative blood loss } \\
\text { Mean units transfused } \\
\text { Number of patients transfused } \\
\text { Radiographic screening time } \\
\text { Cut-out } \\
\text { Non-union (and time to consolidation) } \\
\text { Implant failure } \\
\text { Reoperation } \\
\text { Wound infection } \\
\text { Pneumonia } \\
\text { Pressure sores } \\
\text { Deep vein thrombosis } \\
\text { Pulmonary embolism } \\
\text { Urinary infection } \\
\text { Cardiac failure/infarction } \\
\text { All medical complications } \\
\text { Mortality } \\
\text { Pain at follow-up } \\
\text { Social function } \\
\text { Transfer to long term care } \\
\text { Mobility level }\end{array}$ \\
\hline Notes & $\begin{array}{l}\text { Additional information supplied by authors } \\
\text { This trial was concurrent with Saudan } 2002\end{array}$ \\
\hline
\end{tabular}


Sadowski 2002 (Continued)

\begin{tabular}{l|l|l}
$\begin{array}{l}\text { Risk of bias } \\
\text { Item }\end{array}$ & Authors' judgement & Description \\
\hline Adequate sequence generation? & Yes & $\begin{array}{l}\text { "No patient refused randomization, which } \\
\text { was accomplished with use of computer- } \\
\text { generated random numbers." }\end{array}$ \\
\hline Allocation concealment? & Unclear & $\begin{array}{l}\text { "computer-generated random numbers". } \\
\text { No mention of safeguards. }\end{array}$ \\
\hline $\begin{array}{l}\text { Surgeons were experienced with trial oper- } \\
\text { ations? }\end{array}$ & Yes & $\begin{array}{l}\text { Information from trialist: "All the surgeons } \\
\text { involved in this study had performed an } \\
\text { average of eight procedures with the PFN } \\
\text { prior to the initiation of the randomized } \\
\text { clinical trial." of each operation before the } \\
\text { study) }\end{array}$ \\
\hline
\end{tabular}

\section{Saudan 2002}

Methods

Randomised using computer generated randomised numbers

Surgical experience: Yes (all surgeons had performed at least eight of each operation before the study)

\begin{tabular}{ll} 
Participants & Orthopaedic hospital, Geneva, Switzerland \\
& 206 participants \\
& Trochanteric proximal femoral fractures, types A1 and A2 (AO classification). \\
Age: mean 83 years & \% male: $22 \%$ \\
& Number lost to follow-up: $4 \%$ \\
\hline Interventions & Proximal femoral nail versus Dynamic hip screw \\
\hline \multirow{3}{*}{ Outcomes } & Length of follow-up: 12 months \\
& Length of surgery \\
& Operative blood loss \\
& Mean units transfused \\
Number of patients transfused \\
Radiographic screening time \\
Cut-out \\
Non-union (and time to consolidation) \\
Implant failure \\
Reoperation \\
Wound infection \\
Pneumonia \\
Pressure sores \\
Deep vein thrombosis \\
\hline
\end{tabular}


Saudan 2002 (Continued)

\begin{tabular}{|c|c|c|}
\hline & \multicolumn{2}{|l|}{$\begin{array}{l}\text { Pulmonary embolism } \\
\text { Urinary infection } \\
\text { Cardiac failure/infarction } \\
\text { All medical complications } \\
\text { Mortality } \\
\text { Pain at follow-up } \\
\text { Social function } \\
\text { Transfer to long term care } \\
\text { Mobility level }\end{array}$} \\
\hline Notes & \multicolumn{2}{|c|}{$\begin{array}{l}\text { Additional information supplied by authors } \\
\text { This trial was concurrent with Sadowski } 2002 \text {. }\end{array}$} \\
\hline \multicolumn{3}{|l|}{ Risk of bias } \\
\hline Item & Authors' judgement & Description \\
\hline Adequate sequence generation? & Yes & $\begin{array}{l}\text { "No patient refused randomization, which } \\
\text { was accomplished with use of computer- } \\
\text { generated random numbers." }\end{array}$ \\
\hline Allocation concealment? & Unclear & $\begin{array}{l}\text { "computer-generated random numbers". } \\
\text { No mention of safeguards. }\end{array}$ \\
\hline $\begin{array}{l}\text { Surgeons were experienced with trial oper- } \\
\text { ations? }\end{array}$ & Yes & $\begin{array}{l}\text { Information from trialist: "All the surgeons } \\
\text { involved in this study had performed an } \\
\text { average of eight procedures with the PFN } \\
\text { prior to the initiation of the randomized } \\
\text { clinical trial." of each operation before the } \\
\text { study) }\end{array}$ \\
\hline
\end{tabular}

Utrilla 2005

Methods

Randomised by sealed envelopes, order based on sequence of admission

Surgical experience: Yes (3 prior operations for the nail)

\begin{tabular}{ll}
\hline Participants & $\begin{array}{l}\text { Orthopaedic hospital, Alicante, Spain } \\
210 \text { participants } \\
\text { Trochanteric proximal femoral fractures. No subtrochanteric fractures } \\
\text { Age: mean } 80 \text { years (range } 65 \text { to } 104 \text { years) } \\
\% \text { male: } 31 \% \\
\text { Number lost to follow-up: } 7 \text { (3.3\%) }\end{array}$ \\
\hline Interventions & Gamma intramedullary nail (Trochanteric Gamma Nail version) versus sliding hip screw \\
\hline Outcomes & $\begin{array}{l}\text { Length of follow-up: } 12 \text { months } \\
\text { Length of surgery } \\
\text { Blood transfusion }\end{array}$ \\
\hline
\end{tabular}

Gamma and other cephalocondylic intramedullary nails versus extramedullary implants for extracapsular hip fractures in adults (Review) 73 Copyright (C) 2010 The Cochrane Collaboration. Published by John Wiley \& Sons, Ltd. 
Utrilla 2005 (Continued)

Radiographic screening time

Operative fracture of the femur

Later fracture of the femur

Cut-out of implant

Reoperation

Deep wound sepsis

Local wound healing complications

Deep vein thrombosis

Shortening

Hip flexion

Mobility

Pain (thigh pain)

Mortality at one year

Notes

Risk of bias

\begin{tabular}{|c|c|c|}
\hline Item & Authors' judgement & Description \\
\hline Adequate sequence generation? & Unclear & No details \\
\hline Allocation concealment? & Unclear & $\begin{array}{l}\text { "The patients were randomized for treat- } \\
\text { ment into } 2 \text { groups based on sequence of } \\
\text { admission, sealed envelopes were opened } \\
\text { before the surgeon attempted a closed re- } \\
\text { duction of the fracture." No mention of } \\
\text { safeguards }\end{array}$ \\
\hline $\begin{array}{l}\text { Surgeons were experienced with trial oper- } \\
\text { ations? }\end{array}$ & Yes & $\begin{array}{l}\text { "Four surgeons experienced in the standard } \\
\text { Gamma nail did all the operations; how- } \\
\text { ever, the first } 3 \text { TGN operations performed } \\
\text { by the surgeons were not included in the } \\
\text { study and served as the learning curve for } \\
\text { the new instrumentation." }\end{array}$ \\
\hline
\end{tabular}

Varela-Egocheaga 2009

Methods
Randomised using random numbers table

Surgical experience: likely, referral to prior 'learning curve' period.

Orthopaedic hospital, Gijon, Spain

80 participants

Trochanteric proximal femoral fractures. No subtrochanteric fractures

Age: mean 82 years (range not stated)

$\%$ male: $21 \%$

Number lost to follow-up: 1 (1.25\%) (see Notes) 
Varela-Egocheaga 2009 (Continued)

\begin{tabular}{ll}
\hline Interventions & Gamma 3 intramedullary nail versus the Percutaneous compression plate (PCCP) \\
\hline Outcomes & $\begin{array}{l}\text { Length of follow-up: } 12 \text { months } \\
\text { Length of surgery } \\
\text { Blood transfusion }\end{array}$ \\
Fall in haemoglobin \\
Cut-out of implant \\
Confusion \\
Stroke \\
Congestive cardiac failure \\
Pneumonia \\
Genitourinary infection \\
Length of hospital stay \\
Mortality at one year \\
Discharge to intermediate care \\
Post-operative analgesia (duration and dose of Metamizol) \\
Failure to regain mobility \\
\hline Notes & Number of patients lost to follow-up inferred from mobility data. \\
\hline
\end{tabular}

Risk of bias

\begin{tabular}{lll}
\hline Item & Authors' judgement & Description \\
\hline Adequate sequence generation? & Yes & $\begin{array}{l}\text { "randomized using a table of randomized } \\
\text { numbers" }\end{array}$ \\
\hline Allocation concealment? & Unclear & No details \\
\hline $\begin{array}{l}\text { Surgeons were experienced with trial oper- } \\
\text { ations? }\end{array}$ & Yes & $\begin{array}{l}\text { Referral to prior 'learning curve' period be- } \\
\text { fore start of the trial }\end{array}$ \\
\hline
\end{tabular}

\section{Verettas 2010}

Methods

Quasi-randomised by alternating patients to the two groups

Surgical experience: possible - claimed in the discussion that "surgeons had previous experience of the use of these implants.", but there was a change in nail forced on the surgeon's midway through the trial.

\begin{tabular}{ll} 
Participants & Orthopaedic hospital, Alexandroupolis, Greece \\
120 participants \\
Unstable trochanteric proximal femoral fractures. \\
Age: mean 80 years (range: not stated) \\
$\begin{array}{l}\text { \% male: } 30 \% \\
\text { Number lost to follow-up: not stated (but potential post-randomisation exclusions in } \\
\text { those not operated before } 24 \text { hours) }\end{array}$ \\
\hline Interventions & Intramedullary nail (38 Gamma nail, 22 Endovis BA nail) versus Dynamic hip screw
\end{tabular}

Gamma and other cephalocondylic intramedullary nails versus extramedullary implants for extracapsular hip fractures in adults (Review) 75 Copyright (C) 2010 The Cochrane Collaboration. Published by John Wiley \& Sons, Ltd. 
Verettas 2010 (Continued)

\begin{tabular}{|c|c|c|}
\hline Outcomes & \multicolumn{2}{|c|}{$\begin{array}{l}\text { Length of follow-up: duration of hospital stay (mean } 10 \text { days) } \\
\text { Length of surgery } \\
\text { Blood loss } \\
\text { Radiographic screening time } \\
\text { Number of patients transfused } \\
\text { Operative fracture of the femur } \\
\text { Superficial wound infection } \\
\text { Deep vein thrombosis ("immediate post-operative") } \\
\text { Cardiovascular complication (“immediate post-operative") } \\
\text { Neurologic complication/ delirium ("immediate post-operative") } \\
\text { Respiratory complication ("immediate post-operative") } \\
\text { Haematocrit } \\
\text { Oxygen saturation and pressure } \\
\text { Mental test score } \\
\text { Length of hospital stay } \\
\text { Days to independent walking } \\
\text { Mortality (in hospital) } \\
\text { Pain score }\end{array}$} \\
\hline Notes & \multicolumn{2}{|c|}{$\begin{array}{l}\text { The explanation from the lead author for the change in nail was that it resulted from a } \\
\text { change of supplies policy at the hospital. }\end{array}$} \\
\hline \multicolumn{3}{|l|}{ Risk of bias } \\
\hline Item & Authors' judgement & Description \\
\hline Adequate sequence generation? & No & $\begin{array}{l}\text { "The patients were allocated to each group } \\
\text { alternatively on their admission." }\end{array}$ \\
\hline Allocation concealment? & No & $\begin{array}{l}\text { "The patients were allocated to each group } \\
\text { alternatively on their admission." (In- } \\
\text { formed consent was obtained before inclu- } \\
\text { sion.) }\end{array}$ \\
\hline $\begin{array}{l}\text { Surgeons were experienced with trial oper- } \\
\text { ations? }\end{array}$ & Unclear & $\begin{array}{l}\text { "In our study the operating time was simi- } \\
\text { lar in both groups, possibly because the sur- } \\
\text { geons had previous experience of the use of } \\
\text { these implants." (Statement in the Discus- } \\
\text { sion.) However, a change in nail was forced } \\
\text { on the trialists during the trial. }\end{array}$ \\
\hline
\end{tabular}

Gamma and other cephalocondylic intramedullary nails versus extramedullary implants for extracapsular hip fractures in adults (Review) 76 Copyright (C) 2010 The Cochrane Collaboration. Published by John Wiley \& Sons, Ltd. 


\begin{tabular}{|c|c|c|}
\hline Methods & \multicolumn{2}{|c|}{$\begin{array}{l}\text { Randomised trial, method not stated } \\
\text { Surgical experience: No (unknown) }\end{array}$} \\
\hline Participants & \multicolumn{2}{|c|}{$\begin{array}{l}\text { Orthopaedic hospital, Suzhou, Jiangsu, China } \\
121 \text { participants } \\
\text { Trochanteric proximal femoral fractures. } \\
\text { Age: mean } 65 \text { years (range: not stated) } \\
\% \text { male: } 22 \% \\
\text { Number lost to follow-up: not stated }\end{array}$} \\
\hline Interventions & \multicolumn{2}{|c|}{ Proximal femoral nail antirotation (PFNA) versus Dynamic hip screw } \\
\hline Outcomes & \multicolumn{2}{|c|}{$\begin{array}{l}\text { Length of follow-up: one year } \\
\text { Length of surgery } \\
\text { Operative blood loss } \\
\text { Radiographic screening time } \\
\text { Cut-out of the implant } \\
\text { Later fracture of the femur } \\
\text { Non-union of the fracture } \\
\text { Implant breakage } \\
\text { Reoperation } \\
\text { Superficial wound infection } \\
\text { Deep wound infection } \\
\text { Deep vein thrombosis } \\
\text { Length of hospital stay } \\
\text { Salvati and Wilson Hip score at one year }\end{array}$} \\
\hline \multicolumn{3}{|l|}{ Notes } \\
\hline \multicolumn{3}{|l|}{ Risk of bias } \\
\hline Item & Authors' judgement & Description \\
\hline Adequate sequence generation? & Unclear & No details \\
\hline Allocation concealment? & Unclear & $\begin{array}{l}\text { No details: "consecutive patients ... were } \\
\text { randomised" }\end{array}$ \\
\hline $\begin{array}{l}\text { Surgeons were experienced with trial oper- } \\
\text { ations? }\end{array}$ & Unclear & Not stated \\
\hline
\end{tabular}


"Surgical experience" in the Methods column gives details of prior experience of the operations the surgeons performed in the trial.

"Yes" = 1 in the quality assessment tool (Item 5); "No" = 0 , which could also reflect a lack of information.

IM: intramedullary

IMHS: intramedullary hip screw

PFN: proximal femoral nail

PFNA: proximal femoral nail antirotation

SHS: sliding hip screw

PCCP: percutaneous compression plate

Characteristics of excluded studies [ordered by study ID]

\begin{tabular}{l|l}
\hline Study & Reason for exclusion \\
\hline Azzoni 2004 & $\begin{array}{l}\text { This was a retrospective comparison of } 208 \text { people with a trochanteric fracture treated with either an in- } \\
\text { tramedullary nail or a sliding hip screw. The study was excluded because there was no randomisation of patients. }\end{array}$ \\
\hline Bhatti 2003 & $\begin{array}{l}\text { This was a prospective comparison of } 70 \text { people treated with either the proximal femoral nail or dynamic hip } \\
\text { screw, with the choice of treatment being the preference of the surgeon. It was excluded because it was not a } \\
\text { randomised study. }\end{array}$ \\
\hline
\end{tabular}

Bienkowski 2006 This was a prospective comparison of 60 people with a trochanteric fracture treated with either a trochanteric femoral nail or a sliding hip screw. The study was excluded because the choice of treatment was according to the preference and experience of the attending surgeon, with no randomisation of patients.

Cao 2009 This was reported as a randomised trial of 95 patients with a trochanteric fractures treated with either a Gamma nail, proximal femoral nail or a dynamic hip screw. The English abstract implied that the population was randomly divided according to the Evans classification system. Overall, there was limited reporting of the study methodology within the paper such that it was not possible to determine clearly if it was a randomised controlled trial or an observational study. The study was excluded because it was uncertain that it was a randomised controlled trial.

Davison 1996 An interim report of this randomised trial comparing the intramedullary hip screw with the sliding hip screw was reported in a conference abstract published 1996. In 1995, 134 people had been entered in the study. Of the 63 available for clinic review at 6 months, there had been 6 cut-outs in each group. There were no other implant failures or femoral fractures reported. Pain and mobility were similar in both groups. The trial was stated to be continuing but no further results have been presented or made available and correspondence with the author indicated that further information was not available. The study was excluded because it reported only very limited and interim outcomes.

DiCicco 2000 In this study, people with femoral shaft fractures were allocated antegrade or retrograde nailing of femur fracture according to their medical record numbers. All subtrochanteric fractures, which were not included in the quasirandomised trial, were treated with retrograde nailing. The study was excluded because there was no randomisation of proximal femoral fractures.

Fritz 1999

Randomised comparison with 80 people allocated to either the Gamma nail or a gliding nail, which is the same as a gamma nail except the lag screw is changed to a nail. It was excluded because there was no extramedullary comparison group, but has been included in the Cochrane review comparing different types of intramedullary nails for extracapsular hip fractures. 
Hardy 2003 This randomised trial of 80 people with a trochanteric fracture compared the use of a standard intramedullary hip screw against an intramedullary hip screw with a slotted distal locking hole. It was excluded because there was no extramedullary comparison group, but has been included in the Cochrane review comparing different types of intramedullary nails for extracapsular hip fractures.

Herrera 2002 This was a randomised comparison of 125 people treated with the Gamma nail versus 125 people treated with the proximal femoral nail. It was excluded because there was no extramedullary comparison group, but has been included in the Cochrane review comparing different types of intramedullary nails for extracapsular hip fractures.

Hogh 1992 This randomised trial from Denmark of 299 cases compared the Gamma nail with the sliding hip screw. The study was reported in conference abstracts only. The results as detailed showed "no difference" in mean operative times, operative blood loss, wound drainage or post-operative haemoglobin levels. Mortality was similar in both groups. Cut-out occurred in six cases in the sliding hip screw group and 10 in the Gamma nail group. There were eight cases in the Gamma nail group of operative or later fracture around the nail. Reoperations were required in six cases in the sliding hip screw group and 12 in the Gamma group.

The study was excluded because the exact numbers of cases allocated to each group was not given. Correspondence with medical staff at the trial hospital indicated that no further information was now available.

Hu 2006 This was a study of 88 patients with a trochanteric fractures treated with either a proximal femoral nail, a dynamic condylar screw plate, a proximal femoral plate or a dynamic hip screw. The study was excluded because there was no randomisation of patients.

Kafer 2005 Study, reported in German, comparing the results of 53 people treated with a proximal femoral nail versus 59 people treated with a dynamic hip screw. This study was excluded because there was no randomisation of patients.

Khan 2002 The contact trialist listed in the National Research Register (UK) entry for this study, reported to compare the trochanteric intramedullary nail versus the dynamic compression screw, confirmed that the trial did not "get off the ground".

Klinger 2005 This was a comparative study of 122 people with unstable trochanteric fractures treated with the proximal femoral nail and 51 treated with the dynamic hip screw with a trochanteric buttress-press plate. It was excluded because it was not a randomised study.

Liu 2008 This was reported as a randomised trial of 130 patients with trochanteric fractures treated with either a Gamma nail or a dynamic hip screw. There was limited reporting of the study methodology within the paper such that it was not possible to determine clearly if it was a randomised controlled trial or an observational study. The study was excluded because it was uncertain that it was a randomised controlled trial.

Merenyi 1995 This conference abstract suggested a randomised trial comparing 40 Ender nails with 40 angle plates, and 40 Gamma nails (3 types). Correspondence with the authors indicated that there was no randomisation of patients only a random selection of people who had been previously treated with one of the different implants.

Moran 2000 This was a randomised trial of unstable intertrochanteric fractures comparing the proximal femoral nail and the dynamic hip screw. The trial co-ordinator was Mr CG Morgan, Department of Trauma \& Orthopaedics, C Floor, West Block, University Hospital, Nottingham, NG7 2UH, UK. Recruitment to the study was suspended in 1999 due to problems with the proximal femoral nail and no outcome data for the limited number of trial participants has been made available. 
Prinz 1996 Only preliminary results were provided in the conference abstract report of this randomised trial. There were 38 people treated with a sliding hip screw, 43 with a Gamma nail and 41 with an intramedullary hip screw recruited between 01/03/1995 and 01/03/1996.

The study was excluded because of the inadequate reporting of the trial outcomes; preliminary results only being available. Should a full report of this ever become available, it is likely that we will reconsider this decision.

Roder 1995 This was a randomised trial of 75 people with stable trochanteric fracture: 25 were treated with a sliding hip screw 25 with a Gamma nail and 25 with a Gamma nail with a modification of the surgical technique using a $4.5 \mathrm{~mm}$ drill hole in the lateral femur approximately $5 \mathrm{~cm}$ distal to the tip of the nail. The aim was to determine if the drill hole would reduce the risk of bone marrow vascular embolism. The only outcome measure was the degree of marrow embolisation as determined by transoesophageal ultrasound. The results indicated minimal bone marrow embolisation with the SHS and mild embolisation with the Gamma nail inserted with a distal femoral drill hole. For the 25 people treated with the Gamma nail inserted without a drill hole there was heavy bone marrow embolisation as judged by ultrasound.

The trial was excluded as:

1. There were no clinical outcomes relevant to this review of SHS versus Gamma nail

2. There was no follow up of trial participants

The study is included in the Cochrane review' Osteotomy, compression and reaming techniques for internal fixation of extracapsular hip fractures'

Saarenpaa 2009 This was a comparative matched pair study of 268 people with trochanteric fractures treated with the Gamma nail or the dynamic hip screw. It was excluded because it was not a randomised study.

Schipper 2004 This was a randomised trial comparing the Gamma nail with the proximal femoral nail in 424 people. It was excluded because there was no extramedullary comparison group, but has been included in the Cochrane review comparing different types of intramedullary nails for extracapsular hip fractures.

Tarantino 2005 This was a two-centre comparison between the Gamma nail versus a variable angle sliding hip screw in 142 people with extracapsular hip fractures. Patients who had undergone fixation with the Gamma nail at one hospital were matched by age, sex and type of fracture to patients treated with a sliding screw device at the other hospital. The study was excluded because there was no randomisation of patients. 
Zhao 2009 This was a study comparing 104 patients with a trochanteric fractures treated with either a proximal femoral nail (33 patients) or a dynamic hip screw (71 patients). There was no indication in the English abstract of this report that this was a randomised controlled trial or even a prospective study.

Ziran 2009 This was a comparative study of 94 patients with trochanteric fractures treated with either a Gamma nail or a compression hip screw. Choice of fixation was at the preference of the attending surgeon. The study was excluded because it was not a randomised trial.

\section{Characteristics of studies awaiting assessment [ordered by study ID]}

\section{Ahmad}

\begin{tabular}{|c|c|}
\hline Methods & $\begin{array}{l}\text { Randomised controlled trial: "Computer generated random tables will be used. Delivery of randomisation will be in } \\
\text { opaque sealed envelopes to be opened at the time of operation in the operating theatre." }\end{array}$ \\
\hline Participants & Extracapsular femoral fractures \\
\hline Interventions & intramedullary hip screw versus compression hip screw \\
\hline Outcomes & $\begin{array}{l}\text { Haemodynamic changes during surgical procedure } \\
\text { Oxygen saturation \& blood pressure } \\
\text { Mini-mental scores (post-operative) } \\
\text { Length of hospital stay } \\
\text { Pulmonary embolus } \\
\text { Mortality }\end{array}$ \\
\hline Notes & $\begin{array}{l}\text { Main purpose of trial was to record haemodynamic changes. There was intraoperative monitoring of the cardiovascular } \\
\text { system } \\
\text { Abstract and NRR (UK) registration only } \\
\text { Number of participants not reported in the conference abstract }\end{array}$ \\
\hline
\end{tabular}

\section{Rafiq 2009}

\begin{tabular}{|c|c|}
\hline Methods & Randomised controlled trial using "computer generated random numbers". Single centre. \\
\hline Participants & 64 patients with subtrochanteric fractures \\
\hline Interventions & Interlocking intramedullary nail versus dynamic condylar screw \\
\hline Outcomes & $\begin{array}{l}\text { Follow-up: } 1 \text { year } \\
\text { Length of surgery } \\
\text { Intra-operative blood loss } \\
\text { Non-union } \\
\text { Time to fracture union } \\
\text { Cut-out } \\
\text { Infection }\end{array}$ \\
\hline
\end{tabular}




\section{Rafiq 2009 (Continued)}

\begin{tabular}{ll} 
& Time for full weightbearing \\
& $\begin{array}{l}\text { Functional recovery (Sikorski and Barrington pain and mobility scale) } \\
\text { Range of hip motion } \\
\text { Muscle strength } \\
\text { Radiographic outcomes }\end{array}$ \\
\hline Notes & Abstract only \\
\hline
\end{tabular}

\section{White}

\begin{tabular}{ll}
\hline Methods & Randomised controlled trial. Single centre. \\
\hline Participants & Unstable hip fractures \\
\hline Interventions & DHS versus the PFN \\
\hline Outcomes & Not stated \\
\hline Notes & NRR (UK) registration only - minimum information available \\
\hline
\end{tabular}

\section{Characteristics of ongoing studies [ordered by study ID]}

\section{Matre}

\begin{tabular}{|c|c|}
\hline Trial name or title & $\begin{array}{l}\text { A prospective randomised multicentre study comparing the sliding hip screw and the Intertan nail in } \\
\text { trochanteric and subtrochanteric femoral fractures }\end{array}$ \\
\hline Methods & Randomised controlled trial \\
\hline Participants & $\begin{array}{l}\text { Intended: } 500 \text { participants } \\
\text { Inclusion Criteria: } \\
\text { - Patients older than } 60 \text { years with a trochanteric or subtrochanteric hip fracture. } \\
\text { Exclusion Criteria: } \\
\text { - Patients with pathologic fractures, patients already included with a fracture on the opposite side. }\end{array}$ \\
\hline Interventions & Intertan intramedullary nail versus the Sliding hip screw \\
\hline Outcomes & $\begin{array}{l}\text { Length of follow-up: } 1 \text { year } \\
\text { Early postoperative pain (VAS) and functional mobility (TUG-test) } \\
\text { Pain, functional mobility (TUG-test), Harris Hip Score, quality of life (EQ-5D) and complications at dis- } \\
\text { charge from hospital, and at } 6 \text { weeks, } 3 \text { and } 12 \text { months postop. }\end{array}$ \\
\hline Starting date & February 2008 \\
\hline Contact information & $\begin{array}{l}\text { Kjell Matre, MD, Head of Orthopaedic Trauma, Department of Orthopaedics, Haukeland University Hos- } \\
\text { pital, Norway } \\
\text { kjell.matre@helse-bergen.no }\end{array}$ \\
\hline
\end{tabular}


Notes

Molnar

Trial name or title Prospective randomised pilot study comparing the dynamic hip screw and intramedullary Gamma nail regarding the treatment of intertrochanteric hip fracture

\begin{tabular}{ll}
\hline Methods & Randomised controlled trial, with blinding of participants and outcome assessors \\
\hline Participants & $\begin{array}{l}60 \text { patients, aged between } 18 \text { and } 100 \text { years, with non-pathological intertrochanteric hip fractures resulting } \\
\text { from low-energy injury. Excluded: previous ipsilateral hip or femur surgery, associated neurovascular injury, } \\
\text { unable to understand / comply with follow-up procedures, medical contraindication to surgery or anaesthesia. }\end{array}$ \\
\hline Interventions & Gamma 3 trochanteric nail versus or the Sliding hip screw \\
\hline Outcomes & $\begin{array}{l}\text { Length of follow-up: } 2 \text { years } \\
\text { Operative data: Surgical time, fluoroscopy time, blood loss/ blood transfusion, skin incision length } \\
\text { Post-operative data: Functional recovery score, fracture collapse, } 6 \text { minute walk test }\end{array}$ \\
\hline Starting date & 01/08/2008 \\
\hline Contact information & Rob Molnar, 4 Short St, Kogarah, New South Wales 2217, Australia \\
\hline Notes & \\
\hline
\end{tabular}

Parker

\begin{tabular}{|c|c|}
\hline Trial name or title & Randomised trial of Targon intramedullary nail versus sliding hip screw for trochanteric fractures \\
\hline Methods & Randomised controlled trial, blinded assessors \\
\hline Participants & 600 patients with a trochanteric hip fracture which is to be treated surgically \\
\hline Interventions & Targon intramedullary nail versus sliding hip screw \\
\hline Outcomes & $\begin{array}{l}\text { Length of follow-up: } 1 \text { year. } \\
\text { Full record of operative and follow-up outcomes }\end{array}$ \\
\hline Starting date & 2001 \\
\hline Contact information & $\begin{array}{l}\text { Dr Martyn J Parker, MD, FRCS } \\
\text { Orthopaedic Research Fellow } \\
\text { Department of Trauma \& Orthopaedics } \\
\text { Peterboroughand Stamford Hospitals NHS Foundation Trust } \\
\text { Thorpe Road } \\
\text { Peterborough } \\
\text { PE3 6DA }\end{array}$ \\
\hline
\end{tabular}




Notes $\quad$ Due to be completed December 2010

\section{REGAIN}

Trial name or title Re-Evaluation of GA mma3 Intramedullary Nails in hip fracture: A multi-centre randomised controlled trial of Gamma3 intramedullary nails versus sliding hip screws in the management of intertrochanteric fractures of the hip

Methods $\quad$ Randomised, double blind (participant, outcomes assessor)

\begin{tabular}{|c|c|}
\hline Participants & $\begin{array}{l}\text { Intended: } 90 \text { participants } \\
\text { Inclusion criteria: } \\
\text { - Adult men or women aged } 50 \text { years and older (with no upper age limit). } \\
\text { - An intertrochanteric fracture (stable or unstable) confirmed with anterior and posterior lateral hip } \\
\text { radiographs, computed tomography, or magnetic resonance imaging (MRI). } \\
\text { - Operative treatment within } 3 \text { days (i.e., } 72 \text { hours) after the trauma. } \\
\text { - Patient was ambulatory prior to fracture, though they may have used an aid such as a cane or a walker. } \\
\text { - Anticipated medical optimalisation of the patient for operative fixation of the hip. } \\
\text { - Provision of informed consent by patient or proxy. } \\
\text { - Low energy fracture (defined as a fall from standing height). } \\
\text { - No other major trauma. } \\
\text { Exclusion Criteria: } \\
\text { - Associated major injuries of the lower extremity (i.e., ipsilateral or contralateral fractures of the foot, } \\
\text { ankle, tibia, fibula, knee, or femur; dislocations of the ankle, knee, or hip; or femoral head defects or } \\
\text { fracture). } \\
\text { - Retained hardware around the affected hip. } \\
\text { - Infection around the hip (i.e., soft tissue or bone). } \\
\text { - Patients with disorders of bone metabolism other than osteoporosis (i.e., Paget's disease,renal } \\
\text { osteodystrophy, or osteomalacia). } \\
\text { - Moderate or severe cognitively impaired patients (i.e., Six Item Screener with three or more errors). } \\
\text { - Patients with Parkinson's disease (or dementia) severe enough to increase the likelihood of falling or } \\
\text { severe enough to compromise rehabilitation. } \\
\text { - Likely problems, in the judgment of the investigators, with maintaining follow-up. The investigators } \\
\text { will, for example, exclude patients with no fixed address, those who report a plan to move out of town in the } \\
\text { next year, or intellectually challenged patients without adequate family support. } \\
\text { - If the attending surgeon believes that a patient should be excluded from REGAIN because the patient } \\
\text { is enrolled in another ongoing drug or surgical intervention trial. } \\
\text { - If the attending surgeon believes that there is another reason to exclude this patient from REGAIN. } \\
\text { This reason will be documented on the case report forms. }\end{array}$ \\
\hline Interventions & Gamma3 intramedullary nail (Stryker) versus the sliding hip screw \\
\hline Outcomes & $\begin{array}{l}\text { Length of follow-up: } 2 \text { years } \\
\text { - Rates of revision surgery }\end{array}$ \\
\hline
\end{tabular}




\section{REGAIN (Continued)}

\begin{tabular}{|c|c|}
\hline & $\begin{array}{l}\text { - HRQL (SF-12, WOMAC,EQ-5D, Merle d'Aubigne (MDA), Parker Mobility score) [Time frame: } \\
\text { hospital admission, } 1 \text { and } 2 \text { weeks, 3, 6, 9,12, } 18 \text { and } 24 \text { months] } \\
\text { - Fracture healing rates [Time frame: 3, 6, 9,12, } 18 \text { and } 24 \text { months] } \\
\text { - Complications (mortality, femoral shaft fracture, avascular necrosis, nonunion, malunion, implant } \\
\text { breakage/failure, infection) [Time frame: hospital admission, } 1 \text { and } 2 \text { weeks, } 3,6,9,12,18 \text { and } 24 \text { months ] }\end{array}$ \\
\hline Starting date & May 2007 \\
\hline Contact information & $\begin{array}{l}\text { Helena Viveiros, BSc. BA 905-527-4322 ext } 44696 \\
\text { viveiro@mcmaster.ca } \\
\text { Sheila Sprague, MSc. 905-527-4322 ext } 44490 \\
\text { spags@mcmaster.ca }\end{array}$ \\
\hline Notes & \\
\hline
\end{tabular}

\section{Schipper}

Trial name or title Fixation device related rotational and translational influences in trochanteric femoral fractures: A radio stereometric analysis of the DHS versus the gamma-nail

\begin{tabular}{ll}
\hline Methods & Randomised \\
\hline Participants & $\begin{array}{l}60 \text { patients, aged over } 60 \text { years, with non-pathological intertrochanteric hip fractures. Excluded: severe } \\
\text { arthritis of the involved hip, rheumatoid arthritis, previously immobile }\end{array}$ \\
\hline Interventions & Gamma nail versus the sliding hip screw \\
\hline Outcomes & $\begin{array}{l}\text { Length of follow-up: 1 year } \\
\text { Radiostereometric analysis (RSA) will be used to measure micromotion along the three orthogonal axes of the } \\
\text { fracture fragments. RSA radiographs are obtained postoperatively, on the first day, after } 6 \text { weeks, } 4 \text { months } \\
\text { and one year } \\
\text { Local adverse events (cut-out, implant failure) }\end{array}$ \\
\hline Starting date & Not stated, trial registration: 16/02/2010 \\
\hline Contact information & Dr I B Schipper, Leiden University Medical Center, Leiden, The Netherlands \\
\hline Notes & \\
\hline
\end{tabular}


DATA AND ANALYSES

Comparison 1. Summary: Femoral nail (all types) versus sliding hip screw (SHS)

\begin{tabular}{|c|c|c|c|c|}
\hline Outcome or subgroup title & $\begin{array}{l}\text { No. of } \\
\text { studies }\end{array}$ & $\begin{array}{c}\text { No. of } \\
\text { participants }\end{array}$ & Statistical method & Effect size \\
\hline 1 Length of surgery (minutes) & 12 & 1899 & Mean Difference (IV, Random, 95\% CI) & $1.15[-9.85,12.16]$ \\
\hline 1.1 Gamma nail & 6 & 1045 & Mean Difference (IV, Random, 95\% CI) & $2.48[-3.60,8.56]$ \\
\hline $\begin{array}{l}1.2 \text { Intramedullary hip screw } \\
\text { (IMHS) }\end{array}$ & 3 & 337 & Mean Difference (IV, Random, 95\% CI) & $8.81[-7.43,25.05]$ \\
\hline $\begin{array}{l}1.3 \text { Proximal femoral nail } \\
(\mathrm{PFN})\end{array}$ & 1 & 206 & Mean Difference (IV, Random, 95\% CI) & $-1.0[-9.14,7.14]$ \\
\hline 1.5 Holland nail & 1 & 190 & Mean Difference (IV, Random, 95\% CI) & $13.70[8.15,19.25]$ \\
\hline $\begin{array}{l}\text { 1.6 Proximal femoral nail } \\
\text { antirotation }\end{array}$ & 1 & 121 & Mean Difference (IV, Random, 95\% CI) & $\begin{array}{l}-41.0[-45.11,- \\
36.89]\end{array}$ \\
\hline 2 Operative fracture of the femur & 26 & 3931 & Risk Ratio (M-H, Fixed, 95\% CI) & $3.16[1.73,5.79]$ \\
\hline $\begin{array}{l}\text { 2.1 Gamma nail (minus } \\
\text { Papasimos 2005, see } \\
\text { sub-category } 8 \text { ) }\end{array}$ & 17 & 2650 & Risk Ratio (M-H, Fixed, 95\% CI) & $3.02[1.48,6.14]$ \\
\hline $\begin{array}{l}2.2 \text { Intramedullary hip screw } \\
\text { (IMHS) }\end{array}$ & 5 & 627 & Risk Ratio (M-H, Fixed, 95\% CI) & $5.01[1.11,22.65]$ \\
\hline $\begin{array}{l}\text { 2.3 Proximal femoral nail } \\
(\mathrm{PFN}) \text { (minus Papasimos 2005, } \\
\text { see sub-category } 8 \text { ) }\end{array}$ & 1 & 206 & Risk Ratio (M-H, Fixed, 95\% CI) & Not estimable \\
\hline 2.7 Long Gamma nail & 1 & 210 & Risk Ratio (M-H, Fixed, 95\% CI) & Not estimable \\
\hline $\begin{array}{l}\text { 2.8 Three-group trial results: } \\
\text { Gamma nail or PFN }\end{array}$ & 1 & 120 & Risk Ratio (M-H, Fixed, 95\% CI) & $1.52[0.06,36.46]$ \\
\hline $\begin{array}{l}\text { 2.9 Two nail types (Gamma } \\
\text { or Endovis BA nail) }\end{array}$ & 1 & 118 & Risk Ratio (M-H, Fixed, 95\% CI) & $2.0[0.19,21.46]$ \\
\hline 3 Later fracture of the femur & 29 & 3849 & Risk Ratio (M-H, Fixed, 95\% CI) & $5.22[2.56,10.64]$ \\
\hline $\begin{array}{l}\text { 3.1 Gamma nail (minus } \\
\text { Papasimos 2005, see } \\
\text { sub-category 8) }\end{array}$ & 19 & 2593 & Risk Ratio (M-H, Fixed, 95\% CI) & $5.23[2.46,11.14]$ \\
\hline $\begin{array}{l}3.2 \text { Intramedullary hip screw } \\
\text { (IMHS) }\end{array}$ & 4 & 447 & Risk Ratio (M-H, Fixed, 95\% CI) & $5.12[0.61,43.33]$ \\
\hline $\begin{array}{l}\text { 3.3 Proximal femoral nail } \\
\text { (PFN) (minus Papasimos 2005, } \\
\text { see sub-category 8) }\end{array}$ & 1 & 108 & Risk Ratio (M-H, Fixed, 95\% CI) & Not estimable \\
\hline 3.4 Targon PF nail & 1 & 60 & Risk Ratio (M-H, Fixed, 95\% CI) & Not estimable \\
\hline 3.5 Holland nail & 1 & 190 & Risk Ratio (M-H, Fixed, 95\% CI) & Not estimable \\
\hline $\begin{array}{l}\text { 3.6 Proximal femoral nail } \\
\text { antirotation }\end{array}$ & 1 & 121 & Risk Ratio (M-H, Fixed, 95\% CI) & Not estimable \\
\hline 3.7 Long Gamma nail & 1 & 210 & Risk Ratio (M-H, Fixed, 95\% CI) & Not estimable \\
\hline $\begin{array}{l}\text { 3.8 Three-group trial results: } \\
\text { Gamma nail or PFN }\end{array}$ & 1 & 120 & Risk Ratio (M-H, Fixed, 95\% CI) & Not estimable \\
\hline $\begin{array}{l}4 \text { Cut-out (overall denominators } \\
\text { used) }\end{array}$ & 30 & 4324 & Risk Ratio (M-H, Fixed, 95\% CI) & $1.13[0.79,1.60]$ \\
\hline
\end{tabular}

Gamma and other cephalocondylic intramedullary nails versus extramedullary implants for extracapsular hip fractures in adults (Review) 86 Copyright (C) 2010 The Cochrane Collaboration. Published by John Wiley \& Sons, Ltd. 
Papasimos 2005, se sub-category 8 )

(PFN) (minus Papasimos 2005, see sub-category 8 )

4.4 Targon PF nail

4.5 Holland nail

4.6 Proximal femoral nail

5 Non-union (overall denominators used)

5.1 Gamma nail (minus

Papasimos 2005, see

sub-category 8)

5.2 Intramedullary hip screw (IMHS)

5.3 Proximal femoral nail

(PFN) (minus Papasimos 2005

see sub-category 8 )

5.4 Targon PF nail

5.6 Proximal femoral nail antirotation

5.7 Long Gamma nail

5.8 Three-group trial results:

Gamma nail or PFN

6 Reoperation (overall

denominators used)

6.1 Gamma nail (minus

Papasimos 2005, see

sub-category 8)

6.2 Intramedullary hip screw (IMHS)

6.3 Proximal femoral nail

(PFN) (minus Papasimos 2005 ,

see sub-category 8 )

6.4 Targon PF nail

6.5 Holland nail

6.6 Proximal femoral nail

antirotation

6.7 Long Gamma nail

6.8 Three-group trial results:

Gamma nail or PFN

7 Deep wound infection

7.1 Gamma nail
Risk Ratio (M-H, Fixed, 95\% CI)

Risk Ratio (M-H, Fixed, 95\% CI)

Risk Ratio (M-H, Fixed, 95\% CI)

Risk Ratio (M-H, Fixed, 95\% CI)

Risk Ratio (M-H, Fixed, 95\% CI)

Risk Ratio (M-H, Fixed, 95\% CI)

Risk Ratio (M-H, Fixed, 95\% CI)

Risk Ratio (M-H, Fixed, 95\% CI)

Risk Ratio (M-H, Fixed, 95\% CI)

Risk Ratio (M-H, Fixed, 95\% CI)

Risk Ratio (M-H, Fixed, 95\% CI)

Risk Ratio (M-H, Fixed, 95\% CI)

Risk Ratio (M-H, Fixed, 95\% CI)

Risk Ratio (M-H, Fixed, 95\% CI)

2684

Risk Ratio (M-H, Fixed, 95\% CI)

Risk Ratio (M-H, Fixed, 95\% CI)

Risk Ratio (M-H, Fixed, 95\% CI)
Risk Ratio (M-H, Fixed, 95\% CI) Risk Ratio (M-H, Fixed, 95\% CI) Risk Ratio (M-H, Fixed, 95\% CI)

Risk Ratio (M-H, Fixed, 95\% CI)

Risk Ratio (M-H, Fixed, 95\% CI)

Risk Ratio (M-H, Fixed, 95\% CI) Risk Ratio (M-H, Fixed, 95\% CI)
$1.15[0.21,6.37]$

$0.21[0.01,4.38]$

Not estimable

$1.65[0.28,9.67]$

$0.75[0.13,4.31]$

$0.84[0.34,2.10]$

$1.00[0.25,3.93]$

$1.02[0.21,4.95]$

Not estimable

Not estimable $0.36[0.02,8.70]$

Not estimable $0.5[0.03,7.79]$

$1.49[1.12,1.98]$

$1.71[1.22,2.40]$

$0.53[0.15,1.88]$

$2.07[0.64,6.73]$

$1.15[0.21,6.37]$

$0.35[0.01,8.60]$

$0.15[0.01,2.94]$

$1.65[0.28,9.67]$

$1.33[0.37,4.75]$

$1.08[0.54,2.17]$

$0.99[0.46,2.17]$

Gamma and other cephalocondylic intramedullary nails versus extramedullary implants for extracapsular hip fractures in adults (Review) 87 Copyright (C) 2010 The Cochrane Collaboration. Published by John Wiley \& Sons, Ltd. 


\begin{tabular}{|c|c|c|c|c|}
\hline $\begin{array}{l}7.2 \text { Intramedullary hip screw } \\
\text { (IMHS) }\end{array}$ & 3 & 390 & Risk Ratio (M-H, Fixed, 95\% CI) & $0.33[0.01,8.08]$ \\
\hline $\begin{array}{l}7.3 \text { Proximal femoral nail } \\
(\mathrm{PFN})\end{array}$ & 2 & 276 & Risk Ratio (M-H, Fixed, 95\% CI) & $3.38[0.36,31.84]$ \\
\hline 7.4 Targon PF nail & 1 & 60 & Risk Ratio (M-H, Fixed, 95\% CI) & Not estimable \\
\hline 7.5 Holland nail & 1 & 190 & Risk Ratio (M-H, Fixed, 95\% CI) & Not estimable \\
\hline $\begin{array}{l}\text { 7.6 Proximal femoral nail } \\
\text { antirotation }\end{array}$ & 1 & 121 & Risk Ratio (M-H, Fixed, 95\% CI) & Not estimable \\
\hline 7.7 Long Gamma nail & 1 & 210 & Risk Ratio (M-H, Fixed, 95\% CI) & Not estimable \\
\hline 8 Mortality & 26 & 3641 & Risk Ratio (M-H, Fixed, 95\% CI) & $1.00[0.88,1.15]$ \\
\hline 8.1 Gamma nail & 16 & 2306 & Risk Ratio (M-H, Fixed, 95\% CI) & $0.95[0.81,1.12]$ \\
\hline $\begin{array}{l}8.2 \text { Intramedullary hip screw } \\
\text { (IMHS) }\end{array}$ & 4 & 443 & Risk Ratio (M-H, Fixed, 95\% CI) & $0.91[0.67,1.24]$ \\
\hline $\begin{array}{l}8.3 \text { Proximal femoral nail } \\
(\mathrm{PFN})\end{array}$ & 2 & 314 & Risk Ratio (M-H, Fixed, 95\% CI) & $1.40[0.75,2.62]$ \\
\hline 8.4 Targon PF nail & 1 & 60 & Risk Ratio (M-H, Fixed, 95\% CI) & $1.53[0.15,15.97]$ \\
\hline 8.5 Holland nail & 1 & 190 & Risk Ratio (M-H, Fixed, 95\% CI) & $1.00[0.54,1.86]$ \\
\hline 8.7 Long Gamma nail & 1 & 210 & Risk Ratio (M-H, Fixed, 95\% CI) & $1.47[0.93,2.31]$ \\
\hline $\begin{array}{l}8.8 \text { Two nail types (Gamma } \\
\text { or Endovis BA nail) }\end{array}$ & 1 & 118 & Risk Ratio (M-H, Fixed, 95\% CI) & $1.0[0.06,15.61]$ \\
\hline 9 Pain at follow-up & 8 & 897 & Risk Ratio (M-H, Fixed, 95\% CI) & $1.10[0.93,1.30]$ \\
\hline 9.1 Gamma nail & 5 & 634 & Risk Ratio (M-H, Fixed, 95\% CI) & $1.08[0.90,1.30]$ \\
\hline $\begin{array}{l}9.2 \text { Intramedullary hip screw } \\
\text { (IMHS) }\end{array}$ & 3 & 263 & Risk Ratio (M-H, Fixed, 95\% CI) & $1.17[0.79,1.75]$ \\
\hline $\begin{array}{l}10 \text { Non return to previous } \\
\text { residence or dead }\end{array}$ & 9 & 1070 & Risk Ratio (M-H, Fixed, 95\% CI) & $1.01[0.88,1.16]$ \\
\hline 10.1 Gamma nail & 4 & 439 & Risk Ratio (M-H, Fixed, 95\% CI) & $0.90[0.70,1.15]$ \\
\hline $\begin{array}{l}10.2 \text { Intramedullary hip screw } \\
\text { (IMHS) }\end{array}$ & 3 & 330 & Risk Ratio (M-H, Fixed, 95\% CI) & $1.04[0.82,1.33]$ \\
\hline $\begin{array}{l}10.3 \text { Proximal femoral nail } \\
\text { (PFN) }\end{array}$ & 2 & 301 & Risk Ratio (M-H, Fixed, 95\% CI) & $1.11[0.89,1.39]$ \\
\hline
\end{tabular}

Comparison 2. Gamma nail versus sliding hip screw (SHS)

\begin{tabular}{|c|c|c|c|c|}
\hline Outcome or subgroup title & $\begin{array}{l}\text { No. of } \\
\text { studies }\end{array}$ & $\begin{array}{c}\text { No. of } \\
\text { participants }\end{array}$ & Statistical method & Effect size \\
\hline 1 Length of surgery (minutes) & 6 & 1045 & Mean Difference (IV, Random, 95\% CI) & $2.48[-3.60,8.56]$ \\
\hline 2 Blood loss (ml) & 5 & 953 & Mean Difference (IV, Random, 95\% CI) & $\begin{array}{l}-29.04[-73.17 \\
15.10]\end{array}$ \\
\hline $\begin{array}{l}3 \text { Number of people given } \\
\text { transfusion }\end{array}$ & 3 & 756 & Risk Ratio (M-H, Random, 95\% CI) & $1.06[0.67,1.68]$ \\
\hline $\begin{array}{l}4 \text { Radiographic screening time } \\
\text { (seconds) }\end{array}$ & 4 & & Mean Difference (IV, Fixed, 95\% CI) & Totals not selected \\
\hline 5 Operative fracture of femur & 18 & 2730 & Risk Ratio (M-H, Fixed, 95\% CI) & $3.02[1.51,6.03]$ \\
\hline 5.1 Gamma 1 nail & 15 & 2294 & Risk Ratio (M-H, Fixed, 95\% CI) & $3.26[1.49,7.16]$ \\
\hline 5.2 Trochanteric Gamma nail & 3 & 436 & Risk Ratio (M-H, Fixed, 95\% CI) & $2.23[0.51,9.78]$ \\
\hline
\end{tabular}

Gamma and other cephalocondylic intramedullary nails versus extramedullary implants for extracapsular hip fractures in adults (Review) 88 Copyright (@) 2010 The Cochrane Collaboration. Published by John Wiley \& Sons, Ltd. 
devices)

6.1 Experienced surgeon (low

risk of bias)

6.2 Not experienced surgeon

Risk Ratio (M-H, Fixed, 95\% CI)

$5.05[1.47,17.29]$

(high/unclear risk of bias)

6.3 Mixed experience (high 2

Risk Ratio (M-H, Fixed, 95\% CI)

$1.5[0.26,8.77]$

risk of bias)

7 Later fracture of femur

Risk Ratio (M-H, Fixed, 95\% CI)

Risk Ratio (M-H, Fixed, 95\% CI)

9 Cut-out (reported experience

2695

with devices)

9.1 Experienced surgeon (low

Risk Ratio (M-H, Fixed, 95\% CI)

$5.23[2.46,11.14]$

$1.15[0.76,1.72]$

$1.15[0.76,1.72]$

risk of bias)

1127

Risk Ratio (M-H, Fixed, 95\% CI)

$1.04[0.52,2.08]$

9.2 Not experienced surgeon

Risk Ratio (M-H, Fixed, 95\% CI)

$1.37[0.80,2.36]$

(high/unclear risk of bias)

9.3 Mixed experience (high

risk of bias)

10 Non-union

11 Reoperation

11.1 Gamma 1 nail
11.2 Trochanteric Gamma
nail

nail

12 Wound infection or haematoma

12.1 Wound infection - any 14 type

12.2 Deep wound infection 12.3 Wound haematoma

13 Pneumonia

14 Pressure sore

15 Thromboembolic

complications

15.1 Thromboembolic

complication

15.2 Deep vein thrombosis

15.3 Pulmonary embolism

16 Any medical complication

(other than wound infection or haematoma)

17 Length of hospital stay (days)

18 Anatomical deformity

18.1 Shortening of leg

18.2 Varus deformity

18.3 External rotational

deformity

19 Mortality

20 Mortality (grouped by

allocation concealment)

20.1 Allocation concealment:

fully concealed

289

1050

2665

2276

389

1794

1869

819

921

466

12

11

1627

1506

401

629

620

335

679

229

$16 \quad 2306$

$16 \quad 2306$

4
Risk Ratio (M-H, Fixed, 95\% CI)

Risk Ratio (M-H, Fixed, 95\% CI)

Risk Ratio (M-H, Fixed, 95\% CI)

Risk Ratio (M-H, Fixed, 95\% CI)

Risk Ratio (M-H, Fixed, 95\% CI)

Risk Ratio (M-H, Fixed, 95\% CI)

Risk Ratio (M-H, Fixed, 95\% CI)

Risk Ratio (M-H, Fixed, 95\% CI)

Risk Ratio (M-H, Fixed, 95\% CI)

Risk Ratio (M-H, Fixed, 95\% CI)

Risk Ratio (M-H, Fixed, 95\% CI)

Risk Ratio (M-H, Fixed, 95\% CI)

Risk Ratio (M-H, Fixed, 95\% CI)

Risk Ratio (M-H, Fixed, 95\% CI)

Risk Ratio (M-H, Fixed, 95\% CI)

Risk Ratio (M-H, Random, 95\% CI)

Mean Difference (IV, Fixed, 95\% CI)

Risk Ratio (M-H, Fixed, 95\% CI)

Risk Ratio (M-H, Fixed, 95\% CI)

Risk Ratio (M-H, Fixed, 95\% CI)

Risk Ratio (M-H, Fixed, 95\% CI)

Risk Ratio (M-H, Fixed, 95\% CI)

Risk Ratio (M-H, Fixed, 95\% CI)

Risk Ratio (M-H, Fixed, 95\% CI)

$0.51[0.11,2.28]$

$0.97[0.29,3.31]$

$1.66[1.19,2.31]$

$1.80[1.24,2.62]$

$1.23[0.61,2.47]$

Subtotals only $0.97[0.62,1.50]$

$0.99[0.46,2.17]$

$0.78[0.34,1.79]$

$0.93[0.47,1.83]$

$0.67[0.32,1.42]$

Subtotals only

$1.46[0.90,2.36]$

$1.26[0.77,2.06]$

$1.97[0.50,7.82]$

$1.13[0.69,1.84]$

$-0.13[-1.50,1.24]$

Subtotals only

$0.46[0.21,1.03]$

$0.68[0.34,1.37]$

$1.09[0.28,4.19]$

$0.95[0.81,1.12]$

$0.95[0.81,1.12]$

$1.07[0.81,1.41]$ 


\begin{tabular}{|c|c|c|c|c|}
\hline $\begin{array}{l}20.2 \text { Allocation concealment: } \\
\text { unclear }\end{array}$ & 6 & 943 & Risk Ratio (M-H, Fixed, 95\% CI) & $0.88[0.68,1.14]$ \\
\hline $\begin{array}{l}20.3 \text { Allocation concealment: } \\
\text { not concealed }\end{array}$ & 6 & 649 & Risk Ratio (M-H, Fixed, 95\% CI) & $0.93[0.66,1.31]$ \\
\hline 21 Pain at follow-up & 5 & 634 & Risk Ratio (M-H, Fixed, 95\% CI) & $1.08[0.90,1.30]$ \\
\hline $\begin{array}{l}22 \text { Non-return to previous } \\
\text { residence }\end{array}$ & 4 & & Risk Ratio (M-H, Fixed, 95\% CI) & Subtotals only \\
\hline $\begin{array}{l}22.1 \text { Non-return to previous } \\
\text { residence (survivors) }\end{array}$ & 3 & 189 & Risk Ratio (M-H, Fixed, 95\% CI) & $0.71[0.39,1.31]$ \\
\hline $\begin{array}{l}22.2 \text { Non-return to previous } \\
\text { residence or dead }\end{array}$ & 4 & 439 & Risk Ratio (M-H, Fixed, 95\% CI) & $0.90[0.70,1.15]$ \\
\hline 23 Impaired walking & 8 & & Risk Ratio (M-H, Fixed, 95\% CI) & Subtotals only \\
\hline 23.1 Impaired walking & 8 & 984 & Risk Ratio (M-H, Fixed, 95\% CI) & $0.99[0.89,1.10]$ \\
\hline $\begin{array}{l}23.2 \text { Impaired walking } \\
\text { (overall denominators used) }\end{array}$ & 8 & 1311 & Risk Ratio (M-H, Fixed, 95\% CI) & $1.00[0.89,1.13]$ \\
\hline
\end{tabular}

Comparison 3. Intramedullary hip screw (IMHS) versus sliding hip screw (SHS)

\begin{tabular}{|c|c|c|c|c|}
\hline Outcome or subgroup title & $\begin{array}{l}\text { No. of } \\
\text { studies }\end{array}$ & $\begin{array}{c}\text { No. of } \\
\text { participants }\end{array}$ & Statistical method & Effect size \\
\hline 1 Length of surgery (minutes) & 3 & 337 & Mean Difference (IV, Random, 95\% CI) & $8.81[-7.43,25.05]$ \\
\hline 2 Blood loss (ml) & 2 & 235 & Mean Difference (IV, Fixed, 95\% CI) & $\begin{array}{l}-62.42[-98.56,- \\
26.28]\end{array}$ \\
\hline 3 Transfusion (units of red cells) & 2 & 235 & Mean Difference (IV, Random, 95\% CI) & $-0.00[-0.68,0.67]$ \\
\hline 4 Number of patients transfused & 1 & & Risk Ratio (M-H, Fixed, 95\% CI) & Totals not selected \\
\hline $\begin{array}{l}5 \text { Radiographic screening time } \\
\text { (minutes) }\end{array}$ & 2 & 237 & Mean Difference (IV, Fixed, 95\% CI) & $1.15[0.83,1.47]$ \\
\hline 6 Fracture fixation complications & 5 & & Risk Ratio (M-H, Fixed, 95\% CI) & Subtotals only \\
\hline $\begin{array}{l}\text { 6.1 Operative fracture of } \\
\text { femur }\end{array}$ & 5 & 627 & Risk Ratio (M-H, Fixed, 95\% CI) & $5.01[1.11,22.65]$ \\
\hline 6.2 Later fracture of femur & 4 & 447 & Risk Ratio (M-H, Fixed, 95\% CI) & $5.12[0.61,43.33]$ \\
\hline 6.3 Cut-out & 4 & 517 & Risk Ratio (M-H, Fixed, 95\% CI) & $0.83[0.24,2.84]$ \\
\hline 6.4 Non-union & 3 & 307 & Risk Ratio (M-H, Fixed, 95\% CI) & $1.02[0.21,4.95]$ \\
\hline $\begin{array}{l}\text { 6.5 Detachment of the plate } \\
\text { from the femur }\end{array}$ & 1 & 102 & Risk Ratio (M-H, Fixed, 95\% CI) & $0.35[0.01,8.31]$ \\
\hline 6.6 Reoperation & 2 & 210 & Risk Ratio (M-H, Fixed, 95\% CI) & $0.53[0.15,1.88]$ \\
\hline 7 Wound infection or haematoma & 4 & & Risk Ratio (M-H, Fixed, 95\% CI) & Subtotals only \\
\hline $\begin{array}{l}7.1 \text { Wound infection - any } \\
\text { type }\end{array}$ & 3 & 390 & Risk Ratio (M-H, Fixed, 95\% CI) & $0.4[0.08,2.01]$ \\
\hline 7.2 Deep wound infection & 3 & 390 & Risk Ratio (M-H, Fixed, 95\% CI) & $0.33[0.01,8.08]$ \\
\hline 7.3 Wound haematoma & 3 & 345 & Risk Ratio (M-H, Fixed, 95\% CI) & $1.47[0.54,4.02]$ \\
\hline 8 Post-operative complications & 3 & & Risk Ratio (M-H, Fixed, 95\% CI) & Subtotals only \\
\hline 8.1 Pneumonia & 2 & 210 & Risk Ratio (M-H, Fixed, 95\% CI) & $0.99[0.35,2.83]$ \\
\hline $\begin{array}{l}8.2 \text { Thromboembolic } \\
\text { complication }\end{array}$ & 1 & 100 & Risk Ratio (M-H, Fixed, 95\% CI) & $0.5[0.05,5.34]$ \\
\hline 8.3 Deep vein thrombosis & 2 & 210 & Risk Ratio (M-H, Fixed, 95\% CI) & $0.99[0.17,5.62]$ \\
\hline 8.4 Pulmonary embolism & 1 & 100 & Risk Ratio (M-H, Fixed, 95\% CI) & $0.33[0.01,7.99]$ \\
\hline
\end{tabular}

Gamma and other cephalocondylic intramedullary nails versus extramedullary implants for extracapsular hip fractures in adults (Review) 90 Copyright (@) 2010 The Cochrane Collaboration. Published by John Wiley \& Sons, Ltd. 


\begin{tabular}{|c|c|c|c|c|}
\hline $\begin{array}{l}8.5 \text { Major medical } \\
\text { complication }\end{array}$ & 2 & 245 & Risk Ratio (M-H, Fixed, 95\% CI) & $1.16[0.64,2.10]$ \\
\hline 9 Length of hospital stay (days) & 2 & 237 & Mean Difference (IV, Fixed, 95\% CI) & $1.00[-1.37,3.37]$ \\
\hline 10 Mean limb shortening $(\mathrm{cm})$ & 1 & & Mean Difference (IV, Fixed, 95\% CI) & Totals not selected \\
\hline 11 Final outcome measures & 4 & & Risk Ratio (M-H, Fixed, 95\% CI) & Subtotals only \\
\hline 11.1 Mortality & 4 & 443 & Risk Ratio (M-H, Fixed, 95\% CI) & $0.91[0.67,1.24]$ \\
\hline 11.2 Pain & 3 & 263 & Risk Ratio (M-H, Fixed, 95\% CI) & $1.17[0.79,1.75]$ \\
\hline $\begin{array}{l}11.3 \text { Failure to return home } \\
\text { (survivors) }\end{array}$ & 3 & 256 & Risk Ratio (M-H, Fixed, 95\% CI) & $1.16[0.78,1.73]$ \\
\hline $\begin{array}{l}11.4 \text { Failure to return home } \\
\text { or dead }\end{array}$ & 3 & 330 & Risk Ratio (M-H, Fixed, 95\% CI) & $1.04[0.82,1.33]$ \\
\hline $\begin{array}{l}11.5 \text { Failure to return home } \\
\text { or dead (overall denominators } \\
\text { used) }\end{array}$ & 3 & 341 & Risk Ratio (M-H, Fixed, 95\% CI) & $1.00[0.79,1.28]$ \\
\hline 11.6 Failure to regain mobility & 1 & 105 & Risk Ratio (M-H, Fixed, 95\% CI) & $0.96[0.53,1.73]$ \\
\hline 11.7 Poor mobility & 1 & 88 & Risk Ratio (M-H, Fixed, 95\% CI) & $0.80[0.48,1.35]$ \\
\hline
\end{tabular}

Comparison 4. Proximal femoral nail (PFN) versus sliding hip screw (SHS)

\begin{tabular}{|c|c|c|c|c|}
\hline Outcome or subgroup title & $\begin{array}{l}\text { No. of } \\
\text { studies }\end{array}$ & $\begin{array}{c}\text { No. of } \\
\text { participants }\end{array}$ & Statistical method & Effect size \\
\hline 1 Length of surgery (minutes) & 1 & & Mean Difference (IV, Fixed, 95\% CI) & Totals not selected \\
\hline 2 Blood loss and transfusion & 2 & & Mean Difference (IV, Fixed, 95\% CI) & Subtotals only \\
\hline 2.1 Blood loss (ml) & 1 & 108 & Mean Difference (IV, Fixed, 95\% CI) & $\begin{array}{l}-37.0[-192.78 \\
118.78]\end{array}$ \\
\hline $\begin{array}{l}2.2 \text { Transfusion (units of red } \\
\text { blood cells) }\end{array}$ & 2 & 314 & Mean Difference (IV, Fixed, 95\% CI) & $-0.20[-0.62,0.22]$ \\
\hline 3 Number of patients transfused & 1 & & Risk Ratio (M-H, Fixed, 95\% CI) & Subtotals only \\
\hline $\begin{array}{l}4 \text { Radiographic screening time } \\
\text { (minutes) }\end{array}$ & 1 & & Mean Difference (IV, Fixed, 95\% CI) & Totals not selected \\
\hline 5 Fracture fixation complications & 3 & & Risk Ratio (M-H, Fixed, 95\% CI) & Subtotals only \\
\hline 5.1 Operative fracture femur & 1 & 80 & Risk Ratio (M-H, Fixed, 95\% CI) & Not estimable \\
\hline 5.2 Later fracture of femur & 2 & 188 & Risk Ratio (M-H, Fixed, 95\% CI) & Not estimable \\
\hline 5.3 Cut-out & 3 & 356 & Risk Ratio (M-H, Fixed, 95\% CI) & $1.31[0.36,4.75]$ \\
\hline $\begin{array}{l}\text { 5.4 Cut-out: overall } \\
\text { denominators used }\end{array}$ & 3 & 394 & Risk Ratio (M-H, Fixed, 95\% CI) & $1.28[0.35,4.67]$ \\
\hline 5.5 Non-union & 2 & 248 & Risk Ratio (M-H, Fixed, 95\% CI) & $0.33[0.01,7.95]$ \\
\hline 5.6 Reoperation & 3 & 356 & Risk Ratio (M-H, Fixed, 95\% CI) & $1.94[0.80,4.71]$ \\
\hline $\begin{array}{l}5.7 \text { Reoperation: overall } \\
\text { denominators used }\end{array}$ & 3 & 394 & Risk Ratio (M-H, Fixed, 95\% CI) & $1.90[0.78,4.62]$ \\
\hline 6 Wound infection or haematoma & 3 & & Risk Ratio (M-H, Fixed, 95\% CI) & Subtotals only \\
\hline $\begin{array}{l}\text { 6.1 Superficial wound } \\
\text { infection }\end{array}$ & 2 & 188 & Risk Ratio (M-H, Fixed, 95\% CI) & $1.0[0.06,15.44]$ \\
\hline 6.2 Deep wound infection & 2 & 276 & Risk Ratio (M-H, Fixed, 95\% CI) & $3.38[0.36,31.84]$ \\
\hline 6.3 Haematoma & 1 & 80 & Risk Ratio (M-H, Fixed, 95\% CI) & $1.0[0.21,4.66]$ \\
\hline 7 Post-operative complications & 3 & & Risk Ratio (M-H, Fixed, 95\% CI) & Subtotals only \\
\hline 7.1 Pneumonia & 2 & 286 & Risk Ratio (M-H, Fixed, 95\% CI) & $1.06[0.39,2.91]$ \\
\hline 7.2 Pressure sores & 1 & 206 & Risk Ratio (M-H, Fixed, 95\% CI) & $0.80[0.18,3.46]$ \\
\hline
\end{tabular}

Gamma and other cephalocondylic intramedullary nails versus extramedullary implants for extracapsular hip fractures in adults (Review) 9 I Copyright (@) 2010 The Cochrane Collaboration. Published by John Wiley \& Sons, Ltd. 


\begin{tabular}{|c|c|c|c|c|}
\hline 7.3 Deep vein thrombosis & 3 & 394 & Risk Ratio (M-H, Fixed, 95\% CI) & $0.68[0.12,3.98]$ \\
\hline 7.4 Pulmonary embolism & 2 & 286 & Risk Ratio (M-H, Fixed, 95\% CI) & $0.68[0.12,3.98]$ \\
\hline 7.5 Urinary tract infection & 2 & 286 & Risk Ratio (M-H, Fixed, 95\% CI) & $1.48[0.95,2.30]$ \\
\hline 7.6 Any medical complication & 1 & 206 & Risk Ratio (M-H, Fixed, 95\% CI) & $1.12[0.85,1.49]$ \\
\hline Length of hospital stay (days) & 2 & 314 & Mean Difference (IV, Fixed, 95\% CI) & $0.27[-0.76,1.30]$ \\
\hline Final outcome measures & 3 & & Risk Ratio (M-H, Fixed, 95\% CI) & Totals not selected \\
\hline 9.1 Mortality in hospital & 1 & & Risk Ratio (M-H, Fixed, 95\% CI) & Not estimable \\
\hline 9.2 Mortality at 4 months & 1 & & Risk Ratio (M-H, Fixed, 95\% CI) & Not estimable \\
\hline 9.3 Mortality at 1 year & 1 & & Risk Ratio (M-H, Fixed, 95\% CI) & Not estimable \\
\hline 9.4 In nursing home at 1 year & 1 & & Risk Ratio (M-H, Fixed, 95\% CI) & Not estimable \\
\hline $\begin{array}{l}9.5 \text { In nursing home or dead } \\
\text { at } 1 \text { year }\end{array}$ & 1 & & Risk Ratio (M-H, Fixed, 95\% CI) & Not estimable \\
\hline $\begin{array}{l}9.6 \text { In nursing home or dead } \\
\text { at } 1 \text { year (overall denominators } \\
\text { used) }\end{array}$ & 1 & & Risk Ratio (M-H, Fixed, 95\% CI) & Not estimable \\
\hline $\begin{array}{l}9.7 \text { Failure to regain } \\
\text { pre-fracture residential status at } \\
4 \text { months }\end{array}$ & 1 & & Risk Ratio (M-H, Fixed, 95\% CI) & Not estimable \\
\hline $\begin{array}{l}9.8 \text { Failure to regain } \\
\text { pre-fracture residential status, } \\
\text { seriously ill or dead at } 4 \text { months }\end{array}$ & 1 & & Risk Ratio (M-H, Fixed, 95\% CI) & Not estimable \\
\hline $\begin{array}{l}9.9 \text { Failure to recover previous } \\
\text { mobility at } 4 \text { months }\end{array}$ & 1 & & Risk Ratio (M-H, Fixed, 95\% CI) & Not estimable \\
\hline $\begin{array}{l}9.10 \text { Failure to recover } \\
\text { previous mobility or dead at } 4 \\
\text { months (overall denominators } \\
\text { used) }\end{array}$ & 1 & & Risk Ratio (M-H, Fixed, 95\% CI) & Not estimable \\
\hline
\end{tabular}

Comparison 5. Proximal femoral nail antirotation (PFNA) versus sliding hip screw (SHS)

\begin{tabular}{|c|c|c|c|c|}
\hline Outcome or subgroup title & $\begin{array}{l}\text { No. of } \\
\text { studies }\end{array}$ & $\begin{array}{c}\text { No. of } \\
\text { participants }\end{array}$ & Statistical method & Effect size \\
\hline 1 Length of surgery (minutes) & 1 & & Mean Difference (IV, Fixed, 95\% CI) & Totals not selected \\
\hline 2 Operative blood loss (ml) & 1 & & Mean Difference (IV, Fixed, 95\% CI) & Totals not selected \\
\hline $\begin{array}{l}3 \text { Radiographic screening time } \\
\text { (minutes) }\end{array}$ & 1 & & Mean Difference (IV, Fixed, 95\% CI) & Totals not selected \\
\hline 4 Fracture fixation complications & 1 & & Risk Ratio (M-H, Fixed, 95\% CI) & Totals not selected \\
\hline 4.1 Cut-out of the implant & 1 & & Risk Ratio (M-H, Fixed, 95\% CI) & Not estimable \\
\hline 4.2 Later fracture of the femur & 1 & & Risk Ratio (M-H, Fixed, 95\% CI) & Not estimable \\
\hline 4.3 Fracture non-union & 1 & & Risk Ratio (M-H, Fixed, 95\% CI) & Not estimable \\
\hline $\begin{array}{l}\text { 4.4 Breakage of implant } \\
\text { and/or detachment of the plate } \\
\text { from the femur }\end{array}$ & 1 & & Risk Ratio (M-H, Fixed, 95\% CI) & Not estimable \\
\hline $\begin{array}{l}4.5 \text { Reoperation for fracture } \\
\text { fixation complications }\end{array}$ & 1 & & Risk Ratio (M-H, Fixed, 95\% CI) & Not estimable \\
\hline 5 Wound infection & 1 & & Risk Ratio (M-H, Fixed, 95\% CI) & Totals not selected \\
\hline $\begin{array}{l}5.1 \text { Superficial wound } \\
\text { infection }\end{array}$ & 1 & & Risk Ratio (M-H, Fixed, 95\% CI) & Not estimable \\
\hline
\end{tabular}

Gamma and other cephalocondylic intramedullary nails versus extramedullary implants for extracapsular hip fractures in adults (Review) 92 Copyright $\odot 2010$ The Cochrane Collaboration. Published by John Wiley \& Sons, Ltd. 
5.2 Deep wound infection

6 Post-operative complications

6.1 Deep vein thrombosis

7 Poor or fair hip function score (1 year)
Risk Ratio (M-H, Fixed, 95\% CI)

Risk Ratio (M-H, Fixed, 95\% CI)

Risk Ratio (M-H, Fixed, 95\% CI)

Risk Ratio (M-H, Fixed, 95\% CI)
Not estimable

Totals not selected

Not estimable

Totals not selected

Comparison 6. Targon PF (proximal femoral) nail versus sliding hip screw (SHS)

\begin{tabular}{|c|c|c|c|c|}
\hline Outcome or subgroup title & $\begin{array}{l}\text { No. of } \\
\text { studies }\end{array}$ & $\begin{array}{c}\text { No. of } \\
\text { participants }\end{array}$ & Statistical method & Effect size \\
\hline 1 Fracture fixation complications & 1 & & Risk Ratio (M-H, Fixed, 95\% CI) & Totals not selected \\
\hline 1.1 Later fracture of the femur & 1 & & Risk Ratio (M-H, Fixed, 95\% CI) & Not estimable \\
\hline 1.2 Cut-out & 1 & & Risk Ratio (M-H, Fixed, 95\% CI) & Not estimable \\
\hline 1.3 Non-union & 1 & & Risk Ratio (M-H, Fixed, 95\% CI) & Not estimable \\
\hline 1.4 Reoperation & 1 & & Risk Ratio (M-H, Fixed, 95\% CI) & Not estimable \\
\hline 2 Wound infection & 1 & & Risk Ratio (M-H, Fixed, 95\% CI) & Totals not selected \\
\hline 2.1 All wound infections & 1 & & Risk Ratio (M-H, Fixed, 95\% CI) & Not estimable \\
\hline 2.2 Deep wound infection & 1 & & Risk Ratio (M-H, Fixed, 95\% CI) & Not estimable \\
\hline 3 Post-operative compiications & 1 & & Risk Ratio (M-H, Fixed, 95\% CI) & Totals not selected \\
\hline 3.1 Pneumonia & 1 & & Risk Ratio (M-H, Fixed, 95\% CI) & Not estimable \\
\hline 3.2 Deep vein thrombosis & 1 & & Risk Ratio (M-H, Fixed, 95\% CI) & Not estimable \\
\hline 4 Mortality (3 months) & 1 & & Risk Ratio (M-H, Fixed, 95\% CI) & Totals not selected \\
\hline
\end{tabular}

Comparison 7. Holland nail versus sliding hip screw (SHS)

\begin{tabular}{|c|c|c|c|c|}
\hline Outcome or subgroup title & $\begin{array}{l}\text { No. of } \\
\text { studies }\end{array}$ & $\begin{array}{c}\text { No. of } \\
\text { participants }\end{array}$ & Statistical method & Effect size \\
\hline $\begin{array}{l}1 \text { Length of anaesthesia and } \\
\text { surgery }\end{array}$ & 1 & & Mean Difference (IV, Fixed, 95\% CI) & Totals not selected \\
\hline $\begin{array}{l}\text { 1.1 Length of anaesthesia } \\
\text { (minutes) }\end{array}$ & 1 & & Mean Difference (IV, Fixed, 95\% CI) & Not estimable \\
\hline $\begin{array}{l}1.2 \text { Length of surgery } \\
\text { (minutes) }\end{array}$ & 1 & & Mean Difference (IV, Fixed, 95\% CI) & Not estimable \\
\hline $\begin{array}{l}2 \text { Radiographic screening time } \\
\text { (minutes) }\end{array}$ & 1 & & Mean Difference (IV, Fixed, 95\% CI) & Totals not selected \\
\hline 3 Blood loss (ml) & 1 & & Mean Difference (IV, Fixed, 95\% CI) & Totals not selected \\
\hline $\begin{array}{l}4 \text { Number of patients given } \\
\text { transfusion }\end{array}$ & 1 & & Risk Ratio (M-H, Fixed, 95\% CI) & Totals not selected \\
\hline 5 Days till mobilisation & 1 & & Mean Difference (IV, Fixed, 95\% CI) & Totals not selected \\
\hline 6 Fracture fixation complications & 1 & & Risk Ratio (M-H, Fixed, 95\% CI) & Totals not selected \\
\hline 6.1 Cut-out & 1 & & Risk Ratio (M-H, Fixed, 95\% CI) & Not estimable \\
\hline 6.2 Later fracture of femur & 1 & & Risk Ratio (M-H, Fixed, 95\% CI) & Not estimable \\
\hline 6.3 Reoperation & 1 & & Risk Ratio (M-H, Fixed, 95\% CI) & Not estimable \\
\hline 7 Wound infection & 1 & & Risk Ratio (M-H, Fixed, 95\% CI) & Totals not selected \\
\hline
\end{tabular}

Gamma and other cephalocondylic intramedullary nails versus extramedullary implants for extracapsular hip fractures in adults (Review) 93

Copyright (@) 2010 The Cochrane Collaboration. Published by John Wiley \& Sons, Ltd. 
7.1 Superficial wound infection

7.2 Deep wound infection

8 Postoperative complications

8.1 Pneumonia

8.2 Deep vein thrombosis

8.3 Pulmonary embolism

9 Final outcome measures

9.1 Mortality at 30 days

9.2 Mortality at one year

9.3 Failure to regain mobility

at one year (survivors)

10 Final outcome measures: mobility score (0 to 9: best result)
Risk Ratio (M-H, Fixed, 95\% CI)

Risk Ratio (M-H, Fixed, 95\% CI)

Risk Ratio (M-H, Fixed, 95\% CI)

Risk Ratio (M-H, Fixed, 95\% CI)

Risk Ratio (M-H, Fixed, 95\% CI)

Risk Ratio (M-H, Fixed, 95\% CI)

Risk Ratio (M-H, Fixed, 95\% CI)

Risk Ratio (M-H, Fixed, 95\% CI)

Risk Ratio (M-H, Fixed, 95\% CI)

Risk Ratio (M-H, Fixed, 95\% CI)

Mean Difference (IV, Fixed, 95\% CI)
Not estimable

Not estimable

Totals not selected

Not estimable

Not estimable

Not estimable

Totals not selected

Not estimable

Not estimable

Not estimable

Totals not selected

Comparison 8. Long Gamma nail versus sliding hip screw (SHS)

\begin{tabular}{|c|c|c|c|c|}
\hline Outcome or subgroup title & $\begin{array}{l}\text { No. of } \\
\text { studies }\end{array}$ & $\begin{array}{c}\text { No. of } \\
\text { participants }\end{array}$ & Statistical method & Effect size \\
\hline 1 Number of patients transfused & 1 & & Risk Ratio (M-H, Fixed, 95\% CI) & Totals not selected \\
\hline 2 Fracture fixation complications & 1 & & Risk Ratio (M-H, Fixed, 95\% CI) & Totals not selected \\
\hline $\begin{array}{l}2.1 \text { Operative fracture of } \\
\text { femur }\end{array}$ & 1 & & Risk Ratio (M-H, Fixed, 95\% CI) & Not estimable \\
\hline 2.2 Later fracture of the femur & 1 & & Risk Ratio (M-H, Fixed, 95\% CI) & Not estimable \\
\hline 2.3 Cut-out & 1 & & Risk Ratio (M-H, Fixed, 95\% CI) & Not estimable \\
\hline 2.4 Non-union & 1 & & Risk Ratio (M-H, Fixed, 95\% CI) & Not estimable \\
\hline 2.5 Reoperation & 1 & & Risk Ratio (M-H, Fixed, 95\% CI) & Not estimable \\
\hline 3 Wound infection & 1 & & Risk Ratio (M-H, Fixed, 95\% CI) & Totals not selected \\
\hline 3.1 Deep wound infection & 1 & & Risk Ratio (M-H, Fixed, 95\% CI) & Not estimable \\
\hline 4 Mortality (at one year) & 1 & & Risk Ratio (M-H, Fixed, 95\% CI) & Totals not selected \\
\hline
\end{tabular}

Comparison 9. Mini-invasive static (experimental) nail versus sliding hip screw (SHS)

\begin{tabular}{|c|c|c|c|c|}
\hline Outcome or subgroup title & $\begin{array}{l}\text { No. of } \\
\text { studies }\end{array}$ & $\begin{array}{c}\text { No. of } \\
\text { participants }\end{array}$ & Statistical method & Effect size \\
\hline 1 Length of surgery (minutes) & 1 & & Mean Difference (IV, Fixed, 95\% CI) & Totals not selected \\
\hline 2 Blood loss & 1 & & Mean Difference (IV, Fixed, 95\% CI) & Totals not selected \\
\hline 2.1 Operative blood loss (ml) & 1 & & Mean Difference (IV, Fixed, 95\% CI) & Not estimable \\
\hline 2.2 Total blood loss (ml) & 1 & & Mean Difference (IV, Fixed, 95\% CI) & Not estimable \\
\hline $\begin{array}{l}3 \text { Radiographic screening time } \\
\text { (seconds) }\end{array}$ & 1 & & Mean Difference (IV, Fixed, 95\% CI) & Totals not selected \\
\hline $\begin{array}{l}4 \text { Time to radiographic healing } \\
\text { (weeks) }\end{array}$ & 1 & & Mean Difference (IV, Fixed, 95\% CI) & Subtotals only \\
\hline 5 Mortality (6 months) & 1 & & Risk Ratio (M-H, Fixed, 95\% CI) & Subtotals only \\
\hline
\end{tabular}

Gamma and other cephalocondylic intramedullary nails versus extramedullary implants for extracapsular hip fractures in adults (Review) 94 Copyright $(2010$ The Cochrane Collaboration. Published by John Wiley \& Sons, Ltd. 


\begin{tabular}{|c|c|c|c|c|}
\hline Outcome or subgroup title & $\begin{array}{l}\text { No. of } \\
\text { studies }\end{array}$ & $\begin{array}{c}\text { No. of } \\
\text { participants }\end{array}$ & Statistical method & Effect size \\
\hline 1 Fracture fixation complications & 1 & & Risk Ratio (M-H, Fixed, 95\% CI) & Totals not selected \\
\hline 1.1 Cut-out & 1 & & Risk Ratio (M-H, Fixed, 95\% CI) & Not estimable \\
\hline $\begin{array}{l}1.2 \text { Implant breakage, bending } \\
\text { or uncoupling }\end{array}$ & 1 & & Risk Ratio (M-H, Fixed, 95\% CI) & Not estimable \\
\hline 1.3 Reoperation & 1 & & Risk Ratio (M-H, Fixed, 95\% CI) & Not estimable \\
\hline 2 Wound infection & 1 & & Risk Ratio (M-H, Fixed, 95\% CI) & Totals not selected \\
\hline $\begin{array}{l}2.1 \text { Superficial wound } \\
\text { infection }\end{array}$ & 1 & & Risk Ratio (M-H, Fixed, 95\% CI) & Not estimable \\
\hline 2.2 Deep wound infection & 1 & & Risk Ratio (M-H, Fixed, 95\% CI) & Not estimable \\
\hline 3 Post-operative complications & 1 & & Risk Ratio (M-H, Fixed, 95\% CI) & Totals not selected \\
\hline $\begin{array}{l}3.1 \text { Thromboembolic } \\
\text { complications }\end{array}$ & 1 & & Risk Ratio (M-H, Fixed, 95\% CI) & Not estimable \\
\hline 3.2 Pneumonia & 1 & & Risk Ratio (M-H, Fixed, 95\% CI) & Not estimable \\
\hline 3.3 Pressure sores & 1 & & Risk Ratio (M-H, Fixed, 95\% CI) & Not estimable \\
\hline 3.4 Urinary infection & 1 & & Risk Ratio (M-H, Fixed, 95\% CI) & Not estimable \\
\hline 4 Anatomical deformity & 1 & & Risk Ratio (M-H, Fixed, 95\% CI) & Totals not selected \\
\hline 4.1 Leg shortening $>2.5 \mathrm{~cm}$ & 1 & & Risk Ratio (M-H, Fixed, 95\% CI) & Not estimable \\
\hline $\begin{array}{l}\text { 4.2 Varus deformity > } 15 \\
\text { degrees }\end{array}$ & 1 & & Risk Ratio (M-H, Fixed, 95\% CI) & Not estimable \\
\hline $\begin{array}{l}\text { 4.3 External rotation } \\
\text { deformity }>15 \text { degrees }\end{array}$ & 1 & & Risk Ratio (M-H, Fixed, 95\% CI) & Not estimable \\
\hline 5 Final outcome measures ( 1 year) & 1 & & Risk Ratio (M-H, Fixed, 95\% CI) & Totals not selected \\
\hline 5.1 Mortality & 1 & & Risk Ratio (M-H, Fixed, 95\% CI) & Not estimable \\
\hline $\begin{array}{l}5.2 \text { Failure to regain } \\
\text { pre-fracture mobility }\end{array}$ & 1 & & Risk Ratio (M-H, Fixed, 95\% CI) & Not estimable \\
\hline $\begin{array}{l}5.3 \text { Death or failure to regain } \\
\text { pre-fracture mobility }\end{array}$ & 1 & & Risk Ratio (M-H, Fixed, 95\% CI) & Not estimable \\
\hline
\end{tabular}

Comparison 11. Two nail types versus sliding hip screw (SHS)

\begin{tabular}{|c|c|c|c|c|}
\hline Outcome or subgroup title & $\begin{array}{l}\text { No. of } \\
\text { studies }\end{array}$ & $\begin{array}{c}\text { No. of } \\
\text { participants }\end{array}$ & Statistical method & Effect size \\
\hline 1 Operative outcomes & 1 & & Mean Difference (IV, Fixed, 95\% CI) & Totals not selected \\
\hline $\begin{array}{l}1.1 \text { Radiographic exposure } \\
\left(\mathrm{Gy} / \mathrm{m}^{2}\right)\end{array}$ & 1 & & Mean Difference (IV, Fixed, 95\% CI) & Not estimable \\
\hline 2 Operative fracture of the femur & 1 & & Risk Ratio (M-H, Fixed, 95\% CI) & Totals not selected \\
\hline 3 Superficial wound infection & 1 & & Risk Ratio (M-H, Fixed, 95\% CI) & Totals not selected \\
\hline 4 Post-operative complications & 1 & & Risk Ratio (M-H, Fixed, 95\% CI) & Totals not selected \\
\hline
\end{tabular}


4.1 Deep vein thrombosis

4.2 Delirium

4.3 Cardiovascular

complication

4.4 Respiratory complication 1

5 Mortality (in hospital)

6 Days to independent walking
Risk Ratio (M-H, Fixed, 95\% CI)

Risk Ratio (M-H, Fixed, 95\% CI)

Risk Ratio (M-H, Fixed, 95\% CI)

Risk Ratio (M-H, Fixed, 95\% CI)

Risk Ratio (M-H, Fixed, 95\% CI)

Mean Difference (IV, Fixed, 95\% CI)
Not estimable

Not estimable

Not estimable

Not estimable

Totals not selected Totals not selected

\section{Comparison 12. Femoral nail (2 types) versus Medoff sliding plate}

$\begin{array}{llccc}\text { Outcome or subgroup title } & \begin{array}{c}\text { No. of } \\ \text { studies }\end{array} & \begin{array}{c}\text { No. of } \\ \text { participants }\end{array} & \text { Statistical method } & \text { Effect size }\end{array}$

\begin{tabular}{|c|c|c|c|c|}
\hline 1 Length of surgery (minutes) & 1 & & Mean Difference (IV, Fixed, 95\% CI) & Totals not selected \\
\hline $\begin{array}{l}1.1 \text { Proximal femoral nail } \\
(\mathrm{PFN})\end{array}$ & 1 & & Mean Difference (IV, Fixed, 95\% CI) & Not estimable \\
\hline 2 Operative blood loss (ml) & 1 & & Mean Difference (IV, Fixed, 95\% CI) & Totals not selected \\
\hline $\begin{array}{l}2.1 \text { Proximal femoral nail } \\
(\mathrm{PFN})\end{array}$ & 1 & & Mean Difference (IV, Fixed, 95\% CI) & Not estimable \\
\hline $\begin{array}{l}3 \text { Radiographic screening time } \\
\text { (minutes) }\end{array}$ & 1 & & Mean Difference (IV, Fixed, 95\% CI) & Totals not selected \\
\hline $\begin{array}{l}3.1 \text { Proximal femoral nail } \\
\text { (PFN) }\end{array}$ & 1 & & Mean Difference (IV, Fixed, 95\% CI) & Not estimable \\
\hline 4 Operative fracture of the femur & 2 & 420 & Risk Ratio (M-H, Fixed, 95\% CI) & $4.84[0.57,40.81]$ \\
\hline 4.1 Gamma nail & 1 & 217 & Risk Ratio (M-H, Fixed, 95\% CI) & $6.94[0.36,132.70]$ \\
\hline $\begin{array}{l}4.2 \text { Proximal femoral nail } \\
\text { (PFN) }\end{array}$ & 1 & 203 & Risk Ratio (M-H, Fixed, 95\% CI) & $2.80[0.12,67.98]$ \\
\hline 5 Later fracture of femur & 2 & 420 & Risk Ratio (M-H, Fixed, 95\% CI) & Not estimable \\
\hline 5.1 Gamma nail & 1 & 217 & Risk Ratio (M-H, Fixed, 95\% CI) & Not estimable \\
\hline $\begin{array}{l}5.2 \text { Proximal femoral nail } \\
\text { (PFN) }\end{array}$ & 1 & 203 & Risk Ratio (M-H, Fixed, 95\% CI) & Not estimable \\
\hline 6 Cut-out & 2 & 420 & Risk Ratio (M-H, Fixed, 95\% CI) & $1.44[0.52,4.01]$ \\
\hline 6.1 Gamma nail & 1 & 217 & Risk Ratio (M-H, Fixed, 95\% CI) & $0.74[0.17,3.24]$ \\
\hline $\begin{array}{l}\text { 6.2 Proximal femoral nail } \\
\text { (PFN) }\end{array}$ & 1 & 203 & Risk Ratio (M-H, Fixed, 95\% CI) & $2.8[0.58,13.55]$ \\
\hline 7 Non-union & 1 & & Risk Ratio (M-H, Fixed, 95\% CI) & Totals not selected \\
\hline $\begin{array}{l}7.1 \text { Proximal femoral nail } \\
(\mathrm{PFN})\end{array}$ & 1 & & Risk Ratio (M-H, Fixed, 95\% CI) & Not estimable \\
\hline 8 Reoperation & 2 & & Risk Ratio (M-H, Fixed, 95\% CI) & Totals not selected \\
\hline 8.1 Gamma nail & 1 & & Risk Ratio (M-H, Fixed, 95\% CI) & Not estimable \\
\hline $\begin{array}{l}8.2 \text { Proximal femoral nail } \\
\text { (PFN) }\end{array}$ & 1 & & Risk Ratio (M-H, Fixed, 95\% CI) & Not estimable \\
\hline 9 Wound infection - any type & 2 & & Risk Ratio (M-H, Fixed, 95\% CI) & Totals not selected \\
\hline 9.1 Gamma nail & 1 & & Risk Ratio (M-H, Fixed, 95\% CI) & Not estimable \\
\hline $\begin{array}{l}9.2 \text { Proximal femoral nail } \\
\text { (PFN) }\end{array}$ & 1 & & Risk Ratio (M-H, Fixed, 95\% CI) & Not estimable \\
\hline 10 Deep wound infection & 1 & & Risk Ratio (M-H, Fixed, 95\% CI) & Totals not selected \\
\hline 10.1 Gamma nail & 1 & & Risk Ratio (M-H, Fixed, 95\% CI) & Not estimable \\
\hline 11 Wound haematoma & 1 & & Risk Ratio (M-H, Fixed, 95\% CI) & Totals not selected \\
\hline
\end{tabular}

Gamma and other cephalocondylic intramedullary nails versus extramedullary implants for extracapsular hip fractures in adults (Review) 96

Copyright (@) 2010 The Cochrane Collaboration. Published by John Wiley \& Sons, Ltd. 
11.1 Proximal femoral nail (PFN)

12 Severe medical complications 12.1 Gamma nail

13 Mortality at 1 year

13.1 Gamma nail

13.2 Proximal femoral nail (PFN)

14 Inability to walk 15 metres at one year

14.1 Proximal femoral nail (PFN)

15 Inability to rise from a chair at one year

15.1 Proximal femoral nail (PFN)

16 Inability to climb a curb at one year

16.1 Proximal femoral nail (PFN)

17 Need to use walking aids at one year

17.1 Proximal femoral nail (PFN)
Risk Ratio (M-H, Fixed, 95\% CI)

Risk Ratio (M-H, Fixed, 95\% CI)

Risk Ratio (M-H, Fixed, 95\% CI)

420

217

Risk Ratio (M-H, Fixed, 95\% CI)

Risk Ratio (M-H, Fixed, 95\% CI)

Risk Ratio (M-H, Fixed, 95\% CI)

Risk Ratio (M-H, Fixed, 95\% CI)

Risk Ratio (M-H, Fixed, 95\% CI)

Risk Ratio (M-H, Fixed, 95\% CI)

Risk Ratio (M-H, Fixed, 95\% CI)

Risk Ratio (M-H, Fixed, 95\% CI)

Risk Ratio (M-H, Fixed, 95\% CI)

Risk Ratio (M-H, Fixed, 95\% CI)

Risk Ratio (M-H, Fixed, 95\% CI)
Not estimable

Totals not selected

Not estimable

$0.77[0.53,1.12]$

$0.77[0.48,1.22]$

$0.78[0.42,1.46]$

Totals not selected

Not estimable

Totals not selected

Not estimable

Totals not selected

Not estimable

Totals not selected

Not estimable

Comparison 13. Gamma nail versus percutaneous compression plate (PCCP)

$\begin{array}{llccc}\text { Outcome or subgroup title } & \begin{array}{l}\text { No. of } \\ \text { studies }\end{array} & \begin{array}{c}\text { No. of } \\ \text { participants }\end{array} & \text { Statistical method }\end{array}$

\begin{tabular}{|c|c|c|c|}
\hline 1 Number of patients transfused & 1 & Risk Ratio (M-H, Fixed, 95\% CI) & Totals not selected \\
\hline 2 Fracture fixation complications & 1 & Risk Ratio (M-H, Fixed, 95\% CI) & Totals not selected \\
\hline 2.1 Cut-out & 1 & Risk Ratio (M-H, Fixed, 95\% CI) & Not estimable \\
\hline 3 Post-operative complications & 1 & Risk Ratio (M-H, Fixed, 95\% CI) & Totals not selected \\
\hline 3.1 Pneumonia & 1 & Risk Ratio (M-H, Fixed, 95\% CI) & Not estimable \\
\hline 3.2 Confusion & 1 & Risk Ratio (M-H, Fixed, 95\% CI) & Not estimable \\
\hline 3.3 Stroke & 1 & Risk Ratio (M-H, Fixed, 95\% CI) & Not estimable \\
\hline 3.4 Congestive cardiac failure & 1 & Risk Ratio (M-H, Fixed, 95\% CI) & Not estimable \\
\hline 3.5 Genitourinary infection & 1 & Risk Ratio (M-H, Fixed, 95\% CI) & Not estimable \\
\hline 4 Discharged to intermediate care & 1 & Risk Ratio (M-H, Fixed, 95\% CI) & Totals not selected \\
\hline 5 Mortality & 1 & Risk Ratio (M-H, Fixed, 95\% CI) & Totals not selected \\
\hline 5.1 Hospital mortality & 1 & Risk Ratio (M-H, Fixed, 95\% CI) & Not estimable \\
\hline 5.2 Mortality (one year) & 1 & Risk Ratio (M-H, Fixed, 95\% CI) & Not estimable \\
\hline $\begin{array}{l}6 \text { Failure to regain mobility at one } \\
\text { year }\end{array}$ & 1 & Risk Ratio (M-H, Fixed, 95\% CI) & Totals not selected \\
\hline 6.1 In survivors & 1 & Risk Ratio (M-H, Fixed, 95\% CI) & Not estimable \\
\hline $\begin{array}{l}\text { 6.2 Dead or failed to recover } \\
\text { former mobility }\end{array}$ & 1 & Risk Ratio (M-H, Fixed, 95\% CI) & Not estimable \\
\hline
\end{tabular}

Gamma and other cephalocondylic intramedullary nails versus extramedullary implants for extracapsular hip fractures in adults (Review) 97 Copyright (c) 2010 The Cochrane Collaboration. Published by John Wiley \& Sons, Ltd. 


\begin{tabular}{|c|c|c|c|c|}
\hline Outcome or subgroup title & $\begin{array}{l}\text { No. of } \\
\text { studies }\end{array}$ & $\begin{array}{c}\text { No. of } \\
\text { participants }\end{array}$ & Statistical method & Effect size \\
\hline 1 Length of surgery (minutes) & 1 & & Mean Difference (IV, Fixed, 95\% CI) & Totals not selected \\
\hline $\begin{array}{l}1.1 \text { Proximal femoral nail } \\
\text { (PFN) versus Dynamic } \\
\text { Condylar Plate (DCP) }\end{array}$ & 1 & & Mean Difference (IV, Fixed, 95\% CI) & Not estimable \\
\hline 2 Number of patients transfused & 1 & & Risk Ratio (M-H, Fixed, 95\% CI) & Totals not selected \\
\hline $\begin{array}{l}2.1 \text { Proximal femoral nail } \\
\text { (PFN) versus Dynamic } \\
\text { condylar screw (DCS) }\end{array}$ & 1 & & Risk Ratio (M-H, Fixed, 95\% CI) & Not estimable \\
\hline $\begin{array}{l}3 \text { Radiographic screening time } \\
\text { (minutes) }\end{array}$ & 1 & & Mean Difference (IV, Fixed, 95\% CI) & Totals not selected \\
\hline $\begin{array}{l}3.1 \text { Proximal femoral nail } \\
\text { (PFN) versus Dynamic } \\
\text { condylar screw (DCS) }\end{array}$ & 1 & & Mean Difference (IV, Fixed, 95\% CI) & Not estimable \\
\hline 4 Non-union & 2 & 61 & Risk Ratio (M-H, Fixed, 95\% CI) & $0.42[0.06,2.69]$ \\
\hline $\begin{array}{l}4.1 \text { Proximal femoral nail } \\
\text { (PFN) versus Dynamic } \\
\text { condylar screw (DCS) }\end{array}$ & 1 & 35 & Risk Ratio (M-H, Fixed, 95\% CI) & $0.94[0.06,13.93]$ \\
\hline $\begin{array}{l}4.2 \text { Gamma nail versus } 90 \\
\text { degree blade plate }\end{array}$ & 1 & 26 & Risk Ratio (M-H, Fixed, 95\% CI) & $0.2[0.01,3.80]$ \\
\hline 5 Operative fracture of femur & 1 & & Risk Ratio (M-H, Fixed, 95\% CI) & Totals not selected \\
\hline $\begin{array}{l}5.1 \text { Gamma nail versus } 90 \\
\text { degree blade plate }\end{array}$ & 1 & & Risk Ratio (M-H, Fixed, 95\% CI) & Not estimable \\
\hline 6 Cut-out & 2 & 65 & Risk Ratio (M-H, Fixed, 95\% CI) & $0.32[0.07,1.53]$ \\
\hline $\begin{array}{l}\text { 6.1 Proximal femoral nail } \\
\text { (PFN) versus Dynamic } \\
\text { condylar screw (DCS) }\end{array}$ & 1 & 39 & Risk Ratio (M-H, Fixed, 95\% CI) & $0.09[0.01,1.47]$ \\
\hline $\begin{array}{l}6.2 \text { Gamma nail versus } 90 \\
\text { degree blade plate }\end{array}$ & 1 & 26 & Risk Ratio (M-H, Fixed, 95\% CI) & $3.0[0.13,67.51]$ \\
\hline 7 Plate breakage & 2 & 65 & Risk Ratio (M-H, Fixed, 95\% CI) & $0.33[0.04,2.97]$ \\
\hline $\begin{array}{l}7.1 \text { Proximal femoral nail } \\
\text { (PFN) versus Dynamic } \\
\text { condylar screw (DCS) }\end{array}$ & 1 & 39 & Risk Ratio (M-H, Fixed, 95\% CI) & $0.32[0.01,7.35]$ \\
\hline $\begin{array}{l}7.2 \text { Gamma nail versus } 90 \\
\text { degree blade plate }\end{array}$ & 1 & 26 & Risk Ratio (M-H, Fixed, 95\% CI) & $0.33[0.01,7.50]$ \\
\hline 8 Reoperation (major) & 2 & 65 & Risk Ratio (M-H, Fixed, 95\% CI) & $0.07[0.00,1.22]$ \\
\hline $\begin{array}{l}8.1 \text { Proximal femoral nail } \\
\text { (PFN) versus Dynamic } \\
\text { condylar screw (DCS) }\end{array}$ & 1 & 39 & Risk Ratio (M-H, Fixed, 95\% CI) & $0.07[0.00,1.22]$ \\
\hline $\begin{array}{l}8.2 \text { Gamma nail versus } 90 \\
\text { degree blade plate }\end{array}$ & 1 & 26 & Risk Ratio (M-H, Fixed, 95\% CI) & Not estimable \\
\hline 9 Deep wound infection & 2 & & Risk Ratio (M-H, Fixed, 95\% CI) & Totals not selected \\
\hline $\begin{array}{l}\text { 9.1 Proximal femoral nail } \\
\text { (PFN) versus Dynamic } \\
\text { condylar screw (DCS) }\end{array}$ & 1 & & Risk Ratio (M-H, Fixed, 95\% CI) & Not estimable \\
\hline $\begin{array}{l}9.2 \text { Gamma nail versus } 90 \\
\text { degree blade plate }\end{array}$ & 1 & & Risk Ratio (M-H, Fixed, 95\% CI) & Not estimable \\
\hline
\end{tabular}

Gamma and other cephalocondylic intramedullary nails versus extramedullary implants for extracapsular hip fractures in adults (Review) 98 Copyright (C) 2010 The Cochrane Collaboration. Published by John Wiley \& Sons, Ltd. 
10 Pneumonia

10.1 Proximal femoral

nail (PFN) versus Dynamic

condylar screw (DCS)

11 Pressure sores

11.1 Proximal femoral nail (PFN) versus Dynamic condylar screw (DCS)

12 Deep vein thrombosis

12.1 Proximal femoral nail (PFN) versus Dynamic condylar screw (DCS)

13 Pulmonary embolism

13.1 Proximal femoral nail (PFN) versus Dynamic Condylar Plate (DCP)

13.2 Gamma nail versus 90 degree blade plate

14 All medical complications

14.1 Proximal femoral nail (PFN) versus Dynamic condylar screw (DCS)

14.2 Gamma nail versus 90 degree blade plate

15 Length of hospital stay (days) 15.1 Proximal femoral nail (PFN) versus Dynamic condylar screw (DCS)

16 Mortality (1 year) 16.1 Proximal femoral nail (PFN) versus Dynamic condylar screw (DCS)

16.2 Gamma nail versus 90 degree blade plate

17 Pain at follow-up

17.1 Gamma nail versus 90 degree blade plate

18 In nursing home at one year from injury

18.1 Proximal femoral nail (PFN) versus Dynamic condylar screw (DCS)

19 In nursing home or dead at one year from injury

19.1 Proximal femoral nail (PFN) versus Dynamic condylar screw (DCS)

20 Use of walking aids 20.1 Gamma nail versus 90 degree blade plate
Risk Ratio (M-H, Fixed, 95\% CI)

Risk Ratio (M-H, Fixed, 95\% CI)

Risk Ratio (M-H, Fixed, 95\% CI)

Risk Ratio (M-H, Fixed, 95\% CI)

Risk Ratio (M-H, Fixed, 95\% CI)

Risk Ratio (M-H, Fixed, 95\% CI)

Risk Ratio (M-H, Fixed, 95\% CI)

Risk Ratio (M-H, Fixed, 95\% CI)

Risk Ratio (M-H, Fixed, 95\% CI)

65

Risk Ratio (M-H, Fixed, 95\% CI)

Risk Ratio (M-H, Fixed, 95\% CI)

Risk Ratio (M-H, Fixed, 95\% CI)

Mean Difference (IV, Fixed, 95\% CI)

Mean Difference (IV, Fixed, 95\% CI)

65

Risk Ratio (M-H, Fixed, 95\% CI)

Risk Ratio (M-H, Fixed, 95\% CI)

Risk Ratio (M-H, Fixed, 95\% CI)

Risk Ratio (M-H, Fixed, 95\% CI)

Risk Ratio (M-H, Fixed, 95\% CI)

Risk Ratio (M-H, Fixed, 95\% CI)

Risk Ratio (M-H, Fixed, 95\% CI)

Risk Ratio (M-H, Fixed, 95\% CI)

Risk Ratio (M-H, Fixed, 95\% CI)

Risk Ratio (M-H, Fixed, 95\% CI)

Risk Ratio (M-H, Fixed, 95\% CI)
Totals not selected

Not estimable

Totals not selected

Not estimable

Totals not selected

Not estimable

Totals not selected

Not estimable

Not estimable

$1.20[0.69,2.06]$

$1.22[0.57,2.62]$

$1.17[0.54,2.53]$

Totals not selected

Not estimable

$1.9[0.19,19.27]$

$1.9[0.19,19.27]$

Not estimable

Totals not selected

Not estimable

Totals not selected

Not estimable

Totals not selected

Not estimable

Totals not selected

Not estimable 


\begin{tabular}{|c|c|c|c|c|}
\hline Outcome or subgroup title & $\begin{array}{l}\text { No. of } \\
\text { studies }\end{array}$ & $\begin{array}{c}\text { No. of } \\
\text { participants }\end{array}$ & Statistical method & Effect size \\
\hline 1 Length of surgery (minutes) & 1 & & Mean Difference (IV, Fixed, 95\% CI) & Totals not selected \\
\hline $\begin{array}{l}\text { 1.1 Russell-Taylor nail versus } \\
\text { Dynamic condylar screw }\end{array}$ & 1 & & Mean Difference (IV, Fixed, 95\% CI) & Not estimable \\
\hline $\begin{array}{l}2 \text { Radiographic screening time } \\
\text { (seconds) }\end{array}$ & 1 & & Mean Difference (IV, Fixed, 95\% CI) & Totals not selected \\
\hline $\begin{array}{l}2.1 \text { Russell-Taylor nail versus } \\
\text { Dynamic condylar screw }\end{array}$ & 1 & & Mean Difference (IV, Fixed, 95\% CI) & Not estimable \\
\hline 3 Operative blood loss (ml) & 1 & & Mean Difference (IV, Fixed, 95\% CI) & Totals not selected \\
\hline $\begin{array}{l}\text { 3.1 Russell-Taylor nail versus } \\
\text { Dynamic condylar screw }\end{array}$ & 1 & & Mean Difference (IV, Fixed, 95\% CI) & Not estimable \\
\hline $\begin{array}{l}4 \text { Number of patients given } \\
\text { transfusion }\end{array}$ & 1 & & Risk Ratio (M-H, Fixed, 95\% CI) & Totals not selected \\
\hline $\begin{array}{l}\text { 4.1 Russell-Taylor nail versus } \\
\text { Dynamic condylar screw }\end{array}$ & 1 & & Risk Ratio (M-H, Fixed, 95\% CI) & Not estimable \\
\hline 5 Non-union & 2 & & Risk Ratio (M-H, Fixed, 95\% CI) & Totals not selected \\
\hline $\begin{array}{l}5.1 \text { Proximal femoral nail } \\
\text { (PFN) versus } 95 \text { degree blade } \\
\text { plate }\end{array}$ & 1 & & Risk Ratio (M-H, Fixed, 95\% CI) & Not estimable \\
\hline $\begin{array}{l}5.2 \text { Russell-Taylor nail versus } \\
\text { Dynamic condylar screw }\end{array}$ & 1 & & Risk Ratio (M-H, Fixed, 95\% CI) & Not estimable \\
\hline 6 Reoperation & 2 & & Risk Ratio (M-H, Fixed, 95\% CI) & Totals not selected \\
\hline $\begin{array}{l}\text { 6.1 Proximal femoral nail } \\
\text { (PFN) versus } 95 \text { degree blade } \\
\text { plate }\end{array}$ & 1 & & Risk Ratio (M-H, Fixed, 95\% CI) & Not estimable \\
\hline $\begin{array}{l}\text { 6.2 Russell-Taylor nail versus } \\
\text { Dynamic condylar screw }\end{array}$ & 1 & & Risk Ratio (M-H, Fixed, 95\% CI) & Not estimable \\
\hline 7 Any wound infection & 2 & & Risk Ratio (M-H, Fixed, 95\% CI) & Totals not selected \\
\hline $\begin{array}{l}7.1 \text { Proximal femoral nail } \\
\text { (PFN) versus } 95 \text { degree blade } \\
\text { plate }\end{array}$ & 1 & & Risk Ratio (M-H, Fixed, 95\% CI) & Not estimable \\
\hline $\begin{array}{l}\text { 7.2 Russell-Taylor nail versus } \\
\text { Dynamic Condylar Screw }\end{array}$ & 1 & & Risk Ratio (M-H, Fixed, 95\% CI) & Not estimable \\
\hline 8 Length of hospital stay (days) & 1 & & Mean Difference (IV, Fixed, 95\% CI) & Totals not selected \\
\hline $\begin{array}{l}8.1 \text { Russell-Taylor nail versus } \\
\text { Dynamic condylar screw }\end{array}$ & 1 & & Mean Difference (IV, Fixed, 95\% CI) & Not estimable \\
\hline 9 Mortality & 1 & & Risk Ratio (M-H, Fixed, 95\% CI) & Totals not selected \\
\hline $\begin{array}{l}\text { 9.1 Proximal femoral nail } \\
(\mathrm{PFN}) \text { versus } 95 \text { degree blade } \\
\text { plate }\end{array}$ & 1 & & Risk Ratio (M-H, Fixed, 95\% CI) & Not estimable \\
\hline $\begin{array}{l}10 \text { Pain score (1: no pain to } 4 \text { : } \\
\text { worst pain) }\end{array}$ & 1 & & Mean Difference (IV, Fixed, 95\% CI) & Totals not selected \\
\hline $\begin{array}{l}10.1 \text { Russell-Taylor nail versus } \\
\text { Dynamic condylar screw. Hip } \\
\text { pain }\end{array}$ & 1 & & Mean Difference (IV, Fixed, 95\% CI) & Not estimable \\
\hline
\end{tabular}

Gamma and other cephalocondylic intramedullary nails versus extramedullary implants for extracapsular hip fractures in adults (Review) $\quad 100$ Copyright (C) 2010 The Cochrane Collaboration. Published by John Wiley \& Sons, Ltd. 


\section{Analysis I.I. Comparison I Summary: Femoral nail (all types) versus sliding hip screw (SHS), Outcome I Length of surgery (minutes).}

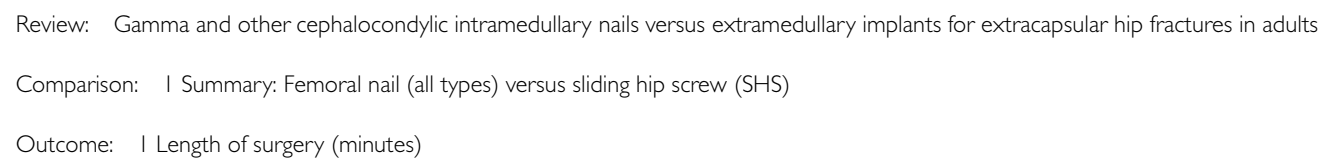

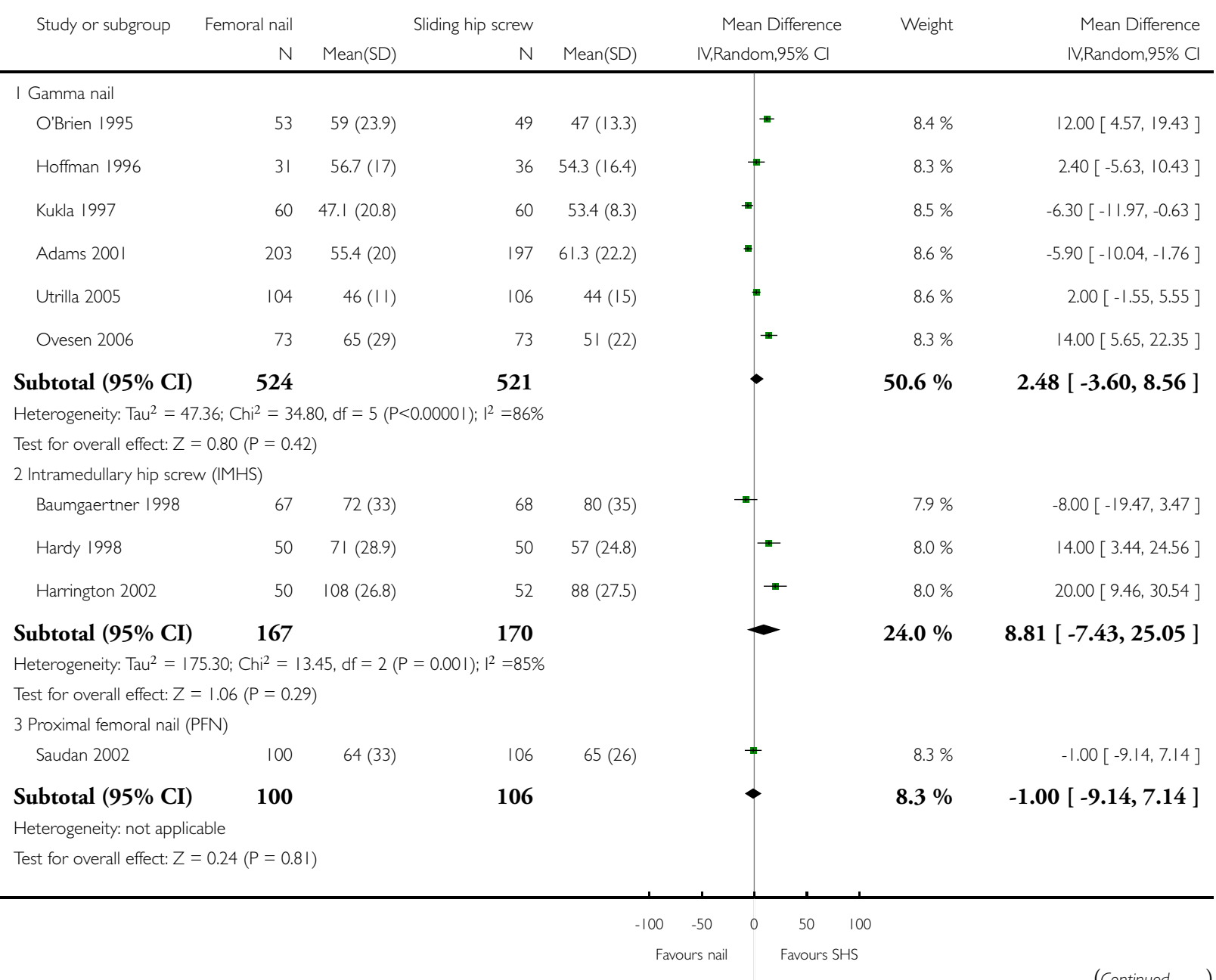

Gamma and other cephalocondylic intramedullary nails versus extramedullary implants for extracapsular hip fractures in adults (Review) I0I Copyright (c) 2010 The Cochrane Collaboration. Published by John Wiley \& Sons, Ltd. 


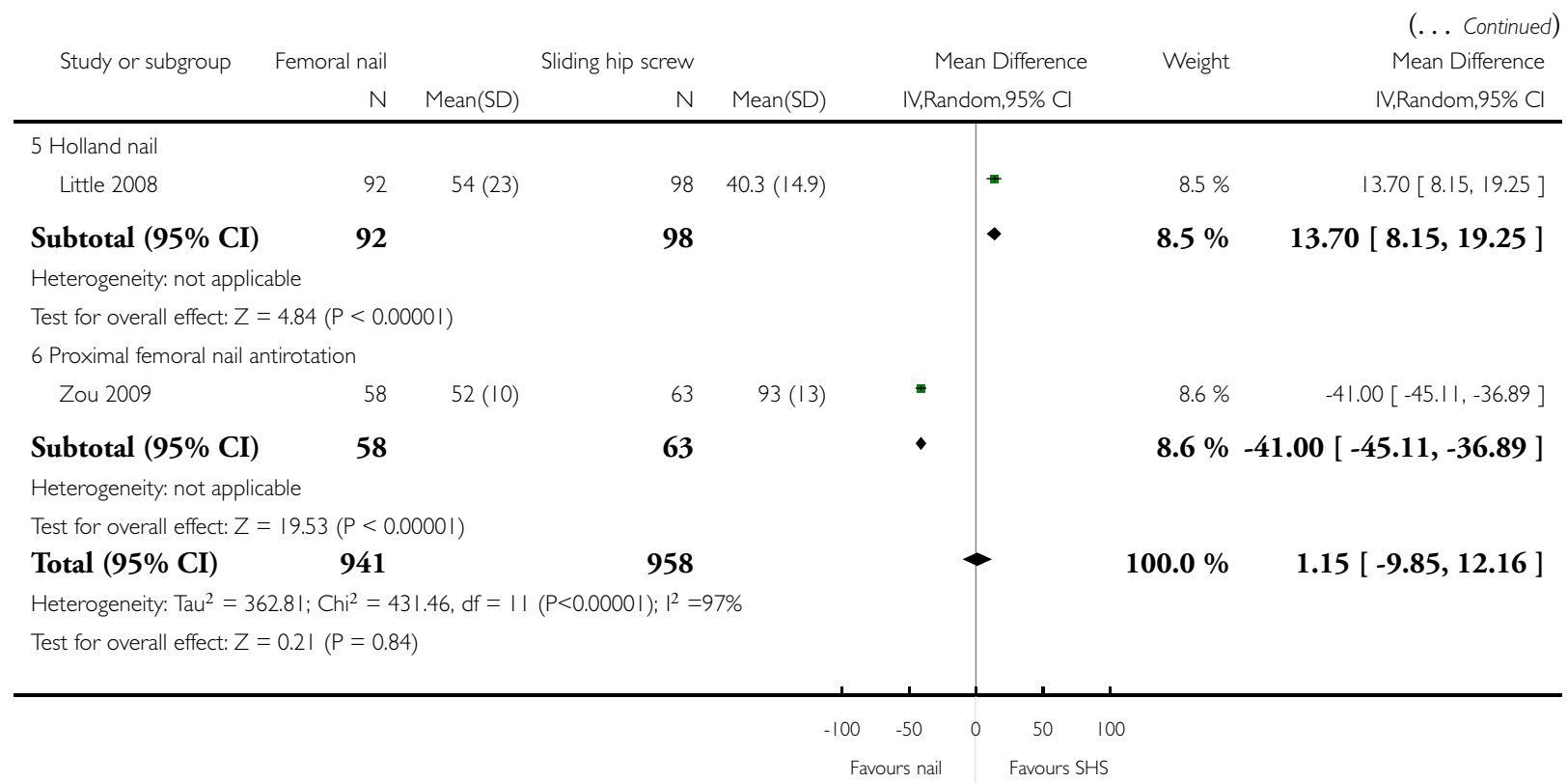

Gamma and other cephalocondylic intramedullary nails versus extramedullary implants for extracapsular hip fractures in adults (Review) $\quad 102$ Copyright (C) 2010 The Cochrane Collaboration. Published by John Wiley \& Sons, Ltd. 
Analysis I.2. Comparison I Summary: Femoral nail (all types) versus sliding hip screw (SHS), Outcome 2 Operative fracture of the femur.

Review: Gamma and other cephalocondylic intramedullary nails versus extramedullary implants for extracapsular hip fractures in adults

Comparison: I Summary: Femoral nail (all types) versus sliding hip screw (SHS)

Outcome: 2 Operative fracture of the femur

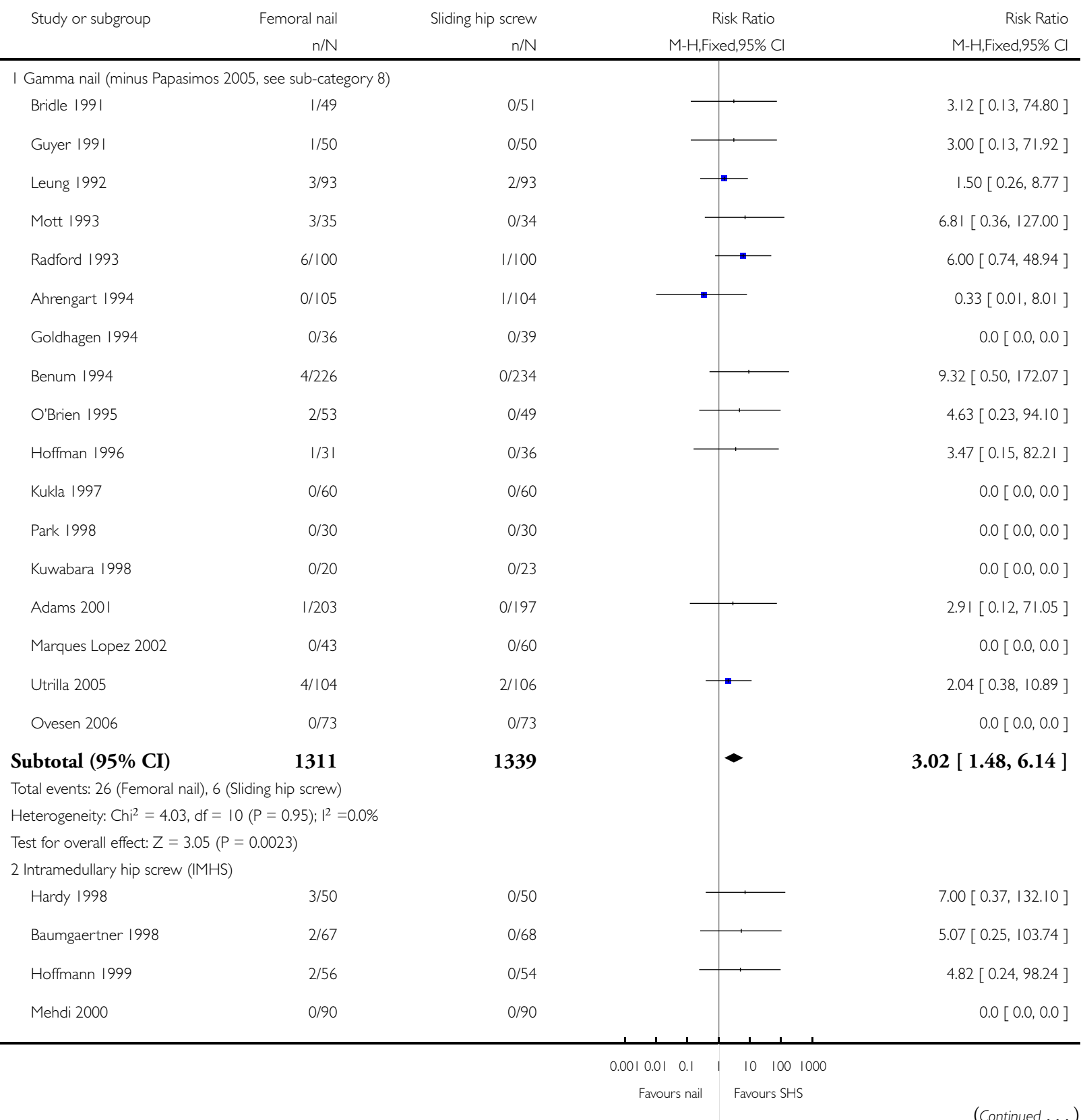

(Continued ... )

Gamma and other cephalocondylic intramedullary nails versus extramedullary implants for extracapsular hip fractures in adults (Review) $\quad$ I03 Copyright (C) 2010 The Cochrane Collaboration. Published by John Wiley \& Sons, Ltd. 


\begin{tabular}{|c|c|c|c|c|}
\hline \multirow[t]{2}{*}{ Study or subgroup } & Femoral nail & Sliding hip screw & Risk Ratio & $\begin{array}{c}\text { (... Continued) } \\
\text { Risk Ratio }\end{array}$ \\
\hline & $n / N$ & $n / N$ & M-H,Fixed,95\% Cl & M-H,Fixed,95\% Cl \\
\hline Harrington 2002 & 1/50 & 0/52 & 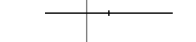 & $3.12[0.13,74.78]$ \\
\hline Subtotal $(95 \% \mathrm{CI})$ & 313 & 314 & $\longrightarrow$ & $5.01[1.11,22.65]$ \\
\hline \multicolumn{5}{|c|}{ Total events: 8 (Femoral nail), 0 (Sliding hip screw) } \\
\hline \multicolumn{5}{|c|}{ Heterogeneity: Chi ${ }^{2}=0.14, \mathrm{df}=3(P=0.99) ; 1^{2}=0.0 \%$} \\
\hline \multicolumn{5}{|c|}{ Test for overall effect: $Z=2.09(P=0.036)$} \\
\hline \multicolumn{5}{|c|}{3 Proximal femoral nail (PFN) (minus Papasimos 2005, see sub-category 8) } \\
\hline Saudan 2002 & $0 / 100$ & 0/106 & & $0.0[0.0,0.0]$ \\
\hline Subtotal $(95 \% \mathrm{CI})$ & 100 & 106 & & $0.0[0.0,0.0]$ \\
\hline \multicolumn{5}{|c|}{ Total events: 0 (Femoral nail), 0 (Sliding hip screw) } \\
\hline \multicolumn{5}{|c|}{ Heterogeneity: not applicable } \\
\hline \multicolumn{5}{|c|}{ Test for overall effect: $Z=0.0(P<0.0000 \mathrm{I})$} \\
\hline \multicolumn{5}{|l|}{7 Long Gamma nail } \\
\hline Barton 2010 & $0 / 100$ & $0 / 110$ & & $0.0[0.0,0.0]$ \\
\hline Subtotal $(95 \% \mathrm{CI})$ & 100 & 110 & & $0.0[0.0,0.0]$ \\
\hline \multicolumn{5}{|c|}{ Total events: 0 (Femoral nail), 0 (Sliding hip screw) } \\
\hline \multicolumn{5}{|c|}{ Heterogeneity: not applicable } \\
\hline \multicolumn{5}{|c|}{ Test for overall effect: $Z=0.0(P<0.0000 \mathrm{I})$} \\
\hline \multicolumn{5}{|c|}{8 Three-group trial results: Gamma nail or PFN } \\
\hline Papasimos 2005 & 1/80 & 0/40 & & $1.52[0.06,36.46]$ \\
\hline Subtotal $(95 \% \mathrm{CI})$ & 80 & 40 & & $1.52[0.06,36.46]$ \\
\hline \multicolumn{5}{|c|}{ Total events: I (Femoral nail), 0 (Sliding hip screw) } \\
\hline \multicolumn{5}{|c|}{ Heterogeneity: not applicable } \\
\hline \multicolumn{5}{|c|}{ Test for overall effect: $Z=0.26(P=0.80)$} \\
\hline \multicolumn{5}{|c|}{9 Two nail types (Gamma or Endovis BA nail) } \\
\hline Verettas 2010 & 2/59 & 1/59 & $=$ & $2.00[0.19,21.46]$ \\
\hline Subtotal $(95 \% \mathrm{CI})$ & 59 & 59 & & $2.00[0.19,21.46]$ \\
\hline \multicolumn{5}{|c|}{ Total events: 2 (Femoral nail), I (Sliding hip screw) } \\
\hline \multicolumn{5}{|c|}{ Heterogeneity: not applicable } \\
\hline \multicolumn{5}{|c|}{ Test for overall effect: $Z=0.57(P=0.57)$} \\
\hline Total $(95 \% \mathrm{CI})$ & 1963 & 1968 & $\bullet$ & $3.16[1.73,5.79]$ \\
\hline \multicolumn{5}{|c|}{ Total events: 37 (Femoral nail), 7 (Sliding hip screw) } \\
\hline \multicolumn{5}{|c|}{ Heterogeneity: $\mathrm{Ch}^{2}=4.89, \mathrm{df}=16(P=1.00) ; 1^{2}=0.0 \%$} \\
\hline Test for overall effect: $Z=$ & $0.00019)$ & & & \\
\hline
\end{tabular}


Analysis I.3. Comparison I Summary: Femoral nail (all types) versus sliding hip screw (SHS), Outcome 3 Later fracture of the femur.

Review: Gamma and other cephalocondylic intramedullary nails versus extramedullary implants for extracapsular hip fractures in adults

Comparison: I Summary: Femoral nail (all types) versus sliding hip screw (SHS)

Outcome: 3 Later fracture of the femur

$\begin{array}{llll}\text { Study or subgroup } & \text { Femoral nail } & \text { Sliding hip screw } & \text { Risk Ratio }\end{array}$

$\mathrm{n} / \mathrm{N} \quad \mathrm{n} / \mathrm{N}$

M-H,Fixed, $95 \% \mathrm{Cl}$

M-H,Fixed,95\% Cl

I Gamma nail (minus Papasimos 2005, see sub-category 8)

Bridle 199| 3/34

Guyer 1991 0/50

$0 / 32$

Leung 1992

2/93

0/50

Mott 1993

1/35

0/93

Radford 1993

$5 / 100$

0/34

Benum 1994

$5 / 226$

$0 / 100$

Ahrengart 1994

2/87

$0 / 234$

Goldhagen 1994

$0 / 81$

O'Brien 1995

1/36

0/39

Butt 1995

|/53

0/49

Hoffman 1996

$8 / 47$

$0 / 48$

Kukla 1997

1/23

$|/ 3|$

Park 1998

$0 / 45$

$0 / 44$

Kuwabara 1998

$0 / 30$

$0 / 30$

Michos 2001

1/20

$0 / 23$

Adams 200।

$1 / 25$

0/24

Marques Lopez 2002

2/203

1/197

Marques Lopez 2002

$0 / 30$

0/38

Utrilla 2005

$0 / 82$

$0 / 81$

Ovesen 2006

$2 / 73$

0/73

1292

1301

M-H,Fixed,95\% Cl

Subtotal (95\% CI)

Total events: 35 (Femoral nail), 2 (Sliding hip screw)

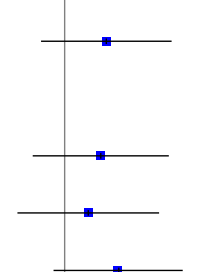

$6.60[0.35,122.96]$

$0.0[0.0,0.0]$

$5.00[0.24,102.75]$

$2.92[0.12,69.20]$

$1.00[0.62,196.33]$

I $1.39[0.63,204.76]$

$4.66[0.23,95.61]$

$3.24[0.14,77.15]$

$2.78[0.12,66.62]$

$17.35[1.03,292.39]$

I.35 $[0.09,20.44]$

$0.0[0.0,0.0]$

$0.0[0.0,0.0]$

$3.43[0.15,79.74]$

$2.88[0.12,67.53]$

$1.94[0.18,21.23]$

$0.0[0.0,0.0]$

$0.0[0.0,0.0]$

$5.00[0.24,102.38]$

Heterogeneity: $\mathrm{Chi}^{2}=3.45, \mathrm{df}=13(\mathrm{P}=1.00) ; \mathrm{I}^{2}=0.0 \%$

Test for overall effect: $Z=4.29(P=0.000018)$

2 Intramedullary hip screw (IMHS)

Baumgaertner 1998

$3 / 67$

Hardy 1998

$0 / 50$

$0 / 68$

0/50

7.10 [0.37, 134.92 ]

$0.0[0.0,0.0]$

(Continued....)

Gamma and other cephalocondylic intramedullary nails versus extramedullary implants for extracapsular hip fractures in adults (Review) 105 Copyright $(2010$ The Cochrane Collaboration. Published by John Wiley \& Sons, Ltd. 


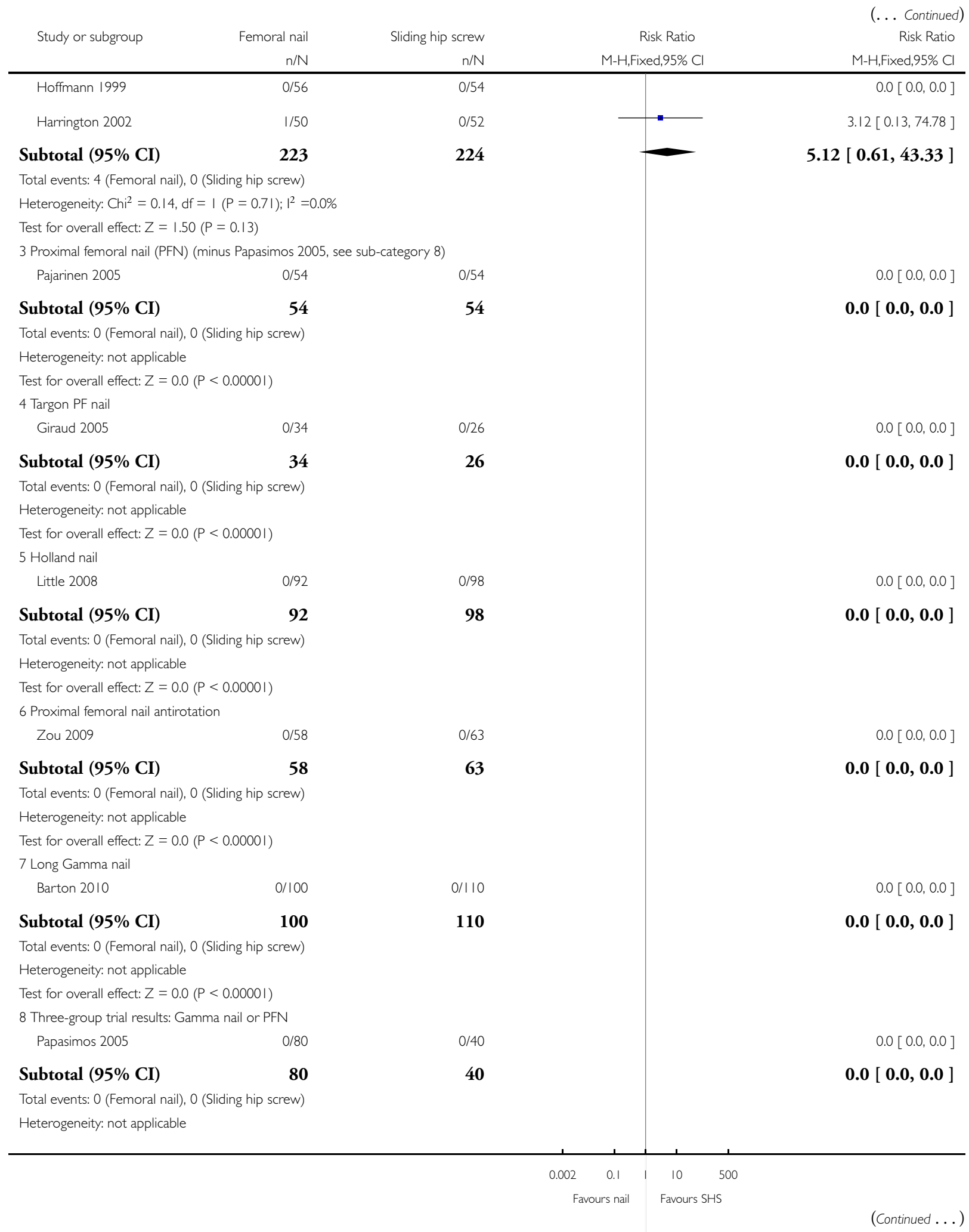

Gamma and other cephalocondylic intramedullary nails versus extramedullary implants for extracapsular hip fractures in adults (Review) 106 Copyright (C) 2010 The Cochrane Collaboration. Published by John Wiley \& Sons, Ltd. 


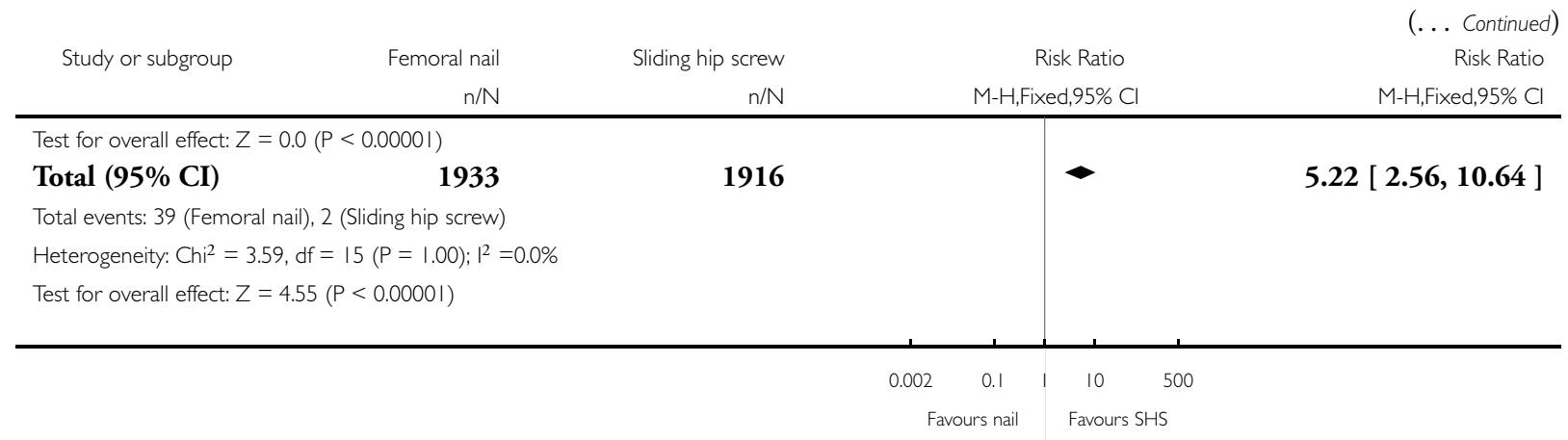

Analysis I.4. Comparison I Summary: Femoral nail (all types) versus sliding hip screw (SHS), Outcome 4 Cut-out (overall denominators used).

Review: Gamma and other cephalocondylic intramedullary nails versus extramedullary implants for extracapsular hip fractures in adults

Comparison: I Summary: Femoral nail (all types) versus sliding hip screw (SHS)

Outcome: 4 Cut-out (overall denominators used)

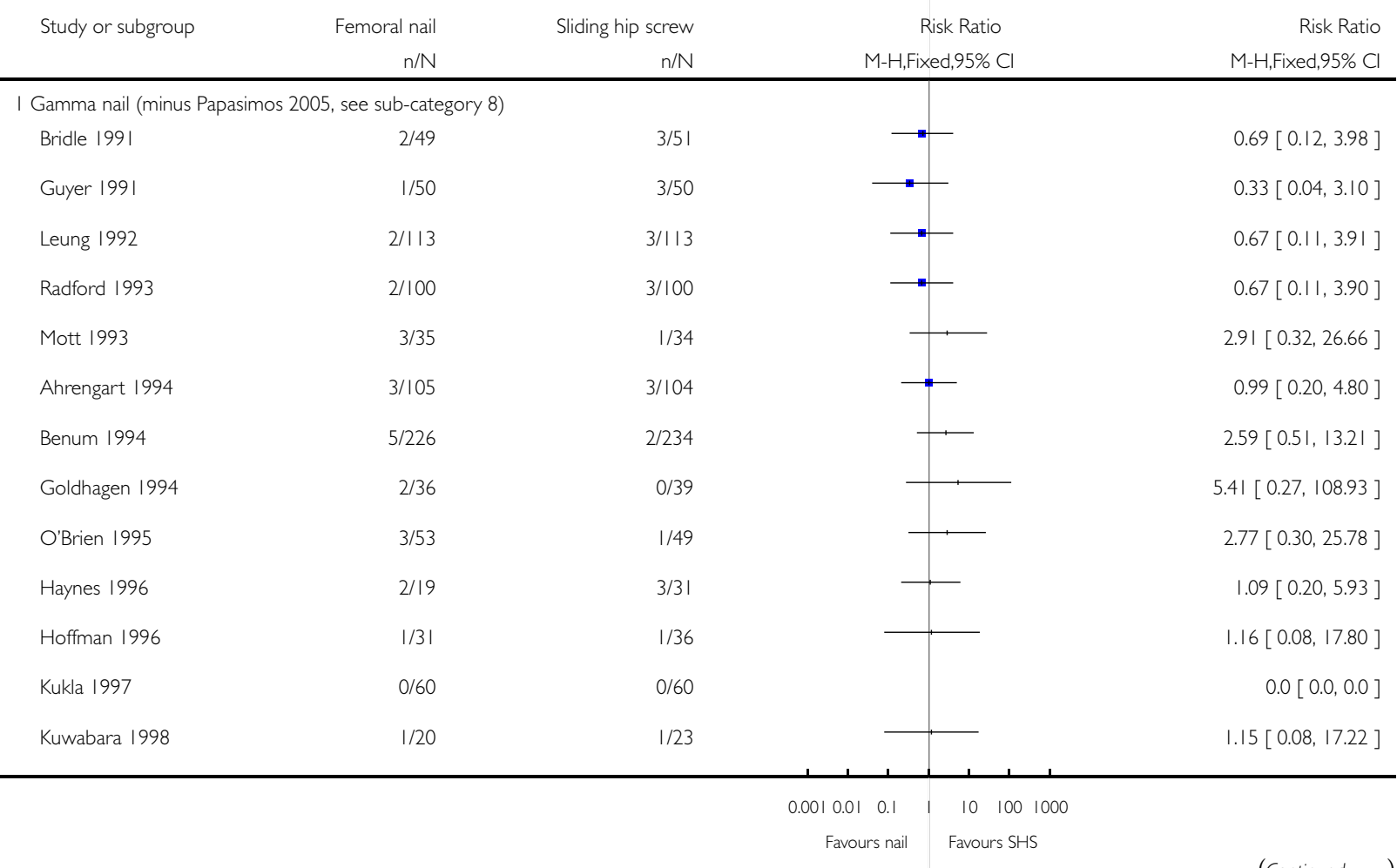

(Continued ... )

Gamma and other cephalocondylic intramedullary nails versus extramedullary implants for extracapsular hip fractures in adults (Review) $\quad$ I07 Copyright (C) 2010 The Cochrane Collaboration. Published by John Wiley \& Sons, Ltd. 


\begin{tabular}{|c|c|c|c|c|}
\hline \multirow[t]{2}{*}{ Study or subgroup } & Femoral nail & Sliding hip screw & $\begin{array}{c}\text { Risk Ratio } \\
\text { M-H,Fixed,95\% Cl }\end{array}$ & $\begin{array}{r}\text { (... Continued }) \\
\text { Risk Ratio } \\
\text { M-H,Fixed,95\% Cl }\end{array}$ \\
\hline & $n / N$ & $n / N$ & M-H,Fixed,95\% Cl & M-H,Fixed,95\% Cl \\
\hline Park 1998 & $1 / 30$ & 1/30 & 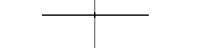 & $1.00[0.07,15.26]$ \\
\hline Adams 2001 & $8 / 203$ & $4 / 197$ & - & $1.94[0.59,6.34]$ \\
\hline Michos 200I & $0 / 26$ & 1/26 & $\overline{-1}$ & $0.33[0.01,7.82]$ \\
\hline Marques Lopez 2002 & $0 / 43$ & $2 / 60$ & - & $0.28[0.01,5.63]$ \\
\hline Utrilla 2005 & $1 / 104$ & $2 / 106$ & + & $0.51[0.05,5.53]$ \\
\hline Ovesen 2006 & $7 / 73$ & $5 / 73$ & - & $1.40[0.47,4.21]$ \\
\hline Subtotal $(95 \% \mathrm{CI})$ & 1376 & 1416 & $\bullet$ & $1.18[0.77,1.79]$ \\
\hline \multicolumn{5}{|c|}{ Total events: 44 (Femoral nail), 39 (Sliding hip screw) } \\
\hline \multicolumn{5}{|c|}{ Heterogeneity: $\mathrm{Chi}^{2}=8.30, \mathrm{df}=\mathrm{I7}(\mathrm{P}=0.96) ; \mathrm{I}^{2}=0.0 \%$} \\
\hline \multicolumn{5}{|c|}{ Test for overall effect: $Z=0.76(P=0.45)$} \\
\hline \multicolumn{5}{|c|}{2 Intramedullary hip screw (IMHS) } \\
\hline Baumgaertner 1998 & $2 / 67$ & $2 / 68$ & - & $1.01[0.15,7.00]$ \\
\hline Hardy 1998 & $0 / 50$ & 1/50 & 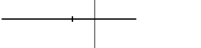 & $0.33[0.01,7.99]$ \\
\hline Mehdi 2000 & $1 / 90$ & $1 / 90$ & & $1.00[0.06,15.74]$ \\
\hline Harrington 2002 & 1/50 & 1/52 & i & $1.04[0.07,16.18]$ \\
\hline Subtotal $(95 \% \mathrm{CI})$ & 257 & 260 & - & $0.83[0.24,2.84]$ \\
\hline \multicolumn{5}{|c|}{ Total events: 4 (Femoral nail), 5 (Sliding hip screw) } \\
\hline \multicolumn{5}{|c|}{ Heterogeneity: $\mathrm{Chi}^{2}=0.40, \mathrm{df}=3(\mathrm{P}=0.94) ; \mathrm{I}^{2}=0.0 \%$} \\
\hline \multicolumn{5}{|c|}{ Test for overall effect: $Z=0.30(P=0.77)$} \\
\hline \multicolumn{5}{|c|}{3 Proximal femoral nail (PFN) (minus Papasimos 2005, see sub-category 8) } \\
\hline Saudan 2002 & $3 / 100$ & 1/106 & & $3.18[0.34,30.07]$ \\
\hline Pajarinen 2005 & $1 / 54$ & $1 / 54$ & $\overline{-}$ & $1.00[0.06,15.58]$ \\
\hline Subtotal $(95 \% \mathrm{CI})$ & 154 & 160 & & $2.07[0.39,11.10]$ \\
\hline \multicolumn{5}{|c|}{ Total events: 4 (Femoral nail), 2 (Sliding hip screw) } \\
\hline \multicolumn{5}{|c|}{ Heterogeneity: $\mathrm{Chi}^{2}=0.41, \mathrm{df}=\mathrm{I}(\mathrm{P}=0.52) ; \mathrm{I}^{2}=0.0 \%$} \\
\hline \multicolumn{5}{|c|}{ Test for overall effect: $Z=0.85(P=0.39)$} \\
\hline \multicolumn{5}{|l|}{4 Targon PF nail } \\
\hline Giraud 2005 & $3 / 34$ & 2/26 & - & $1.15[0.21,6.37]$ \\
\hline Subtotal $(95 \% \mathrm{CI})$ & 34 & 26 & - & $1.15[0.21,6.37]$ \\
\hline \multicolumn{5}{|c|}{ Total events: 3 (Femoral nail), 2 (Sliding hip screw) } \\
\hline \multicolumn{5}{|c|}{ Heterogeneity: not applicable } \\
\hline \multicolumn{5}{|c|}{ Test for overall effect: $Z=0.16(P=0.88)$} \\
\hline \multicolumn{5}{|l|}{5 Holland nail } \\
\hline Little 2008 & 0/92 & 2/98 & & $0.21[0.01,4.38]$ \\
\hline Subtotal $(95 \% \mathrm{CI})$ & 92 & 98 & & $0.21[0.01,4.38]$ \\
\hline \multicolumn{5}{|c|}{ Total events: 0 (Femoral nail), 2 (Sliding hip screw) } \\
\hline \multicolumn{5}{|c|}{ Heterogeneity: not applicable } \\
\hline \multicolumn{5}{|c|}{ Test for overall effect: $Z=1.00(P=0.32)$} \\
\hline 6 Proximal femoral nail an & & & & \\
\hline
\end{tabular}




\begin{tabular}{|c|c|c|c|c|}
\hline \multirow[t]{2}{*}{ Study or subgroup } & Femoral nail & Sliding hip screw & \multirow{2}{*}{$\begin{array}{c}\text { Risk Ratio } \\
\text { M-H,Fixed,95\% Cl }\end{array}$} & \multirow{2}{*}{$\begin{array}{c}\text { (... Continued) } \\
\text { Risk Ratio } \\
\text { M-H,Fixed,95\% Cl }\end{array}$} \\
\hline & $n / N$ & $\mathrm{n} / \mathrm{N}$ & & \\
\hline Zou 2009 & $0 / 58$ & $0 / 63$ & & $0.0[0.0,0.0]$ \\
\hline Subtotal (95\% CI) & 58 & 63 & & $0.0[0.0,0.0]$ \\
\hline \multicolumn{5}{|c|}{ Total events: 0 (Femoral nail), 0 (Sliding hip screw) } \\
\hline \multicolumn{5}{|c|}{ Heterogeneity: not applicable } \\
\hline \multicolumn{5}{|c|}{ Test for overall effect: $Z=0.0(P<0.0000 \mathrm{I})$} \\
\hline \multicolumn{5}{|l|}{7 Long Gamma nail } \\
\hline Barton 2010 & $3 / 100$ & $2 / 110$ & - & $1.65[0.28,9.67]$ \\
\hline Subtotal $(95 \% \mathrm{CI})$ & 100 & 110 & - & $1.65[0.28,9.67]$ \\
\hline \multicolumn{5}{|c|}{ Total events: 3 (Femoral nail), 2 (Sliding hip screw) } \\
\hline \multicolumn{5}{|c|}{ Heterogeneity: not applicable } \\
\hline \multicolumn{5}{|c|}{ Test for overall effect: $Z=0.55(P=0.58)$} \\
\hline \multicolumn{5}{|c|}{8 Three-group trial results: Gamma nail or PFN } \\
\hline Papasimos 2005 & $3 / 80$ & $2 / 40$ & & $0.75[0.13,4.31]$ \\
\hline Subtotal $(95 \% \mathrm{CI})$ & 80 & 40 & & $0.75[0.13,4.31]$ \\
\hline \multicolumn{5}{|c|}{ Total events: 3 (Femoral nail), 2 (Sliding hip screw) } \\
\hline \multicolumn{5}{|c|}{ Heterogeneity: not applicable } \\
\hline \multicolumn{5}{|c|}{ Test for overall effect: $Z=0.32(P=0.75)$} \\
\hline Total $(95 \% \mathrm{CI})$ & 2151 & 2173 & $\bullet$ & $1.13[0.79,1.60]$ \\
\hline \multicolumn{5}{|c|}{ Total events: 61 (Femoral nail), 54 (Sliding hip screw) } \\
\hline \multicolumn{5}{|c|}{ Heterogeneity: $\mathrm{Ch}^{2}=11.29, \mathrm{df}=27(\mathrm{P}=1.00) ; \mathrm{I}^{2}=0.0 \%$} \\
\hline Test for overall effect: $Z=$ & $0.51)$ & & & \\
\hline
\end{tabular}


Analysis I.5. Comparison I Summary: Femoral nail (all types) versus sliding hip screw (SHS), Outcome 5 Non-union (overall denominators used).

Review: Gamma and other cephalocondylic intramedullary nails versus extramedullary implants for extracapsular hip fractures in adults

Comparison: I Summary: Femoral nail (all types) versus sliding hip screw (SHS)

Outcome: 5 Non-union (overall denominators used)

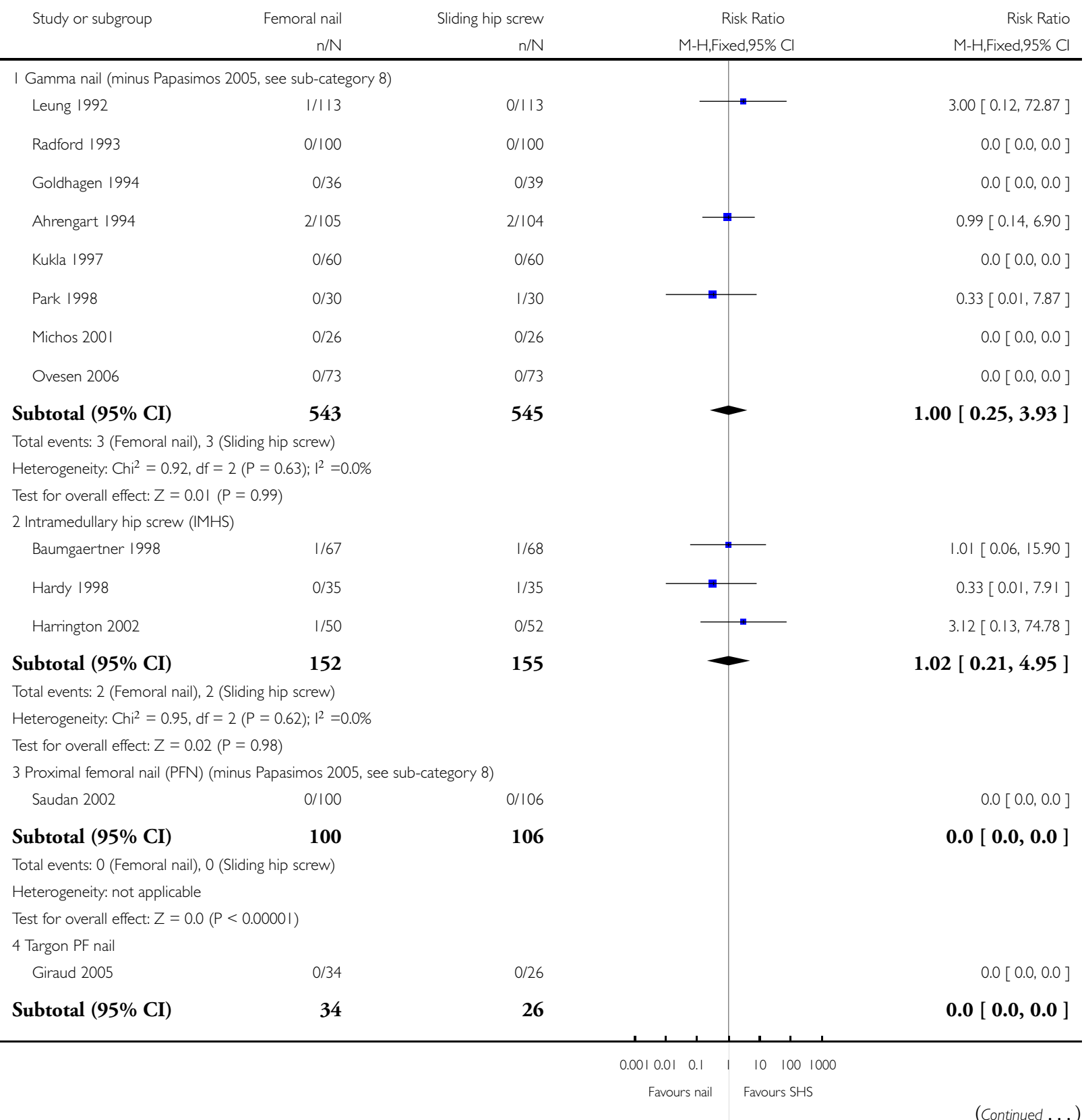

Gamma and other cephalocondylic intramedullary nails versus extramedullary implants for extracapsular hip fractures in adults (Review) I I0 Copyright (C) 2010 The Cochrane Collaboration. Published by John Wiley \& Sons, Ltd. 


\begin{tabular}{|c|c|c|c|c|}
\hline Study or subgroup & $\begin{array}{r}\text { Femoral nail } \\
n / N\end{array}$ & Sliding hip screw & Risk Ratio & $\begin{array}{r}\text { (... Continued } \\
\text { Risk Ratio } \\
\text { M-H.Fixed.95\% Cl }\end{array}$ \\
\hline \multicolumn{5}{|c|}{ Total events: 0 (Femoral nail), 0 (Sliding hip screw) } \\
\hline \multicolumn{5}{|c|}{ Heterogeneity: not applicable } \\
\hline \multicolumn{5}{|c|}{ Test for overall effect: $Z=0.0(P<0.0000 \mathrm{I})$} \\
\hline \multicolumn{5}{|c|}{6 Proximal femoral nail antirotation } \\
\hline Zou 2009 & $0 / 58$ & $1 / 63$ & $=$ & $0.36[0.02,8.70]$ \\
\hline Subtotal $(95 \% \mathrm{CI})$ & 58 & 63 & & $0.36[0.02,8.70]$ \\
\hline \multicolumn{5}{|c|}{ Total events: 0 (Femoral nail), I (Sliding hip screw) } \\
\hline \multicolumn{5}{|c|}{ Heterogeneity: not applicable } \\
\hline \multicolumn{5}{|c|}{ Test for overall effect: $Z=0.63(P=0.53)$} \\
\hline \multicolumn{5}{|l|}{7 Long Gamma nail } \\
\hline Barton 2010 & $0 / 100$ & $0 / 110$ & & $0.0[0.0,0.0]$ \\
\hline Subtotal (95\% CI) & 100 & 110 & & $0.0[0.0,0.0]$ \\
\hline \multicolumn{5}{|c|}{ Total events: 0 (Femoral nail), 0 (Sliding hip screw) } \\
\hline \multicolumn{5}{|c|}{ Heterogeneity: not applicable } \\
\hline \multicolumn{5}{|c|}{ Test for overall effect: $Z=0.0(P<0.0000 \mathrm{I})$} \\
\hline \multicolumn{5}{|c|}{8 Three-group trial results: Gamma nail or PFN } \\
\hline Papasimos 2005 & $1 / 80$ & $1 / 40$ & - & $0.50[0.03,7.79]$ \\
\hline Subtotal $(95 \% \mathrm{CI})$ & 80 & 40 & & $0.50[0.03,7.79]$ \\
\hline \multicolumn{5}{|c|}{ Total events: I (Femoral nail), I (Sliding hip screw) } \\
\hline \multicolumn{5}{|c|}{ Heterogeneity: not applicable } \\
\hline \multicolumn{5}{|c|}{ Test for overall effect: $Z=0.49(P=0.62)$} \\
\hline Total $(95 \% \mathrm{CI})$ & 1067 & 1045 & 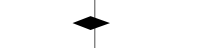 & $0.84[0.34,2.10]$ \\
\hline \multicolumn{5}{|c|}{ Total events: 6 (Femoral nail), 7 (Sliding hip screw) } \\
\hline \multicolumn{5}{|c|}{ Heterogeneity: $\mathrm{Chi}^{2}=2.37, \mathrm{df}=7(\mathrm{P}=0.94) ; \mathrm{I}^{2}=0.0 \%$} \\
\hline Test for overall effect: $Z=$ & $0.71)$ & & & \\
\hline
\end{tabular}


Analysis I.6. Comparison I Summary: Femoral nail (all types) versus sliding hip screw (SHS), Outcome 6 Reoperation (overall denominators used).

Review: Gamma and other cephalocondylic intramedullary nails versus extramedullary implants for extracapsular hip fractures in adults

Comparison: I Summary: Femoral nail (all types) versus sliding hip screw (SHS)

Outcome: 6 Reoperation (overall denominators used)

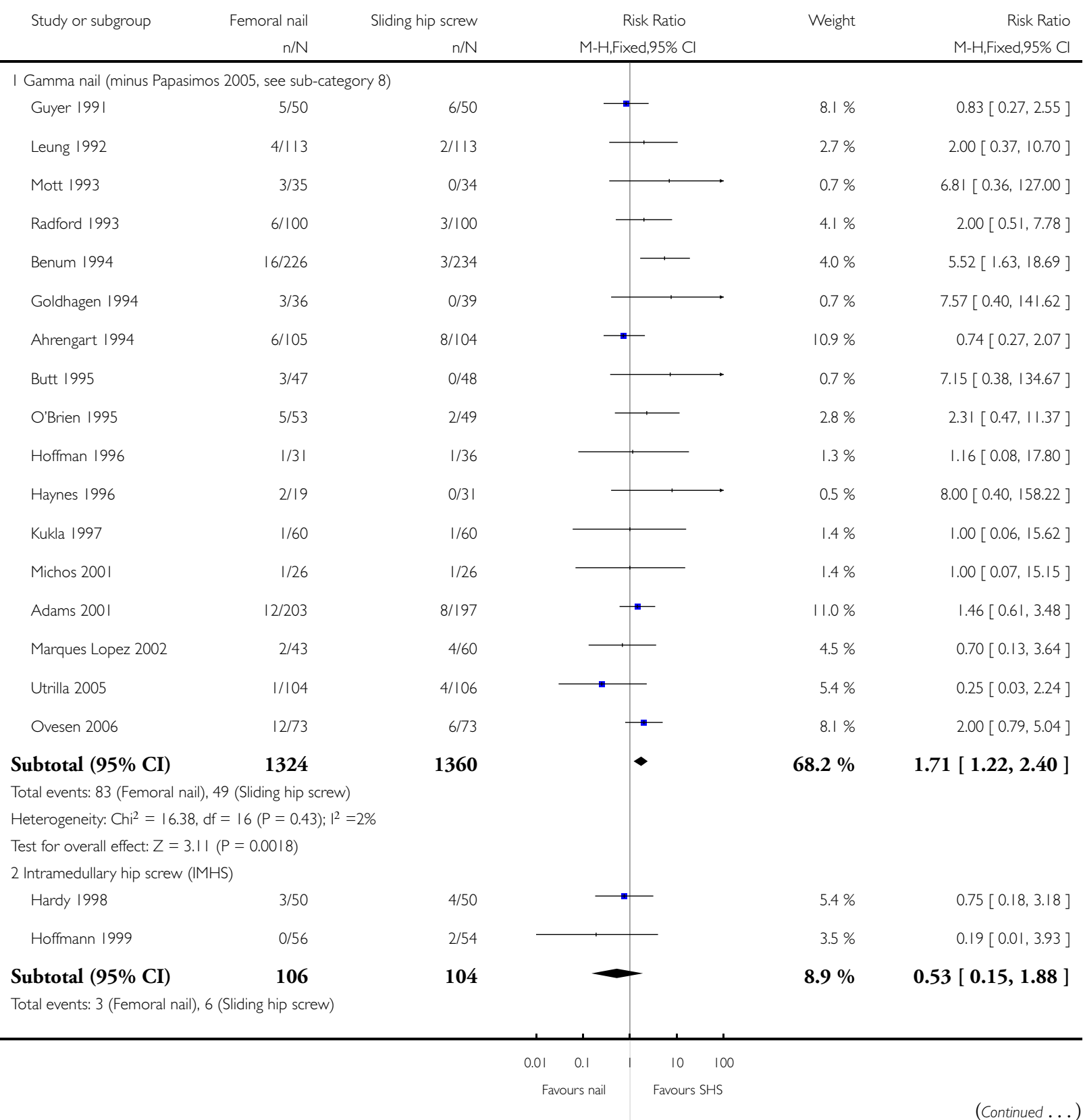

Gamma and other cephalocondylic intramedullary nails versus extramedullary implants for extracapsular hip fractures in adults (Review) I I 2 Copyright (C) 2010 The Cochrane Collaboration. Published by John Wiley \& Sons, Ltd. 


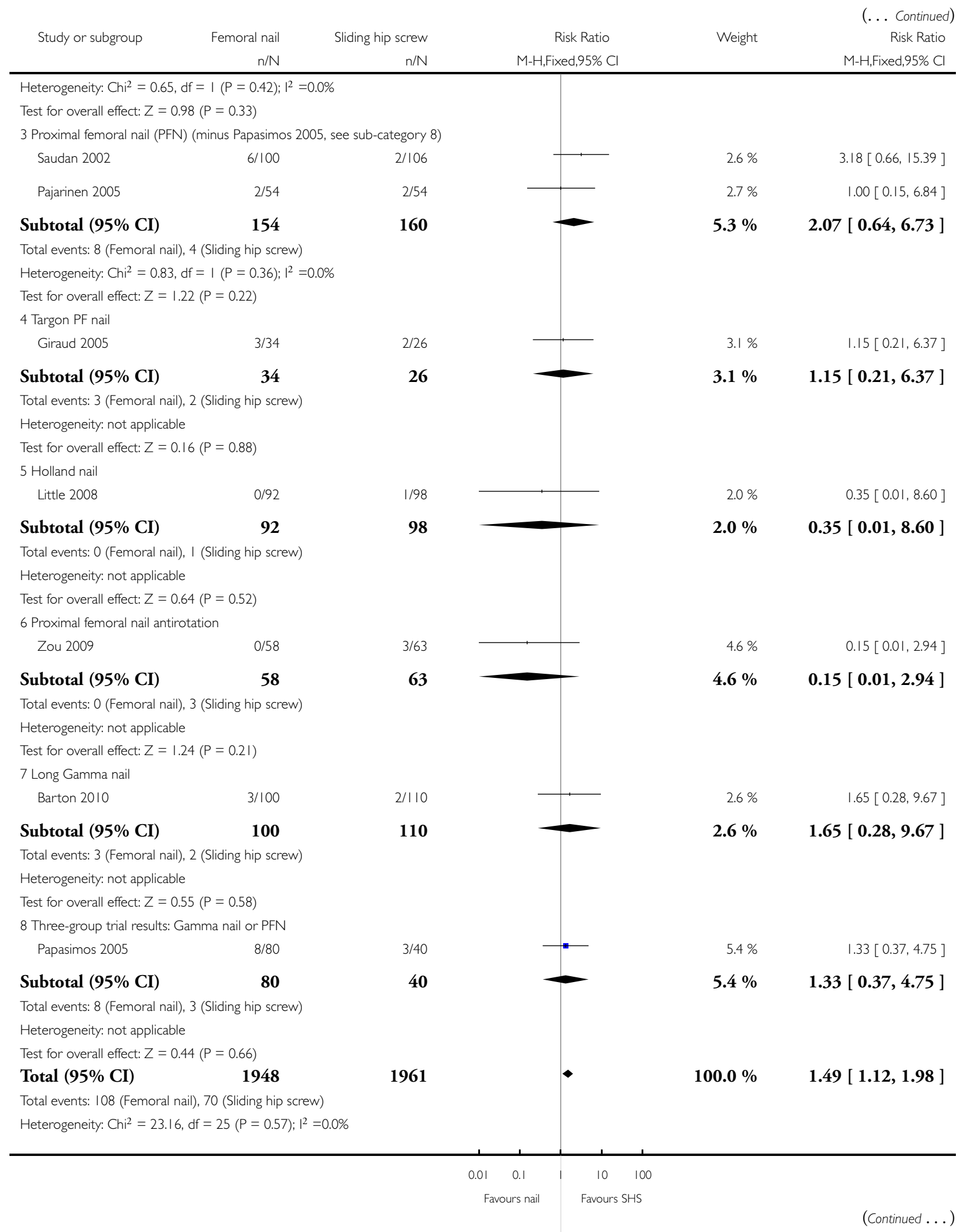

Gamma and other cephalocondylic intramedullary nails versus extramedullary implants for extracapsular hip fractures in adults (Review) I I 3 Copyright (C) 2010 The Cochrane Collaboration. Published by John Wiley \& Sons, Ltd. 


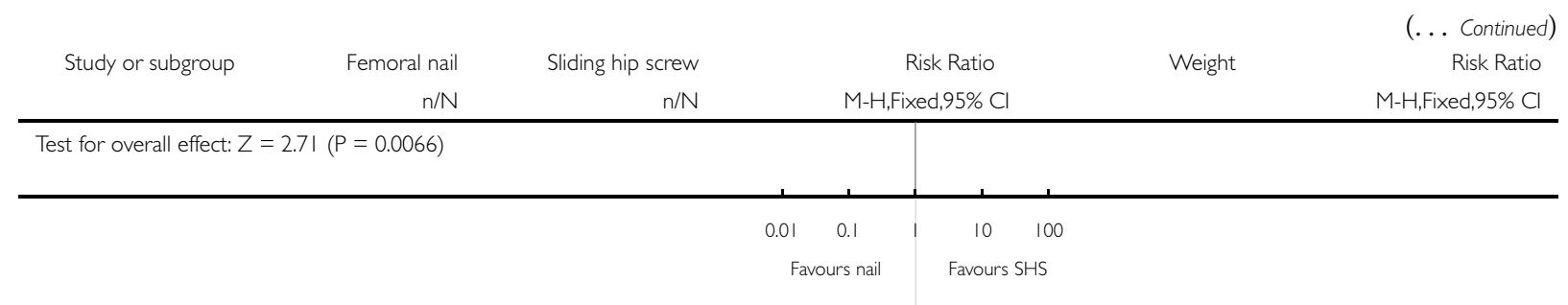

\section{Analysis I.7. Comparison I Summary: Femoral nail (all types) versus sliding hip screw (SHS), Outcome 7 Deep wound infection.}

Review: Gamma and other cephalocondylic intramedullary nails versus extramedullary implants for extracapsular hip fractures in adults

Comparison: I Summary: Femoral nail (all types) versus sliding hip screw (SHS)

Outcome: 7 Deep wound infection

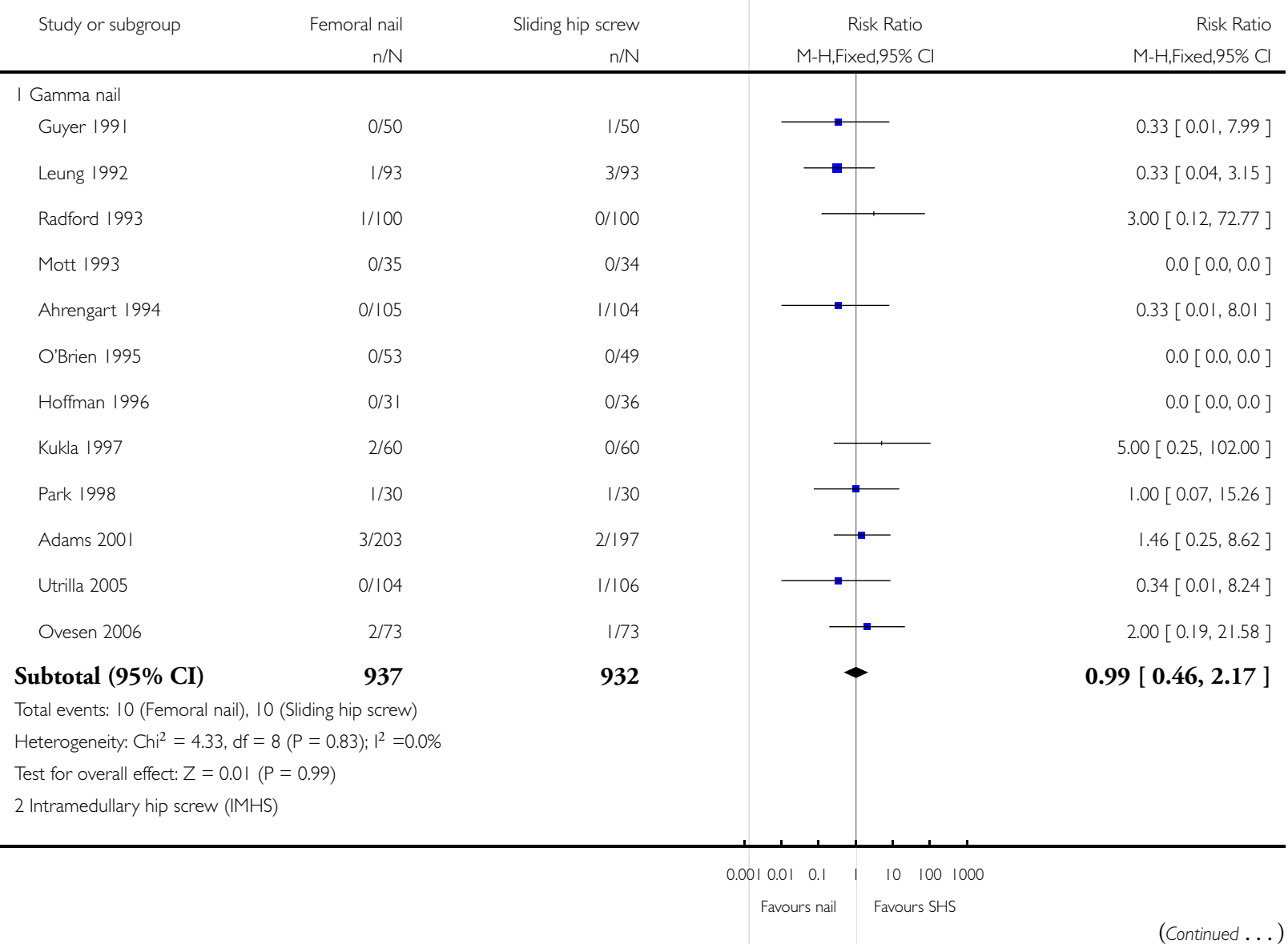

Gamma and other cephalocondylic intramedullary nails versus extramedullary implants for extracapsular hip fractures in adults (Review) I I4 Copyright (C) 2010 The Cochrane Collaboration. Published by John Wiley \& Sons, Ltd. 


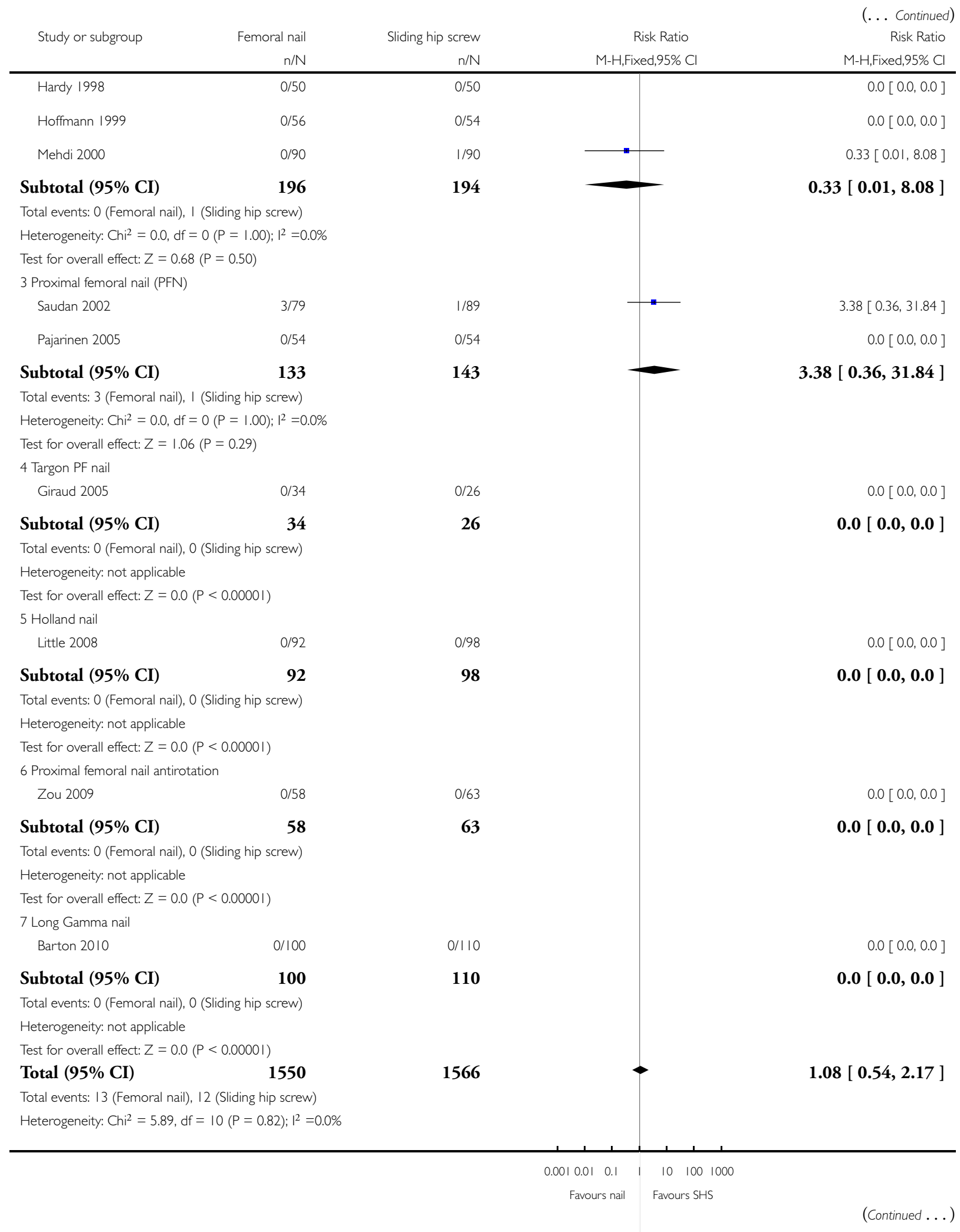

Gamma and other cephalocondylic intramedullary nails versus extramedullary implants for extracapsular hip fractures in adults (Review) II 5 Copyright (C) 2010 The Cochrane Collaboration. Published by John Wiley \& Sons, Ltd. 


\begin{tabular}{|c|c|c|c|c|}
\hline \multirow[t]{2}{*}{ Study or subgroup } & Femoral nail & Sliding hip screw & Risk Ratio & $\begin{array}{c}\text { (.... Continued) } \\
\text { Risk Ratio }\end{array}$ \\
\hline & $n / N$ & $n / N$ & M-H,Fixed,95\% Cl & M-H,Fixed,95\% Cl \\
\hline
\end{tabular}

Test for overall effect: $Z=0.21(P=0.83)$

$0.0010 .010 .1 \quad 1 \quad 10 \quad 1001000$

Favours nail Favours SHS

Analysis I.8. Comparison I Summary: Femoral nail (all types) versus sliding hip screw (SHS), Outcome 8 Mortality.

Review: Gamma and other cephalocondylic intramedullary nails versus extramedullary implants for extracapsular hip fractures in adults

Comparison: I Summary: Femoral nail (all types) versus sliding hip screw (SHS)

Outcome: 8 Mortality

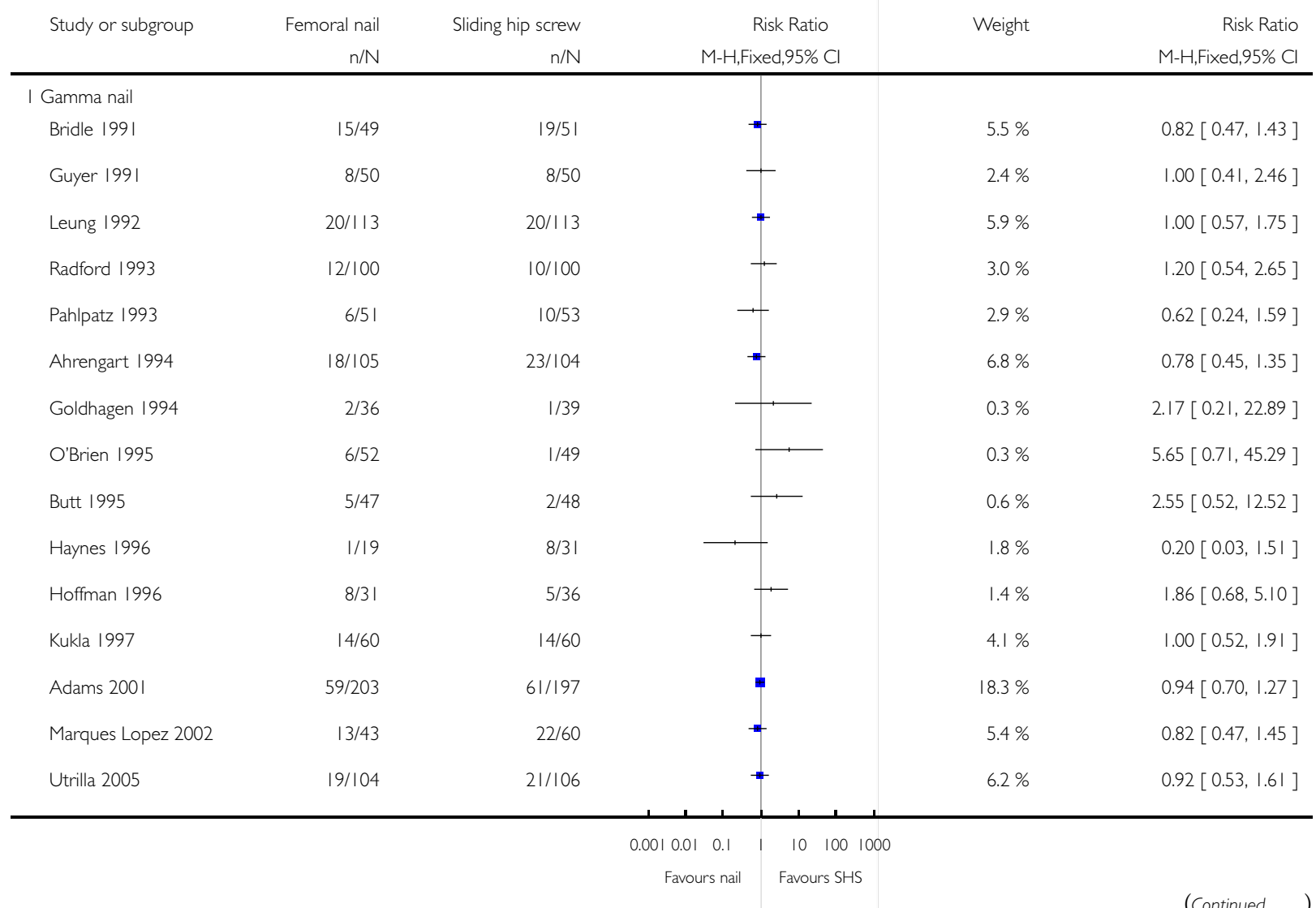

Gamma and other cephalocondylic intramedullary nails versus extramedullary implants for extracapsular hip fractures in adults (Review) I I6 Copyright (c) 2010 The Cochrane Collaboration. Published by John Wiley \& Sons, Ltd. 


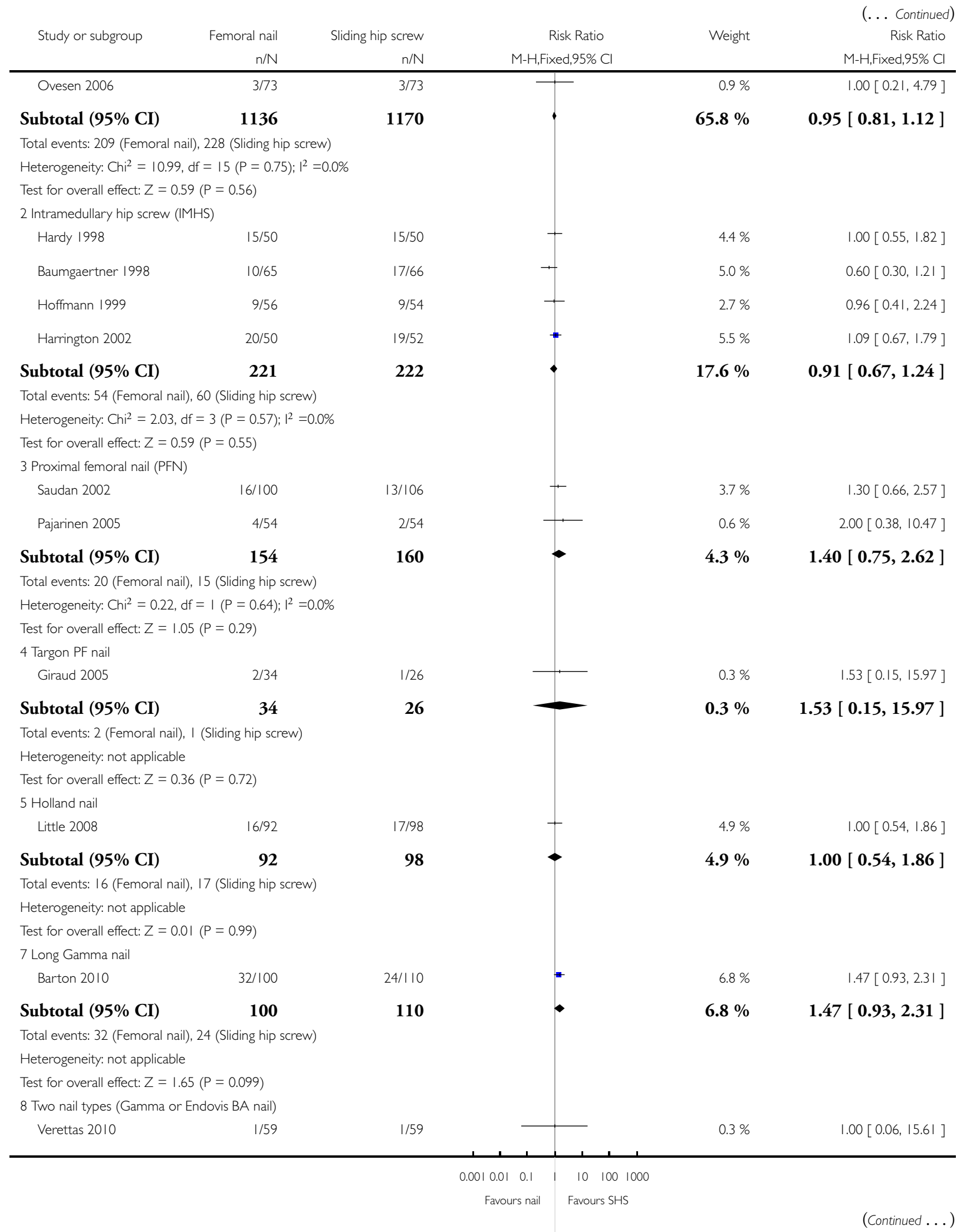

Gamma and other cephalocondylic intramedullary nails versus extramedullary implants for extracapsular hip fractures in adults (Review) II 7 Copyright (C) 2010 The Cochrane Collaboration. Published by John Wiley \& Sons, Ltd. 


\begin{tabular}{|c|c|c|c|c|c|}
\hline \multirow[t]{2}{*}{ Study or subgroup } & Femoral nail & Sliding hip screw & Risk Ratio & Weight & $\begin{array}{r}\text { (... Continued } \\
\text { Risk Ratio } \\
\text { M-H.Fixed.95\% Cl }\end{array}$ \\
\hline & $\mathrm{n} / \mathrm{N}$ & $\mathrm{n} / \mathrm{N}$ & M-H,Fixed,95\% Cl & & M-H,Fixed,95\% Cl \\
\hline Subtotal $(95 \% \mathrm{CI})$ & 59 & 59 & & $0.3 \%$ & $1.00[0.06,15.61]$ \\
\hline \multicolumn{6}{|c|}{ Total events: I (Femoral nail), I (Sliding hip screw) } \\
\hline \multicolumn{6}{|c|}{ Heterogeneity: not applicable } \\
\hline \multicolumn{6}{|c|}{ Test for overall effect: $Z=0.0(P=1.0)$} \\
\hline Total $(95 \% \mathrm{CI})$ & 1796 & 1845 & 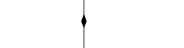 & $100.0 \%$ & $1.00[0.88,1.15]$ \\
\hline \multicolumn{6}{|c|}{ Total events: 334 (Femoral nail), 346 (Sliding hip screw) } \\
\hline \multicolumn{6}{|c|}{ Heterogeneity: $\mathrm{Chi}^{2}=17.80, \mathrm{df}=25(\mathrm{P}=0.85) ; \mathrm{I}^{2}=0.0 \%$} \\
\hline \multicolumn{6}{|c|}{ Test for overall effect: $Z=0.05(P=0.96)$} \\
\hline
\end{tabular}

\section{Analysis I.9. Comparison I Summary: Femoral nail (all types) versus sliding hip screw (SHS), Outcome 9} Pain at follow-up.

Review: Gamma and other cephalocondylic intramedullary nails versus extramedullary implants for extracapsular hip fractures in adults

Comparison: I Summary: Femoral nail (all types) versus sliding hip screw (SHS)

Outcome: 9 Pain at follow-up

$\begin{array}{llll}\text { Study or subgroup } & \text { Femoral nail } & \text { Sliding hip screw } & \text { Risk Ratio }\end{array}$

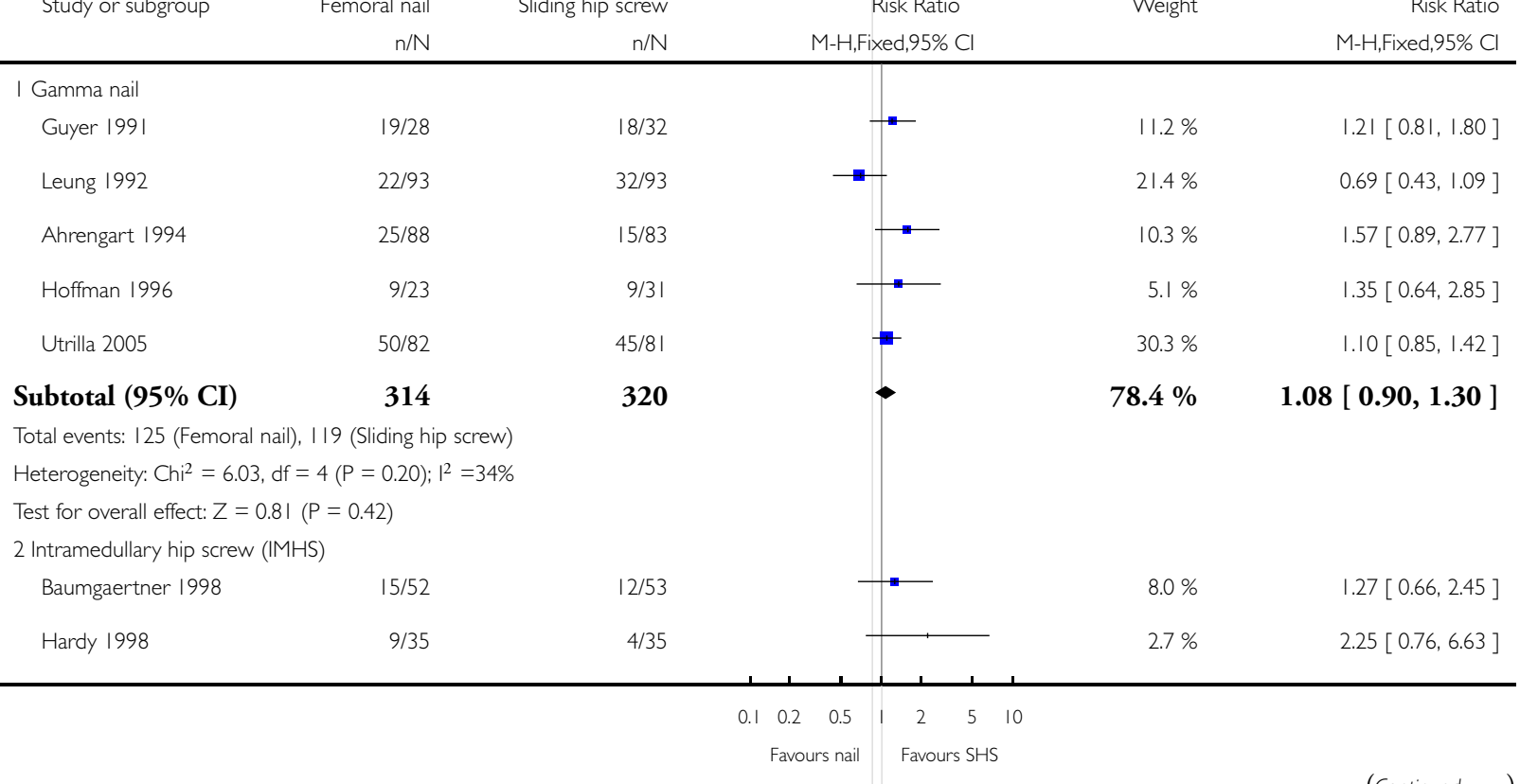

(Continued ...)

Gamma and other cephalocondylic intramedullary nails versus extramedullary implants for extracapsular hip fractures in adults (Review) II 8 Copyright (C) 2010 The Cochrane Collaboration. Published by John Wiley \& Sons, Ltd. 


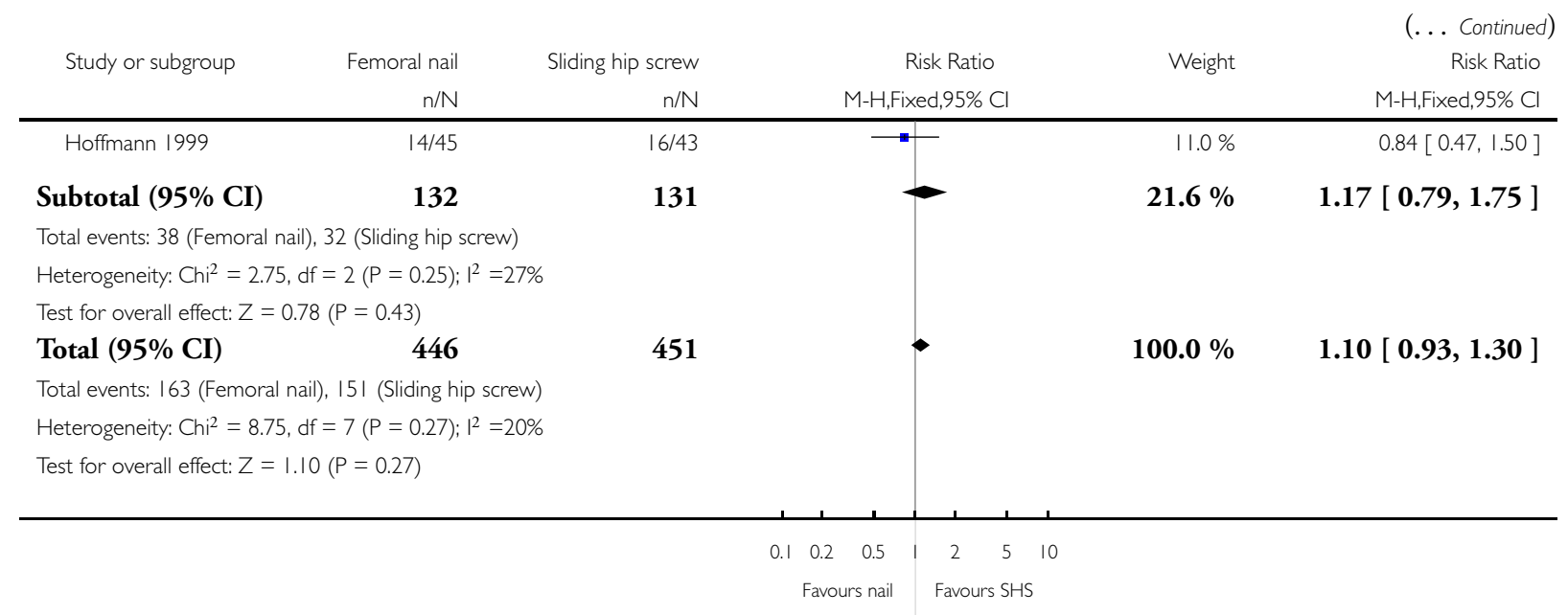

Analysis I.10. Comparison I Summary: Femoral nail (all types) versus sliding hip screw (SHS), Outcome 10 Non return to previous residence or dead.

Review: Gamma and other cephalocondylic intramedullary nails versus extramedullary implants for extracapsular hip fractures in adults

Comparison: I Summary: Femoral nail (all types) versus sliding hip screw (SHS)

Outcome: 10 Non return to previous residence or dead

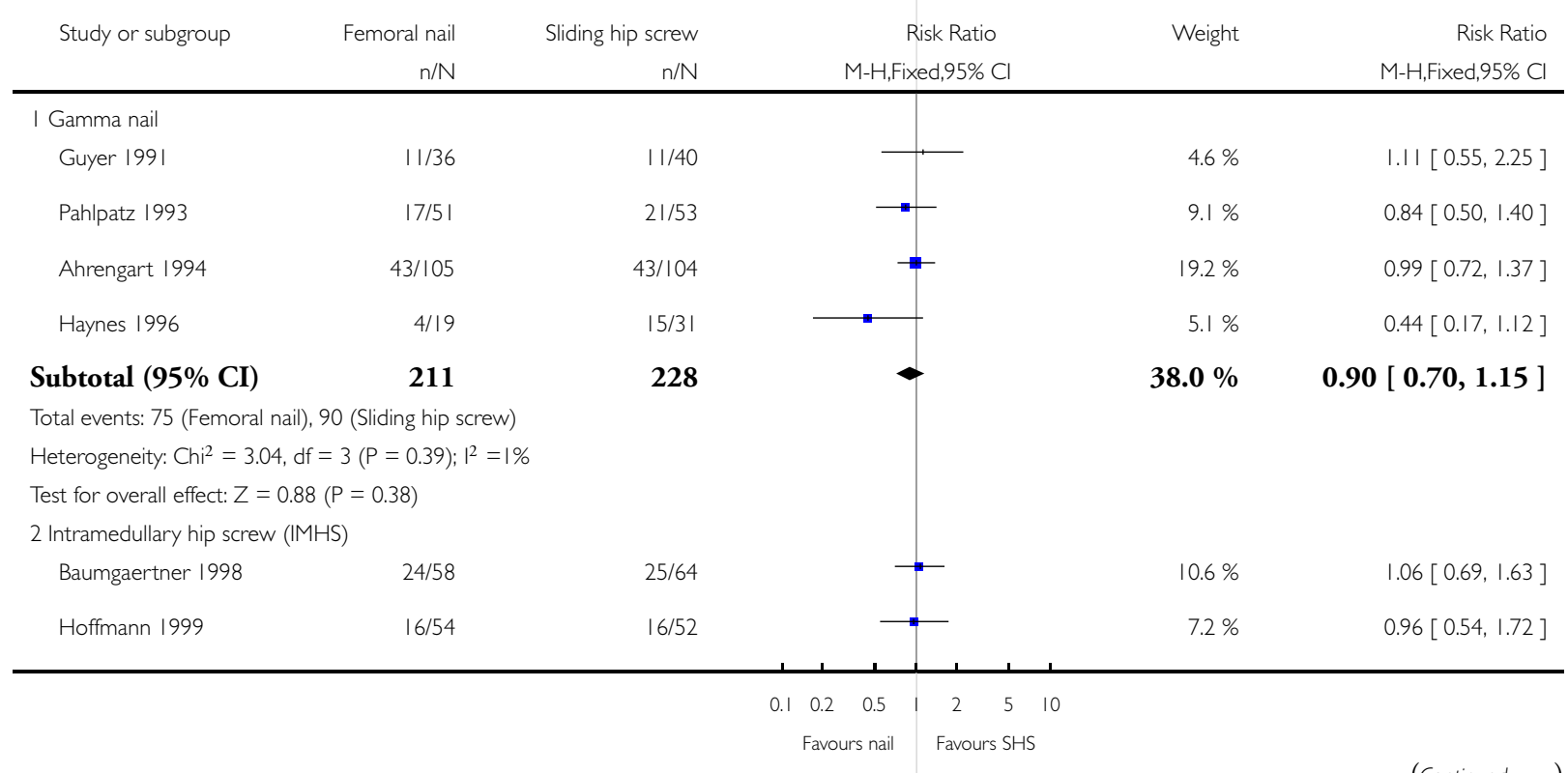

(Continued ...)

Gamma and other cephalocondylic intramedullary nails versus extramedullary implants for extracapsular hip fractures in adults (Review) II9 Copyright (@) 2010 The Cochrane Collaboration. Published by John Wiley \& Sons, Ltd. 


\begin{tabular}{|c|c|c|c|c|c|}
\hline \multirow[t]{2}{*}{ Study or subgroup } & Femoral nail & Sliding hip screw & Risk Ratio & Weight & $\begin{array}{c}\text { (... Continued) } \\
\text { Risk Ratio }\end{array}$ \\
\hline & $\mathrm{n} / \mathrm{N}$ & $n / N$ & M-H,Fixed,95\% Cl & & M-H,Fixed,95\% Cl \\
\hline Harrington 2002 & $31 / 50$ & $30 / 52$ & $\rightarrow$ & $13.1 \%$ & $1.07[0.78,1.48]$ \\
\hline Subtotal $(95 \% \mathrm{CI})$ & 162 & 168 & - & $30.8 \%$ & $1.04[0.82,1.33]$ \\
\hline \multicolumn{6}{|c|}{ Total events: 71 (Femoral nail), 71 (Sliding hip screw) } \\
\hline \multicolumn{6}{|c|}{ Heterogeneity: $\mathrm{Ch}^{2}=0.1 \mathrm{l}, \mathrm{df}=2(\mathrm{P}=0.95) ; \mathrm{I}^{2}=0.0 \%$} \\
\hline \multicolumn{6}{|c|}{ Test for overall effect: $Z=0.34(P=0.73)$} \\
\hline \multicolumn{6}{|c|}{3 Proximal femoral nail (PFN) } \\
\hline Saudan 2002 & $58 / 95$ & $52 / 102$ & 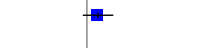 & $22.3 \%$ & $1.20[0.93,1.54]$ \\
\hline Pajarinen 2005 & $18 / 52$ & $20 / 52$ & - & $8.9 \%$ & $0.90[0.54,1.50]$ \\
\hline Subtotal $(95 \% \mathrm{CI})$ & 147 & 154 & $\rightarrow$ & $31.1 \%$ & $1.11[0.89,1.39]$ \\
\hline \multicolumn{6}{|c|}{ Total events: 76 (Femoral nail), 72 (Sliding hip screw) } \\
\hline \multicolumn{6}{|c|}{ Heterogeneity: $\mathrm{Chi}^{2}=1.01, \mathrm{df}=1(P=0.32) ; 1^{2}=1 \%$} \\
\hline \multicolumn{6}{|c|}{ Test for overall effect: $Z=0.93(P=0.35)$} \\
\hline Total $(95 \% \mathrm{CI})$ & 520 & 550 & $\bullet$ & $100.0 \%$ & $1.01[0.88,1.16]$ \\
\hline \multicolumn{6}{|c|}{ Total events: 222 (Femoral nail), 233 (Sliding hip screw) } \\
\hline \multicolumn{6}{|c|}{ Heterogeneity: $\mathrm{Chi}^{2}=5.87, \mathrm{df}=8(\mathrm{P}=0.66) ; \mathrm{I}^{2}=0.0 \%$} \\
\hline Test for overall effect: $Z=$ & $P=0.90)$ & & & & \\
\hline
\end{tabular}




\section{Analysis 2.I. Comparison 2 Gamma nail versus sliding hip screw (SHS), Outcome I Length of surgery}

(minutes).

Review: Gamma and other cephalocondylic intramedullary nails versus extramedullary implants for extracapsular hip fractures in adults

Comparison: 2 Gamma nail versus sliding hip screw (SHS)

Outcome: I Length of surgery (minutes)

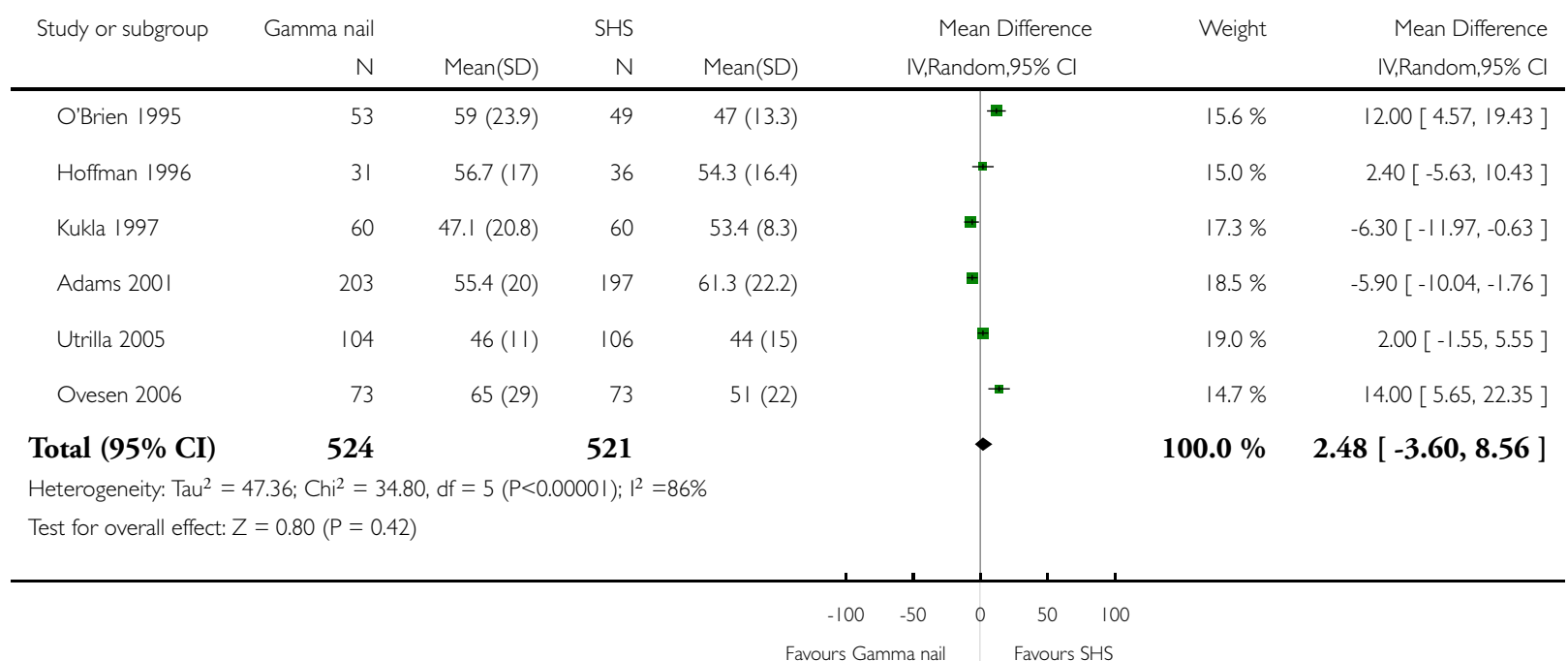


Analysis 2.2. Comparison 2 Gamma nail versus sliding hip screw (SHS), Outcome 2 Blood loss (ml).

Review: Gamma and other cephalocondylic intramedullary nails versus extramedullary implants for extracapsular hip fractures in adults

Comparison: 2 Gamma nail versus sliding hip screw (SHS)

Outcome: 2 Blood loss ( $\mathrm{ml})$

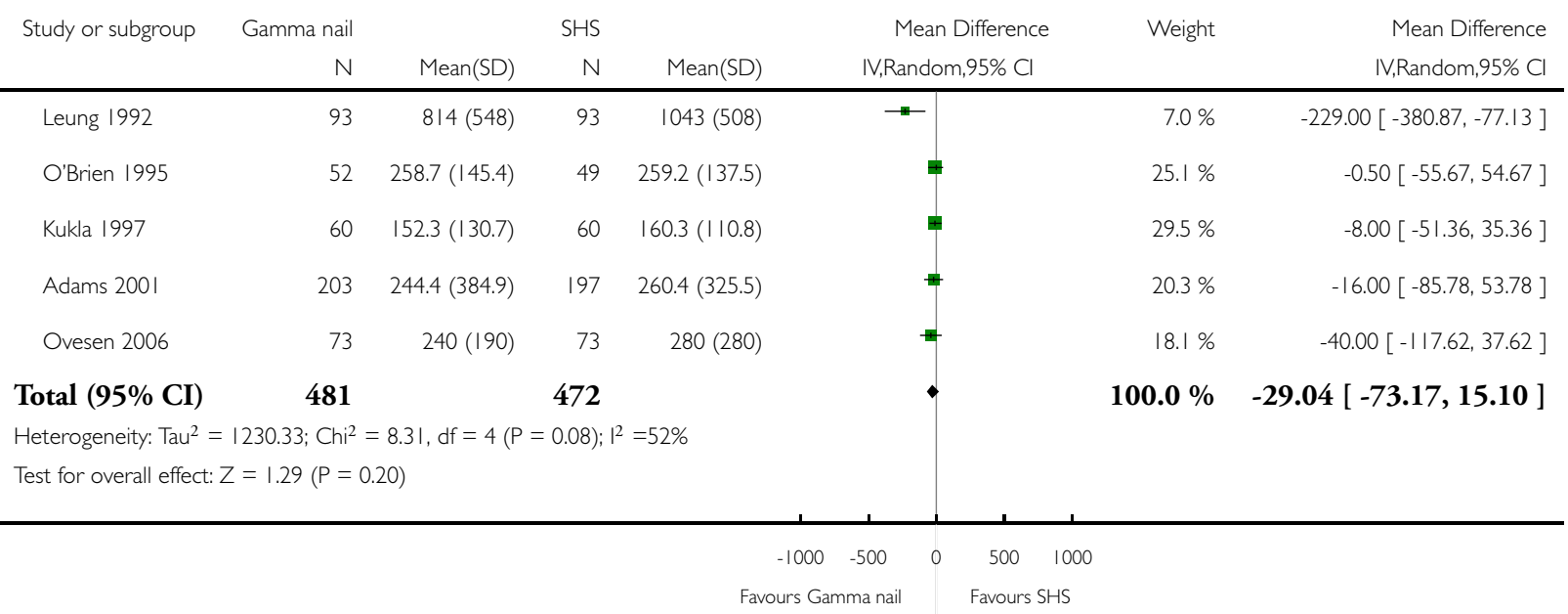

Analysis 2.3. Comparison 2 Gamma nail versus sliding hip screw (SHS), Outcome 3 Number of people given transfusion.

Review: Gamma and other cephalocondylic intramedullary nails versus extramedullary implants for extracapsular hip fractures in adults

Comparison: 2 Gamma nail versus sliding hip screw (SHS)

Outcome: 3 Number of people given transfusion

\begin{tabular}{|c|c|c|c|c|c|}
\hline \multirow[t]{2}{*}{ Study or subgroup } & Gamma nail & SHS & Risk Ratio & \multirow[t]{2}{*}{ Weight } & Risk Ratio \\
\hline & $\mathrm{n} / \mathrm{N}$ & $\mathrm{n} / \mathrm{N}$ & $\mathrm{M}-\mathrm{H}, \mathrm{Random}, 95 \% \mathrm{Cl}$ & & $\mathrm{M}-\mathrm{H}$, Random, $95 \% \mathrm{Cl}$ \\
\hline Adams 2001 & $108 / 203$ & $88 / 197$ & $\mathbf{\theta}$ & $39.7 \%$ & $1.19[0.97,1.46]$ \\
\hline Utrilla 2005 & $28 / 104$ & $44 / 106$ & $=$ & $32.9 \%$ & $0.65[0.44,0.96]$ \\
\hline Ovesen 2006 & $26 / 73$ & $16 / 73$ & 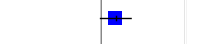 & $27.4 \%$ & $1.63[0.95,2.77]$ \\
\hline Total (95\% CI) & 380 & 376 & - & $100.0 \%$ & $1.06[0.67,1.68]$ \\
\hline \multicolumn{6}{|c|}{ Total events: I62 (Gamma nail), I48 (SHS) } \\
\hline \multicolumn{6}{|c|}{ Heterogeneity: $\operatorname{Tau}^{2}=0.13 ; \mathrm{Chi}^{2}=9.77, \mathrm{df}=2(\mathrm{P}=0.0 \mathrm{I}) ; \mathrm{I}^{2}=80 \%$} \\
\hline \multicolumn{6}{|c|}{ Test for overall effect: $Z=0.25(P=0.80)$} \\
\hline
\end{tabular}

$\begin{array}{lllll}0.01 & 0.1 & 1 & 10 & 100\end{array}$

Favours Gamma nail $\quad$ Favours SHS

Gamma and other cephalocondylic intramedullary nails versus extramedullary implants for extracapsular hip fractures in adults (Review) $\quad 22$ Copyright (C) 2010 The Cochrane Collaboration. Published by John Wiley \& Sons, Ltd. 
Analysis 2.4. Comparison 2 Gamma nail versus sliding hip screw (SHS), Outcome 4 Radiographic screening time (seconds).

Review: Gamma and other cephalocondylic intramedullary nails versus extramedullary implants for extracapsular hip fractures in adults

Comparison: 2 Gamma nail versus sliding hip screw (SHS)

Outcome: 4 Radiographic screening time (seconds)

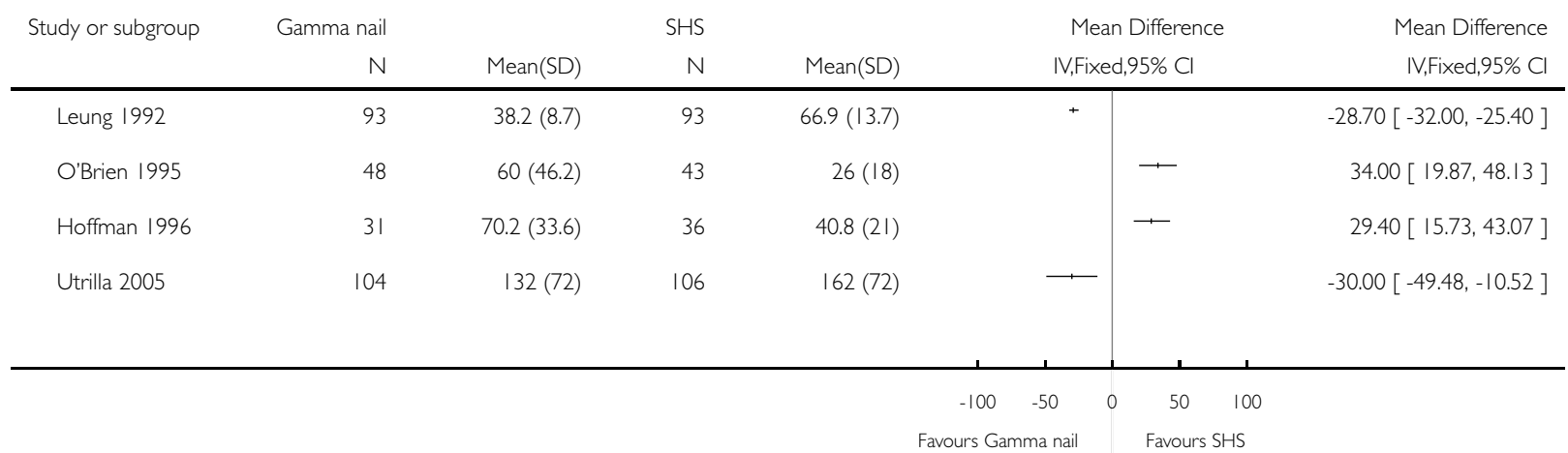

Analysis 2.5. Comparison 2 Gamma nail versus sliding hip screw (SHS), Outcome 5 Operative fracture of femur.

Review: Gamma and other cephalocondylic intramedullary nails versus extramedullary implants for extracapsular hip fractures in adults

Comparison: 2 Gamma nail versus sliding hip screw (SHS)

Outcome: 5 Operative fracture of femur

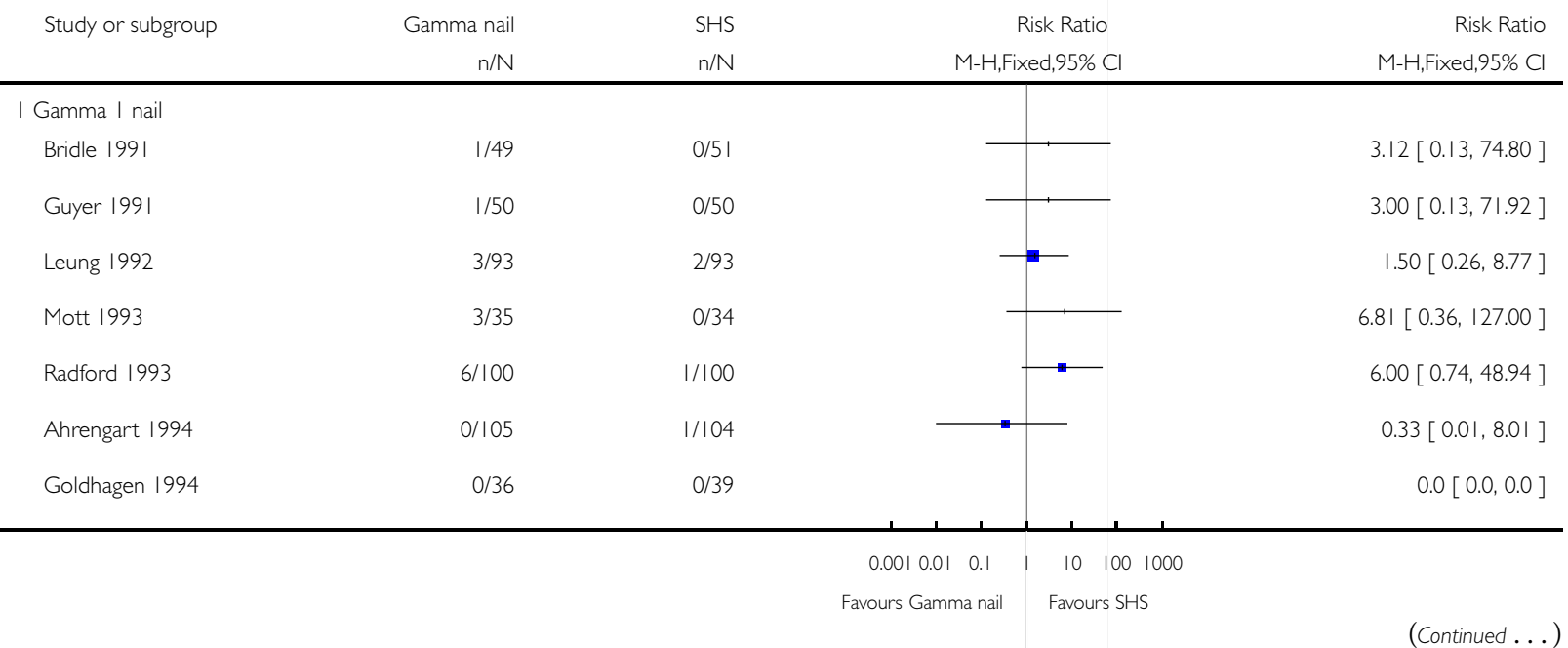

Gamma and other cephalocondylic intramedullary nails versus extramedullary implants for extracapsular hip fractures in adults (Review) I 23 Copyright (C) 2010 The Cochrane Collaboration. Published by John Wiley \& Sons, Ltd. 


\begin{tabular}{|c|c|c|c|c|}
\hline \multirow[t]{2}{*}{ Study or subgroup } & $\begin{array}{r}\text { Gamma nail } \\
n / N\end{array}$ & SHS & Risk Ratio & \multirow[t]{2}{*}{$\begin{array}{c}\text { (... Continued) } \\
\text { Risk Ratio } \\
\text { M-H,Fixed, } 95 \% \text { Cl }\end{array}$} \\
\hline & $n / N$ & $n / N$ & M-H,Fixed,95\% Cl & \\
\hline Benum 1994 & $4 / 226$ & $0 / 234$ & + & $9.32[0.50,172.07]$ \\
\hline O'Brien 1995 & $2 / 53$ & $0 / 49$ & $\longrightarrow$ & $4.63[0.23,94.10]$ \\
\hline Hoffman 1996 & $|/ 3|$ & $0 / 36$ & & $3.47[0.15,82.21]$ \\
\hline Kukla 1997 & $0 / 60$ & $0 / 60$ & & $0.0[0.0,0.0]$ \\
\hline Park 1998 & $0 / 30$ & $0 / 30$ & & $0.0[0.0,0.0]$ \\
\hline Kuwabara 1998 & $0 / 20$ & $0 / 23$ & & $0.0[0.0,0.0]$ \\
\hline Adams 2001 & $1 / 203$ & $0 / 197$ & & $2.91[0.12,71.05]$ \\
\hline Marques Lopez 2002 & $0 / 43$ & $0 / 60$ & & $0.0[0.0,0.0]$ \\
\hline Subtotal $(95 \% \mathrm{CI})$ & 1134 & 1160 & $<$ & $3.26[1.49,7.16]$ \\
\hline \multicolumn{5}{|c|}{ Total events: 22 (Gamma nail), 4 (SHS) } \\
\hline \multicolumn{5}{|c|}{ Heterogeneity: $\mathrm{Chi}^{2}=3.85, \mathrm{df}=9(\mathrm{P}=0.92) ; \mathrm{I}^{2}=0.0 \%$} \\
\hline \multicolumn{5}{|c|}{ Test for overall effect: $Z=2.95(P=0.0032)$} \\
\hline \multicolumn{5}{|l|}{2 Trochanteric Gamma nail } \\
\hline Papasimos 2005 & $1 / 40$ & $0 / 40$ & 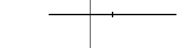 & $3.00[0.13,71.51]$ \\
\hline Utrilla 2005 & $4 / 104$ & $2 / 106$ & - & $2.04[0.38,10.89]$ \\
\hline Ovesen 2006 & $0 / 73$ & $0 / 73$ & & $0.0[0.0,0.0]$ \\
\hline Subtotal $(95 \% \mathrm{CI})$ & 217 & 219 & - & $2.23[0.51,9.78]$ \\
\hline \multicolumn{5}{|c|}{ Total events: 5 (Gamma nail), 2 (SHS) } \\
\hline \multicolumn{5}{|c|}{ Heterogeneity: $\mathrm{Ch}^{2}=0.04, \mathrm{df}=|(P=0.83) ;|^{2}=0.0 \%$} \\
\hline \multicolumn{5}{|c|}{ Test for overall effect: $Z=1.07(P=0.29)$} \\
\hline Total $(95 \%$ CI $)$ & 1351 & 1379 & $\bullet$ & $3.02[1.51,6.03]$ \\
\hline \multicolumn{5}{|c|}{ Total events: 27 (Gamma nail), 6 (SHS) } \\
\hline \multicolumn{5}{|c|}{ Heterogeneity: $\mathrm{Ch}^{2}=4.03, \mathrm{df}=1 \mathrm{I}(\mathrm{P}=0.97) ;\left.\right|^{2}=0.0 \%$} \\
\hline Test for overall effect: $Z=$ & 018) & & & \\
\hline
\end{tabular}


Analysis 2.6. Comparison 2 Gamma nail versus sliding hip screw (SHS), Outcome 6 Operative fracture of femur (reported experience with devices).

Review: Gamma and other cephalocondylic intramedullary nails versus extramedullary implants for extracapsular hip fractures in adults

Comparison: 2 Gamma nail versus sliding hip screw (SHS)

Outcome: 6 Operative fracture of femur (reported experience with devices)

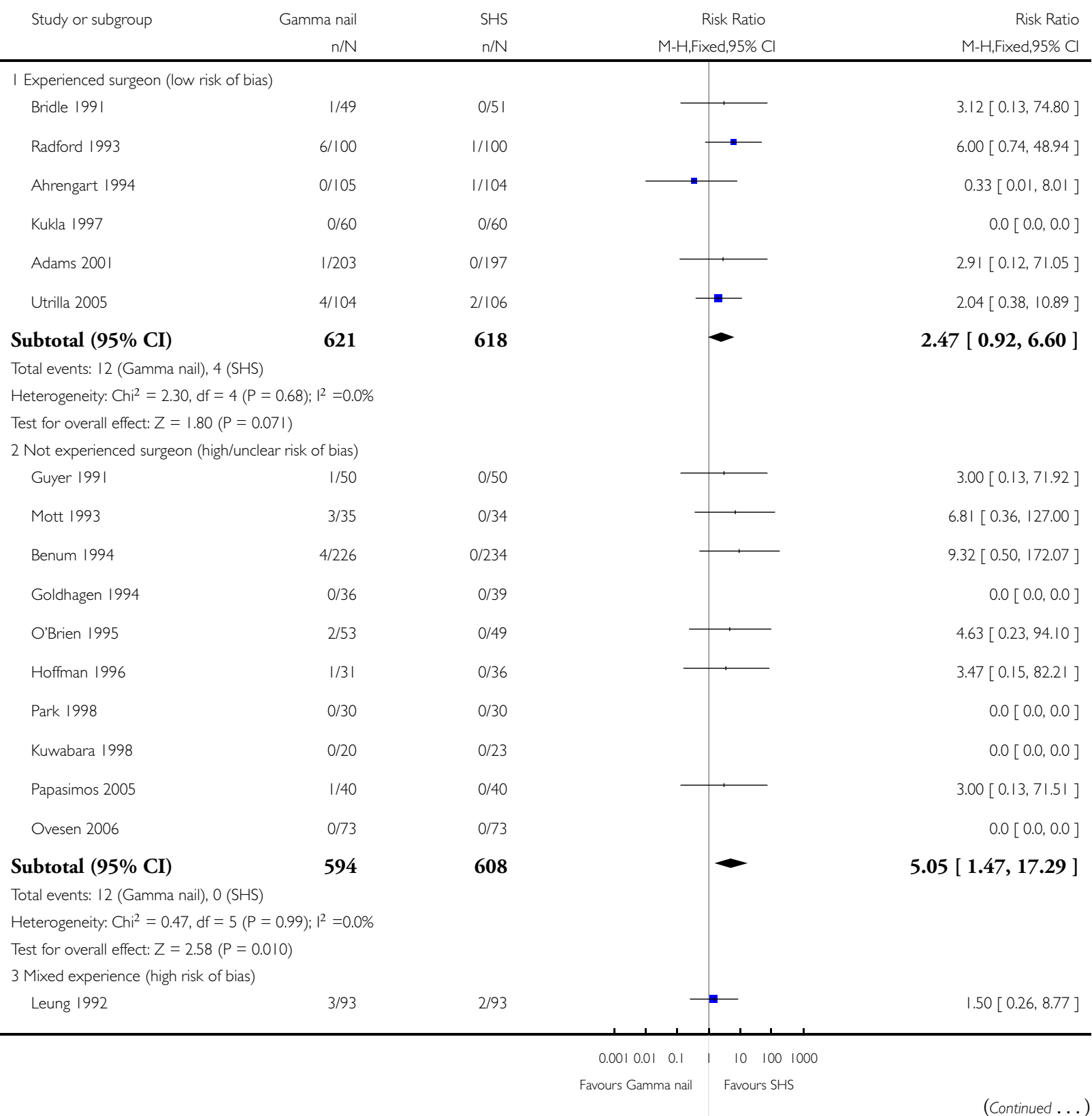

Gamma and other cephalocondylic intramedullary nails versus extramedullary implants for extracapsular hip fractures in adults (Review) $\quad 25$ Copyright (C) 2010 The Cochrane Collaboration. Published by John Wiley \& Sons, Ltd. 


\begin{tabular}{|c|c|c|c|c|}
\hline \multirow[t]{2}{*}{ Study or subgroup } & \multirow{2}{*}{$\begin{array}{r}\text { Gamma nail } \\
n / N\end{array}$} & $\begin{array}{l}\mathrm{SHS} \\
\mathrm{n} / \mathrm{N}\end{array}$ & \multirow{2}{*}{$\begin{array}{c}\text { Risk Ratio } \\
\text { M-H,Fixed,95\% Cl }\end{array}$} & \multirow[t]{2}{*}{$\begin{array}{c}\text { (... Continued) } \\
\text { Risk Ratio } \\
\text { M-H,Fixed,95\% Cl }\end{array}$} \\
\hline & & $\mathrm{n} / \mathrm{N}$ & & \\
\hline Marques Lopez 2002 & $0 / 43$ & $0 / 60$ & & $0.0[0.0,0.0]$ \\
\hline Subtotal $(95 \% \mathrm{CI})$ & 136 & 153 & - & $1.50[0.26,8.77]$ \\
\hline \multicolumn{5}{|c|}{ Total events: 3 (Gamma nail), 2 (SHS) } \\
\hline \multicolumn{5}{|c|}{ Heterogeneity: $\mathrm{Chi}^{2}=0.0, \mathrm{df}=0(\mathrm{P}=1.00) ; 1^{2}=0.0 \%$} \\
\hline \multicolumn{5}{|c|}{ Test for overall effect: $Z=0.45(P=0.65)$} \\
\hline Total $(95 \% \mathrm{CI})$ & 1351 & 1379 & $\bullet$ & $3.02[1.51,6.03]$ \\
\hline \multicolumn{5}{|c|}{ Total events: 27 (Gamma nail), 6 (SHS) } \\
\hline \multicolumn{5}{|c|}{ Heterogeneity: $\mathrm{Ch}^{2}=4.03, \mathrm{df}=1 \mathrm{I}(\mathrm{P}=0.97) ; \mathrm{I}^{2}=0.0 \%$} \\
\hline Test for overall effect: $Z=$ & $0018)$ & & & \\
\hline
\end{tabular}

$0.0010 .01 \quad 0.1 \quad 1 \quad 10 \quad 100 \quad 1000$

Favours Gamma nail Favours SHS

\section{Analysis 2.7. Comparison 2 Gamma nail versus sliding hip screw (SHS), Outcome 7 Later fracture of femur.}

Review: Gamma and other cephalocondylic intramedullary nails versus extramedullary implants for extracapsular hip fractures in adults

Comparison: 2 Gamma nail versus sliding hip screw (SHS)

Outcome: 7 Later fracture of femur

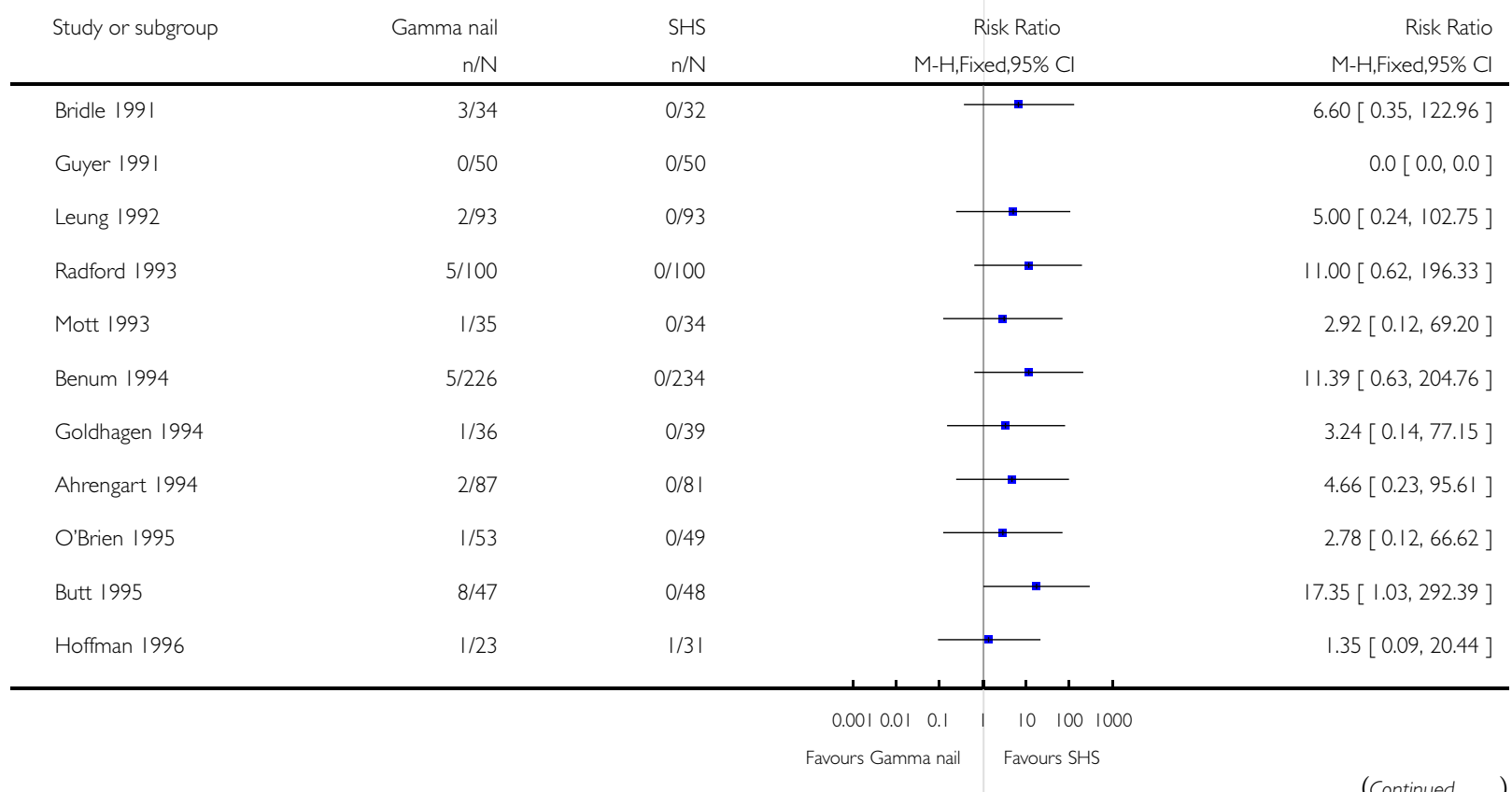

Gamma and other cephalocondylic intramedullary nails versus extramedullary implants for extracapsular hip fractures in adults (Review) $\quad 26$ Copyright (C) 2010 The Cochrane Collaboration. Published by John Wiley \& Sons, Ltd. 


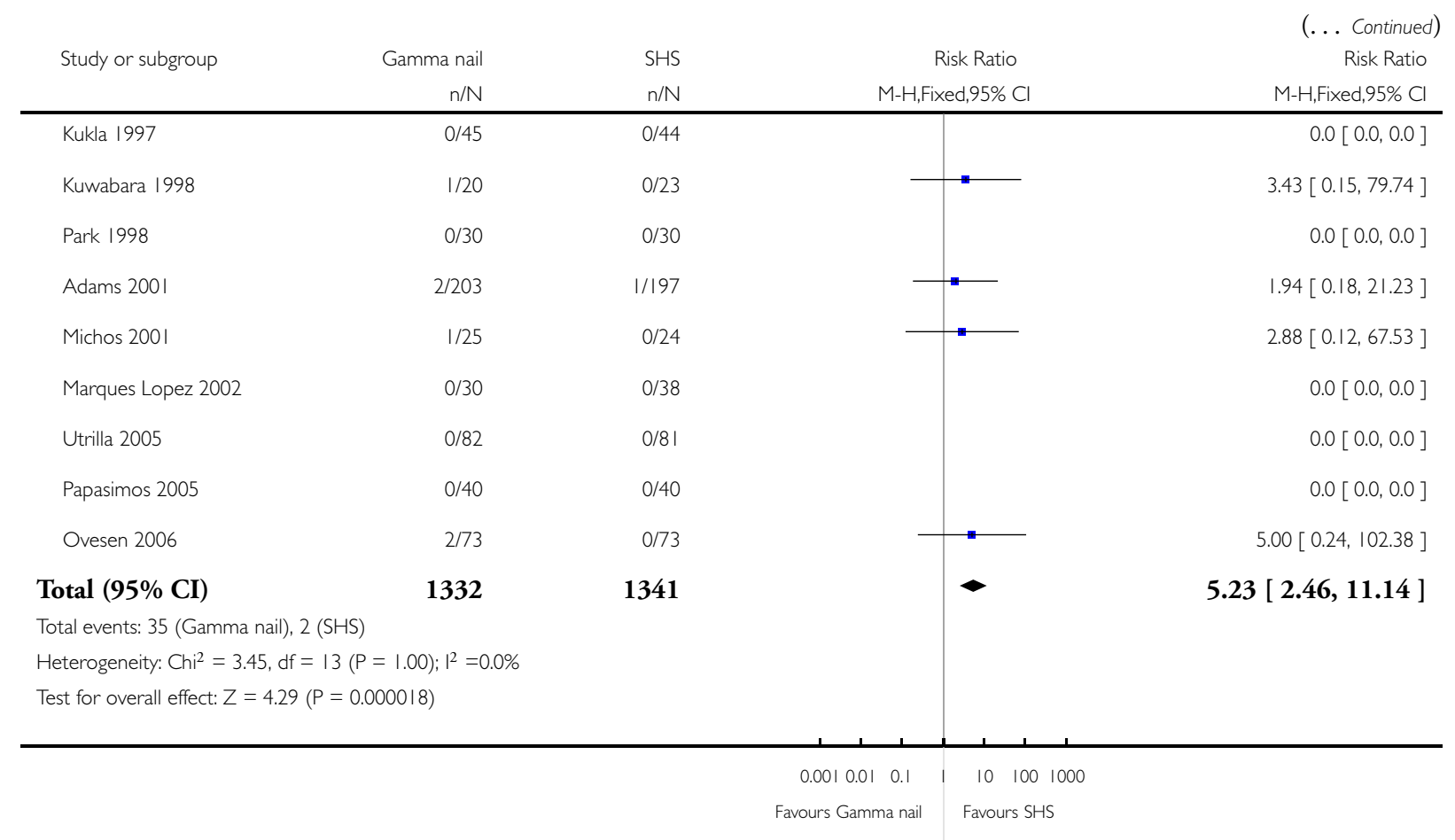

Gamma and other cephalocondylic intramedullary nails versus extramedullary implants for extracapsular hip fractures in adults (Review) $\quad$ I27 Copyright $\odot 2010$ The Cochrane Collaboration. Published by John Wiley \& Sons, Ltd. 


\section{Analysis 2.8. Comparison 2 Gamma nail versus sliding hip screw (SHS), Outcome 8 Cut-out.}

Review: Gamma and other cephalocondylic intramedullary nails versus extramedullary implants for extracapsular hip fractures in adults

Comparison: 2 Gamma nail versus sliding hip screw (SHS)

Outcome: 8 Cut-out

\begin{tabular}{|c|c|c|c|c|}
\hline \multirow[t]{2}{*}{ Study or subgroup } & Gamma nail & SHS & \multirow{2}{*}{$\begin{array}{c}\text { Risk Ratio } \\
\text { M-H,Fixed,95\% Cl }\end{array}$} & \multirow{2}{*}{$\begin{array}{r}\text { Risk Ratio } \\
\text { M-H,Fixed,95\% Cl }\end{array}$} \\
\hline & $\mathrm{n} / \mathrm{N}$ & $\mathrm{n} / \mathrm{N}$ & & \\
\hline Guyer 1991 & $1 / 50$ & $3 / 50$ & 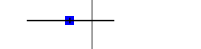 & $0.33[0.04,3.10]$ \\
\hline Bridle 1991 & $2 / 34$ & $3 / 32$ & - & $0.63[0.11,3.51]$ \\
\hline Leung 1992 & 2/93 & $3 / 93$ & - & $0.67[0.11,3.90]$ \\
\hline Mott 1993 & $3 / 35$ & $1 / 34$ & & $2.91[0.32,26.66]$ \\
\hline Radford 1993 & $2 / 100$ & $3 / 100$ & - & $0.67[0.11,3.90]$ \\
\hline Goldhagen 1994 & $2 / 36$ & $0 / 39$ & & $5.41[0.27,108.93]$ \\
\hline Ahrengart 1994 & $3 / 105$ & $3 / 104$ & & $0.99[0.20,4.80]$ \\
\hline Benum 1994 & $5 / 226$ & $2 / 234$ & & $2.59[0.51,13.21]$ \\
\hline O'Brien 1995 & $3 / 53$ & $1 / 49$ & & $2.77[0.30,25.78]$ \\
\hline Haynes 1996 & $2 / 18$ & $3 / 23$ & & $0.85[0.16,4.57]$ \\
\hline Hoffman 1996 & $1 / 23$ & $|/ 3|$ & & $1.35[0.09,20.44]$ \\
\hline Kukla 1997 & $0 / 45$ & $0 / 44$ & & $0.0[0.0,0.0]$ \\
\hline Park 1998 & $1 / 30$ & $1 / 30$ & & $1.00[0.07,15.26]$ \\
\hline Kuwabara 1998 & $1 / 20$ & $1 / 23$ & & $1.15[0.08,17.22]$ \\
\hline Adams 200I & $8 / 203$ & $4 / 197$ & & $1.94[0.59,6.34]$ \\
\hline Michos 200I & $0 / 25$ & $1 / 24$ & & $0.32[0.01,7.50]$ \\
\hline Marques Lopez 2002 & $0 / 43$ & $2 / 60$ & & $0.28[0.01,5.63]$ \\
\hline Papasimos 2005 & $2 / 40$ & $2 / 40$ & - & $1.00[0.15,6.76]$ \\
\hline Utrilla 2005 & $1 / 82$ & $2 / 81$ & + & $0.49[0.05,5.34]$ \\
\hline Ovesen 2006 & $7 / 73$ & $5 / 73$ & - & $1.40[0.47,4.21]$ \\
\hline Total (95\% CI) & 1334 & 1361 & 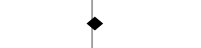 & $1.15[0.76,1.72]$ \\
\hline \multicolumn{5}{|c|}{ Total events: 46 (Gamma nail), 4I (SHS) } \\
\hline \multicolumn{5}{|c|}{ Heterogeneity: $\mathrm{Chi}^{2}=8.69, \mathrm{df}=18(\mathrm{P}=0.97) ;\left.\right|^{2}=0.0 \%$} \\
\hline \multicolumn{5}{|c|}{ Test for overall effect: $Z=0.66(P=0.5 \mathrm{I})$} \\
\hline
\end{tabular}

Gamma and other cephalocondylic intramedullary nails versus extramedullary implants for extracapsular hip fractures in adults (Review) $\quad 28$ Copyright (C) 2010 The Cochrane Collaboration. Published by John Wiley \& Sons, Ltd. 
Analysis 2.9. Comparison 2 Gamma nail versus sliding hip screw (SHS), Outcome 9 Cut-out (reported experience with devices).

Review: Gamma and other cephalocondylic intramedullary nails versus extramedullary implants for extracapsular hip fractures in adults

Comparison: 2 Gamma nail versus sliding hip screw (SHS)

Outcome: 9 Cut-out (reported experience with devices)

\begin{tabular}{|c|c|c|c|c|}
\hline \multirow[t]{2}{*}{ Study or subgroup } & \multirow{2}{*}{$\begin{array}{r}\text { Gamma nail } \\
n / N\end{array}$} & \multirow{2}{*}{$\begin{array}{l}\mathrm{SHS} \\
\mathrm{n} / \mathrm{N}\end{array}$} & \multirow{2}{*}{$\begin{array}{c}\text { Risk Ratio } \\
\text { M-H,Fixed,95\% Cl }\end{array}$} & \multirow{2}{*}{$\begin{array}{r}\text { Risk Ratio } \\
\mathrm{M}-\mathrm{H}, \text { Fixed,95\% Cl }\end{array}$} \\
\hline & & & & \\
\hline \multicolumn{5}{|c|}{ I Experienced surgeon (low risk of bias) } \\
\hline Bridle 1991 & $2 / 34$ & $3 / 32$ & 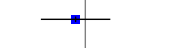 & $0.63[0.11,3.51]$ \\
\hline Radford 1993 & $2 / 100$ & $3 / 100$ &. & $0.67[0.11,3.90]$ \\
\hline Ahrengart 1994 & $3 / 105$ & $3 / 104$ & 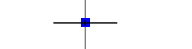 & $0.99[0.20,4.80]$ \\
\hline Kukla 1997 & $0 / 45$ & $0 / 44$ & & $0.0[0.0,0.0]$ \\
\hline Adams 2001 & $8 / 203$ & $4 / 197$ & - & $1.94[0.59,6.34]$ \\
\hline Utrilla 2005 & $1 / 82$ & $2 / 81$ & - & $0.49[0.05,5.34]$ \\
\hline Subtotal (95\% CI) & 569 & 558 & - & $1.04[0.52,2.08]$ \\
\hline \multicolumn{5}{|c|}{ Total events: 16 (Gamma nail), I5 (SHS) } \\
\hline \multicolumn{5}{|c|}{ Heterogeneity: Chi $^{2}=2.02, \mathrm{df}=4(P=0.73) ; 1^{2}=0.0 \%$} \\
\hline \multicolumn{5}{|c|}{ Test for overall effect: $Z=0.11(P=0.91)$} \\
\hline \multicolumn{5}{|c|}{2 Not experienced surgeon (high/unclear risk of bias) } \\
\hline Guyer 1991 & $1 / 50$ & $3 / 50$ & 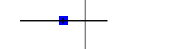 & $0.33[0.04,3.10]$ \\
\hline Mott 1993 & $3 / 35$ & $1 / 34$ & & $2.91[0.32,26.66]$ \\
\hline Goldhagen 1994 & $2 / 36$ & $0 / 39$ & & $5.41[0.27,108.93]$ \\
\hline Benum 1994 & $5 / 226$ & $2 / 234$ & & $2.59[0.51,13.21]$ \\
\hline O'Brien 1995 & $3 / 53$ & $1 / 49$ & & $2.77[0.30,25.78]$ \\
\hline Haynes 1996 & $2 / 18$ & $3 / 23$ & - & $0.85[0.16,4.57]$ \\
\hline Hoffman 1996 & $1 / 23$ & $|/ 3|$ & & $1.35[0.09,20.44]$ \\
\hline Kuwabara 1998 & $1 / 20$ & $1 / 23$ & & I.I $5[0.08,17.22]$ \\
\hline Park 1998 & $1 / 30$ & $1 / 30$ & & $1.00[0.07,15.26]$ \\
\hline Michos 200I & $0 / 25$ & $1 / 24$ & & $0.32[0.01,7.50]$ \\
\hline Papasimos 2005 & $2 / 40$ & $2 / 40$ & 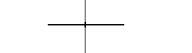 & $1.00[0.15,6.76]$ \\
\hline Ovesen 2006 & $7 / 73$ & $5 / 73$ & $\longrightarrow$ & $1.40[0.47,4.21]$ \\
\hline Subtotal (95\% CI) & 629 & 650 & $\bullet$ & $1.37[0.80,2.36]$ \\
\hline \multicolumn{5}{|c|}{ Total events: 28 (Gamma nail), 21 (SHS) } \\
\hline Heterogeneity: $\mathrm{Chi}^{2}=5.0$ & $0.93) ;\left.\right|^{2}=0.0 \%$ & & & \\
\hline
\end{tabular}

$0.0010 .01 \quad 0.1 \quad 1 \quad 10 \quad 100 \quad 1000$

Favours Gamma nail Favours SHS

(Continued ... )

Gamma and other cephalocondylic intramedullary nails versus extramedullary implants for extracapsular hip fractures in adults (Review) I29 Copyright (C) 2010 The Cochrane Collaboration. Published by John Wiley \& Sons, Ltd. 


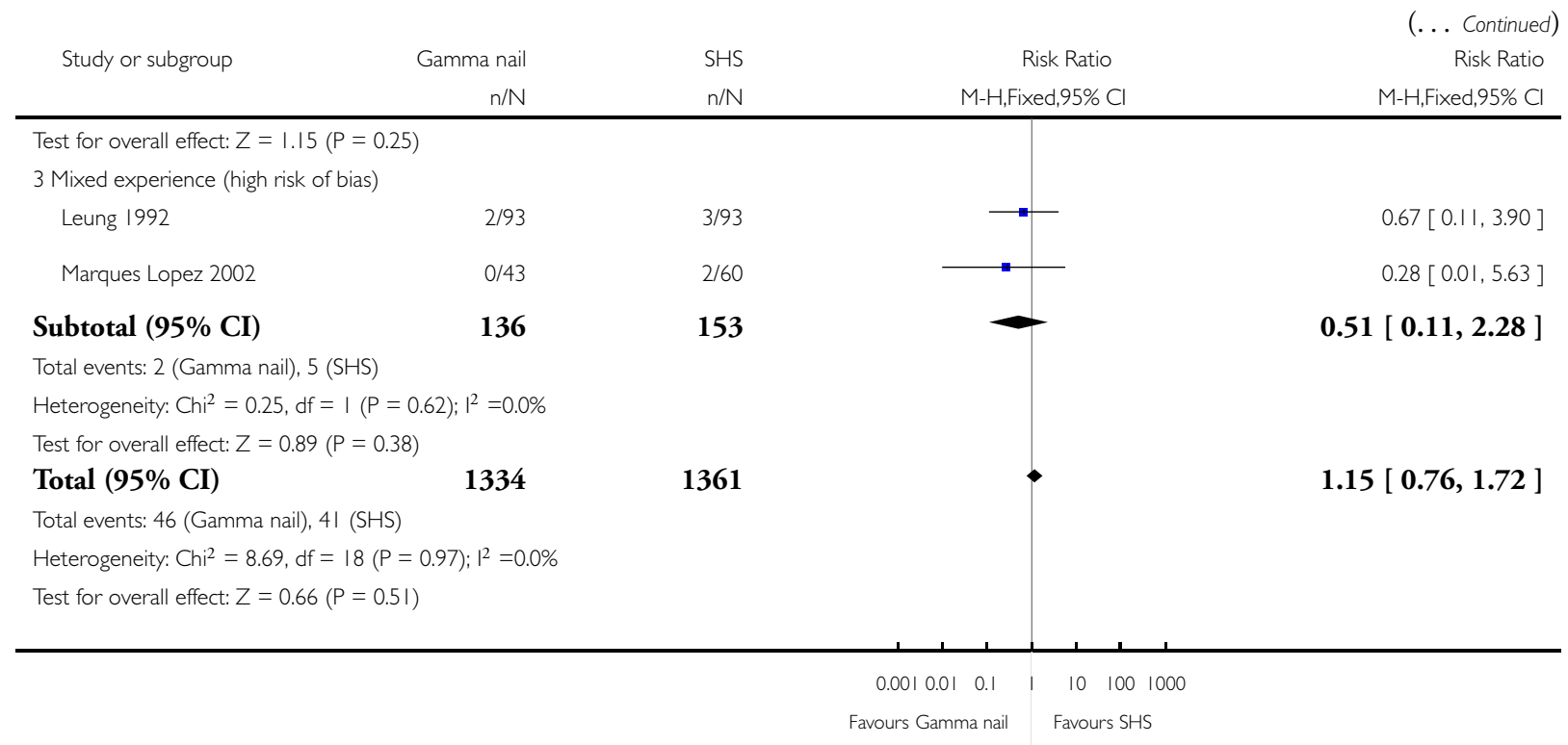

\section{Analysis 2.10. Comparison 2 Gamma nail versus sliding hip screw (SHS), Outcome I0 Non-union.}

Review: Gamma and other cephalocondylic intramedullary nails versus extramedullary implants for extracapsular hip fractures in adults

Comparison: 2 Gamma nail versus sliding hip screw (SHS)

Outcome: 10 Non-union

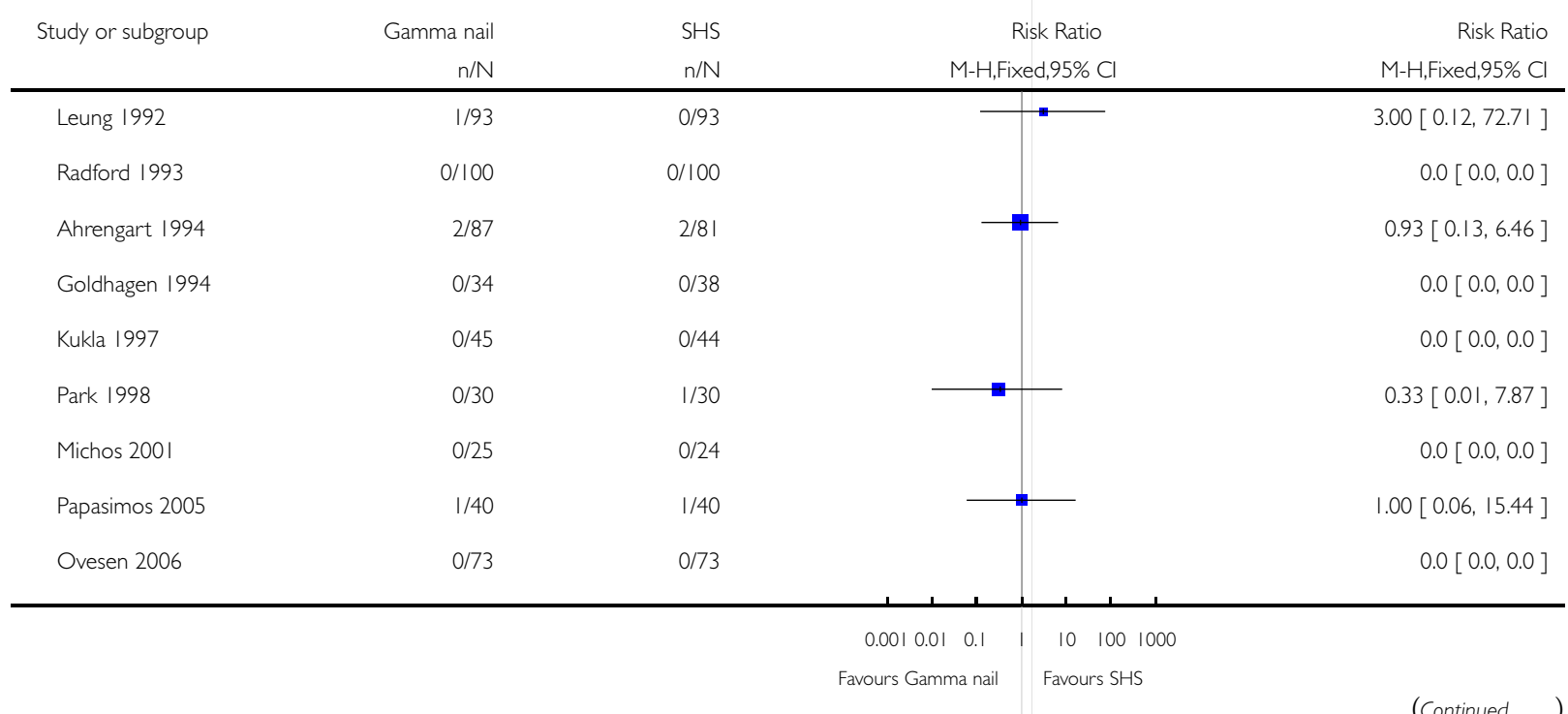

Gamma and other cephalocondylic intramedullary nails versus extramedullary implants for extracapsular hip fractures in adults (Review) $\quad 130$ Copyright (C) 2010 The Cochrane Collaboration. Published by John Wiley \& Sons, Ltd. 


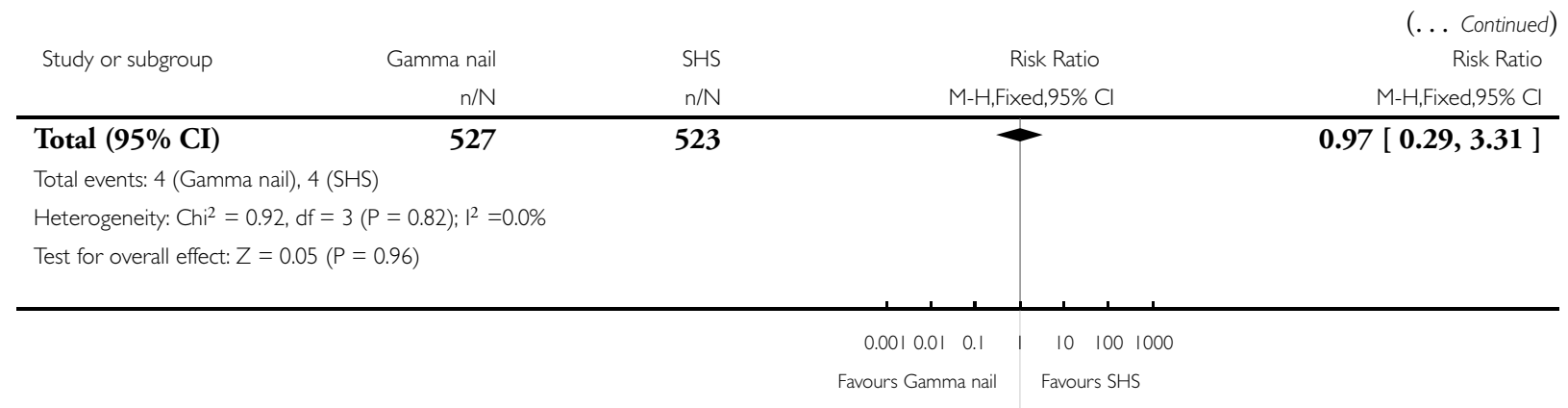

\section{Analysis 2.I I. Comparison 2 Gamma nail versus sliding hip screw (SHS), Outcome I I Reoperation.}

Review: Gamma and other cephalocondylic intramedullary nails versus extramedullary implants for extracapsular hip fractures in adults

Comparison: 2 Gamma nail versus sliding hip screw (SHS)

Outcome: II Reoperation

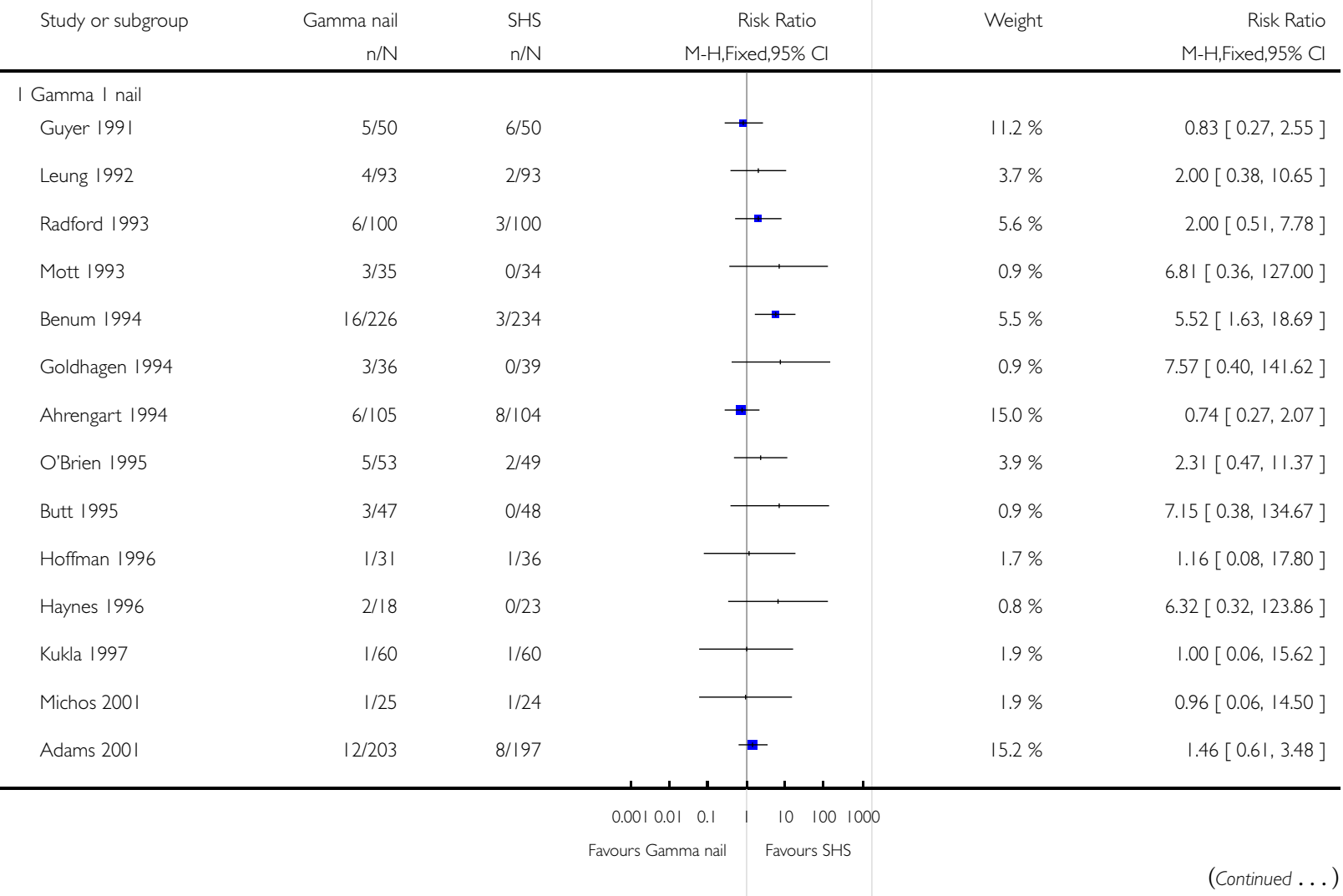

Gamma and other cephalocondylic intramedullary nails versus extramedullary implants for extracapsular hip fractures in adults (Review) I3 I Copyright (C) 2010 The Cochrane Collaboration. Published by John Wiley \& Sons, Ltd. 


\begin{tabular}{|c|c|c|c|c|c|}
\hline \multirow[t]{2}{*}{ Study or subgroup } & Gamma nail & SHS & \multirow[t]{2}{*}{$\begin{array}{c}\text { Risk Ratio } \\
\text { M-H,Fixed,95\% Cl }\end{array}$} & \multirow[t]{2}{*}{ Weight } & \multirow[t]{2}{*}{$\begin{array}{r}\text { (. . . Continued) } \\
\text { Risk Ratio } \\
\text { M-H,Fixed,95\% Cl }\end{array}$} \\
\hline & $n / N$ & $n / N$ & & & \\
\hline Marques Lopez 2002 & $2 / 43$ & $4 / 60$ & $\rightarrow-$ & $6.3 \%$ & $0.70[0.13,3.64]$ \\
\hline Subtotal $(95 \% \mathrm{CI})$ & 1125 & 1151 & $\bullet$ & $75.6 \%$ & $1.80[1.24,2.62]$ \\
\hline \multicolumn{6}{|c|}{ Total events: 70 (Gamma nail), 39 (SHS) } \\
\hline \multicolumn{6}{|c|}{ Heterogeneity: $\mathrm{Ch}^{2}=13.29, \mathrm{df}=14(\mathrm{P}=0.50) ; \mathrm{I}^{2}=0.0 \%$} \\
\hline \multicolumn{6}{|c|}{ Test for overall effect: $Z=3.07(P=0.0021)$} \\
\hline \multicolumn{6}{|l|}{2 Trochanteric Gamma nail } \\
\hline Papasimos 2005 & $3 / 40$ & $3 / 40$ & $\longrightarrow$ & $5.6 \%$ & $1.00[0.21,4.66]$ \\
\hline Utrilla 2005 & $1 / 82$ & $4 / 81$ & $=$ & $7.5 \%$ & $0.25[0.03,2.16]$ \\
\hline Ovesen 2006 & $12 / 73$ & $6 / 73$ & - & $11.2 \%$ & $2.00[0.79,5.04]$ \\
\hline Subtotal $(95 \% \mathrm{CI})$ & 195 & 194 & - & $24.4 \%$ & $1.23[0.61,2.47]$ \\
\hline \multicolumn{6}{|c|}{ Total events: 16 (Gamma nail), 13 (SHS) } \\
\hline \multicolumn{6}{|c|}{ Heterogeneity: $\mathrm{Ch}^{2}=3.24, \mathrm{df}=2(P=0.20) ; \mathrm{I}^{2}=38 \%$} \\
\hline \multicolumn{6}{|c|}{ Test for overall effect: $Z=0.58(P=0.56)$} \\
\hline Total $(95 \% \mathrm{CI})$ & 1320 & 1345 & $\bullet$ & $100.0 \%$ & $1.66[1.19,2.31]$ \\
\hline \multicolumn{6}{|c|}{ Total events: 86 (Gamma nail), 52 (SHS) } \\
\hline \multicolumn{6}{|c|}{ Heterogeneity: $\mathrm{Ch}^{2}=16.52, \mathrm{df}=17(\mathrm{P}=0.49) ; \mathrm{I}^{2}=0.0 \%$} \\
\hline \multicolumn{6}{|c|}{ Test for overall effect: $Z=3.01(P=0.0026)$} \\
\hline
\end{tabular}


Analysis 2.12. Comparison 2 Gamma nail versus sliding hip screw (SHS), Outcome 12 Wound infection or haematoma.

Review: Gamma and other cephalocondylic intramedullary nails versus extramedullary implants for extracapsular hip fractures in adults

Comparison: 2 Gamma nail versus sliding hip screw (SHS)

Outcome: 12 Wound infection or haematoma

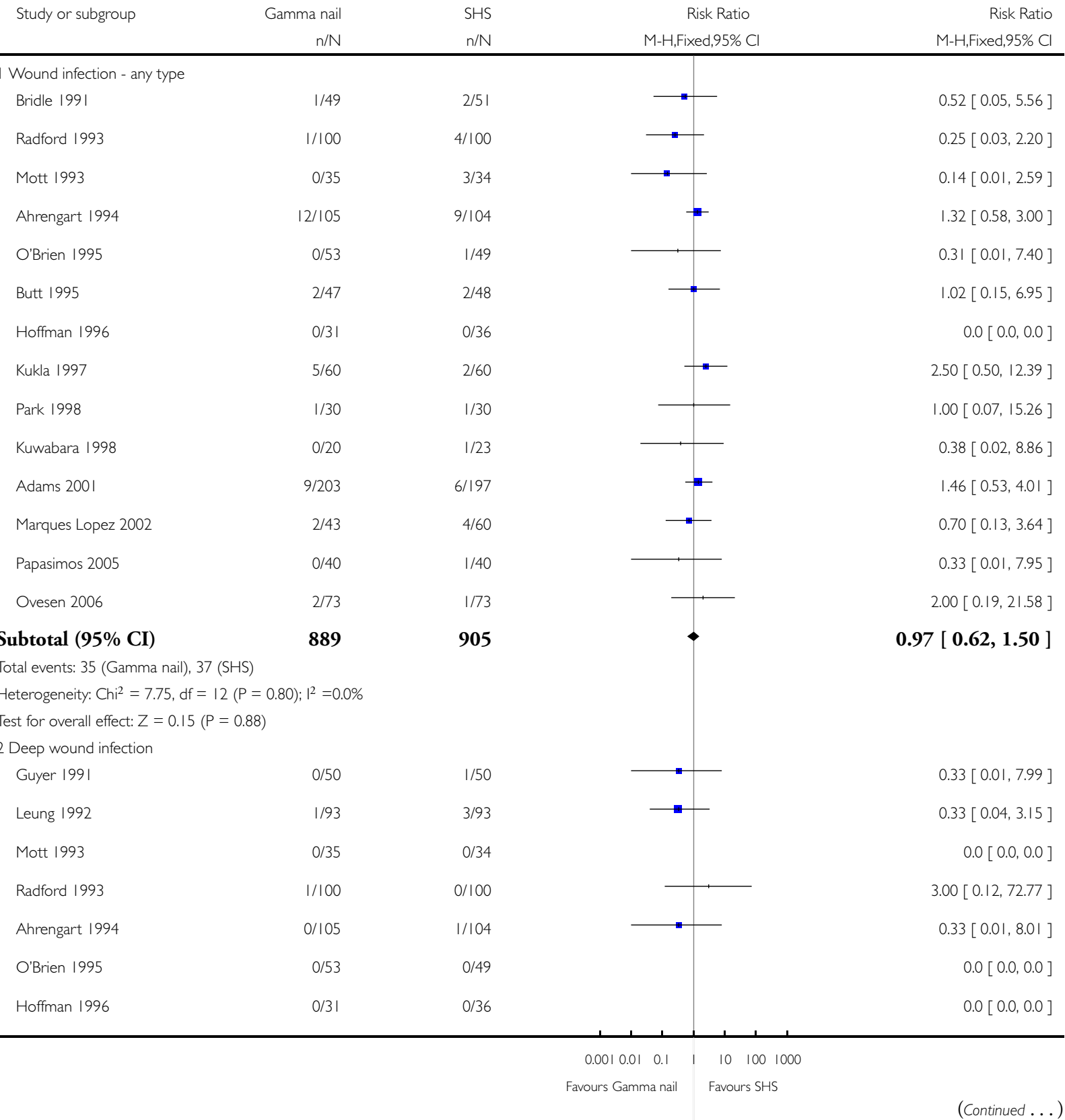

Gamma and other cephalocondylic intramedullary nails versus extramedullary implants for extracapsular hip fractures in adults (Review) $\quad$ I33 Copyright (C) 2010 The Cochrane Collaboration. Published by John Wiley \& Sons, Ltd. 


\begin{tabular}{|c|c|c|c|c|}
\hline Study or subgroup & $\begin{array}{r}\text { Gamma nail } \\
n / N\end{array}$ & $\begin{array}{l}\mathrm{SHS} \\
\mathrm{n} / \mathrm{N}\end{array}$ & $\begin{array}{c}\text { Risk Ratio } \\
\text { M-H,Fixed,95\% Cl }\end{array}$ & $\begin{array}{r}\text { (. . . Continued }) \\
\text { Risk Ratio } \\
\text { M-H,Fixed, } 95 \% \text { Cl }\end{array}$ \\
\hline Kukla 1997 & $2 / 60$ & $0 / 60$ & 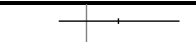 & $5.00[0.25,102.00]$ \\
\hline Park 1998 & 1/30 & 1/30 & $\because$ & $1.00[0.07,15.26]$ \\
\hline Adams 2001 & 3/203 & $2 / 197$ & - & $1.46[0.25,8.62]$ \\
\hline Utrilla 2005 & 0/104 & $1 / 106$ & - & $0.34[0.01,8.24]$ \\
\hline Ovesen 2006 & $2 / 73$ & $1 / 73$ & $=$ & $2.00[0.19,21.58]$ \\
\hline Subtotal (95\% CI) & 937 & 932 & 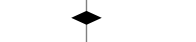 & $0.99[0.46,2.17]$ \\
\hline \multicolumn{5}{|c|}{ Total events: 10 (Gamma nail), 10 (SHS) } \\
\hline \multicolumn{5}{|c|}{ Heterogeneity: $\mathrm{Ch}^{2}=4.33, \mathrm{df}=8(\mathrm{P}=0.83) ; \mathrm{I}^{2}=0.0 \%$} \\
\hline \multicolumn{5}{|c|}{ Test for overall effect: $Z=0.01(P=0.99)$} \\
\hline \multicolumn{5}{|l|}{3 Wound haematoma } \\
\hline Bridle 1991 & 0/49 & $2 / 51$ & 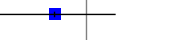 & $0.21[0.01,4.23]$ \\
\hline Guyer 1991 & 2/50 & $2 / 50$ & & $1.00[0.15,6.82]$ \\
\hline Mott 1993 & 0/35 & 1/34 & - & $0.32[0.01,7.69]$ \\
\hline O'Brien 1995 & 1/52 & 0/49 & 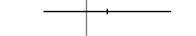 & $2.83[0.12,67.87]$ \\
\hline Kukla 1997 & $0 / 60$ & $1 / 60$ & - & $0.33[0.01,8.02]$ \\
\hline Marques Lopez 2002 & 1/43 & $1 / 60$ & & $1.40[0.09,21.70]$ \\
\hline Papasimos 2005 & $2 / 40$ & $3 / 40$ & $\longrightarrow-$ & $0.67[0.12,3.78]$ \\
\hline Ovesen 2006 & 1/73 & 0/73 & 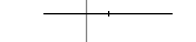 & $3.00[0.12,72.45]$ \\
\hline Subtotal $(95 \% \mathrm{CI})$ & 402 & 417 & $<$ & $0.78[0.34,1.79]$ \\
\hline \multicolumn{5}{|c|}{ Total events: 7 (Gamma nail), 10 (SHS) } \\
\hline \multicolumn{5}{|c|}{ Heterogeneity: Chi $^{2}=2.90, d f=7(P=0.89) ; 1^{2}=0.0 \%$} \\
\hline Test for overall effect: $Z=$ & & & & \\
\hline
\end{tabular}


Analysis 2.13. Comparison 2 Gamma nail versus sliding hip screw (SHS), Outcome 13 Pneumonia.

Review: Gamma and other cephalocondylic intramedullary nails versus extramedullary implants for extracapsular hip fractures in adults

Comparison: 2 Gamma nail versus sliding hip screw (SHS)

Outcome: 13 Pneumonia

\begin{tabular}{|c|c|c|c|c|}
\hline \multirow[t]{2}{*}{ Study or subgroup } & Gamma nail & SHS & Risk Ratio & Risk Ratio \\
\hline & $\mathrm{n} / \mathrm{N}$ & $n / \mathrm{N}$ & & M-H,Fixed,95\% Cl \\
\hline Bridle 1991 & $1 / 49$ & $3 / 51$ & $\longrightarrow$ & $0.35[0.04,3.22]$ \\
\hline Leung 1992 & 2/93 & $3 / 93$ & & $0.67[0.11,3.90]$ \\
\hline Mott 1993 & $0 / 35$ & $1 / 34$ & & $0.32[0.01,7.69]$ \\
\hline O'Brien 1995 & $3 / 52$ & $2 / 49$ & & $1.41[0.25,8.10]$ \\
\hline Butt 1995 & $3 / 47$ & $4 / 48$ & & $0.77[0.18,3.24]$ \\
\hline Hoffman 1996 & $|/ 3|$ & $1 / 36$ & & $1.16[0.08,17.80]$ \\
\hline Kukla 1997 & $1 / 60$ & 1/60 & & $1.00[0.06,15.62]$ \\
\hline Marques Lopez 2002 & $3 / 43$ & $1 / 60$ & $\rightarrow$ & $4.19[0.45,38.89]$ \\
\hline Papasimos 2005 & $0 / 40$ & $0 / 40$ & & $0.0[0.0,0.0]$ \\
\hline Total (95\% CI) & 450 & 471 & - & $0.93[0.47,1.83]$ \\
\hline \multicolumn{5}{|c|}{ Total events: 14 (Gamma nail), 16 (SHS) } \\
\hline \multicolumn{5}{|c|}{ Heterogeneity: $\mathrm{Chi}^{2}=3.38, \mathrm{df}=7(\mathrm{P}=0.85) ; \mathrm{I}^{2}=0.0 \%$} \\
\hline \multicolumn{5}{|c|}{ Test for overall effect: $Z=0.22(P=0.82)$} \\
\hline
\end{tabular}

$0.0010 .01 \quad 0.1 \quad 1 \quad 10 \quad 100 \quad 1000$

Favours Gamma nail Favours SHS 


\section{Analysis 2.14. Comparison 2 Gamma nail versus sliding hip screw (SHS), Outcome 14 Pressure sore.}

Review: Gamma and other cephalocondylic intramedullary nails versus extramedullary implants for extracapsular hip fractures in adults

Comparison: 2 Gamma nail versus sliding hip screw (SHS)

Outcome: 14 Pressure sore

\begin{tabular}{|c|c|c|c|c|c|}
\hline \multirow[t]{2}{*}{ Study or subgroup } & Gamma nail & SHS & Risk Ratio & Weight & Risk Ratio \\
\hline & $\mathrm{n} / \mathrm{N}$ & $\mathrm{n} / \mathrm{N}$ & M-H,Fixed,95\% Cl & & M-H,Fixed,95\% Cl \\
\hline Bridle |99| & $4 / 49$ & $|/ 5|$ & $\square$ & $6.0 \%$ & $4.16[0.48,35.95]$ \\
\hline Butt 1995 & $1 / 47$ & $5 / 48$ & $\longrightarrow$ & $30.1 \%$ & $0.20[0.02,1.68]$ \\
\hline O'Brien 1995 & 2/52 & $4 / 49$ & $\rightarrow-$ & $25.0 \%$ & $0.47[0.09,2.46]$ \\
\hline Hoffman 1996 & $0 / 31$ & $1 / 36$ & $\square$ & $8.5 \%$ & $0.39[0.02,9.13]$ \\
\hline Marques Lopez 2002 & $3 / 43$ & $6 / 60$ & - & $30.5 \%$ & $0.70[0.18,2.64]$ \\
\hline Total (95\% CI) & 222 & 244 & 1 & $100.0 \%$ & $0.67[0.32,1.42]$ \\
\hline \multicolumn{6}{|c|}{ Total events: 10 (Gamma nail), 17 (SHS) } \\
\hline \multicolumn{6}{|c|}{ Heterogeneity: $\mathrm{Chi}^{2}=4.27, \mathrm{df}=4(\mathrm{P}=0.37) ; \mathrm{I}^{2}=6 \%$} \\
\hline \multicolumn{6}{|c|}{ Test for overall effect: $Z=1.04(P=0.30)$} \\
\hline
\end{tabular}

$0.0010 .010 .1 \quad 1 \quad 10 \quad 100 \quad 1000$

Favours Gamma nail $\quad$ Favours SHS 
Analysis 2.15. Comparison 2 Gamma nail versus sliding hip screw (SHS), Outcome 15 Thromboembolic complications.

Review: Gamma and other cephalocondylic intramedullary nails versus extramedullary implants for extracapsular hip fractures in adults

Comparison: 2 Gamma nail versus sliding hip screw (SHS)

Outcome: 15 Thromboembolic complications

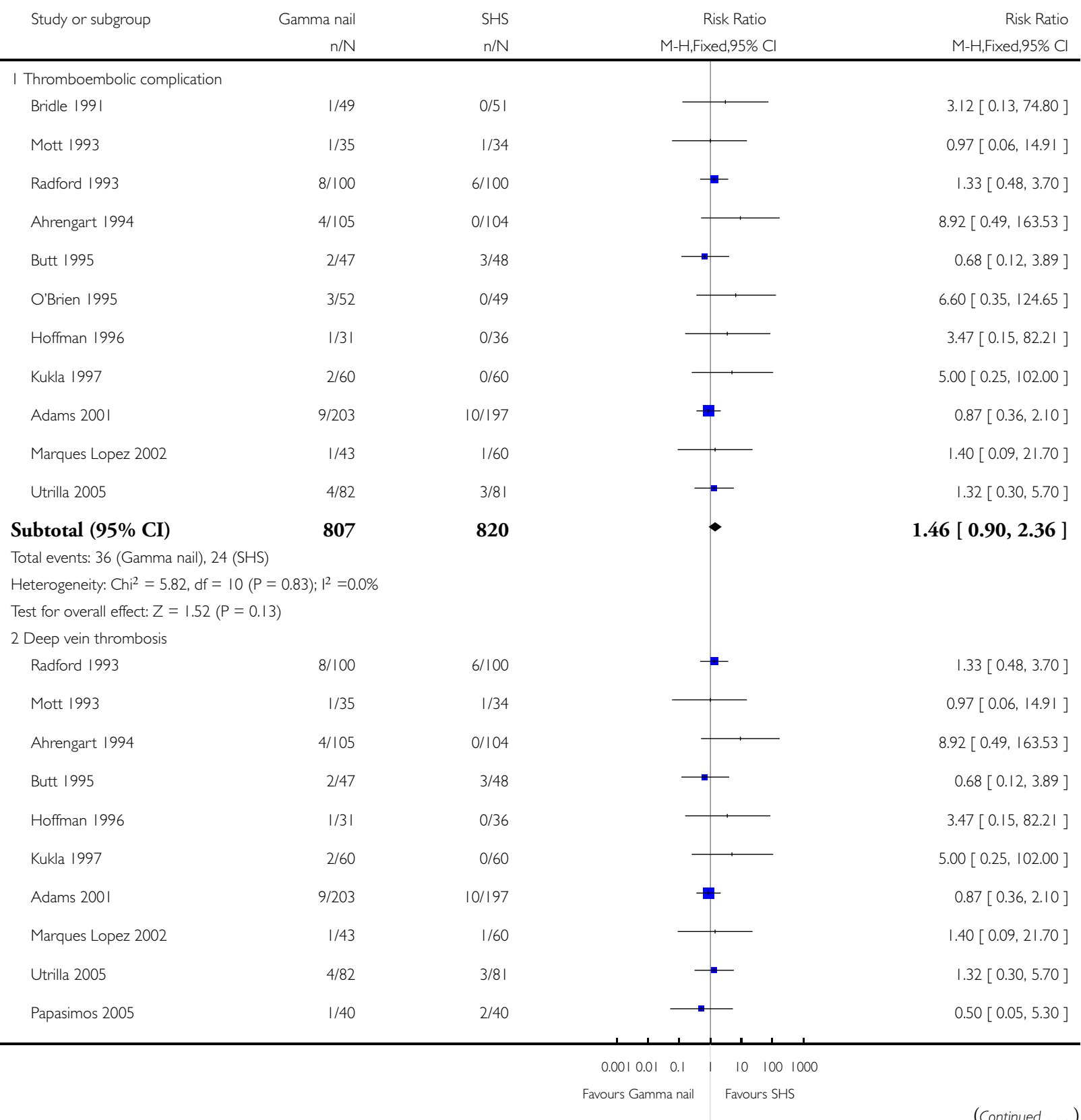

Gamma and other cephalocondylic intramedullary nails versus extramedullary implants for extracapsular hip fractures in adults (Review) $\quad$ I37 Copyright (C) 2010 The Cochrane Collaboration. Published by John Wiley \& Sons, Ltd. 


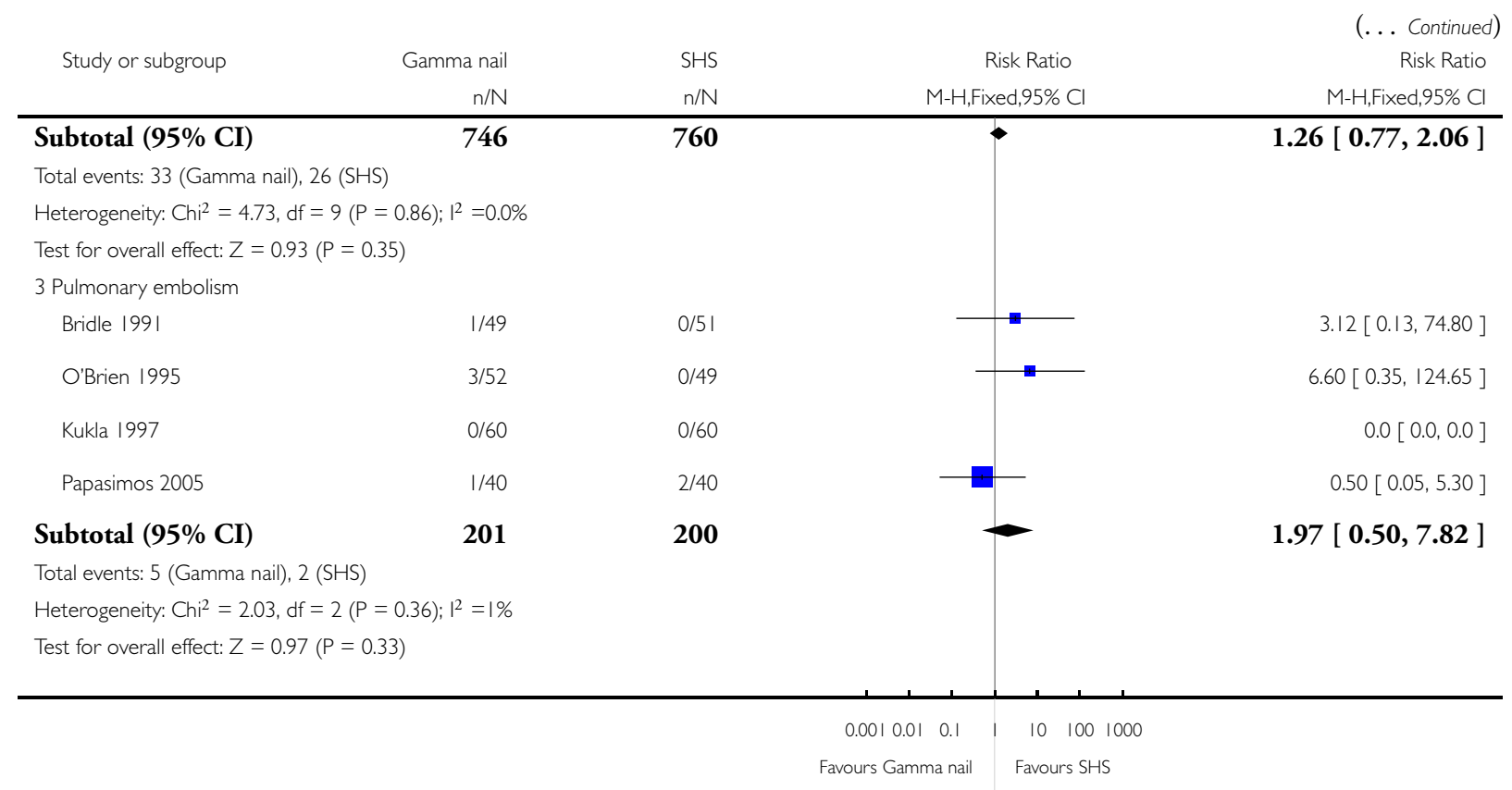


Analysis 2.16. Comparison 2 Gamma nail versus sliding hip screw (SHS), Outcome 16 Any medical complication (other than wound infection or haematoma).

Review: Gamma and other cephalocondylic intramedullary nails versus extramedullary implants for extracapsular hip fractures in adults

Comparison: 2 Gamma nail versus sliding hip screw (SHS)

Outcome: 16 Any medical complication (other than wound infection or haematoma)

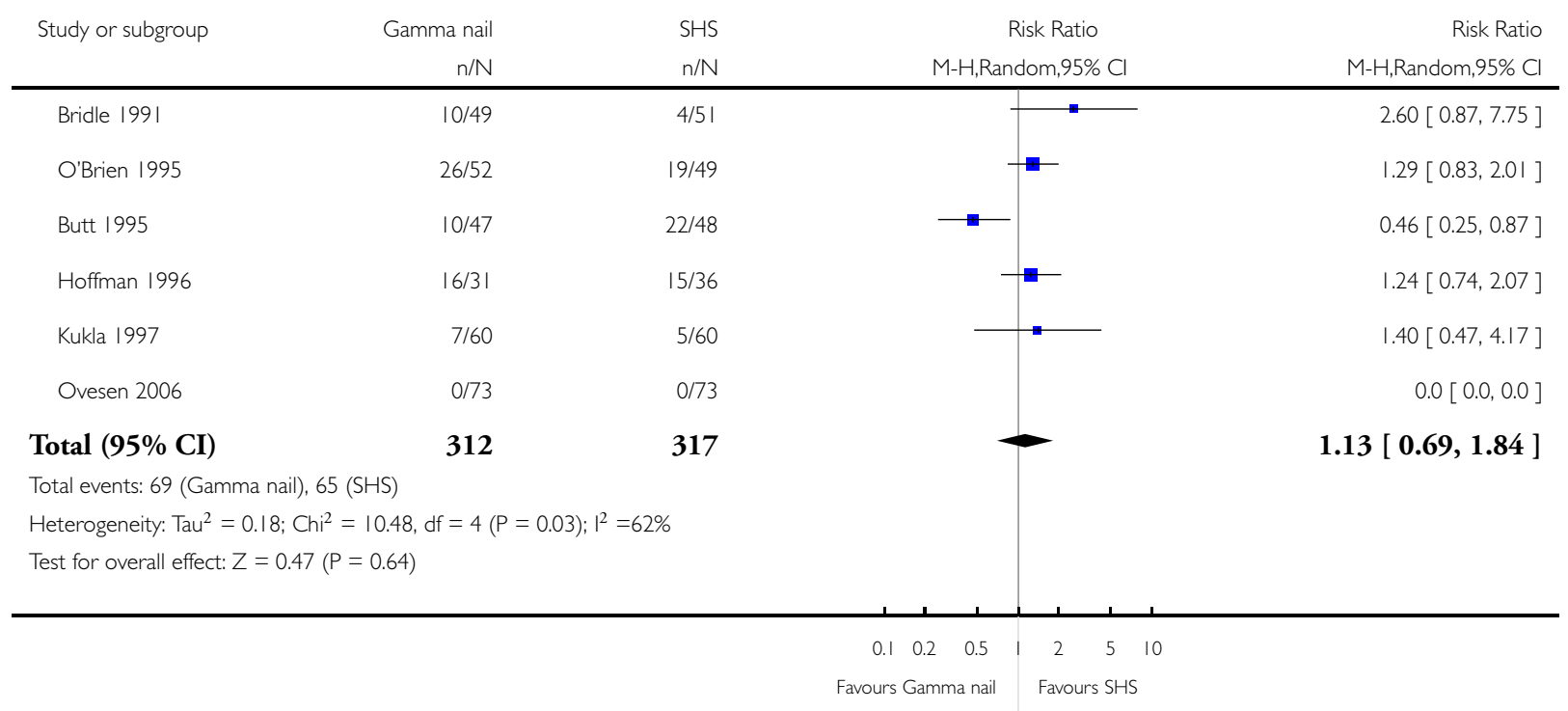

Gamma and other cephalocondylic intramedullary nails versus extramedullary implants for extracapsular hip fractures in adults (Review) $\quad$ I39 Copyright (c) 2010 The Cochrane Collaboration. Published by John Wiley \& Sons, Ltd. 
Analysis 2.17. Comparison 2 Gamma nail versus sliding hip screw (SHS), Outcome 17 Length of hospital stay (days).

Review: Gamma and other cephalocondylic intramedullary nails versus extramedullary implants for extracapsular hip fractures in adults

Comparison: 2 Gamma nail versus sliding hip screw (SHS)

Outcome: 17 Length of hospital stay (days)

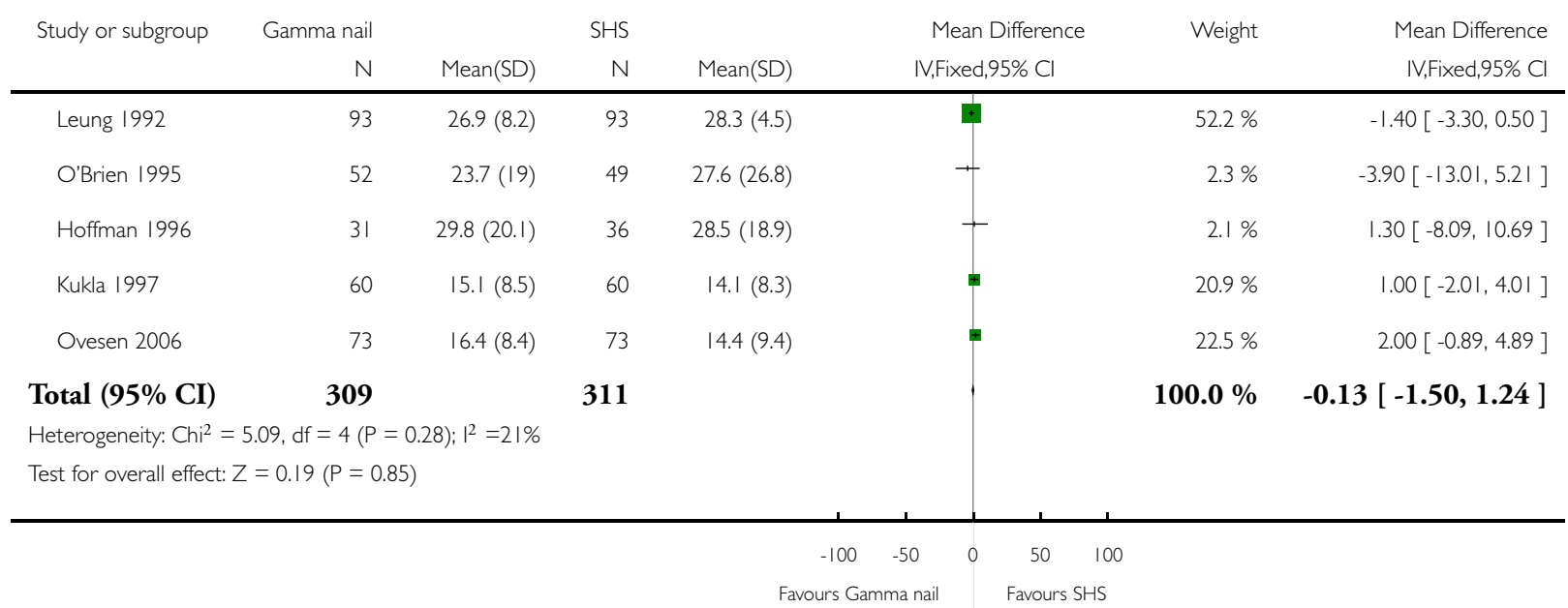

Gamma and other cephalocondylic intramedullary nails versus extramedullary implants for extracapsular hip fractures in adults (Review) $\quad$ I40 Copyright (c) 2010 The Cochrane Collaboration. Published by John Wiley \& Sons, Ltd. 
Analysis 2.18. Comparison 2 Gamma nail versus sliding hip screw (SHS), Outcome 18 Anatomical deformity.

Review: Gamma and other cephalocondylic intramedullary nails versus extramedullary implants for extracapsular hip fractures in adults

Comparison: 2 Gamma nail versus sliding hip screw (SHS)

Outcome: 18 Anatomical deformity

\begin{tabular}{|c|c|c|c|c|c|}
\hline \multirow[t]{2}{*}{ Study or subgroup } & Gamma nail & SHS & Risk Ratio & \multirow{2}{*}{ Weight } & \multirow{2}{*}{$\begin{array}{r}\text { Risk Ratio } \\
\mathrm{M}-\mathrm{H}, \text { Fixed,95\% Cl } \\
\end{array}$} \\
\hline & $\mathrm{n} / \mathrm{N}$ & $\mathrm{n} / \mathrm{N}$ & M-H,Fixed,95\% Cl & & \\
\hline \multicolumn{6}{|l|}{ I Shortening of leg } \\
\hline Guyer 1991 & $4 / 28$ & $12 / 32$ & & $66.9 \%$ & $0.38[0.14,1.05]$ \\
\hline Leung 1992 & $3 / 93$ & 2/93 & - & $11.9 \%$ & $1.50[0.26,8.77]$ \\
\hline Kukla 1997 & $0 / 45$ & $3 / 44$ & $\longrightarrow$ & $21.1 \%$ & $0.14[0.01,2.63]$ \\
\hline Subtotal (95\% CI) & 166 & 169 & & $100.0 \%$ & $0.46[0.21,1.03]$ \\
\hline \multicolumn{6}{|c|}{ Total events: 7 (Gamma nail), 17 (SHS) } \\
\hline \multicolumn{6}{|c|}{ Heterogeneity: $\mathrm{Chi}^{2}=2.48, \mathrm{df}=2(\mathrm{P}=0.29) ; \mathrm{I}^{2}=19 \%$} \\
\hline \multicolumn{6}{|c|}{ Test for overall effect: $Z=1.89(P=0.059)$} \\
\hline \multicolumn{6}{|c|}{2 Varus deformity } \\
\hline Leung 1992 & 2/93 & 2/93 & & $10.8 \%$ & $1.00[0.14,6.95]$ \\
\hline Ahrengart 1994 & $6 / 87$ & $8 / 81$ & & $44.8 \%$ & $0.70[0.25,1.93]$ \\
\hline O'Brien 1995 & $3 / 53$ & $5 / 49$ & 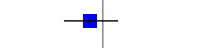 & $28.1 \%$ & $0.55[0.14,2.20]$ \\
\hline Park 1998 & $1 / 30$ & $2 / 30$ & $\longrightarrow$ & $10.8 \%$ & $0.50[0.05,5.22]$ \\
\hline Utrilla 2005 & $1 / 82$ & $|/ 8|$ & & $5.4 \%$ & $0.99[0.06,15.53]$ \\
\hline Subtotal (95\% CI) & 345 & 334 & $<$ & $100.0 \%$ & $0.68[0.34,1.37]$ \\
\hline \multicolumn{6}{|c|}{ Total events: 13 (Gamma nail), 18 (SHS) } \\
\hline \multicolumn{6}{|c|}{ Heterogeneity: Chi $^{2}=0.37, d f=4(P=0.98) ; 1^{2}=0.0 \%$} \\
\hline \multicolumn{6}{|c|}{ Test for overall effect: $Z=1.08(P=0.28)$} \\
\hline \multicolumn{6}{|c|}{3 External rotational deformity } \\
\hline Leung 1992 & 2/93 & $1 / 93$ & + & $26.4 \%$ & $2.00[0.18,21.68]$ \\
\hline Kuwabara 1998 & $2 / 20$ & $3 / 23$ & & $73.6 \%$ & $0.77[0.14,4.14]$ \\
\hline Subtotal (95\% CI) & 113 & 116 & - & $100.0 \%$ & $1.09[0.28,4.19]$ \\
\hline \multicolumn{6}{|c|}{ Total events: 4 (Gamma nail), 4 (SHS) } \\
\hline \multicolumn{6}{|c|}{ Heterogeneity: $\mathrm{Ch}^{2}=0.42, \mathrm{df}=\mathrm{I}(\mathrm{P}=0.52) ; \mathrm{I}^{2}=0.0 \%$} \\
\hline Test for overall effect: $Z=$ & $=0.90)$ & & & & \\
\hline
\end{tabular}

$0.0010 .01 \quad 0.1 \quad 1 \quad 10 \quad 100 \quad 1000$

Favours Gamma nail Favours SHS

Gamma and other cephalocondylic intramedullary nails versus extramedullary implants for extracapsular hip fractures in adults (Review) I4I Copyright (c) 2010 The Cochrane Collaboration. Published by John Wiley \& Sons, Ltd. 


\section{Analysis 2.19. Comparison 2 Gamma nail versus sliding hip screw (SHS), Outcome 19 Mortality.}

Review: Gamma and other cephalocondylic intramedullary nails versus extramedullary implants for extracapsular hip fractures in adults

Comparison: 2 Gamma nail versus sliding hip screw (SHS)

Outcome: 19 Mortality

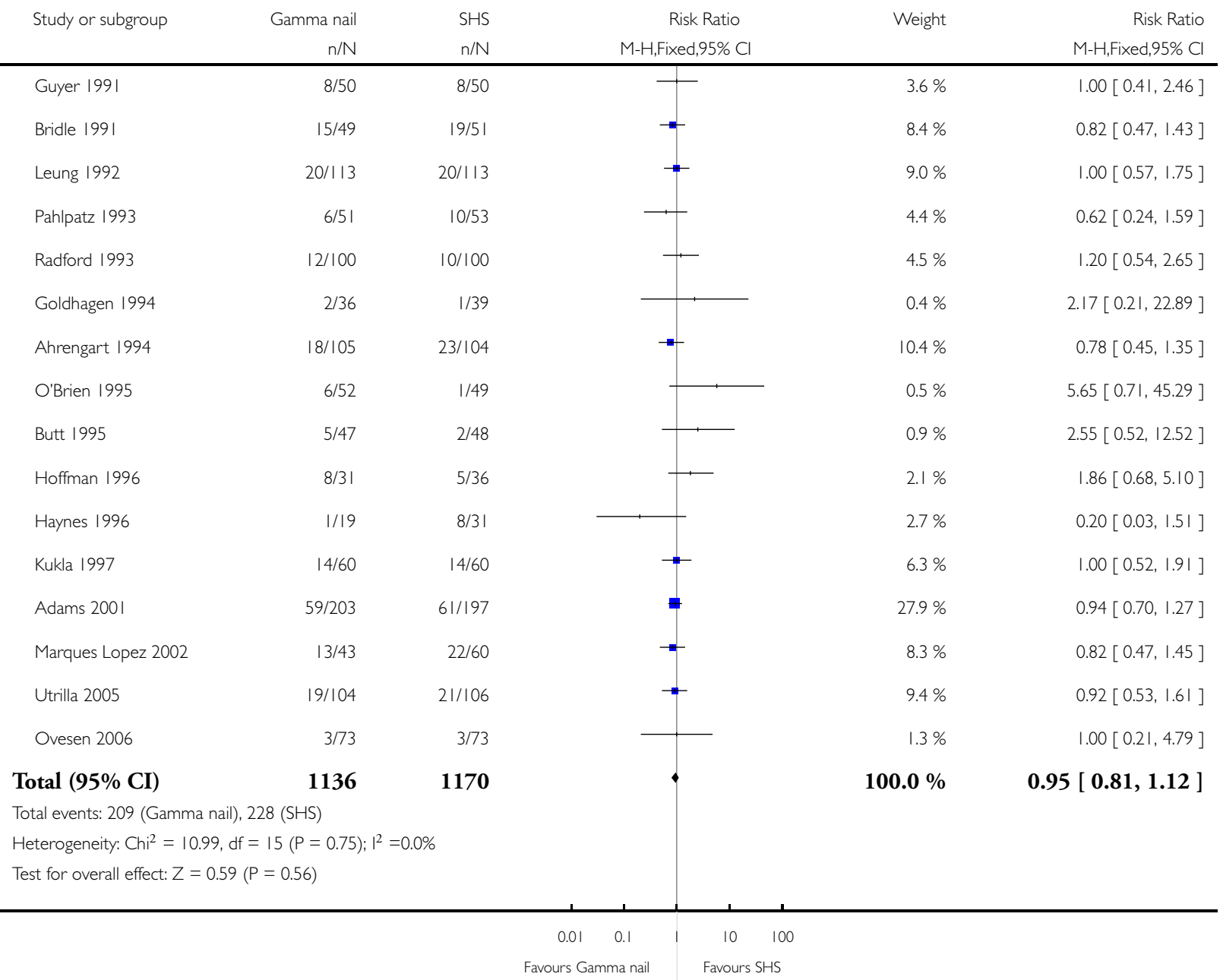

Gamma and other cephalocondylic intramedullary nails versus extramedullary implants for extracapsular hip fractures in adults (Review) $\quad$ |42 
Analysis 2.20. Comparison 2 Gamma nail versus sliding hip screw (SHS), Outcome 20 Mortality (grouped by allocation concealment).

Review: Gamma and other cephalocondylic intramedullary nails versus extramedullary implants for extracapsular hip fractures in adults

Comparison: 2 Gamma nail versus sliding hip screw (SHS)

Outcome: 20 Mortality (grouped by allocation concealment)

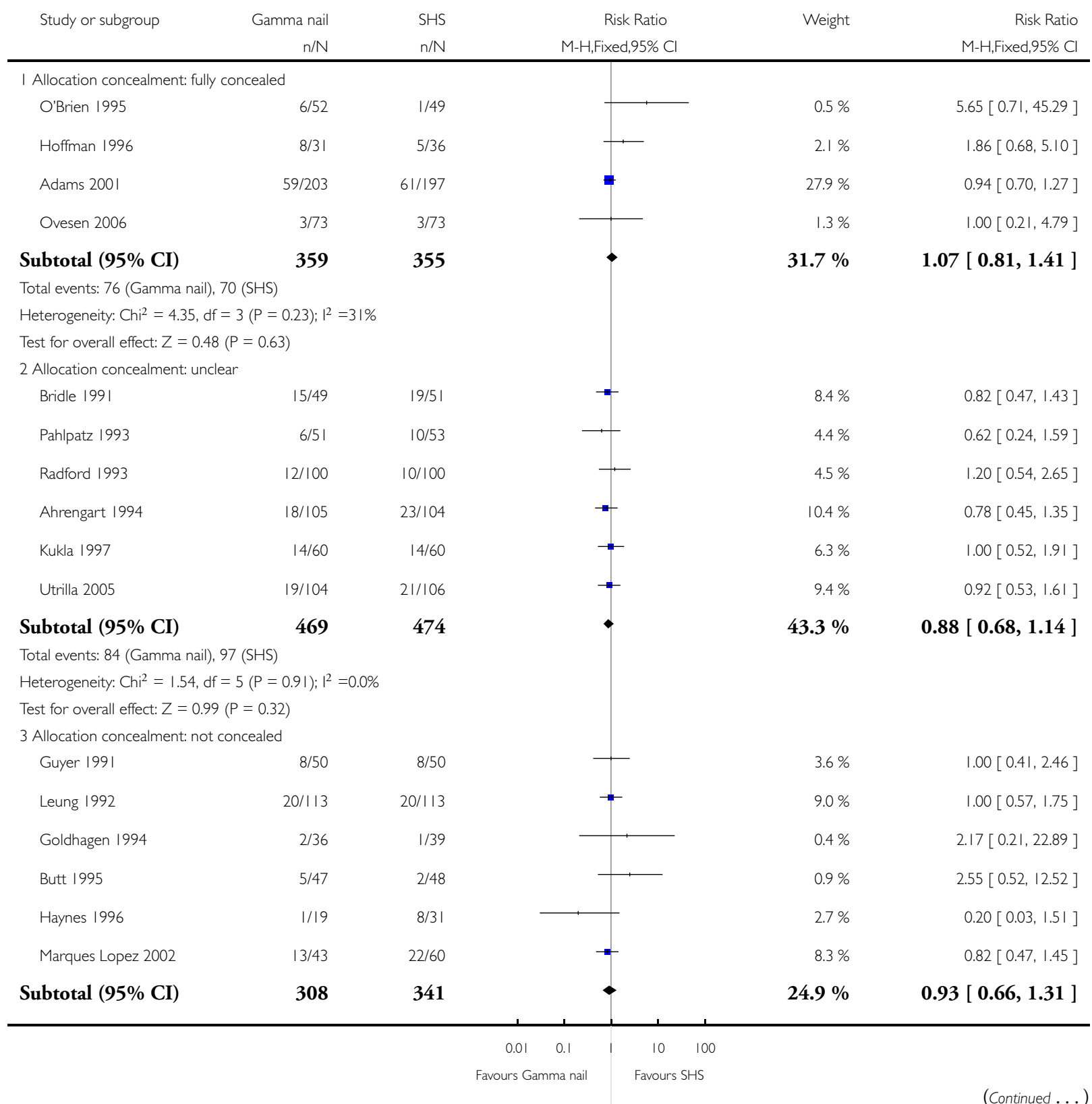

Gamma and other cephalocondylic intramedullary nails versus extramedullary implants for extracapsular hip fractures in adults (Review) I43 Copyright (C) 2010 The Cochrane Collaboration. Published by John Wiley \& Sons, Ltd. 


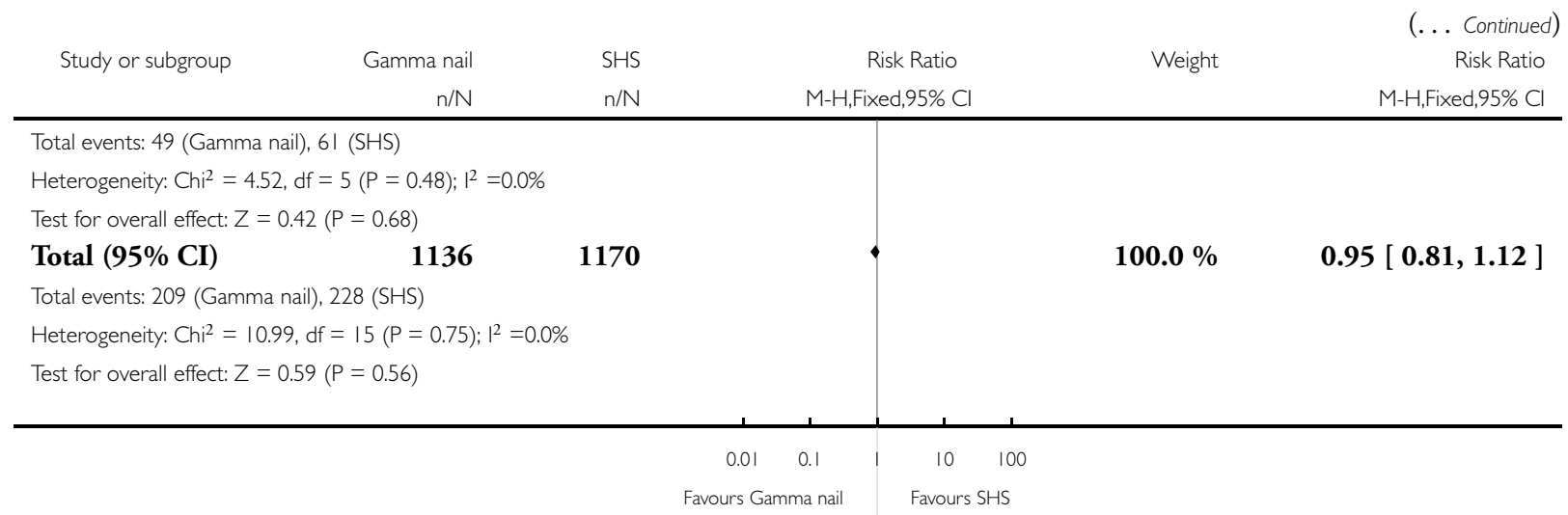

\section{Analysis 2.21. Comparison 2 Gamma nail versus sliding hip screw (SHS), Outcome 2 I Pain at follow-up.}

Review: Gamma and other cephalocondylic intramedullary nails versus extramedullary implants for extracapsular hip fractures in adults

Comparison: 2 Gamma nail versus sliding hip screw (SHS)

Outcome: 21 Pain at follow-up

\begin{tabular}{|c|c|c|c|c|c|}
\hline \multirow[t]{2}{*}{ Study or subgroup } & Gamma nail & SHS & Risk Ratio & Weight & Risk Ratio \\
\hline & $\mathrm{n} / \mathrm{N}$ & $\mathrm{n} / \mathrm{N}$ & M-H,Fixed,95\% Cl & & M-H,Fixed,95\% Cl \\
\hline Guyer 1991 & $19 / 28$ & $18 / 32$ & $\rightarrow$ & $14.3 \%$ & $1.21[0.81,1.80]$ \\
\hline Leung 1992 & $22 / 93$ & $32 / 93$ & $\rightarrow$ & $27.3 \%$ & $0.69[0.43,1.09]$ \\
\hline Ahrengart 1994 & $25 / 88$ & $15 / 83$ & - & $13.2 \%$ & $1.57[0.89,2.77]$ \\
\hline Hoffman 1996 & $9 / 23$ & $9 / 31$ & - & $6.5 \%$ & $1.35[0.64,2.85]$ \\
\hline Utrilla 2005 & $50 / 82$ & $45 / 81$ & 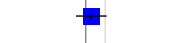 & $38.6 \%$ & $1.10[0.85,1.42]$ \\
\hline Total (95\% CI) & 314 & 320 & $\longrightarrow$ & $100.0 \%$ & $1.08[0.90,1.30]$ \\
\hline \multicolumn{6}{|c|}{ Total events: I25 (Gamma nail), II 9 (SHS) } \\
\hline \multicolumn{6}{|c|}{ Heterogeneity: Chi $^{2}=6.03, d f=4(P=0.20) ; 1^{2}=34 \%$} \\
\hline \multicolumn{6}{|c|}{ Test for overall effect: $Z=0.81$ ( $P=0.42)$} \\
\hline
\end{tabular}

$\begin{array}{lllllll}0.1 & 0.2 & 0.5 & 1 & 2 & 5 & 10\end{array}$

Favours Gamma nail Favours SHS 
Analysis 2.22. Comparison 2 Gamma nail versus sliding hip screw (SHS), Outcome 22 Non-return to previous residence.

Review: Gamma and other cephalocondylic intramedullary nails versus extramedullary implants for extracapsular hip fractures in adults

Comparison: 2 Gamma nail versus sliding hip screw (SHS)

Outcome: 22 Non-return to previous residence

\begin{tabular}{|c|c|c|c|c|c|}
\hline \multirow[t]{2}{*}{ Study or subgroup } & Gamma nail & SHS & Risk Ratio & \multirow[t]{2}{*}{ Weight } & \multirow{2}{*}{$\begin{array}{r}\text { Risk Ratic } \\
\text { M-H,Fixed,95\% C }\end{array}$} \\
\hline & $\mathrm{n} / \mathrm{N}$ & $\mathrm{n} / \mathrm{N}$ & M-H,Fixed,95\% Cl & & \\
\hline \multicolumn{6}{|c|}{ I Non-return to previous residence (survivors) } \\
\hline Guyer 1991 & $3 / 28$ & $3 / 32$ & & $13.9 \%$ & $1.14[0.25,5.21]$ \\
\hline Pahlpatz 1993 & $8 / 45$ & $11 / 43$ & & $55.7 \%$ & $0.69[0.31,1.56]$ \\
\hline Haynes 1996 & $3 / 18$ & $7 / 23$ & + & $30.4 \%$ & $0.55[0.16,1.82]$ \\
\hline Subtotal (95\% CI) & 91 & 98 & & $100.0 \%$ & $0.71[0.39,1.31]$ \\
\hline \multicolumn{6}{|c|}{ Total events: 14 (Gamma nail), 2 I (SHS) } \\
\hline \multicolumn{6}{|c|}{ Heterogeneity: Chi $^{2}=0.56, d f=2(P=0.76) ; 1^{2}=0.0 \%$} \\
\hline \multicolumn{6}{|c|}{ Test for overall effect: $Z=1.09(P=0.28)$} \\
\hline \multicolumn{6}{|c|}{2 Non-return to previous residence or dead } \\
\hline Guyer 1991 & $11 / 36$ & $11 / 40$ & $=$ & $12.2 \%$ & $1.11[0.55,2.25]$ \\
\hline Pahlpatz 1993 & $|7 / 5|$ & $21 / 53$ & - & $24.1 \%$ & $0.84[0.50,1.40]$ \\
\hline Ahrengart 1994 & $43 / 105$ & $43 / 104$ & & $50.5 \%$ & $0.99[0.72,1.37]$ \\
\hline Haynes 1996 & $4 / 19$ & $|5 / 3|$ & & $13.3 \%$ & $0.44[0.17,1.12]$ \\
\hline Subtotal (95\% CI) & 211 & 228 & & $100.0 \%$ & $0.90[0.70,1.15]$ \\
\hline \multicolumn{6}{|c|}{ Total events: 75 (Gamma nail), 90 (SHS) } \\
\hline \multicolumn{6}{|c|}{ Heterogeneity: $\mathrm{Chi}^{2}=3.04, \mathrm{df}=3(\mathrm{P}=0.39) ; \mathrm{I}^{2}=1 \%$} \\
\hline Test for overall effect: $Z=$ & $=0.38)$ & & & & \\
\hline
\end{tabular}

$\begin{array}{lllllll}0.1 & 0.2 & 0.5 & 1 & 2 & 5 & 10\end{array}$

Favours Gamma nail $\quad$ Favours SHS 
Analysis 2.23. Comparison 2 Gamma nail versus sliding hip screw (SHS), Outcome 23 Impaired walking.

Review: Gamma and other cephalocondylic intramedullary nails versus extramedullary implants for extracapsular hip fractures in adults

Comparison: 2 Gamma nail versus sliding hip screw (SHS)

Outcome: 23 Impaired walking

\begin{tabular}{|c|c|c|c|c|c|}
\hline \multirow[t]{2}{*}{ Study or subgroup } & Gamma nail & SHS & \multirow{2}{*}{$\begin{array}{c}\text { Risk Ratio } \\
\text { M-H,Fixed,95\% Cl }\end{array}$} & \multirow[t]{2}{*}{ Weight } & \multirow{2}{*}{$\begin{array}{r}\text { Risk Ratio } \\
\text { M-H,Fixed,95\% Cl }\end{array}$} \\
\hline & $\mathrm{n} / \mathrm{N}$ & $\mathrm{n} / \mathrm{N}$ & & & \\
\hline \multicolumn{6}{|l|}{ I Impaired walking } \\
\hline Guyer 1991 & $24 / 28$ & $26 / 32$ & + & $8.6 \%$ & $1.05[0.84,1.32]$ \\
\hline Leung 1992 & $59 / 93$ & $62 / 93$ & $\#$ & $21.9 \%$ & $0.95[0.77,1.17]$ \\
\hline Ahrengart 1994 & $53 / 87$ & $61 / 81$ & - & $22.3 \%$ & $0.81[0.66,1.00]$ \\
\hline Haynes 1996 & $13 / 18$ & $11 / 23$ & 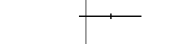 & $3.4 \%$ & $1.51[0.90,2.53]$ \\
\hline Kukla 1997 & $17 / 45$ & $17 / 44$ & 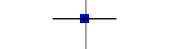 & $6.1 \%$ & $0.98[0.58,1.66]$ \\
\hline Park 1998 & $14 / 30$ & $16 / 30$ & $\rightarrow$ & $5.7 \%$ & $0.88[0.53,1.45]$ \\
\hline Adams 200I & $70 / 126$ & $66 / 121$ & - & $23.8 \%$ & $1.02[0.81,1.28]$ \\
\hline Ovesen 2006 & $30 / 67$ & $23 / 66$ & - & $8.2 \%$ & $1.28[0.84,1.96]$ \\
\hline Subtotal (95\% CI) & 494 & 490 & $\varphi$ & $100.0 \%$ & $0.99[0.89,1.10]$ \\
\hline \multicolumn{6}{|c|}{ Total events: 280 (Gamma nail), 282 (SHS) } \\
\hline \multicolumn{6}{|c|}{ Heterogeneity: $\mathrm{Chi}^{2}=8.33, \mathrm{df}=7(P=0.30) ;\left.\right|^{2}=16 \%$} \\
\hline \multicolumn{6}{|c|}{ Test for overall effect: $Z=0.22(P=0.82)$} \\
\hline \multicolumn{6}{|c|}{2 Impaired walking (overall denominators used) } \\
\hline Guyer 1991 & $24 / 50$ & $26 / 50$ & $\rightarrow$ & $9.3 \%$ & $0.92[0.62,1.37]$ \\
\hline Leung 1992 & $59 / 113$ & $62 / 113$ & - & $22.1 \%$ & $0.95[0.75,1.21]$ \\
\hline Ahrengart 1994 & $53 / 105$ & $61 / 104$ & $\rightarrow$ & $21.8 \%$ & $0.86[0.67,1.10]$ \\
\hline Haynes 1996 & $13 / 19$ & ||$/ 3 \mid$ & - & $3.0 \%$ & $1.93[1.10,3.39]$ \\
\hline Kukla 1997 & $17 / 60$ & $17 / 60$ & $\longrightarrow$ & $6.1 \%$ & $1.00[0.57,1.77]$ \\
\hline Park 1998 & $14 / 30$ & $16 / 30$ & $\longrightarrow$ & $5.7 \%$ & $0.88[0.53,1.45]$ \\
\hline Adams 200। & $70 / 203$ & $66 / 197$ & - & $23.9 \%$ & $1.03[0.78,1.35]$ \\
\hline Ovesen 2006 & $30 / 73$ & $23 / 73$ & - & $8.2 \%$ & $1.30[0.84,2.02]$ \\
\hline Subtotal (95\% CI) & 653 & 658 & 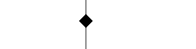 & $100.0 \%$ & $1.00[0.89,1.13]$ \\
\hline \multicolumn{6}{|c|}{ Total events: 280 (Gamma nail), 282 (SHS) } \\
\hline \multicolumn{6}{|c|}{ Heterogeneity: $\mathrm{Chi}^{2}=8.67, \mathrm{df}=7(\mathrm{P}=0.28) ; \mathrm{I}^{2}=19 \%$} \\
\hline Test for overall effect: $Z=$ & $=0.95)$ & & & & \\
\hline
\end{tabular}

$\begin{array}{lllllll}0.1 & 0.2 & 0.5 & 1 & 2 & 5 & 10\end{array}$

Favours Gamma nail $\quad$ Favours SHS

Gamma and other cephalocondylic intramedullary nails versus extramedullary implants for extracapsular hip fractures in adults (Review) I46 Copyright (C) 2010 The Cochrane Collaboration. Published by John Wiley \& Sons, Ltd. 
Analysis 3.I. Comparison 3 Intramedullary hip screw (IMHS) versus sliding hip screw (SHS), Outcome I Length of surgery (minutes).

Review: Gamma and other cephalocondylic intramedullary nails versus extramedullary implants for extracapsular hip fractures in adults

Comparison: 3 Intramedullary hip screw (IMHS) versus sliding hip screw (SHS)

Outcome: I Length of surgery (minutes)

\begin{tabular}{|c|c|c|c|c|c|c|c|}
\hline \multirow[t]{2}{*}{ Study or subgroup } & \multirow{2}{*}{$\begin{array}{r}\text { IMHS } \\
\mathrm{N}\end{array}$} & \multicolumn{3}{|c|}{ SHS } & \multirow{2}{*}{$\begin{array}{l}\text { Mean Difference } \\
\text { IV,Random,95\% Cl }\end{array}$} & \multirow[t]{2}{*}{ Weight } & \multirow{2}{*}{$\begin{array}{l}\text { Mean Difference } \\
\text { IV,Random,95\% Cl }\end{array}$} \\
\hline & & Mean(SD) & N & Mean(SD) & & & \\
\hline Baumgaertner 1998 & 67 & $72(33)$ & 68 & $80(35)$ & $\mp$ & $32.8 \%$ & $-8.00[-19.47,3.47]$ \\
\hline Hardy 1998 & 50 & 7I (28.9) & 50 & $57(24.8)$ & $\Psi$ & $33.6 \%$ & $14.00[3.44,24.56]$ \\
\hline Harrington 2002 & 50 & $108(26.8)$ & 52 & $88(27.5)$ & $\mp$ & $33.6 \%$ & $20.00[9.46,30.54]$ \\
\hline Total $(95 \%$ CI $)$ & 167 & & 170 & & & $100.0 \%$ & $8.81[-7.43,25.05]$ \\
\hline
\end{tabular}

Heterogeneity: $\mathrm{Tau}^{2}=$ 175.30; $\mathrm{Chi}^{2}=13.45, \mathrm{df}=2(\mathrm{P}=0.00 \mathrm{I}) ; \mathrm{I}^{2}=85 \%$

Test for overall effect: $Z=1.06(P=0.29)$

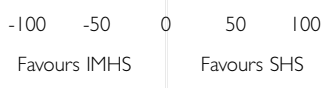

Analysis 3.2. Comparison 3 Intramedullary hip screw (IMHS) versus sliding hip screw (SHS), Outcome 2 Blood loss $(\mathrm{ml})$.

Review: Gamma and other cephalocondylic intramedullary nails versus extramedullary implants for extracapsular hip fractures in adults

Comparison: 3 Intramedullary hip screw (IMHS) versus sliding hip screw (SHS)

Outcome: 2 Blood loss (ml)

\begin{tabular}{|c|c|c|c|c|c|c|c|}
\hline \multirow[t]{2}{*}{ Study or subgroup } & \multirow{2}{*}{$\begin{array}{r}\text { IMHS } \\
\mathrm{N}\end{array}$} & \multicolumn{3}{|c|}{ SHS } & \multirow{2}{*}{$\begin{array}{l}\text { Mean Difference } \\
\text { IV,Fixed,95\% Cl }\end{array}$} & \multirow[t]{2}{*}{ Weight } & \multirow{2}{*}{$\begin{array}{r}\text { Mean Difference } \\
\text { IV,Fixed,95\% Cl }\end{array}$} \\
\hline & & Mean(SD) & N & $\operatorname{Mean}(\mathrm{SD})$ & & & \\
\hline Baumgaertner 1998 & 67 & $245(145)$ & 68 & $340(302)$ & \# & $20.5 \%$ & $-95.00[-174.74,-15.26]$ \\
\hline Hardy 1998 & 50 & $144(120.5)$ & 50 & $198(82.9)$ & + & $79.5 \%$ & $-54.00[-94.54,-13.46]$ \\
\hline
\end{tabular}

Total (95\% CI) $117 \quad 118$

Heterogeneity: Chi $^{2}=0.8 \mathrm{I}, \mathrm{df}=\mathrm{I}(\mathrm{P}=0.37) ; \mathrm{I}^{2}=0.0 \%$

Test for overall effect: $Z=3.39(P=0.0007$ I)

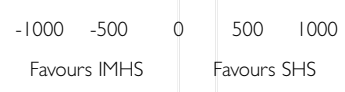

Gamma and other cephalocondylic intramedullary nails versus extramedullary implants for extracapsular hip fractures in adults (Review) 147 Copyright (C) 2010 The Cochrane Collaboration. Published by John Wiley \& Sons, Ltd. 
Analysis 3.3. Comparison 3 Intramedullary hip screw (IMHS) versus sliding hip screw (SHS), Outcome 3 Transfusion (units of red cells).

Review: Gamma and other cephalocondylic intramedullary nails versus extramedullary implants for extracapsular hip fractures in adults

Comparison: 3 Intramedullary hip screw (IMHS) versus sliding hip screw (SHS)

Outcome: 3 Transfusion (units of red cells)

\begin{tabular}{|c|c|c|c|c|c|c|c|}
\hline \multirow[t]{2}{*}{ Study or subgroup } & \multirow{2}{*}{$\begin{array}{r}\mathrm{IMHS} \\
\mathrm{N}\end{array}$} & \multicolumn{3}{|c|}{ SHS } & \multirow{2}{*}{$\begin{array}{l}\text { Mean Difference } \\
\text { IV,Random,95\% Cl }\end{array}$} & \multirow[t]{2}{*}{ Weight } & \multirow{2}{*}{$\begin{array}{l}\text { Mean Difference } \\
\text { IV,Random,95\% Cl }\end{array}$} \\
\hline & & Mean(SD) & $N$ & Mean(SD) & & & \\
\hline Hardy 1998 & 50 & $0.9(0.96)$ & 50 & $1.2(1.29)$ & $\rightarrow$ & $57.8 \%$ & $-0.30[-0.75,0.15]$ \\
\hline Baumgaertner 1998 & 67 & $2.2(2.4)$ & 68 & $1.8(1.7)$ & 1 & $42.2 \%$ & $0.40[-0.30,1.10]$ \\
\hline
\end{tabular}

Total (95\% CI) $117 \quad 118$

Heterogeneity: Tau $^{2}=0.15 ; \mathrm{Chi}^{2}=2.72, \mathrm{df}=\mathrm{I}(\mathrm{P}=0.10) ; \mathrm{I}^{2}=63 \%$

Test for overall effect: $Z=0.01(P=0.99)$

$100.0 \% \quad 0.00[-0.68,0.67]$

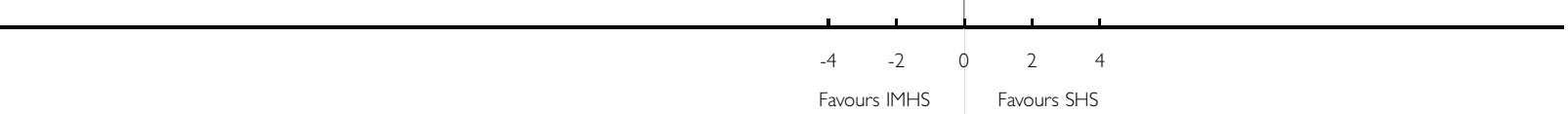

Analysis 3.4. Comparison 3 Intramedullary hip screw (IMHS) versus sliding hip screw (SHS), Outcome 4 Number of patients transfused.

Review: Gamma and other cephalocondylic intramedullary nails versus extramedullary implants for extracapsular hip fractures in adults

Comparison: 3 Intramedullary hip screw (IMHS) versus sliding hip screw (SHS)

Outcome: 4 Number of patients transfused

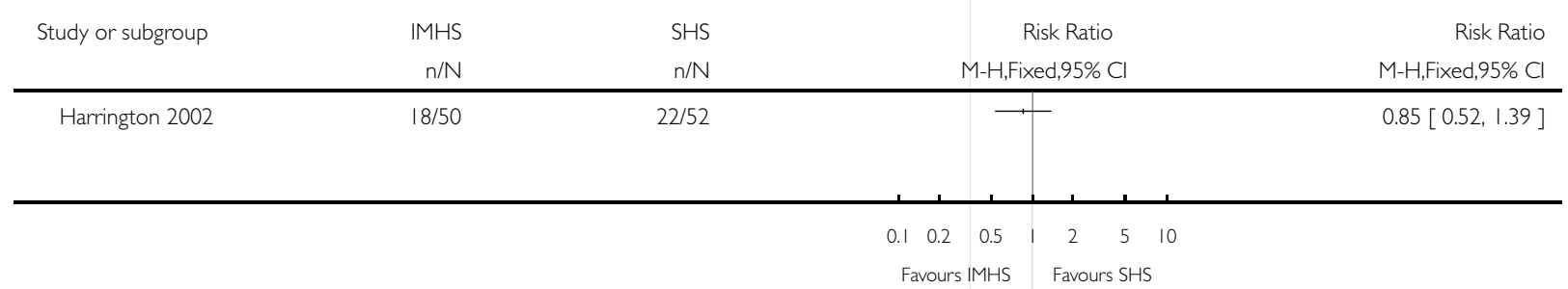

Gamma and other cephalocondylic intramedullary nails versus extramedullary implants for extracapsular hip fractures in adults (Review) $\quad$ I48 Copyright (@) 2010 The Cochrane Collaboration. Published by John Wiley \& Sons, Ltd. 
Analysis 3.5. Comparison 3 Intramedullary hip screw (IMHS) versus sliding hip screw (SHS), Outcome 5 Radiographic screening time (minutes).

Review: Gamma and other cephalocondylic intramedullary nails versus extramedullary implants for extracapsular hip fractures in adults

Comparison: 3 Intramedullary hip screw (IMHS) versus sliding hip screw (SHS)

Outcome: 5 Radiographic screening time (minutes)

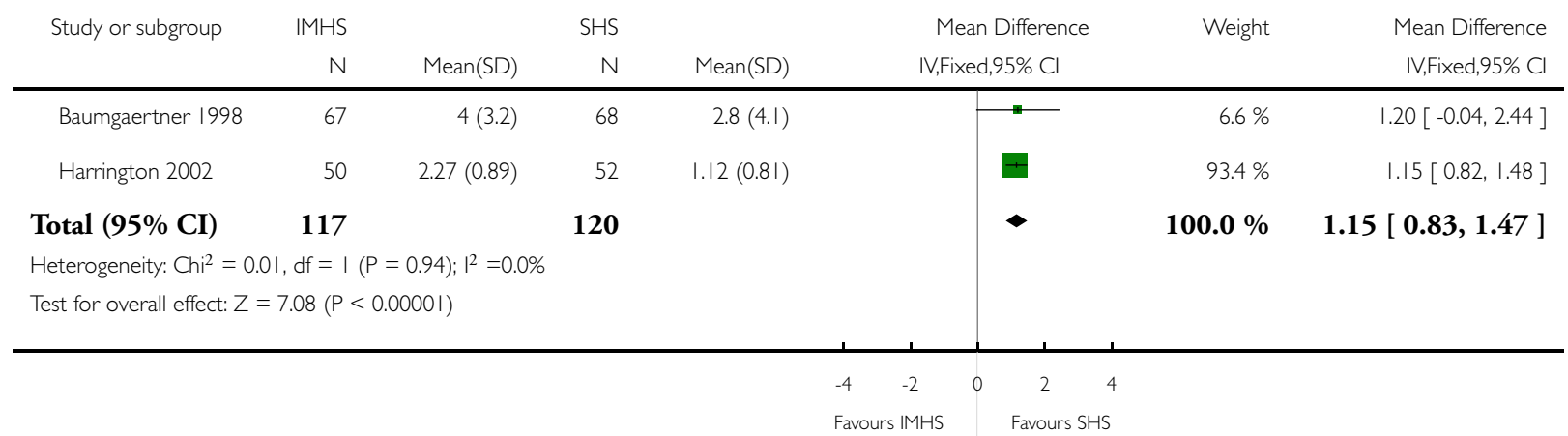

Analysis 3.6. Comparison 3 Intramedullary hip screw (IMHS) versus sliding hip screw (SHS), Outcome 6 Fracture fixation complications.

Review: Gamma and other cephalocondylic intramedullary nails versus extramedullary implants for extracapsular hip fractures in adults

Comparison: 3 Intramedullary hip screw (IMHS) versus sliding hip screw (SHS)

Outcome: 6 Fracture fixation complications

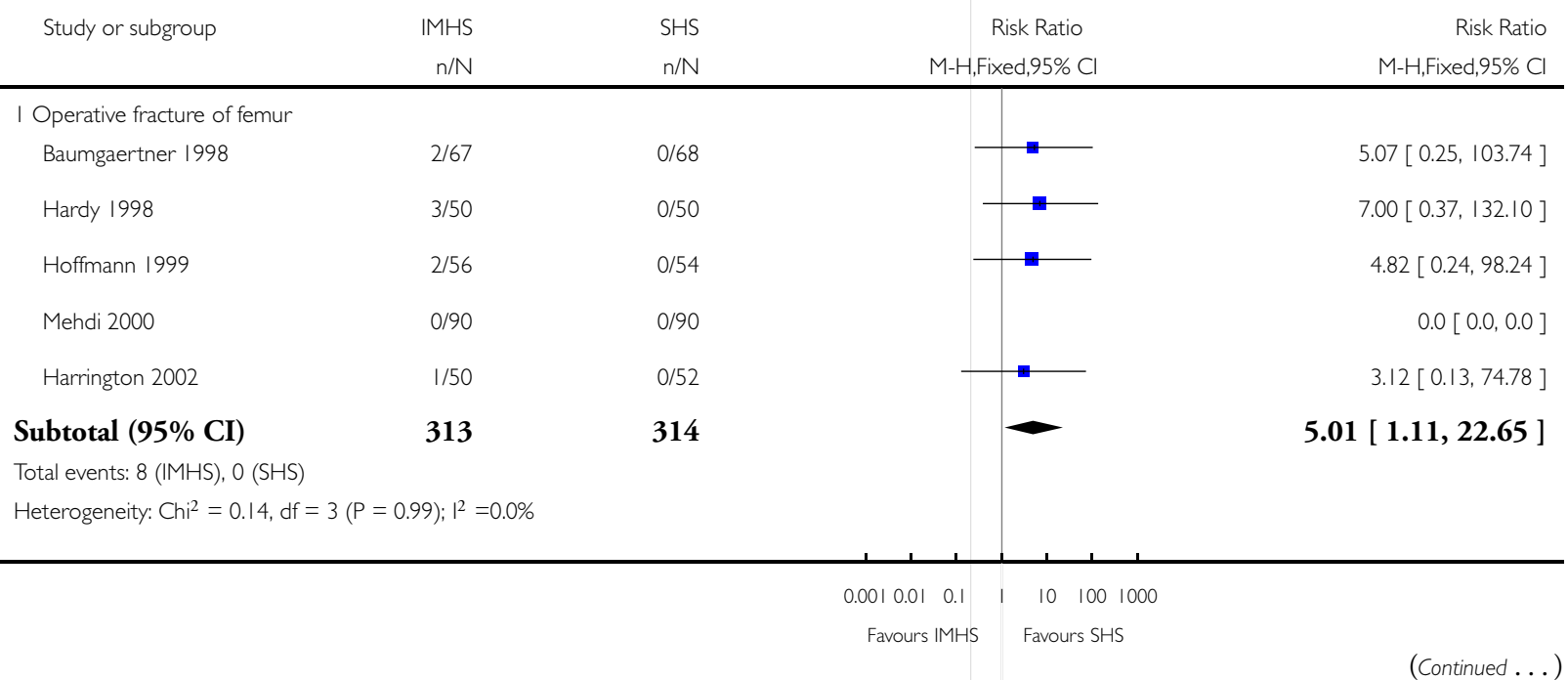

Gamma and other cephalocondylic intramedullary nails versus extramedullary implants for extracapsular hip fractures in adults (Review) I49 Copyright (C) 2010 The Cochrane Collaboration. Published by John Wiley \& Sons, Ltd. 


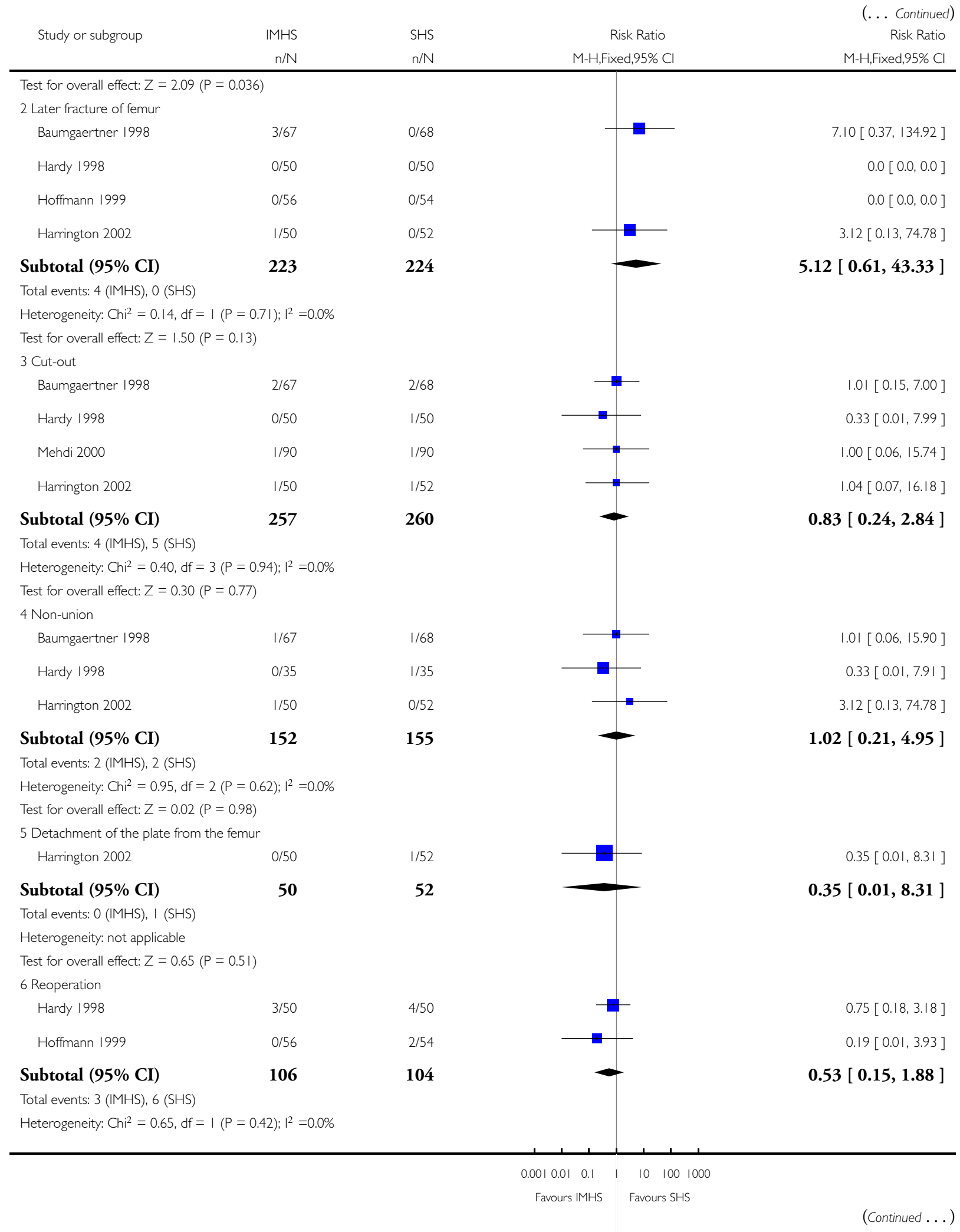

Gamma and other cephalocondylic intramedullary nails versus extramedullary implants for extracapsular hip fractures in adults (Review) $\quad$ I50 Copyright (C) 2010 The Cochrane Collaboration. Published by John Wiley \& Sons, Ltd. 


\begin{tabular}{ccccc} 
& & & Risk Ratio \\
Study or subgroup & IMHS & SHS & M-H,Fixed,95\% Cl & Risk Ratio \\
\hline
\end{tabular}

Test for overall effect: $Z=0.98(P=0.33)$

$0.0010 .010 .1 \quad 1 \quad 10 \quad 1001000$

Favours IMHS Favours SHS

Analysis 3.7. Comparison 3 Intramedullary hip screw (IMHS) versus sliding hip screw (SHS), Outcome 7 Wound infection or haematoma.

Review: Gamma and other cephalocondylic intramedullary nails versus extramedullary implants for extracapsular hip fractures in adults

Comparison: 3 Intramedullary hip screw (IMHS) versus sliding hip screw (SHS)

Outcome: 7 Wound infection or haematoma

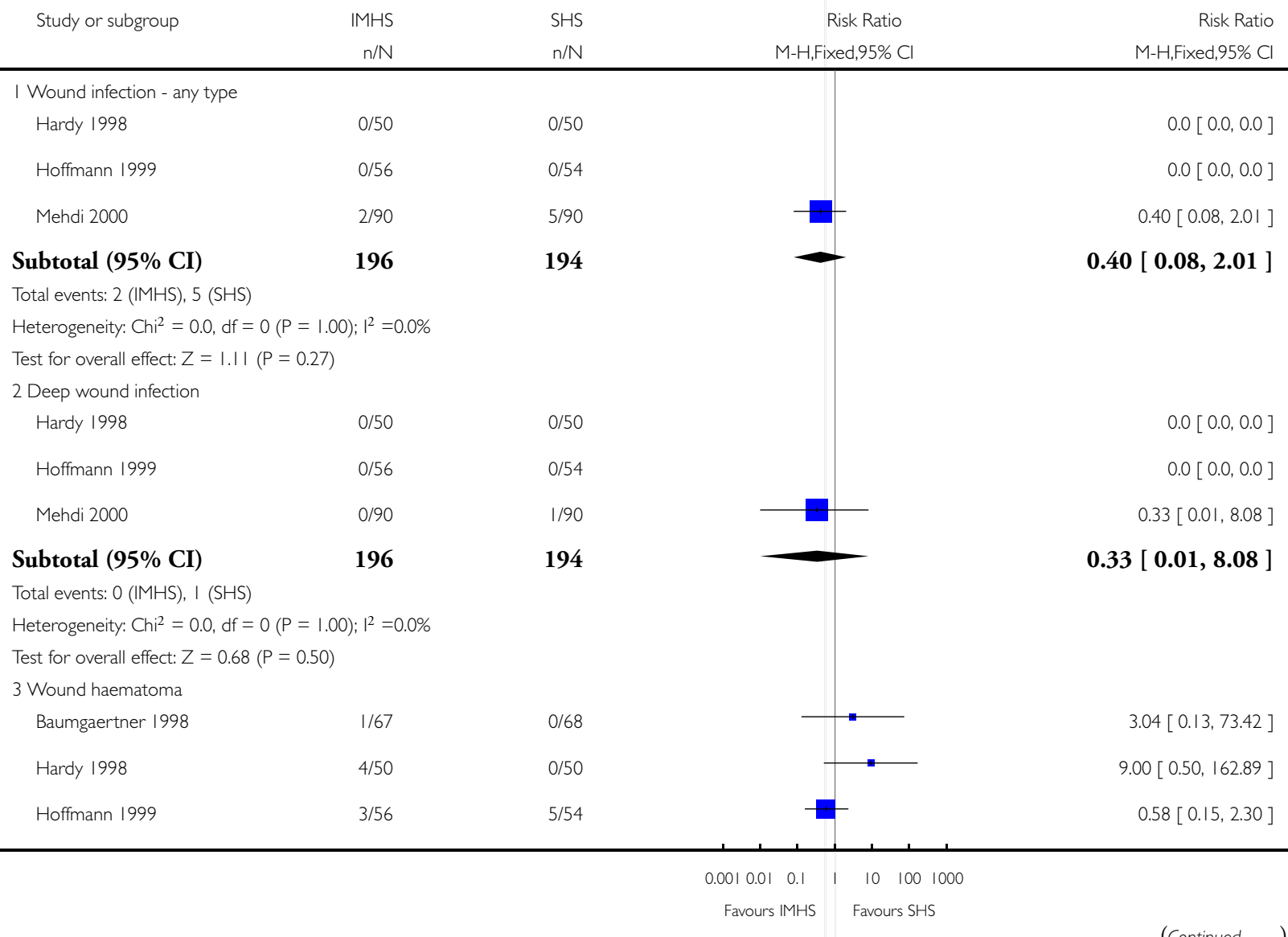

(Continued....)

Gamma and other cephalocondylic intramedullary nails versus extramedullary implants for extracapsular hip fractures in adults (Review) I5 I Copyright (c) 2010 The Cochrane Collaboration. Published by John Wiley \& Sons, Ltd. 


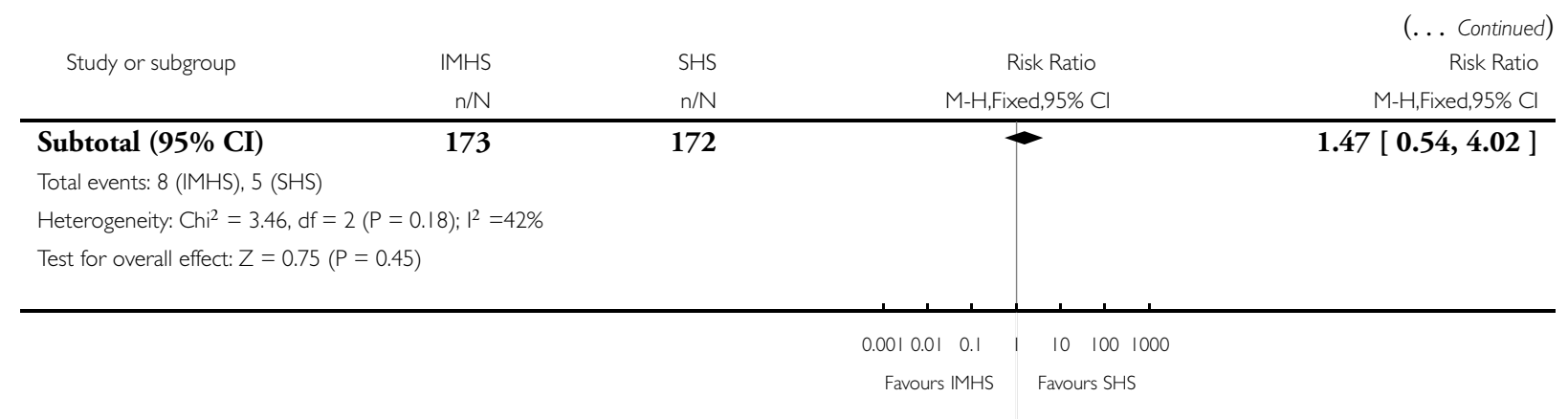

\section{Analysis 3.8. Comparison 3 Intramedullary hip screw (IMHS) versus sliding hip screw (SHS), Outcome 8} Post-operative complications.

Review: Gamma and other cephalocondylic intramedullary nails versus extramedullary implants for extracapsular hip fractures in adults

Comparison: 3 Intramedullary hip screw (IMHS) versus sliding hip screw (SHS)

Outcome: 8 Post-operative complications

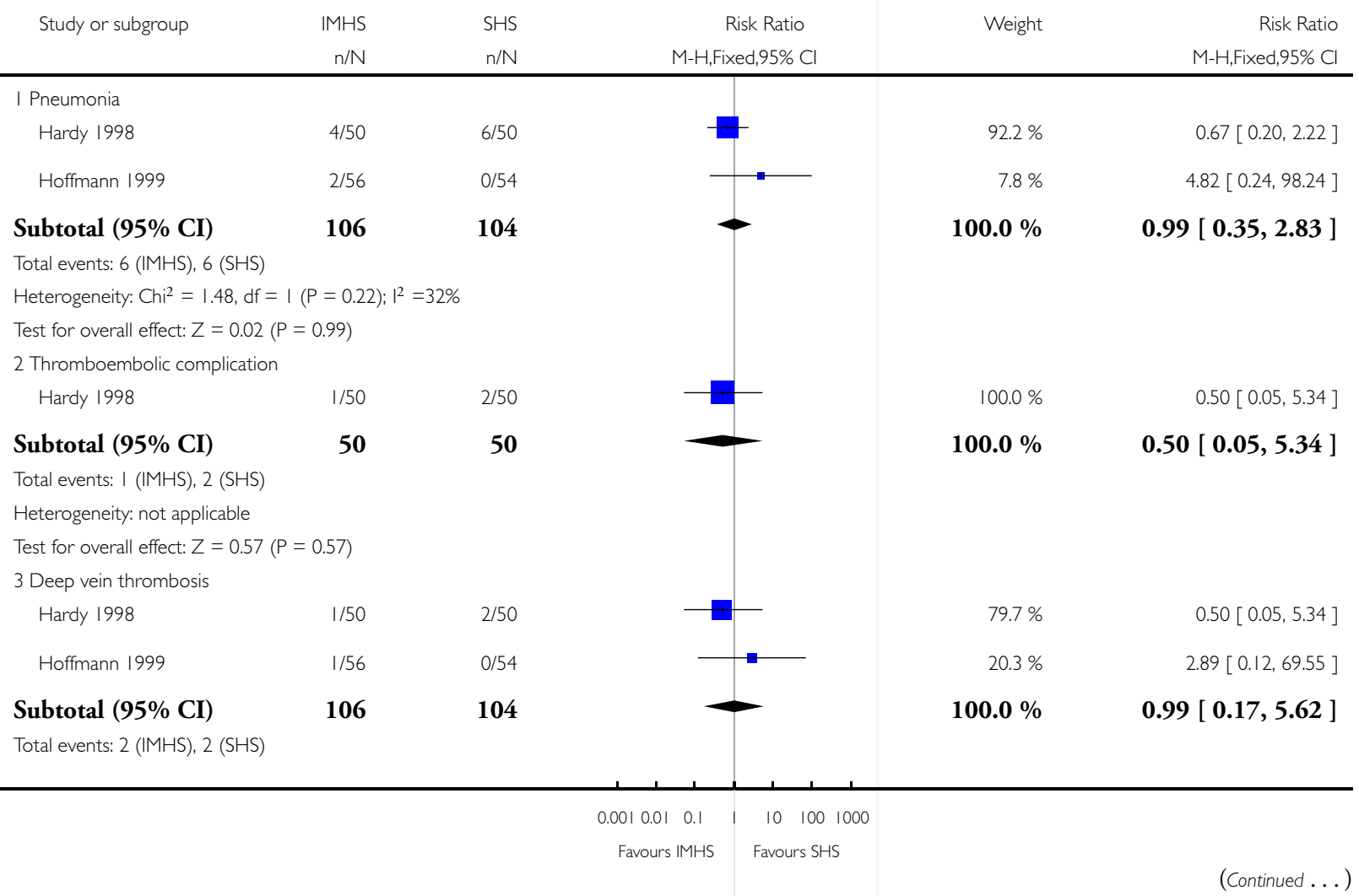

Gamma and other cephalocondylic intramedullary nails versus extramedullary implants for extracapsular hip fractures in adults (Review) $\quad 152$ Copyright (C) 2010 The Cochrane Collaboration. Published by John Wiley \& Sons, Ltd. 


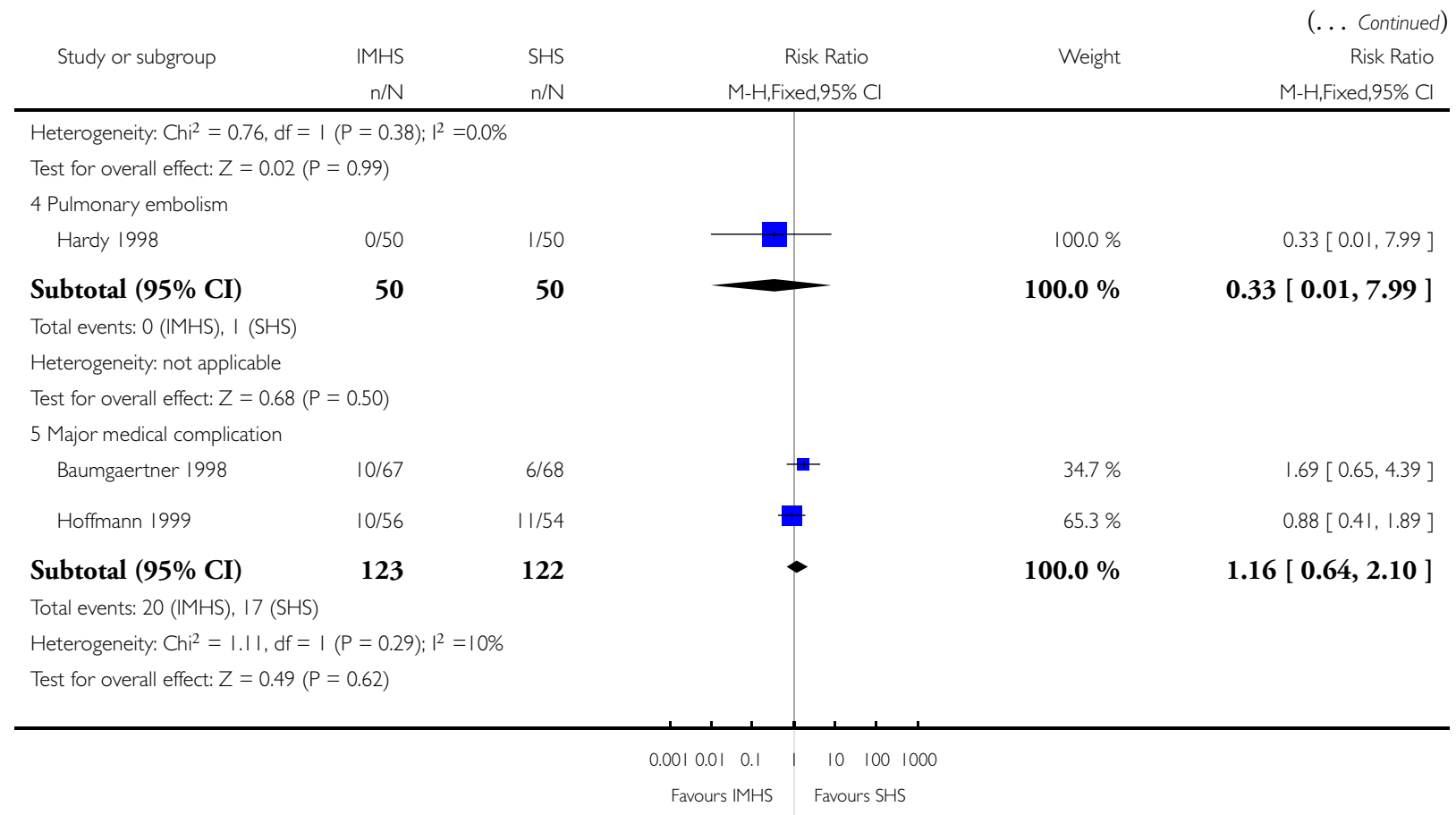

\section{Analysis 3.9. Comparison 3 Intramedullary hip screw (IMHS) versus sliding hip screw (SHS), Outcome 9} Length of hospital stay (days).

Review: Gamma and other cephalocondylic intramedullary nails versus extramedullary implants for extracapsular hip fractures in adults

Comparison: 3 Intramedullary hip screw (IMHS) versus sliding hip screw (SHS)

Outcome: 9 Length of hospital stay (days)

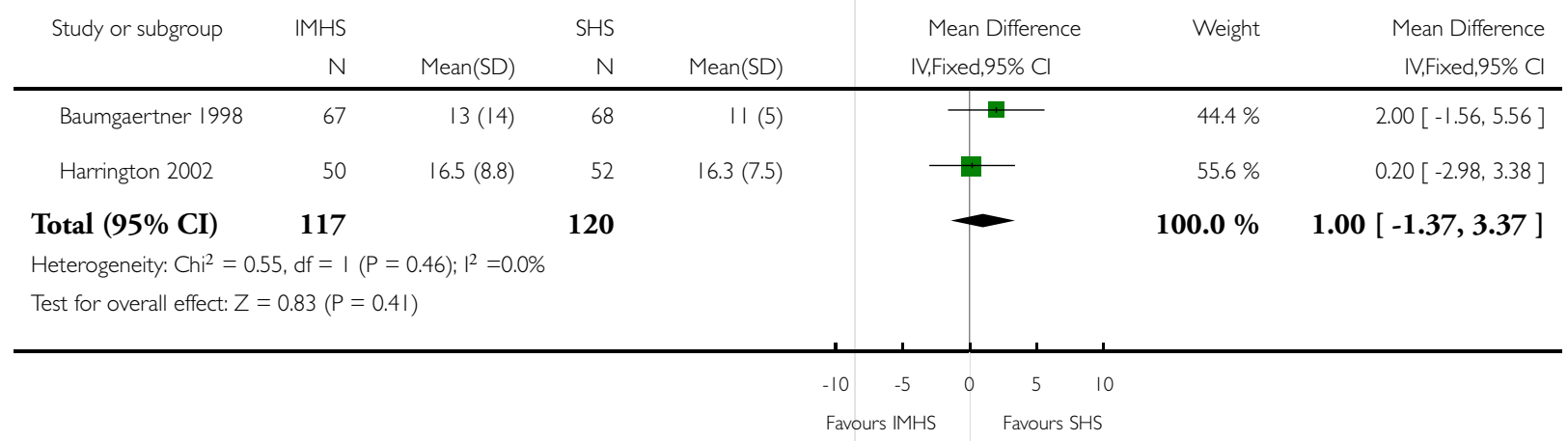

Gamma and other cephalocondylic intramedullary nails versus extramedullary implants for extracapsular hip fractures in adults (Review) $\quad$ I53 Copyright (C) 2010 The Cochrane Collaboration. Published by John Wiley \& Sons, Ltd. 
Analysis 3.10. Comparison 3 Intramedullary hip screw (IMHS) versus sliding hip screw (SHS), Outcome 10 Mean limb shortening $(\mathrm{cm})$.

Review: Gamma and other cephalocondylic intramedullary nails versus extramedullary implants for extracapsular hip fractures in adults

Comparison: 3 Intramedullary hip screw (IMHS) versus sliding hip screw (SHS)

Outcome: 10 Mean limb shortening $(\mathrm{cm})$

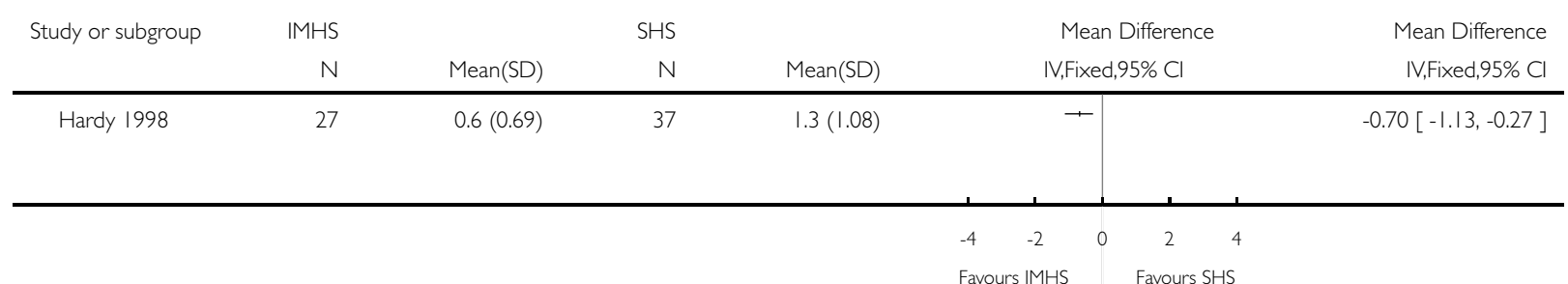

Analysis 3.1 I. Comparison 3 Intramedullary hip screw (IMHS) versus sliding hip screw (SHS), Outcome II Final outcome measures.

Review: Gamma and other cephalocondylic intramedullary nails versus extramedullary implants for extracapsular hip fractures in adults

Comparison: 3 Intramedullary hip screw (IMHS) versus sliding hip screw (SHS)

Outcome: II Final outcome measures

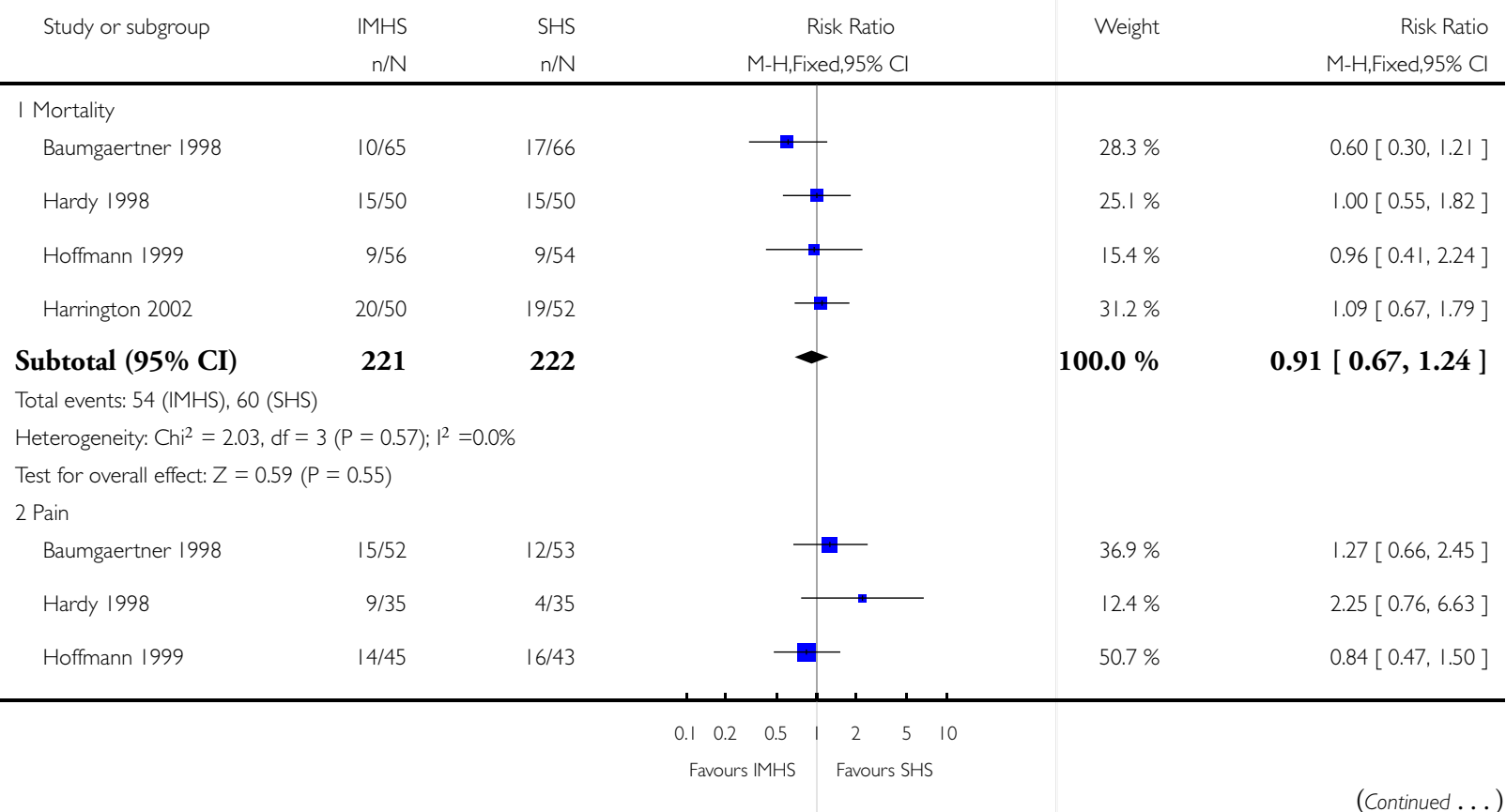

Gamma and other cephalocondylic intramedullary nails versus extramedullary implants for extracapsular hip fractures in adults (Review) $\quad$ I54 Copyright (C) 2010 The Cochrane Collaboration. Published by John Wiley \& Sons, Ltd. 


\begin{tabular}{|c|c|c|c|c|c|}
\hline Study or subgroup & $\begin{array}{r}\mathrm{MHHS} \\
\mathrm{n} / \mathrm{N}\end{array}$ & $\begin{array}{l}\mathrm{SHS} \\
\mathrm{n} / \mathrm{N}\end{array}$ & $\begin{array}{c}\text { Risk Ratio } \\
\text { M-H,Fixed,95\% Cl }\end{array}$ & Weight & $\begin{array}{r}\text { (... Continued) } \\
\text { Risk Ratio } \\
\text { M-H,Fixed,95\% Cl }\end{array}$ \\
\hline Subtotal $(95 \% \mathrm{CI})$ & 132 & 131 & - & $100.0 \%$ & $1.17[0.79,1.75]$ \\
\hline \multicolumn{6}{|c|}{ Total events: 38 (IMHS), 32 (SHS) } \\
\hline \multicolumn{6}{|c|}{ Heterogeneity: $\mathrm{Ch}^{2}=2.75, \mathrm{df}=2(P=0.25) ; \mathrm{I}^{2}=27 \%$} \\
\hline \multicolumn{6}{|c|}{ Test for overall effect: $Z=0.78(P=0.43)$} \\
\hline \multicolumn{6}{|c|}{3 Failure to return home (survivors) } \\
\hline Baumgaertner 1998 & $18 / 52$ & $14 / 53$ & - & $44.0 \%$ & $1.31[0.73,2.35]$ \\
\hline Hoffmann 1999 & $7 / 45$ & $7 / 43$ & & $22.7 \%$ & $0.96[0.37,2.50]$ \\
\hline Harrington 2002 & $11 / 30$ & $11 / 33$ & 一 & $33.3 \%$ & $1.10[0.56,2.16]$ \\
\hline Subtotal $(95 \% \mathrm{CI})$ & 127 & 129 & . & $100.0 \%$ & $1.16[0.78,1.73]$ \\
\hline \multicolumn{6}{|c|}{ Total events: 36 (IMHS), 32 (SHS) } \\
\hline \multicolumn{6}{|c|}{ Heterogeneity: $\mathrm{Chi}^{2}=0.35, \mathrm{df}=2(\mathrm{P}=0.84) ; \mathrm{I}^{2}=0.0 \%$} \\
\hline \multicolumn{6}{|c|}{ Test for overall effect: $Z=0.72(P=0.47)$} \\
\hline \multicolumn{6}{|c|}{4 Failure to return home or dead } \\
\hline Baumgaertner 1998 & $24 / 58$ & $25 / 64$ & & $34.2 \%$ & $1.06[0.69,1.63]$ \\
\hline Hoffmann 1999 & $16 / 54$ & $16 / 52$ & & $23.5 \%$ & $0.96[0.54,1.72]$ \\
\hline Harrington 2002 & $31 / 50$ & $30 / 52$ & & $42.3 \%$ & $1.07[0.78,1.48]$ \\
\hline Subtotal $(95 \% \mathrm{CI})$ & 162 & 168 & & $100.0 \%$ & $1.04[0.82,1.33]$ \\
\hline \multicolumn{6}{|c|}{ Total events: 7I (IMHS), 7I (SHS) } \\
\hline \multicolumn{6}{|c|}{ Heterogeneity: $\mathrm{Chi}^{2}=0.1 \mathrm{l}, \mathrm{df}=2(\mathrm{P}=0.95) ; \mathrm{I}^{2}=0.0 \%$} \\
\hline \multicolumn{6}{|c|}{ Test for overall effect: $Z=0.34(P=0.73)$} \\
\hline \multicolumn{6}{|c|}{5 Failure to return home or dead (overall denominators used) } \\
\hline Baumgaertner 1998 & $24 / 65$ & $25 / 64$ & & $35.5 \%$ & $0.95[0.61,1.47]$ \\
\hline Hoffmann 1999 & $16 / 56$ & $16 / 54$ & & $23.0 \%$ & $0.96[0.54,1.73]$ \\
\hline Harrington 2002 & $31 / 50$ & $30 / 52$ & 1 & $41.5 \%$ & $1.07[0.78,1.48]$ \\
\hline Subtotal $(95 \% \mathrm{CI})$ & 171 & 170 & & $100.0 \%$ & $1.00[0.79,1.28]$ \\
\hline \multicolumn{6}{|c|}{ Total events: 7I (IMHS), 7I (SHS) } \\
\hline \multicolumn{6}{|c|}{ Heterogeneity: $\mathrm{Chi}^{2}=0.27, \mathrm{df}=2(\mathrm{P}=0.88) ; \mathrm{I}^{2}=0.0 \%$} \\
\hline \multicolumn{6}{|c|}{ Test for overall effect: $Z=0.03(P=0.98)$} \\
\hline \multicolumn{6}{|l|}{6 Failure to regain mobility } \\
\hline Baumgaertner 1998 & $15 / 52$ & $16 / 53$ & & $100.0 \%$ & $0.96[0.53,1.73]$ \\
\hline Subtotal $(95 \% \mathrm{CI})$ & 52 & 53 & & $100.0 \%$ & $0.96[0.53,1.73]$ \\
\hline \multicolumn{6}{|c|}{ Total events: 15 (IMHS), 16 (SHS) } \\
\hline \multicolumn{6}{|c|}{ Heterogeneity: not applicable } \\
\hline \multicolumn{6}{|c|}{ Test for overall effect: $Z=0.15(P=0.88)$} \\
\hline \multicolumn{6}{|l|}{7 Poor mobility } \\
\hline Hoffmann 1999 & $16 / 45$ & $19 / 43$ & & $100.0 \%$ & $0.80[0.48,1.35]$ \\
\hline Subtotal (95\% CI) & 45 & 43 & & $100.0 \%$ & $0.80[0.48,1.35]$ \\
\hline \multicolumn{6}{|c|}{ Total events: 16 (IMHS), 19 (SHS) } \\
\hline \multicolumn{6}{|c|}{ Heterogeneity: not applicable } \\
\hline Test for overall effect: $Z=$ & $0.41)$ & & & & \\
\hline
\end{tabular}

$\begin{array}{lllllll}0.1 & 0.2 & 0.5 & 1 & 2 & 5 & 10\end{array}$

Favours IMHS Favours SHS

Gamma and other cephalocondylic intramedullary nails versus extramedullary implants for extracapsular hip fractures in adults (Review) $\quad$ I55 Copyright (C) 2010 The Cochrane Collaboration. Published by John Wiley \& Sons, Ltd. 
Analysis 4.I. Comparison 4 Proximal femoral nail (PFN) versus sliding hip screw (SHS), Outcome I Length of surgery (minutes).

Review: Gamma and other cephalocondylic intramedullary nails versus extramedullary implants for extracapsular hip fractures in adults

Comparison: 4 Proximal femoral nail (PFN) versus sliding hip screw (SHS)

Outcome: I Length of surgery (minutes)

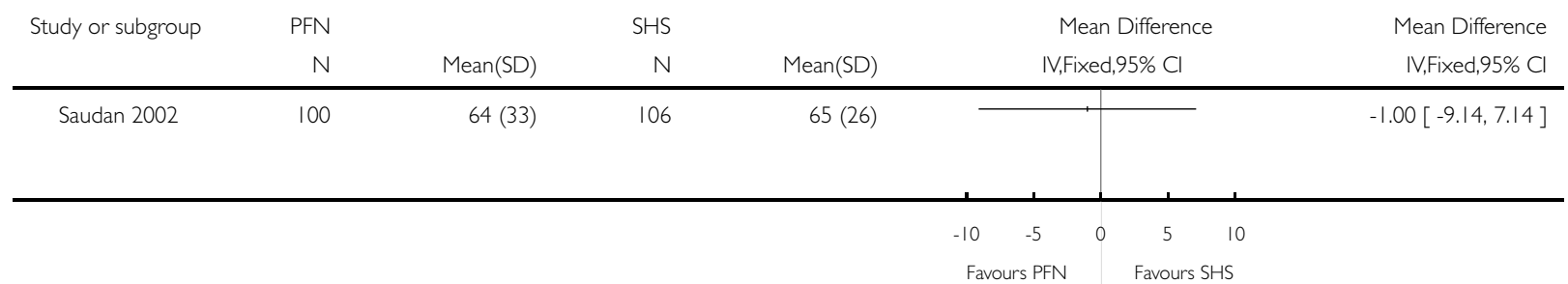

Analysis 4.2. Comparison 4 Proximal femoral nail (PFN) versus sliding hip screw (SHS), Outcome 2 Blood loss and transfusion.

Review: Gamma and other cephalocondylic intramedullary nails versus extramedullary implants for extracapsular hip fractures in adults

Comparison: 4 Proximal femoral nail (PFN) versus sliding hip screw (SHS)

Outcome: 2 Blood loss and transfusion

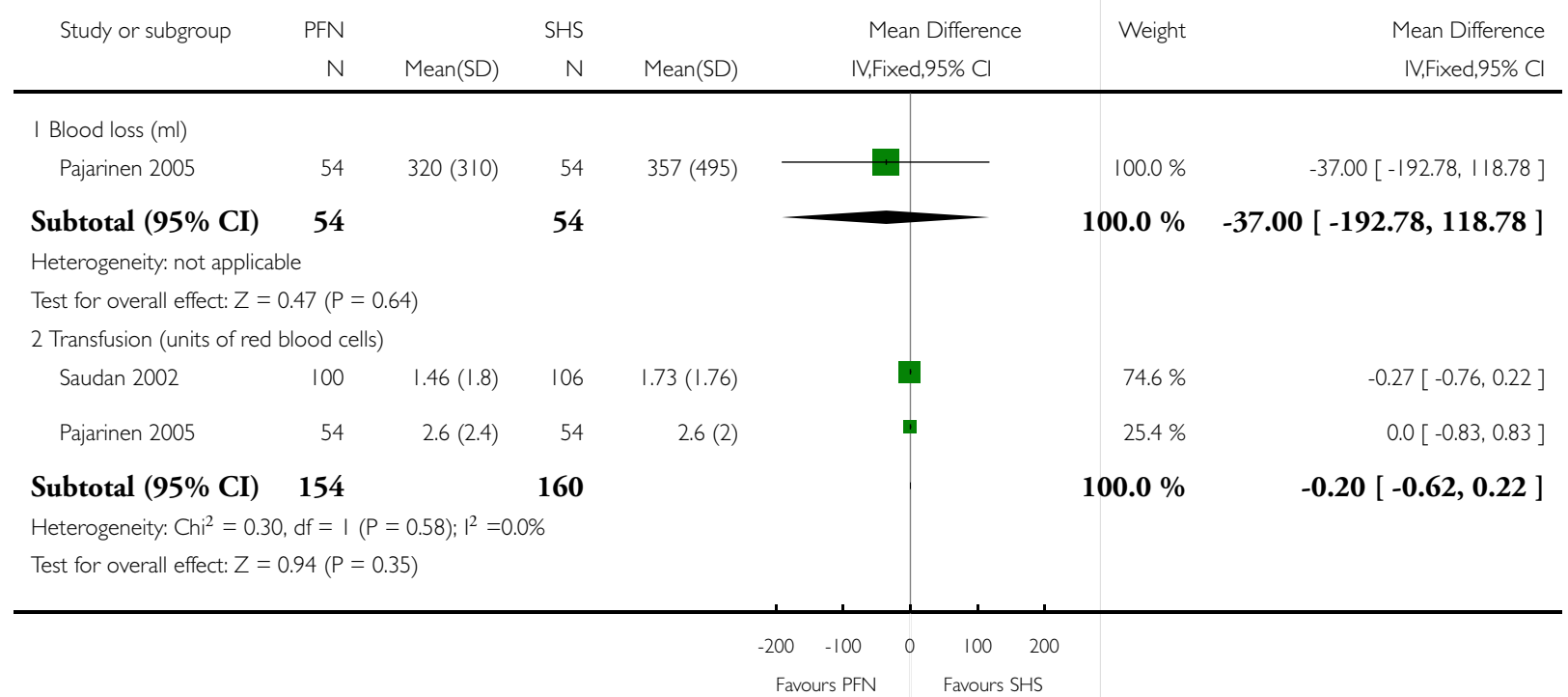

Gamma and other cephalocondylic intramedullary nails versus extramedullary implants for extracapsular hip fractures in adults (Review) I56 Copyright (C) 2010 The Cochrane Collaboration. Published by John Wiley \& Sons, Ltd. 
Analysis 4.3. Comparison 4 Proximal femoral nail (PFN) versus sliding hip screw (SHS), Outcome 3 Number of patients transfused.

Review: Gamma and other cephalocondylic intramedullary nails versus extramedullary implants for extracapsular hip fractures in adults

Comparison: 4 Proximal femoral nail (PFN) versus sliding hip screw (SHS)

Outcome: 3 Number of patients transfused

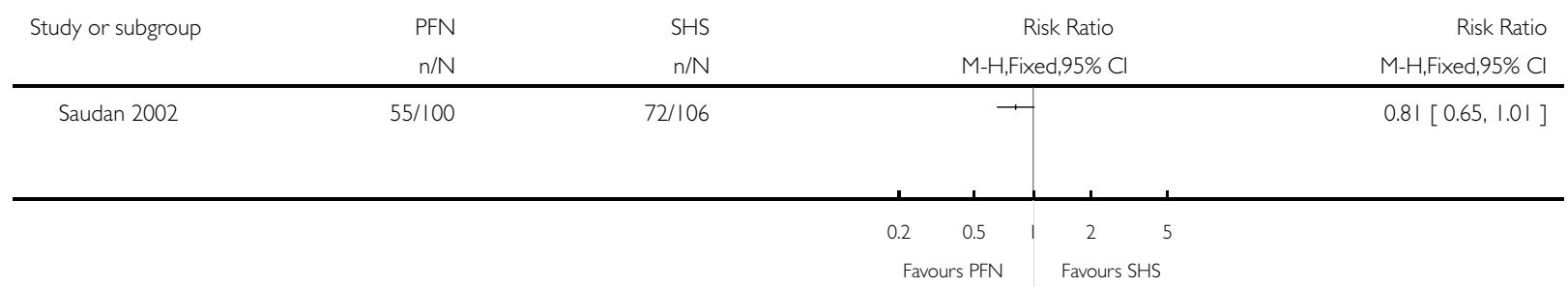

Analysis 4.4. Comparison 4 Proximal femoral nail (PFN) versus sliding hip screw (SHS), Outcome 4 Radiographic screening time (minutes).

Review: Gamma and other cephalocondylic intramedullary nails versus extramedullary implants for extracapsular hip fractures in adults

Comparison: 4 Proximal femoral nail (PFN) versus sliding hip screw (SHS)

Outcome: 4 Radiographic screening time (minutes)

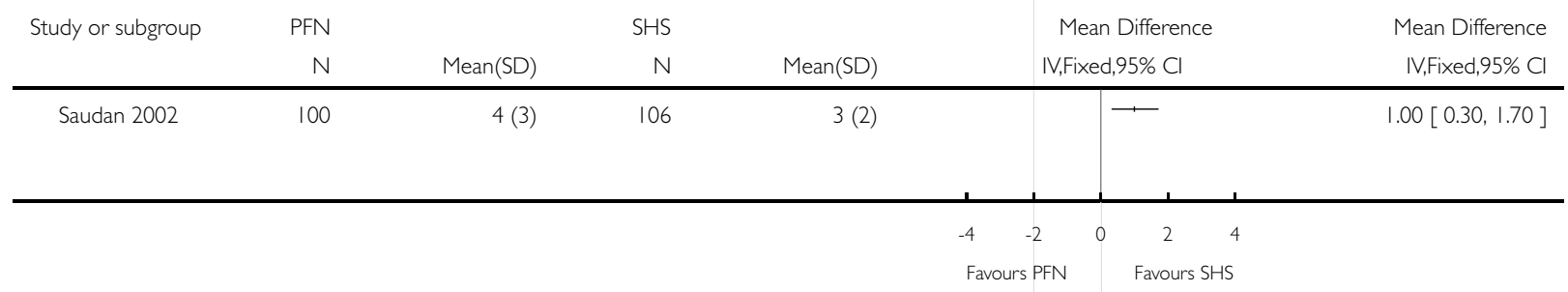


Analysis 4.5. Comparison 4 Proximal femoral nail (PFN) versus sliding hip screw (SHS), Outcome 5 Fracture fixation complications.

Review: Gamma and other cephalocondylic intramedullary nails versus extramedullary implants for extracapsular hip fractures in adults

Comparison: 4 Proximal femoral nail (PFN) versus sliding hip screw (SHS)

Outcome: 5 Fracture fixation complications

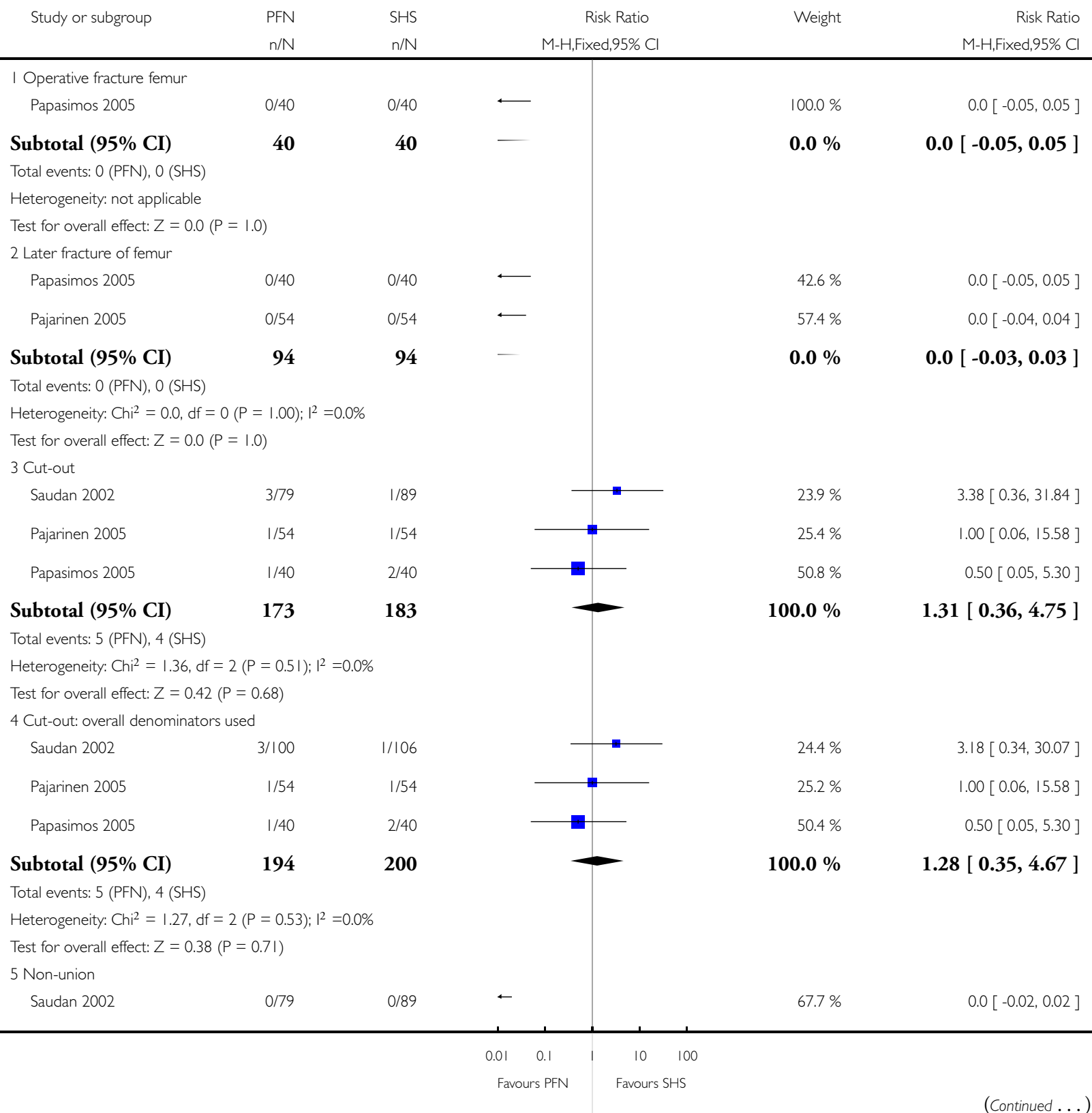

Gamma and other cephalocondylic intramedullary nails versus extramedullary implants for extracapsular hip fractures in adults (Review) $\quad$ I58 Copyright (C) 2010 The Cochrane Collaboration. Published by John Wiley \& Sons, Ltd. 


\begin{tabular}{|c|c|c|c|c|c|}
\hline \multirow[t]{2}{*}{ Study or subgroup } & $\begin{array}{l}\text { PFN } \\
n / N\end{array}$ & SHS & Risk Ratio & \multirow[t]{2}{*}{ Weight } & \multirow[t]{2}{*}{$\begin{array}{c}\text { (... Continued) } \\
\text { Risk Ratio } \\
\text { M-H,Fixed,95\% Cl }\end{array}$} \\
\hline & $\mathrm{n} / \mathrm{N}$ & $n / N$ & M-H,Fixed, $95 \% \mathrm{Cl}$ & & \\
\hline Papasimos 2005 & $0 / 40$ & $1 / 40$ & + & $100.0 \%$ & $0.33[0.01,7.95]$ \\
\hline Subtotal $(95 \% \mathrm{CI})$ & 119 & 129 & & $100.0 \%$ & $0.33[0.01,7.95]$ \\
\hline \multicolumn{6}{|c|}{ Total events: 0 (PFN), I (SHS) } \\
\hline \multicolumn{6}{|c|}{ Heterogeneity: $\mathrm{Chi}^{2}=0.0, \mathrm{df}=0(\mathrm{P}=1.00) ; \mathrm{I}^{2}=0.0 \%$} \\
\hline \multicolumn{6}{|c|}{ Test for overall effect: $Z=0.68(P=0.50)$} \\
\hline \multicolumn{6}{|l|}{6 Reoperation } \\
\hline Saudan 2002 & $6 / 79$ & 2/89 & - & $27.3 \%$ & $3.38[0.70,16.27]$ \\
\hline Pajarinen 2005 & $2 / 54$ & 2/54 & & $29.1 \%$ & $1.00[0.15,6.84]$ \\
\hline Papasimos 2005 & $5 / 40$ & $3 / 40$ & 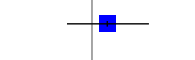 & $43.6 \%$ & $1.67[0.43,6.51]$ \\
\hline Subtotal $(95 \% \mathrm{CI})$ & 173 & 183 & - & $100.0 \%$ & $1.94[0.80,4.71]$ \\
\hline \multicolumn{6}{|c|}{ Total events: 13 (PFN), 7 (SHS) } \\
\hline \multicolumn{6}{|c|}{ Heterogeneity: Chi $^{2}=0.98, d f=2(P=0.61) ; 1^{2}=0.0 \%$} \\
\hline \multicolumn{6}{|c|}{ Test for overall effect: $Z=1.47(P=0.14)$} \\
\hline \multicolumn{6}{|c|}{7 Reoperation: overall denominators used } \\
\hline Saudan 2002 & $6 / 100$ & 2/106 & $=$ & $28.0 \%$ & $3.18[0.66,15.39]$ \\
\hline Pajarinen 2005 & $2 / 54$ & $2 / 54$ & 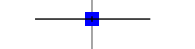 & $28.8 \%$ & $1.00[0.15,6.84]$ \\
\hline Papasimos 2005 & $5 / 40$ & $3 / 40$ & $=$ & $43.2 \%$ & $1.67[0.43,6.51]$ \\
\hline Subtotal $(95 \% \mathrm{CI})$ & 194 & 200 & - & $100.0 \%$ & $1.90[0.78,4.62]$ \\
\hline \multicolumn{6}{|c|}{ Total events: 13 (PFN), 7 (SHS) } \\
\hline \multicolumn{6}{|c|}{ Heterogeneity: $\mathrm{Chi}^{2}=0.87, \mathrm{df}=2(\mathrm{P}=0.65) ; \mathrm{I}^{2}=0.0 \%$} \\
\hline Test for overall effect: $Z=$ & $0.16)$ & & & & \\
\hline
\end{tabular}


Analysis 4.6. Comparison 4 Proximal femoral nail (PFN) versus sliding hip screw (SHS), Outcome 6 Wound infection or haematoma.

Review: Gamma and other cephalocondylic intramedullary nails versus extramedullary implants for extracapsular hip fractures in adults

Comparison: 4 Proximal femoral nail (PFN) versus sliding hip screw (SHS)

Outcome: 6 Wound infection or haematoma

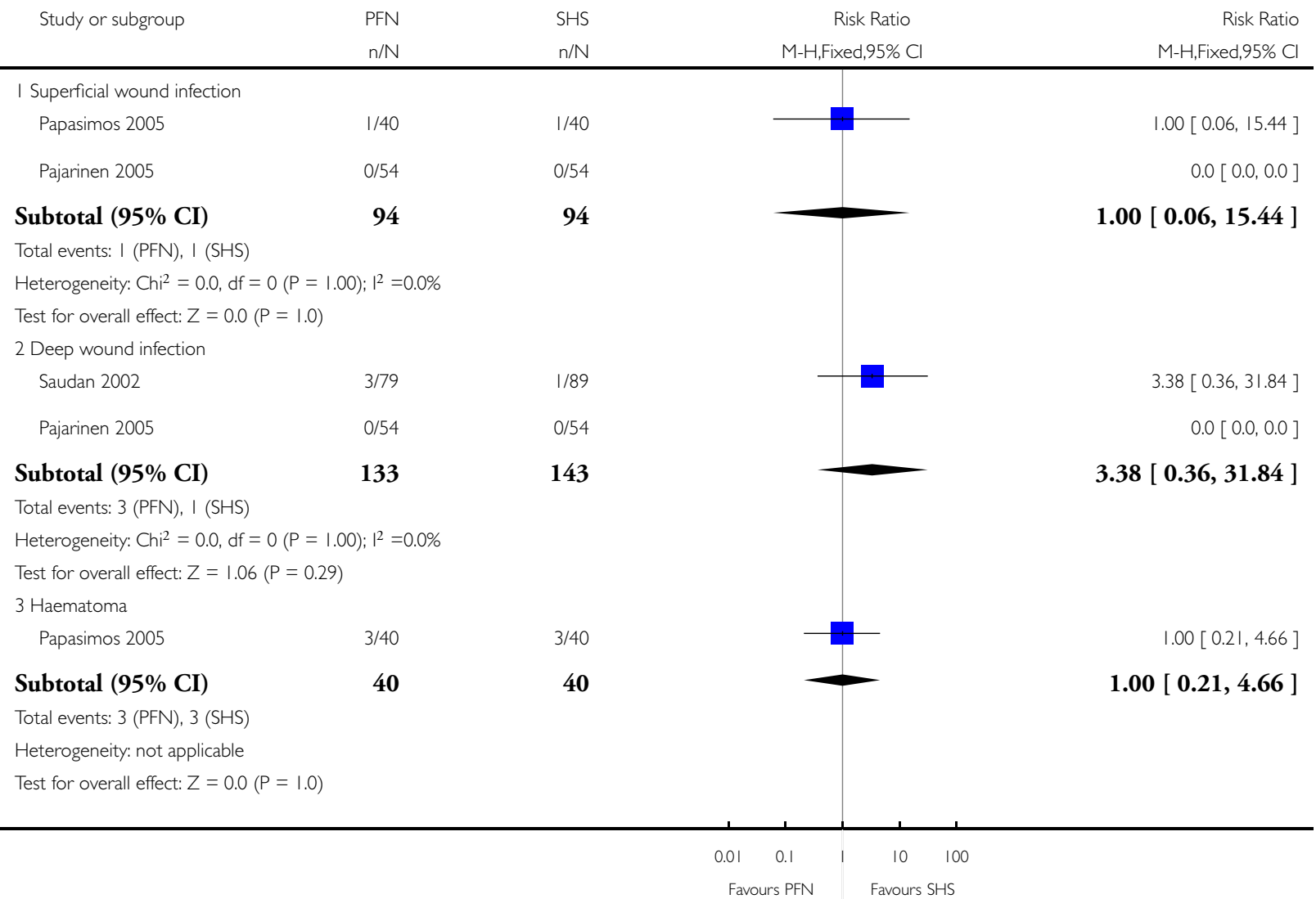

Gamma and other cephalocondylic intramedullary nails versus extramedullary implants for extracapsular hip fractures in adults (Review) 160 Copyright (c) 2010 The Cochrane Collaboration. Published by John Wiley \& Sons, Ltd. 
Analysis 4.7. Comparison 4 Proximal femoral nail (PFN) versus sliding hip screw (SHS), Outcome 7 Postoperative complications.

Review: Gamma and other cephalocondylic intramedullary nails versus extramedullary implants for extracapsular hip fractures in adults

Comparison: 4 Proximal femoral nail (PFN) versus sliding hip screw (SHS)

Outcome: 7 Post-operative complications

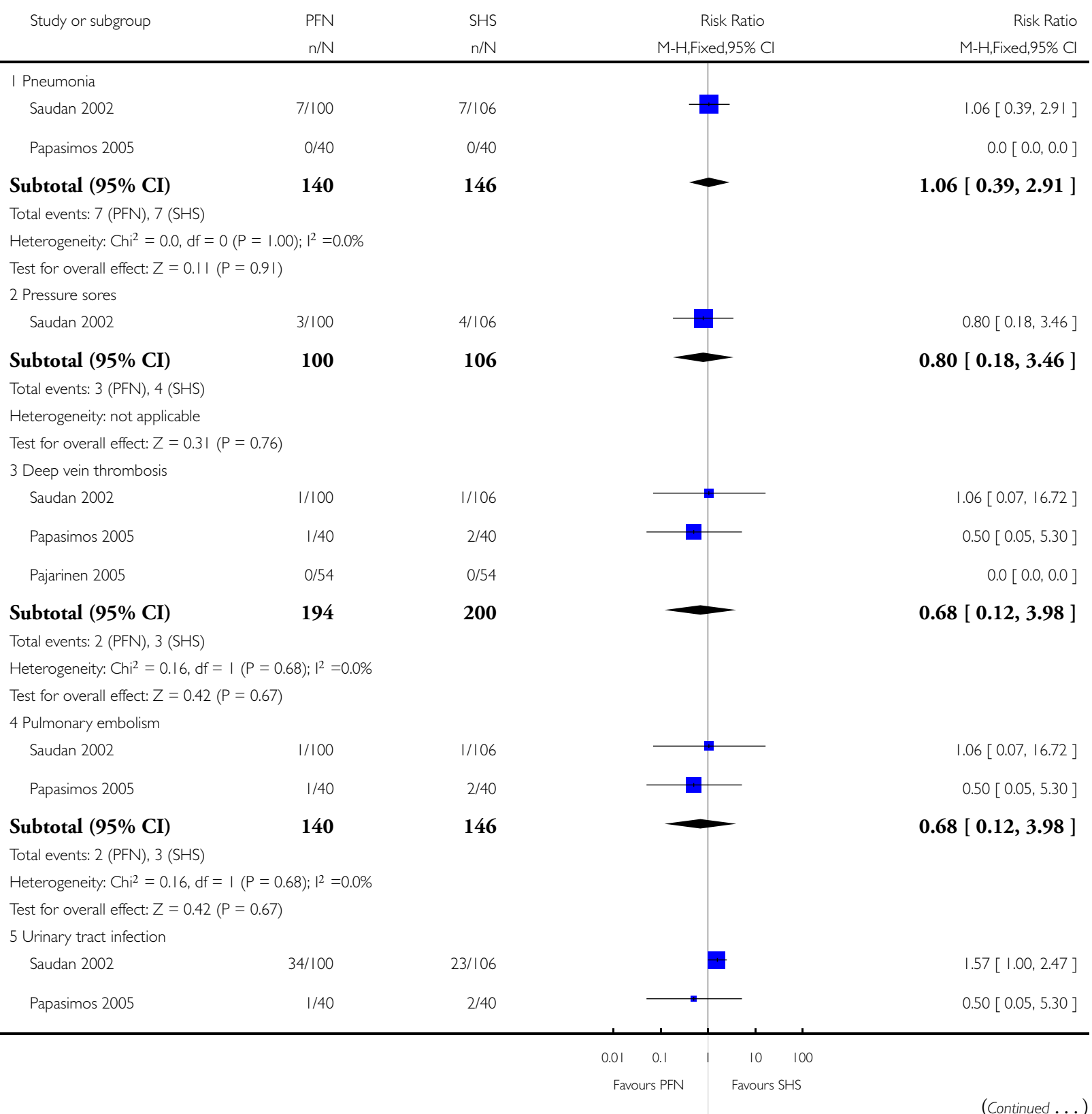

Gamma and other cephalocondylic intramedullary nails versus extramedullary implants for extracapsular hip fractures in adults (Review) I6 I Copyright ( $) 2010$ The Cochrane Collaboration. Published by John Wiley \& Sons, Ltd. 


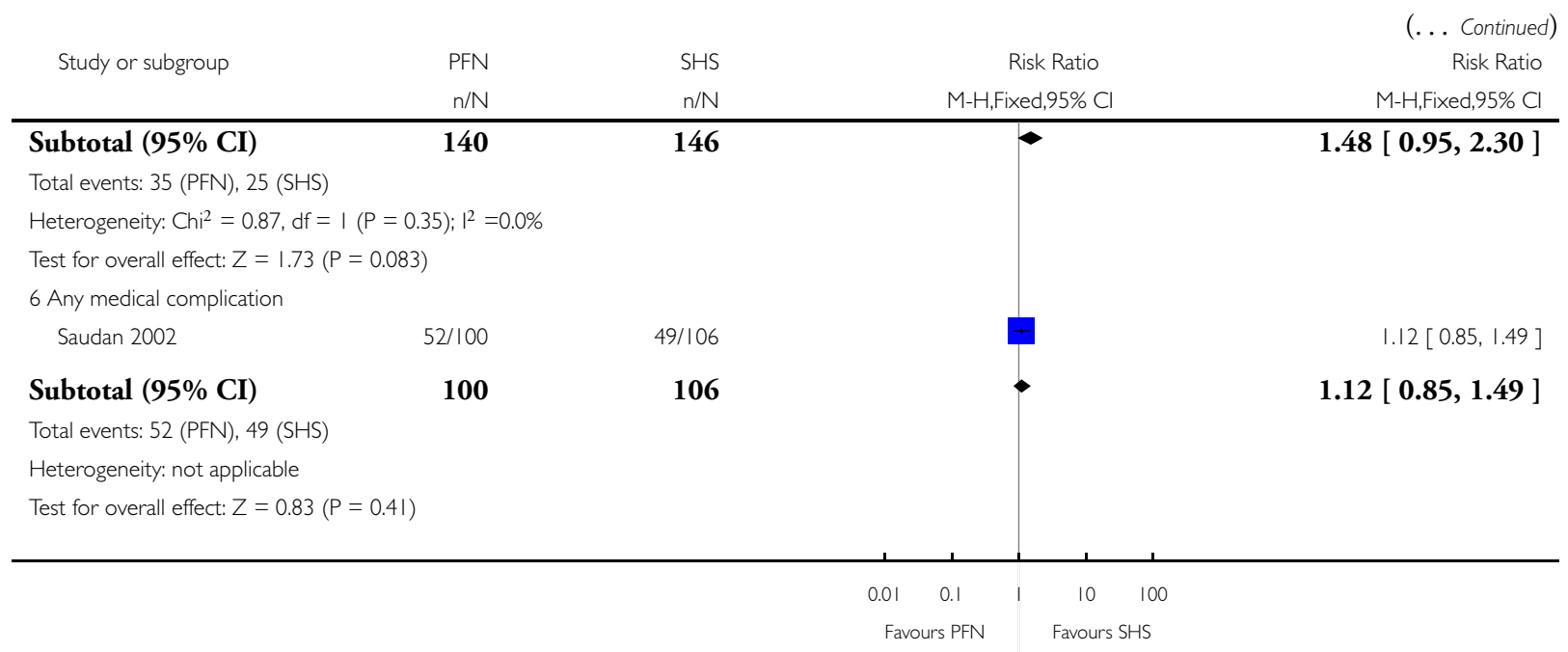

\section{Analysis 4.8. Comparison 4 Proximal femoral nail (PFN) versus sliding hip screw (SHS), Outcome 8 Length of hospital stay (days).}

Review: Gamma and other cephalocondylic intramedullary nails versus extramedullary implants for extracapsular hip fractures in adults

Comparison: 4 Proximal femoral nail (PFN) versus sliding hip screw (SHS)

Outcome: 8 Length of hospital stay (days)

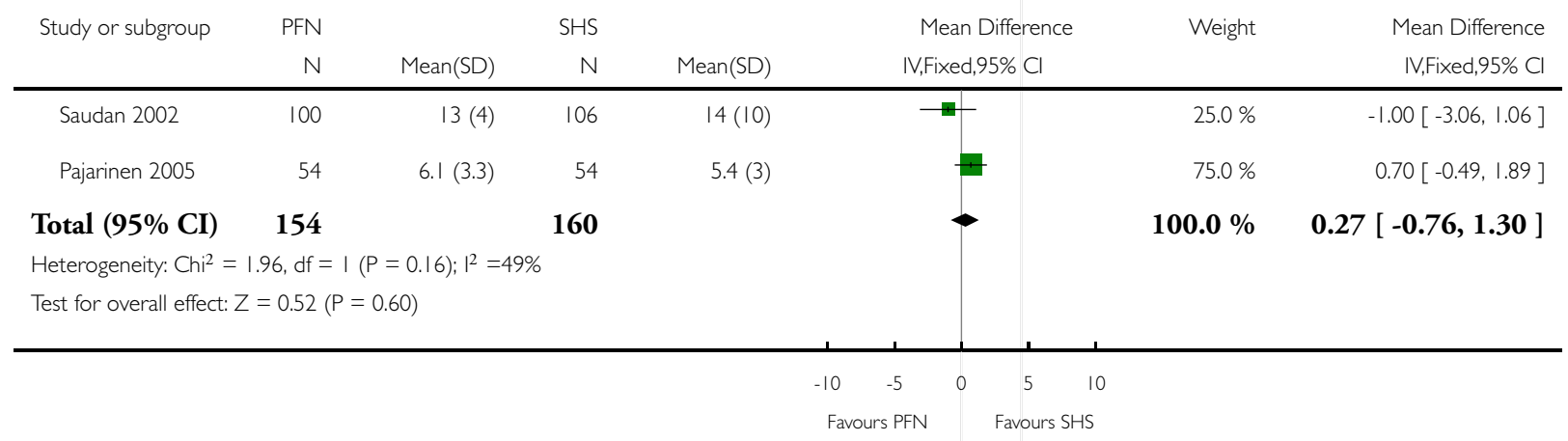


Analysis 4.9. Comparison 4 Proximal femoral nail (PFN) versus sliding hip screw (SHS), Outcome 9 Final outcome measures.

Review: Gamma and other cephalocondylic intramedullary nails versus extramedullary implants for extracapsular hip fractures in adults

Comparison: 4 Proximal femoral nail (PFN) versus sliding hip screw (SHS)

Outcome: 9 Final outcome measures

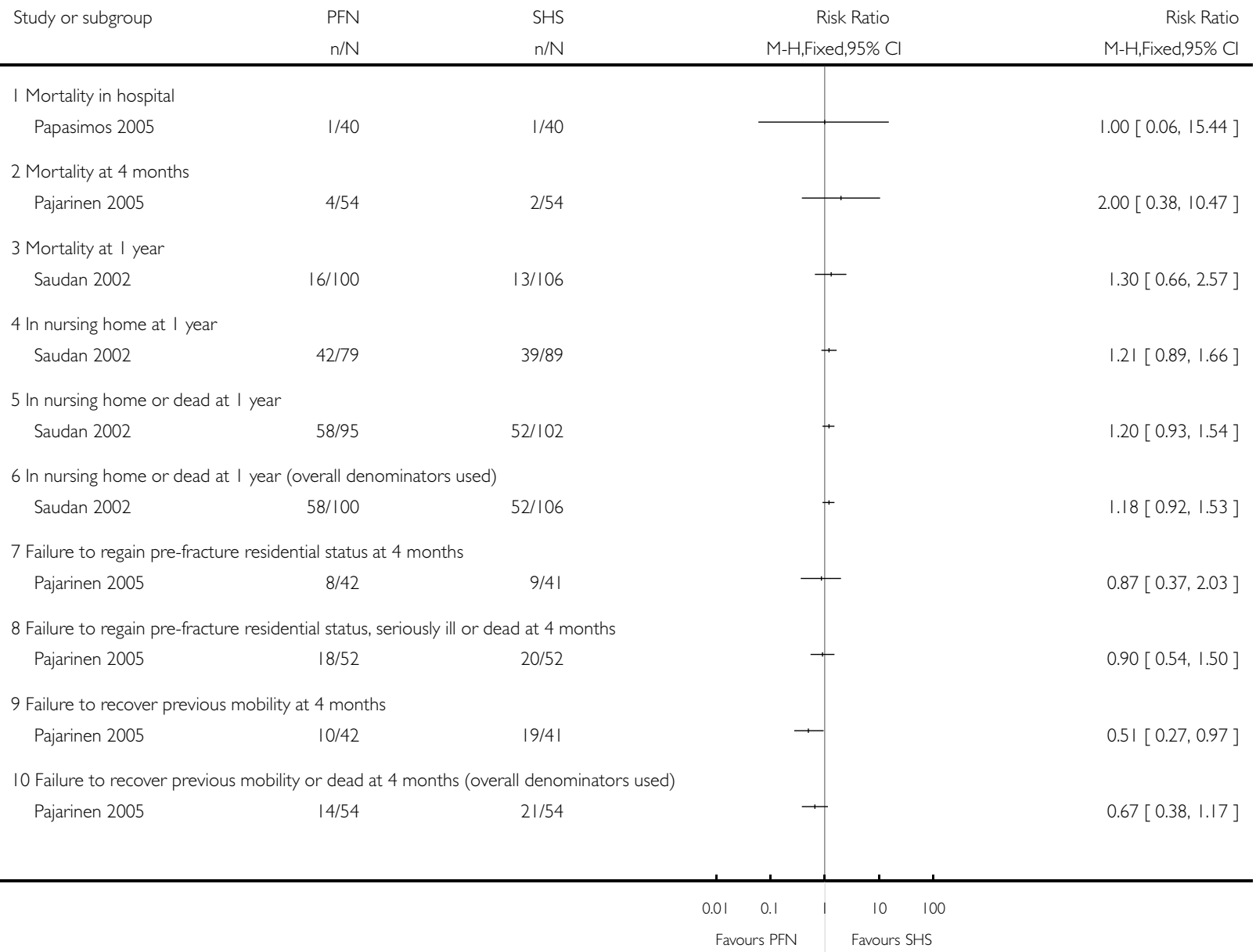

Gamma and other cephalocondylic intramedullary nails versus extramedullary implants for extracapsular hip fractures in adults (Review) $\quad 163$ Copyright (C) 2010 The Cochrane Collaboration. Published by John Wiley \& Sons, Ltd. 
Analysis 5.I. Comparison 5 Proximal femoral nail antirotation (PFNA) versus sliding hip screw (SHS), Outcome I Length of surgery (minutes).

Review: Gamma and other cephalocondylic intramedullary nails versus extramedullary implants for extracapsular hip fractures in adults

Comparison: 5 Proximal femoral nail antirotation (PFNA) versus sliding hip screw (SHS)

Outcome: I Length of surgery (minutes)

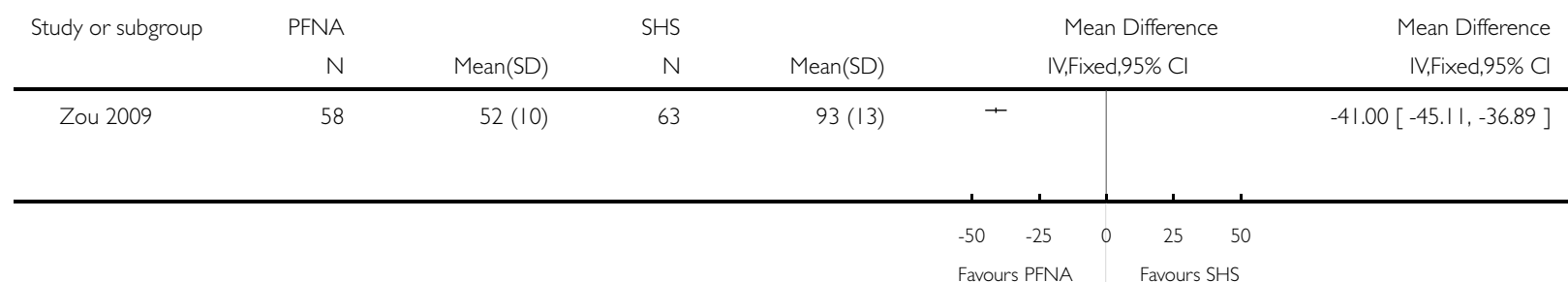

Analysis 5.2. Comparison 5 Proximal femoral nail antirotation (PFNA) versus sliding hip screw (SHS), Outcome 2 Operative blood loss $(\mathrm{ml})$.

Review: Gamma and other cephalocondylic intramedullary nails versus extramedullary implants for extracapsular hip fractures in adults

Comparison: 5 Proximal femoral nail antirotation (PFNA) versus sliding hip screw (SHS)

Outcome: 2 Operative blood loss $(\mathrm{ml})$

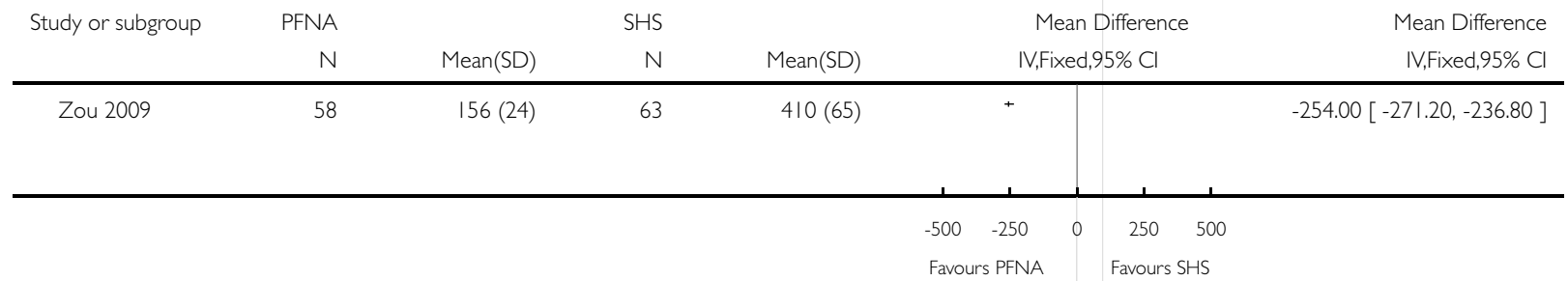


Analysis 5.3. Comparison 5 Proximal femoral nail antirotation (PFNA) versus sliding hip screw (SHS), Outcome 3 Radiographic screening time (minutes).

Review: Gamma and other cephalocondylic intramedullary nails versus extramedullary implants for extracapsular hip fractures in adults

Comparison: 5 Proximal femoral nail antirotation (PFNA) versus sliding hip screw (SHS)

Outcome: 3 Radiographic screening time (minutes)

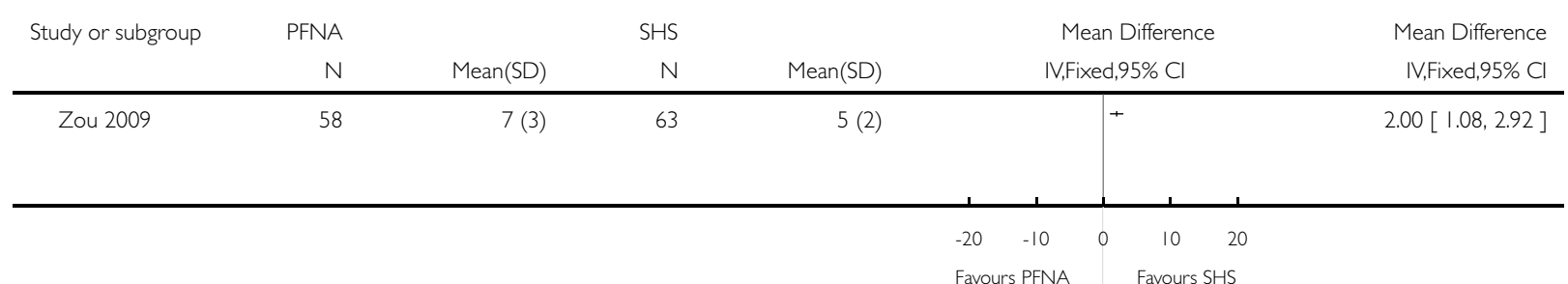

Analysis 5.4. Comparison 5 Proximal femoral nail antirotation (PFNA) versus sliding hip screw (SHS), Outcome 4 Fracture fixation complications.

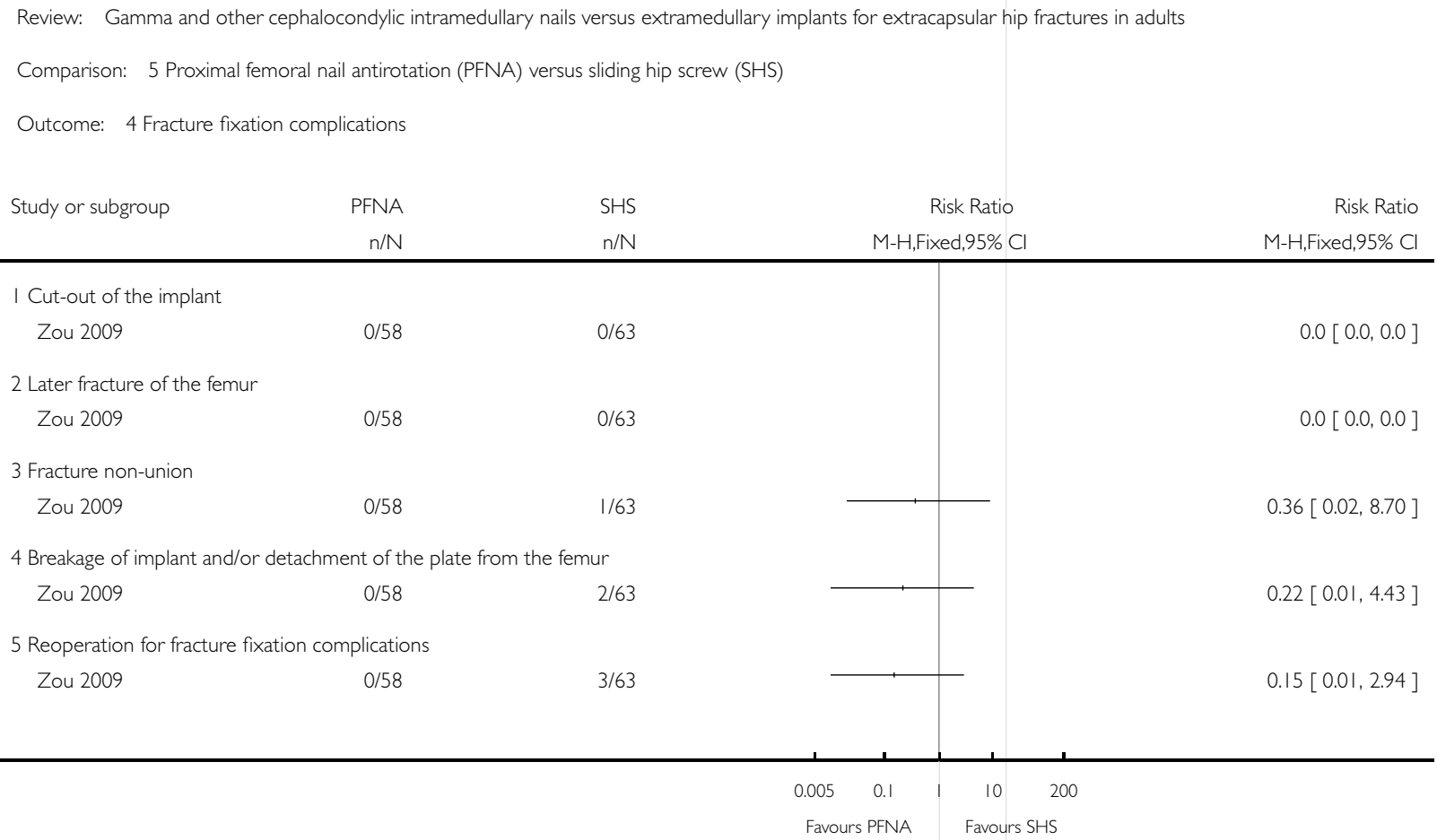

Gamma and other cephalocondylic intramedullary nails versus extramedullary implants for extracapsular hip fractures in adults (Review) 165 Copyright (C) 2010 The Cochrane Collaboration. Published by John Wiley \& Sons, Ltd. 
Analysis 5.5. Comparison 5 Proximal femoral nail antirotation (PFNA) versus sliding hip screw (SHS), Outcome 5 Wound infection.

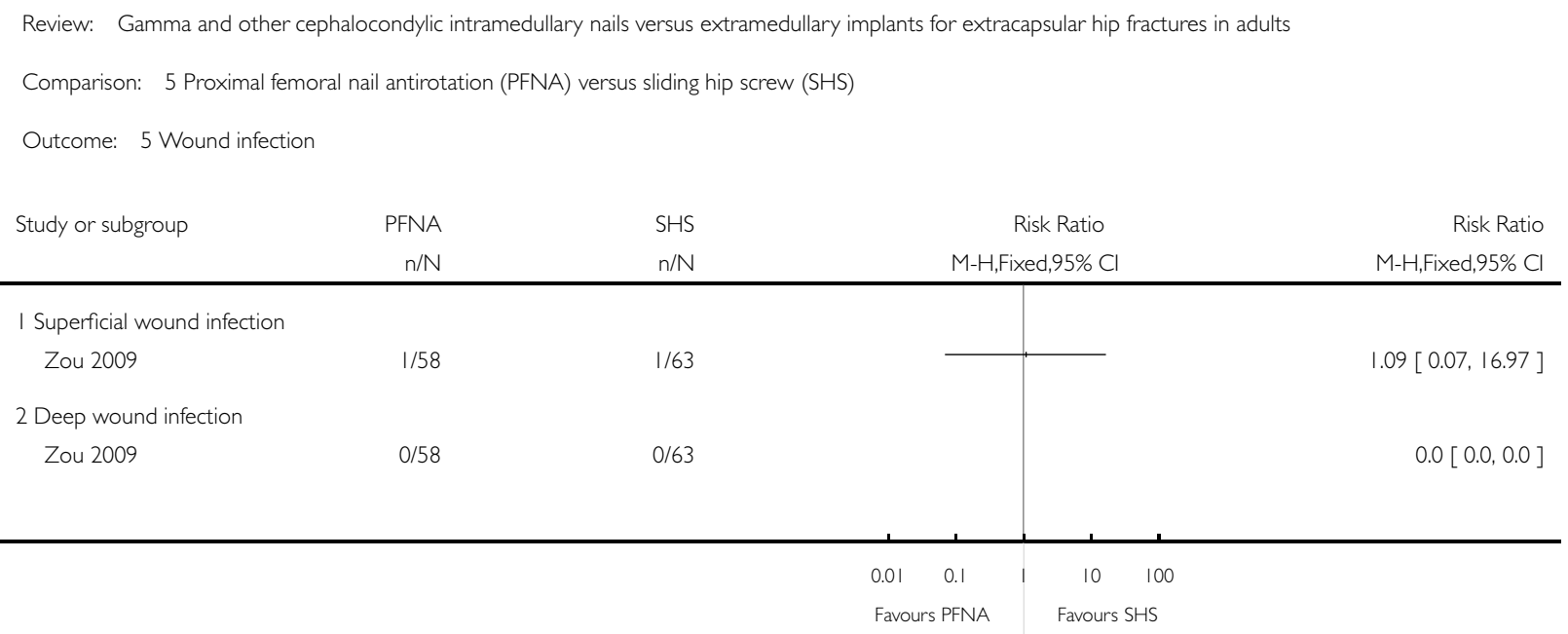

Analysis 5.6. Comparison 5 Proximal femoral nail antirotation (PFNA) versus sliding hip screw (SHS), Outcome 6 Post-operative complications.

Review: Gamma and other cephalocondylic intramedullary nails versus extramedullary implants for extracapsular hip fractures in adults

Comparison: 5 Proximal femoral nail antirotation (PFNA) versus sliding hip screw (SHS)

Outcome: 6 Post-operative complications

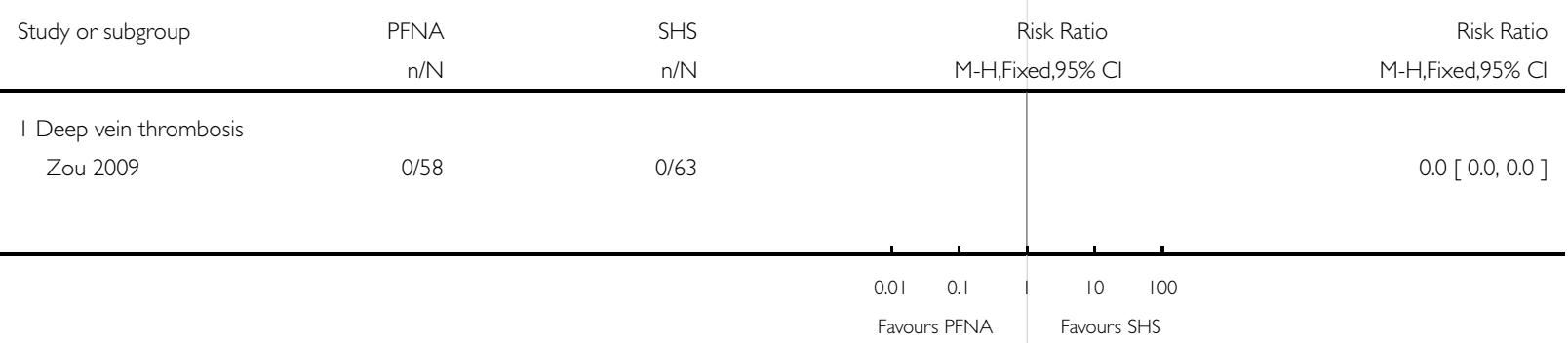

Gamma and other cephalocondylic intramedullary nails versus extramedullary implants for extracapsular hip fractures in adults (Review) 166 Copyright (@) 2010 The Cochrane Collaboration. Published by John Wiley \& Sons, Ltd. 
Analysis 5.7. Comparison 5 Proximal femoral nail antirotation (PFNA) versus sliding hip screw (SHS), Outcome 7 Poor or fair hip function score (I year).

Review: Gamma and other cephalocondylic intramedullary nails versus extramedullary implants for extracapsular hip fractures in adults

Comparison: 5 Proximal femoral nail antirotation (PFNA) versus sliding hip screw (SHS)

Outcome: 7 Poor or fair hip function score (I year)

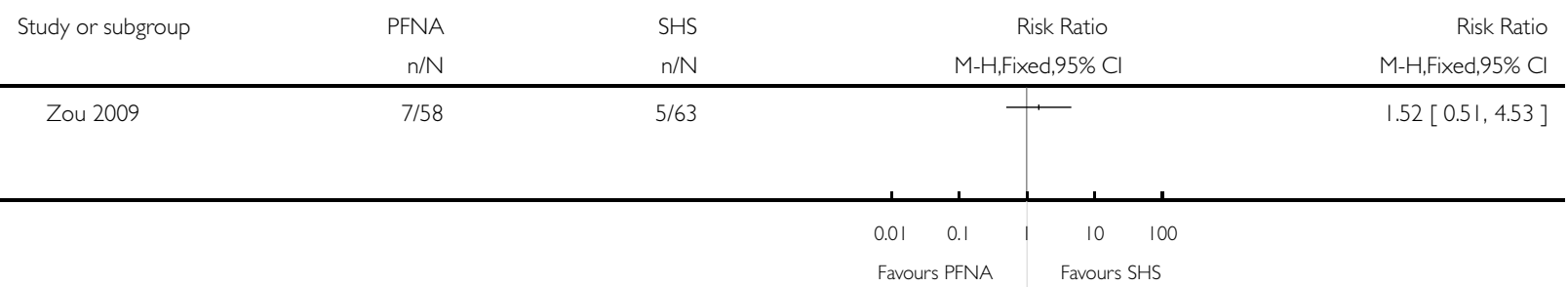

Analysis 6.I. Comparison 6 Targon PF (proximal femoral) nail versus sliding hip screw (SHS), Outcome I Fracture fixation complications.

Review: Gamma and other cephalocondylic intramedullary nails versus extramedullary implants for extracapsular hip fractures in adults

Comparison: 6 Targon PF (proximal femoral) nail versus sliding hip screw (SHS)

Outcome: I Fracture fixation complications

\begin{tabular}{|c|c|c|c|c|}
\hline Study or subgroup & Targon PF nail & SHS & Risk Ratio & Risk Ratio \\
\hline & $\mathrm{n} / \mathrm{N}$ & $\mathrm{n} / \mathrm{N}$ & M-H,Fixed,95\% Cl & M-H,Fixed,95\% Cl \\
\hline I Later fracture of $t$ & & & & \\
\hline Giraud 2005 & $0 / 34$ & $0 / 26$ & & $0.0[0.0,0.0]$ \\
\hline 2 Cut-out & & & & \\
\hline Giraud 2005 & $3 / 34$ & $2 / 26$ & & I.I $5[0.21,6.37]$ \\
\hline 3 Non-union & & & & \\
\hline Giraud 2005 & $0 / 34$ & $0 / 26$ & & $0.0[0.0,0.0]$ \\
\hline 4 Reoperation & & & & \\
\hline Giraud 2005 & $3 / 34$ & $2 / 26$ & & I.I $5[0.21,6.37]$ \\
\hline
\end{tabular}

Gamma and other cephalocondylic intramedullary nails versus extramedullary implants for extracapsular hip fractures in adults (Review) $\quad 167$ Copyright (C) 2010 The Cochrane Collaboration. Published by John Wiley \& Sons, Ltd. 
Analysis 6.2. Comparison 6 Targon PF (proximal femoral) nail versus sliding hip screw (SHS), Outcome 2 Wound infection.

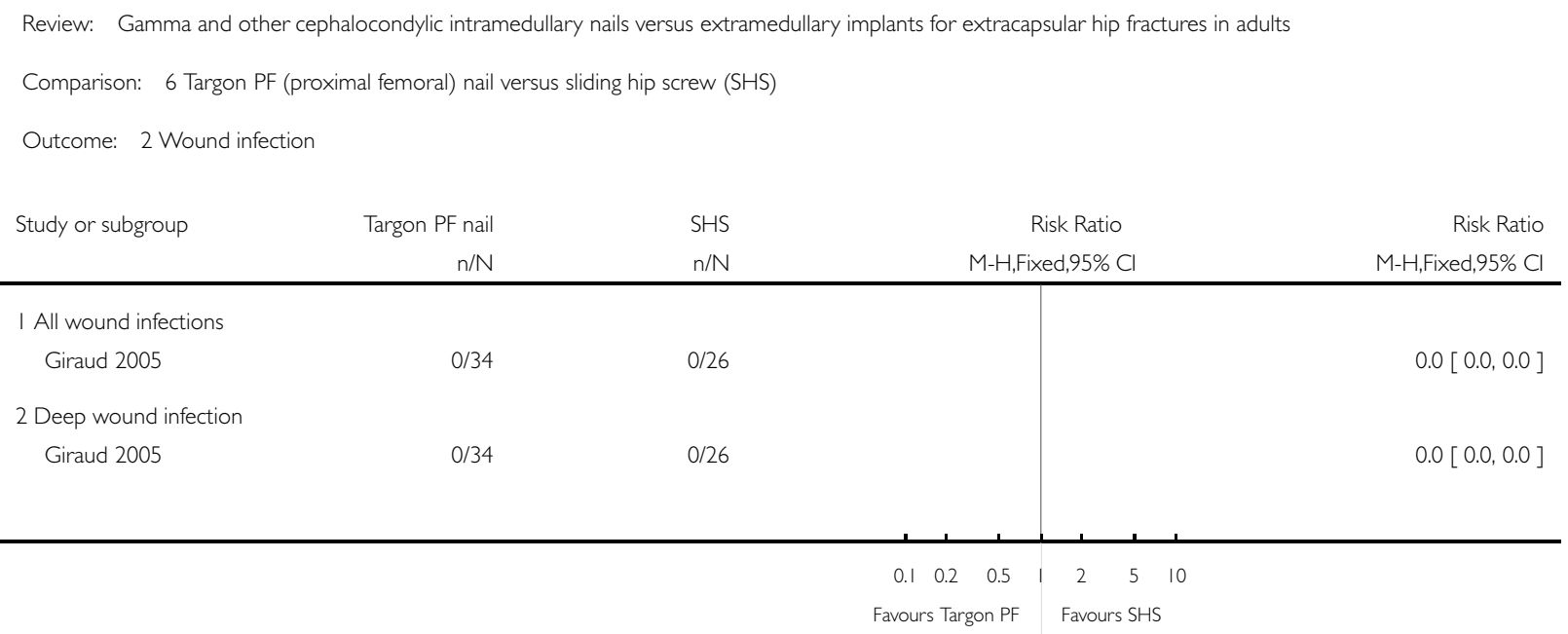

Analysis 6.3. Comparison 6 Targon PF (proximal femoral) nail versus sliding hip screw (SHS), Outcome 3 Post-operative compiications.

Review: Gamma and other cephalocondylic intramedullary nails versus extramedullary implants for extracapsular hip fractures in adults

Comparison: 6 Targon PF (proximal femoral) nail versus sliding hip screw (SHS)

Outcome: 3 Post-operative complications

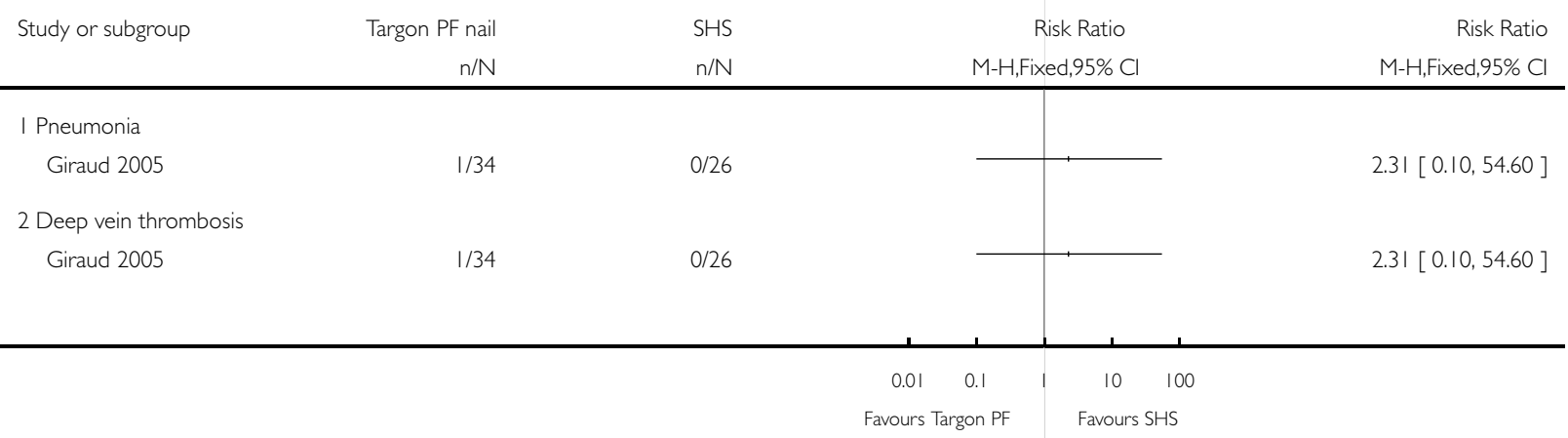

Gamma and other cephalocondylic intramedullary nails versus extramedullary implants for extracapsular hip fractures in adults (Review) 168 Copyright (@) 2010 The Cochrane Collaboration. Published by John Wiley \& Sons, Ltd. 
Analysis 6.4. Comparison 6 Targon PF (proximal femoral) nail versus sliding hip screw (SHS), Outcome 4 Mortality (3 months).

Review: Gamma and other cephalocondylic intramedullary nails versus extramedullary implants for extracapsular hip fractures in adults

Comparison: 6 Targon PF (proximal femoral) nail versus sliding hip screw (SHS)

Outcome: 4 Mortality (3 months)

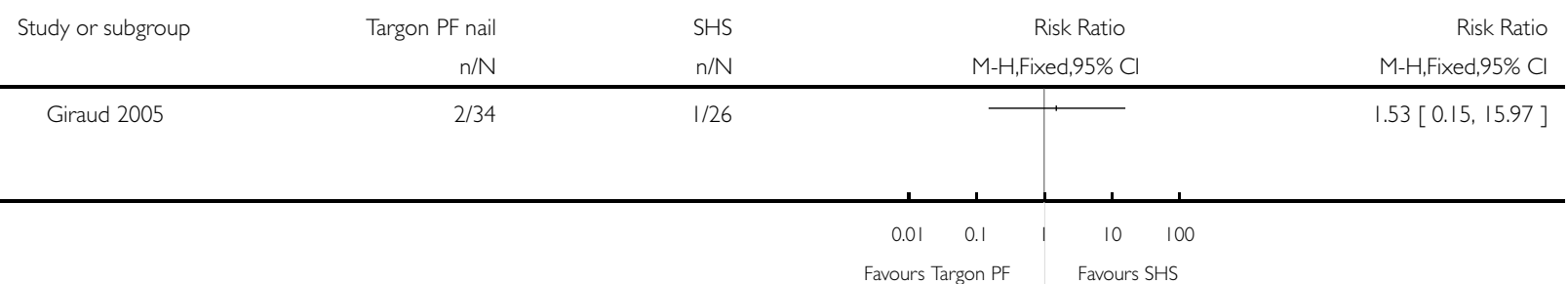

Analysis 7.I. Comparison 7 Holland nail versus sliding hip screw (SHS), Outcome I Length of anaesthesia and surgery.

Review: Gamma and other cephalocondylic intramedullary nails versus extramedullary implants for extracapsular hip fractures in adults

Comparison: 7 Holland nail versus sliding hip screw (SHS)

Outcome: I Length of anaesthesia and surgery

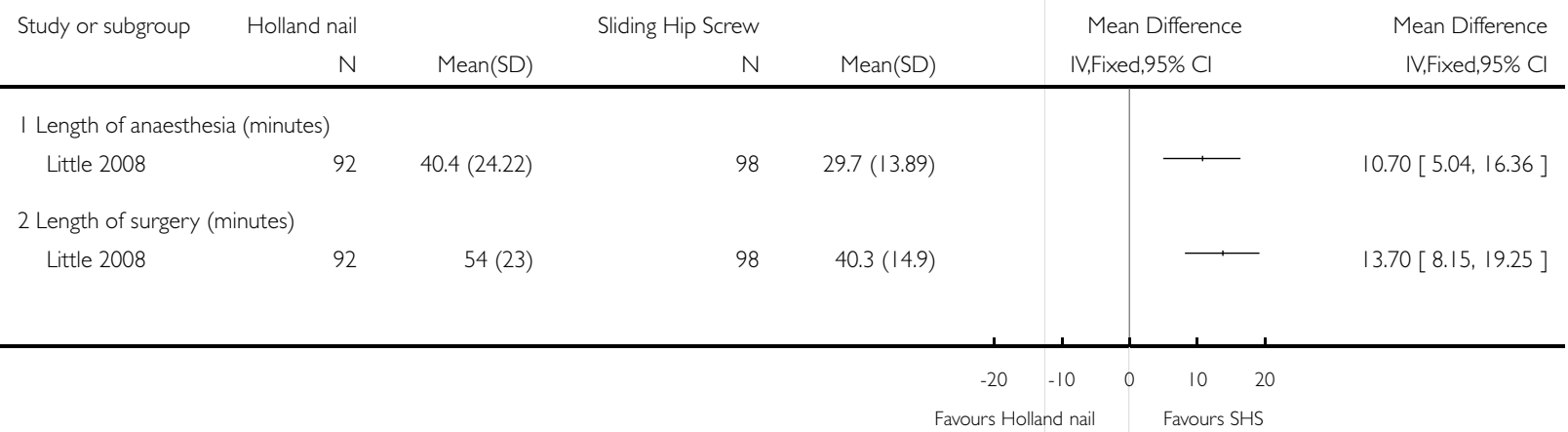

Gamma and other cephalocondylic intramedullary nails versus extramedullary implants for extracapsular hip fractures in adults (Review) 169 Copyright (C) 2010 The Cochrane Collaboration. Published by John Wiley \& Sons, Ltd. 
Analysis 7.2. Comparison 7 Holland nail versus sliding hip screw (SHS), Outcome 2 Radiographic screening time (minutes).

Review: Gamma and other cephalocondylic intramedullary nails versus extramedullary implants for extracapsular hip fractures in adults

Comparison: 7 Holland nail versus sliding hip screw (SHS)

Outcome: 2 Radiographic screening time (minutes)

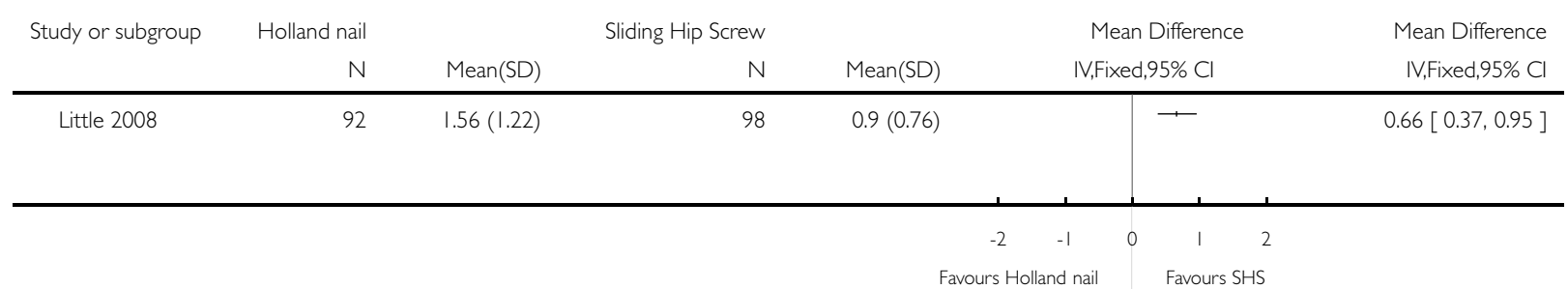

Analysis 7.3. Comparison 7 Holland nail versus sliding hip screw (SHS), Outcome 3 Blood loss (ml).

Review: Gamma and other cephalocondylic intramedullary nails versus extramedullary implants for extracapsular hip fractures in adults

Comparison: 7 Holland nail versus sliding hip screw (SHS)

Outcome: 3 Blood loss $(\mathrm{ml})$

\begin{tabular}{|c|c|c|c|c|c|c|c|c|c|}
\hline \multirow[t]{2}{*}{ Study or subgroup } & Holland nail & \multicolumn{3}{|c|}{ Sliding Hip Screw } & \multicolumn{4}{|c|}{ Mean Difference } & Mean Difference \\
\hline & N & Mean(SD) & $\mathrm{N}$ & Mean(SD) & \multicolumn{4}{|c|}{ IV,Fixed,95\% Cl } & IV,Fixed,95\% Cl \\
\hline Little 2008 & 92 & $78(129.68)$ & 98 & $160(179.3)$ & $\longleftrightarrow$ & $\overline{ }$ & & & $-82.00[-126.30,-37.70]$ \\
\hline & & & & & -100 & -50 & 50 & 100 & \\
\hline
\end{tabular}


Analysis 7.4. Comparison 7 Holland nail versus sliding hip screw (SHS), Outcome 4 Number of patients given transfusion.

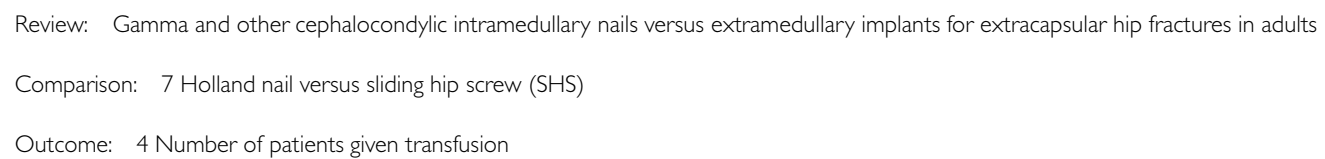

\begin{tabular}{ccccc} 
& $\mathrm{n} / \mathrm{N}$ & $\mathrm{n} / \mathrm{N}$ & $\mathrm{M}-\mathrm{H}, \mathrm{Fixed}, 95 \% \mathrm{Cl}$ & $\mathrm{M}-\mathrm{H}, \mathrm{Fixed}, 95 \% \mathrm{Cl}$ \\
\hline Little 2008 & $7 / 92$ & $23 / 98$ & - & $0.32[0.15,0.72]$
\end{tabular}

, , , , , , , , , , , , , , , ,

$\begin{array}{lllll}0.01 & 0.1 & 1 & 10 & 100\end{array}$

Favours Holland nail Favours SHS

\section{Analysis 7.5. Comparison 7 Holland nail versus sliding hip screw (SHS), Outcome 5 Days till mobilisation.}

Review: Gamma and other cephalocondylic intramedullary nails versus extramedullary implants for extracapsular hip fractures in adults

Comparison: 7 Holland nail versus sliding hip screw (SHS)

Outcome: 5 Days till mobilisation

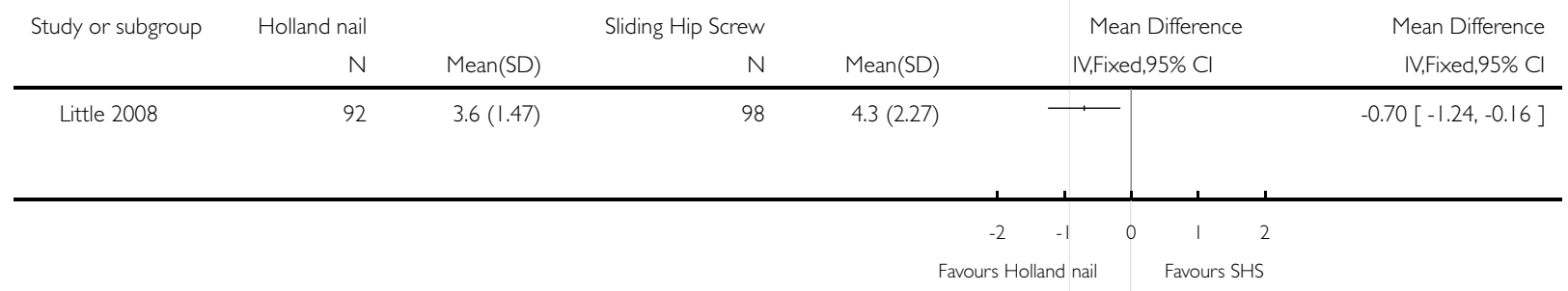


Analysis 7.6. Comparison 7 Holland nail versus sliding hip screw (SHS), Outcome 6 Fracture fixation complications.

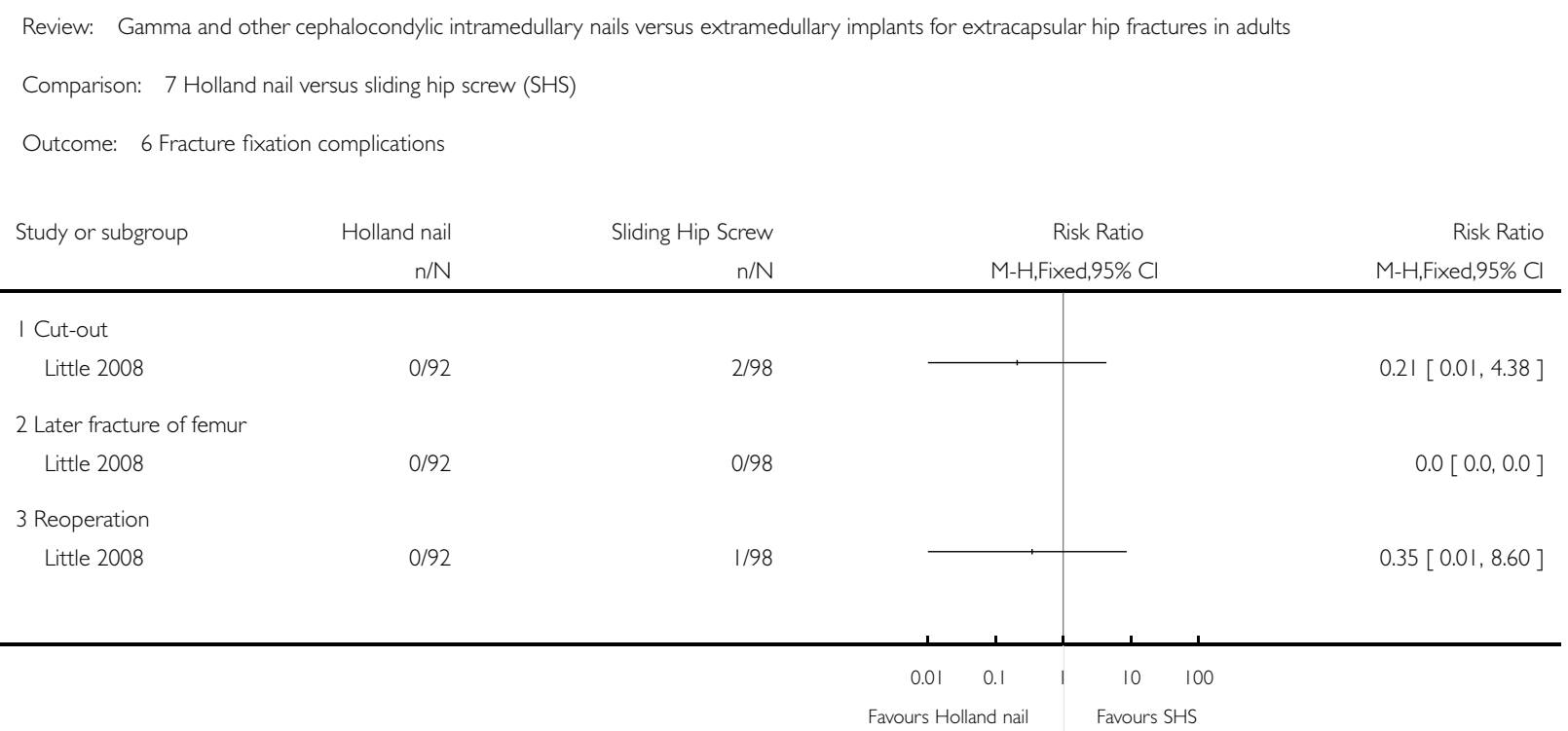

Analysis 7.7. Comparison 7 Holland nail versus sliding hip screw (SHS), Outcome 7 Wound infection.

Review: Gamma and other cephalocondylic intramedullary nails versus extramedullary implants for extracapsular hip fractures in adults

Comparison: 7 Holland nail versus sliding hip screw (SHS)

Outcome: 7 Wound infection

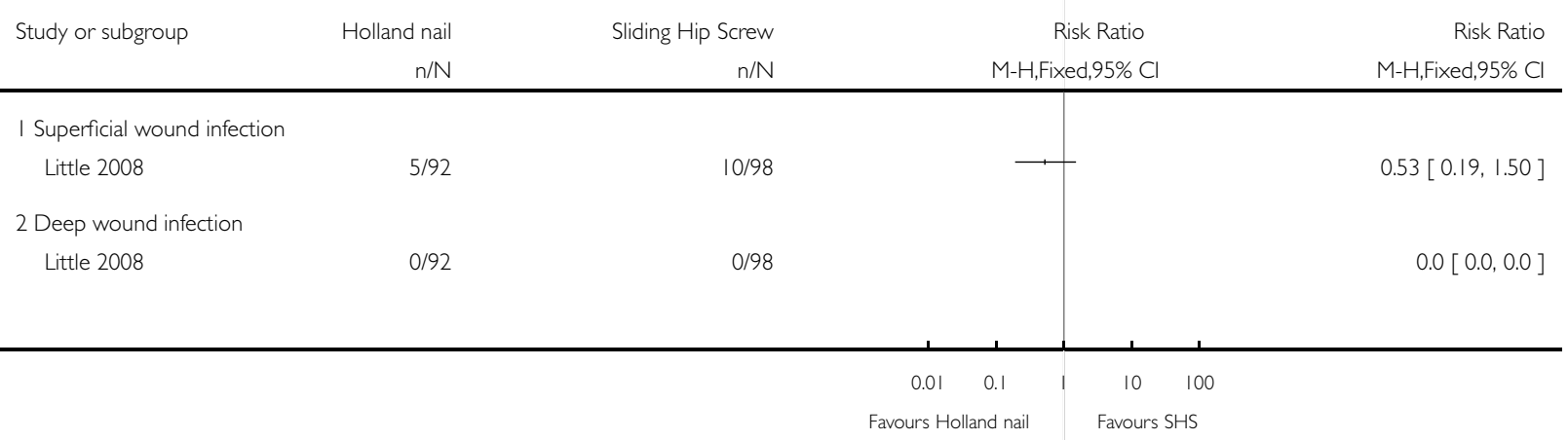

Gamma and other cephalocondylic intramedullary nails versus extramedullary implants for extracapsular hip fractures in adults (Review) $\quad$ I72 Copyright (C) 2010 The Cochrane Collaboration. Published by John Wiley \& Sons, Ltd. 
Analysis 7.8. Comparison 7 Holland nail versus sliding hip screw (SHS), Outcome 8 Postoperative complications.

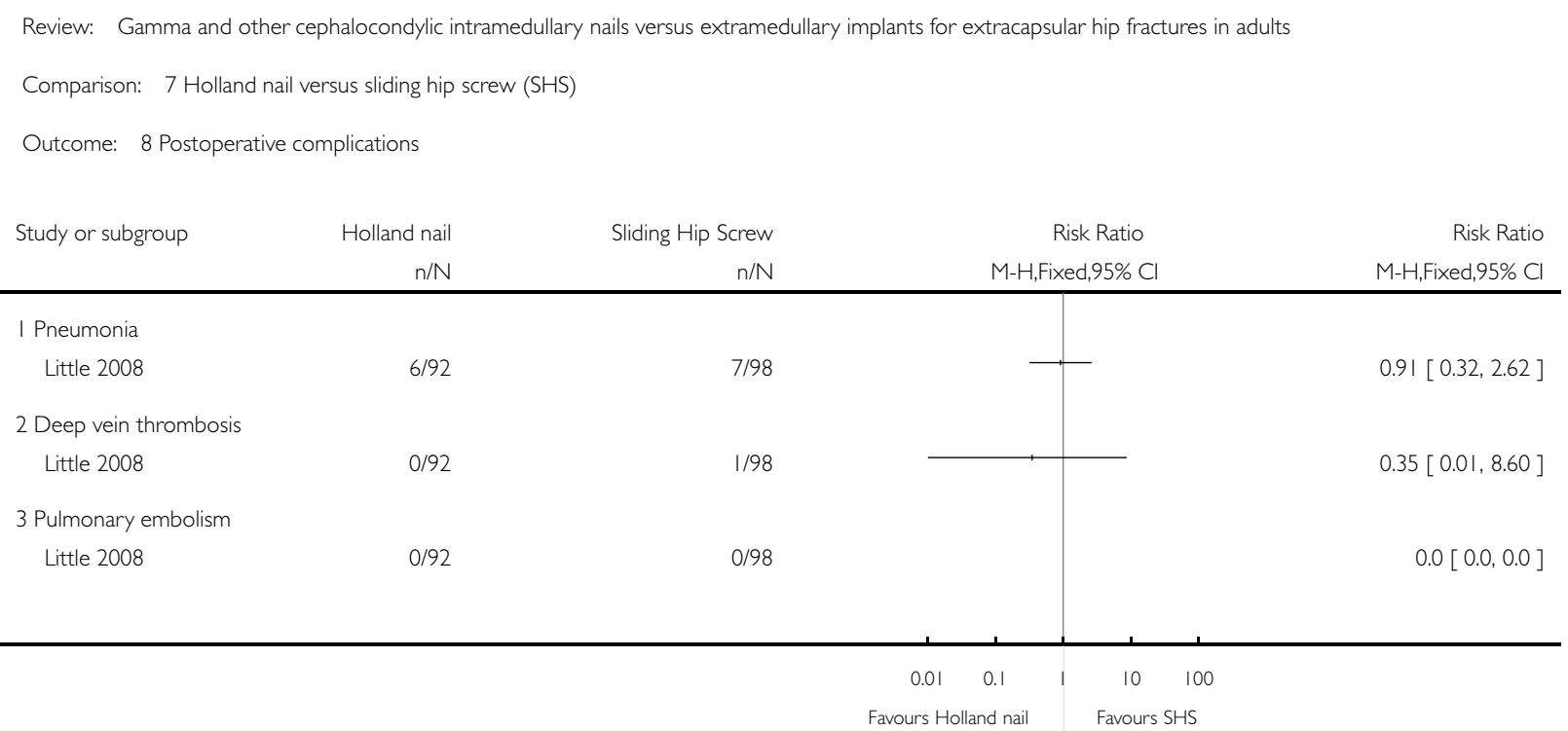

Analysis 7.9. Comparison 7 Holland nail versus sliding hip screw (SHS), Outcome 9 Final outcome measures.

Review: Gamma and other cephalocondylic intramedullary nails versus extramedullary implants for extracapsular hip fractures in adults

Comparison: 7 Holland nail versus sliding hip screw (SHS)

Outcome: 9 Final outcome measures

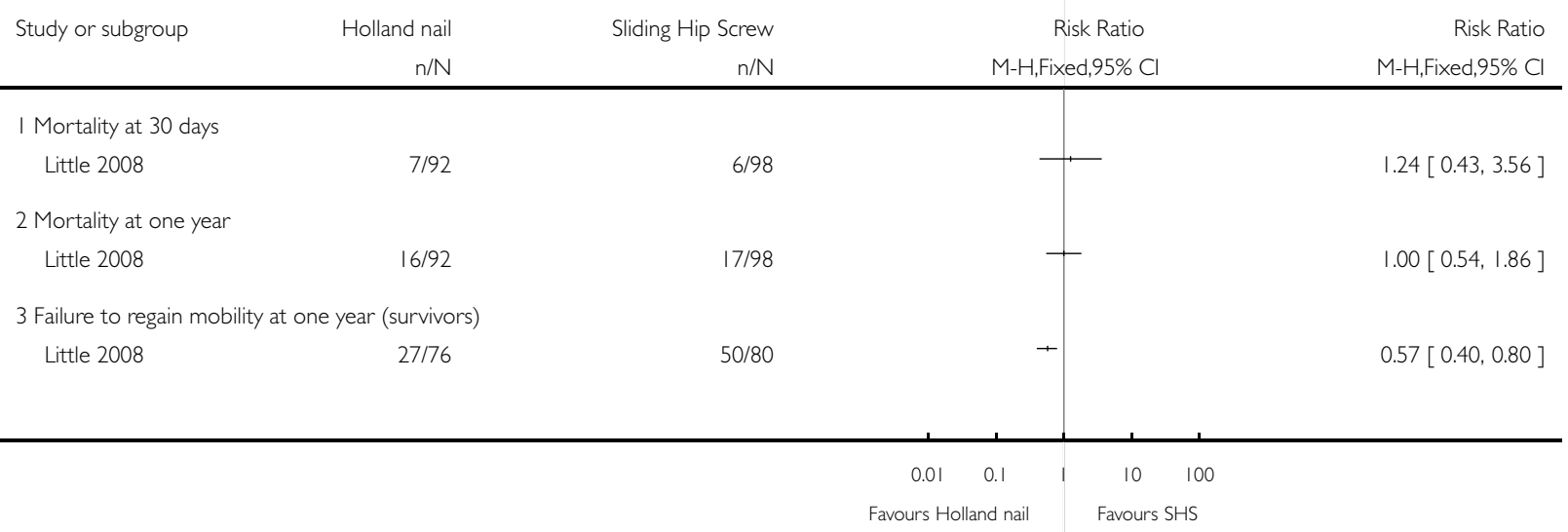

Gamma and other cephalocondylic intramedullary nails versus extramedullary implants for extracapsular hip fractures in adults (Review) I73 Copyright (C) 2010 The Cochrane Collaboration. Published by John Wiley \& Sons, Ltd. 
Analysis 7.10. Comparison 7 Holland nail versus sliding hip screw (SHS), Outcome 10 Final outcome measures: mobility score ( 0 to 9: best result).

Review: Gamma and other cephalocondylic intramedullary nails versus extramedullary implants for extracapsular hip fractures in adults

Comparison: 7 Holland nail versus sliding hip screw (SHS)

Outcome: 10 Final outcome measures: mobility score (0 to 9: best result)

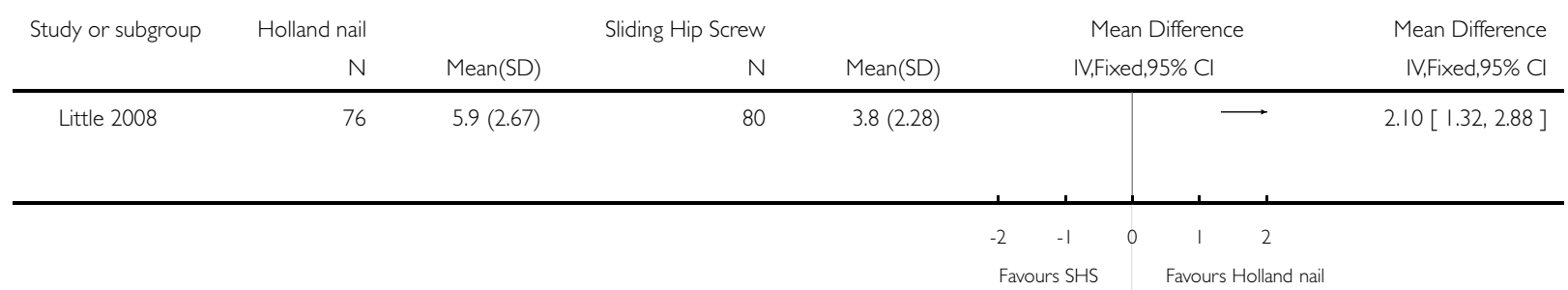

Analysis 8.I. Comparison 8 Long Gamma nail versus sliding hip screw (SHS), Outcome I Number of patients transfused.

Review: Gamma and other cephalocondylic intramedullary nails versus extramedullary implants for extracapsular hip fractures in adults

Comparison: 8 Long Gamma nail versus sliding hip screw (SHS)

Outcome: I Number of patients transfused

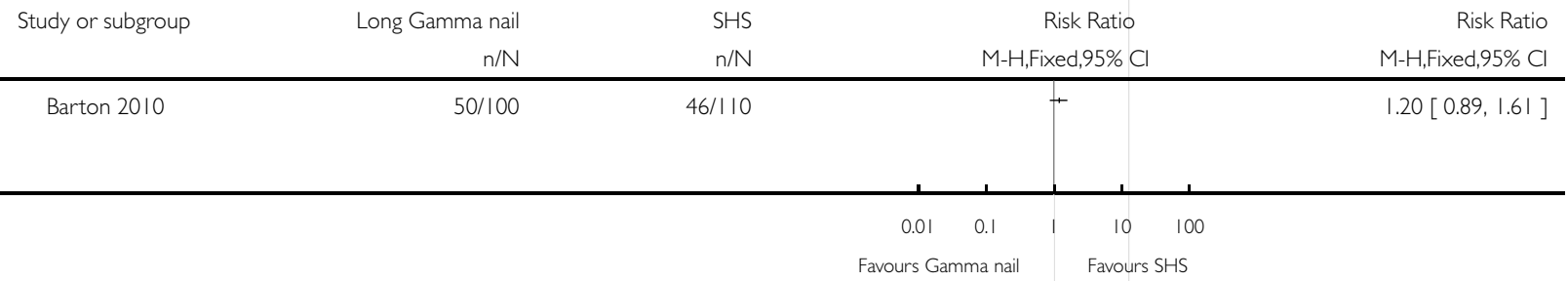


Analysis 8.2. Comparison 8 Long Gamma nail versus sliding hip screw (SHS), Outcome 2 Fracture fixation complications.

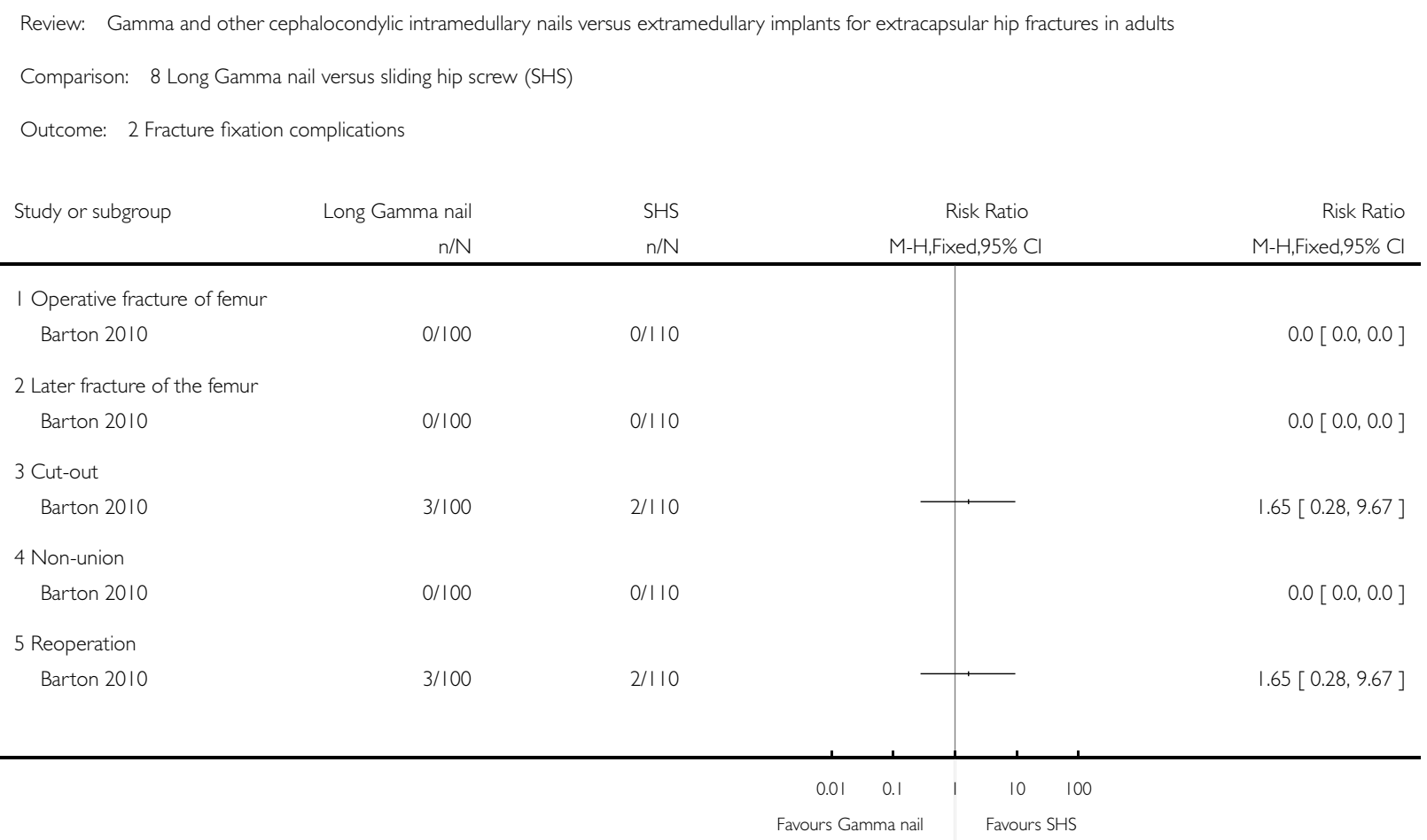

\section{Analysis 8.3. Comparison 8 Long Gamma nail versus sliding hip screw (SHS), Outcome 3 Wound infection.}

Review: Gamma and other cephalocondylic intramedullary nails versus extramedullary implants for extracapsular hip fractures in adults

Comparison: 8 Long Gamma nail versus sliding hip screw (SHS)

Outcome: 3 Wound infection

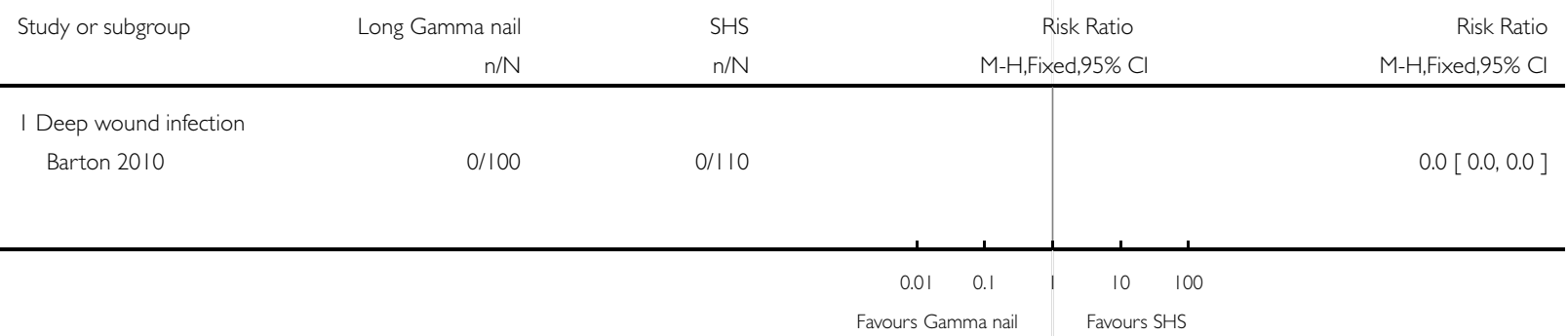

Gamma and other cephalocondylic intramedullary nails versus extramedullary implants for extracapsular hip fractures in adults (Review) $\quad$ I75 Copyright (C) 2010 The Cochrane Collaboration. Published by John Wiley \& Sons, Ltd. 
Analysis 8.4. Comparison 8 Long Gamma nail versus sliding hip screw (SHS), Outcome 4 Mortality (at one year).

Review: Gamma and other cephalocondylic intramedullary nails versus extramedullary implants for extracapsular hip fractures in adults

Comparison: 8 Long Gamma nail versus sliding hip screw (SHS)

Outcome: 4 Mortality (at one year)

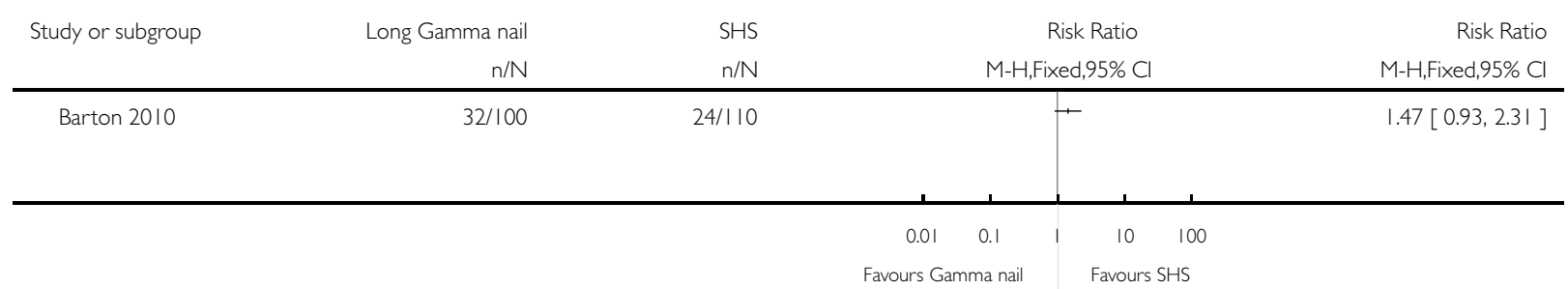

Analysis 9.1. Comparison 9 Mini-invasive static (experimental) nail versus sliding hip screw (SHS), Outcome I Length of surgery (minutes).

Review: Gamma and other cephalocondylic intramedullary nails versus extramedullary implants for extracapsular hip fractures in adults

Comparison: 9 Mini-invasive static (experimental) nail versus sliding hip screw (SHS)

Outcome: I Length of surgery (minutes)

\begin{tabular}{|c|c|c|c|c|c|c|c|c|c|}
\hline \multirow{3}{*}{$\begin{array}{l}\text { Study or subgroup } \\
\text { Dujardin } 2001\end{array}$} & \multirow{3}{*}{$\begin{array}{r}\text { Mini-invasive nail } \\
\mathrm{N} \\
30\end{array}$} & \multicolumn{3}{|c|}{ Sliding hip screw } & \multirow{2}{*}{\multicolumn{4}{|c|}{$\begin{array}{l}\text { Mean Difference } \\
\text { IV,Fixed,95\% Cl }\end{array}$}} & \multirow{3}{*}{$\begin{array}{r}\text { Mean Difference } \\
\text { IV,Fixed,95\% Cl } \\
-22.00[-26.08,-17.92]\end{array}$} \\
\hline & & Mean(SD) & $N$ & Mean(SD) & & & & & \\
\hline & & $24(7)$ & 30 & $46(9)$ & & + & & & \\
\hline & & & & & -50 & -25 & 25 & 50 & \\
\hline
\end{tabular}


Analysis 9.2. Comparison 9 Mini-invasive static (experimental) nail versus sliding hip screw (SHS), Outcome 2 Blood loss.

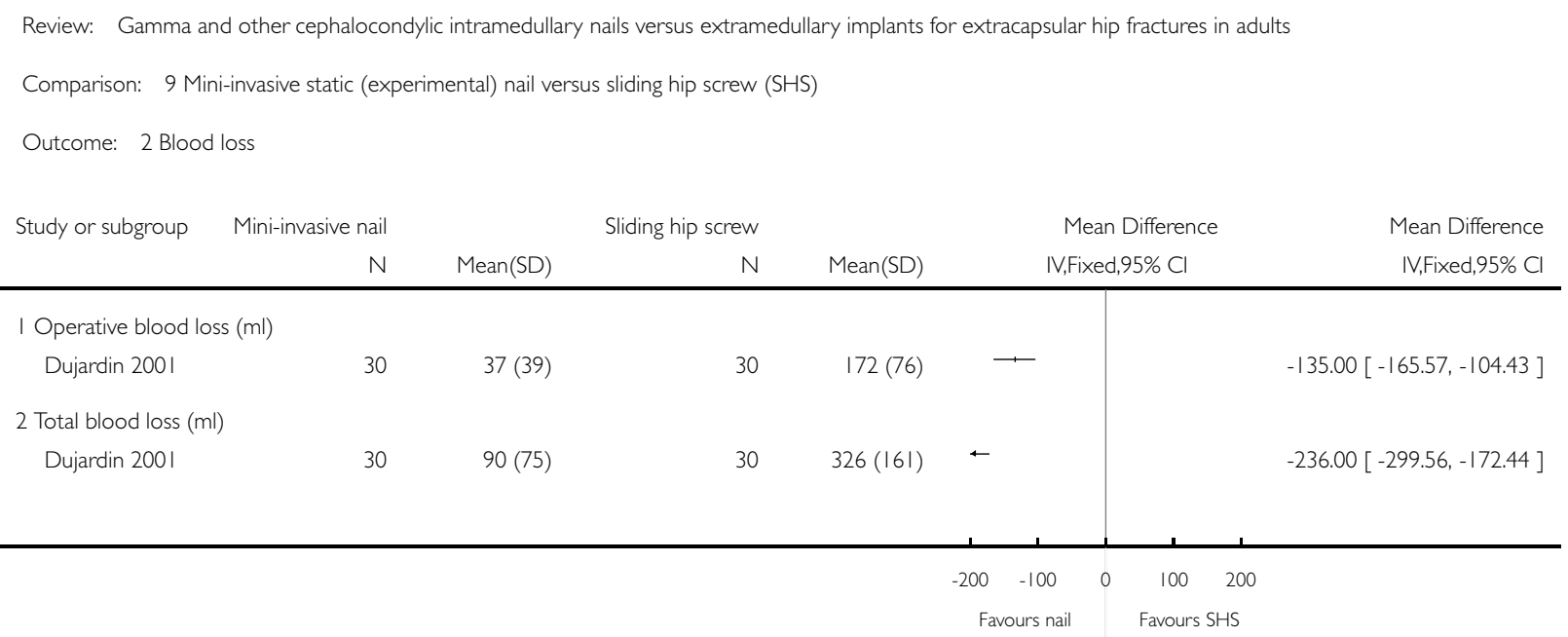

Analysis 9.3. Comparison 9 Mini-invasive static (experimental) nail versus sliding hip screw (SHS), Outcome 3 Radiographic screening time (seconds).

Review: Gamma and other cephalocondylic intramedullary nails versus extramedullary implants for extracapsular hip fractures in adults

Comparison: 9 Mini-invasive static (experimental) nail versus sliding hip screw (SHS)

Outcome: 3 Radiographic screening time (seconds)

\begin{tabular}{|c|c|c|c|c|c|c|c|c|c|}
\hline \multirow[t]{2}{*}{ Study or subgroup } & Mini-invasive nail & \multicolumn{3}{|c|}{ Sliding hip screw } & & \multicolumn{3}{|c|}{ Mean Difference } & \multirow{2}{*}{$\begin{array}{r}\text { Mean Difference } \\
\text { IV,Fixed,95\% Cl }\end{array}$} \\
\hline & $\mathrm{N}$ & Mean(SD) & $\mathrm{N}$ & Mean(SD) & & & xed, $95 \% \mathrm{Cl}$ & & \\
\hline Dujardin 200I & 30 & $62(35)$ & 30 & $63(40)$ & $\longleftarrow$ & & & & $-1.00[-20.02,18.02]$ \\
\hline & & & & & -20 & -10 & 10 & 20 & \\
\hline
\end{tabular}


Analysis 9.4. Comparison 9 Mini-invasive static (experimental) nail versus sliding hip screw (SHS), Outcome 4 Time to radiographic healing (weeks).

Review: Gamma and other cephalocondylic intramedullary nails versus extramedullary implants for extracapsular hip fractures in adults

Comparison: 9 Mini-invasive static (experimental) nail versus sliding hip screw (SHS)

Outcome: 4 Time to radiographic healing (weeks)

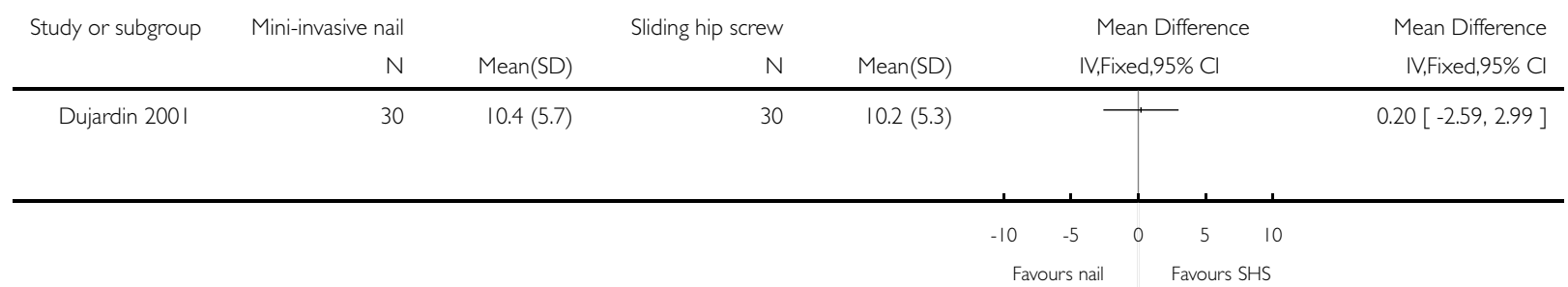

Analysis 9.5. Comparison 9 Mini-invasive static (experimental) nail versus sliding hip screw (SHS), Outcome 5 Mortality (6 months).

Review: Gamma and other cephalocondylic intramedullary nails versus extramedullary implants for extracapsular hip fractures in adults

Comparison: 9 Mini-invasive static (experimental) nail versus sliding hip screw (SHS)

Outcome: 5 Mortality (6 months)

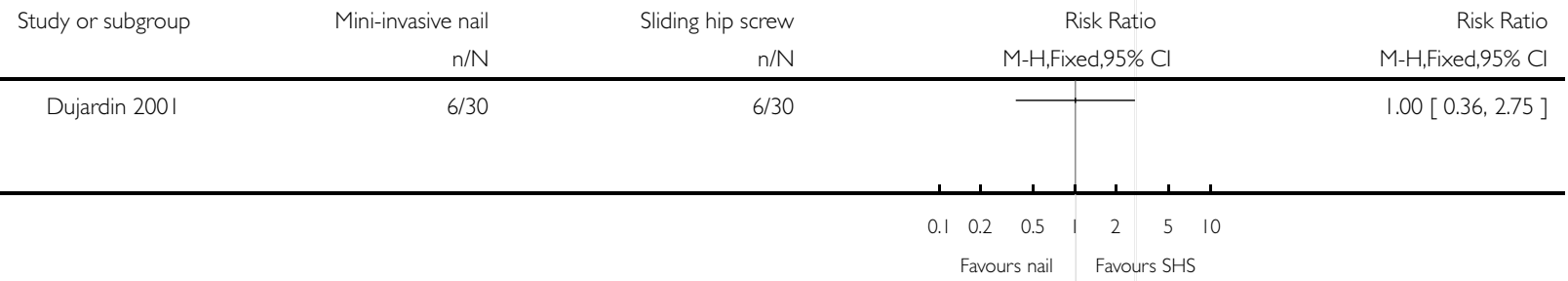


Analysis 9.6. Comparison 9 Mini-invasive static (experimental) nail versus sliding hip screw (SHS), Outcome 6 Time to effective weight bearing (weeks).

Review: Gamma and other cephalocondylic intramedullary nails versus extramedullary implants for extracapsular hip fractures in adults

Comparison: 9 Mini-invasive static (experimental) nail versus sliding hip screw (SHS)

Outcome: 6 Time to effective weight bearing (weeks)

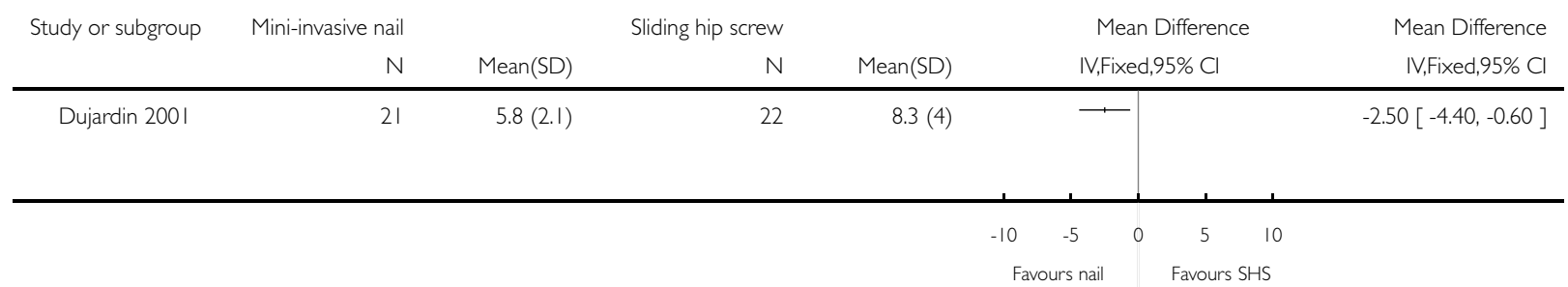

Analysis I0.I. Comparison IO Kuntscher-Y nail versus sliding hip screw (SHS), Outcome I Fracture fixation complications.

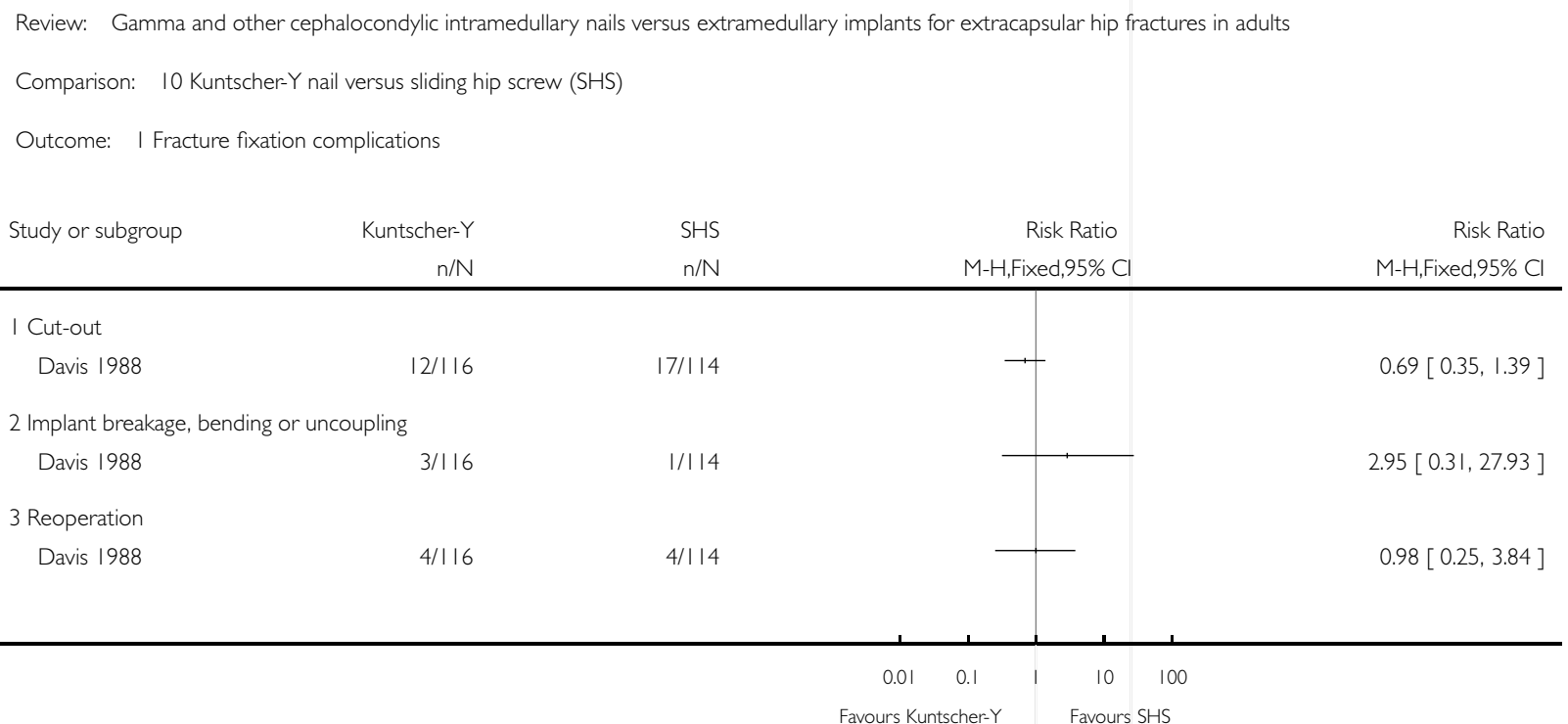

Gamma and other cephalocondylic intramedullary nails versus extramedullary implants for extracapsular hip fractures in adults (Review) I79 Copyright (C) 2010 The Cochrane Collaboration. Published by John Wiley \& Sons, Ltd. 


\section{Analysis 10.2. Comparison 10 Kuntscher-Y nail versus sliding hip screw (SHS), Outcome 2 Wound infection.}

Review: Gamma and other cephalocondylic intramedullary nails versus extramedullary implants for extracapsular hip fractures in adults

Comparison: 10 Kuntscher-Y nail versus sliding hip screw (SHS)

Outcome: 2 Wound infection

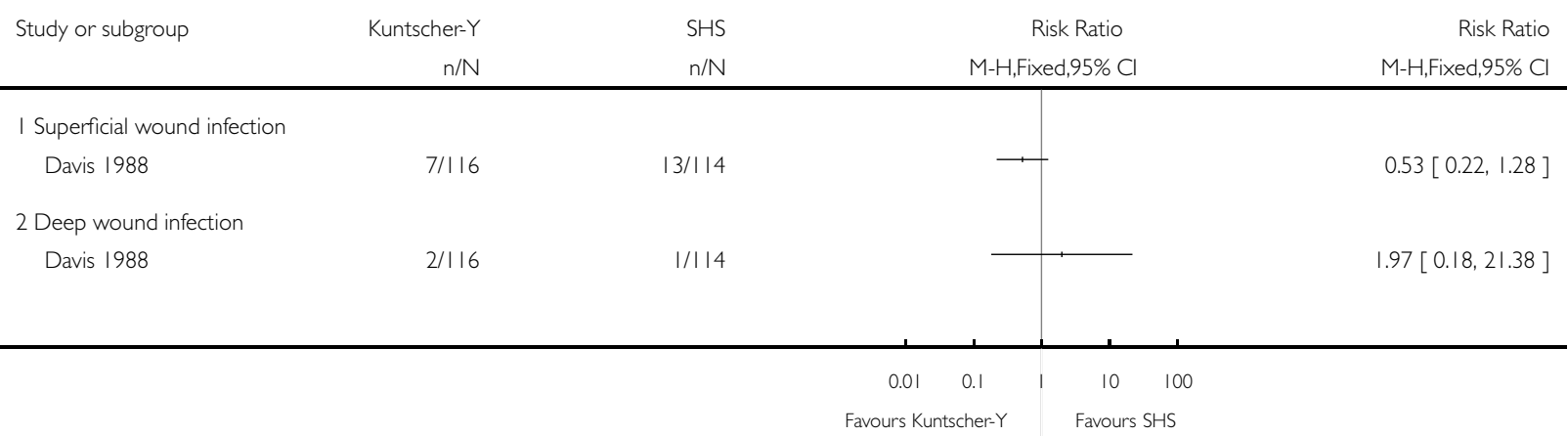

Analysis 10.3. Comparison 10 Kuntscher-Y nail versus sliding hip screw (SHS), Outcome 3 Post-operative complications.

Review: Gamma and other cephalocondylic intramedullary nails versus extramedullary implants for extracapsular hip fractures in adults

Comparison: 10 Kuntscher-Y nail versus sliding hip screw (SHS)

Outcome: 3 Post-operative complications

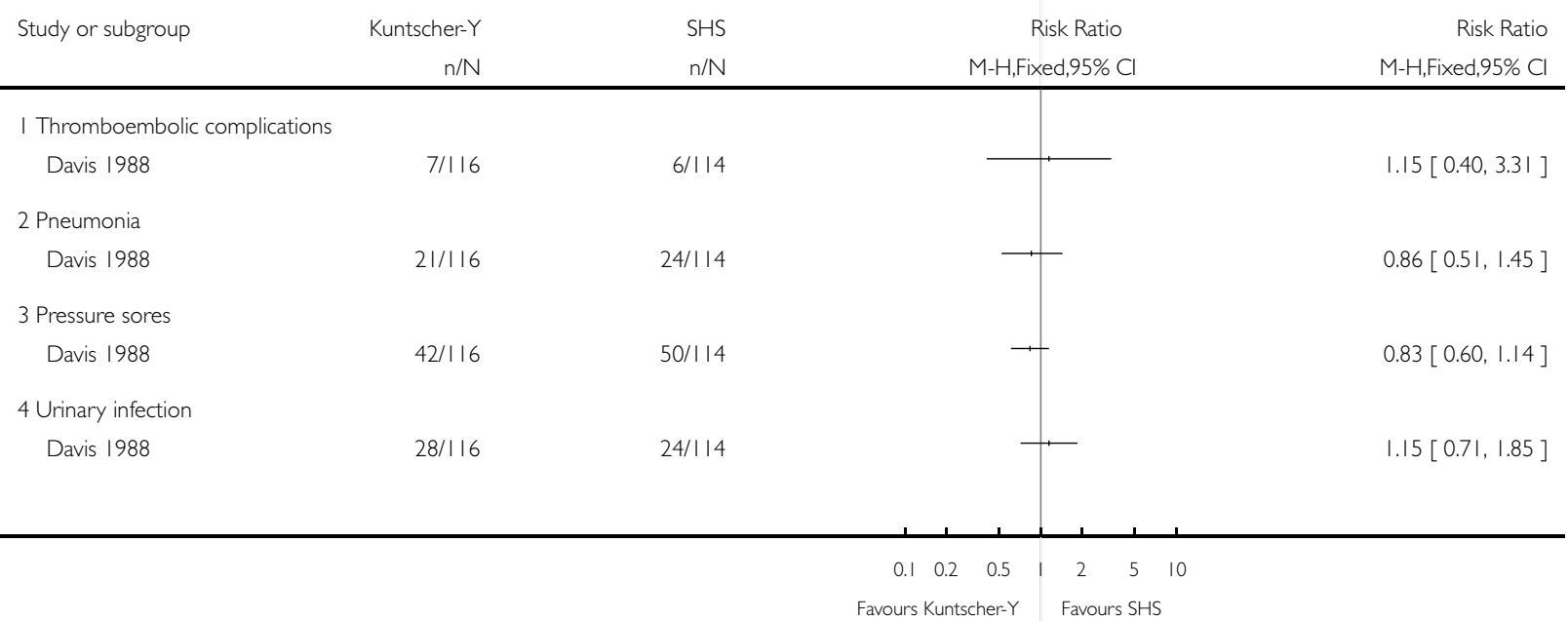

Gamma and other cephalocondylic intramedullary nails versus extramedullary implants for extracapsular hip fractures in adults (Review) $\quad$ I80 Copyright (C) 2010 The Cochrane Collaboration. Published by John Wiley \& Sons, Ltd. 
Analysis 10.4. Comparison 10 Kuntscher-Y nail versus sliding hip screw (SHS), Outcome 4 Anatomical deformity.

Review: Gamma and other cephalocondylic intramedullary nails versus extramedullary implants for extracapsular hip fractures in adults

Comparison: 10 Kuntscher-Y nail versus sliding hip screw (SHS)

Outcome: 4 Anatomical deformity

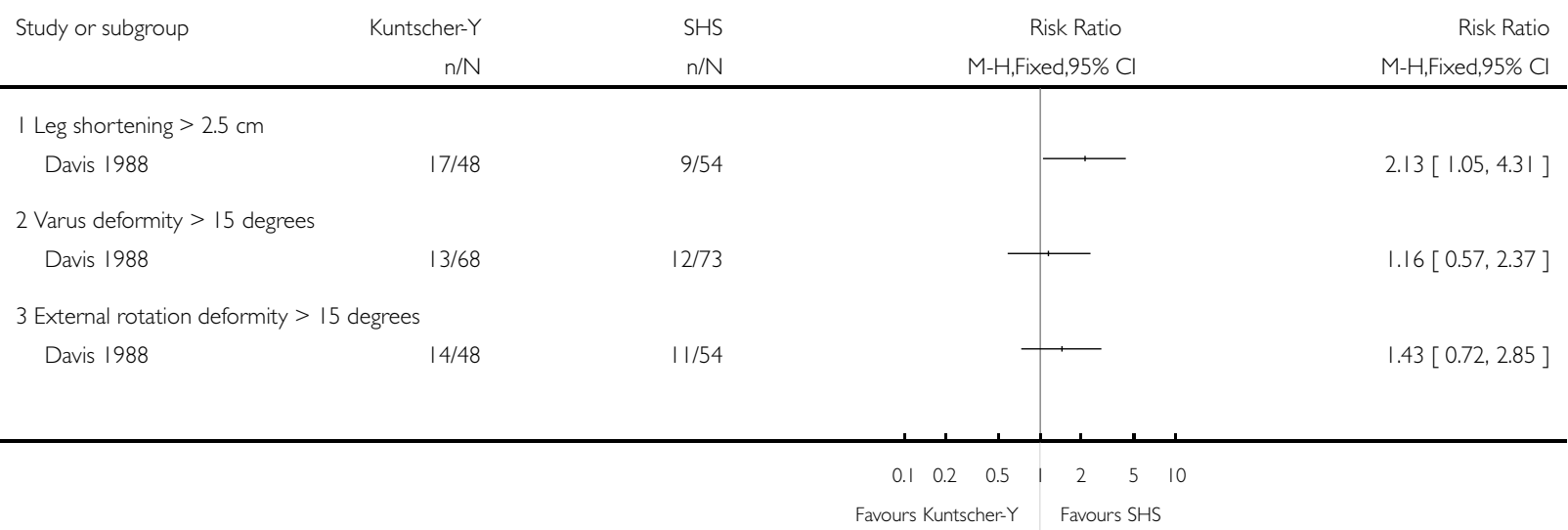

Analysis 10.5. Comparison 10 Kuntscher-Y nail versus sliding hip screw (SHS), Outcome 5 Final outcome measures (I year).

Review: Gamma and other cephalocondylic intramedullary nails versus extramedullary implants for extracapsular hip fractures in adults

Comparison: 10 Kuntscher-Y nail versus sliding hip screw (SHS)

Outcome: 5 Final outcome measures (I year)

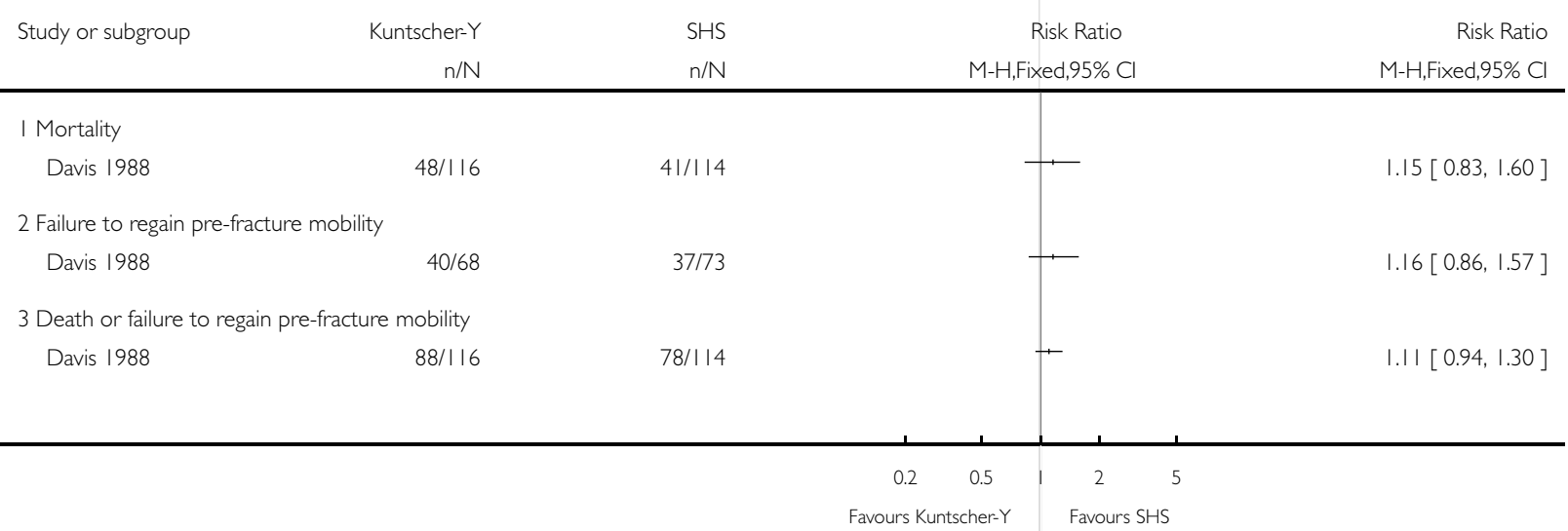

Gamma and other cephalocondylic intramedullary nails versus extramedullary implants for extracapsular hip fractures in adults (Review) I8I Copyright (C) 2010 The Cochrane Collaboration. Published by John Wiley \& Sons, Ltd. 
Analysis I I.I. Comparison II Two nail types versus sliding hip screw (SHS), Outcome I Operative outcomes.

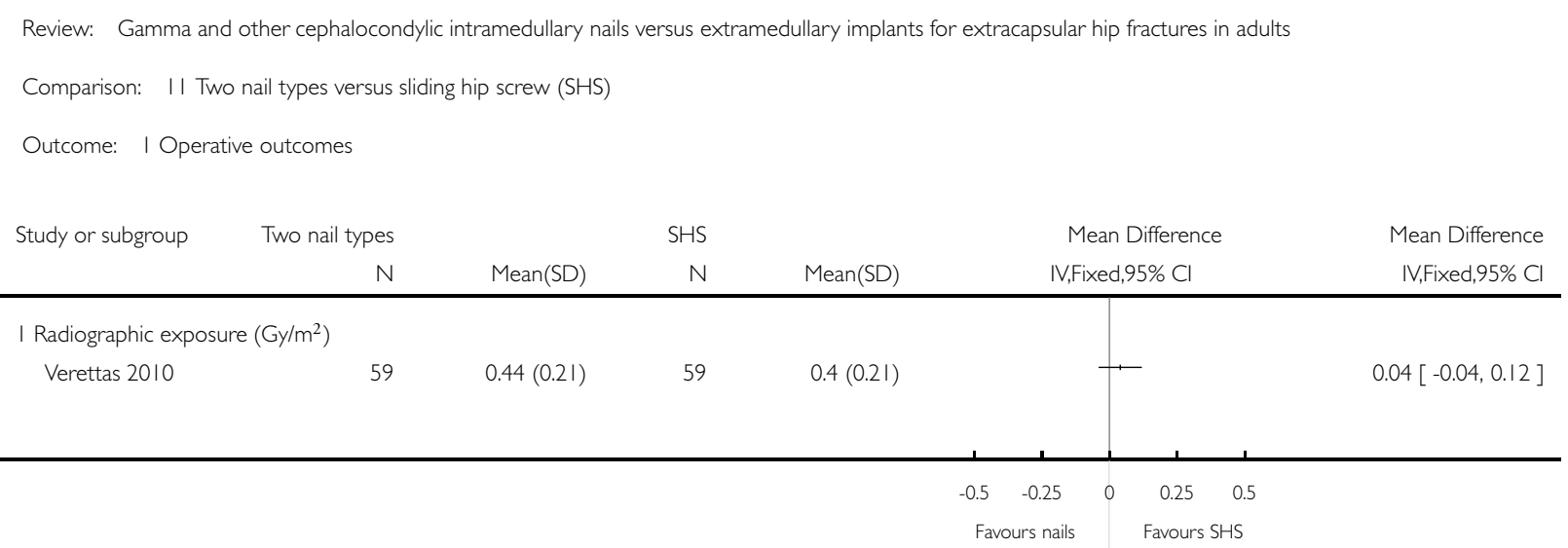

\section{Analysis II.2. Comparison II Two nail types versus sliding hip screw (SHS), Outcome 2 Operative fracture} of the femur.

Review: Gamma and other cephalocondylic intramedullary nails versus extramedullary implants for extracapsular hip fractures in adults

Comparison: II Two nail types versus sliding hip screw (SHS)

Outcome: 2 Operative fracture of the femur

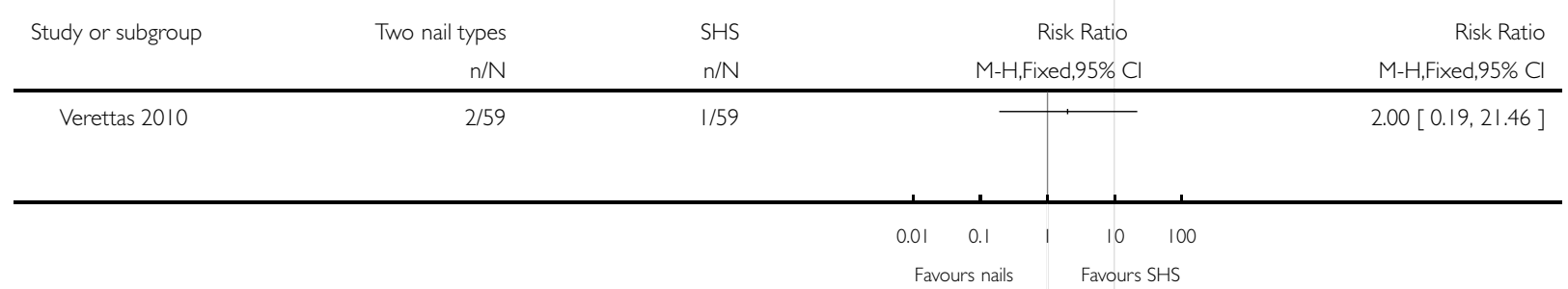




\section{Analysis II.3. Comparison II Two nail types versus sliding hip screw (SHS), Outcome 3 Superficial wound infection.}

Review: Gamma and other cephalocondylic intramedullary nails versus extramedullary implants for extracapsular hip fractures in adults

Comparison: II Two nail types versus sliding hip screw (SHS)

Outcome: 3 Superficial wound infection

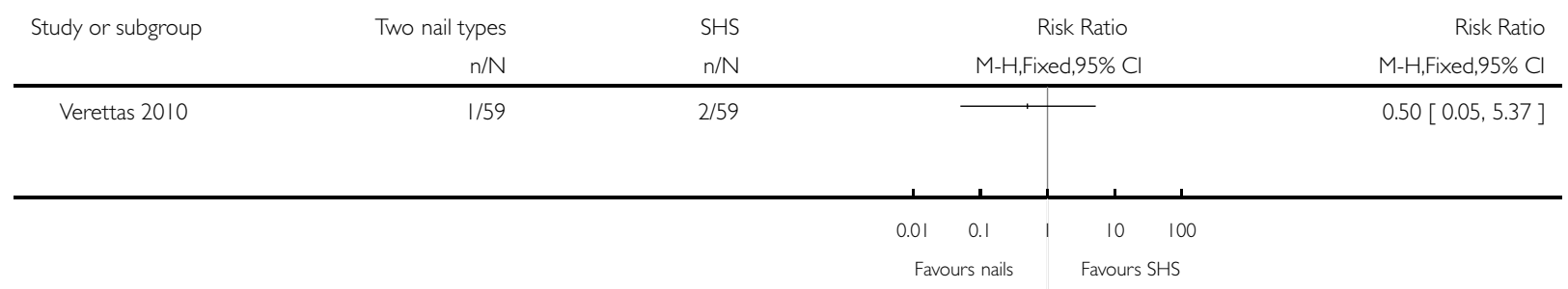

Analysis I I.4. Comparison II Two nail types versus sliding hip screw (SHS), Outcome 4 Post-operative complications.

Review: Gamma and other cephalocondylic intramedullary nails versus extramedullary implants for extracapsular hip fractures in adults

Comparison: II Two nail types versus sliding hip screw (SHS)

Outcome: 4 Post-operative complications

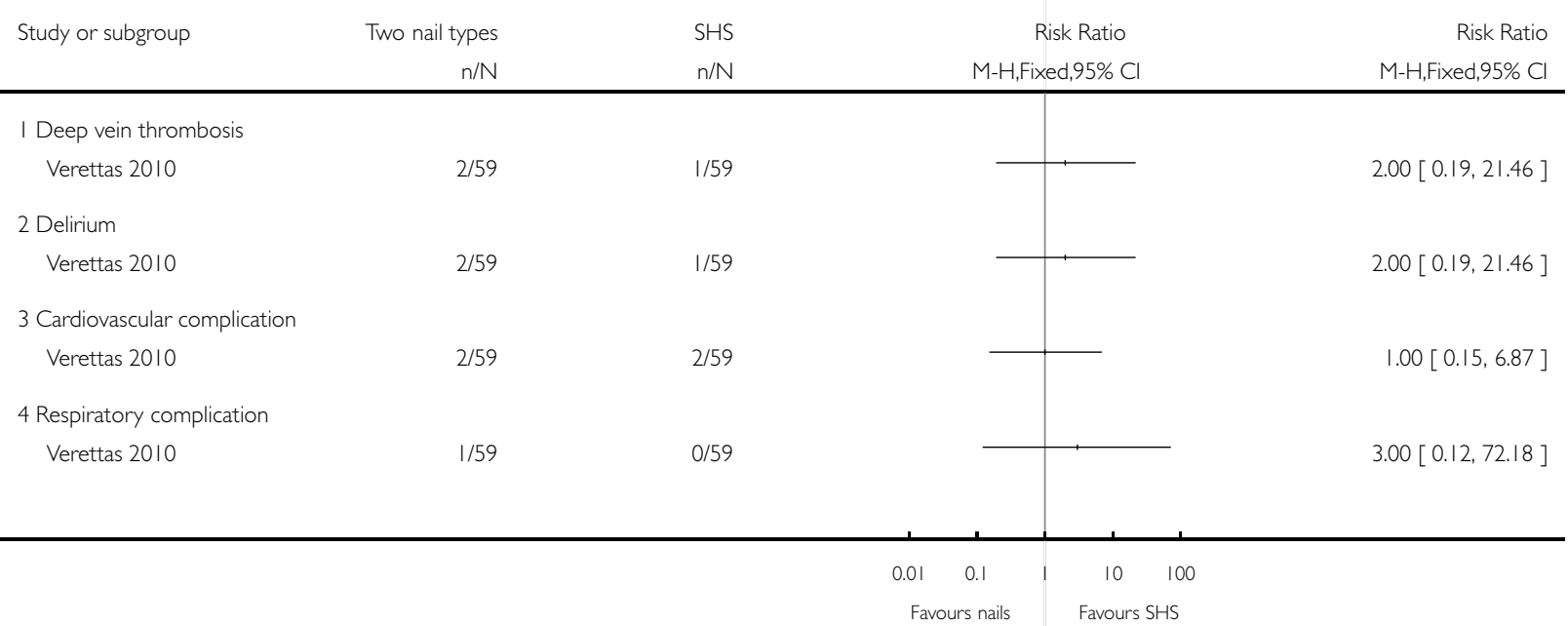

Gamma and other cephalocondylic intramedullary nails versus extramedullary implants for extracapsular hip fractures in adults (Review) 183 Copyright (C) 2010 The Cochrane Collaboration. Published by John Wiley \& Sons, Ltd. 
Analysis I I.5. Comparison I I Two nail types versus sliding hip screw (SHS), Outcome 5 Mortality (in hospital).

Review: Gamma and other cephalocondylic intramedullary nails versus extramedullary implants for extracapsular hip fractures in adults

Comparison: II Two nail types versus sliding hip screw (SHS)

Outcome: 5 Mortality (in hospital)

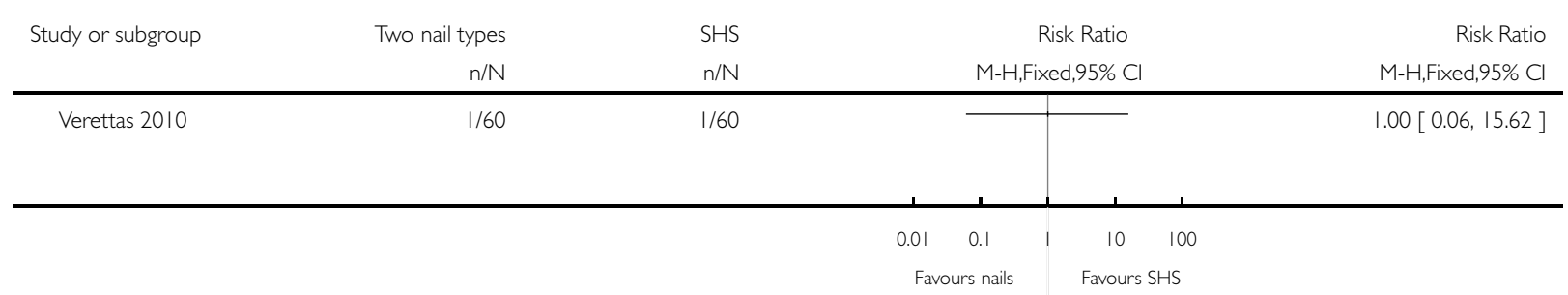

Analysis I I.6. Comparison II Two nail types versus sliding hip screw (SHS), Outcome 6 Days to independent walking.

Review: Gamma and other cephalocondylic intramedullary nails versus extramedullary implants for extracapsular hip fractures in adults

Comparison: II Two nail types versus sliding hip screw (SHS)

Outcome: 6 Days to independent walking

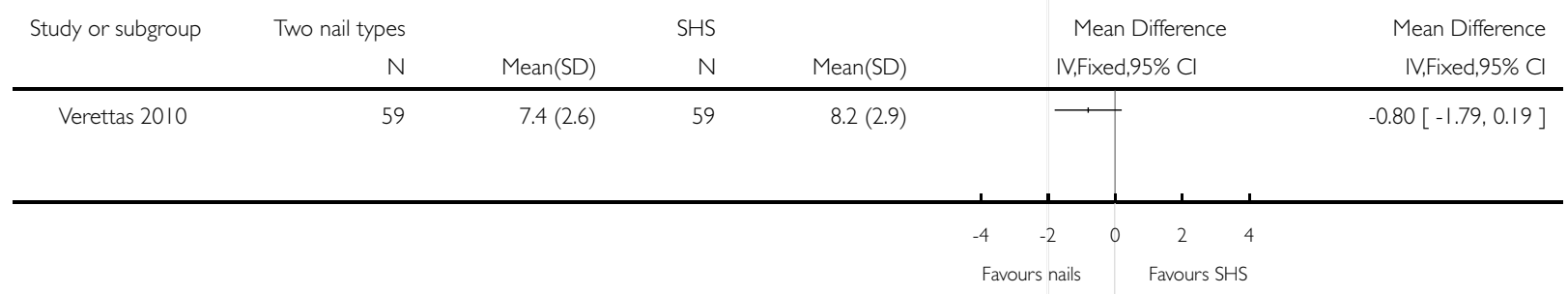


Analysis I 2.I. Comparison I2 Femoral nail (2 types) versus Medoff sliding plate, Outcome I Length of surgery (minutes).

Review: Gamma and other cephalocondylic intramedullary nails versus extramedullary implants for extracapsular hip fractures in adults

Comparison: 12 Femoral nail (2 types) versus Medoff sliding plate

Outcome: I Length of surgery (minutes)

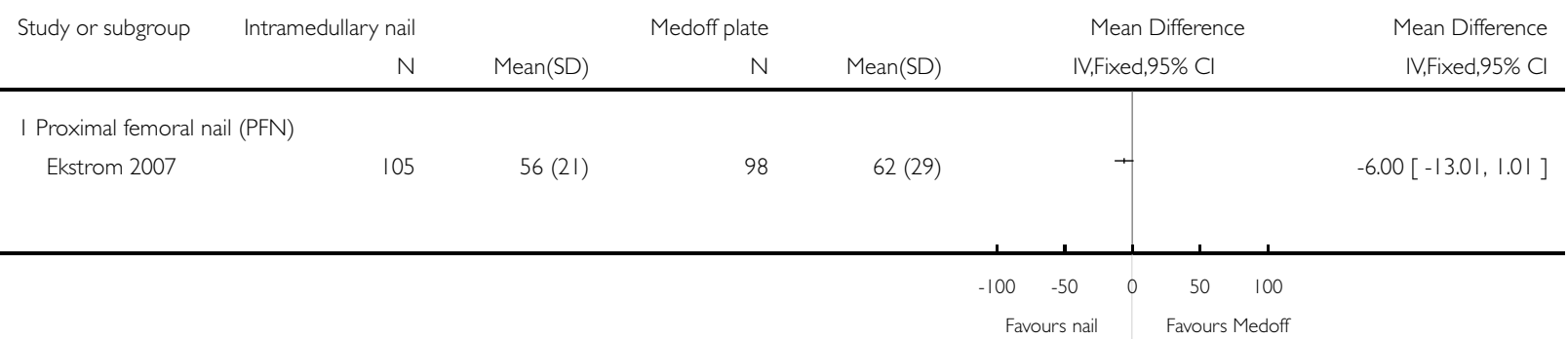

\section{Analysis 12.2. Comparison I 2 Femoral nail (2 types) versus Medoff sliding plate, Outcome 2 Operative} blood loss $(\mathrm{ml})$.

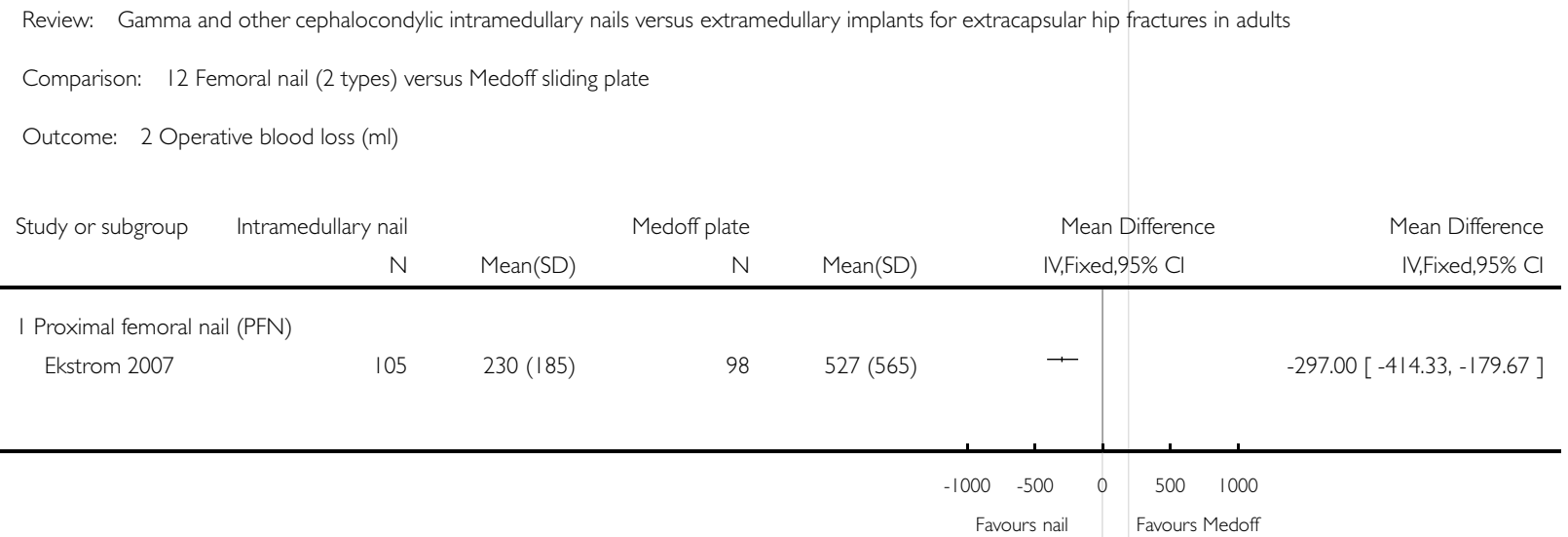

Gamma and other cephalocondylic intramedullary nails versus extramedullary implants for extracapsular hip fractures in adults (Review) $\quad$ I85 Copyright (C) 2010 The Cochrane Collaboration. Published by John Wiley \& Sons, Ltd. 
Analysis 12.3. Comparison 12 Femoral nail (2 types) versus Medoff sliding plate, Outcome 3 Radiographic screening time (minutes).

Review: Gamma and other cephalocondylic intramedullary nails versus extramedullary implants for extracapsular hip fractures in adults

Comparison: 12 Femoral nail (2 types) versus Medoff sliding plate

Outcome: 3 Radiographic screening time (minutes)

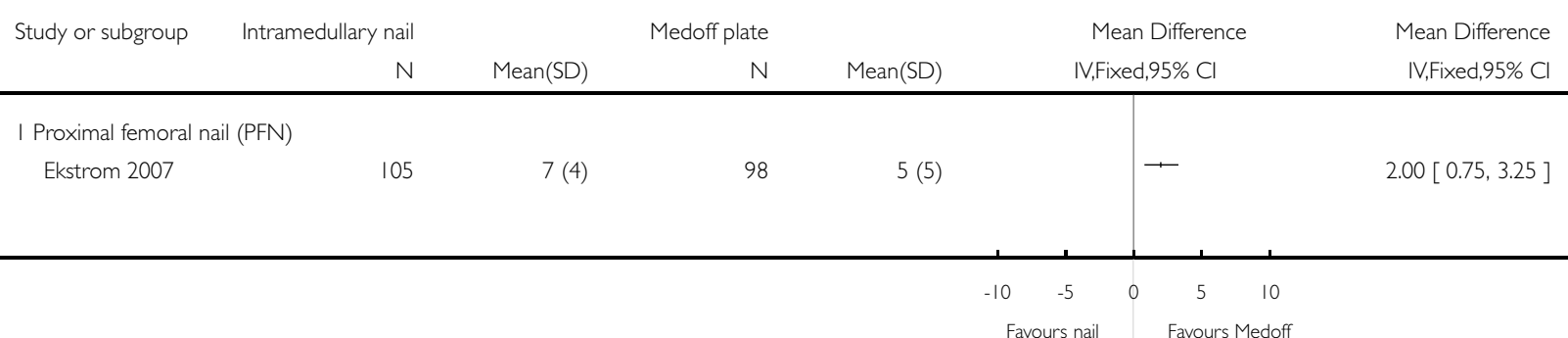

Analysis 12.4. Comparison I 2 Femoral nail (2 types) versus Medoff sliding plate, Outcome 4 Operative fracture of the femur.

Review: Gamma and other cephalocondylic intramedullary nails versus extramedullary implants for extracapsular hip fractures in adults

Comparison: 12 Femoral nail (2 types) versus Medoff sliding plate

Outcome: 4 Operative fracture of the femur

$\begin{array}{llll}\text { Study or subgroup } & \text { Intramedullary nail } & \text { Medoff plate } & \text { Risk Ratio }\end{array}$

$\mathrm{n} / \mathrm{N} \quad \mathrm{n} / \mathrm{N} \quad \mathrm{M}-\mathrm{H}$, Fixed,95\% Cl M-H,Fixed,95\% Cl

\begin{tabular}{|c|c|c|c|c|}
\hline \multicolumn{5}{|l|}{ I Gamma nail } \\
\hline Miedel 2005 & $3 / 109$ & $0 / 108$ & $49.3 \%$ & $6.94[0.36,132.70]$ \\
\hline Subtotal (95\% CI) & 109 & 108 & $49.3 \%$ & $6.94[0.36,132.70]$ \\
\hline \multicolumn{5}{|c|}{ Total events: 3 (Intramedullary nail), 0 (Medoff plate) } \\
\hline \multicolumn{5}{|c|}{ Heterogeneity: not applicable } \\
\hline \multicolumn{5}{|c|}{ Test for overall effect: $Z=1.29(P=0.20)$} \\
\hline \multicolumn{5}{|c|}{2 Proximal femoral nail (PFN) } \\
\hline Ekstrom 2007 & $1 / 105$ & $0 / 98$ & $50.7 \%$ & $2.80[0.12,67.98]$ \\
\hline Subtotal (95\% CI) & 105 & 98 & $50.7 \%$ & $2.80[0.12,67.98]$ \\
\hline \multicolumn{5}{|c|}{ Total events: I (Intramedullary nail), 0 (Medoff plate) } \\
\hline \multicolumn{5}{|c|}{ Heterogeneity: not applicable } \\
\hline \multicolumn{5}{|c|}{ Test for overall effect: $Z=0.63(P=0.53)$} \\
\hline Total (95\% CI) & 214 & 206 & $100.0 \%$ & $4.84[0.57,40.81]$ \\
\hline \multicolumn{5}{|c|}{ Total events: 4 (Intramedullary nail), 0 (Medoff plate) } \\
\hline \multicolumn{5}{|c|}{ Heterogeneity: $\mathrm{Chi}^{2}=0.17, \mathrm{df}=\mathrm{I}(P=0.68) ; \mathrm{I}^{2}=0.0 \%$} \\
\hline Test for overall effect: $Z=$ & & & & \\
\hline
\end{tabular}

$0.0010 .010 .1 \quad 1 \quad 10 \quad 100 \quad 1000$

Favours nail Favours Medoff

Gamma and other cephalocondylic intramedullary nails versus extramedullary implants for extracapsular hip fractures in adults (Review) I86 Copyright (C) 2010 The Cochrane Collaboration. Published by John Wiley \& Sons, Ltd. 


\section{Analysis I 2.5. Comparison I 2 Femoral nail (2 types) versus Medoff sliding plate, Outcome 5 Later fracture}

of femur.

Review: Gamma and other cephalocondylic intramedullary nails versus extramedullary implants for extracapsular hip fractures in adults

Comparison: 12 Femoral nail (2 types) versus Medoff sliding plate

Outcome: 5 Later fracture of femur

Study or subgroup Intramedullary nail

Medoff plate

Risk Ratio

Risk Ratio

\begin{tabular}{|c|c|c|c|c|}
\hline & $\mathrm{n} / \mathrm{N}$ & $\mathrm{n} / \mathrm{N}$ & M-H,Fixed,95\% Cl & M-H,Fixed,95\% Cl \\
\hline \multicolumn{5}{|l|}{ I Gamma nail } \\
\hline Miedel 2005 & 0/109 & $0 / 108$ & & $0.0[0.0,0.0]$ \\
\hline Subtotal (95\% CI) & 109 & 108 & & $0.0[0.0,0.0]$ \\
\hline \multicolumn{5}{|c|}{ Total events: 0 (Intramedullary nail), 0 (Medoff plate) } \\
\hline \multicolumn{5}{|l|}{ Heterogeneity: not applicable } \\
\hline \multicolumn{5}{|c|}{ Test for overall effect: $Z=0.0(P<0.0000 I)$} \\
\hline \multicolumn{5}{|c|}{2 Proximal femoral nail (PFN) } \\
\hline Ekstrom 2007 & $0 / 105$ & $0 / 98$ & & $0.0[0.0,0.0]$ \\
\hline Subtotal (95\% CI) & 105 & 98 & & $0.0[0.0,0.0]$ \\
\hline \multicolumn{5}{|c|}{ Total events: 0 (Intramedullary nail), 0 (Medoff plate) } \\
\hline \multicolumn{5}{|l|}{ Heterogeneity: not applicable } \\
\hline \multicolumn{5}{|c|}{ Test for overall effect: $Z=0.0(P<0.0000 I)$} \\
\hline Total $(95 \% \mathrm{CI})$ & 214 & 206 & & $0.0[0.0,0.0]$ \\
\hline \multicolumn{5}{|c|}{ Total events: 0 (Intramedullary nail), 0 (Medoff plate) } \\
\hline \multicolumn{5}{|c|}{ Heterogeneity: Chi $^{2}=0.0, d f=0(P<0.0000 I) ; I^{2}=0.0 \%$} \\
\hline \multicolumn{5}{|c|}{ Test for overall effect: $Z=0.0(P<0.0000 I)$} \\
\hline
\end{tabular}

Gamma and other cephalocondylic intramedullary nails versus extramedullary implants for extracapsular hip fractures in adults (Review) $\quad$ (87 Copyright (C) 2010 The Cochrane Collaboration. Published by John Wiley \& Sons, Ltd. 


\section{Analysis 1 2.6. Comparison 12 Femoral nail (2 types) versus Medoff sliding plate, Outcome 6 Cut-out.}

Review: Gamma and other cephalocondylic intramedullary nails versus extramedullary implants for extracapsular hip fractures in adults

Comparison: 12 Femoral nail (2 types) versus Medoff sliding plate

Outcome: 6 Cut-out

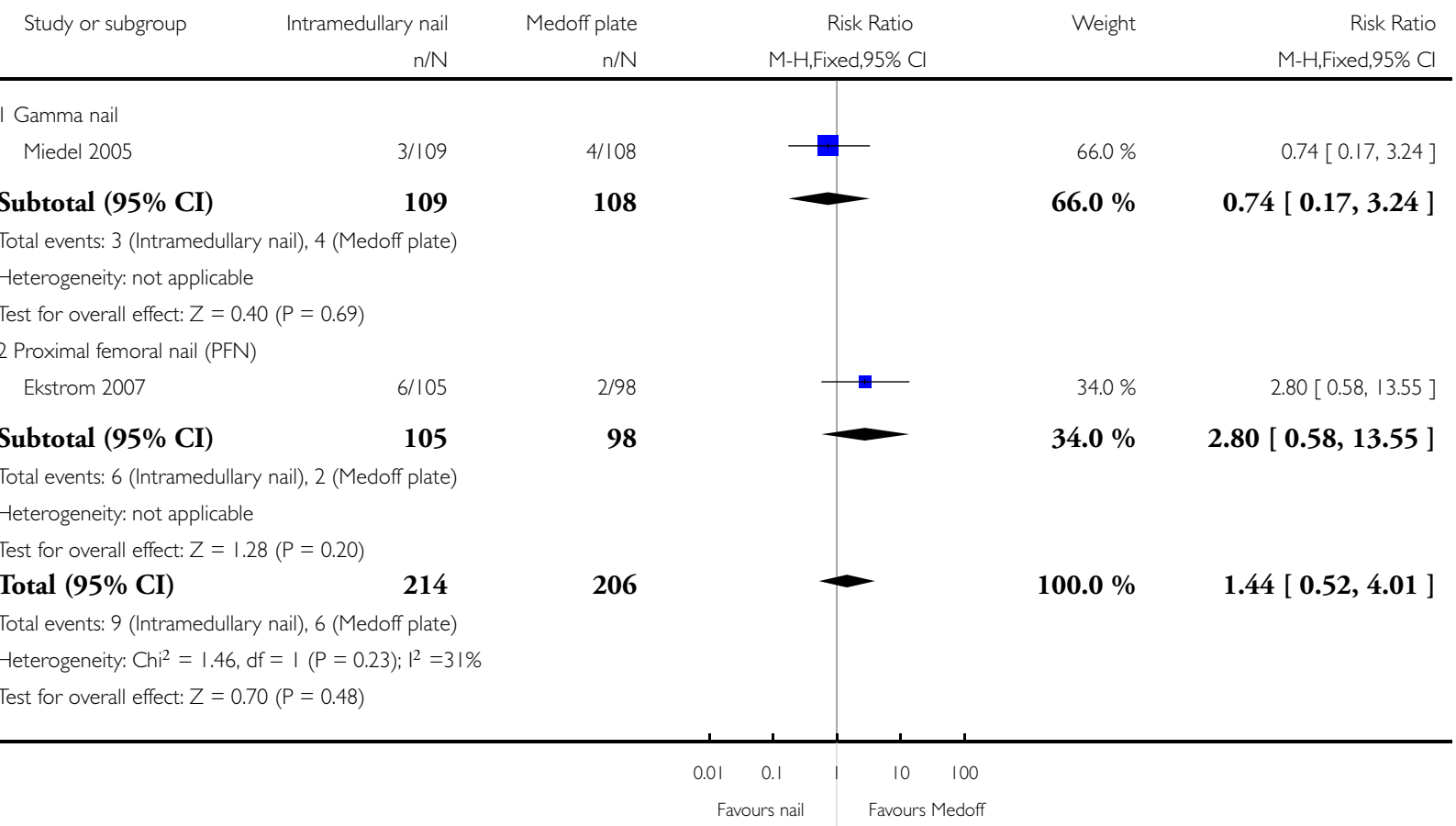

\section{Analysis 12.7. Comparison 12 Femoral nail (2 types) versus Medoff sliding plate, Outcome 7 Non-union.}

Review: Gamma and other cephalocondylic intramedullary nails versus extramedullary implants for extracapsular hip fractures in adults

Comparison: 12 Femoral nail (2 types) versus Medoff sliding plate

Outcome: 7 Non-union

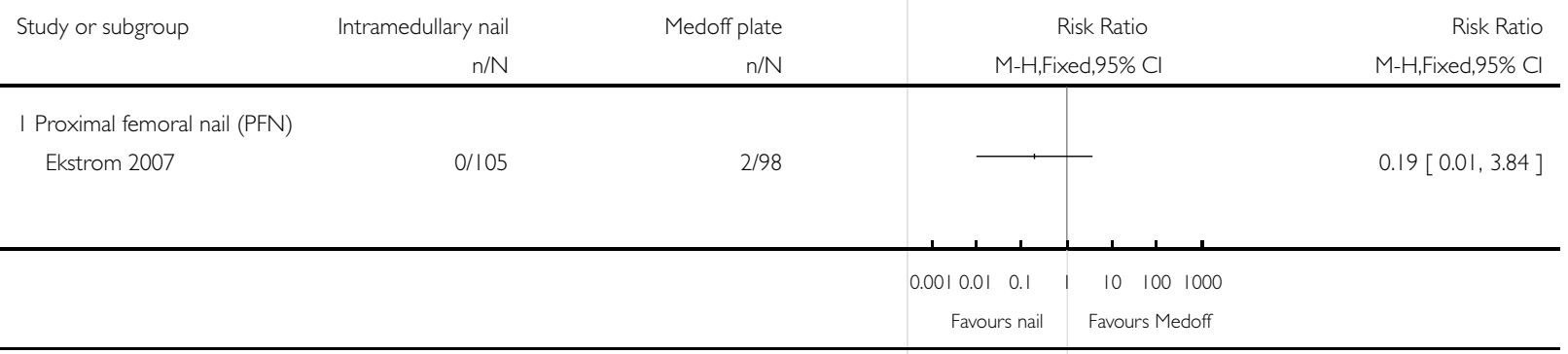

Gamma and other cephalocondylic intramedullary nails versus extramedullary implants for extracapsular hip fractures in adults (Review) $\quad$ 88 Copyright (C) 2010 The Cochrane Collaboration. Published by John Wiley \& Sons, Ltd. 
Analysis 12.8. Comparison I2 Femoral nail (2 types) versus Medoff sliding plate, Outcome 8 Reoperation.

Review: Gamma and other cephalocondylic intramedullary nails versus extramedullary implants for extracapsular hip fractures in adults

Comparison: 12 Femoral nail (2 types) versus Medoff sliding plate

Outcome: 8 Reoperation

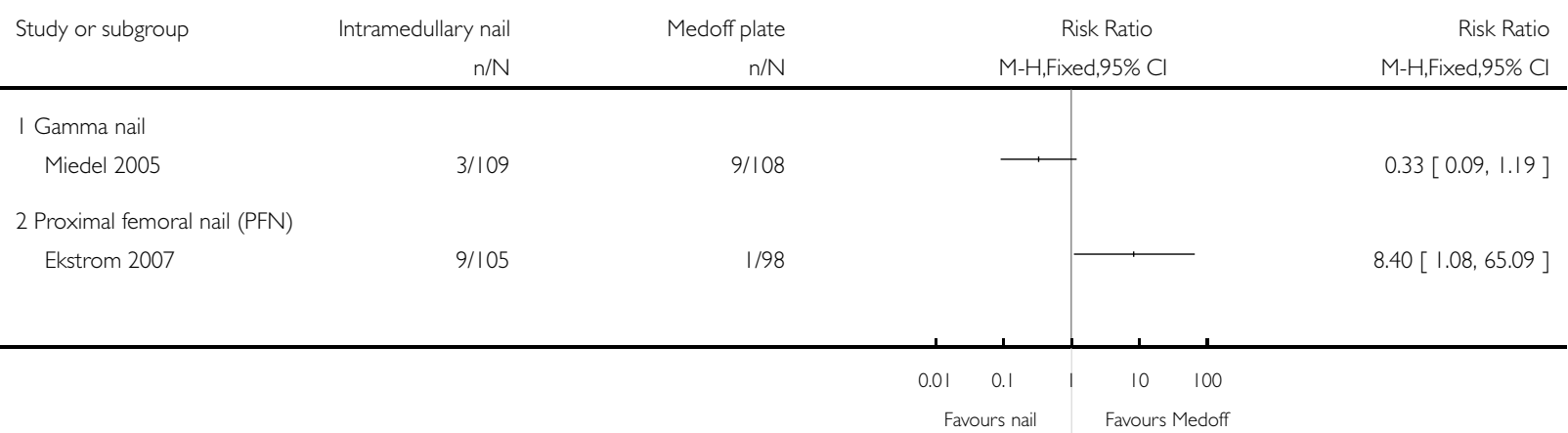

Analysis I 2.9. Comparison I 2 Femoral nail (2 types) versus Medoff sliding plate, Outcome 9 Wound infection - any type.

Review: Gamma and other cephalocondylic intramedullary nails versus extramedullary implants for extracapsular hip fractures in adults

Comparison: 12 Femoral nail (2 types) versus Medoff sliding plate

Outcome: 9 Wound infection - any type

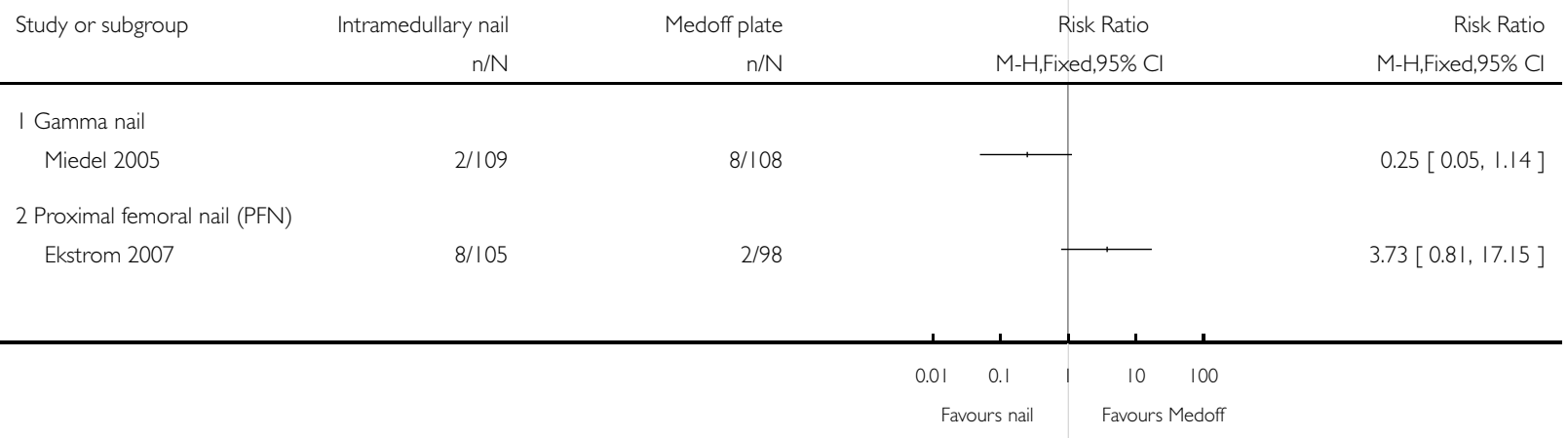

Gamma and other cephalocondylic intramedullary nails versus extramedullary implants for extracapsular hip fractures in adults (Review) $\quad$ (89 Copyright (C) 2010 The Cochrane Collaboration. Published by John Wiley \& Sons, Ltd. 
Analysis 12.10. Comparison 12 Femoral nail (2 types) versus Medoff sliding plate, Outcome 10 Deep wound infection.

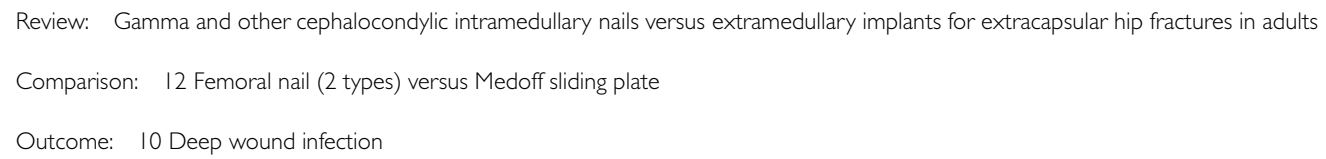

\begin{tabular}{|c|c|c|c|c|}
\hline \multirow[t]{2}{*}{ Study or subgroup } & Intramedullary nail & Medoff plate & Risk Ratio & Risk Ratio \\
\hline & $n / N$ & $\mathrm{n} / \mathrm{N}$ & M-H,Fixed,95\% Cl & M-H,Fixed, $95 \% \mathrm{Cl}$ \\
\hline \multicolumn{5}{|l|}{ I Gamma nail } \\
\hline Miedel 2005 & $0 / 109$ & $2 / 108$ & \begin{tabular}{l|l}
$\cdot$ & \\
\end{tabular} & $0.20[0.01,4.08]$ \\
\hline
\end{tabular}

$0.0010 .01 \quad 0.1 \quad 1 \quad 10 \quad 1001000$

Favours nail Favours Medoff

Analysis 12.11. Comparison I2 Femoral nail (2 types) versus Medoff sliding plate, Outcome II Wound haematoma.

Review: Gamma and other cephalocondylic intramedullary nails versus extramedullary implants for extracapsular hip fractures in adults

Comparison: 12 Femoral nail (2 types) versus Medoff sliding plate

Outcome: II Wound haematoma

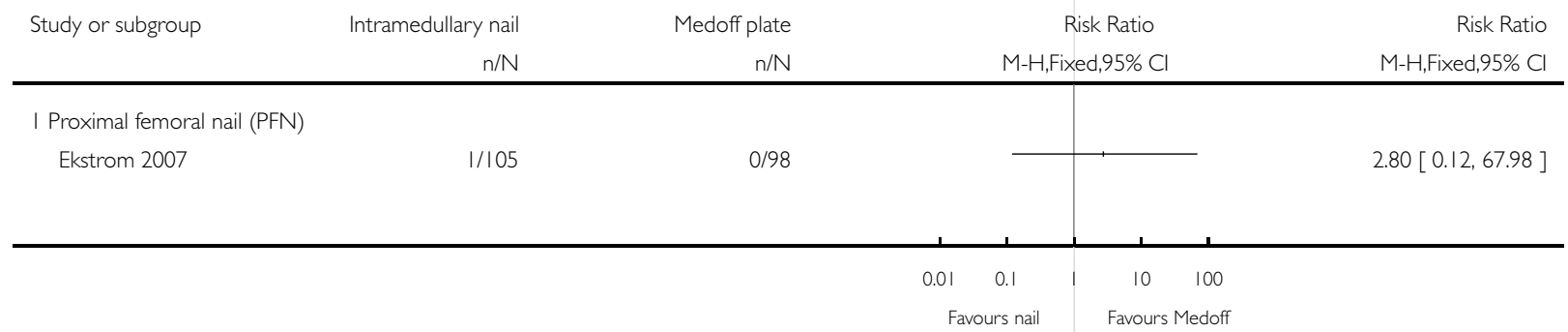


Analysis 12.12. Comparison I 2 Femoral nail (2 types) versus Medoff sliding plate, Outcome 12 Severe medical complications.

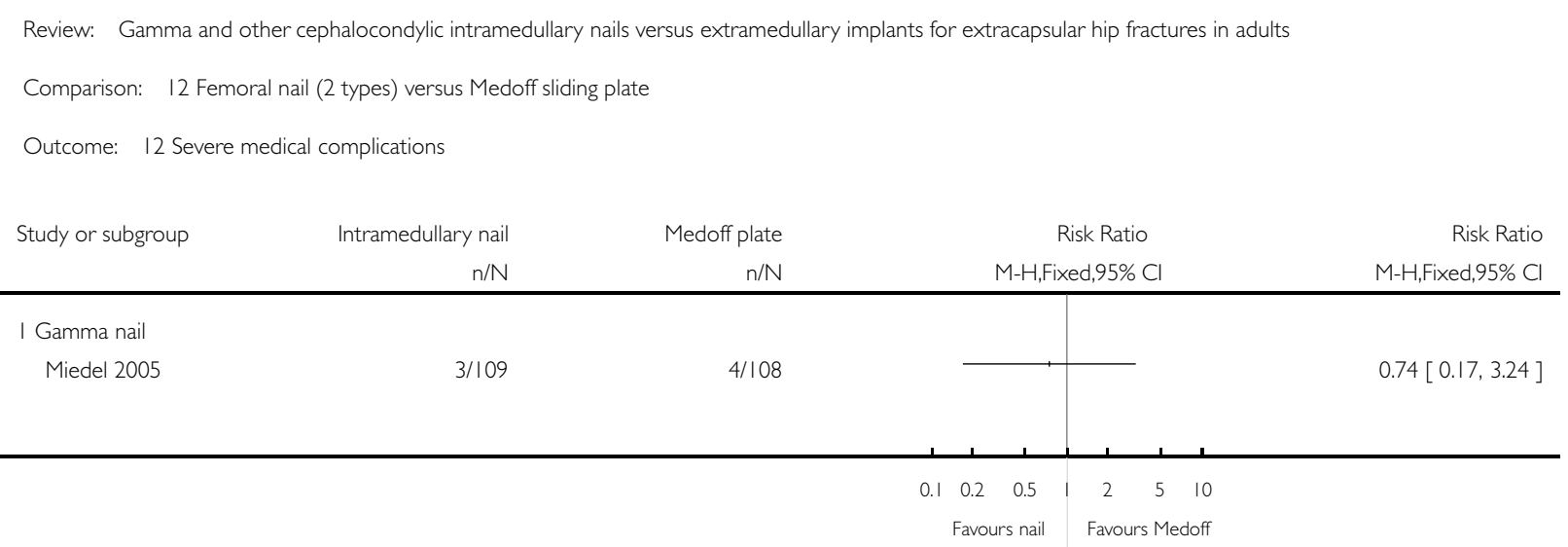

Analysis 12.13. Comparison I2 Femoral nail (2 types) versus Medoff sliding plate, Outcome I3 Mortality at I year.

Review: Gamma and other cephalocondylic intramedullary nails versus extramedullary implants for extracapsular hip fractures in adults

Comparison: 12 Femoral nail (2 types) versus Medoff sliding plate

Outcome: 13 Mortality at I year

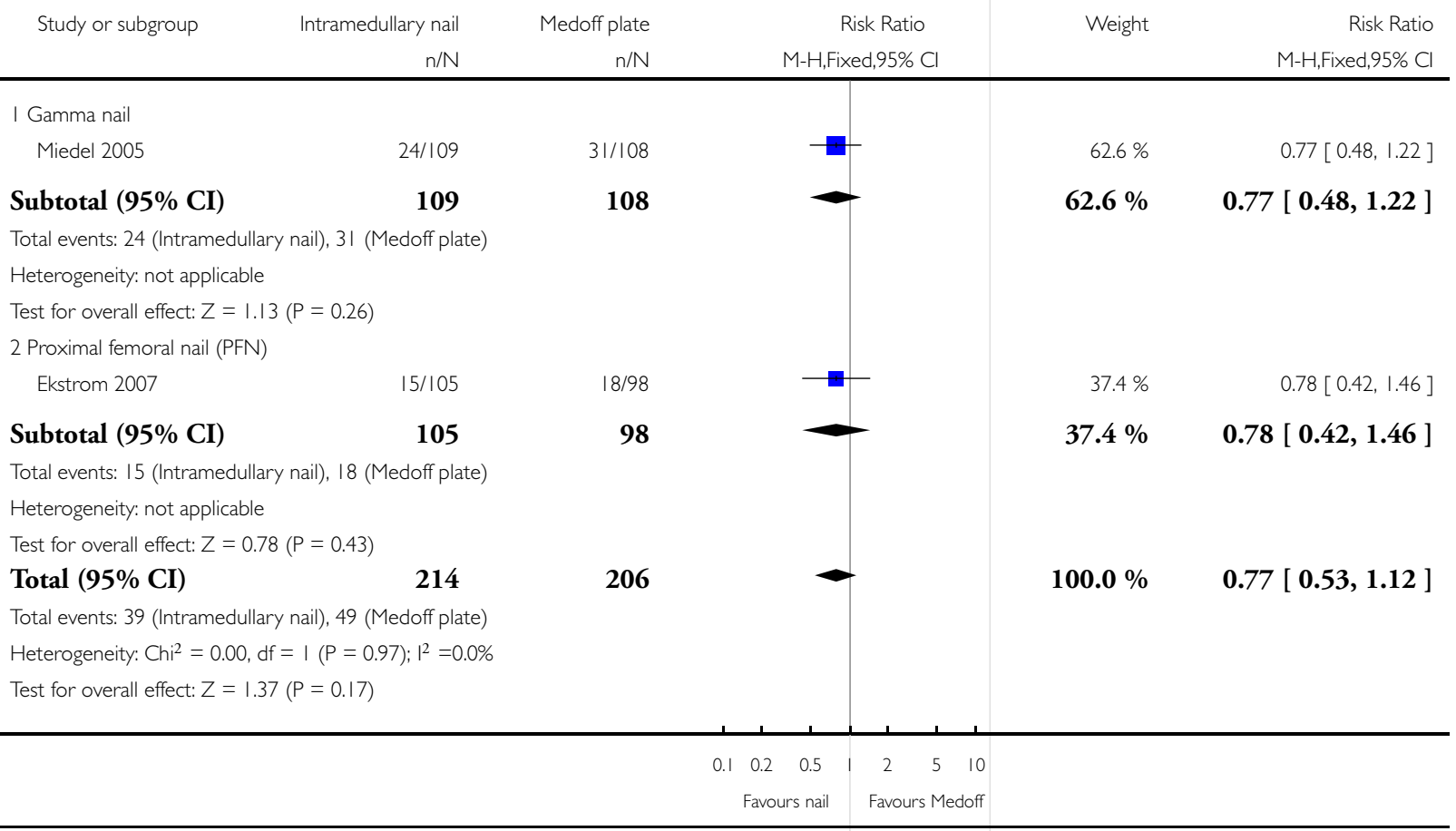

Gamma and other cephalocondylic intramedullary nails versus extramedullary implants for extracapsular hip fractures in adults (Review) I91 Copyright (@) 2010 The Cochrane Collaboration. Published by John Wiley \& Sons, Ltd. 


\section{Analysis 12.14. Comparison I 2 Femoral nail (2 types) versus Medoff sliding plate, Outcome 14 Inability to} walk 15 metres at one year.

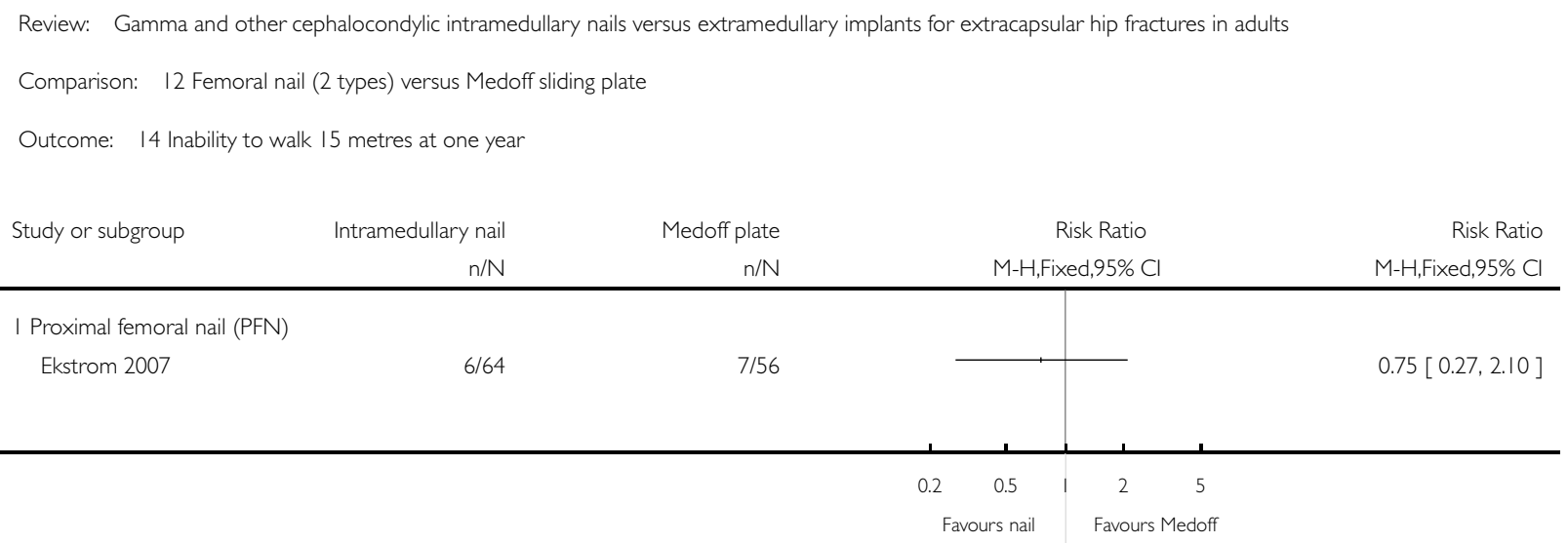

Analysis 12.15. Comparison I2 Femoral nail (2 types) versus Medoff sliding plate, Outcome 15 Inability to rise from a chair at one year.

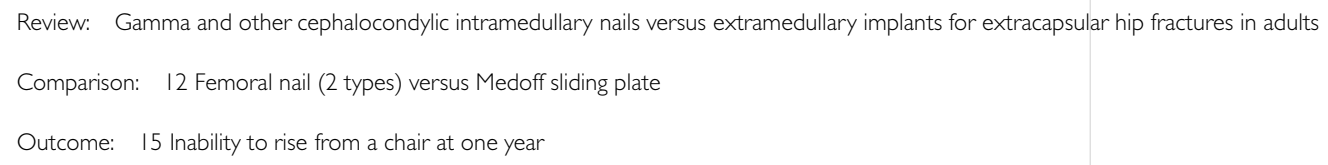

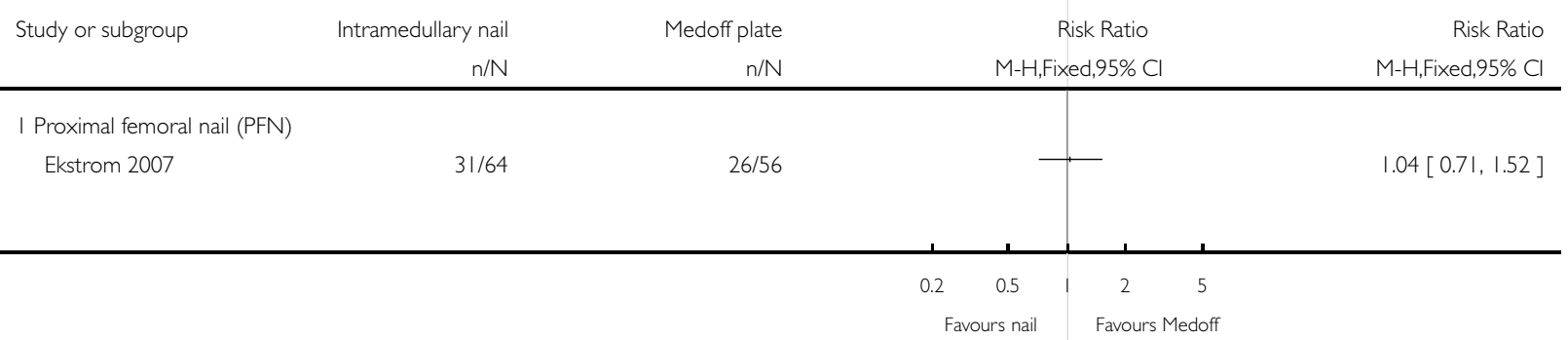


Analysis 12.16. Comparison 12 Femoral nail (2 types) versus Medoff sliding plate, Outcome 16 Inability to climb a curb at one year.

Review: Gamma and other cephalocondylic intramedullary nails versus extramedullary implants for extracapsular hip fractures in adults

Comparison: 12 Femoral nail (2 types) versus Medoff sliding plate

Outcome: 16 Inability to climb a curb at one year

Study or subgroup Intramedullary nail $\quad$ Medoff plate Risk Ratio

$\mathrm{n} / \mathrm{N} \quad \mathrm{n} / \mathrm{N} \quad \mathrm{M}-\mathrm{H}, \mathrm{Fixed}, 95 \% \mathrm{Cl} \quad \mathrm{M}-\mathrm{H}, \mathrm{Fixed}, 95 \% \mathrm{Cl}$

\begin{tabular}{lcc|cc}
\hline $\begin{array}{l}\text { I Proximal femoral nail (PFN) } \\
\text { Ekstrom } 2007\end{array}$ & $50 / 64$ & $38 / 56$ & & \\
& & & & \\
\hline
\end{tabular}

Analysis 12.17. Comparison I2 Femoral nail (2 types) versus Medoff sliding plate, Outcome 17 Need to use walking aids at one year.

Review: Gamma and other cephalocondylic intramedullary nails versus extramedullary implants for extracapsular hip fractures in adults

Comparison: 12 Femoral nail (2 types) versus Medoff sliding plate

Outcome: 17 Need to use walking aids at one year

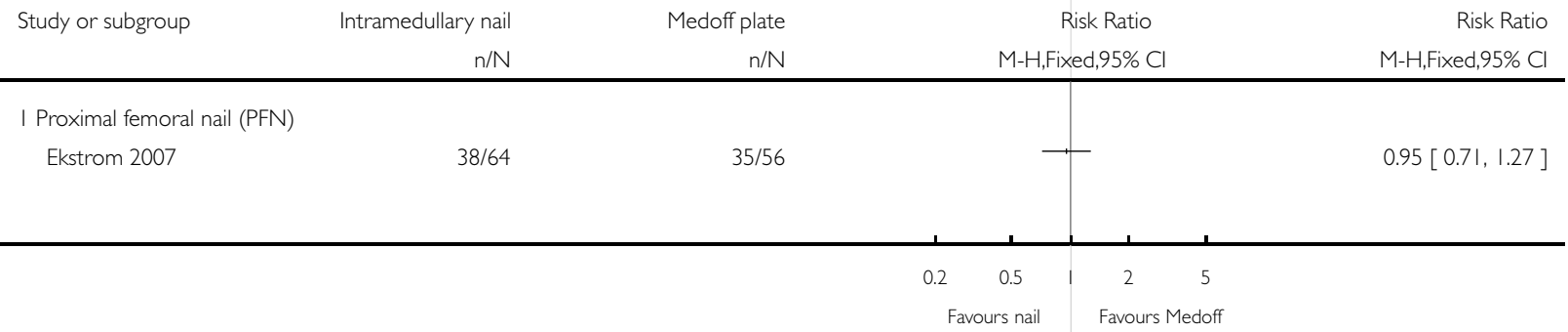


Analysis 13.I. Comparison I3 Gamma nail versus percutaneous compression plate (PCCP), Outcome I Number of patients transfused.

Review: Gamma and other cephalocondylic intramedullary nails versus extramedullary implants for extracapsular hip fractures in adults

Comparison: 13 Gamma nail versus percutaneous compression plate (PCCP)

Outcome: I Number of patients transfused

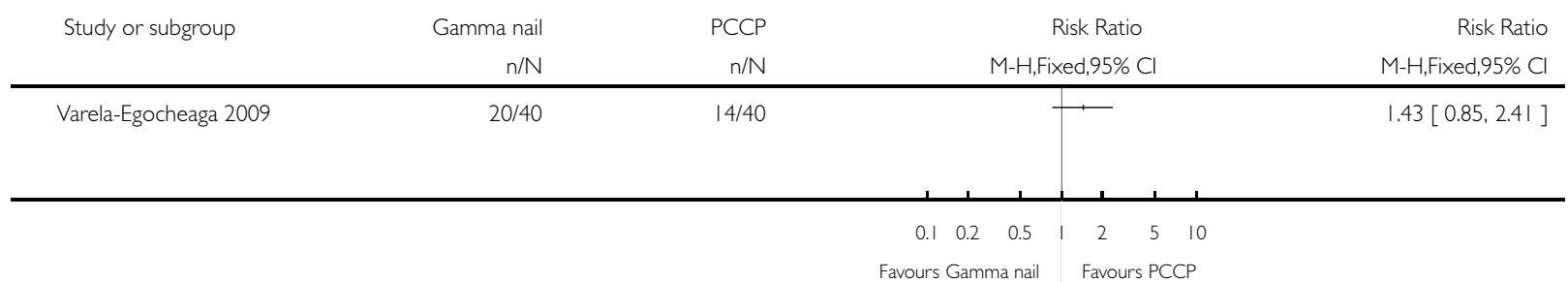

Analysis 13.2. Comparison I 3 Gamma nail versus percutaneous compression plate (PCCP), Outcome 2 Fracture fixation complications.

Review: Gamma and other cephalocondylic intramedullary nails versus extramedullary implants for extracapsular hip fractures in adults

Comparison: 13 Gamma nail versus percutaneous compression plate (PCCP)

Outcome: 2 Fracture fixation complications

Study or subgroup $\quad$ Gamma nail $\quad$ PCCP Risk Ratio Risk Ratio

$n / \mathrm{N} \quad \mathrm{n} / \mathrm{N}$ M-H,Fixed, $95 \% \mathrm{Cl}$ M-H,Fixed,95\% Cl

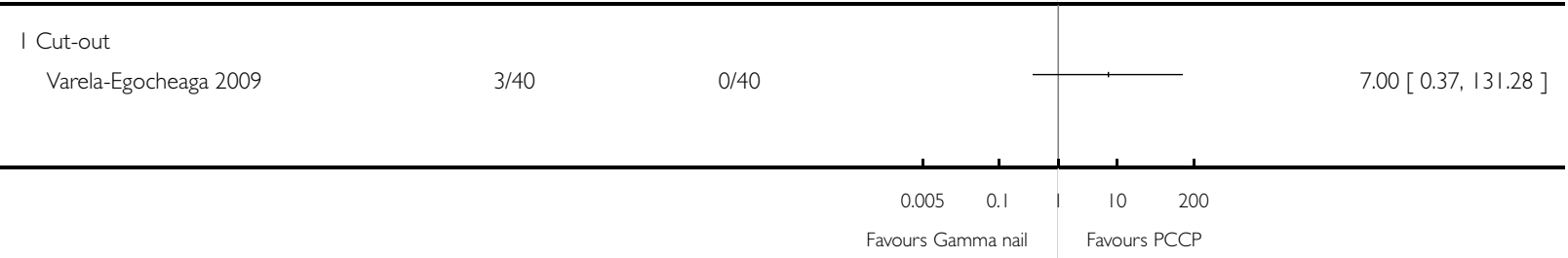

Gamma and other cephalocondylic intramedullary nails versus extramedullary implants for extracapsular hip fractures in adults (Review) 194 Copyright (C) 2010 The Cochrane Collaboration. Published by John Wiley \& Sons, Ltd. 
Analysis 13.3. Comparison 13 Gamma nail versus percutaneous compression plate (PCCP), Outcome 3 Post-operative complications.

Review: Gamma and other cephalocondylic intramedullary nails versus extramedullary implants for extracapsular hip fractures in adults

Comparison: 13 Gamma nail versus percutaneous compression plate (PCCP)

Outcome: 3 Post-operative complications

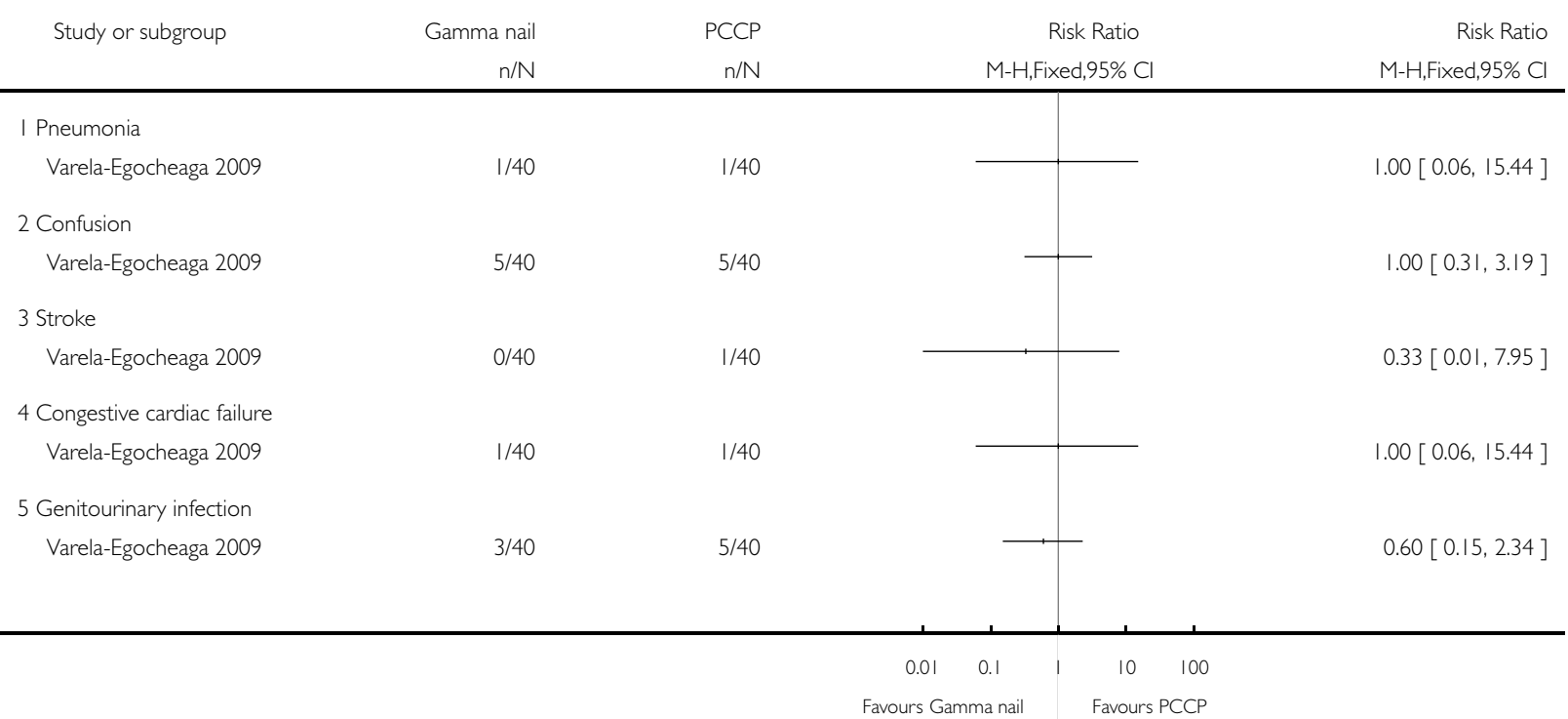

Analysis 13.4. Comparison I3 Gamma nail versus percutaneous compression plate (PCCP), Outcome 4 Discharged to intermediate care.

Review: Gamma and other cephalocondylic intramedullary nails versus extramedullary implants for extracapsular hip fractures in adults

Comparison: 13 Gamma nail versus percutaneous compression plate (PCCP)

Outcome: 4 Discharged to intermediate care

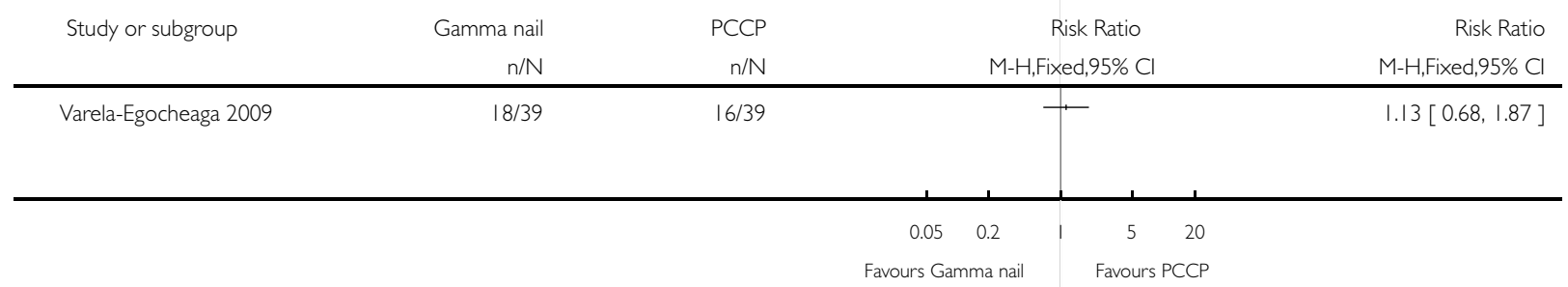

Gamma and other cephalocondylic intramedullary nails versus extramedullary implants for extracapsular hip fractures in adults (Review) 195 Copyright (C) 2010 The Cochrane Collaboration. Published by John Wiley \& Sons, Ltd. 
Analysis 13.5. Comparison I3 Gamma nail versus percutaneous compression plate (PCCP), Outcome 5 Mortality.

Review: Gamma and other cephalocondylic intramedullary nails versus extramedullary implants for extracapsular hip fractures in adults

Comparison: 13 Gamma nail versus percutaneous compression plate (PCCP)

Outcome: 5 Mortality

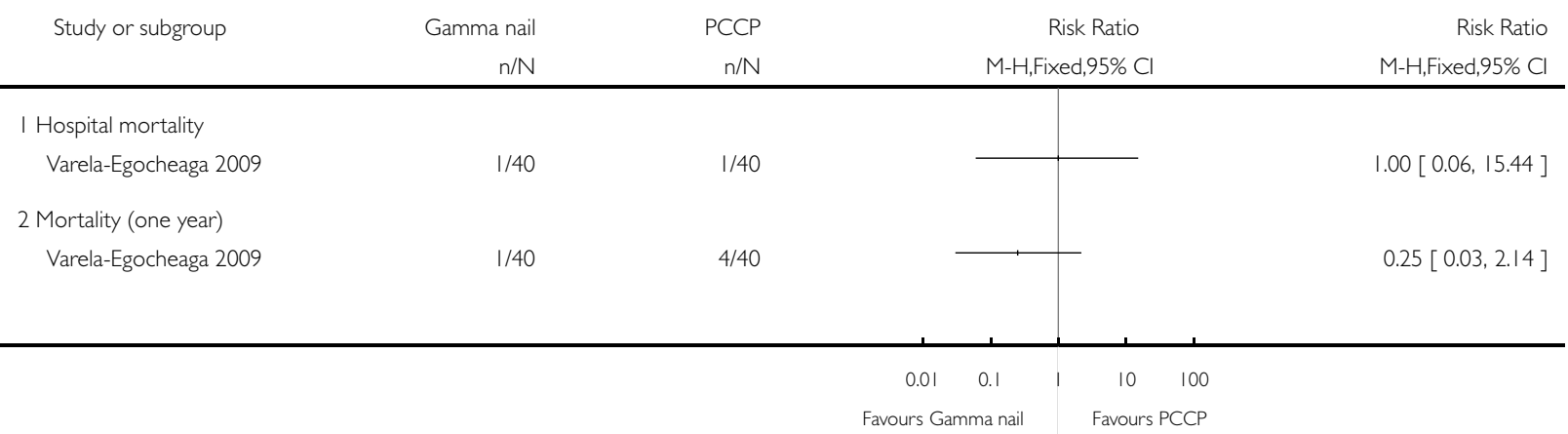

Analysis 13.6. Comparison 13 Gamma nail versus percutaneous compression plate (PCCP), Outcome 6 Failure to regain mobility at one year.

Review: Gamma and other cephalocondylic intramedullary nails versus extramedullary implants for extracapsular hip fractures in adults

Comparison: 13 Gamma nail versus percutaneous compression plate (PCCP)

Outcome: 6 Failure to regain mobility at one year

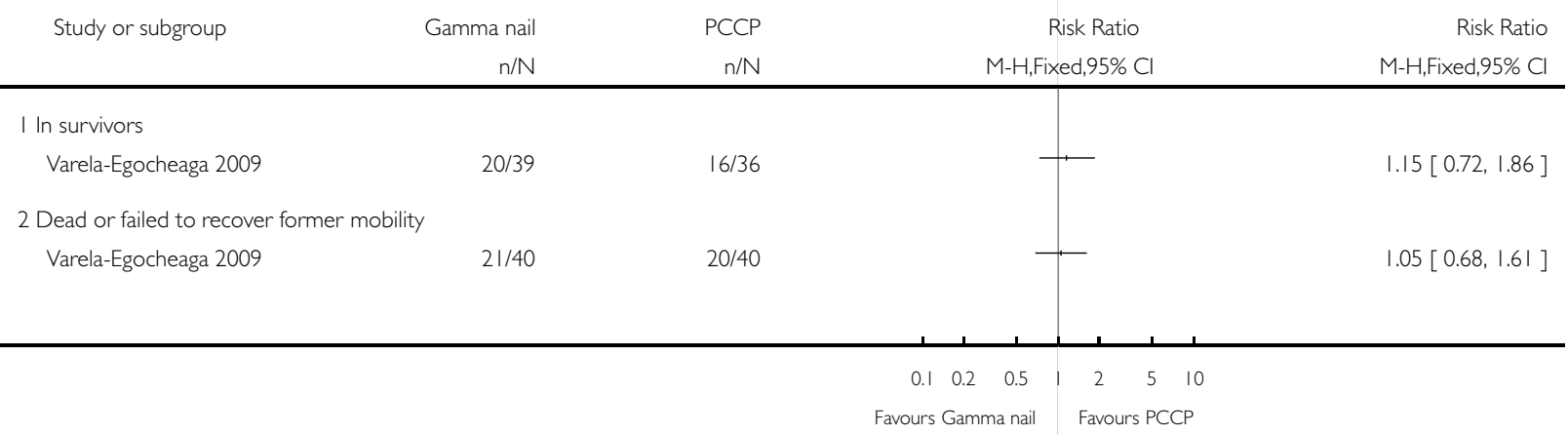

Gamma and other cephalocondylic intramedullary nails versus extramedullary implants for extracapsular hip fractures in adults (Review) 196 Copyright (C) 2010 The Cochrane Collaboration. Published by John Wiley \& Sons, Ltd. 
Analysis 14.I. Comparison 14 Femoral nail versus condylar screw or blade plate for trochanteric fractures, Outcome I Length of surgery (minutes).

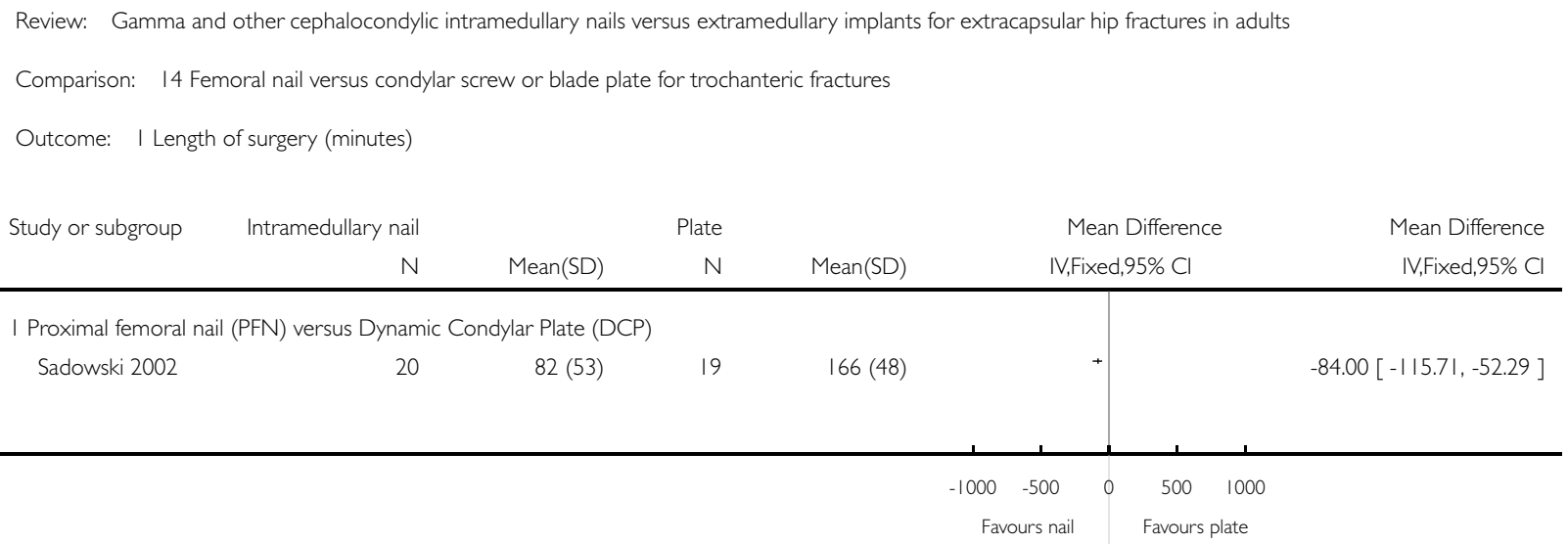

Analysis 14.2. Comparison I4 Femoral nail versus condylar screw or blade plate for trochanteric fractures, Outcome 2 Number of patients transfused.

Review: Gamma and other cephalocondylic intramedullary nails versus extramedullary implants for extracapsular hip fractures in adults

Comparison: 14 Femoral nail versus condylar screw or blade plate for trochanteric fractures

Outcome: 2 Number of patients transfused

Study or subgroup $\quad$ Intramedullary nail $\quad$ Plate Risk Ratio Ratio

$\mathrm{n} / \mathrm{N} \quad \mathrm{n} / \mathrm{N} \quad \mathrm{M}-\mathrm{H}, \mathrm{Fixed}, 95 \% \mathrm{Cl} \quad \mathrm{M}-\mathrm{H}, \mathrm{Fixed}, 95 \% \mathrm{Cl}$

I Proximal femoral nail (PFN) versus Dynamic condylar screw (DCS)

Sadowski 2002

$1 \mid / 20$

$18 / 19$

$0.58[0.39,0.88]$

Gamma and other cephalocondylic intramedullary nails versus extramedullary implants for extracapsular hip fractures in adults (Review) 197 Copyright (C) 2010 The Cochrane Collaboration. Published by John Wiley \& Sons, Ltd. 
Analysis 14.3. Comparison 14 Femoral nail versus condylar screw or blade plate for trochanteric fractures, Outcome 3 Radiographic screening time (minutes).

Review: Gamma and other cephalocondylic intramedullary nails versus extramedullary implants for extracapsular hip fractures in adults

Comparison: 14 Femoral nail versus condylar screw or blade plate for trochanteric fractures

Outcome: 3 Radiographic screening time (minutes)

Study or subgroup Intramedullary nail Plate Mean Difference

N Mean(SD) N $\quad$ Mean(SD) I,Fixed,95\% Cl IV,Fixed,95\% Cl

I Proximal femoral nail (PFN) versus Dynamic condylar screw (DCS)

Sadowski $2002 \quad 20 \quad 4.2(2.4)$

$194(1.6)$

$0.20[-1.07,1.47]$

Analysis 14.4. Comparison I4 Femoral nail versus condylar screw or blade plate for trochanteric fractures, Outcome 4 Non-union.

Review: Gamma and other cephalocondylic intramedullary nails versus extramedullary implants for extracapsular hip fractures in adults

Comparison: 14 Femoral nail versus condylar screw or blade plate for trochanteric fractures

Outcome: 4 Non-union

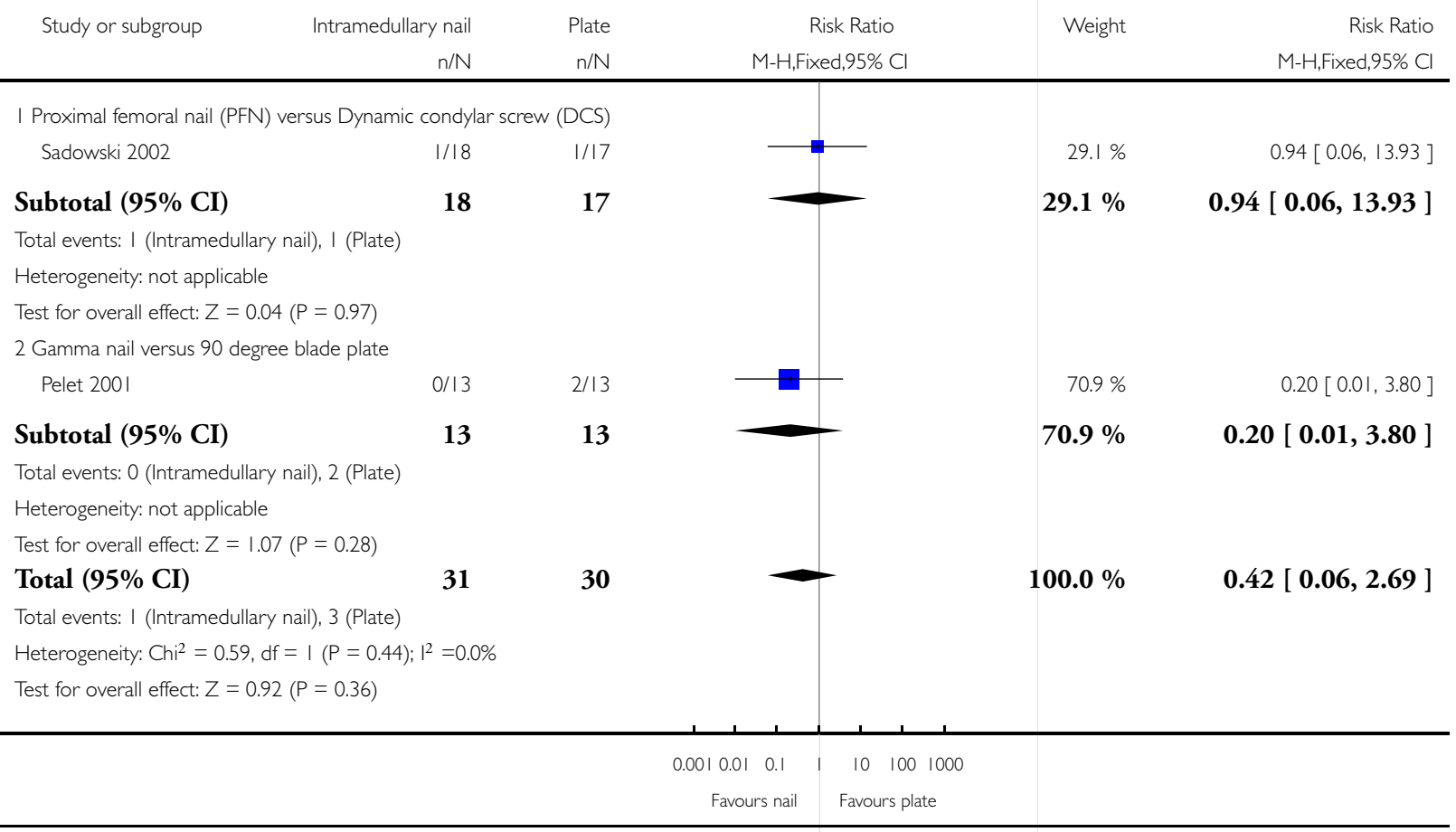

Gamma and other cephalocondylic intramedullary nails versus extramedullary implants for extracapsular hip fractures in adults (Review) 198 Copyright (C) 2010 The Cochrane Collaboration. Published by John Wiley \& Sons, Ltd. 
Analysis 14.5. Comparison I 4 Femoral nail versus condylar screw or blade plate for trochanteric fractures, Outcome 5 Operative fracture of femur.

Review: Gamma and other cephalocondylic intramedullary nails versus extramedullary implants for extracapsular hip fractures in adults

Comparison: 14 Femoral nail versus condylar screw or blade plate for trochanteric fractures

Outcome: 5 Operative fracture of femur

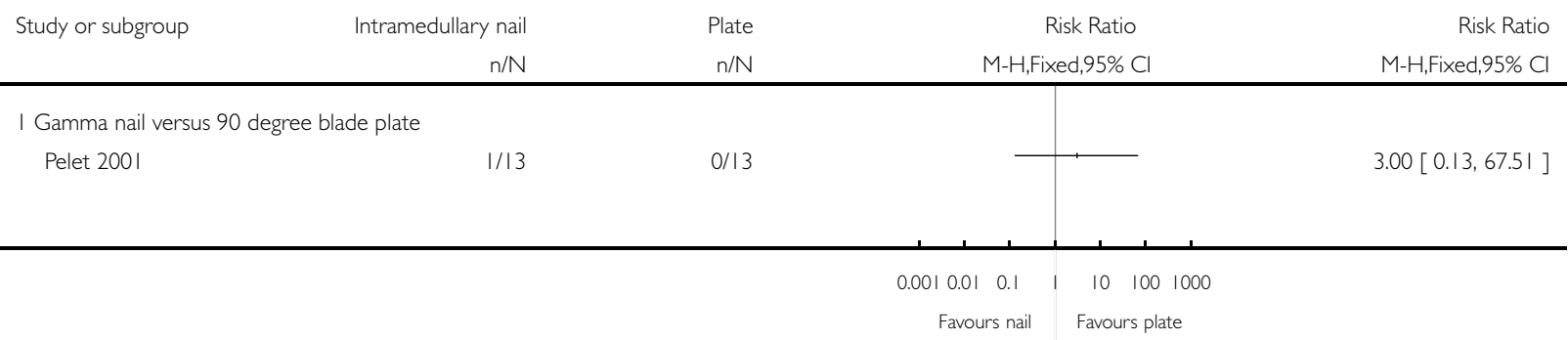

Gamma and other cephalocondylic intramedullary nails versus extramedullary implants for extracapsular hip fractures in adults (Review) 199 Copyright (@) 2010 The Cochrane Collaboration. Published by John Wiley \& Sons, Ltd. 
Analysis 14.6. Comparison 14 Femoral nail versus condylar screw or blade plate for trochanteric fractures, Outcome 6 Cut-out.

Review: Gamma and other cephalocondylic intramedullary nails versus extramedullary implants for extracapsular hip fractures in adults

Comparison: 14 Femoral nail versus condylar screw or blade plate for trochanteric fractures

Outcome: 6 Cut-out

$\begin{array}{lllll}\text { Study or subgroup } & \text { Intramedullary nail } & \text { fixation } & \text { Risk Ratio } & \text { Weight }\end{array}$

$n / \mathrm{N} \quad \mathrm{n} / \mathrm{N}-\mathrm{H}$, Fixed,95\% Cl M-H,Fixed,95\% Cl

I Proximal femoral nail (PFN) versus Dynamic condylar screw (DCS)

Sadowski $2002 \quad 0 / 20 \quad 5 / 19$

Subtotal (95\% CI)

20

19

$91.8 \%$

$0.09[0.01,1.47]$

Total events: 0 (Intramedullary nail), 5 (fixation)

Heterogeneity: not applicable

Test for overall effect: $Z=1.69(P=0.090)$

2 Gamma nail versus 90 degree blade plate Pelet 200 I

Subtotal (95\% CI)

13

13

$91.8 \%$

$0.09[0.01,1.47]$

Total events: I (Intramedullary nail), 0 (fixation)

Heterogeneity: not applicable

Test for overall effect: $Z=0.69(P=0.49)$

Total (95\% CI)

32

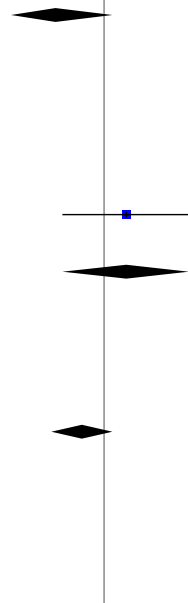

Total events: I (Intramedullary nail), 5 (fixation)

Heterogeneity: $\mathrm{Chi}^{2}=2.80, \mathrm{df}=\mathrm{I}(\mathrm{P}=0.09) ; \mathrm{I}^{2}=64 \%$

Test for overall effect: $Z=1.43(P=0.15)$

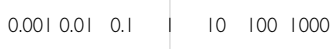

Favours nail Favours plate 
Analysis 14.7. Comparison 14 Femoral nail versus condylar screw or blade plate for trochanteric fractures, Outcome 7 Plate breakage.

Review: Gamma and other cephalocondylic intramedullary nails versus extramedullary implants for extracapsular hip fractures in adults

Comparison: 14 Femoral nail versus condylar screw or blade plate for trochanteric fractures

Outcome: 7 Plate breakage

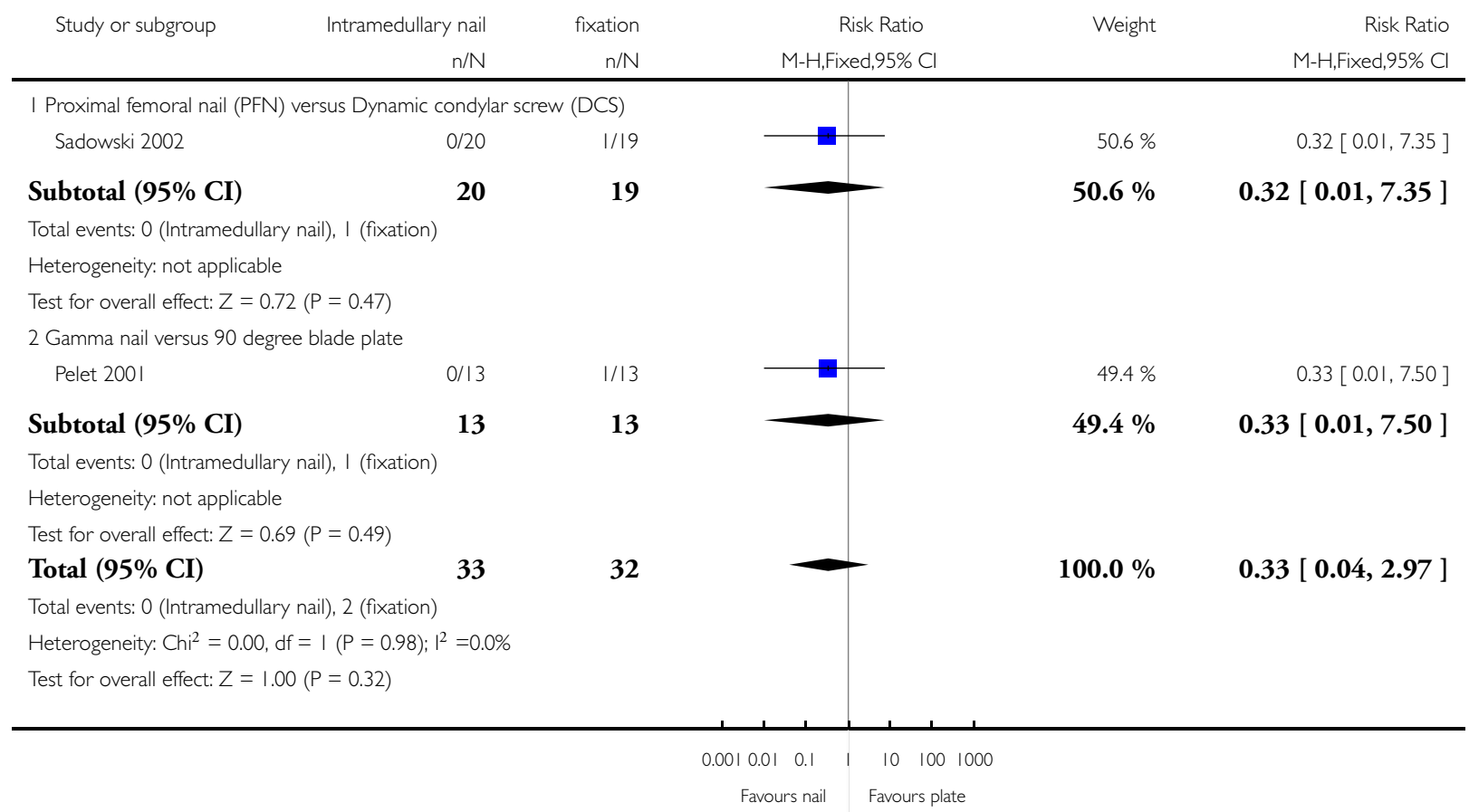

Gamma and other cephalocondylic intramedullary nails versus extramedullary implants for extracapsular hip fractures in adults (Review) 20I Copyright (c) 2010 The Cochrane Collaboration. Published by John Wiley \& Sons, Ltd. 
Analysis 14.8. Comparison 14 Femoral nail versus condylar screw or blade plate for trochanteric fractures, Outcome 8 Reoperation (major).

Review: Gamma and other cephalocondylic intramedullary nails versus extramedullary implants for extracapsular hip fractures in adults

Comparison: 14 Femoral nail versus condylar screw or blade plate for trochanteric fractures

Outcome: 8 Reoperation (major)

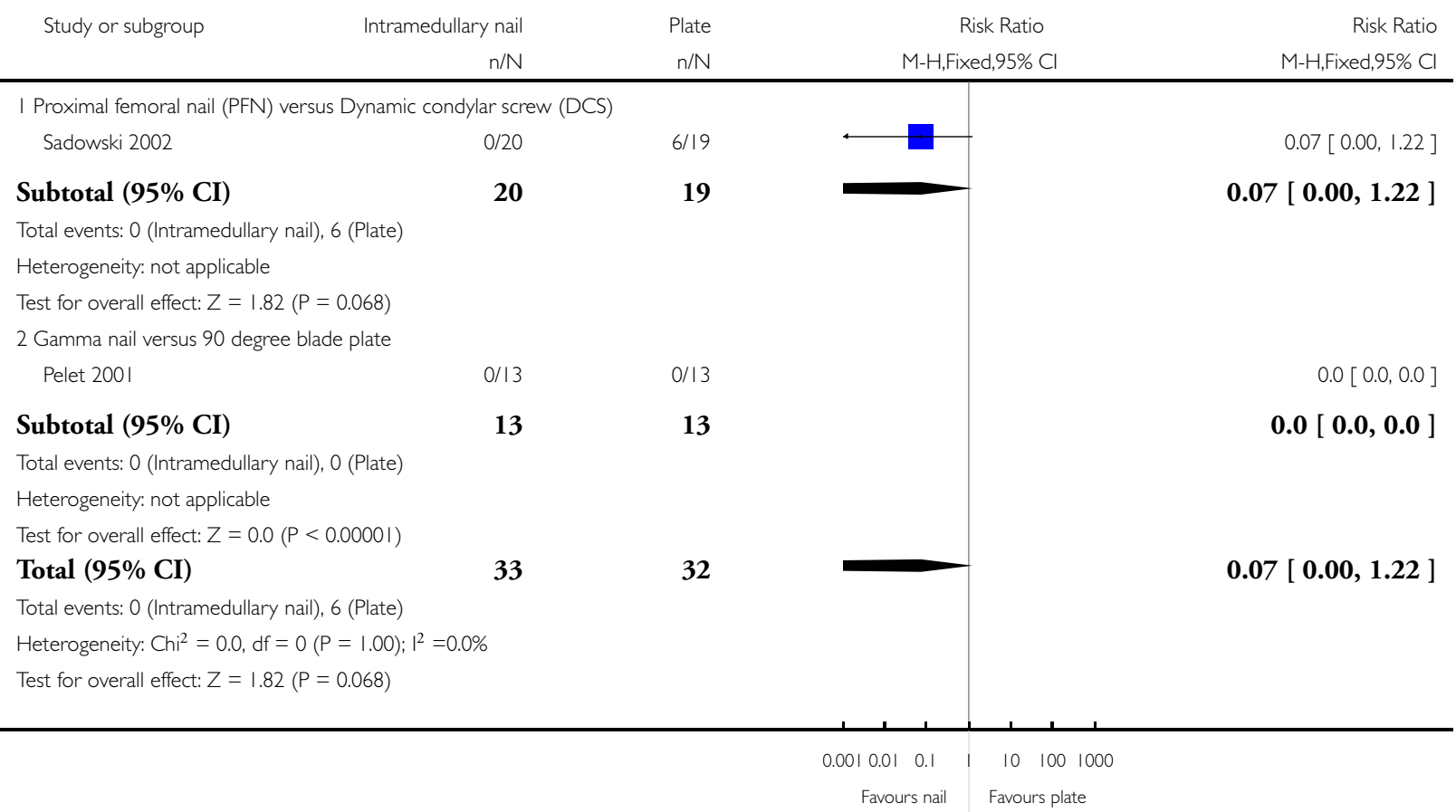

Gamma and other cephalocondylic intramedullary nails versus extramedullary implants for extracapsular hip fractures in adults (Review) 202 Copyright (C) 2010 The Cochrane Collaboration. Published by John Wiley \& Sons, Ltd. 
Analysis 14.9. Comparison 14 Femoral nail versus condylar screw or blade plate for trochanteric fractures, Outcome 9 Deep wound infection.

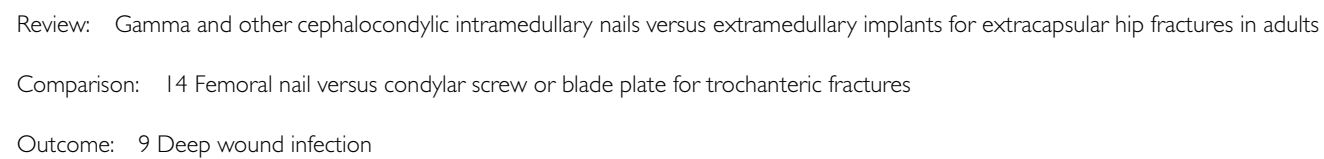

2 Gamma nail versus 90 degree blade plate

\section{Analysis 14.10. Comparison I4 Femoral nail versus condylar screw or blade plate for trochanteric fractures,} Outcome 10 Pneumonia.

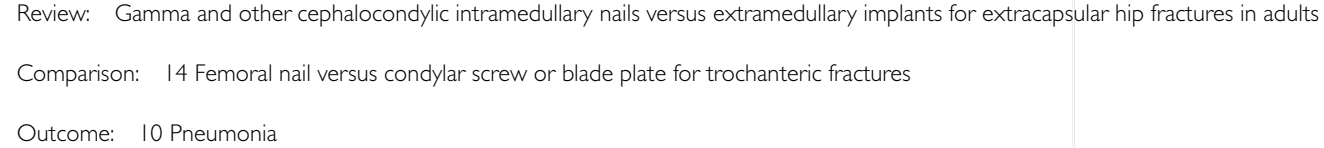


Analysis 14.II. Comparison I4 Femoral nail versus condylar screw or blade plate for trochanteric fractures, Outcome II Pressure sores.

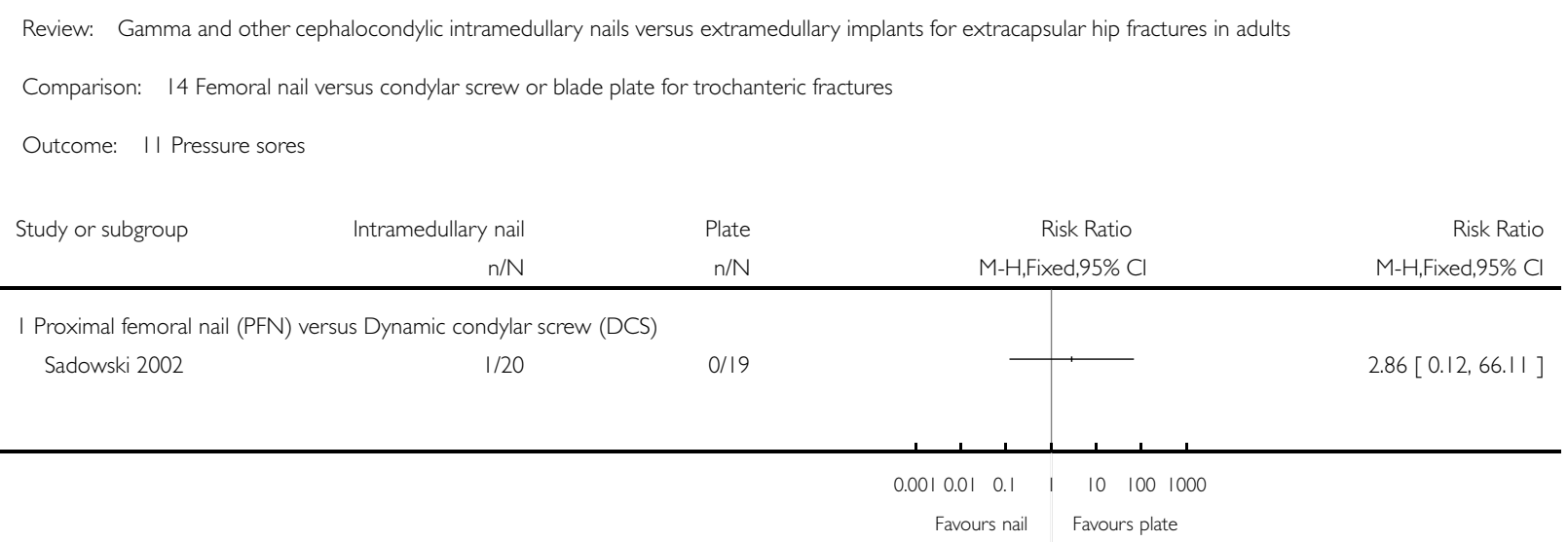

Analysis 14.12. Comparison I4 Femoral nail versus condylar screw or blade plate for trochanteric fractures, Outcome 12 Deep vein thrombosis.

Review: Gamma and other cephalocondylic intramedullary nails versus extramedullary implants for extracapsular hip fractures in adults

Comparison: 14 Femoral nail versus condylar screw or blade plate for trochanteric fractures

Outcome: 12 Deep vein thrombosis

\begin{tabular}{rrrr} 
Study or subgroup & Plate & Risk Ratio \\
$\mathrm{n} / \mathrm{N}$ & $\mathrm{n} / \mathrm{N}$ & $\mathrm{M}-\mathrm{H}$, Fixed, $95 \% \mathrm{Cl}$ & $\mathrm{M}-\mathrm{H}, \mathrm{Fixed}, 95 \% \mathrm{Cl}$ \\
\hline
\end{tabular}

I Proximal femoral nail (PFN) versus Dynamic condylar screw (DCS)

Sadowski 2002

$0 / 20$

$0 / 19$

$0.0[0.0,0.0]$

$0.0010 .01 \quad 0.1 \quad 1 \quad 10 \quad 100 \quad 1000$

Favours nail Favours plate 
Analysis 14.13. Comparison 14 Femoral nail versus condylar screw or blade plate for trochanteric fractures, Outcome 13 Pulmonary embolism.

Review: Gamma and other cephalocondylic intramedullary nails versus extramedullary implants for extracapsular hip fractures in adults

Comparison: 14 Femoral nail versus condylar screw or blade plate for trochanteric fractures

Outcome: 13 Pulmonary embolism

$\begin{array}{lll}\text { Study or subgroup } \quad \text { Intramedullary nail } & \text { Plate Risk Ratio }\end{array}$

$n / N \quad n / N \quad M-H, F i x e d, 95 \% \mathrm{Cl} \quad$ M-H,Fixed,95\% Cl

I Proximal femoral nail (PFN) versus Dynamic Condylar Plate (DCP)

Sadowski $2002 \quad 0 / 20 \quad 0 / 19$

$0.0[0.0,0.0]$

2 Gamma nail versus 90 degree blade plate

Pelet 2001

$1 / 13$

$0 / 13$

$3.00[0.13,67.51]$

$\begin{array}{llllll}0.001 & 0.01 & 0.1 \quad 1 & 10 & 100 & 1000\end{array}$

Favours nail Favours plate

Analysis 14.14. Comparison I4 Femoral nail versus condylar screw or blade plate for trochanteric fractures, Outcome 14 All medical complications.

Review: Gamma and other cephalocondylic intramedullary nails versus extramedullary implants for extracapsular hip fractures in adults

Comparison: 14 Femoral nail versus condylar screw or blade plate for trochanteric fractures

Outcome: 14 All medical complications

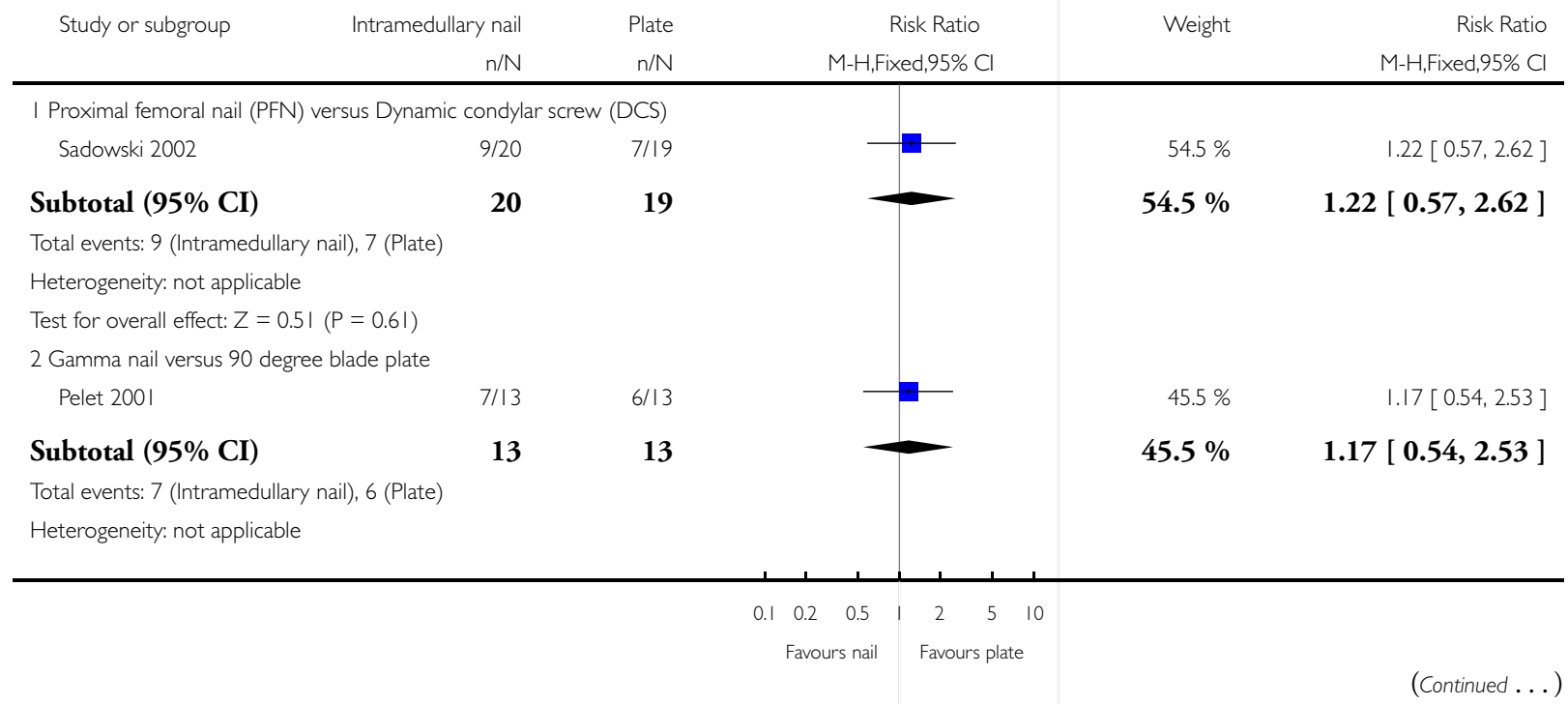

Gamma and other cephalocondylic intramedullary nails versus extramedullary implants for extracapsular hip fractures in adults (Review) 205 Copyright (C) 2010 The Cochrane Collaboration. Published by John Wiley \& Sons, Ltd. 


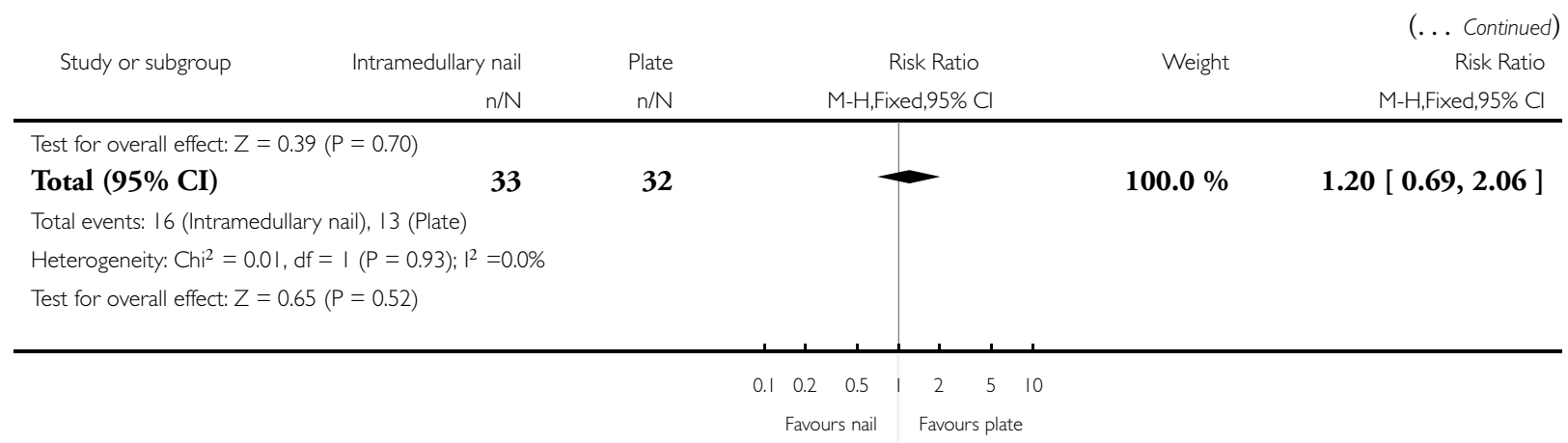

Analysis 14.15. Comparison I4 Femoral nail versus condylar screw or blade plate for trochanteric fractures, Outcome 15 Length of hospital stay (days).

Review: Gamma and other cephalocondylic intramedullary nails versus extramedullary implants for extracapsular hip fractures in adults

Comparison: 14 Femoral nail versus condylar screw or blade plate for trochanteric fractures

Outcome: 15 Length of hospital stay (days)

\begin{tabular}{rrrrr} 
Study or subgroup & Intramedullary nail & Plate & Mean Difference & Mean Difference \\
N & Mean(SD) & $N$ & Mean(SD) & IV,Fixed,95\% Cl \\
\hline
\end{tabular}

I Proximal femoral nail (PFN) versus Dynamic condylar screw (DCS)

Sadowski 2002

20

$13(4)$

19

$18(7)$ 
Analysis 14.16. Comparison I4 Femoral nail versus condylar screw or blade plate for trochanteric fractures, Outcome 16 Mortality (I year).

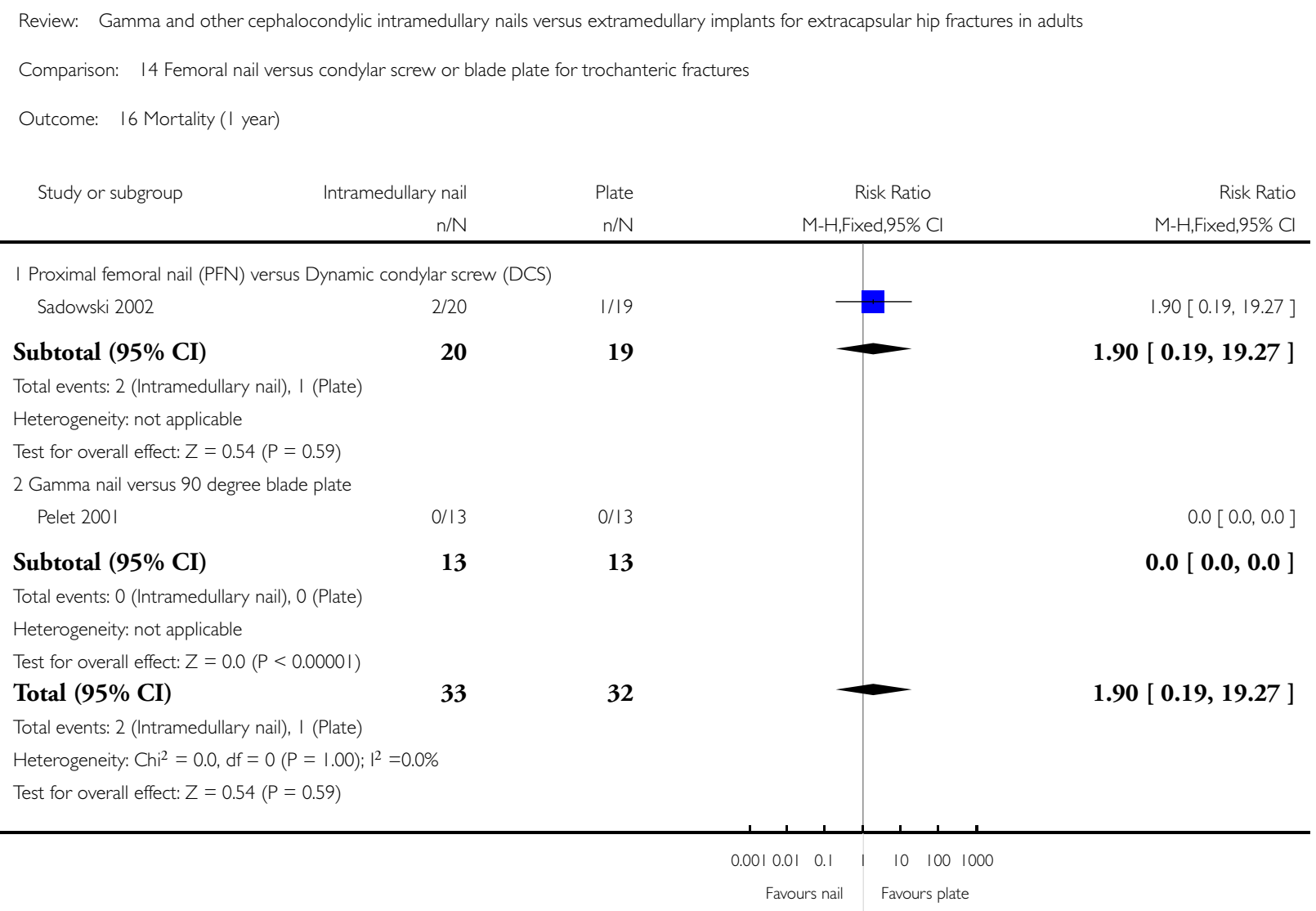

Analysis 14.17. Comparison I4 Femoral nail versus condylar screw or blade plate for trochanteric fractures, Outcome 17 Pain at follow-up.

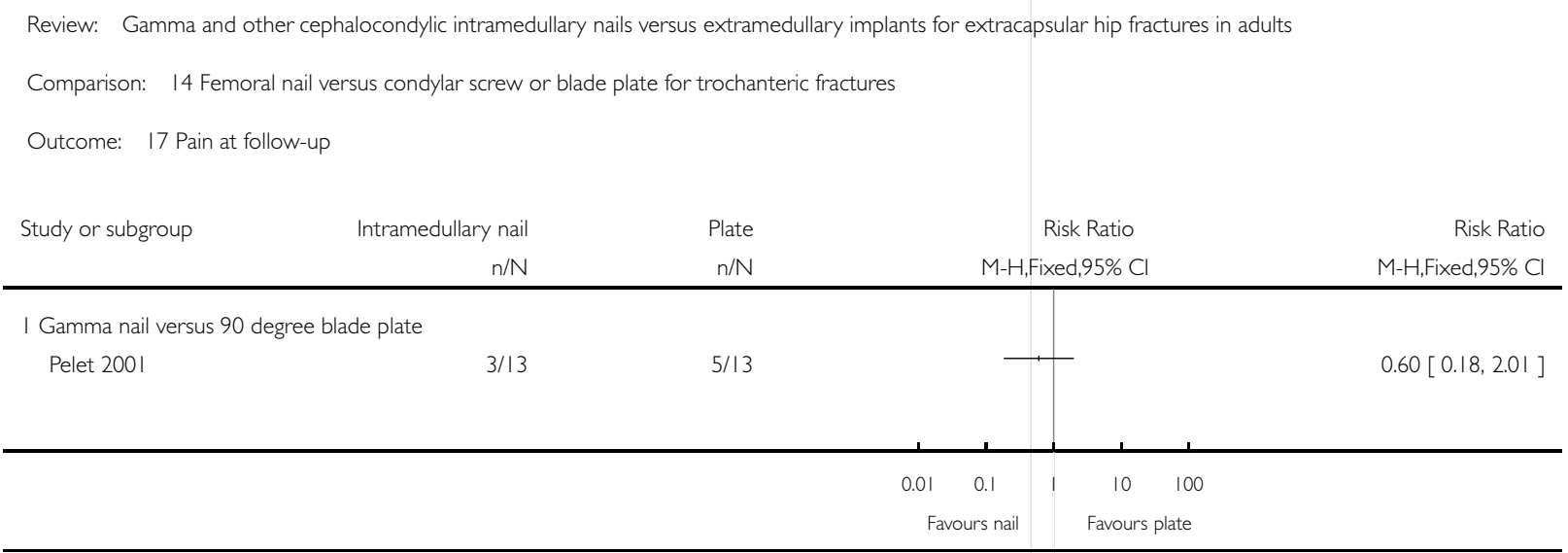

Gamma and other cephalocondylic intramedullary nails versus extramedullary implants for extracapsular hip fractures in adults (Review) 207 Copyright (C) 2010 The Cochrane Collaboration. Published by John Wiley \& Sons, Ltd. 
Analysis 14.18. Comparison I4 Femoral nail versus condylar screw or blade plate for trochanteric fractures, Outcome 18 In nursing home at one year from injury.

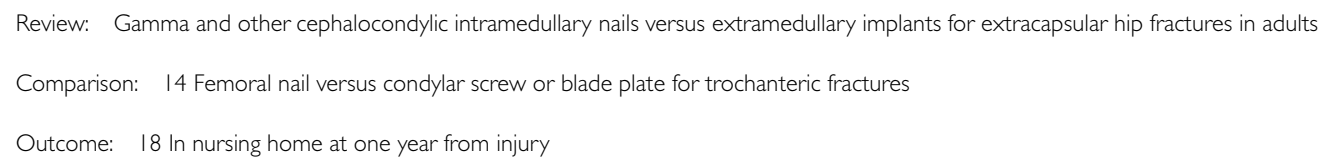

Analysis 14.19. Comparison 14 Femoral nail versus condylar screw or blade plate for trochanteric fractures, Outcome 19 In nursing home or dead at one year from injury.

Review: Gamma and other cephalocondylic intramedullary nails versus extramedullary implants for extracapsular hip fractures in adults

Comparison: 14 Femoral nail versus condylar screw or blade plate for trochanteric fractures

Outcome: 19 In nursing home or dead at one year from injury

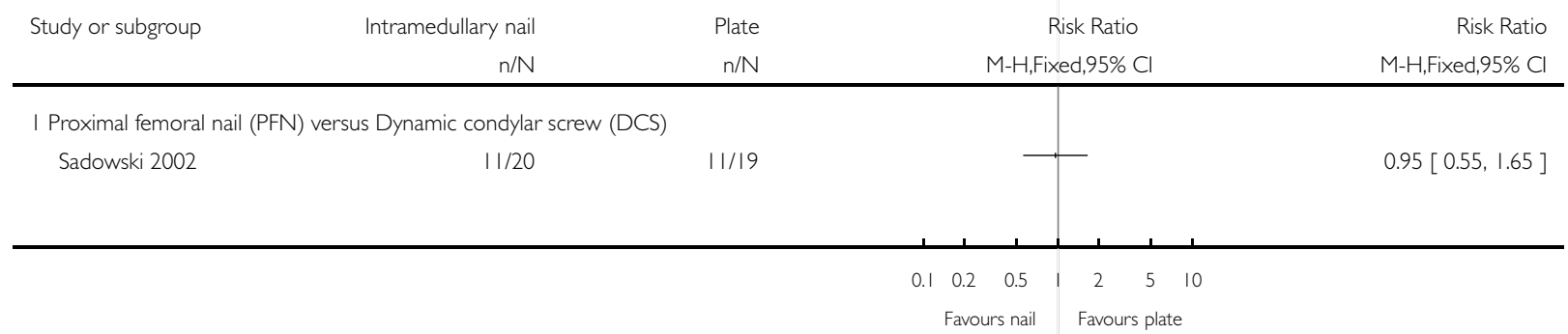


Analysis 14.20. Comparison I4 Femoral nail versus condylar screw or blade plate for trochanteric fractures, Outcome 20 Use of walking aids.

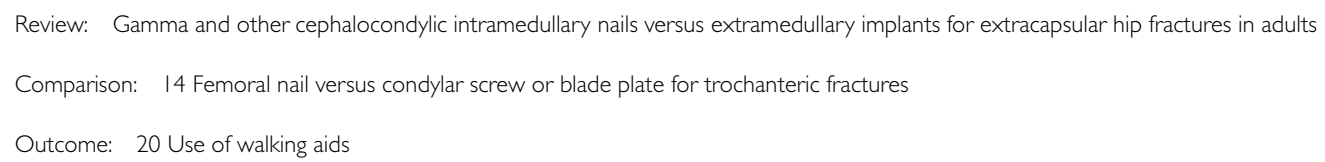

\section{Analysis 15.I. Comparison I5 Femoral nail versus condylar screw or blade plate for subtrochanteric} fractures, Outcome I Length of surgery (minutes).

Review: Gamma and other cephalocondylic intramedullary nails versus extramedullary implants for extracapsular hip fractures in adults

Comparison: 15 Femoral nail versus condylar screw or blade plate for subtrochanteric fractures

Outcome: I Length of surgery (minutes)

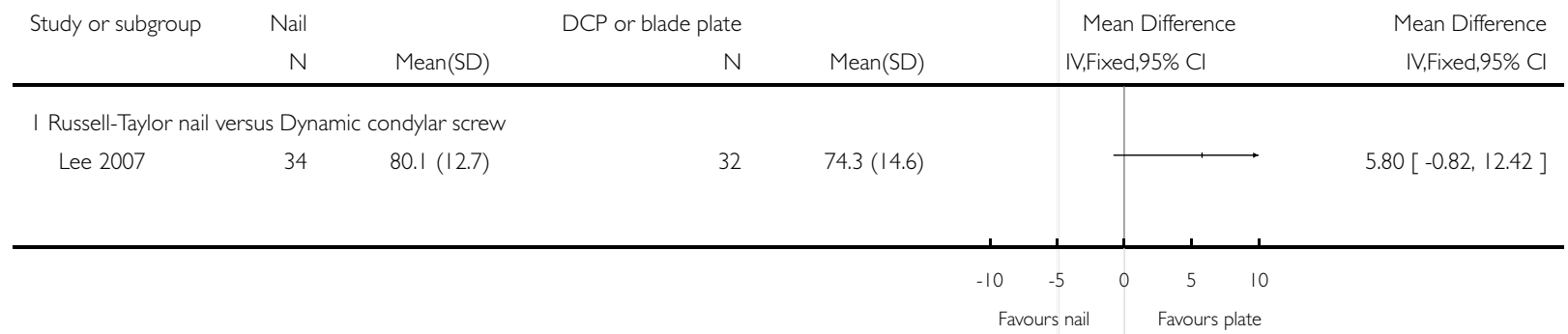




\section{Analysis I5.2. Comparison I 5 Femoral nail versus condylar screw or blade plate for subtrochanteric fractures, Outcome 2 Radiographic screening time (seconds).}

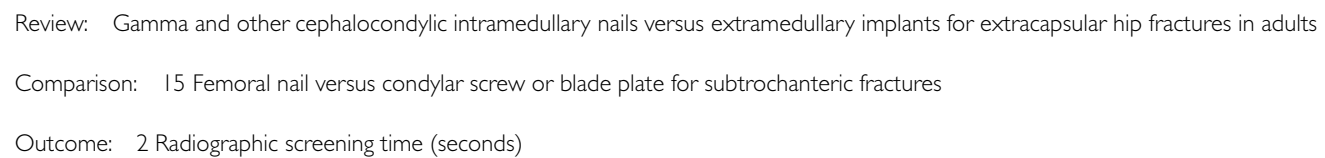

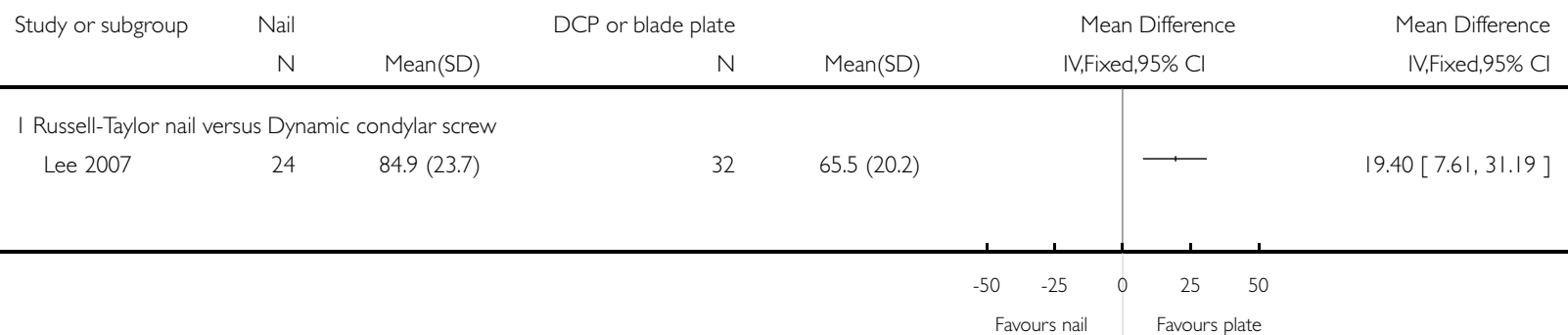

Analysis 15.3. Comparison I5 Femoral nail versus condylar screw or blade plate for subtrochanteric fractures, Outcome 3 Operative blood loss ( $\mathrm{ml})$.

Review: Gamma and other cephalocondylic intramedullary nails versus extramedullary implants for extracapsular hip fractures in adults

Comparison: 15 Femoral nail versus condylar screw or blade plate for subtrochanteric fractures

Outcome: 3 Operative blood loss $(\mathrm{ml})$

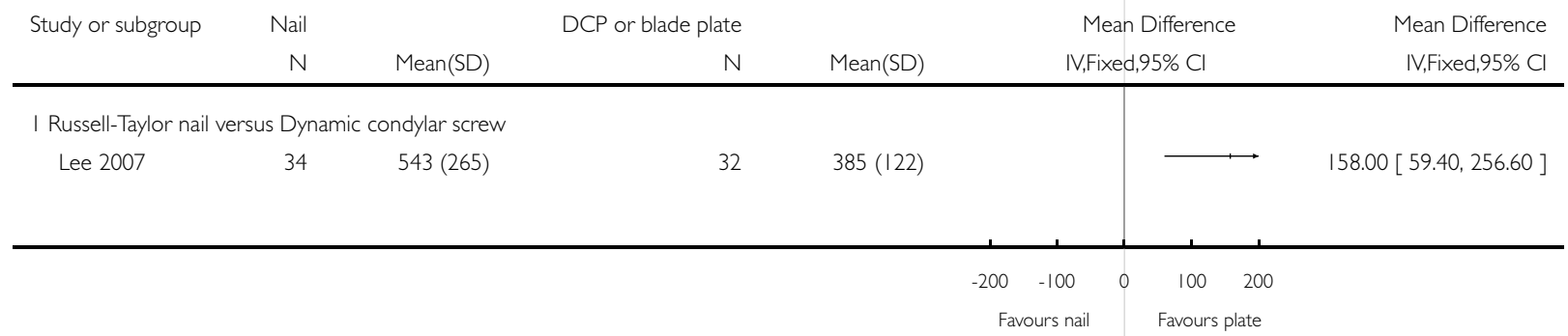


Analysis 15.4. Comparison I5 Femoral nail versus condylar screw or blade plate for subtrochanteric fractures, Outcome 4 Number of patients given transfusion.

Review: Gamma and other cephalocondylic intramedullary nails versus extramedullary implants for extracapsular hip fractures in adults

Comparison: $\quad 15$ Femoral nail versus condylar screw or blade plate for subtrochanteric fractures

Outcome: 4 Number of patients given transfusion

Study or subgroup Nail DCP or blade plate Risk Ratio Ratio

$\mathrm{n} / \mathrm{N} \quad \mathrm{n} / \mathrm{N} \quad \mathrm{M}-\mathrm{H}, \mathrm{Fixed}, 95 \% \mathrm{Cl}$
M-H,Fixed,95\% Cl

I Russell-Taylor nail versus Dynamic condylar screw

Lee 2007

20/34

$8 / 32$

$2.35[1.21,4.56]$

\section{Analysis I5.5. Comparison I5 Femoral nail versus condylar screw or blade plate for subtrochanteric} fractures, Outcome 5 Non-union.

Review: Gamma and other cephalocondylic intramedullary nails versus extramedullary implants for extracapsular hip fractures in adults

Comparison: 15 Femoral nail versus condylar screw or blade plate for subtrochanteric fractures

Outcome: 5 Non-union

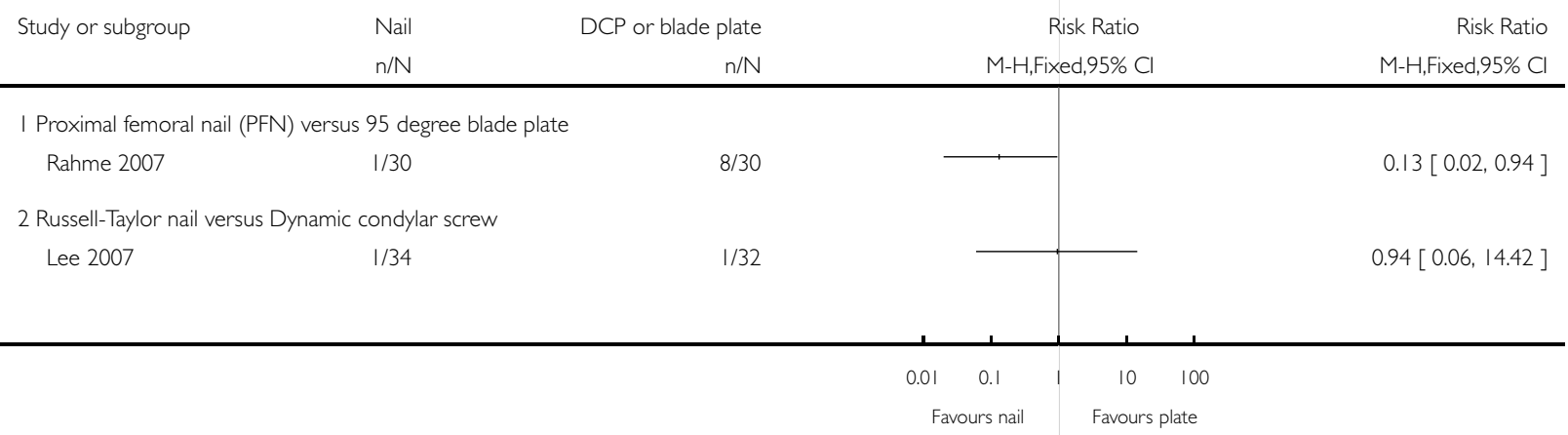

Gamma and other cephalocondylic intramedullary nails versus extramedullary implants for extracapsular hip fractures in adults (Review) 21 I Copyright (C) 2010 The Cochrane Collaboration. Published by John Wiley \& Sons, Ltd. 
Analysis 15.6. Comparison I5 Femoral nail versus condylar screw or blade plate for subtrochanteric fractures, Outcome 6 Reoperation.

Review: Gamma and other cephalocondylic intramedullary nails versus extramedullary implants for extracapsular hip fractures in adults

Comparison: 15 Femoral nail versus condylar screw or blade plate for subtrochanteric fractures

Outcome: 6 Reoperation

Study or subgroup Nail DCP or blade plate Risk Ratio Ratio

$\mathrm{n} / \mathrm{N} \quad \mathrm{n} / \mathrm{N} \quad \mathrm{M}-\mathrm{H}$, Fixed,95\% Cl M-H,Fixed,95\% Cl

I Proximal femoral nail (PFN) versus 95 degree blade plate

$0 / 30$

$8 / 30$

$0.06[0.00,0.98]$

2 Russell-Taylor nail versus Dynamic condylar screw

Lee 2007

Analysis 15.7. Comparison I5 Femoral nail versus condylar screw or blade plate for subtrochanteric fractures, Outcome 7 Any wound infection.

Review: Gamma and other cephalocondylic intramedullary nails versus extramedullary implants for extracapsular hip fractures in adults

Comparison: $\quad 15$ Femoral nail versus condylar screw or blade plate for subtrochanteric fractures

Outcome: 7 Any wound infection

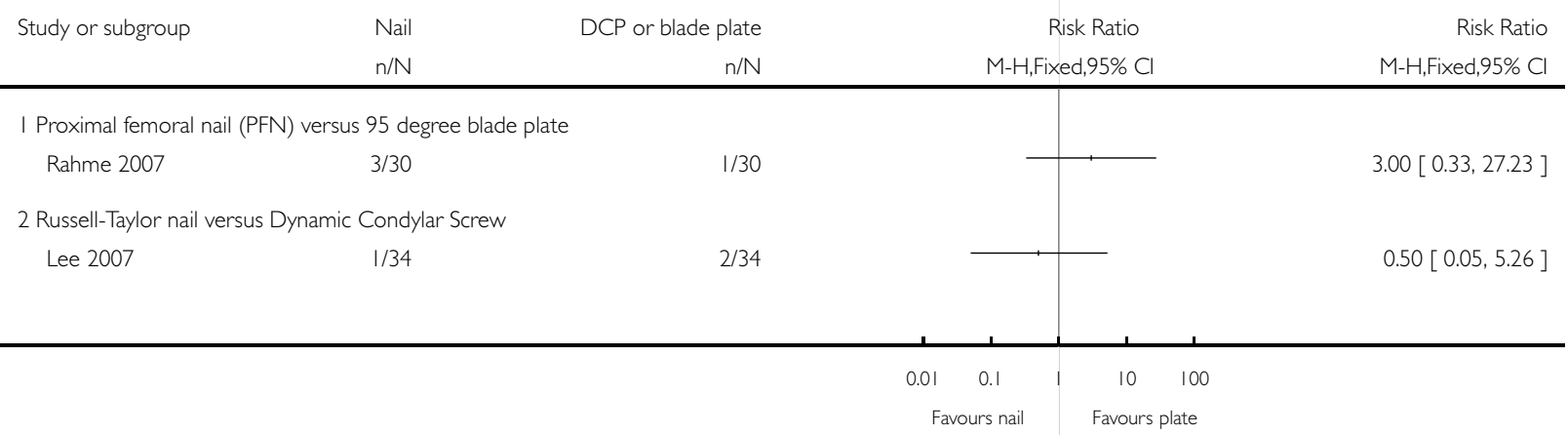

Gamma and other cephalocondylic intramedullary nails versus extramedullary implants for extracapsular hip fractures in adults (Review) 212 Copyright (C) 2010 The Cochrane Collaboration. Published by John Wiley \& Sons, Ltd. 
Analysis 15.8. Comparison I5 Femoral nail versus condylar screw or blade plate for subtrochanteric fractures, Outcome 8 Length of hospital stay (days).

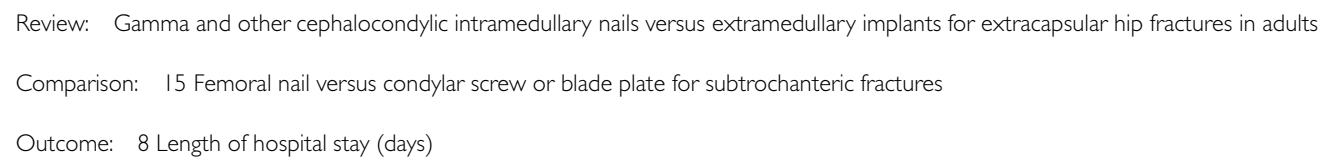

\begin{tabular}{lllll}
$\mathrm{N}$ & $\mathrm{N}$ & Mean(SD) & Mean(SD) & $\mathrm{IV}$, Fixed,95\% $95 \%$ \\
\hline
\end{tabular}

I Russell-Taylor nail versus Dynamic condylar screw

$\begin{array}{llll}\text { Lee } 2007 & 34 & 12.9(6.9) & 32\end{array}$

\begin{tabular}{l|l}
\hline \\
\hline
\end{tabular}

Analysis 15.9. Comparison I5 Femoral nail versus condylar screw or blade plate for subtrochanteric fractures, Outcome 9 Mortality.

Review: Gamma and other cephalocondylic intramedullary nails versus extramedullary implants for extracapsular hip fractures in adults

Comparison: 15 Femoral nail versus condylar screw or blade plate for subtrochanteric fractures

Outcome: 9 Mortality

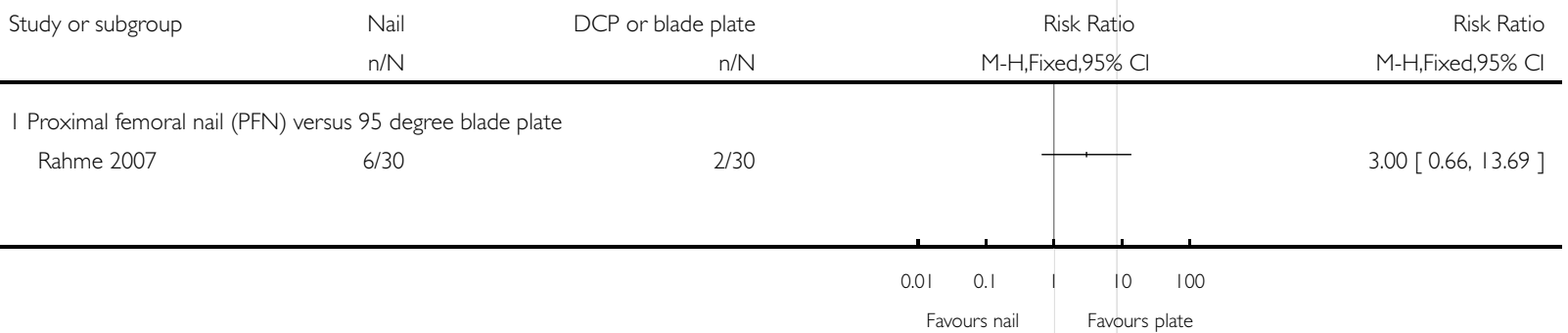


Analysis 15.10. Comparison 15 Femoral nail versus condylar screw or blade plate for subtrochanteric fractures, Outcome 10 Pain score (I: no pain to 4: worst pain).

Review: Gamma and other cephalocondylic intramedullary nails versus extramedullary implants for extracapsular hip fractures in adults

Comparison: 15 Femoral nail versus condylar screw or blade plate for subtrochanteric fractures

Outcome: 10 Pain score (I: no pain to 4: worst pain)

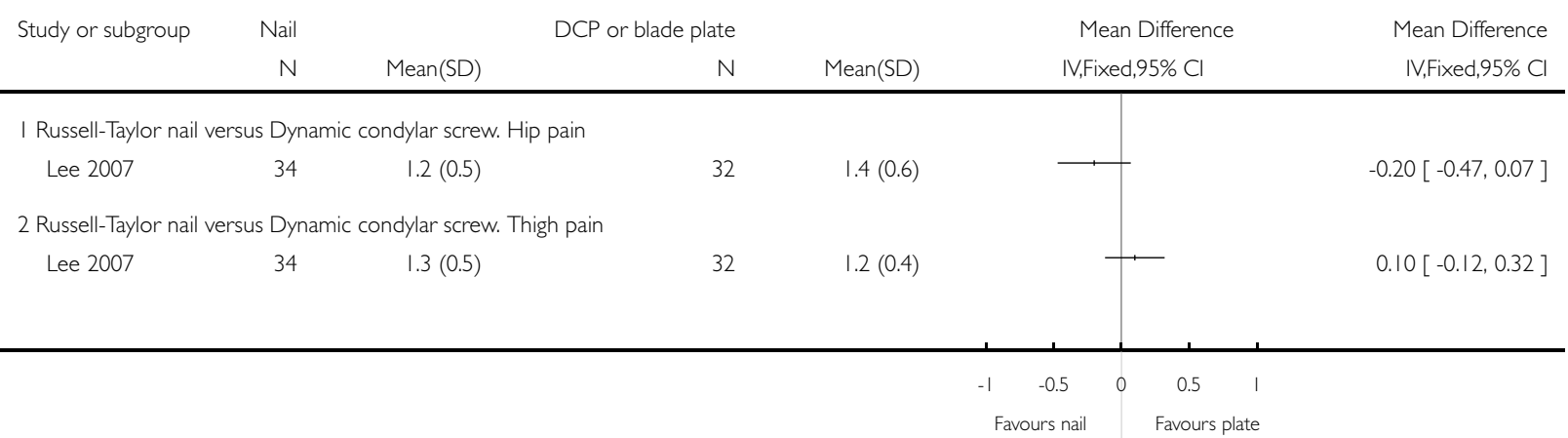

Analysis 15.I I. Comparison I5 Femoral nail versus condylar screw or blade plate for subtrochanteric fractures, Outcome I I Mobility score (0: complete disability, 9: no difficulty).

Review: Gamma and other cephalocondylic intramedullary nails versus extramedullary implants for extracapsular hip fractures in adults

Comparison: 15 Femoral nail versus condylar screw or blade plate for subtrochanteric fractures

Outcome: II Mobility score (0: complete disability, 9: no difficulty)

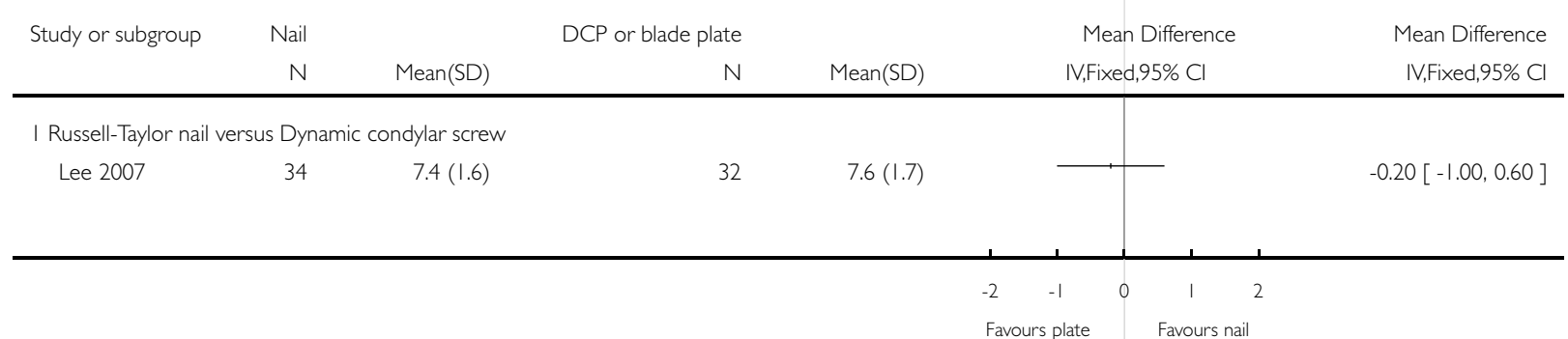

Gamma and other cephalocondylic intramedullary nails versus extramedullary implants for extracapsular hip fractures in adults (Review) 214 Copyright (C) 2010 The Cochrane Collaboration. Published by John Wiley \& Sons, Ltd. 


\section{A P P E N D I CES}

\section{Appendix I. Search strategies}

\section{The Cochrane Library (Wiley InterScience)}

\#1 MeSH descriptor Hip Fractures explode all trees (893)

\#2 ((hip* or femur* or femoral* or trochant* or pertrochant* or intertrochant* or subtrochant* or intracapsular* or extracapsular*)

NEAR fracture*):ti,ab,kw (1957)

\#3 (\#1 OR \#2) (1957)

\#4 4 (pin* or nail* or screw* or plate* or arthroplasty* or fix* or prosthes*):ti,ab,kw (30380)

\#5 MeSH descriptor Internal Fixators, this term only (98)

\#6 MeSH descriptor Bone Screws, this term only (381)

\#7 MeSH descriptor Fracture Fixation, Internal explode all trees (611)

\#8 MeSH descriptor Bone Plates, this term only (198)

\#9 MeSH descriptor Bone Nails, this term only (239)

\#10 MeSH descriptor Arthroplasty explode all trees (2083)

\#11 (\#4 OR \#5 OR \#6 OR \#7 OR \#8 OR \#9 OR \#10) (30380)

\#12 (\#3 AND \#11) (689)

\section{MEDLINE (OVID-WEB)}

1 exp Hip Fractures/ (14374)

2 ( (hip \$ or femur\$ or femoral\$ or trochant\$ or pertrochant $\$$ or intertrochant $\$$ or subtrochant $\$$ or intracapsular $\$$ or extracapsular\$) adj 4 fracture $\$$ ).tw. (20530)

3 or/1-2 (24368)

4 (pin $\$ 1$ or nail $\$$ or screw $\$ 1$ or plate $\$ 1$ or arthroplast $\$$ or fix $\$$ or prosthes $\$$ ).tw. (373702)

5 Internal Fixators/ or Bone Screws/ or Fracture Fixation, Internal/ or Bone Plates/ or Bone Nails/ (38946)

6 Arthroplasty/ Or Arthroplasty, Replacement, Hip/ (16673)

7 or/4-6 (392189)

8 and/3,7 (10200)

9 Randomized Controlled Trial.pt. (288019)

10 Controlled Clinical Trial.pt. (81031)

11 Randomized Controlled Trials/ (65860)

12 Random Allocation/ (67746)

13 Double Blind Method/ (105794)

14 Single Blind Method/ (13807)

15 or/9-14 (485594)

16 exp Animals/ not Humans/ (3456023)

1715 not $16(451438)$

18 Clinical Trial.pt. (459990)

19 exp Clinical Trials as topic/ (226174)

20 (clinic\$ adj25 trial\$).tw. (171640)

21 ((singl\$ or doubl\$ or trebl\$ or tripl\$) adj25 (blind\$ or mask\$)).tw. (105960)

22 Placebos/ (28689)

23 placebo \$.tw. (122017)

24 random\$.tw. (476309)

25 Research Design/ (58709)

26 or/18-25 (1023571)

2726 not 16 (947728)

2827 not 17 (527927)

29 Comparative Study.pt. (1474572)

Gamma and other cephalocondylic intramedullary nails versus extramedullary implants for extracapsular hip fractures in adults (Review) 215 Copyright @ 2010 The Cochrane Collaboration. Published by John Wiley \& Sons, Ltd. 
30 Evaluation Studies.pt. (131579)

31 Follow Up Studies/ (401470)

32 Prospective Studies/ (276848)

33 (control\$ or prospectiv\$ or volunteer\$).tw. (2176203)

34 or/29-33 (3719846)

3534 not 16 (2854342)

3635 not (17 or 28$)$ (2332392)

3717 or 28 or 36 (3311757)

38 and/8,37 (3989)

\section{EMBASE (OVID-WEB)}

1 exp Hip Fracture/ (13988)

2 ( (hip \$ or femur \$ or femoral\$ or trochant $\$$ or pertrochant $\$$ or intertrochant $\$$ or subtrochant $\$$ or intracapsular $\$$ or extracapsular\$) adj4 fracture\$).tw. (16123)

3 or/1-2 (20930)

4 (pin $\$ 1$ or nail $\$$ or screw $\$ 1$ or plate $\$ 1$ or arthroplast $\$$ or fix $\$$ or prosthes $\$$ ).tw. (289999)

5 Bone Screws/ or Fracture Fixation/ or Bone Plate/ or Bone Nail/ or Intramedullary Nailing/ (21965)

6 Arthroplasty/ or Hip Arthroplasty/ (11271)

7 or/4-6 (297747)

8 and/3,7 (7706)

9 exp Randomized Controlled Trial/ (184888)

10 exp Double Blind Procedure/ (77062)

11 exp Single Blind Procedure/ (9242)

12 exp Crossover Procedure/ (22728)

13 Controlled Study/ (3133549)

14 or/9-13 (3153381)

15 ((clinical or controlled or comparative or placebo or prospective\$ or randomi\#ed) adj3 (trial or study)).tw. (369503)

16 (random\$ adj7 (allocat\$ or allot\$ or assign\$ or basis\$ or divid\$ or order\$)).tw. (89643)

17 ((singl\$ or doubl\$ or trebl\$ or tripl\$) adj7 (blind\$ or mask\$)).tw. (100047)

18 (cross?over $\$$ or (cross adj1 over\$)).tw. (42042)

19 ( $($ allocat $\$$ or allot $\$$ or assign $\$$ or divid $\$$ ) adj3 (condition $\$$ or experiment $\$$ or intervention $\$$ or treatment $\$$ or therap $\$$ or control\$ or group\$)).tw. (100779)

20 or/15-19 (549553)

21 or/14,20 (3365913)

22 limit 21 to human (2014087)

23 and/8,22 (1856)

\section{Appendix 2. Searches prior to 2000}

Search activity

Electronic searching of MEDLINE up to August 1999 with the following search terms: (Gamma and nail) and (screw and (dynamic or compression or Ambi)).

Handsearches of the following journals from 1990 when the first reports of the use of the Gamma nail were published: Journal of Bone and Joint Surgery - American Volume, Journal of Bone and Joint Surgery - British Volume, Acta Orthopaedica Scandinavica, Journal of Trauma, Injury, Clinical Orthopaedics, Orthopaedic Clinics of North America, International Orthopaedics, and Journal of Royal College of Surgeons (Edinburgh).

Gamma and other cephalocondylic intramedullary nails versus extramedullary implants for extracapsular hip fractures in adults (Review) 216 Copyright $\odot 2010$ The Cochrane Collaboration. Published by John Wiley \& Sons, Ltd. 
Handsearching of conference abstracts from 1990 reported within the Journal of Bone and Joint Surgery - American Volume, Journal of Bone and Joint Surgery - British Volume, Acta Orthopaedica Scandinavica Supplementum, and Injury.

\section{Appendix 3. Methodological quality assessment results (see Table 2 for criteria)}

\begin{tabular}{|c|c|c|c|c|c|c|c|c|c|c|c|}
\hline \multicolumn{12}{|c|}{ Gamma nail versus sliding hip screw } \\
\hline $\begin{array}{l}\text { Study } \\
\text { ID }\end{array}$ & Item 1 & Item 2 & Item 3 & Item 4 & Item 5 & Item 6 & Item 7 & Item 8 & Item 9 & Item 10 & Item 11 \\
\hline $\begin{array}{l}\text { Adams } \\
2001\end{array}$ & 3 & 1 & 1 & 1 & 1 & 1 & 1 & 1 & 1 & 1 & 1 \\
\hline $\begin{array}{l}\text { Ahren- } \\
\text { gart } \\
1994\end{array}$ & 2 & 1 & 0 & 1 & 1 & 0 & 0 & 0 & 1 & 0 & 1 \\
\hline $\begin{array}{l}\text { Benum } \\
1994\end{array}$ & 1 & 0 & 0 & 1 & 0 & 0 & 0 & 0 & 1 & 0 & 0 \\
\hline $\begin{array}{l}\text { Bridle } \\
1991\end{array}$ & 1 & 1 & 0 & 1 & 1 & 0 & 0 & 0 & 1 & 0 & 0 \\
\hline $\begin{array}{l}\text { Butt } \\
1995\end{array}$ & 0 & 1 & 0 & 1 & 0 & 0 & 0 & 0 & 0 & 1 & 0 \\
\hline $\begin{array}{l}\text { Goldha- } \\
\text { gen } \\
1994\end{array}$ & 0 & 1 & 0 & 1 & 0 & 0 & 1 & 0 & 1 & 1 & 0 \\
\hline $\begin{array}{l}\text { Guyer } \\
1991\end{array}$ & 0 & 0 & 0 & 0 & 0 & 1 & 0 & 0 & 0 & 0 & 0 \\
\hline $\begin{array}{l}\text { Haynes } \\
1996\end{array}$ & 0 & 1 & 0 & 1 & 0 & 0 & 0 & 0 & 1 & 1 & 0 \\
\hline $\begin{array}{l}\text { Hoff- } \\
\text { man } \\
1996\end{array}$ & 3 & 1 & 1 & 1 & 0 & 1 & 1 & 1 & 1 & 1 & 1 \\
\hline $\begin{array}{l}\text { Kukla } \\
1997\end{array}$ & 2 & 1 & 1 & 1 & 1 & 0 & 1 & 0 & 1 & 1 & 1 \\
\hline
\end{tabular}




\begin{tabular}{|c|c|c|c|c|c|c|c|c|c|c|c|}
\hline $\begin{array}{l}\text { Kuwabara } \\
1998\end{array}$ & 1 & 0 & 0 & 1 & 0 & 0 & 0 & 0 & 1 & 0 & 0 \\
\hline $\begin{array}{l}\text { Leung } \\
1992\end{array}$ & 0 & 0 & 0 & 0 & 0 & 0 & 0 & 0 & 1 & 1 & 1 \\
\hline $\begin{array}{l}\text { Marques } \\
\text { Lopez } \\
2002\end{array}$ & 0 & 1 & 0 & 1 & 0 & 0 & 0 & 0 & 1 & 0 & 0 \\
\hline $\begin{array}{l}\text { Michos } \\
2001\end{array}$ & 1 & 0 & 0 & 0 & 0 & 0 & 0 & 0 & 0 & 0 & 0 \\
\hline $\begin{array}{l}\text { Mott } \\
1993\end{array}$ & 2 & 1 & 0 & 0 & 0 & 0 & 1 & 0 & 0 & 0 & 1 \\
\hline $\begin{array}{l}\text { O'Brien } \\
1995\end{array}$ & 3 & 1 & 0 & 1 & 0 & 0 & 1 & 0 & 0 & 0 & 1 \\
\hline $\begin{array}{l}\text { Ovesen } \\
2006\end{array}$ & 3 & 1 & 1 & 1 & 0 & 1 & 0 & 0 & 1 & 0 & 1 \\
\hline $\begin{array}{l}\text { Pahlpatz } \\
1993\end{array}$ & 1 & 0 & 0 & 0 & 0 & 0 & 0 & 0 & 1 & 0 & 0 \\
\hline $\begin{array}{l}\text { Papasi- } \\
\text { mos } \\
2005\end{array}$ & 1 & 1 & 0 & 1 & 0 & 1 & 0 & 0 & 1 & 0 & 0 \\
\hline $\begin{array}{l}\text { Park } \\
1998\end{array}$ & 0 & 1 & 1 & 1 & 0 & 0 & 1 & 0 & 0 & 1 & 0 \\
\hline $\begin{array}{l}\text { Radford } \\
1993\end{array}$ & 1 & 0 & 0 & 1 & 1 & 0 & 0 & 0 & 1 & 0 & 0 \\
\hline $\begin{array}{l}\text { Utrilla } \\
2005\end{array}$ & 2 & 1 & 1 & 0 & 1 & 1 & 1 & 0 & 1 & 1 & 0 \\
\hline
\end{tabular}

\section{Intramedullary hip screw (IMHS) versus sliding hip screw}

\section{$\begin{array}{llllllllllll}\text { Study } & \text { Item } 1 & \text { Item } 2 & \text { Item } 3 & \text { Item } 4 & \text { Item } 5 & \text { Item } 6 & \text { Item } 7 & \text { Item } 8 & \text { Item } 9 & \text { Item } 10 & \text { Item } 11\end{array}$} ID

\begin{tabular}{l|l|l|l|l|l|l|l|l|l|l}
\hline $\begin{array}{l}\text { Baum- } \\
\text { gaertner } \\
1998\end{array}$ & 3 & 1 & 0 & 0 & 0 & 1 & 1 & 0 & 1 & 1 \\
\hline $\begin{array}{l}\text { Hardy } \\
1998\end{array}$ & 0 & 1 & 1 & 1 & 0 & 1 & 1 & 1 & 1 & 0 \\
\hline
\end{tabular}

Gamma and other cephalocondylic intramedullary nails versus extramedullary implants for extracapsular hip fractures in adults (Review) 218 Copyright (C) 2010 The Cochrane Collaboration. Published by John Wiley \& Sons, Ltd. 


\begin{tabular}{l|l|l|l|l|l|l|l|l|l|l|l|}
\hline $\begin{array}{l}\text { Har- } \\
\text { rington } \\
2002\end{array}$ & 2 & 1 & 0 & 1 & 0 & 1 & 1 & 1 & 1 & 1 & 1 \\
\hline $\begin{array}{l}\text { Hoff- } \\
\text { mann } \\
1999\end{array}$ & 3 & 1 & 1 & 1 & 0 & 1 & 1 & 0 & 0 & 1 & 0 \\
\hline $\begin{array}{l}\text { Mehdi } \\
2000\end{array}$ & 2 & 0 & 0 & 0 & 0 & 0 & 0 & 0 & 1 & 0 & 1 \\
\hline
\end{tabular}

Proximal femoral nail (PFN) versus sliding hip screw

\begin{tabular}{l|l|l|l|l|l|l|l|l|l|l|l}
\hline $\begin{array}{l}\text { Study } \\
\text { ID }\end{array}$ & Item 1 & Item 2 & Item 3 & Item 4 & Item 5 & Item 6 & Item 7 & Item 8 & Item 9 & Item 10 & Item 11 \\
\hline $\begin{array}{l}\text { Pajari- } \\
\text { nen } \\
2005\end{array}$ & 3 & 1 & 1 & 1 & 1 & 1 & 1 & 0 & 0 & 0 & 1 \\
\hline $\begin{array}{l}\text { Papasi- } \\
\text { mos } \\
2005\end{array}$ & 1 & 1 & 0 & 1 & 0 & 1 & 0 & 0 & 1 & 0 & 0 \\
\hline $\begin{array}{l}\text { Saudan } \\
2002\end{array}$ & 2 & 1 & 1 & 1 & 1 & 1 & 1 & 0 & 1 & 1 & 1 \\
\hline
\end{tabular}

Proximal femoral nail antirotation (PFNA) versus sliding hip screw

\begin{tabular}{lllllllllllllll}
\hline $\begin{array}{l}\text { Study } \\
\text { ID }\end{array}$ & Item 1 & Item 2 & Item 3 & Item 4 & Item 5 & Item 6 & Item 7 & Item 8 & Item 9 & Item 10 & Item 11 \\
\hline $\begin{array}{l}\text { Zou } \\
2009\end{array}$ & 1 & 1 & 0 & 0 & 0 & 1 & 1 & 0 & 1 & 0 & 0 \\
\hline
\end{tabular}

Targon PF (proximal femoral) nail versus sliding hip screw

\begin{tabular}{|c|c|c|c|c|c|c|c|c|c|c|c|}
\hline $\begin{array}{l}\text { Study } \\
\text { ID }\end{array}$ & Item 1 & Item 2 & Item 3 & Item 4 & Item 5 & Item 6 & Item 7 & Item 8 & Item 9 & Item 10 & Item 11 \\
\hline $\begin{array}{l}\text { Giraud } \\
2005\end{array}$ & 2 & 1 & 1 & 1 & 0 & 0 & 1 & 0 & 0 & 0 & 1 \\
\hline
\end{tabular}

Long Holland nail versus sliding hip screw

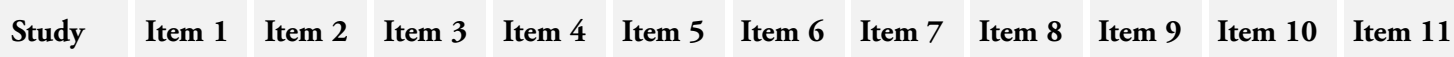
ID

Gamma and other cephalocondylic intramedullary nails versus extramedullary implants for extracapsular hip fractures in adults (Review) 219 Copyright (C) 2010 The Cochrane Collaboration. Published by John Wiley \& Sons, Ltd. 


\begin{tabular}{l|l|l|l|l|l|l|l|l|l|l|l|l}
\hline $\begin{array}{l}\text { Little } \\
2008\end{array}$ & 2 & 1 & 1 & 1 & 0 & 1 & 1 & 0 & 1 & 1 & 0 \\
\hline
\end{tabular}

\section{Long Gamma nail versus sliding hip screw}

\begin{tabular}{l|l|l|l|l|l|l|l|l|l|l|l}
\hline $\begin{array}{l}\text { Study } \\
\text { ID }\end{array}$ & Item 1 & Item 2 & Item 3 & Item 4 & Item 5 & Item 6 & Item 7 & Item 8 & Item 9 & Item 10 & Item 11 \\
\hline $\begin{array}{l}\text { Barton } \\
2010\end{array}$ & 2 & 1 & 0 & 1 & 1 & 1 & 1 & 0 & 1 & 0 & 1 \\
\hline
\end{tabular}

Mini-invasive static intramedullary nail versus sliding hip screw

\begin{tabular}{l|l|l|l|l|l|l|l|l|l|l|l}
\hline $\begin{array}{l}\text { Study } \\
\text { ID }\end{array}$ & Item 1 & Item 2 & Item 3 & Item 4 & Item 5 & Item 6 & Item 7 & Item 8 & Item 9 & Item 10 & Item 11 \\
\hline $\begin{array}{l}\text { Du- } \\
\text { jardin } \\
2001\end{array}$ & 1 & 1 & 0 & 1 & 1 & 1 & 1 & 0 & 1 & 0 & 0 \\
\hline
\end{tabular}

Kuntscher-Y nail versus sliding hip screw

\begin{tabular}{|c|c|c|c|c|c|c|c|c|c|c|c|}
\hline $\begin{array}{l}\text { Study } \\
\text { ID }\end{array}$ & Item 1 & Item 2 & Item 3 & Item 4 & Item 5 & Item 6 & Item 7 & Item 8 & Item 9 & Item 10 & Item 11 \\
\hline $\begin{array}{l}\text { Davis } \\
1988\end{array}$ & 3 & 1 & 0 & 1 & 0 & 0 & 1 & 0 & 0 & 1 & 1 \\
\hline
\end{tabular}

Intramedullary nail (two types) versus the SHS

\begin{tabular}{|c|c|c|c|c|c|c|c|c|c|c|c|}
\hline $\begin{array}{l}\text { Study } \\
\text { ID }\end{array}$ & Item 1 & Item 2 & Item 3 & Item 4 & Item 5 & Item 6 & Item 7 & Item 8 & Item 9 & Item 10 & Item 11 \\
\hline $\begin{array}{l}\text { Verettas } \\
2010\end{array}$ & 0 & 1 & 0 & 1 & 0 & 1 & 1 & 0 & 0 & 1 & 1 \\
\hline
\end{tabular}

\begin{tabular}{|c|c|c|c|c|c|c|c|c|c|c|c|}
\hline $\begin{array}{l}\text { Study } \\
\text { ID }\end{array}$ & Item 1 & Item 2 & Item 3 & Item 4 & Item 5 & Item 6 & Item 7 & Item 8 & Item 9 & Item 10 & Item 11 \\
\hline $\begin{array}{l}\text { Ekstrom } \\
2007\end{array}$ & 2 & 1 & 0 & 1 & 0 & 1 & 1 & 0 & 1 & 0 & 0 \\
\hline $\begin{array}{l}\text { Miedel } \\
2005\end{array}$ & 2 & 1 & 1 & 1 & 0 & 1 & 1 & 0 & 1 & 1 & 0 \\
\hline
\end{tabular}

Gamma nail versus the percutaneous compression plate (PCCP)

Gamma and other cephalocondylic intramedullary nails versus extramedullary implants for extracapsular hip fractures in adults (Review) 220 Copyright (@) 2010 The Cochrane Collaboration. Published by John Wiley \& Sons, Ltd. 


\begin{tabular}{l|l|l|l|l|l|l|l|l|l|l|l}
\hline $\begin{array}{l}\text { Study } \\
\text { ID }\end{array}$ & Item 1 & Item 2 & Item 3 & Item 4 & Item 5 & Item 6 & Item 7 & Item 8 & Item 9 & Item 10 & Item 11 \\
\hline $\begin{array}{l}\text { Varela- } \\
\text { Egocheaga } \\
2009\end{array}$ & 1 & 0 & 1 & 1 & 1 & 1 & 0 & 1 & 1 & 0 \\
\hline
\end{tabular}

Intramedullary nails versus fixed (static) extramedullary plates for trochanteric fractures

\begin{tabular}{llllllllllllllll}
\hline $\begin{array}{l}\text { Study } \\
\text { ID }\end{array}$ & Item 1 & Item 2 & Item 3 & Item 4 & Item 5 & Item 6 & Item 7 & Item 8 & Item 9 & Item 10 & Item 11 \\
\hline $\begin{array}{l}\text { Pelet } \\
2001\end{array}$ & 2 & 1 & 1 & 1 & 0 & 1 & 1 & 0 & 1 & 1 & 1 \\
\hline $\begin{array}{l}\text { Sad- } \\
\text { owski } \\
2002\end{array}$ & 2 & 1 & 1 & 1 & 1 & 1 & 1 & 0 & 1 & 1 & 1 \\
\hline
\end{tabular}

Intramedullary nails versus fixed (static) extramedullary plates for subtrochanteric fractures

\begin{tabular}{lllllllllllllll}
\hline $\begin{array}{l}\text { Study } \\
\text { ID }\end{array}$ & Item 1 & Item 2 & Item 3 & Item 4 & Item 5 & Item 6 & Item 7 & Item 8 & Item 9 & Item 10 & Item 11 \\
\hline $\begin{array}{l}\text { Lee } \\
2007\end{array}$ & 0 & 1 & 0 & 0 & 1 & 1 & 1 & 0 & 1 & 0 & 0 \\
\hline $\begin{array}{l}\text { Rahme } \\
2007\end{array}$ & 1 & 1 & 0 & 1 & 0 & 0 & 1 & 0 & 1 & 0 & 0 \\
\hline
\end{tabular}

\section{WHAT'S NEW}

Last assessed as up-to-date: 7 July 2010.

\begin{tabular}{l|l|l}
\hline Date & Event & Description \\
\hline 3 August 2010 & New search has been performed & $\begin{array}{l}\text { For the seventh substantive update, which first appeared in } \\
\text { Issue } 9,2010, \text { the main changes were as follows. } \\
1 . \text { The search for trials was updated to April } 2010 .\end{array}$ \\
& $\begin{array}{l}\text { 2. Risk of bias was assessed for sequence generation, allo- } \\
\text { cation concealment and surgeons' experience with the de- } \\
\text { vices. } \\
\text { 3. There were seven newly included trials (Barton 2010; Lee } \\
\text { 2007; Little 2008; Rahme 2007; Vareal-Egocheaga 2009; } \\
\text { Verettas 2010; Zou 2009). Little 2008 was formerly Fer- }\end{array}$ \\
\end{tabular}

Gamma and other cephalocondylic intramedullary nails versus extramedullary implants for extracapsular hip fractures in adults (Review) 221 Copyright $(2010$ The Cochrane Collaboration. Published by John Wiley \& Sons, Ltd. 


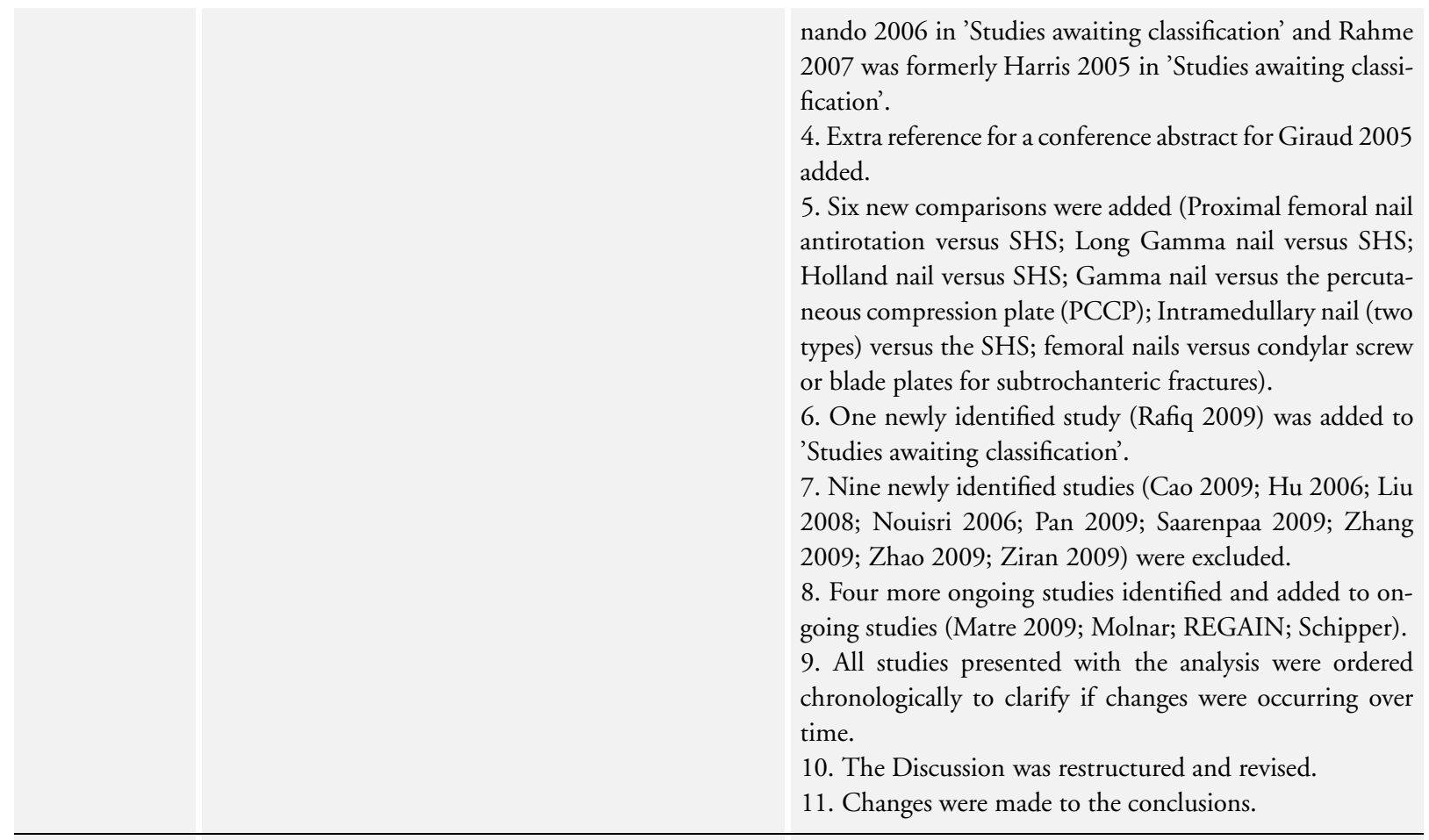

\section{H I S T O R Y}

Protocol first published: Issue 2, 1995

Review first published: Issue 3, 1996

\begin{tabular}{lll}
\hline Date & Event & Description \\
\hline 1 April 2008 & New search has been performed & Converted to new review format. \\
\hline 4 March 2008 & New citation required and conclusions have changed & $\begin{array}{l}\text { For the sixth substantive update, which first appeared } \\
\text { in Issue 3, 2008, the main changes were as follows. } \\
\text { 1. The search for trials was updated to June 2007. } \\
\text { 2. Four newly identified studies (Ekstrom 2007; Giraud } \\
\text { 2005; Ovesen 2006; Papasimos 2005) were included. } \\
\text { 3. One new comparison was added (Targon PF nail } \\
\text { versus SHS) and one category extended to include the } \\
\text { PFN versus Medoff plate comparison. } \\
\text { 4. One previously ongoing study (Khaleel) was moved }\end{array}$
\end{tabular}




\begin{tabular}{|l|l} 
to awaiting assessment and renamed Fernando 2006. \\
5. One newly identified study (Harris 2005) was added \\
to awaiting assessment. \\
6. Five newly identified studies (Azzoni 2004; Bi- \\
enkowski 2006; Kafer 2005; Klinger 2005; Tarantino \\
2005) were excluded. \\
7. Additional information and data for an already in- \\
cluded trial were added (Mehdi 2000). \\
8. The'Synopsis' was rewritten as a'Plain language sum- \\
mary'; and other changes made to comply with format \\
and methodological requirements. \\
9. There were no substantial changes made to the con- \\
clusions.
\end{tabular}

15 August 2005 New search has been performed

For the fifth substantive update, which first appeared in Issue 4, 2005, the main changes were as follows.

1. The search for trials was updated to June 2005.

2. The newly identified studies of Miedel 2005, Pajarinen 2005 and Utrilla 2005 were included.

3. Study of Mott 1993 moved from excluded to included on receipt of additional information.

4. Three newly identified studies (Bhatti 2004; Khan 2002; Schipper 2004) were excluded.

5. One newly identified study (Khaleel) is listed as an ongoing trial and two other studies (Ahmad; White) await assessment.

6. The length of the 'Abstract' was reduced and other format changes undertaken to comply with the Cochrane Style Guide (November 2004). Other changes, such as the consideration of the I-squared statistic were made to comply with the Cochrane Handbook for Systematic Reviews of Interventions (March 2005).

7. Graphical presentation of the results was revised and compressed to reduce the number of graphs.

8. There were no substantial changes made to the conclusions.

1 November 2003 New search has been performed
For the fourth substantive update, which first appeared in Issue 1, 2004, the main changes were as follows.

1. The update of the search for trials to May 2003.

2. Newly identified study of Marques Lopez 2002 included.

3. Though a further report of Ahrengart 1994 was identified giving results for more patients we kept the results from the previous report, pending clarification.

4. Three newly identified studies (Hardy 2003; Herrera 2002; Nuber 2003) were excluded.

5. The studies of Davidson 1996 and Prinz 1996 were 


\begin{tabular}{|c|c|c|}
\hline & & $\begin{array}{l}\text { moved from 'Awaiting assessment' to excluded. } \\
\text { 6. Study of Moran } 2000 \text { moved from ongoing to ex- } \\
\text { cluded. } \\
\text { 7. Reference to letter on study of Hardy } 1998 \text { added. } \\
\text { 8. Details of newly identified ongoing study (Parker) } \\
\text { added. }\end{array}$ \\
\hline 1 August 2002 & New search has been performed & $\begin{array}{l}\text { For the third substantive update, which first appeared } \\
\text { in Issue 4, 2002, the main changes were as follows. } \\
\text { 1. The update of the search for trials to August } 2002 \text {. } \\
\text { 2. Inclusion of newly identified study (Pelet 2001) com- } \\
\text { paring the Gamma nail with a blade plate. } \\
\text { 3. Exclusion of another newly identified study (Dicicco } \\
\text { 2000). } \\
\text { 4. Incorporation of further details and results of three al- } \\
\text { ready included trials (Harrington 2002; Sadowski 2002; } \\
\text { Saudan 2002), previously Harrington 1999, Saudan } \\
\text { 2001b and Saudan 2001a respectively, obtained from } \\
\text { newly published full reports of these trials. } \\
\text { 5. Some restructuring of the text and tables to give em- } \\
\text { phasis on overall results of short femoral nails and lessen } \\
\text { the emphasis on the outdated Kuntscher-Y nail. } \\
6 \text {. Some adjustments to the 'Conclusions' but no sub- } \\
\text { stantive changes in implications. }\end{array}$ \\
\hline
\end{tabular}

1 November 2001 New search has been performed

For the second substantive update, which first appeared in Issue 1, 2002, the main changes were as follows.

1. The update of the search for trials to August 2001.

2. The inclusion of three new Gamma nail trials (Adams 2001; Kuwabara 1998; Michos 2001) and three new intermedullary hip screw trials (Harrington 1999; Hoffmann 1999; Mehdi 2000).

3. Two Gamma nail studies (Hogh 1992; Mott 1993) previously in studies awaiting assessment are now excluded as no further information has been forthcoming.

4. The inclusion of two new comparisons, each represented by one study: proximal femoral nail versus the sliding hip screw (Saudan 2001a) and proximal femoral nail versus the dynamic condylar screw (Saudan 2001b)

5. The inclusion of one trial on a mini-invasive nail (Dujardin 2001).

6. Peto odds ratios changed to relative risks in accordance with Cochrane Review Group requirements.

7. The addition of a new outcome, 'All technical complications of fixation' and the clarification of the outcome: 'operative fracture'.

8. Pooling of the results for key outcomes for three of 


\begin{tabular}{l|l|l}
\hline 1 February 1999 & Amended & $\begin{array}{l}\text { The first substantive update, appearing in Issue 2, 1999, } \\
\text { involved an expansion of the original review, "Gamma } \\
\text { nail versus sliding hip screw for extracapsular hip frac- } \\
\text { tures", to include other cephalocondylic nails. Four } \\
\text { more studies on the Gamma nail (Haynes 1996; Kukla } \\
\text { 1997; Pahlpatz 1993; Park 1998), and two studies } \\
\text { on the intramedullary hip screw (Baumgaertner 1998; } \\
\text { Hardy 1998) were included. }\end{array}$
\end{tabular}

\section{CONTRIBUTIONS OF AUTHORS}

Martyn Parker initiated and designed the review, usually contacted trialists for further information and compiled the first drafts of all versions. Helen Handoll located the review studies for most versions, occasionally contacted trialists for further information, always checked data entry and critically rewrote all drafts for all versions. All other tasks, including independent data extraction and quality assessment, were shared. Martyn Parker is the guarantor of the review.

\section{DECLARATIONS OF INTEREST}

Martyn Parker has received and may continue to receive financial payment from manufacturing companies of orthopaedic implants for attending meeting organised by these companies and for advising on the design and use of hip fracture implants. Helen Handoll has no connection with any manufacturing company.

\section{SOURCES OF SUPPORT}

\section{Internal sources}

- University of Teesside, Middlesbrough, UK.

- Peterborough and Stamford Hospitals NHS Foundation Trust, Peterborough, UK.

\section{External sources}

- Department of Health (England) Incentive Scheme, UK.

- National Institute for Health Research, UK. 


\section{DIFFERENCES BETWEEN PROTOCOL AND REVIEW}

In the update of the review (2010) we made two key changes to Methods.

1. The outcome "all technical complications of fixation" is no longer presented. This reflected concerns voiced by one editor regarding potential unit of analysis problems, where some participants may have experienced more than one of the major complications of fracture healing, and the general problems of composite outcomes. It is possible that, after further checks of the data, we may reintroduce a similar outcome measure to account for major complications of fracture healing that generally require revision surgery or a change of surgical procedure during the primary operation, such as using a longer nail, but where a reoperation was not performed.

2. Three aspects of risk of bias were assessed and reported: sequence generation, allocation concealment and surgeons' experience with the devices.

\section{NDEX TERMS}

\section{Medical Subject Headings (MeSH)}

${ }^{*}$ Bone Nails; *Bone Screws; Fracture Fixation, Internal [adverse effects; *instrumentation]; Fracture Fixation, Intramedullary [adverse effects; instrumentation]; Hip Fractures [mortality; *surgery]; Randomized Controlled Trials as Topic

\section{MeSH check words}

Adult; Humans 